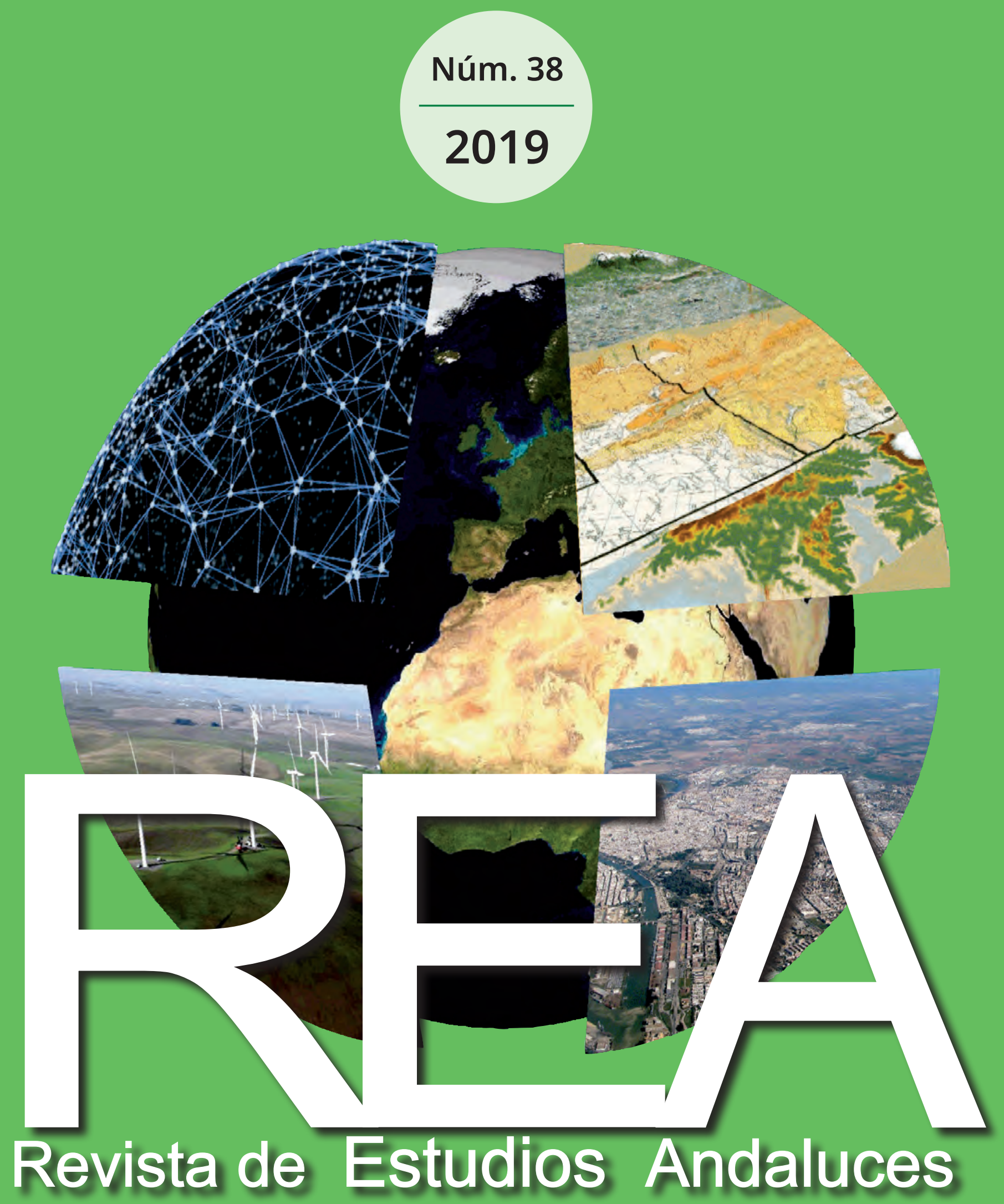

Universidad de Sevilla

Editorial Universidad de Sevilla

https://editorial.us.es/es/revistas/revista-de-estudios-andaluces

https://revistascientificas.us.es/index.php/REA

$\mathrm{u} v^{2}$ eus

Editorial Universidad de Sevilla 


\section{Equipo Editorial}

Directora

Rosa Jordá Borrell. Universidad de Sevilla. <borrell@us.es>

SECRETARÍA DE REVISIÓN, REDACCIÓN Y EDICIÓN

Francisca Ruiz Rodríguez. Universidad de Sevilla. <fruiz@us.es>

Inmaculada España Ríos. Universidad de Sevilla.<irios@us.es>

EDITORES ADJUNTOS (2019)

Marco Garrido Cumbrera. Universidad de Sevilla.<mcumbrera@us.es>

\section{CONSEJO DE REDACCIÓN}

Roberto Bustos Cara. Universidad Nacional del Sur (Argentina).<Usbustos@uns.edu.ar>

Rafael Cámara Artiga. Universidad de Sevilla. <rcamara@us.es>

Javier Esparcía Pérez. Universidad de Valencia.<javier.esparcia@uv.es>

Cayetano Espejo Marín. Universidad de Murcia. <cespejo@um.es>

Javier Gutiérrez Puebla. Universidad Complutense de Madrid.<javiergutierrez@ghis.ucm>

Amado Antonio Guerrero Rincón. Universidad de Santander (Colombia). <santiamen47@hotmail.com>

Teodoro Lasanta Martínez. Instituto Pirenaico de Ecología, Zaragoza. <fm@ipe.csic.es>

Stefania Mangano. Universita' Degli Studi Di Genova, Genova (Italy). <stefania.mangano@unige.it>

Juan Márquez Domínguez. Universidad de Huelva.<antonio@uhu.es>

Alberto Martí Ezpeleta. Universidad de Santiago de Compostela. <alberto.marti@usc.es>

Antonio Narváez Bueno. Universidad de Cádiz. <ajnarva@ono.com>

Jorge Olcina Cantos. Universidad de Alicante. < jorge.olcina@ua.es>

Fermín Rodríguez Gutiérrez. Universidad de Oviedo. <farragut@ uniovi.es>

Jesús Ventura Fernández. Universidad de Sevilla. < jventura@us.es>

\section{CONSEJO ASESOR}

Alberto Capacci. Universidad de Génova (Italia)

Gabriel Cano García. Universidad Sevilla

Javier Contreras Díaz. Universidad Autónoma de Zacatecas (México)

Fernando Díaz del Olmo. Universidad de Sevilla

Dominik Faust. Universidad de Dresde (Alemania)

Andrés García Lorca. Universidad de Almería

Karolina Golemo. Universidad Jagellónica de Cracovia (Polonia)

Javier Martín Vide. Universidad de Barcelona

Ricardo Méndez Gutiérrez. Instituto de Economía, Ga y Población CSIC

Adriano Rovira Pinto. Universidad Austral (Chile)

Kamal Targuisti El Khalifi. Universidad Andelmalek Essaadi (Marruecos)

José Valles Ferrer. Universidad de Sevilla

Revista de Estudios Andaluces (REA). Núm. 38, Julio (2019)

Edita: Editorial de la Universidad de Sevilla.

(c) Editorial Universidad de Sevilla 2019

https://editorial.us.es/es/revistas/revista-de-estudios-andaluces

https://revistascientificas.us.es/index.php/REA

\section{Periodicidad Bianual (febrero, Julio)}

Depósito Legal: SE-221-1984

ISSN: 0212-8594

ISSN-e: $2340-2776$

DOI: http://dx.doi.org/10.12795/rea.2019.i38

Diseño Portada: Ángel Luis Lucendo Monedero

Maquetación: Referencias Cruzadas - referencias.maquetacion@gmail.com

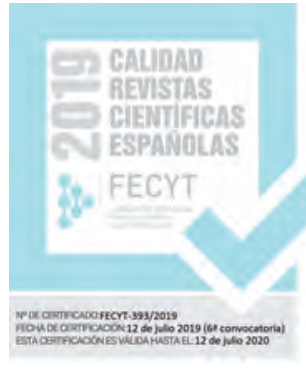




\section{ÍNDICE}

Trayectorias Económicas de las Regiones Españolas en un Escenario Post-crisis: Efectos de Vecindad, Especialización y Aglomeración/ Economic Trajectories of the Spanish Regions in the PostCrisis Scenario: Neighborhood, Specialization and Agglomeration Effects

Juan Miguel Albertos-Puebla. @ https://orcid.org/0000-0001-7915-2610

DOI: http://dx.doi.org/10.12795/rea.2019.i38.01

Transporte Marítimo, Redes Portuarias Atlánticas y Mediterráneas. El Ejemplo de Canarias/ Maritime Transport, Atlantic and Mediterranean Port Networks. The Example of the Canary Islands

Gerardo Delgado-Aguiar. @ https://orcid.org/0000-0002-5947-0483

José Ángel Hernández Luis. @ https://orcid.org/0000-0002-7680-2574

DOI: http://dx.doi.org/10.12795/rea.2019.i38.02

La Importancia de la Articulación Territorial de Escala Intermedia en la Recuperación de la Memoria del Trabajo. El Caso de Barbate/ The Importance of the Territorial Articulation of the Intermediate Scale in the Recovery of the Work Memory. The Case of Barbate

Virginia Arnet-Callealta. (1) https://orcid.org/0000-0001-8068-8383

DOI: http://dx.doi.org/10.12795/rea.2019.i38.03

Delimitación de los Conjuntos Poblacionales Rurales de la Comarca del Altiplano en la Región de Murcia/ Delimitation of the Rural Population Sets of the Region of Altiplano in the Region of Murcia

Miguel Ángel Sánchez-Sánchez. @ https://orcid.org/0000-0003-0774-2560

DOI: http://dx.doi.org/10.12795/rea.2019.i38.04

Vulnerabilidad Territorial y Accesibilidad a los Servicios de Proximidad para las Personas Mayores en la Ciudad de Valencia/ Territorial Vulnerability and Accessibility to Proximity Services for Older People in the City of Valencia

María Dolores Pitarch-Garrido. @ https://orcid.org/0000-0001-9109-4687

Félix Fajardo-Magraner. (1) https://orcid.org/0000-0003-1516-6655

DOI: http://dx.doi.org/10.12795/rea.2019.i38.05

El Transporte Aéreo de Mercancías en los Aeropuertos Españoles: Hacia una Concentración e Internacionalización Selectivas/ The Air Freight Transport at Spanish Airports: Towards Selective Concentration and Internationalization

Carlos López-Escolano. @ https://orcid.org/0000-0002-1653-7780

Daniel Cruz-Alonso. io https://orcid.org/0000-0001-8264-1263

Ángel Pueyo-Campos. @ https://orcid.org/0000-0003-4103-2116

DOI: http://dx.doi.org/10.12795/rea.2019.i38.06

De Concesiones Lineales a Contratos de Gestión Zonales: Una Propuesta para el Transporte Público Interurbano de Viajeros por Carretera en Aragón/ From Linear to Zonal Management Contracts: A Proposal for the Public Inter-Urban Transportation of ravelers by Road in Aragón

Ricardo Badía-Lázaro. (1) https://orcid.org/0000-0003-0572-3681

Eugenio Antonio Climent-López. @ https://orcid.org/0000-0001-6788-4873

DOI: http://dx.doi.org/10.12795/rea.2019.i38.07. 
Sectores Estratégicos en la Economía del Conocimiento y Desarrollo en la Ciudad de Madrid y su Región/ Strategic Sectors in the Knowledge Economy and Development in the City of Madrid and its Region

Simón Sánchez-Moral. @ https://orcid.org/0000-0001-6381-2653

Roberto Díez-Pisonero. @ https://orcid.org/0000-0002-7817-628X

Candida Gago-García. (1) https://orcid.org/0000-0003-2315-7943

Alfonso Arellano-Espinar. (1) https://orcid.org/0000-0002-1464-8751

DOI: http://dx.doi.org/10.12795/rea.2019.i38.08

Zonas con Potencial para el Pago de Servicios Ambientales en el Valle del Mezquital, Hidalgo/ Zones with Potential for the Payment of Environmental Services in the Valle del Mezquital, Hidalgo

Genaro Aguilar-Sánchez. (1) https://orcid.org/0000-0003-1518-0801

Reynol González-Vizcarra. @ https://orcid.org/0000-0002-4983-3164

DOI: http://dx.doi.org/10.12795/rea.2019.i38.09

Aproximación Metodológica a los Itinerarios no Motorizados de Mayor Potencialidad para la Intermodalidad "Tren+Bici" en Andalucía/ A methodological approach to non-motorized itineraries with greater potentiality for the "train+bike" intermodality in Andalusia

Isabel Aránzazu García-Bello. @ https://orcid.org/0000-0001-9239-4331

Jesús Ventura-Fernández. (1) https://orcid.org/0000-0002-8271-1011

DOI: http://dx.doi.org/10.12795/rea.2019.i38.10 


\section{INDEX}

\section{Summary of Articles}

Economic Trajectories of the Spanish Regions in the Post-Crisis Scenario: Neighborhood, Specialization and Agglomeration Effects

Juan Miguel Albertos-Puebla. (1) https://orcid.org/0000-0001-7915-2610

DOI: http://dx.doi.org/10.12795/rea.2019.i38.01

Maritime Transport, Atlantic and Mediterranean Port Networks. The Example of the Canary Islands

Gerardo Delgado-Aguiar. (1) https://orcid.org/0000-0002-5947-0483

José Ángel Hernández Luis. @ https://orcid.org/0000-0002-7680-2574

DOI: http://dx.doi.org/10.12795/rea.2019.i38.02

The Importance of the Territorial Articulation of the Intermediate Scale in the Recovery of the Work Memory. The Case of Barbate

Virginia Arnet-Callealta. (1) https://orcid.org/0000-0001-8068-8383

DOI: http://dx.doi.org/10.12795/rea.2019.i38.03

Delimitation of the Rural Population Sets of the Region of Altiplano in the Region of Murcia

Miguel Ángel Sánchez-Sánchez. @ https://orcid.org/0000-0003-0774-2560

DOI: http://dx.doi.org/10.12795/rea.2019.i38.04

Territorial Vulnerability and Accessibility to Proximity Services for Older People in the City of Valencia

María Dolores Pitarch-Garrido. @ https://orcid.org/0000-0001-9109-4687

Félix Fajardo-Magraner. (1) https://orcid.org/0000-0003-1516-6655

DOI: http://dx.doi.org/10.12795/rea.2019.i38.05

The Air Freight Transport at Spanish Airports: Towards Selective Concentration and Internationalization

Carlos López-Escolano. @ https://orcid.org/0000-0002-1653-7780

Daniel Cruz-Alonso. (1) https://orcid.org/0000-0001-8264-1263

Ángel Pueyo-Campos. https://orcid.org/0000-0003-4103-2116

DOI: http://dx.doi.org/10.12795/rea.2019.i38.06

From Linear to Zonal Management Contracts: A Proposal for the Public Inter-Urban Transportation of ravelers by Road in Aragón

Ricardo Badía-Lázaro. (1) https://orcid.org/0000-0003-0572-3681

Eugenio Antonio Climent-López. (1) https://orcid.org/0000-0001-6788-4873

DOI: http://dx.doi.org/10.12795/rea.2019.i38.07.

Strategic Sectors in the Knowledge Economy and Development in the City of Madrid and its Region

Simón Sánchez-Moral. @ https://orcid.org/0000-0001-6381-2653

Roberto Díez-Pisonero. (1) https://orcid.org/0000-0002-7817-628X

Candida Gago-García. (1) https://orcid.org/0000-0003-2315-7943

Alfonso Arellano-Espinar. (1) https://orcid.org/0000-0002-1464-8751

DOI: http://dx.doi.org/10.12795/rea.2019.i38.08. 
Zones with Potential for the Payment of Environmental Services in the Valle del Mezquital, Hidalgo

Genaro Aguilar-Sánchez. @ https://orcid.org/0000-0003-1518-0801

Reynol Gonzalez-Vizcarra. (1) https://orcid.org/0000-0002-4983-3164

DOI: http://dx.doi.org/10.12795/rea.2019.i38.09....

A methodological approach to non-motorized itineraries with greater potentiality for the "train+bike" intermodality in Andalusia

Isabel Aránzazu García-Bello. @ https://orcid.org/0000-0001-9239-4331

Jesús Ventura-Fernández. @ https://orcid.org/0000-0002-8271-1011

DOI: http://dx.doi.org/10.12795/rea.2019.i38.10 
Artículos

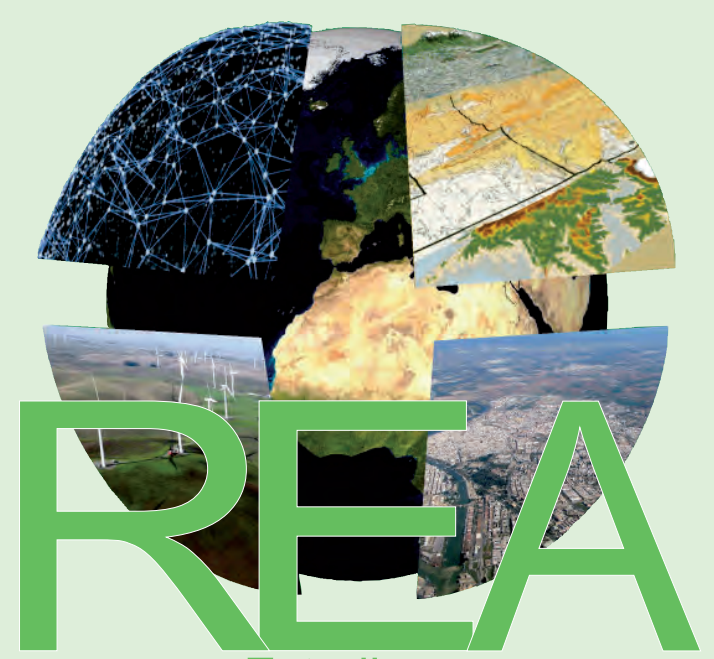

Revista de Estudios Andaluces 


\title{
Trayectorias Económicas de las Regiones Españolas en un Escenario Post-crisis: Efectos de Vecindad, Especialización y Aglomeración*
}

\section{Economic Trajectories of the Spanish Regions in the Post-Crisis Scenario: Neighborhood, Specialization and Agglomeration Effects}

\author{
Juan Miguel Albertos-Puebla \\ juan.m.albertos@uv.es (1) https://orcid.org/0000-0001-7915-2610 \\ Departamento de Geografía e Instituto Interuniversitario de Desarrollo Local. \\ Universitat de València. Av. Blasco Ibañez 2846010 Valencia.
}

\section{INFO ARTÍCULO}

Recibido: 10/1/2019

Revisado: 21/4/2019

Aceptado: 6/5/2019

\section{PALABRAS CLAVE}

Shift-share espacial Competitividad territorial Escenario post-crisis Desigualdades regionales España

\begin{abstract}
RESUMEN
A lo largo de la última década las regiones españolas han experimentado profundas transformaciones económicas ligadas a los cambios que ha experimentado el modelo productivo. Tras el estallido de la burbuja inmobiliaria se ha retomado el crecimiento en línea con una recuperación de la competitividad internacional y una reorientación hacia el mercado exterior. Este nuevo modelo tiene una dimensión territorial claramente visible en términos de un crecimiento regional desigual que apunta hacia una nueva configuración territorial. Para definir este nuevo marco territorial aplicaremos un análisis shift-share espacial a las regiones españolas para los periodos 2008-13 (recesión) y 2013-17 (recuperación), lo que permitirá descomponer el crecimiento registrado en los efectos derivados de la vecindad, la especialización sectorial o la presencia de economías de aglomeración, esto es, en los elementos que determinan la competitividad territorial. Así, una vez superada la recesión, las regiones del corredor mediterráneo junto a las principales aglomeraciones metropolitanas (Madrid, País Vasco) han pasado a liderar el crecimiento regional como consecuencia de una superior competitividad territorial, mostrando que las divergentes trayectorias económicas de las regiones solo pueden explicarse desde el territorio atendiendo a conceptos como aglomeración y vecindad.
\end{abstract}

\begin{abstract}
Over the last decade, the Spanish regions have undergone deep economic transformations that have gone hand in hand with changes in the production model. After the bursting of the housing bubble, growth has resumed through a recovery of the international competitiveness and a reorientation towards the foreign market. This new model has a clear territorial dimension visible in terms of unequal regional growth showing specific patterns and driving to a new territorial configuration. In order to define this nee configuration, we shall apply a spatial shift-share analysis to the Spanish regions for the periods 2008-13 (recession) and 2013-17 (recovery) aiming to split growth into its composing effects derived from neighborhood, sectorial specialization or the presence of economies of agglomeration. Thus, once the recession is over, the regions of the Mediterranean corridor along with the main metropolitan agglomerations (Madrid, Basque Country) are leading Spanish regional growth as a consequence of superior territorial competitiveness, showing that the divergent economic trajectories of regions can only be explained from the territory attending to concepts such as agglomeration and neighborhood.
\end{abstract}

and neighborhood.
Spatial shift-share

Post-crisis scenario Regional inequalities Spain 


\section{INTRODUCCIÓN}

El paisaje económico español y las dinámicas de crecimiento regionales se han visto alteradas durante la última década a consecuencia de la sucesión de una profunda crisis (2008-2013) y de una recuperación aún en curso (2013-2017). Aunque existen diferencias considerables entre lo ocurrido en los años de recesión y en los años de recuperación de la actividad en el actual escenario post-crisis, es posible detectar algunas tendencias de fondo que implican cambios estructurales y que afectan al modelo de desarrollo español y a su plasmación territorial (Albertos y Sánchez Hernández, 2014, 2017; Cuadrado, 2010; Méndez, 2015, 2016; Méndez et al., 2015; Sánchez Hernández y Albertos, 2014; Sánchez Moral, 2015):

1. Una creciente fractura social, visible a través de la distribución del ingreso y del volumen de población en riesgo de pobreza y a la que no es ajena la evolución del mercado de trabajo y de unas condiciones laborales marcadas por una caída d e la remuneración del trabajo en clara divergencia con la evolución de la productividad.

2. Una aceleración en los procesos de integración de la economía española en el orden global, con un peso creciente del mercado internacional. Se trata de un giro copernicano en el modelo de desarroIlo, ahora claramente orientado hacia afuera, hasta el extremo de mostrar desde 2012 una balanza comercial de bienes y servicios positiva, algo insólito en la historia económica española.

3. Una profundización en los procesos de especialización productiva regional y de concentración territorial de la actividad. Los espacios regionales se especializan crecientemente en aquellas actividades en las que tienen mayor experiencia, capacidades y recursos y, en suma, disponen de una ventaja competitiva. Al mismo tiempo se incrementan las disparidades regionales en términos de riqueza relativa y concentración de la actividad.

En este marco de cambio de modelo de desarrollo resulta interesante observar qué transformaciones se están produciendo en el mapa del crecimiento económico, determinar qué efectos ha tenido el shock producido por la crisis y establecer qué regiones están mostrando dinámicas más positivas en el nuevo escenario post-crisis y cómo estas nuevas tendencias están afectando a los niveles de desigualdad regional en España.

A partir de los trabajos de Williamson (1965) sobre el caso de Estados Unidos suele admitirse que las disparidades regionales evolucionan a largo plazo siguiendo una forma de $\mathrm{U}$ invertida, aumentando en las primeras fases de desarrollo y disminuyendo de forma ininterrumpida en un segundo momento tras haber alcanzado un pico de desigualdad. A grandes rasgos el caso español se ha ajustado a este modelo: los análisis más completos de las series estadísticas disponibles (Diez et al., 2014; Tirado et al., 2010, 2015) sitúan este pico de desigualdad en torno a 1930, iniciándose a partir de ese momento un proceso de convergencia condicionado probablemente por los fuertes movimientos migratorios de las décadas de los años 1960 y 1970 y por una cierta homogeneización de las estructuras productivas regionales. No obstante, este proceso de convergencia se detuvo, o al menos se ralentizó, en las últimas décadas del siglo XX (Cuadrado, 2010; Tirado et al., 2015). Además, ya en clara contradicción con lo que sería de prever según la tesis de la convergencia regional, contamos ya con suficiente evidencia para afirmar que a partir del estallido de la crisis en 2008 se produce un punto de inflexión y se entra en una nueva etapa de incremento de las desigualdades: en términos generales, las regiones más ricas han resistido mejor la fase de recesión y están creciendo más rápidamente en la fase de recuperación que las regiones más pobres.

En este contexto, resulta relevante analizar en detalle el crecimiento regional y sus componentes a partir del estallido de la crisis, con el fin de establecer cuáles son los factores explicativos de esta nueva dinámica divergente y si hay elementos sobre los que sería todavía posible plantear ventanas de oportunidad para el desarrollo en las regiones más atrasadas. Siguiendo la concepción sintética del crecimiento regional propuesta por Roberta Capello -modelos MASST: MAcroeconomic, Sectoral, Social and Territorial model- (Capello y Fratesi 2012; Capello 2016), el diferencial de crecimiento de una región puede explicarse, además de por elementos sectoriales derivados de su mix industrial, por su capital territorial derivado de activos sociales, institucionales y espaciales (innovatividad, cualificaciones, infraestructuras, relaciones de confianza y capital social, derrames espaciales y economías de aglomeración). Dentro de este marco conceptual intentaremos 
cuantificar este dinamismo diferencial y cuál es su naturaleza y origen en el contexto de la evolución reciente de las regiones españolas. Esto nos ofrecerá una imagen de cuáles son las regiones ganadoras en el nuevo escenario post-crisis, así como determinar hasta qué punto se está conformando una nueva configuración territorial en el modelo de desarrollo económico español.

\section{METODOLOGÍA}

La metodología empleada consiste en la aplicación de un análisis shift-share con el fin de desglosar los diferentes componentes que explican la evolución económica diferencial que han mostrado las comunidades autónomas españolas durante la última década, distinguiendo la evolución seguida durante los años de fuerte recesión y caída del empleo y la actividad (2008-2013) de la emprendida en el período de recuperación post-crisis en que nos encontramos (2013-2017)'.

Pocas técnicas de análisis regional como el shift-share han merecido una difusión y un uso tan amplio en los campos de la ciencia regional y la geografía económica y, a la vez, han suscitado una crítica tan intensa y sostenida desde que ésta fue formalizada por primera vez por Dunn (Dunn 1960; Esteban 1972, Haynes y Parajuli 2016). En su forma estándar esta técnica permite desagregar el crecimiento de una economía regional integrada en un contexto nacional más amplio en tres componentes o efectos: 1) un efecto nacional, equivalente a la tasa de crecimiento del conjunto nacional, 2) un efecto estructural, derivado de la especialización, ventajosa o desfavorable, de la estructura sectorial de la región, y 3) un efecto regional, derivado de la mayor o menor eficiencia, dinamismo o competitividad de las actividades localizadas en la región más allá del sector al que pertenezcan.

La siguiente expresión [1] muestra esta descomposición del crecimiento para la variable $x$ (empleo, valor añadido, etc.) en la región $r$ entre el momento $t$ y $t+1$ considerando un total de $n$ sectores $i$ :

$[1]$

$$
\sum_{i}^{n} x_{i r} g_{i}=\sum_{i}^{n} x_{i r} G+\sum_{i}^{n} x_{i r}\left(G_{i}-G\right)+\sum_{i}^{n} x_{i r}\left(g_{i}-G_{i}\right)
$$

\section{Donde}

$G$ es la tasa de crecimiento del conjunto de los sectores en la nación

$G_{i}$ es la tasa de crecimiento del sector $i$ en la nación

$g_{i}$ es la tasa de crecimiento del sector $i$ en la región $r$.

$\sum_{i}^{n} x_{i r}$ es el efecto nacional

$\sum_{i}^{n} x_{i r}\left(G_{i}-G\right)$ es el efecto estructural

$\sum_{i}^{n} x_{i r}\left(g_{i}-G\right)$ es el efecto regional

La popularidad de esta técnica se explica por su sencillez de cálculo, su fácil -casi intuitiva- interpretación, y la facilidad para acceder a la información necesaria. Desde su primera formulación se han ido sugiriendo extensiones del modelo inicial tendentes a ir mejorando su utilidad (Haynes y Parajuli, 2016). En este trabajo aplicaremos una de las extensiones propuestas en estos últimos años, la denominada shift-share espacial (Na-

1. Como variable de estudio se utiliza el Valor Añadido Bruto en las 17 comunidades autónomas en 2008 2013 y 2017. La información procede de la serie homogénea de la Contabilidad Regional de España con base en el año 2010, publicada por el Instituto Nacional de Estadística. El desglose sectorial es el denominado A*1 de 11 sectores. La consideración de 2013 viene motivada porque en este año se registra el mínimo de VAB y, en su tercer trimestre, se produce el punto de inflexión a partir del cual se retoma el crecimiento económico. 
zara y Hewings (2004). La idea principal que subyace en su planteamiento es que, en función de la posición geográfica de cada región dentro del conjunto nacional, se producen relaciones privilegiadas y más intensas con las regiones vecinas o más próximas; la introducción de la variable distancia (o proximidad) provoca que para cada región considerada el entorno nacional de referencia sea diferente y único, según cuál sea la dinámica de las regiones con las que mantiene relaciones más intensas de vecindad. El artículo seminal de Nazara y Hewings (2004) propuso una extensa serie de posibles formulaciones, desarrollos y análisis. Aquí aplicaremos la propuesta de Ramajo y Márquez (2008) que, en forma comparable a la empleada en la expresión del modelo estándar [1] y referido al crecimiento experimentado entre el momento $t$ y $t+1$ por la variable $x$ en la región $r$, podría formularse de la siguiente manera:

$$
\sum_{i}^{n} x_{i r} g_{i}=\sum_{i}^{n} x_{i r} \overleftrightarrow{G}+\sum_{i}^{n} x_{i r}\left(\overleftrightarrow{G_{i}}-\overleftrightarrow{G}\right)+\sum_{i}^{n} x_{i r}\left(g_{i}-\overleftrightarrow{G}_{i}\right)
$$

donde los términos $G$ y $G_{i}$ han sido sustituidos por sus correlatos $\overleftrightarrow{G}$ y $\overleftrightarrow{G_{i}}$ que ya incorporan los elementos de vecindad derivados de la estructura espacial. La consideración de la estructura espacial se realiza a través de una matriz de pesos $\overleftrightarrow{W}$ derivada de una matriz de flujos origen ldestino estandarizada por filas en la que cada elemento $\overleftrightarrow{w}_{r s}$ muestra la interacción de la región $r$ con la región $s$ y puede considerase como un indicador del grado de proximidad o vecindad existente entre ambas. Se empleará la matriz de viajes por razones profesionales entre comunidades autónomas de residencia y de destino publicada por el Ministerio de Fomento como parte de la encuesta MOVILIA de 2007 (Mapa 1). El valor de este flujo entre dos comunidades

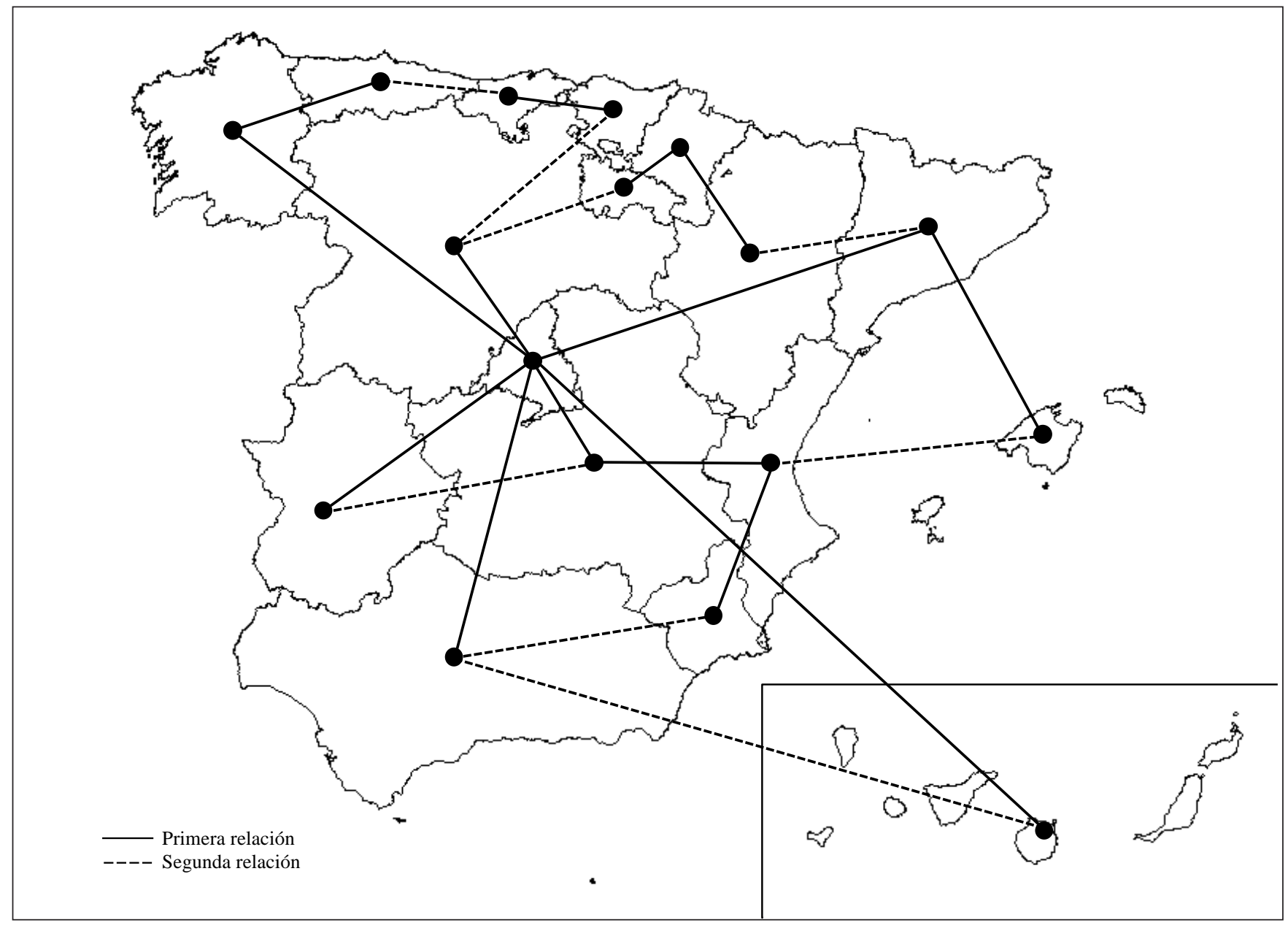

Mapa 1. Primer y segundo flujo de viajes por motivos profesionales. Fuente: Encuesta Movilia-2007 del Ministerio de Fomento. Elaboración propia. 
autónomas puede considerarse como una aproximación genérica y suficiente a la interacción económica, mejor que otras alternativas como la matriz de viajes por turismo o, incluso, la matriz de intercambios comerciales, que ofrecen una visión del fenómeno más parcial y limitada.

En definitiva, según lo anterior, podrían redefinirse los tres componentes clásicos del análisis shift-share en su extensión espacial de la siguiente forma:

$\sum_{i}^{n} x_{i r} \overleftrightarrow{G}$, como el efecto nacional ponderado por vecindad

$\sum_{i}^{n} x_{i r}(\overleftrightarrow{G}-\overleftrightarrow{G})$, como el efecto estructural ponderado por vecindad

$\sum_{i}^{n} x_{i r}\left(g_{i}-\overleftrightarrow{G}_{i}\right)$, como el efecto regional ponderado por vecindad

Ese desglose de la dinámica particular seguida por cada región permite distinguir tres diferentes componentes (o efectos), que pueden asimilarse, y ser considerados como aproximaciones válidas, a los principales factores explicativos del crecimiento diferencial regional propuestos por Capello en su modelo MASST (Capello y Fratesi 2012; Capello 2016):

1. Un componente relacional, que puede calcularse como la diferencia entre el efecto nacional registrado bruto y el efecto nacional ponderado por vecindad. Ese componente podría considerarse como el efecto relativo, positivo o negativo, que la región recibe como consecuencia de su posición dentro de la red de relaciones, interacciones e intercambios interregionales, y estaría reflejando, al menos parcialmente, los efectos que sobre el crecimiento tiene "la capacidad de la región para crecer en virtud de recursos provenientes de otras regiones - growth spillovers" (Capello y Fratesi, 2016, 301).

2. Un componente sectorial regional -el efecto estructural ponderado por vecindad- que, en función de la presencia relativa mayor o menor de sectores con dinámicas más o menos favorables, condiciona el crecimiento total registrado en la región, y constituiría una parte fundamental del "componente sectorial del crecimiento" propuesto por Capello y Fratesi $(2016,300)$. Su volumen y sentido, positivo o negativo, vendrá condicionado por las diferencias estructurales entre la región considerada y el resto de regiones españolas con la que está especialmente relacionada.

3. Un componente derivado del comportamiento específico de los sectores en la región -el efecto regional ponderado por vecindad- que captura los elementos de la dinámica que tienen una raíz más claramente territorial, y que integraría la mayor parte de los "activos del capital territorial" considerados en las diversas teorías de desarrollo local y desarrollo endógeno e integradas por Capello en el modelo MASST (Capello y Fratesi 2016, 299-301): dotación de capital físico e infraestructuras, productividad y cualificación del trabajo, comportamiento y características de las empresas, capital social, marco regulatorio e institucional, o, de forma más genérica, economías de aglomeración, localización y urbanización. Este tercer componente regional del crecimiento, el de naturaleza más marcadamente territorial, es el que indica de forma más precisa el dinamismo diferencial basado en la existencia de ventajas competitivas construidas en la escala local/regional y es el que nos permitirá identificar los comportamientos más dinámicos y resilientes. Aquí también, la consideración de la vecindad significa que esa evaluación de las ventajas competitivas de cada región se hace en relación a los territorios con los que interactúa más intensamente.

Adicionalmente, se trabajará con las matrices de localización-especialización para las 17 comunidades españolas y 11 sectores en los años 2008, 2013 y 2017 con el fin de establecer los procesos generales en curso en cuanto a la distribución de la actividad económica en el territorio e identificar la emergencia de regiones en los que las economías de localización/urbanización están presumiblemente contribuyendo a generar/consolidar espacios económicos más dinámicos y competitivos. Es decir, se establecerá si existe alguna relación entre la presencia de procesos de profundización en determinadas especializaciones productivas regionales, presumiblemente relacionadas con el funcionamiento y el fortalecimiento de econo- 
mías de aglomeración, y las dinámicas de crecimiento, medidas a través del tercer componente -o efecto regional- derivado del análisis shift-share.

\section{RESULTADOS}

Los resultados del análisis shift-share espacial aplicado en los períodos 2008-2013 y 2013-17 permiten separar los tres elementos principales que componen el comportamiento diferencial que cada región muestra respecto al general de España (ver Tabla 1 y Figuras 1, 2, 3, y 4).

Tabla 1. Análisis shift-share espacial. Evolución del valor añadido bruto. Efectos relacional, estructural y territorial.

\begin{tabular}{|c|c|c|c|c|c|c|}
\hline \multirow{2}{*}{ CC.AA. } & \multicolumn{3}{|c|}{$2008-2013$} & \multicolumn{3}{|c|}{$2013-2017$} \\
\hline & Relacional & Estructural & Territorial & Relacional & Estructural & Territorial \\
\hline Andalucía & $+0,79 \%$ & $+0,49 \%$ & $-2,49 \%$ & $+0,19 \%$ & $-1,46 \%$ & $+0,73 \%$ \\
\hline Aragón & $+0,53 \%$ & $-0,86 \%$ & $+0,00 \%$ & $+1,19 \%$ & $-0,83 \%$ & $-3,26 \%$ \\
\hline Asturias & $+0,62 \%$ & $-0,57 \%$ & $-5,43 \%$ & $+0,22 \%$ & $-0,63 \%$ & $-3,23 \%$ \\
\hline Baleares & $+0,44 \%$ & $+1,93 \%$ & $-0,60 \%$ & $+1,45 \%$ & $-2,07 \%$ & $+4,52 \%$ \\
\hline Canarias & $+0,96 \%$ & $+2,50 \%$ & $-2,42 \%$ & $+0,12 \%$ & $-0,90 \%$ & $-0,87 \%$ \\
\hline Cantabria & $+0,82 \%$ & $-0,02 \%$ & $-3,90 \%$ & $+0,36 \%$ & $-0,82 \%$ & $-1,68 \%$ \\
\hline Castilla y León & $+2,56 \%$ & $+0,04 \%$ & $-3,80 \%$ & $+0,20 \%$ & $-1,05 \%$ & $-2,64 \%$ \\
\hline Castilla-La Mancha & $+2,37 \%$ & $-2,18 \%$ & $-1,03 \%$ & $+0,33 \%$ & $-1,14 \%$ & $-3,27 \%$ \\
\hline Cataluña & $+2,19 \%$ & $+0,13 \%$ & $-1,70 \%$ & $+0,83 \%$ & $-0,23 \%$ & $+1,91 \%$ \\
\hline Comunidad Valenciana & $+0,04 \%$ & $-0,55 \%$ & $-3,27 \%$ & $+0,19 \%$ & $-0,37 \%$ & $+1,04 \%$ \\
\hline Extremadura & $+2,45 \%$ & $-0,74 \%$ & $-1,21 \%$ & $+0,05 \%$ & $-1,90 \%$ & $-1,28 \%$ \\
\hline Galicia & $+1,39 \%$ & $-1,33 \%$ & $-0,53 \%$ & $+0,17 \%$ & $-0,44 \%$ & $+0,01 \%$ \\
\hline Madrid & $+0,26 \%$ & $-0,27 \%$ & $+4,07 \%$ & $-0,58 \%$ & $+0,61 \%$ & $+0,70$ \\
\hline Murcia & $-0,58 \%$ & $-0,37 \%$ & $+0,52 \%$ & $+0,30 \%$ & $+0,22 \%$ & $+0,61 \%$ \\
\hline Navarra & $+0,26 \%$ & $-0,71 \%$ & $+1,58 \%$ & $-0,76 \%$ & $+1,56 \%$ & $-0,86 \%$ \\
\hline País Vasco & $+0,95 \%$ & $-1,06 \%$ & $+0,33 \%$ & $-0,23 \%$ & $+0,87 \%$ & $+0,45 \%$ \\
\hline La Rioja & $+0,11 \%$ & $-0,76 \%$ & $-0,27 \%$ & $-1,24 \%$ & $+0,39 \%$ & $-4,35 \%$ \\
\hline
\end{tabular}

Fuente: INE, Contabilidad Regional de España, Serie homogénea. Elaboración propia.

\subsection{Efecto relacional}

El efecto relacional obedece a la posición que cada región ocupa en la red nacional de interacciones. Cada región presenta un patrón de relaciones diferente con el resto del territorio español, siendo normalmente estas relaciones más intensas con regiones vecinas o próximas que con otras más alejadas. Así, los impactos positivos o negativos que cada región recibe de la evolución registrada en el resto de España -que pueden identificarse como derrames favorecedores del crecimiento (growth spillovers) -, varía según cuales son las 


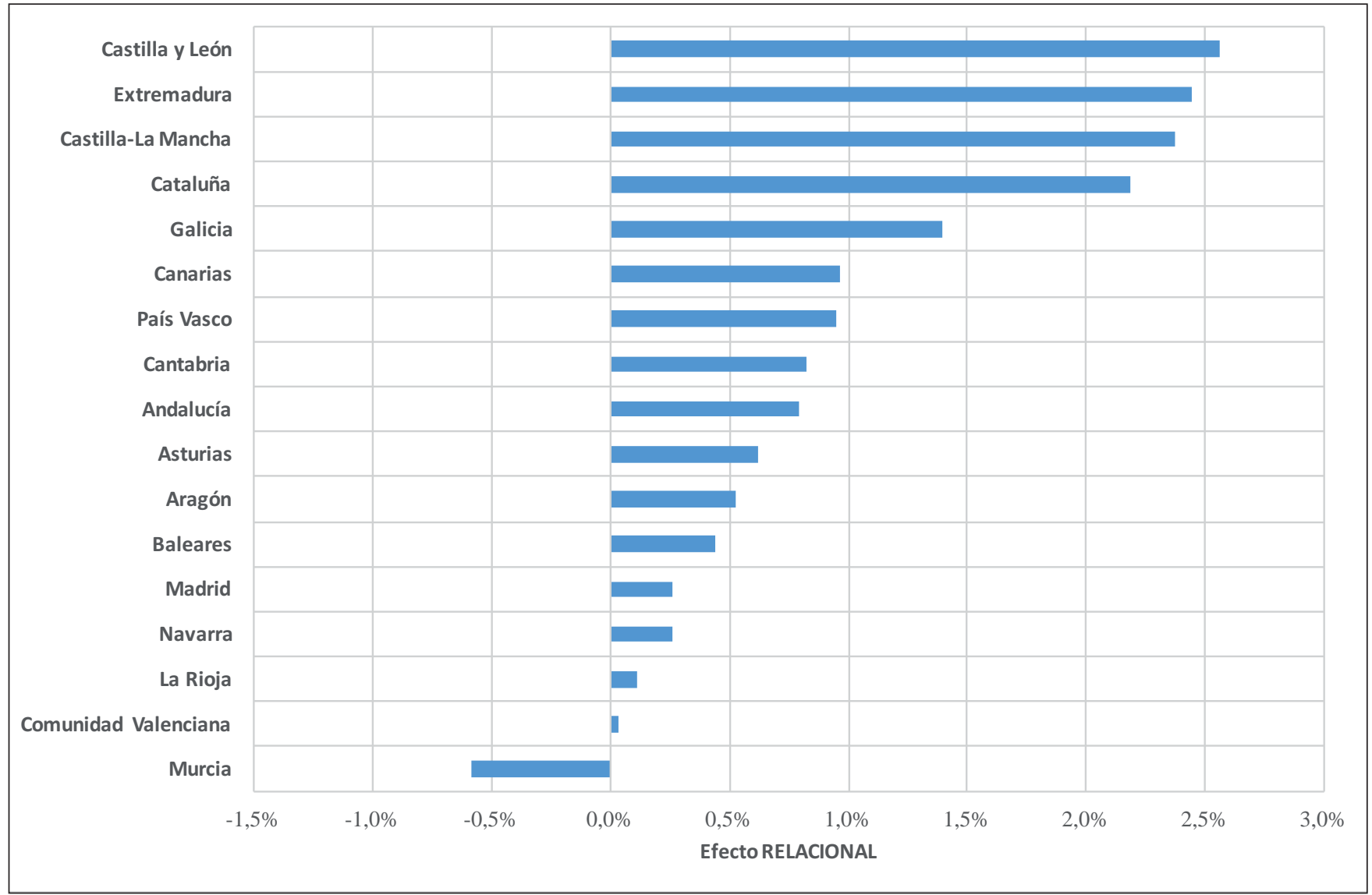

Figura 1. Análisis shift-share espacial. VAB. 2008-2013. Efecto relacional.

Fuente: INE, Contabilidad Regional de España, serie homogénea. Elaboración propia.

regiones con las que mantiene relaciones más intensas. Al tener en cuenta la posición de cada región en la red de relaciones interregionales (ver Mapa 1), el territorio español de referencia para la aplicación del análisis shift-share es ligeramente distinto en cada caso, tanto su composición sectorial como en su dinamismo relativo. Las regiones con un espacio de interacción preferente especialmente dinámico recibirán mayores impactos positivos de crecimiento, mientras que si la interacción se produce fundamentalmente con territorios menos dinámicos este impacto tenderá a ser menor.

En el período de recesión (Figura 1), las regiones del cuadrante noroeste, junto a Castilla-La Mancha, son las que según este modelo obtuvieron más beneficios de su posición en la red de relaciones interregionales. El peso relativamente importante que para muchas de estas regiones tiene su relación con Madrid, y en un segundo nivel con el País Vasco y Navarra, habría contribuido a mitigar hasta cierto punto los impactos de la crisis. Así, en muchas de las regiones del interior y del noroeste la caída de actividad hubiera sido incluso más importante de la que efectivamente se habría producido sin este efecto relacional positivo. Este efecto no se circunscribe a las regiones vecinas del cuadrante noroeste o del interior peninsular, sino que también se deja sentir en otros territorios más alejados pero que tienen en Madrid uno de los principales focos de interacción (Canarias o Cataluña). En cualquier caso, este efecto posicional es limitado, de entre el $+1,0$ y el $+2,5 \%$ en relación a caídas totales de actividad que oscilan entre el -15 y el -20\%, y no ha impedido que muchas de estas regiones hayan sufrido un deterioro muy importante en los años de recesión. En algunos casos este efecto relacional es neutro o incluso negativo, especialmente en el caso de Murcia, reflejando sus relaciones especialmente intensas con Andalucía y la Comunidad Valenciana, dos de las regiones que peor se han comportado en los años de crisis.

En cambio, en el período post-crisis que se abre en 2013 el efecto relacional muestra un comportamiento bastante diferente (Figura 2). En esta ocasión las regiones más beneficiadas por su posición en la red regional se sitúan en el este, las que presentan conexiones especialmente importantes con el espacio medite- 


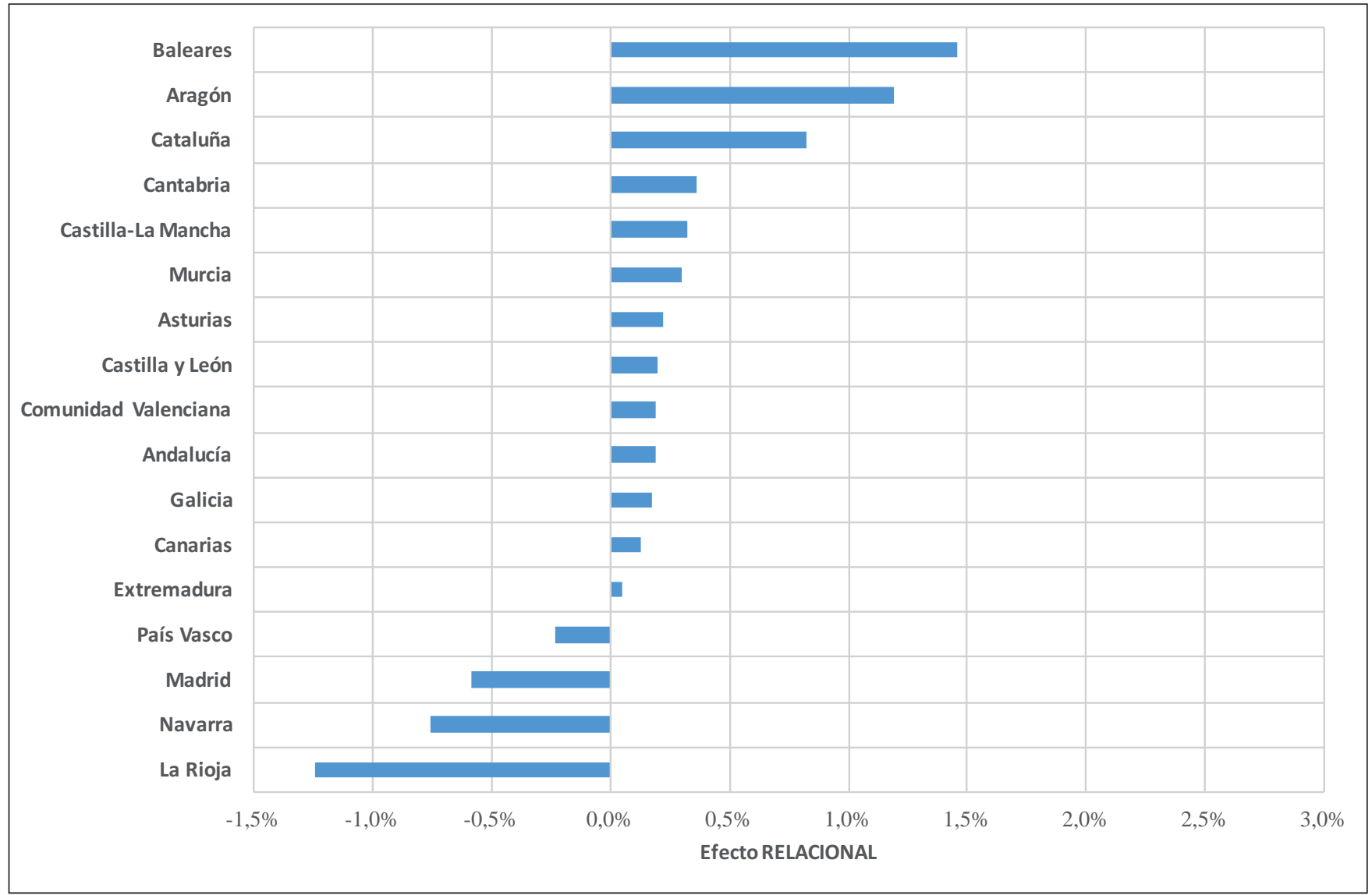

Figura 2. Análisis shift-share espacial. VAB. 2013-2017. Efecto relacional.

Fuente: INE, Contabilidad Regional de España, serie homogénea. Elaboración propia.

rráneo que, en esta coyuntura post-crisis lidera el crecimiento económico; esto incluye las propias regiones mediterráneas que están muy interrelacionadas entre sí, derramando también estos efectos positivos hacia Aragón y otros espacios próximos. Por su parte, el País Vasco sigue comportándose relativamente bien e induciendo un efecto relacional positivo en Cantabria, mientras que el efecto positivo de Madrid en su entorno permanece, aunque mitigado. En esta ocasión, los efectos relacionales más negativos, salvando los casos especiales de Madrid y el País Vasco que se relacionan con entornos circundantes menos dinámicos que ellos mismos, se encuentran en algunas comunidades del valle del Ebro (la Rioja y Navarra).

\subsection{Efecto estructural}

El efecto estructural está derivado del peculiar mix industrial de cada región y de la presencia mayor o menor de sectores más o menos dinámicos en comparación al conjunto nacional de referencia. Este componente estructural ha llegado a determinar cambios en el dinamismo regional de entre el $\pm 2,5 \%$ del VAB regional en el periodo $2008-13$ y de entre el $+1,0$ y el $-2,5 \%$ entre 2013 y 2017 (Tabla 1 y Figuras 3 y 4).

En el período 2008-2013 los dos sectores que mejor se comportaron fueron el turismo y la agricultura. La especialización turística se advierte en el efecto estructural positivo que muestran de forma muy nítida las Islas Baleares (+1.93\%) y Canarias (+2,5\%), y en menor medida Andalucía (+0.49\%) donde ayuda también a este resultado la especialización en el sector primario. En el otro extremo, Castilla-La Mancha es la región más perjudicada $(-2,18 \%)$, acusando la fuerte presencia relativa que tenía aquí el sector de la construcción, situación que también afecta notablemente a Extremadura (-0,74\%), Galicia (-1,33\%) y Asturias (-0,57\%). También las regiones especializadas en industria manufacturera que, en términos globales, decayó más que el conjunto de la actividad económica muestran un efecto estructural negativo, aunque algo más ligero; este 


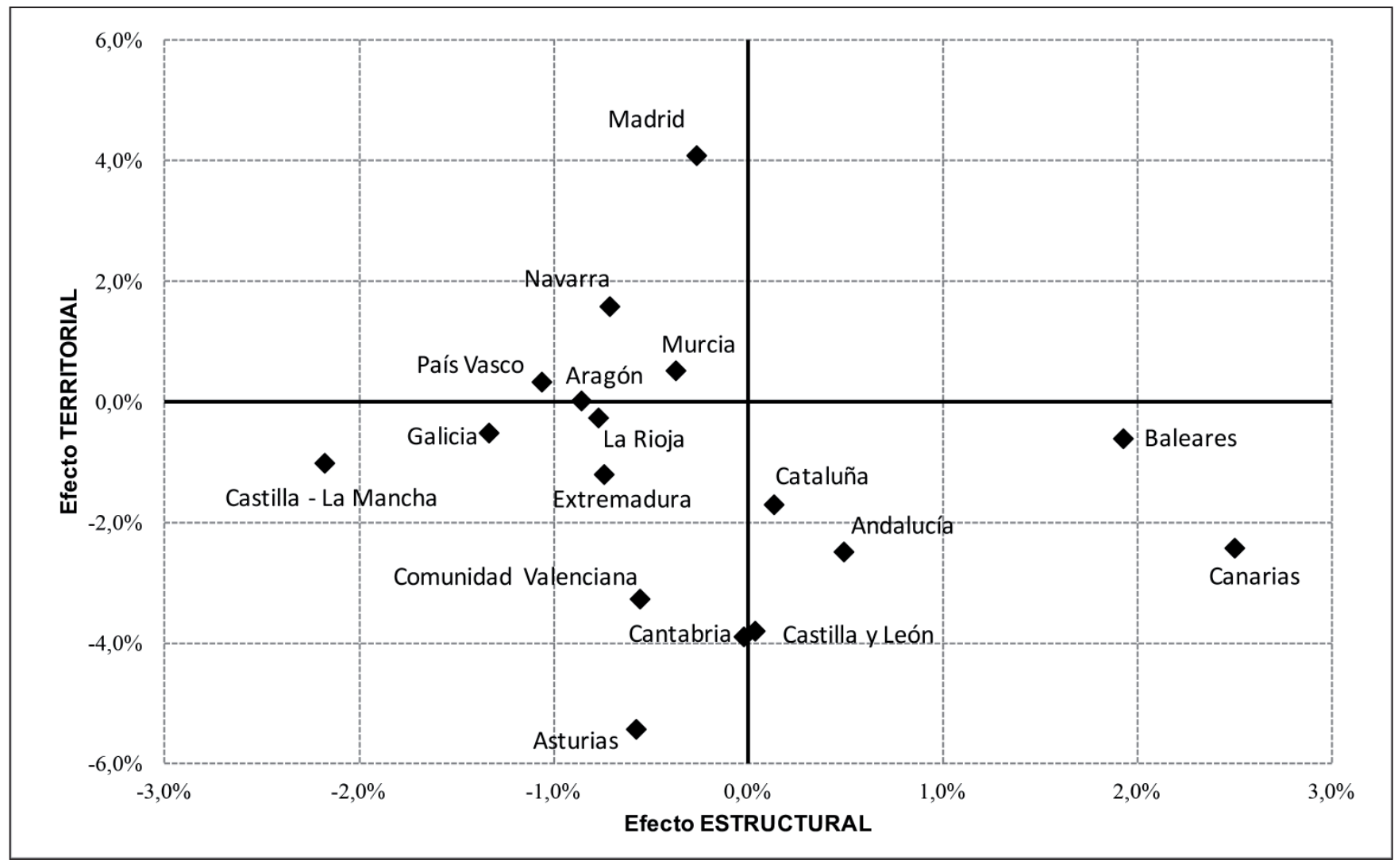

Figura 3. Análisis shift-share espacial. VAB. 2008-2013. Efectos estructural y territorial. Fuente: INE, Contabilidad Regional de España, serie homogénea. Elaboración propia.

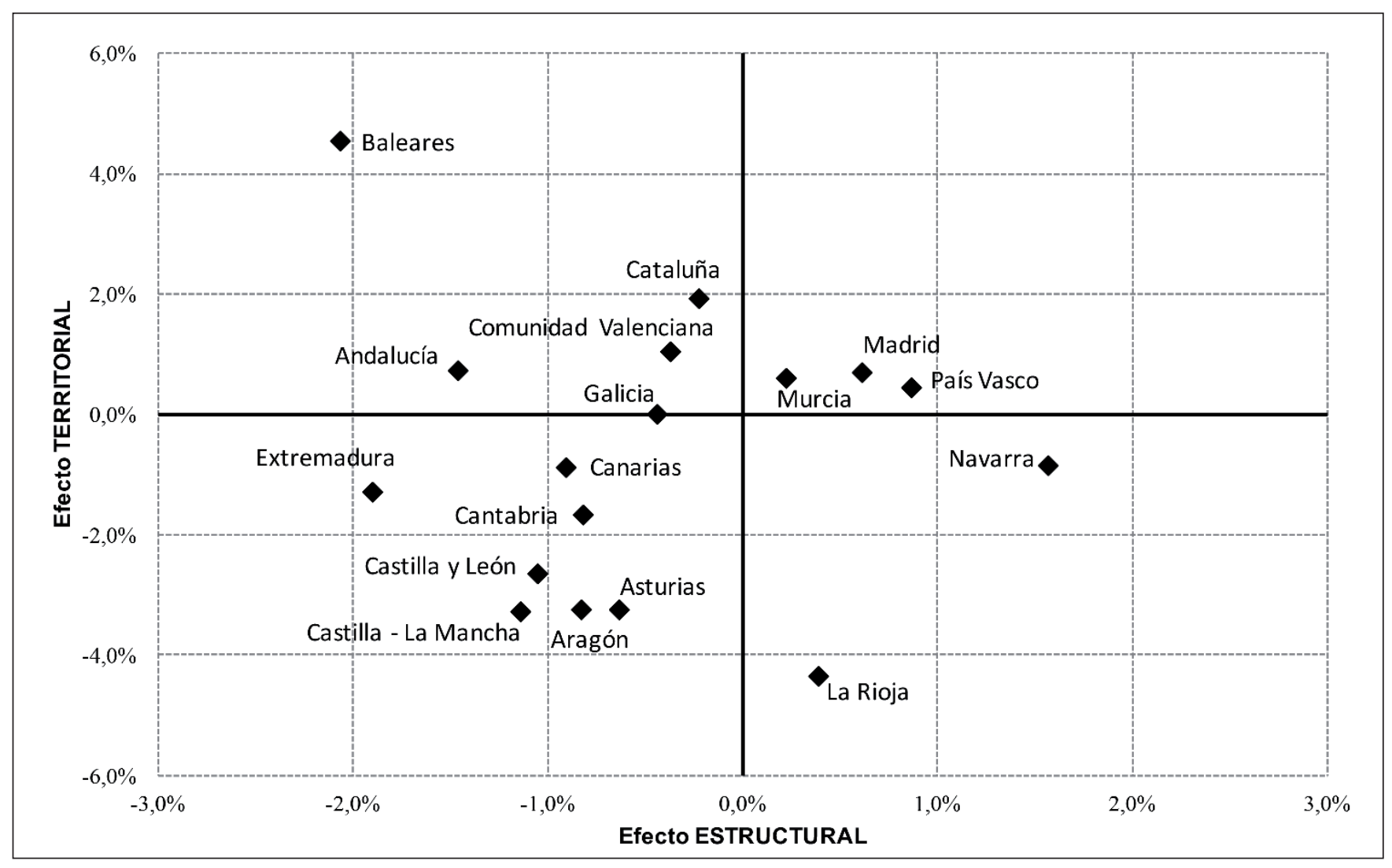

Figura 4. Análisis shift-share espacial. VAB. 2013-2017. Efectos estructural y territorial. Fuente: INE, Contabilidad Regional de España, serie homogénea. Elaboración propia. 
es el caso de la Comunidad Valenciana donde además existe un cierto impacto negativo derivado de la especialización en el sector de la construcción (-0.55\%), el País Vasco (-1.06\%), Navarra (-0.71\%), Aragón (-0.86\%) o la Rioja (-0.76\%). Otras regiones muestran un efecto estructural neutro, muy próximo a 0 , entre las que merece la pena mencionar Madrid, donde el efecto es ligeramente negativo (-0.27\%) como consecuencia de la especialización en el sector financiero, y Cataluña, donde es mínimamente positivo $(+0.13 \%)$ por su ligera especialización turística.

El tránsito de la recesión al crecimiento en el escenario postcrisis que se abre en 2013 es testigo de un cambio radical en los sectores económicos líderes y también en el efecto estructural que acusan las regiones. Ahora son la industria manufacturera, el sector financiero y las actividades profesionales y de servicios a las empresas, los que presentan crecimientos generales más elevados, a los que se añade el sector agrario que mantiene su buena dinámica anterior. En consecuencia, las regiones turísticas, especialmente Baleares (-2.07\%) y Canarias (-0.90\%), pero también Cataluña (-0.23\%) o Andalucía (-1.46\%), pierden ahora su ventaja anterior, mientras que entre las regiones que mejoran el componente estructural destacan Madrid (+0.61\%), que hace valer su especialización en actividades financieras y profesionales y servicios a las empresas, el País Vasco $(+0,87 \%)$, con especialización en industria manufacturera, o Navarra $(+1,56 \%)$, La Rioja $(+0,39 \%)$ y Murcia $(+0,22 \%)$, que la principal especialización en industria manufacturera se combina con una cierta y favorable especialización agraria. Finalmente, otras regiones con un cierto peso de la industria manufacturera y estructuras sectoriales bastante equilibradas, como la Comunidad Valenciana (-0,37\%), también mejoran su componente estructural, aunque este siga siendo todavía ligeramente negativo.

\subsection{Efecto territorial}

Finalmente, el efecto territorial es probablemente el más interesante y el que tiene una interpretación más compleja. Una vez depurados los aportes al crecimiento derivados de la posición relativa de la región en la red de interacción interregional y de la propia estructura sectorial y su carácter más o menos proclive al crecimiento, el resto que nos queda, el componente territorial, muestra el comportamiento diferencial de los sectores en la región, reflejo de una competitividad que encuentra su raíz en características propias del territorio y que deberíamos poder relacionar con el funcionamiento, entre otras cuestiones, de economías externas de localización y urbanización.

Su impacto es claramente superior al de los otros dos componentes, con un rango que oscila entre el $+4,07 \%$ de Madrid y el $-5,43 \%$ de Asturias en $2008-13$, y entre el $+4,52 \%$ de Baleares y el $-4,35 \%$ de la Rioja en 2013-17.

En los años de fuerte crisis, el relativo mejor comportamiento de Madrid $(+4,07 \%)$ y de algunas regiones de alto nivel de renta como Navarra $(+1,58 \%)$ o el País Vasco $(+0,33 \%)$ puede ponerse en relación con estructuras empresariales y entornos institucionales más favorables; en el lado opuesto, este componente territorial fue especialmente negativo en regiones de vieja industrialización (Asturias, -5.43\%; Cantabria, -3,90\%) o en regiones en las que el estallido de la burbuja inmobiliaria y la crisis bancaria se hicieron más patentes (Comunidad Valenciana, -3.27\%; Andalucía, -2.49\%).

La fase de crecimiento ha introducido cambios sensibles en este panorama. A partir de 2013 son las regiones del Mediterráneo (Cataluña, $+1.91 \%$; Baleares, $+4.52 \%$; Comunidad Valenciana, $+1.04 \%$; Murcia, $+0.61 \%$; Andalucía, $+0.73 \%$ ) las que se muestran más dinámicas y competitivas; fuera de este ámbito, solo Madrid $(+0,70 \%)$ y el País Vasco $(+0.45 \%)$ registran un componente positivo, mientras que Galicia, Canarias y Navarra se sitúan en una zona neutra. El resto de regiones del interior, incluido el valle del Ebro que muestra un deterioro notorio, presenta componentes territoriales claramente negativos, destacando La Rioja (-4.35\%), Aragón (-3.26\%), Castilla la Mancha (-3.27\%), Castilla y León (-2.64\%) y Asturias $(-3.23 \%)$. 


\section{DISCUSIÓN}

Los resultados obtenidos con el análisis shift-share permiten discutir el papel que han tenido en la evolución reciente de las regiones españolas los tres ámbitos de análisis propuestos: vecindad, especialización y aglomeración. El papel de cada uno de estos efectos, además, ha cambiado entre la fase de crisis y la de posterior recuperación lo que aconseja realizar análisis diferenciados.

\subsection{Vecindad}

En el contexto de los años de fuerte crisis, los efectos beneficiosos derivados de la vecindad, es decir de que el espacio de relaciones externas propio de cada región fuera especialmente dinámico, paliaron en alguna medida la caída de actividad en algunas comunidades autónomas. Éste fue el caso de buena parte del interior peninsular y de las regiones del noroeste que estaban mejor conectadas con Madrid, o de Cataluña que se beneficia de relaciones especialmente intensas con dos regiones que se comportan relativamente mejor: Madrid y Baleares. También se observa algún efecto de vecindad positivo en el entorno del País Vasco, especialmente en Cantabria y Castilla y León. El panorama cambia radicalmente cuando entramos en la fase de crecimiento. En este momento, las dinámicas más positivas se trasladan a las comunidades del litoral mediterráneo (Baleares, Cataluña, Comunidad Valenciana y Murcia) y son estas regiones, que presentan muchas interrelaciones mutuas, y otras áreas próximas como Aragón, Castilla-La Mancha o Andalucía, las que más se benefician de los efectos positivos de la vecindad. En definitiva, los efectos de derrame desde Madrid y el País Vasco sirvieron durante los años de recesión como un factor de cierta resistencia frente a la crisis para las regiones del interior y del norte de España. Sin embargo, cuando el crecimiento se recupera, y vuelve a entrar en funcionamiento el eje mediterráneo de desarrollo es en este corredor y en las regiones mejor conectadas con él donde se observa los mayores derrames positivos para el crecimiento.

En todo caso, se trata en cualquier caso de efectos pequeños, que incluso se reducen en la fase de recuperación, y bastante menores a los que se registran como consecuencia de las aportaciones al crecimiento de los componentes estructural (especialización) y territorial (aglomeración).

\subsection{Especialización}

La diferente especialización sectorial, muy visible incluso a una escala territorial tan agregada como es la comunidad autónoma, ha tenido un fuerte impacto en la evolución regional que, además, ha ido cambiando a medida que la recesión dejaba paso a la recuperación.

En los años de recesión, era fundamentalmente la especialización en el sector turístico, y en menor medida en el sector primario (agricultura, ganadería y pesca), la que permitió paliar en algunas regiones los efectos de la crisis, algo particularmente visible en las islas Baleares y Canarias; en cambio, la especialización en el sector de la construcción, y en menor medida en la industria manufacturera, agudizó la crisis en los casos de Castilla-la Mancha o la Comunidad Valenciana.

Por el contrario, en los años en que se recupera el crecimiento, aunque las actividades ligadas al turismo y el sector agrario siguen creciendo por encima de la media, el liderazgo en el crecimiento pasa a la industria manufacturera, los servicios financieros y los servicios profesionales y a las empresas. Son ahora las regiones industriales y Madrid las que de forma más nítida mejoran su componente estructural de crecimiento. El liderazgo de estos sectores se entiende mejor en el marco del nuevo modelo de desarrollo emergente con la salida de la crisis, mucho más orientado hacia la demanda externa y apoyado en el proceso de devaluación interna de precios y salarios derivado de la crisis. El sector agrario, la industria manufacturera y un turismo cada vez más internacional constituyen los nuevos sectores de base de las economías regionales, apoyados en la expansión de los servicios avanzados (información y comunicaciones, financieros, profesionales y a las empresas) que a su vez constituyen nuevos sectores básicos en las principales economías metropolitanas y muy significativamente en Madrid, que asume las funciones de ciudad global (Sánchez Moral, 2010). 
Aunque los sectores líderes han ido cambiando entre la fase de crisis y la de recuperación, la naturaleza del proceso es la misma y es posible por tanto detectar tendencias muy estables y que tiene una dimensión territorial muy llamativa. Así, entre 2008 y 2017 se observa una tendencia estable y constante hacia la concentración territorial de los diferentes sectores de actividad económica y muy significativamente de los que hemos identificado como sectores de base de las economías regionales o de servicios avanzados (Tabla 2). Los coeficientes de localización de la mayor parte de los sectores económicos experimentan un fuerte incremento entre 2008 y 2017, muy significativamente en los casos de la agricultura $(+0,075$, de 0,762 a 0,837$)$, la industria manufacturera $(+0.035$, de 0,355 a 0,390$)$ y en servicios avanzados: Información y comunicaciones $(+0,080$, de 0,492 a 0,571) o actividades profesionales y servicios a las empresas $(+0,036$, de 0,291 a 0,327). Incluso los servicios financieros han seguido esta tendencia hacia la concentración territorial, aunque en este caso solo a partir de 2013 y una vez superados los efectos de la crisis $(+0,011$, de 0,158 a 0,169$)$.

Como es de esperar, esta creciente concentración territorial de los diferentes sectores se deja sentir en una creciente especialización de las estructuras regionales (Tabla 3). Los coeficientes de especialización de las comunidades autónomas crecen en líneas generales entre 2008 y 2017. Esto ocurre en todo tipo de regiones, desde las de fuerte especialización agraria como Extremadura (+0,048, de 0,316 a 0,377), hasta las de especialización turística como Baleares $(+0,061$, de 0,316 a 0.377) o Canarias $(+0,037$, de 0,292 a 0,328), industrial como Cantabria (de 0,145 a 0,179), Navarra (+0,026, de 0,289 a 0,315), Aragón $(+0,024$, de 0,183 a $0,207)$ o el País Vasco $(+0,023$, de 0,218 a 0,241), o de carácter metropolitano como Madrid $(+0,022$, de 0,282 a 0,304). Esta dinámica reciente de especialización también es visible, atenuada, en Andalucía o en la Comunidad Valenciana, donde la crisis fue especialmente profunda y las tendencias hacia la especialización solo son visibles a partir de 2013 (Andalucía, de 0,199 a 0,219; Comunidad Valenciana, de 0.109 a 0,114), o incluso en una región con una estructura productiva tan diversificada como Cataluña (de 0,139 a 0,144).

\subsection{Aglomeración: economías de localización y urbanización}

Más que en factores de tipo posicional o sectorial, la dinámica de salida de la crisis se está apoyando en las ventajas competitivas internas con que cada región cuenta, y que ha construido través de su peculiar trayectoria de desarrollo. Incluso a esta escala regional, muy agregada y heterogénea, es posible detectar el funcionamiento de economías de aglomeración, tanto de localización (especialización) como de urbanización (escala y gama).

La nueva dinámica territorial de la actividad económica en España que se inicia con la crisis en 2008 y que continúa hasta la actualidad, se deja sentir en dos procesos que discurren en paralelo, 1) la profundización en la concentración territorial de los sectores y 2 ) la especialización sectorial de los territorios. Estos procesos son el resultado de la respuesta que las distintas regiones han dado a los desafíos que ha planteado la crisis. En un contexto de globalización y creciente importancia del mercado internacional, cada región ha tendido a profundizar en las especializaciones previas en las que se podía alcanzar una mayor competitividad en virtud de la existencia de los necesarios recursos, cualificaciones, experiencia, tejido empresarial previo y servicios e industrias auxiliares, en definitiva, en aquellas actividades en las que se podía contar con suficientes economías de localización previas. Así, la crisis y la posterior recuperación ha tenido el efecto de fortalecer aglomeraciones sectoriales preexistentes. Este proceso tiene además continuidad en el tiempo: aunque comienza en la fase de contracción de la actividad se mantiene durante la fase de recuperación. Los cambios observados en las pautas de localización de las actividades económicas y en los niveles de especialización regional no son el fruto de una mera adaptación pasiva como consecuencia de la caída generalizada del sector de la construcción, sino que están mostrando procesos activos de crecimiento diferencial en base a las fortalezas internas de cada territorio.

Las matrices de localización-especialización construidas permiten vislumbrar donde están teniendo lugar estos procesos y a qué sectores están afectando. Para detectarlos hemos seleccionado aquellos casos en los que están teniendo lugar entre 2008 y 2017 procesos de profundización en especializaciones preexistentes. 
Tabla 2. Coeficientes de localización de los sectores de actividad económica. en las comunidades autónomas (20082013-2017).

\begin{tabular}{|c|c|c|c|c|}
\hline \multirow{2}{*}{ Sector de actividad } & \multicolumn{4}{|c|}{ Coeficiente de localización } \\
\hline & 2008 & 2013 & 2017 & $\Delta 2008-2017$ \\
\hline Información y comunicaciones & 0,492 & 0,537 & 0,571 & 0,080 \\
\hline Agricultura, ganadería y pesca & 0,762 & 0,792 & 0,837 & 0,075 \\
\hline Actividades profesionales y servicios a empresas & 0,291 & 0,327 & 0,327 & 0,036 \\
\hline Industria manufacturera & 0,355 & 0,369 & 0,390 & 0,035 \\
\hline Minería, energía y agua & 0,176 & 0,189 & 0,183 & 0,008 \\
\hline Actividades artísticas y otros servicios & 0,081 & 0,082 & 0,086 & 0,005 \\
\hline Actividades inmobiliarias & 0,149 & 0,154 & 0,154 & 0,004 \\
\hline Comercio, transporte y hostelería & 0,091 & 0,094 & 0,087 & $-0,004$ \\
\hline Administración pública, salud y educación & 0,140 & 0,136 & 0,135 & $-0,004$ \\
\hline Construcción & 0,151 & 0,144 & 0,142 & $-0,009$ \\
\hline Actividades financieras y de seguros & 0,180 & 0,158 & 0,169 & $-0,011$ \\
\hline
\end{tabular}

Fuente: INE, Contabilidad Regional de España, serie homogénea. Elaboración propia.

Tabla 3. Coeficientes de especialización de la estructura sectorial de las comunidades autónomas (2008-2013-2017).

\begin{tabular}{|c|c|c|c|c|}
\hline \multirow{2}{*}{ Comunidad autónoma } & \multicolumn{4}{|c|}{ Coeficientes de especialización } \\
\hline & 2008 & 2013 & 2017 & $\Delta 2008-2017$ \\
\hline Baleares & 0,316 & 0,357 & 0,377 & 0,061 \\
\hline Extremadura & 0,360 & 0,370 & 0,408 & 0,048 \\
\hline Canarias & 0,292 & 0,298 & 0,328 & 0,037 \\
\hline Cantabria & 0,145 & 0,163 & 0,179 & 0,034 \\
\hline Navarra & 0,289 & 0,326 & 0,315 & 0,026 \\
\hline Aragón & 0,183 & 0,204 & 0,207 & 0,024 \\
\hline País Vasco & 0,218 & 0,228 & 0,241 & 0,023 \\
\hline Madrid & 0,282 & 0,286 & 0,304 & 0,022 \\
\hline Murcia & 0,124 & 0,130 & 0,144 & 0,019 \\
\hline La Rioja & 0,270 & 0,319 & 0,281 & 0,012 \\
\hline Andalucía & 0,209 & 0,199 & 0,219 & 0,010 \\
\hline Castilla y León & 0,212 & 0,224 & 0,222 & 0,010 \\
\hline Cataluña & 0,139 & 0,143 & 0,144 & 0,005 \\
\hline Comunidad Valenciana & 0,113 & 0,109 & 0,114 & 0,001 \\
\hline Castilla-La Mancha & 0,267 & 0,283 & 0,267 & 0,000 \\
\hline Galicia & 0,161 & 0,161 & 0,141 & $-0,020$ \\
\hline Asturias & 0,162 & 0,137 & 0,138 & $-0,024$ \\
\hline
\end{tabular}

Fuente: INE, Contabilidad Regional de España, serie homogénea. Elaboración propia. 
Es decir, seleccionaremos aquellos sectores/regiones que presentaban cocientes de localización superiores a 1 en 2008 y que se han incrementado entre esta fecha y 2017 (Figura 5 y Tabla 4).

La presencia y fortalecimiento de economías de localización, que intuimos a partir de la evolución de la especialización productiva en determinadas regiones, debería reflejarse en un componente territorial del crecimiento superior y creciente. Este es el caso de las dos regiones insulares y del conjunto de las comunidades del litoral mediterráneo, desde Cataluña a Andalucía. Fuera de este ámbito solo Galicia y el País Vasco muestran una dinámica claramente positiva. Si a estas comunidades añadimos Madrid, -que reduce la magnitud de su componente diferencial territorial, pero lo mantiene en valores positivos-, reunimos a todas las comunidades autónomas que están liderando el crecimiento español en esta fase de recuperación. En estos

Tabla 4. Fortalecimiento de la especialización y la localización en sectores de base económica y servicios avanzados durante la última década (2008-2013-2017).

\begin{tabular}{|c|c|c|c|c|c|}
\hline \multirow{2}{*}{ Sector de especialización } & \multirow{2}{*}{ Comunidades autónomas } & \multicolumn{4}{|c|}{ Cocientes de localización } \\
\hline & & 2008 & 2013 & 2017 & $\Delta 2008-2017$ \\
\hline \multirow{8}{*}{ Agricultura } & Extremadura & 2,65 & 2,31 & 3,11 & 0,48 \\
\hline & Aragón & 1,77 & 2,22 & 2,20 & 0,43 \\
\hline & Galicia & 1,74 & 1,98 & 2,08 & 0,34 \\
\hline & Castilla-La Mancha & 2,60 & 3,09 & 2,97 & 0,33 \\
\hline & Murcia & 1,62 & 1,87 & 1,93 & 0,31 \\
\hline & La Rioja & 2,28 & 2,10 & 2,50 & 0,22 \\
\hline & Andalucía & 2,04 & 1,97 & 2,15 & 0,11 \\
\hline & Comunidad Valenciana & 0,82 & 0,84 & 0,84 & 0,02 \\
\hline \multirow{9}{*}{ Industria manufacturera } & Murcia & 0,94 & 1,06 & 1,08 & 0,14 \\
\hline & Navarra & 1,94 & 2.15 & 2,05 & 0,11 \\
\hline & Cantabria & 1,30 & 1,35 & 1,38 & 0,08 \\
\hline & Castilla y León & 1,16 & 1,20 & 1,24 & 0,08 \\
\hline & Comunidad Valenciana & 1,06 & 1,11 & 1,14 & 0,08 \\
\hline & País Vasco & 1,75 & 1,80 & 1,82 & 0,07 \\
\hline & Aragón & 1,35 & 1,33 & 1,39 & 0,04 \\
\hline & La Rioja & 1,69 & 1,94 & 1,73 & 0,04 \\
\hline & Cataluña & 1,31 & 1.30 & 1,33 & 0,02 \\
\hline \multirow{2}{*}{ Comercio y hostelería } & Baleares & 1,50 & 1,52 & 1,57 & 0,07 \\
\hline & Canarias & 1,43 & 1,43 & 1,48 & 0,05 \\
\hline Información y comunicaciones & Madrid & 2,35 & 2,42 & 2,51 & 0,07 \\
\hline \multirow{3}{*}{$\begin{array}{l}\text { Actividades profesionales y ser- } \\
\text { vicios a empresas }\end{array}$} & Madrid & 1.71 & 1,80 & 1,76 & 0,05 \\
\hline & Cataluña & 1.08 & 1,07 & 1,10 & 0,02 \\
\hline & País Vasco & 0,94 & 0,96 & 0,96 & 0,02 \\
\hline
\end{tabular}

Fuente: INE, Contabilidad Regional de España, serie homogénea. Elaboración propia. 


\begin{tabular}{|c|c|c|c|c|c|c|}
\hline & Territorio & 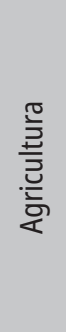 & 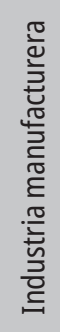 & 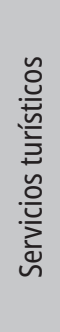 & 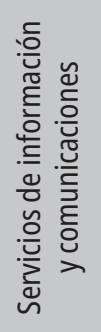 & 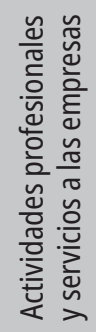 \\
\hline \multirow{2}{*}{ Regiones insulares } & Baleares & & & & & \\
\hline & Canarias & & & & & \\
\hline \multirow{2}{*}{ Regiones metropolitanas } & Madrid & & & & & \\
\hline & Cataluña & & & & & \\
\hline \multirow{2}{*}{$\begin{array}{l}\text { Regiones industriales del } \\
\text { norte }\end{array}$} & País Vasco & & & & & \\
\hline & Cantabria & & & & & \\
\hline Noroeste & Galicia & & & & & \\
\hline \multirow{3}{*}{ Regiones del interior } & Castilla y León & & & & & \\
\hline & Castilla-La Mancha & & & & & \\
\hline & Extremadura & & & & & \\
\hline \multirow{3}{*}{ Valle del Ebro } & Navarra & & & & & \\
\hline & La Rioja & & & & & \\
\hline & Aragón & & & & & \\
\hline \multirow{3}{*}{ Corredor mediterráneo } & Comunidad Valenciana & & & & & \\
\hline & Murcia & & & & & \\
\hline & Andalucía & & & & & \\
\hline
\end{tabular}

Figura 5. Presencia de procesos de fortalecimiento de aglomeraciones sectoriales (2008-2017). Fuente: INE, Contabilidad Regional de España, serie homogénea. Elaboración propia.

1. Regiones insulares (Baleares y Canarias): se detectan procesos muy activos en el sector turístico.

2. Principales regiones metropolitanas: en Madrid son observables de forma muy nítida y potente en los sectores de servicios avanzados de información y comunicación y servicios profesionales y a las empresas, mientras que en Cataluña estas dinámicas son algo más débiles y se restringen a los servicios profesionales y a las empresas, aunque también son evidentes tendencias de fortalecimiento de la industria manufacturera.

3. Regiones de antigua industrialización: en el País Vasco y Cantabria se encuentran tendencias al fortalecimiento de las aglomeraciones industriales, aunque en el primer caso estas tendencias positivas se extienden al sector de servicios profesionales y a las empresas lo que emparenta su evolución con las de las regiones con un carácter más metropolitano.

4. Cuadrante noroeste: se observan también este tipo de procesos ligados a la industria manufacturera en Castilla y León y a la agricultura y al turismo en Galicia.

5. Regiones del interior-sur: en Castilla-La Mancha y Extremadura se aprecian procesos muy intensos de sobre-especialización en agricultura.

6. Valle del Ebro: estos procesos se vinculan a la industria manufacturera en Navarra, la Rioja y Aragón, y en estas dos últimas también se observa una evolución positiva en el sector agrario.

7. Corredor mediterráneo: la industria es protagonista de estos procesos en la Comunidad Valenciana, mientras que en Murcia este dinamismo se observa en industria y agricultura, en Andalucía se restringe a la agricultura. 
casos, los procesos de creciente localización y aglomeración de la actividad económica afectan fundamentalmente al sector servicios, -tanto los servicios a la producción como los ligados a la actividad turística-, y a la industria, y el componente territorial, además de verse favorecido por la presencia de economías de localización, estaría también reflejando otros elementos de carácter más específico y propio de cada trayectoria regional pero entre los que probablemente, la presencia de economías de urbanización debe jugar un papel central. Por el contrario, y a pesar de mostrar algunos procesos de creciente localización de algunos sectores económicos (especialmente en agricultura y en industria), el conjunto de las regiones del interior peninsular- incluido el valle del Ebro- y del arco atlántico (Asturias y Cantabria), estarían mostrando un menor dinamismo en la salida de la crisis.

La correspondencia entre un componente territorial del crecimiento positivo y la presencia de fenómenos de aglomeración y localización de sectores económicos existe, aunque no sea perfecta. En las regiones en las que este componente territorial es más alto y creciente están presentes estos fenómenos de localización sectorial y sobre especialización. No obstante, es también cierto que no siempre los procesos de aglomeración sectorial se muestran lo suficientemente potentes como para cristalizar en un componente territorial positivo o creciente, especialmente allí donde las economías de urbanización son débiles y/o la dinámica sociodemográfica general es marcadamente regresiva.

\subsection{Las raíces de la desigualdad: el territorio importa}

En apoyo a la Estrategia 2020, uno de los objetivos declarados de la Unión europea es la disminución de las disparidades económicas regionales a través de una política de cohesión a la que se destina un importante volumen de recursos, casi un tercio del presupuesto comunitario en el período 2014-2020. Pese a ello, la desigualdad regional en Europa es creciente siguiendo una tendencia de largo plazo que se ha agudizado notablemente en la última década como efecto de la crisis, con importantes caídas reales del PIB y del PIB per cápita en buena parte del sur del continente, el continuo declive de antiguas regiones industriales y la creciente concentración de la actividad económica y de la riqueza en la grandes aglomeraciones urbanas, muchas de ellas ciudades globales y a menudo capitales de sus respectivos estados (European Union, 2018).

En el caso de España, la perdida de actividad y de riqueza como consecuencia de la crisis se ha saldado con un incremento de la desigualdad interregional. El carácter asimétrico de los efectos de la crisis y de la posterior recuperación ha conducido a una creciente concentración territorial de la actividad económica y a un mayor desequilibrio en términos de PIB per cápita. Así, el índice de concentración de Gini de la producción económica en relación a la superficie calculado para las 17 comunidades autónomas pasa de 0,783 en 2008 a 0,788 en 2017, mientras que el coeficiente de variación del PIB per cápita en las 50 provincias es creciente (0,200 en 2008 y 0,214 en 2015), mostrando la cada vez mayor disparidad de trayectorias y situaciones (Albertos, 2018). Este renovado impulso reciente hacia la desigualdad territorial es coherente con lo observado por otros autores (Cuadrado, 2010; Tirado et al., 2015; Diez et al. 2018), de forma que recientemente los territorios que presentan las mayores aglomeraciones y niveles de producción per cápita se han comportado relativamente mejor profundizando la divisoria entre regiones pobres y ricas.

La evolución de las regiones españolas en la última década avalaría la tesis de Amos (1988), según la cual la evolución de las disparidades regionales tendría a largo plazo una forma de N (aumento-descenso-aumento), mostrando un marcado incremento en las fases de desarrollo más avanzado. La tesis de Williamson (1965) según la cual los desequilibrios regionales seguirían una pauta de U invertida (aumento-descenso) tendría sentido solo en un contexto histórico determinado. La hegemonía y expansión del modo de acumulación fordista en los 30 Gloriosos (1945-1975), con la preponderancia de la industria manufacturera, la producción y el consumo en masa de bienes estandarizados y una intensa intervención del estado en la economía a múltiples niveles, acompaña y explica este descenso de las disparidades regionales ligado al crecimiento. Sin embargo, el cambio de paradigma hacia un modo de acumulación flexible post-fordista, basado en la diferenciación y segmentación de los mercados y de la producción y en el papel central de la 
información y sus tecnologías, ha alimentado un renovado proceso de incremento de las desigualdades, puesto que solo algunos territorios cuentan con los recursos tangibles e intangibles para ser competitivos en este nuevo entorno.

La visión desde el territorio es pues imprescindible para entender el reciente incremento de la desigualdad, y la creciente divergencia en las trayectorias seguidas por las regiones españolas. A partir de la discusión realizada en el apartado anterior podemos afirmar que esta evolución diferencial tiene una raíz fundamentalmente territorial.

A la luz de la evolución española de la última década, la especialización sectorial de las estructuras económicas regionales tiene un impacto relativamente pequeño, y sirve sobre todo para explicar por qué algunas regiones han resistido mejor la crisis, o por qué en otras ésta ha sido especialmente aguda. Sin embargo, para explicar el crecimiento hay que acudir a las bases territoriales del mismo. La evolución diferencial de las regiones tiene su base en el territorio, -es geográfica en su naturaleza-, entendiendo aquí el territorio como la expresión de un proceso histórico de desarrollo que ha generado economías de aglomeración, de urbanización y localización, que se traduce en competitividad. Es este el componente diferencial de origen territorial que hemos obtenido aquí, y que resulta compatible con los efectos positivos de la aglomeración detectados por Diez et al. (2018). Finalmente, aunque de menor entidad, la existencia del componente de vecindad, también aislado con el análisis shift-share espacial, permitiría en el largo plazo, explicar la lógica de la distribución espacial de regiones ricas y pobres en España, o por qué "las regiones pobres tienden a seguir pobres y a estar juntas" (Tirado et al., 2015).

\section{CONCLUSIONES}

La evolución económica seguida por las regiones españolas durante la última década, en la que se han sucedido una crisis muy aguda (2008-2013) y una recuperación post-crisis también intensa (2013-2017), se ha caracterizado por cambios en el modelo de desarrollo con consecuencias económicas, sociales y territoriales muy profundas. En el ámbito territorial, la salida de la crisis se ha resuelto con un marcado incremento de las desigualdades interregionales y una creciente concentración territorial de la actividad económica. La nueva pauta de crecimiento, muy ligada a la demanda internacional (turismo, exportaciones), ha concentrado el crecimiento en las regiones que contaban con ventajas competitivas en función de su peculiar dotación de recursos, de su trayectoria productiva y de la existencia de economías de localización y urbanización. Esto ha propiciado un proceso de profundización en especializaciones productivas previas aprovechando experiencia, conocimientos, y capacidades existentes, bien sea en la industria manufacturera, el turismo, la agricultura o los servicios avanzados. Aunque la escala regional de trabajo aquí utilizada no permite detallar estos procesos a la escala territorial subregional a la que estas aglomeraciones sectoriales se sustancian, sí podemos detectar su presencia y los sectores en que es presumible encontrarlas cuando llega a afectar las estructuras regionales.

La revitalización de la industria manufacturera es protagonista de muchos de estos procesos en buena parte de las regiones de especialización industrial del norte y noroeste (Castilla y León, Cantabria, País Vasco, Navarra), del valle del Ebro (La Rioja, Aragón) y del Mediterráneo (Cataluña, Comunidad Valenciana y Murcia). El sector de agricultura, ganadería y pesca está comportándose especialmente bien en la mitad sur peninsular, Galicia y parte del valle del Ebro (Aragón y La Rioja), mientras que las actividades asociadas al turismo incrementan su concentración principalmente en Baleares y Canarias aunque también se observan síntomas similares en Galicia. Finalmente, en Madrid son los sectores de servicios avanzados los que protagonizan estos procesos, que también están presentes, aunque de forma no tan intensa, en Cataluña y el País Vasco. Se trata de procesos de profundización en especializaciones productivas que contribuyen al fortalecimiento de economías de aglomeración/localización y que explican la existencia de un componente territorial diferencial positivo del crecimiento regional.

El componente territorial del crecimiento que hemos aislado para cada región y período con el análisis shift-share, una vez eliminadas las influencias de la vecindad y la estructura, puede considerarse como una 
aproximación al comportamiento diferencial de los sectores en los territorios dependiendo de elementos de carácter puramente local: trayectoria histórica, elementos institucionales y culturales, calidad del emprendimiento, estructura empresarial y un cúmulo de elementos que podemos englobar bajo el concepto de economías de aglomeración, tanto de localización como de urbanización. Es, por tanto, la fuerza subyacente fundamental de una configuración territorial del desarrollo económico en transformación, que se deja sentir sobre todo en el periodo de crecimiento que se inicia en 2013.

En efecto, puede afirmarse que existe una geografía de la recuperación económica muy diferente de la geografía de la crisis. En los años de recesión, solo Madrid, el País Vasco y Navarra presentan un componente territorial positivo como resultado de estructuras empresariales más sólidas y un comportamiento innovador más intenso, sin olvidar el papel que puede haber jugado en un contexto de depresión generalizada el contar con un sistema fiscal más saneado. Esta mayor resistencia a la crisis de los polos madrileño y vasco-navarro se habría traducido, además, en efectos de derrame hacia regiones vecinas que habrían sido especialmente evidentes en el cuadrante noroccidental y en parte del valle del Ebro. Al mismo tiempo, el componente territorial del crecimiento en las regiones del Mediterráneo, desde Cataluña a Andalucía, era marcadamente negativo, como consecuencia de un impacto mayor del pinchazo de la burbuja inmobiliaria y de la crisis financiera y fiscal asociadas. El impacto de la crisis fue sin duda, asimétrico, como también lo está siendo el impacto de la recuperación. A partir de 2013 son las regiones del Mediterráneo las que, junto al País Vasco y Madrid, lideran el crecimiento gracias, fundamentalmente, al espectacular aumento que experimenta su componente territorial. Este nuevo basculamiento hacia el Mediterráneo del mapa de crecimiento económico regional está en relación con estructuras económicas regionales más volcadas hacia mercados exteriores que construyen su competitividad, al menos en parte, gracias al aprovechamiento de economías de localización surgidas a partir de procesos de concentración espacial de la actividad y especialización territorial.

No obstante, los efectos de la aglomeración sectorial no explican en su totalidad los diferenciales observados en cuanto al componente territorial del crecimiento. Es preciso explorar también otras dimensiones explicativas que tienen más que ver con las economías de urbanización, tanto derivadas del tamaño urbano como de la variedad interna de las estructuras económicas, así como otros elementos específicos como el comportamiento innovador, elementos socio-institucionales o el capital humano. Es ésta una línea de investigación futura que debería permitir esclarecer cuáles han sido los factores determinantes del comportamiento regional diferencial tanto durante la crisis como en la recuperación. Ello permitirá calibrar mejor cuáles son los fundamentos de la actual recuperación económica, es decir, hasta qué punto, tal y como plantea Ricardo Méndez (Méndez et al., 2015, 267) citando a Jeffrey Sachs (2012) se está avanzando en el difícil proceso de "hacer una transformación productiva en medio de una crisis".

Parece claro, a partir de los análisis presentados en este trabajo, que esa transformación productiva está realmente teniendo lugar y que, además, este cambio productivo está asociado a una nueva 'solución espacial' (Harvey, 2001a, 2001b), una nueva configuración del mapa de crecimiento regional que no supone una simple vuelta a las pautas imperantes en los años previos a la crisis. Lo que queda por determinar es si efectivamente esta transformación productiva va en la línea de lograr un "crecimiento inteligente, equitativo y sostenible" (Méndez, 2016, 505). Un cierto retorno a la industria como recuperado sector básico en un buen número de regiones, o el espectacular desarrollo del sector de servicios avanzados a la producción en Madrid, y en menor medida en Cataluña y en el País Vasco, son elementos que apoyarían la tesis de que se está produciendo un cambio hacia unas bases más sólidas para el crecimiento. No obstante, se precisa de un análisis pormenorizado de base territorial que establezca cuales son los factores que explican los crecimientos más intensos; esto es, si los mayores componentes territoriales están asociados a comportamientos innovadores o a una superior cualificación del capital humano o, si, por el contrario, tienen más que ver con mejoras de la competitividad derivadas del proceso de devaluación interna (precios y salarios) o con dinámicas insostenibles a largo plazo en el uso (y abuso) de recursos territoriales. 


\section{REFERENCIAS}

Albertos, J.M. y Sánchez Hernández, J.L. (2014). Geografía de la crisis económica. Valencia, España: Publicacions de la Universitat de València.

Albertos, J.M. y Sánchez Hernández, J.L. (2017). Caracterización y especialización industrial y del terciario avanzado en las regiones españolas. En Farinós, J. y Olcina, J., Geografía Regional de España. Espacios y comunidades (pp. 291-370). Valencia, España: Tirant Humanidades.

Albertos, J.M. (2018). Las regiones españolas en la crisis. Ponencia en el VII Congreso de Estudios Regionales. Sevilla, España: Asociación de Geógrafos Españoles.

Amos, O. J. (1988). Unbalanced regional growth and regional income inequality in the latter stages of development. Regional Science and Urban Economics, 18.4, pp.549-566. doi: https://doi.org/10.1016/0166-0462(88)90026-9

Capello, R. (2016). Regional Economics (2nd ed.). Oxon: Routledge. doi: https://doi.org/10.4324/9781315720074

Capello, R. y Fratesi, U. (2012). Regional Growth: An Advanced MASST Model. Spatial Economic Analysis, 7.3, pp. $293-318$. doi: https://doi.org/10.1080/17421772.2012.694143

Cuadrado, J.R. (ed.). (2010). Regional policy, economic growth and convergence: Lessons from the Spanish Case. Heidelberg: Springer, $311 \mathrm{pp}$.

Díez, A., Galarraga, J. y Tirado, D.A. (2018). Regional inequality in Spain. 1860-2015, Basingstoke, Hampshire: Palgrave Macmillan. doi: https://doi.org/10.1007/978-3-319-96110-1

Dunn, E.S. (1960). A statistical and analytical technique for regional analysis. Papers of the Regional Science Association, 6 , pp. 97-112. doi: https://doi.org/10.1111/j.1435-5597.1960.tb01705.x

Esteban, J.M. (1972). A reinterpretation of shift-share analysis. Regional and Urban Economics, 2.3, pp.249-255. doi: https://doi.org/10.1016/0034-3331(72)90033-4

European Union (2018). Eurostat regional book. 2018 edition. Luxembourg: Publications Office of the European Union. doi: https://doi:10.2785/231975

Instituto Nacional de Estadística (INE). (2018) Contabilidad Regional de España. Serie Homogenea, Base 2010, $2000-2017$ [en línea]. Madrid, España: INE. Recuperado de http://www.ine.es/dyngs/INEbase/es/operacion.htm?c=Estadistica_C\&cid=1254736167628\&menu=resultados\&idp=1254735576581\#. Última consulta: 1 de octubre, 2018.

Harvey, D. (2001a). Spaces of Capital. Towards a Critical Geography. Nueva York: Routledge (tr. al español en Espacios del capital: hacia una geografía critica, Madrid: Akal, 2007)

Harvey. D. (2001b). Globalization and the 'Spatial Fix'. Geographische Revue, 3.2, pp. 23-30.

Haynes, K.E. y Parajuli, J. (2016). Shift-Share and its new extensions. En Karlssonm M., Andersson, M. y Norman, T. Handbook of Research Methods and Applications in Economic Geography (pp. 83-117). Cheltenham UK: Edward Elgar. doi: https://doi.org/10.4337/9780857932679.00010

Méndez, R. (2015). Geografía de la crisis. La mitad oriental de la Península y las islas se han mostrado más vulnerables al batacazo económico. El mapa de la crisis permite sacar lecciones cara al futuro. Alternativas económicas, 24, pp. 46-48

Méndez, R. (2016). Organización espacial del sistema económico en un contexto globalizado. En Romero, J, (ed.) Geografía humana de España: curso de introducción (pp. 449-525). Valencia, España: Tirant Humanidades.

Méndez, R., Abad, L. y Echaves, C. (2015). Atlas de la Crisis. Valencia: Tirant lo Blanch.

Ministerio de Fomento, (2007). Encuesta MOVILIA. 2006-2007. Principales resultados. Movilidad a larga distancia. Madrid, España: Ministerio de Fomento, 2007. Recuperado de http://www.fomento.gob.es/BE2/?nivel=2\&orden=27000000. Última consulta: 1 de abril, 2013.

Nazara, S. y Hewings, G. (2004). Spatial Structure and Taxonomy of Decompotition in Shift-Share Analysis. Growth and Change, 35.4, pp. 476-490. doi: https://doi.org/10.1111/j.1468-2257.2004.00258.x

Ramajo, J. y Márquez, M.A. (2008). Componentes espaciales en el modelo Shift-Share. Una aplicación al caso de las regiones peninsulares españolas. Estadística Española, 168, pp. 247-272.

Sachs, J. (2012). El precio de la civilización. Barcelona, España: Galaxia Gutenberg.

Sánchez Hernández, J.L. y Albertos, J.M. (2014). Dimensiones y escalas de la crisis económica en España: ¿Hay una alternativa territorial? En Albertos, J.M. y Sánchez Hernández, J.L., Geografía de la crisis económica en España (pp. 745770). Valencia, España: Publicacions de la Universitat de València. 
Sánchez Moral, S. (2010). Iberian Cities. En Taylor, P.J, Ni, P., Derudder, B-, Hoyler, M. Huang, J. y Witlox, F. (Editors), Global Urban Analysis: A Survey of Cities in Globalization (pp. 312-317). Londres: Earthscan.

Sánchez Moral, S. (2015). Territorio, transformación productiva, equidad y redes. Revista de Estudios Andaluces, 32, pp. 4975. doi: http://dx.doi.org/10.12795/rea.2015.i32.03

Tirado, D.A., Roses, J.R. y Martínez, J. (2010). The Long-Term Patterns of Regional Income Inequality in Spain (1860-2000). Madrid, España: Universidad Carlos III, Workings papers in Economic History, WP 10-08, 23 pp.

Tirado, D.A., Díez, A. y Martínez, J. (2015). A closer look at the long-term patterns of regional income inequality in Spain: The poor stay poor (and stay together). Valencia, España: Instituto Valenciano de Investigaciones Económicas, Working paper, Serie EC, WP-EC 2015-05, 32 pp. doi: http://dx.medra.org/10.12842/WPASEC-2015-05

Williamson, J.G. (1965). Regional inequality and the process of national development: a description of the patterns. Economic Development and Cultural Change, 13.4, pp. 1-84. doi: http://dx.doi.org/10.1086/450136. 


\title{
Transporte Marítimo, Redes Portuarias Atlánticas y Mediterráneas. El Ejemplo de Canarias
}

\section{Maritime Transport, Atlantic and Mediterranean Port Networks The Example of the Canary Islands}

\author{
Gerardo Delgado-Aguiar \\ gerardo.delgado@ulpgc.es @ https://orcid.org/0000-0002-5947-0483 \\ José Ángel Hernández-Luis \\ jose.hernandez@ulpgc.es @ https://orcid.org/0000-0002-7680-2574 \\ Departamento de Geografía. Universidad de Las Palmas de Gran Canaria. \\ Calle Pérez del Toro, 1. 35004-Las Palmas de Gran Canaria.
}

\section{INFO ARTÍCULO}

Recibido: 6/12/2018

Revisado: 3/4/2019

Aceptado: 8/5/2019

\section{PALABRAS CLAVE}

Puertos

Transporte marítimo

Sistemas de redes

Espacios regionales

Canarias

\section{KEYWORDS}

Ports

Maritime transport

Network systems

Regional spaces

Canary islands

\section{RESUMEN}

El transporte marítimo presenta en la actualidad un papel fundamental en las relaciones socioeconómicas a nivel mundial. Determinadas políticas como la globalización, no podrían comprenderse sin el desarrollo de la conectividad marítima y su grado de accesibilidad. El objetivo de este trabajo, además de realizar una aproximación al marco teórico y metodológico, es poner en relación el desarrollo con el transporte marítimo, y su aplicación al caso concreto de Canarias, donde analizamos su accesibilidad desde el punto de vista de la conectividad y, en particular, de los horarios y tarifas en el contexto de la propuesta del Eje Transinsular de Transportes, una política encaminada a cohesionar el territorio a través del transporte marítimo y terrestre. Se ahonda en las deficiencias de accesibilidad, discutiendo sus debilidades.

\begin{abstract}
Maritime transport currently plays a key role in global socio-economic relations. Certain policies, such as globalization, could not be understood without the development of maritime connectivity and its degree of accessibility. The aim of this work, in addition to making an approximation to the theoretical and methodological framework, is to relate development to maritime transport and its application to the specific case of the Canary Islands, where we analyse accessibility from the point of view of connectivity and, in particular, timetables and taxes in the context of the proposal for the Transinsular Axis of Transport, a policy aimed at cohering the territory through maritime and land transport. It delves into accessibility deficiencies, discussing their weaknesses.
\end{abstract}




\section{INTRODUCCIÓN}

Esta contribución se sustenta en tres ejes de un proyecto de investigación ${ }^{1}$ en desarrollo:

a. Las infraestructuras de transporte marítimo contribuyen a la transformación económica del territorio, especialmente en ámbitos regionales y subregionales.

b. El territorio es el escenario de los procesos de localización y, en consecuencia, de materialización de la movilidad y el transporte.

c. Los puertos europeos (atlánticos y mediterráneos) y los africanos forman parte de un proceso de globalización articulada y jerarquizada a través de redes intrincadas, asignando funciones y especialización portuaria marítima.

De una parte, uno de los objetivos principales se centra en el rol que desempeña el transporte en el territorio y, de modo particular, el transporte marítimo, aportando algunas reflexiones y análisis teórico conceptuales de base para comprender la función espacial del transporte marítimo, en especial, en ámbitos insulares. De otra, se aborda una visión conceptual geográfica y topológica de las redes de transporte para mostrar el escenario de las redes de transporte marítimo en el Atlántico medio y oriental, analizando el caso de Canarias.

Los puertos de Canarias están insertos en una estructura modular doble: insular y exterior, ocupando los puertos principales una posición de liderazgo regional y una posición de hub de segundo o tercer orden en el Atlántico medio occidental.

Los espacios regionales se organizan en múltiples formas y aparecen dotados de cualidades diversas que han sido determinadas por la posición que ocupan en una jerarquía más compleja de espacios, constituyendo un conjunto extenso de conexiones que interactúan jerárquicamente. Representa una estructura topológica de espacios que forman sucesivos conjuntos (con nodos espaciales) homogéneos o heterogéneos. Adopta una forma poligonal arbórea (figura 1), en donde diferentes áreas y unidades asumen un rol específico según las dimensiones, cualidades naturales, condiciones ambientales intrínsecas y el rango del vínculo que establece con los demás, creando así una jerarquización del sistema (Newman, 2003, 2).

Las aportaciones a este análisis, desde una perspectiva geográfica, son numerosas y fecundas, destacando las referencias a Taylor y Potrykowski (1984), Haggett (1976, 1988), Hoyle (1998), Rodrigue (2006, 2013) y Lavissière (2017); aunque hay también otras interesantes contribuciones que proceden del análisis económico regional.

Las conexiones y las redes expresan los flujos e intercambios de bienes y personas (movilidad), sin reciprocidad por igual en las dimensiones de valor y volumen, pues cada unidad territorial, portuaria, ha adquirido o desarrollado propiedades que le han sido asignadas por su posición, distancia y acceso a los recursos. La existencia de un espacio de máximo valor y, en consecuencia, de elevada centralidad se debe a la existencia de otros periféricos, pues, por sí mismos, aislados, no podrían ser autónomos y constituirían unidades autárquicas y caóticas, con tendencia a la extinción por la pérdida de sus propiedades iniciales. El espacio económico actual dibuja territorialmente un grafo abierto, con múltiples entradas y numerosas salidas como corresponde a un complejo sistema relacional dinámico. El valor de cada punto está representado por el conjunto de propiedades (naturales, demográficas, económicas, tecnológicas, culturales, ...) que han sido definidas históricamente por sus respectivas formaciones sociales y que han conformado sus características actuales. Incluso pueden aparecer lugares de menor rango, aislados y sin trabazón con la red principal, que podrán ser incorporados en el momento en que el propio sistema de transporte necesite de su intervención, bien por razones estratégicas o, incluso, por sus nuevas cualidades y oportunidades. Otros, de nivel secundario, podrían alcanzar un estatus superior y crecer de modo significativo.

Las redes de transporte favorecen la formación de estos espacios y estructuras territoriales. Una compleja malla de líneas y conexiones facilitan el flujo entre los nodos y establece el grado de accesibilidad y de

1. "Global South. Puertos y desarrollo económico y social en el Atlántico meridional (1850-2010)", Proyecto HAR201564044-R y Red de Excelencia HAR2016-81812-REDT, Ministerio de Economía y Competitividad. 
transferencia entre ámbitos locales, regionales o nacionales (figura 2). En amplios y extensos espacios continentales desarrollados (Norteamérica y Europa) han dado lugar a sistemas y subsistemas cohesionados y funcionalmente estructurados (Rodrigue, 2013). Por el contrario, en otros, de menor amplitud y fragmentados, debemos reflexionar y aportar análisis específicos en cada caso; por ejemplo, en las áreas insulares o, por el contrario, en extensos territorios que ha sido aislados por el borde fronterizo que impone el relieve abrupto. No obstante, la tecnología, la planificación y la financiación resuelve en gran medida algunos de esos obstáculos y mejora la posición de un nodo particular.

\section{MARCO TEÓRICO}

\subsection{Las infraestructuras de transporte marítimo en la organización espacial y económica del territorio}

La historia de la humanidad está trazada en el territorio y sus huellas nos muestran un proceso continuo de búsqueda de lugares con nuevos recursos, incorporándolos al dominio humano y a su explotación. Un territorio está constituido por multitud de espacios entrelazados a través de sus componentes. Éstos le atribuyen las características de función, ocupación, extensión, influencia, estratificación, escala y valor. Pero, por sí mismo, el territorio, aislado, sin la presencia humana, sin actividad alguna, no posee interés económico y queda marginal o en reserva a la expectativa de nuevas tecnologías que transformen favorablemente su valor (cambio/uso). De este modo, la tecnología y la acción humana añaden cualidades que realzan e integran un territorio en la maquinaria de la producción capitalista. El territorio se convierte en espacio productivo y consumido. Es, por tanto, el lugar en el que intervienen todos los agentes y procesos de la economía capitalista, del que históricamente las sociedades que conocemos se han apropiado de sus valiosos recursos para la subsistencia, desarrollo y expansión. Tres fases, por tanto, que identifican la historia económica, de modo genérico, con sus matices regionales y locales.

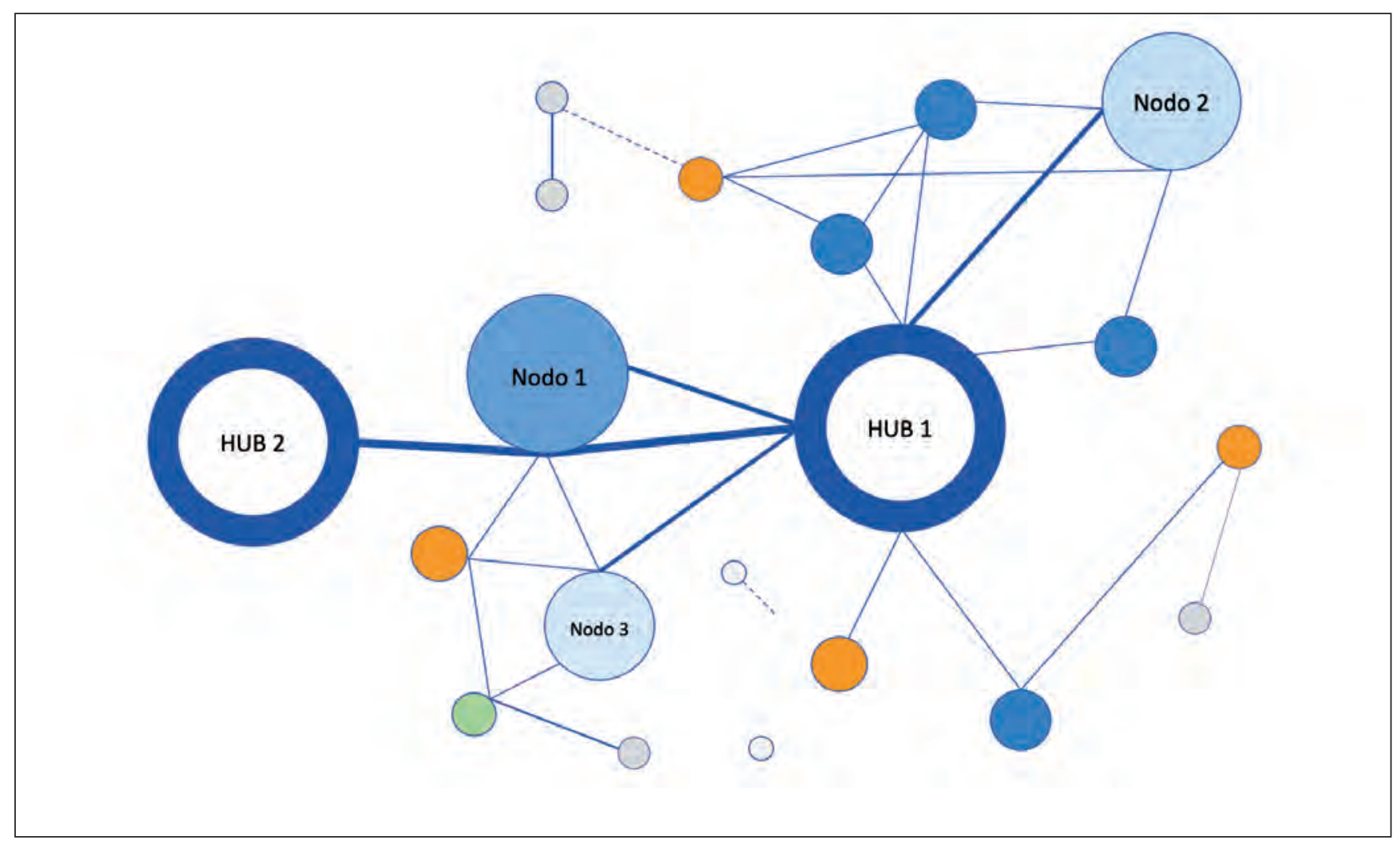

Figura 1. Red espacial y jerarquizada de un sistema regional de nodos de transporte. Fuente: Elaboración propia. 


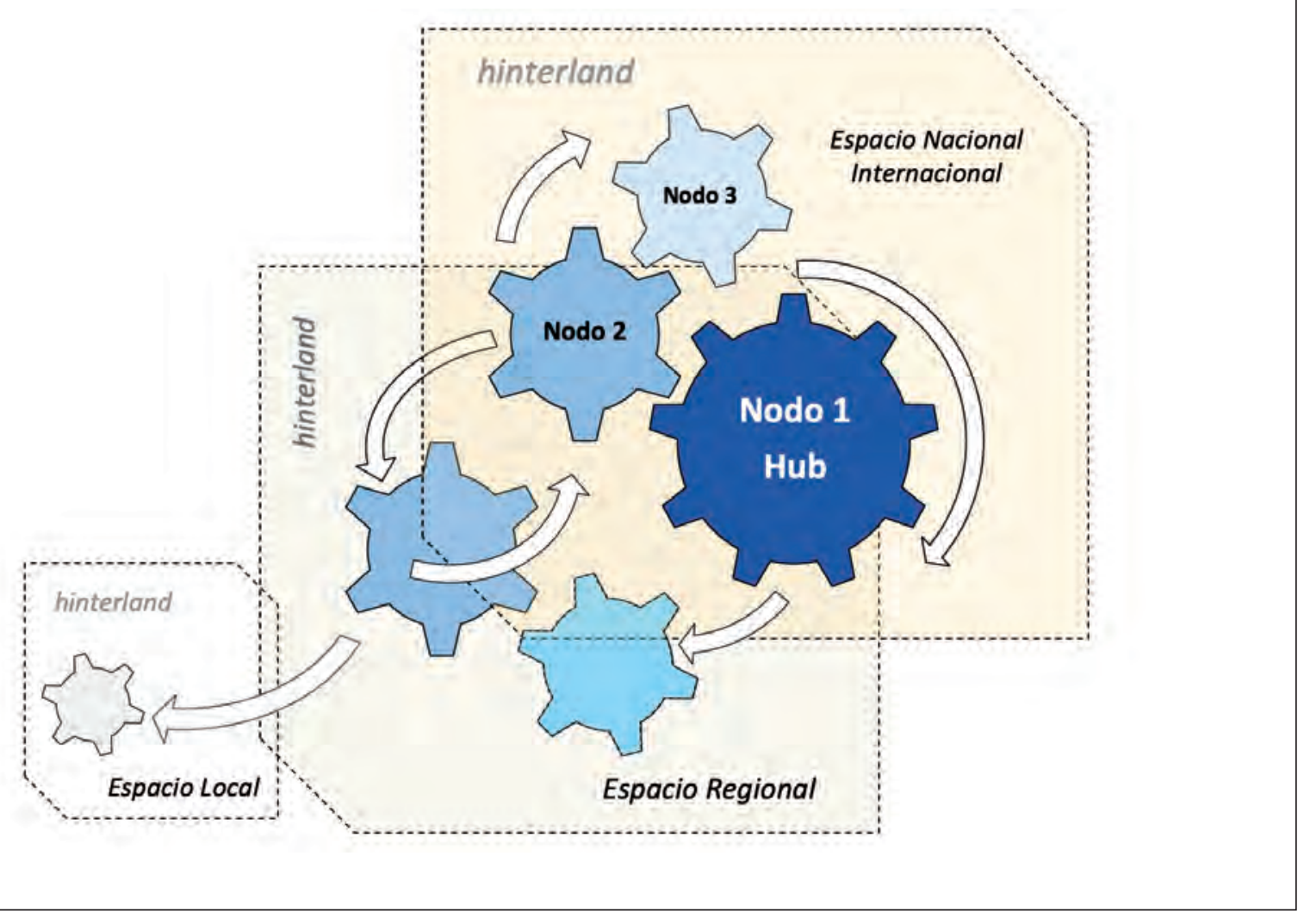

Figura 2. Engranaje nodal en el espacio regional. Fuente: Elaboración propia.

Las infraestructuras consumen territorio y le agregan valor, incluso en amplias zonas casi inertes. En consecuencia, son unidades físicas que facilitan y favorecen la conexión entre las piezas de un territorio (sea cual sea su escala) a modo de hub que recibe, almacena, discrimina, clasifica, organiza, intercambia, procesa y distribuye a otros de categoría idéntica, inferior o superior (figura 3). La intermodalidad adquiere un papel protagonista determinante. En la literatura geográfica y económica corresponde a regiones o sistemas regionales complejos (Vallega, 1995) con el arbitrio de centros operacionales complejos que actúan de gateway (figura 4). Podemos afirmar que se trata de un núcleo de movilidad perenemente activo y oscilante, desempeñando el rol que le reserva el sistema en cada momento histórico, adquiriendo o perdiendo rango y orden.

La movilidad es un factor clave que añade valor a los bienes y servicios que necesitan soportes físicos estratégicos. Las infraestructuras de transporte marítimo no intervienen de modo aislado, pues forman parte de un sistema modulable, abierto y jerarquizado que gráficamente se identifica con una malla de nodos que se refuerza y modifica continuamente; si bien es cierto que, al contrario de lo que acaeció con anterioridad a la primera mitad del siglo XX, ahora hay una mayor permanencia y estabilidad, en donde es posible apreciar puertos dominantes y que, por su posición relevante, centralizan acciones y procesos productivos (sustentado en la actividad industrial, turística o cultural) en la economía internacional.

Históricamente, los medios marítimos de transporte y sus infraestructuras han participado de modo decisivo a la accesibilidad (Rodrigue, 2009, 68), aunque hay espacios que ocuparon una posición relevante que ahora están relegados a funciones dependientes o desligados del sistema como es el caso de regiones en América Central y Sur y del África Subsahariana y Sur (figura 5). El sistema atlántico de transporte de contenedores, elevado a su máxima expresión por la creciente capacidad de las redes en las que operan transportistas y compañías marítimas destacadas como Mediterranean Shipping Company (MSC) y AP Moller-Maersk, está estructurada siguiendo el modelo de organización territorial antes expuesto. 


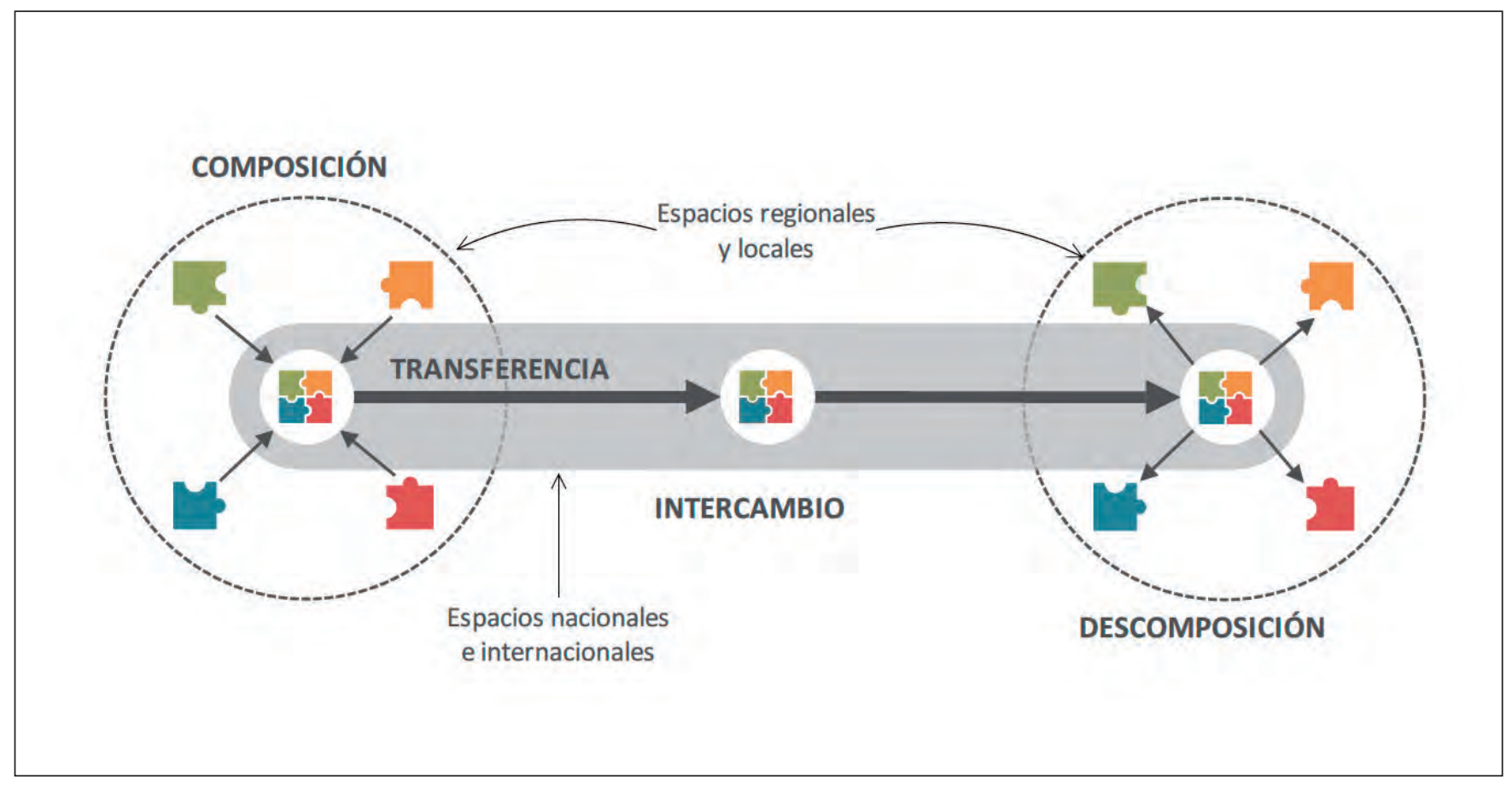

Figura 3. El nodo intermodal.

Fuente: Rodrigue $(2013,111)$. Elaboración propia.

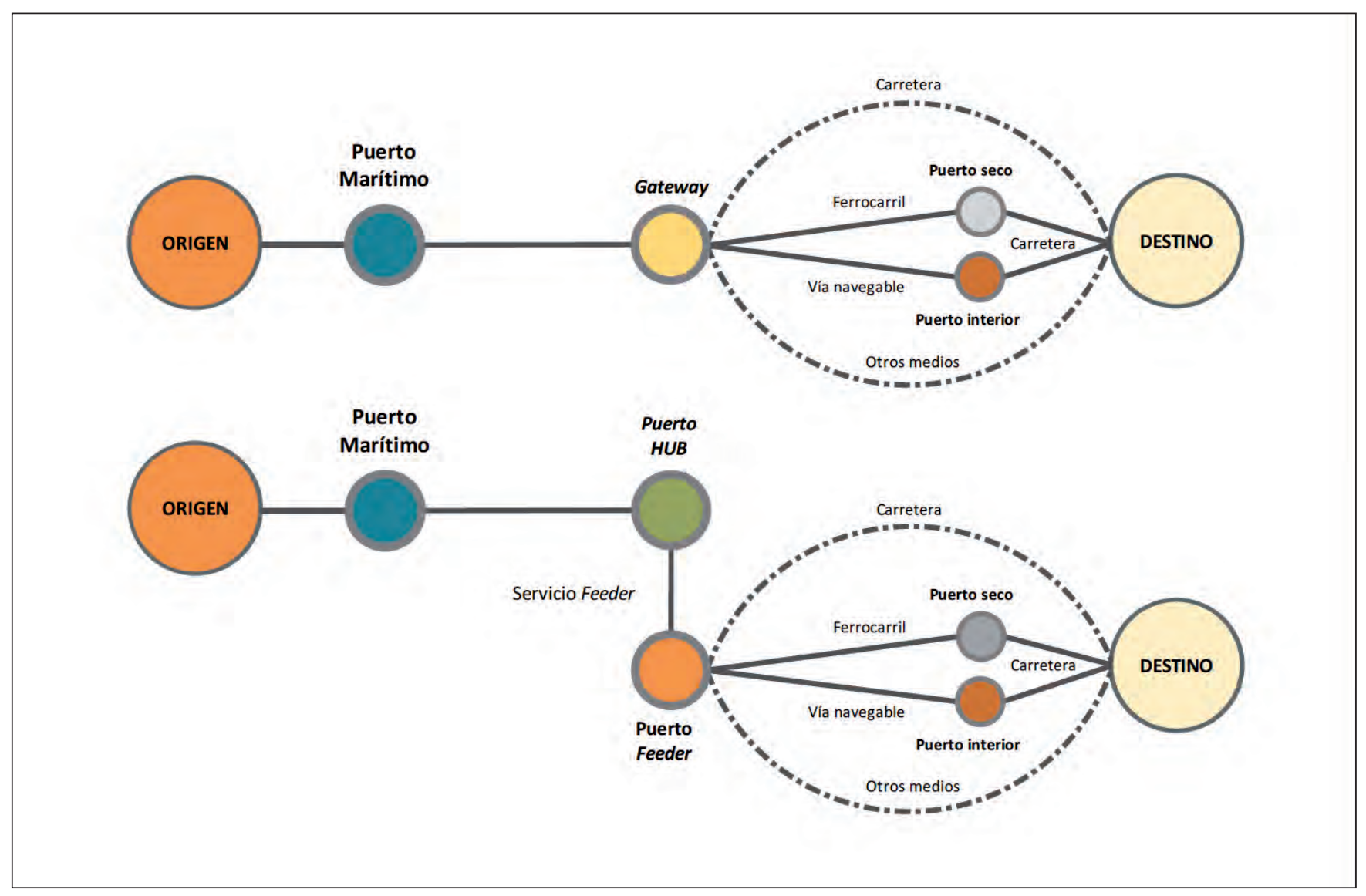

Figura 4. Cadenas de transporte intermodales.

Fuente: Rodríguez (2013). Elaboración propia. 


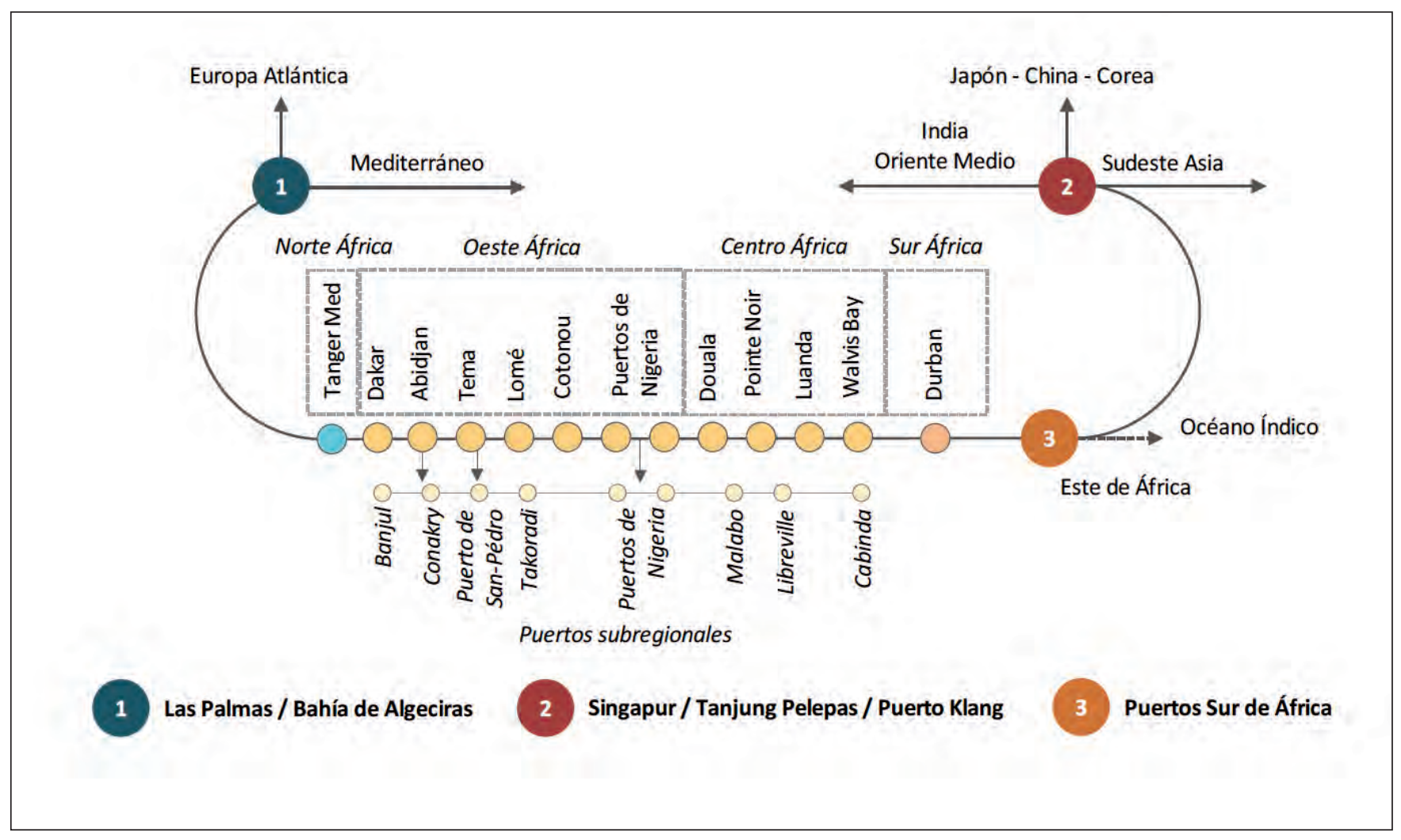

Figura 5. Red regional de puertos hubs y feeders de la región africana y su posición global con relación a las potentes regiones que lideran el tráfico mundial de mercancías y contenedores.

Fuente: Rodríguez (2013). Elaboración propia.

Las infraestructuras de transporte marítimo han transformado el territorio en el que se despliegan y en toda el área de su influencia, aportando valor añadido y propiciando mecanismos de atracción de actividades económicas diversas. El acceso y la movilidad garantizan la producción del espacio y su transformación económica o, al menos, establece los pilares sobre los que se apoyará la futura transformación del territorio. Lo incorpora en masa al proceso de producción capitalista, sea industrial, comercial, inmobiliario, de servicios o como reserva participativa de la especulación. En suma, son ineludibles en la circulación del capital, al tiempo que aseguran al poder su continua producción-reproducción.

Una infraestructura portuaria constituye una arquitectura modular del paisaje y representa la posición de enclave territorial, con capacidad de regular los flujos (current flow regulator) de mercancías y de personas (móviles). Estos nodos urbanos portuarios, espacialmente articulados y estratificados, representan flowpolis (Rodrigue, 2006) agresivas y determinantemente influyentes, en donde los agentes políticos y económicos se asocian para alcanzar el mayor volumen de beneficios y circulación del capital a través del intercambio entre espacios diferenciados que están sometidos a las fuerzas productivas y al control del capital (Sánchez, 1981, 86). Estos nodos, reconocidos como centros reguladores y potenciadores de las comunicaciones, adquieren una relevancia sustancial en la formación de redes y sistemas de redes funcionalmente reconocibles.

\subsection{El territorio, escenario de los procesos de localización y de actividad del transporte marítimo}

El transporte marítimo organiza el espacio marítimo, facilita la accesibilidad y la movilidad. Es un factor para la localización y la ubicación de las actividades y de la producción (Rodrigue, 2009, 60). Se unen dos componentes decisivos en la formación de la ecuación: el acceso medido en tiempo y lugar, considerando la distancia. 
Podemos utilizar diversas formulaciones y simulaciones numéricas para representar gráficamente la accesibilidad, mediante las que podemos expresar las variables tiempo, distancia y trayecto que nos proveerá una matriz con el grado de accesibilidad de un nodo y de su conjunto (Rodrigue, 2009, 68-72). El resultado nos muestra valores de distancia entre lugares que presentan un rango de accesibilidad proporcionalmente inverso a ésta. Sin embargo, habrá que considerar otros efectos de fricción que limitan o condicionan el comportamiento de un nodo, un par de nodos o entre conjuntos de nodos y que son inherentes a la propia configuración o caracterización del lugar y de su área de dominio. La repercusión negativa de la variable distancia real (no cognitiva) será menor cuando los elementos que limitan o condicionan son ampliamente rebasados por la tecnología de transportes y de infraestructuras que irrumpe para propiciar la relación entre los espacios (Petrus y Seguí, 1991, 40).

En la lógica del transporte en general, y del marítimo en particular, hay una serie de factores que son imputables a la localización y a la capacidad para integrarse en sistemas complejos de comunicaciones intermodales. Esta es una condición que está asociada a las cualidades y características intrínsecas del territorio y, especialmente, del espacio geográfico. El acceso a un recurso natural (tangibles como el agua, el suelo o la vegetación; intangibles como la disposición, la orientación, la altitud y la latitud, relacionado con las horas de sol, la temperatura, la precipitación y la humedad) o la posibilidad de una actividad económica en ciernes requiere del análisis de los factores de localización en cada caso y de sus atributos, de la tecnología y de los medios de transporte que sean necesarios en cada situación (Rodrigue, 2006).

El transporte aparece como un elemento con capacidad de atribuir al territorio el valor de localización y en directa correspondencia con las condiciones que éste posee: naturales, sociales, económicos, culturales, etc. En relación con éstos, la actividad económica posee factores propios según el tipo de actividad y producto (Rodrigue, 2006). Por tanto, el factor de localización para la producción agraria de cítricos, frutales u hortalizas es diferente al que tiene asignado la extracción de bauxita, cobre, petróleo o gas y, del mismo modo, al que tiene la propia prestación de servicios. La inversión en transporte marítimo, en su amplio concepto de sistema, genera impactos económicos crecientes en el espacio con el límite que impone la saturación de las comunicaciones, de los enlaces entre sitios, lugar de residencia y empresa, fábrica y mercado. En este punto los beneficios serán más laxos y los impactos tendrán la tendencia a disminuir (Banister y Berechman, 2000).

La localización portuaria posee límites definidos, pero no es una estructura cerrada. El hinterland y el foreland de un puerto, de un espacio económicamente producido, está en directa relación con la asignación de accesibilidad y movilidad a sus componentes. Esto facilita y contribuye de modo significativo a que los valores de localización sean óptimos y actúa, a su vez, de catalizador para nuevas inversiones por la proximidad a un centro de distribución y de comunicaciones en la inercia de reducir costes y en la dinámica productiva del espacio capitalizado (figura 6).

Pero el lugar, expresión geográfica de un territorio particularizado está organizado con puntos de conexión que lo coloca en situación de enlazar con otros lugares. Aparece dispuesto para que sea incorporado a un conjunto de lugares, de espacios económicamente productivos, que diseñan un armazón de escala mayor y que representa un complejo sistema espacial de transportes y comunicaciones perfectamente articulado que funciona como un ente económico vivo, en permanente ajuste y adaptación a las necesidades sociales y económicas que se generan de modo continuado. Esta superestructura territorial no es casual; por el contrario, se antoja diseñada ex profeso para responder a los mecanismos que ha establecido el sistema capitalista y la economía global.

En extensas regiones del Atlántico, del Mediterráneo y del Pacífico se disponen conjuntos organizados que actúan engranados a una cadena ininterrumpida que asocia ejes territoriales nacionales y transnacionales de transporte con sus nodos intermodales de distribución e integración regional (figura 7). Los llamados corredores internacionales de transporte son complejos y extensos sistemas de flujos que circulan en amplios espacios marítimos regionales y nacionales. Estos pasillos muestran las relaciones de dominio y jerarquía entre espacios regionales y suprarregionales, así como los procesos, las dinámicas, las relaciones y la desigual organización del territorio, así como la notoria descompensación en la distribución de los ingresos y las rentas. 


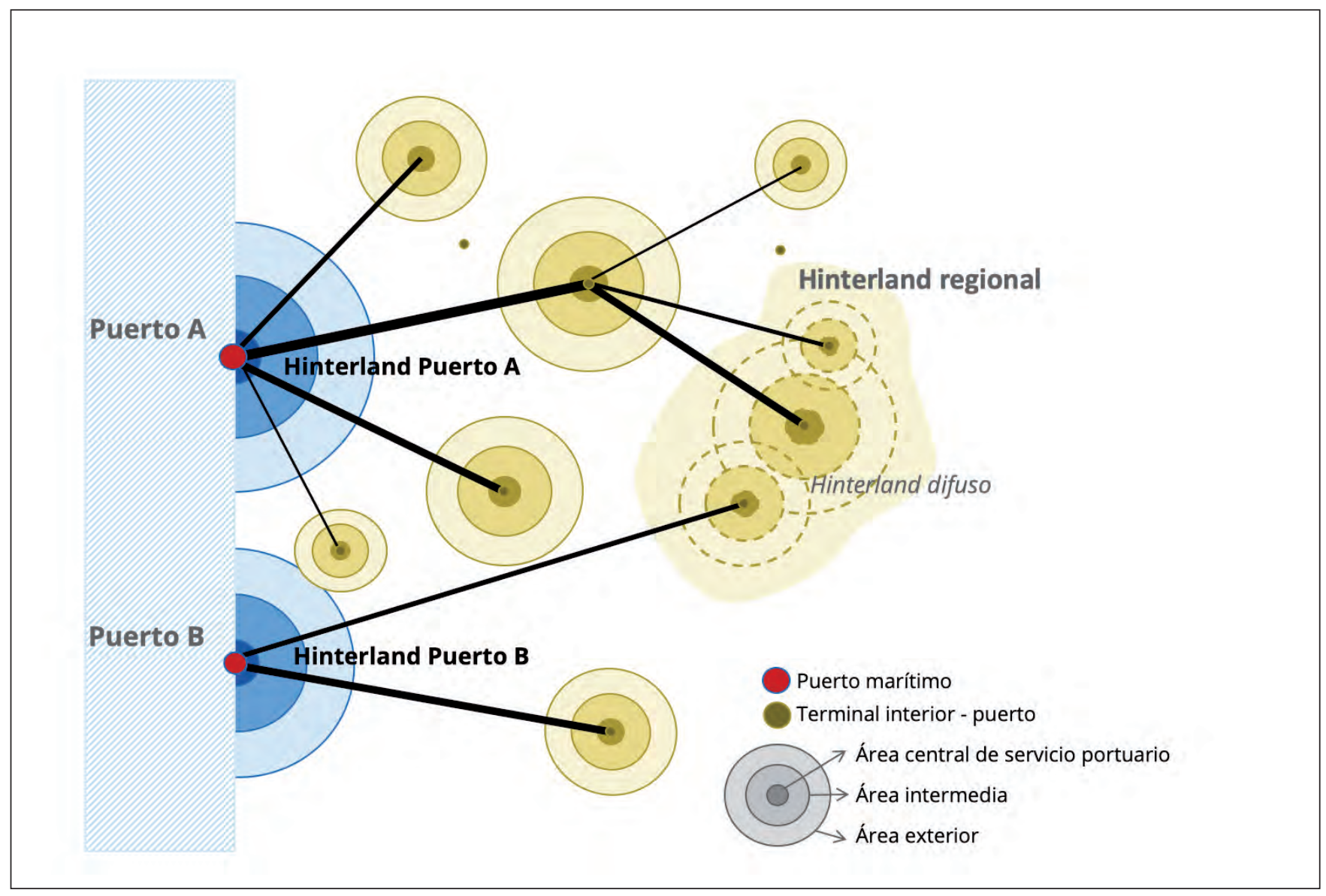

Figura 6. El hinterland portuario.

Fuente: Hoyle y Knowles (1998). Elaboración propia.

Espacialmente se ordenan como arterias que producen un continuo flujo tipo OD (Origen-Destino) entre lugares económicamente muy activos y de enorme potencialidad productiva y de consumo. En estos corredores el territorio aparece acentuadamente modificado y sustancialmente alterado en sus componentes naturales, siendo difícil su reconocimiento, desprendiéndose de sus prístinas cualidades naturales y sustituidas por otras de contenidos y formas netamente antropogénicas.

En el informe "Extension of the major trans-European transport axes to the neighbouring countries and regions" se definen los cinco grandes ejes de comunicaciones europeos que enlazan diferentes modos de transporte con los principales hubs industriales y de consumo, creando una malla extensa intermodal articulada desde los centros productivos de primer orden de las zonas del norte de Europa hacia el sur mediterráneo, euroasiático y africano, con el propósito de robustecer los corredores paneuropeos tras la ampliación de la UE (CEC, 2007, 7). Estas son:

- Los ejes marítimos que unen el Báltico, Barents, Atlántico, Mediterráneo, Negro y el Mar Caspio, así como los países ribereños en las zonas del mar y con una extensión a través del Canal de Suez hacia el Mar Rojo.

- El eje norte que conecta el norte de la UE con Noruega al norte y con Bielorrusia y Rusia hacia el Este.

- El eje Central que vincula las regiones centroeuropeas con Ucrania y el Mar Negro y través de una conexión por vía navegable hasta el mar Caspio y previsiblemente su extensión hacia el Asia Central y el Cáucaso.

- El Sur del eje occidental que une la UE al sur-oeste con Suiza y Marruecos, incluyendo el enlace trans-magrebí conectando Marruecos, Argelia y Túnez.

- El eje Sur Oriental que asocia la UE con los Balcanes y Turquía en el Cáucaso y el Mar Caspio, así como a Egipto y el Mar Rojo. 


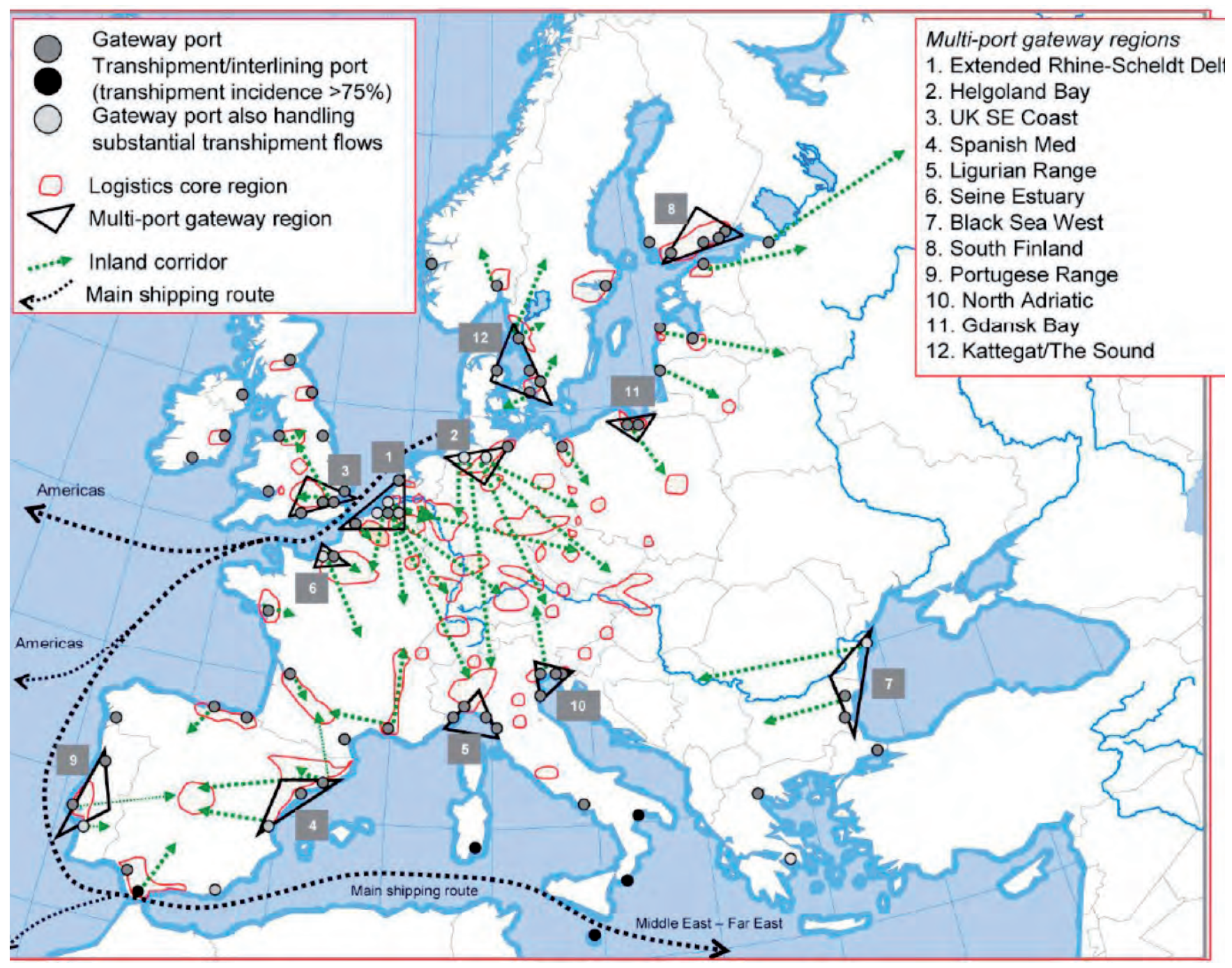

Figura 7. Redes, gateways y corredores regionales europeos de transporte marítimo. Fuente: ITMMA (2009).

En regiones menos extensas o separadas por efecto de las barreras del medio natural y que produce una cierta discontinuidad (por ejemplo, en áreas insulares), los esfuerzos se dirigen a buscar un agrupamiento que reduzca los costes, mejore la accesibilidad y una posición competitiva ventajosa en el mercado que permita atraer inversiones. El cluster de transporte marítimo surge como mecanismo de protección y de seguridad ante los factores sobre los que no hay control directo, e inmunizador de las externalidades más perjudiciales que fortalezca el desarrollo de éstas. El proceso asociativo impulsado habitualmente por los gobiernos nacionales y locales, y otros como la Unión Europea, mejora la gestión, asegura los servicios de transporte, impulsa nuevas actividades vinculadas al tiempo que interviene en el mercado para generar mayor capacidad productiva y de empleo.

Los registros de TEUs movilizados en el área euroatlántica y mediterránea desvelan un proceso incesante y creciente de tráfico de contenedores, sobresaliendo las conexiones entre el área asiática del este con el norte de Europa y el Mediterráneo (figura 8). Los corredores portuarios se han establecido para consolidar la fuerza noratlántica, que proyecta su influencia hacia el Mediterráneo y los puertos del nordeste africano y Canarias, como puede apreciarse en los datos expresados en la figura 9, en donde reconocemos cuatro grandes grupos encabezados por los puertos de Rotterdam, Amberes y Hamburgo que poseen un significativo foreland de alto valor estratégico. Los puertos de Las Palmas situados en el grupo 4, ocupan una posición periférica, tratándose de un hub de transbordo internacional y puerto feeder regional. 


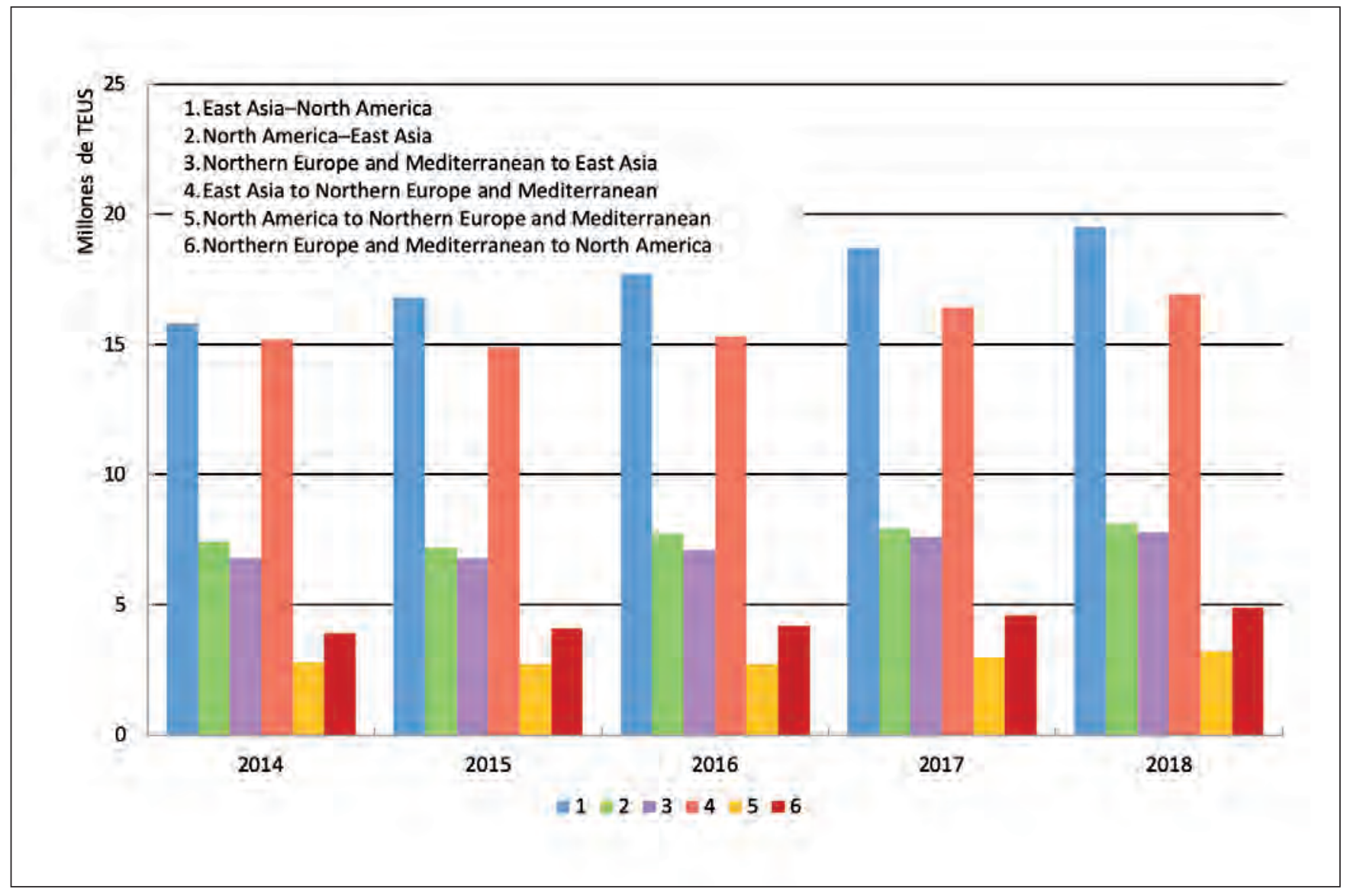

Figura 8. Comercio mundial de contenedores y sus principales rutas marítimas 2014-2018.

Fuente: UNCTAD (2018).

Mill. TEUS

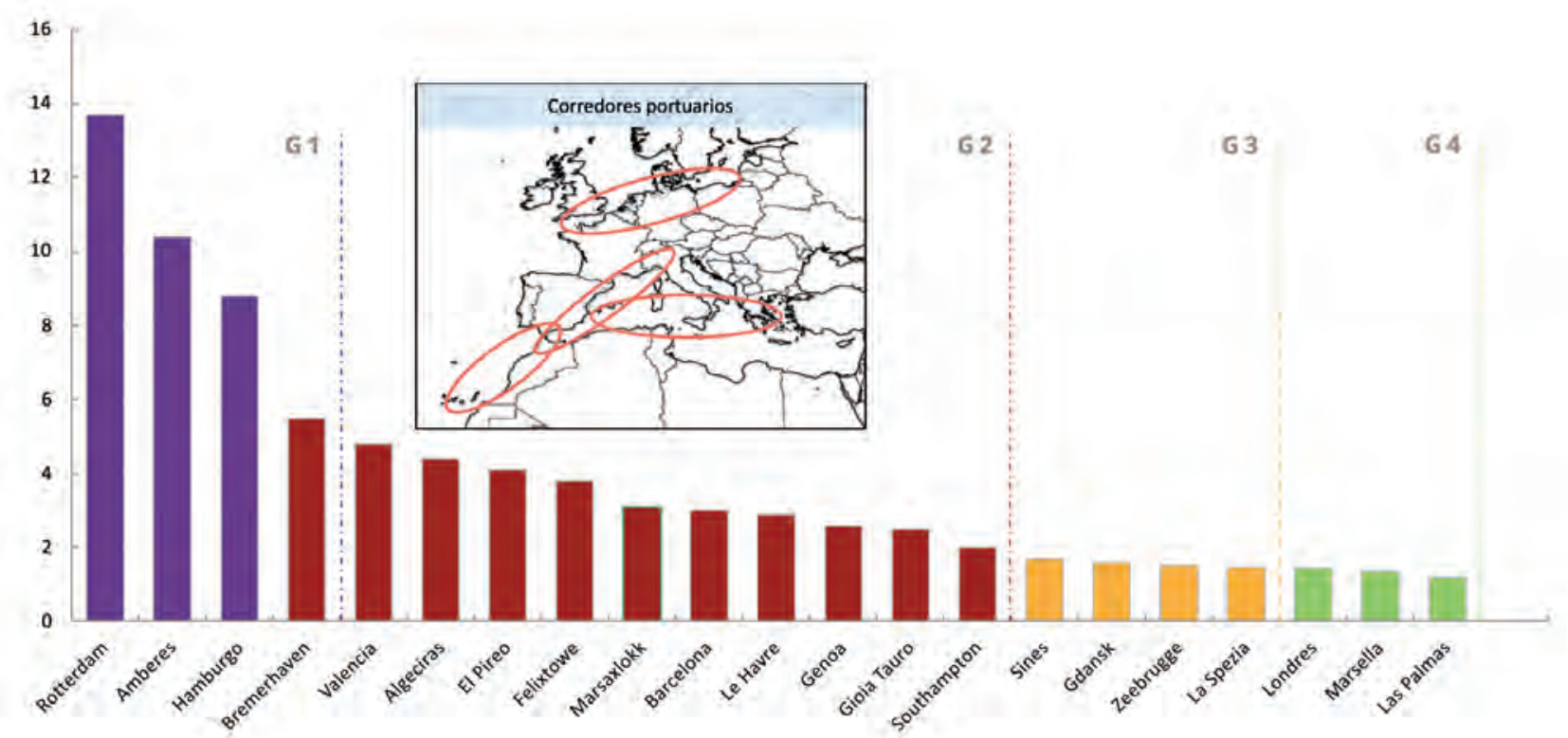

Figura 9. Tráfico de TEU en los diferentes ejes marítimos europeos. Fuente: Notteboom (2018). Elaboración propia. 


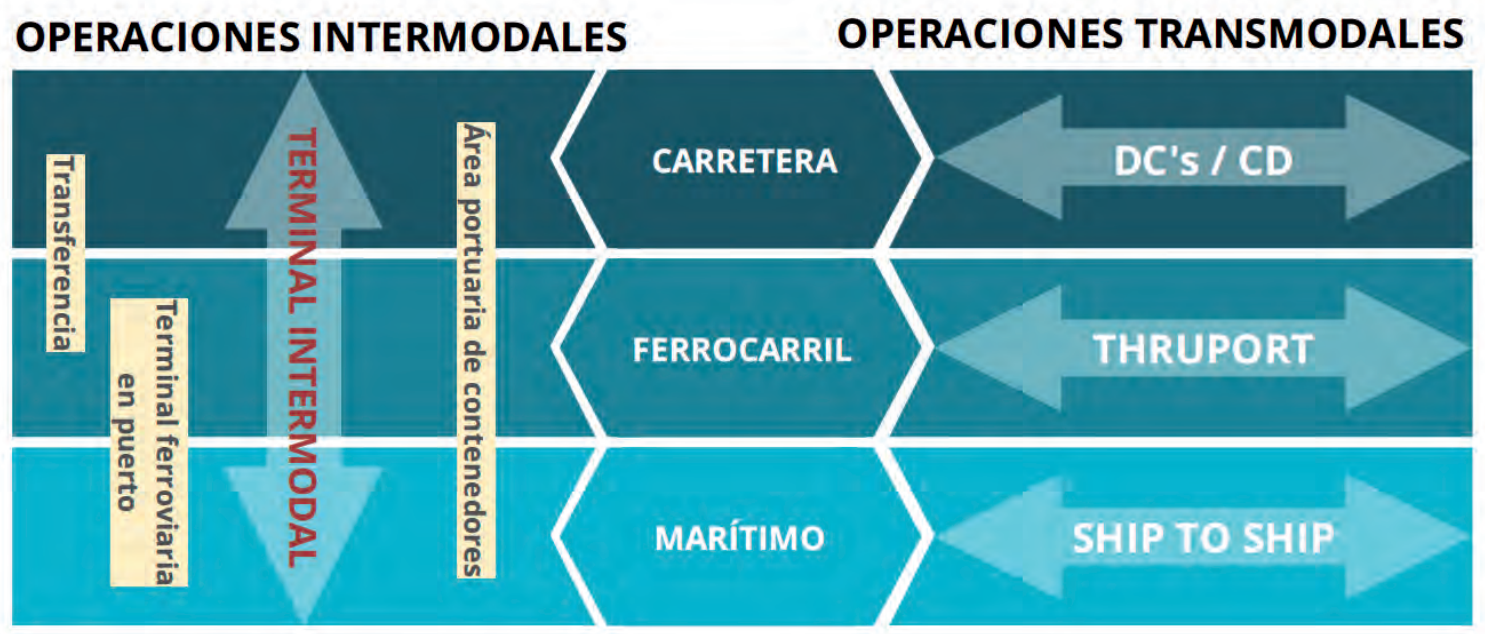

Figura 10. Sistemas integrados: intermodal y transmodal. Fuente: Rodrigue $(2006,12)$.

La logística no parece que sea un término de reciente incorporación y expresa un conjunto de procesos que operan de modo conjunto para optimizar los recursos y mejorar la gestión y la distribución; asimismo, utiliza avanzados procedimientos de tecnologías de la comunicación satelital que minimiza el tiempo de entrega de la mercancía y abarata el costo final del producto. Un ejemplo es la operativa de estiba y desestiba de contenedores a través de procesos digitalizados y robotizados, con escasa presencia humana.

El denominado "door to door" requiere un sistema sincronizado de transporte multimodal (figura 10) que aprovecha las ventajas de cada medio de transporte y la eficacia en el traslado del producto en la combinación origen $(O)$ destino (D). La elección del modo de transporte más óptimo, la ruta de mayor acceso y el precio más ajustado al coste final deseable marcan la práctica de este servicio. La aplicación de modelos y procedimientos combinados permiten alcanzar el nivel óptimo del sistema y de la red multimodal (De Jong, 2004, 11-12).

\section{METODOLOGÍA}

Tras realizar un planteamiento teórico sobre cómo intervienen los sistemas portuarios en el desarrollo territorial, pasamos al caso práctico aplicado en este caso a las Islas Canarias, un territorio donde la lejanía del continente y la fragmentación territorial dejan entrever una alta dependencia del transporte y, en particular, del marítimo (Fundación Tomillo, 2001; Ramos, 2001; Hernández, 2002).

Así pues, partiendo de la base de la filosofía integradora a través del transporte que emana de las Redes Transeuropeas del Transporte y que, en el caso de las Islas, se sintetiza en la política del Eje Transinsular del Transporte, nos centramos en un análisis básico de la accesibilidad terrestre y marítima entre las Islas.

Para ello, evaluamos en primer término -y de modo somero-, los condicionantes de las infraestructuras portuarias y viarias, en tanto que éstas nos van a indicar los posibles problemas de accesibilidad física. Tomamos para ello la información facilitada por la Autoridad Portuaria de Las Palmas; la Autoridad Portuaria de Tenerife; así como Puertos Canarios, organismo este último dependiente de la Consejería de Obras Públicas del Gobierno de Canarias. También recopilamos información del Servicio de Carreteras del Gobierno autónomo, en especial para las vías terrestres que conectan las capitales insulares con los puertos que sirven de soporte para realizar la conexión marítima con las restantes islas. 
A posteriori realizamos un análisis de accesibilidad temporal, siguiendo los pasos de estudios metodológicos anteriores (Yamaguchi, 2007; Neutens, 2012; Chowdhury, 2015). Y es que el Eje Transinsular de Transportes tiene como uno de los objetivos principales el que una mercancía rodada atraviese de un extremo a otro del Archipiélago en la misma jornada. Por ello mismo, es fundamental este análisis de los horarios marítimos, en tanto que nos van a indicar la capacidad de integración territorial que emana de la actual oferta de las navieras. Desde este punto de vista, la fuente principal para medir la mentada accesibilidad temporal, van a ser los horarios de las navieras, plasmados en dos situaciones (la real, es decir, basada en la operatividad horaria que nos han facilitado las mencionadas navieras, y el horario ideal, que es fruto de nuestra elaboración en función de los tiempos de transporte terrestre entre uno y otro puerto, siempre primando que el tiempo de permanencia de las mercancías en el puerto sea el mínimo y, por ende, proporcionando mayor velocidad comercial entre uno y otro extremo del Archipiélago). También por supuesto, se recogió información de la Consejería de Obras Públicas del Gobierno de Canarias, en tanto que ésta nos recomendó los tiempos medios de transporte de un vehículo tipo furgoneta, entre las capitales insulares y los respectivos puertos dentro de cada una de las Islas.

Por otra parte, también nos adentramos en un análisis de accesibilidad económica, en tanto que es la otra gran variable que mide la capacidad de movilidad de las unidades de tráfico en el territorio. Evidentemente, la fuente básica serán las tarifas de los principales operadores marítimos (Fred. Olsen y Naviera Armas), aunque partiendo de la base de que consideramos un sistema puerta - puerta, tal y como preconiza el Eje Transinsular de Transportes, también incluimos una aproximación a los costes de amortización del vehículo, reparaciones, coste del conductor, etc. y que fue facilitado por el Observatorio de Transportes de Canarias, dependiente de la Consejería de Obras Públicas del Gobierno de Canarias.

De este modo, tras evaluar el estado de las infraestructuras y la accesibilidad económica y de tiempo, se llega a una conclusión en el que se analiza si el estado actual de desarrollo de la red marítima interinsular posibilita los objetivos de integración territorial que se derivan de la política del Eje Transinsular de Transportes.

\section{RESULTADOS Y DISCUSIÓN DEL CASO DE ESTUDIO}

\subsection{Caracterización general de los puertos canarios}

El archipiélago canario lo conforman ocho islas habitadas y dieciséis puertos con tráfico regular de pasaje y mercancías. Estos puertos presentan una importancia bien dispar, pues los principales, que coinciden -para el caso de las mercancías-, con los capitalinos de cada isla, presentan a su vez una desigual relevancia en función de su hinterland. De igual modo, hay que señalar que, en el caso del tráfico de pasajeros, son algunos puertos comarcales los que adquieren ese protagonismo, pues aquí prima sobre todo la menor distancia entre enclaves terrestres de dos o más islas, como es el caso de Los Cristianos, Agaete, Morro Jable, etc. Ni que decir tiene que el movimiento de estos puertos comarcales también está altamente condicionado por el hinterland de cada isla.

De modo muy sintético y para aproximarnos a este hinterland, los datos del cuadro 1 revelan, con parámetros básicos de población y producción, la enorme disparidad existente; especialmente, entre las islas de Tenerife y Gran Canaria de un lado y el resto de otro. Las consecuencias que se derivan, en cuanto a la demanda de transporte, son muy relevantes, condicionando las frecuencias marítimas, horarios, capacidad de bodega, etc., traduciéndose también en posibilidades diferenciales de desarrollo económico y social.

En efecto, como se deduce de lo comentado, la disparidad en cuanto a la demanda de tráfico es notoria en consonancia con el mencionado hinterland e, incluso, con la actividad económica principal desarrollada, como es fundamentalmente el caso del turismo en las islas de Lanzarote y de Fuerteventura, con consecuencias muy relevantes desde el punto de vista de la demanda de los tráficos, tal y como podemos apreciar en los datos del cuadro 2, referenciados a 2016. Cabe decir también que la particularidad del transporte marítimo, en especial su menor velocidad de transporte en relación con el modo aéreo, tiene implicaciones severas desde el punto de vista de la potenciación de los puertos comarcales, de ahí que, por ejemplo, para 
Cuadro 1. Principales características de las Islas Canarias en 2015.

\begin{tabular}{|l|c|c|}
\hline \multicolumn{1}{|c|}{ Islas } & Población & VAB sectores económicos (\%) \\
\hline Tenerife & 888.184 & 42.0 \\
\hline Gran Canaria & 847.830 & 62.0 \\
\hline Lanzarote & 143.209 & 5.0 \\
\hline Fuerteventura & 107.367 & 4.0 \\
\hline La Palma & 82.346 & 0.5 \\
\hline La Gomera & 20.783 & 0.5 \\
\hline El Hierro & 10.587 & 100.0 \\
\hline Total & 2.100 .306 & 5.0 \\
\hline
\end{tabular}

Fuente: Instituto Canario de Estadística, 2015. Elaboración propia.

Cuadro 2. Tráfico regular de viajeros y vehículos en régimen de pasaje en Canarias en 2016.

\begin{tabular}{|c|c|c|}
\hline Puertos del Estado & Pasajeros regulares & Vehículos en roll-on / roll-off \\
\hline Arrecife & 124.816 & 44.372 \\
\hline Puerto del Rosario & 61.087 & 17.278 \\
\hline Puerto de La Luz & 1.099 .482 & 357.079 \\
\hline $\mathrm{S} / \mathrm{C}$ de Tenerife & 1.286 .006 & 385.286 \\
\hline Los Cristianos & 1.589 .339 & 327.366 \\
\hline S. S. de La Gomera & 1.153 .797 & 215.017 \\
\hline S/C de La Palma & 244.613 & 85.716 \\
\hline Valverde & 108.568 & 40.346 \\
\hline Subtotal & 5.667 .708 & 1.472 .460 \\
\hline Puertos canarios & & - \\
\hline Caleta del Sebo & 325.199 & - \\
\hline Puerto de Órzola & 325.199 & - \\
\hline Playa Blanca & 1.029 .651 & 225.468 \\
\hline Corralejo & 1.029 .651 & 225.468 \\
\hline Morro Jable & 518.875 & 199.075 \\
\hline Agaete & 833.687 & 289.017 \\
\hline Subtotal & 4.062 .262 & 939.028 \\
\hline Total & 9.729 .970 & 2.411.488 \\
\hline
\end{tabular}

Fuente: Estadísticas de los Departamentos comerciales de Puertos del Estado y Puertos Canarios. Elaboración propia. 


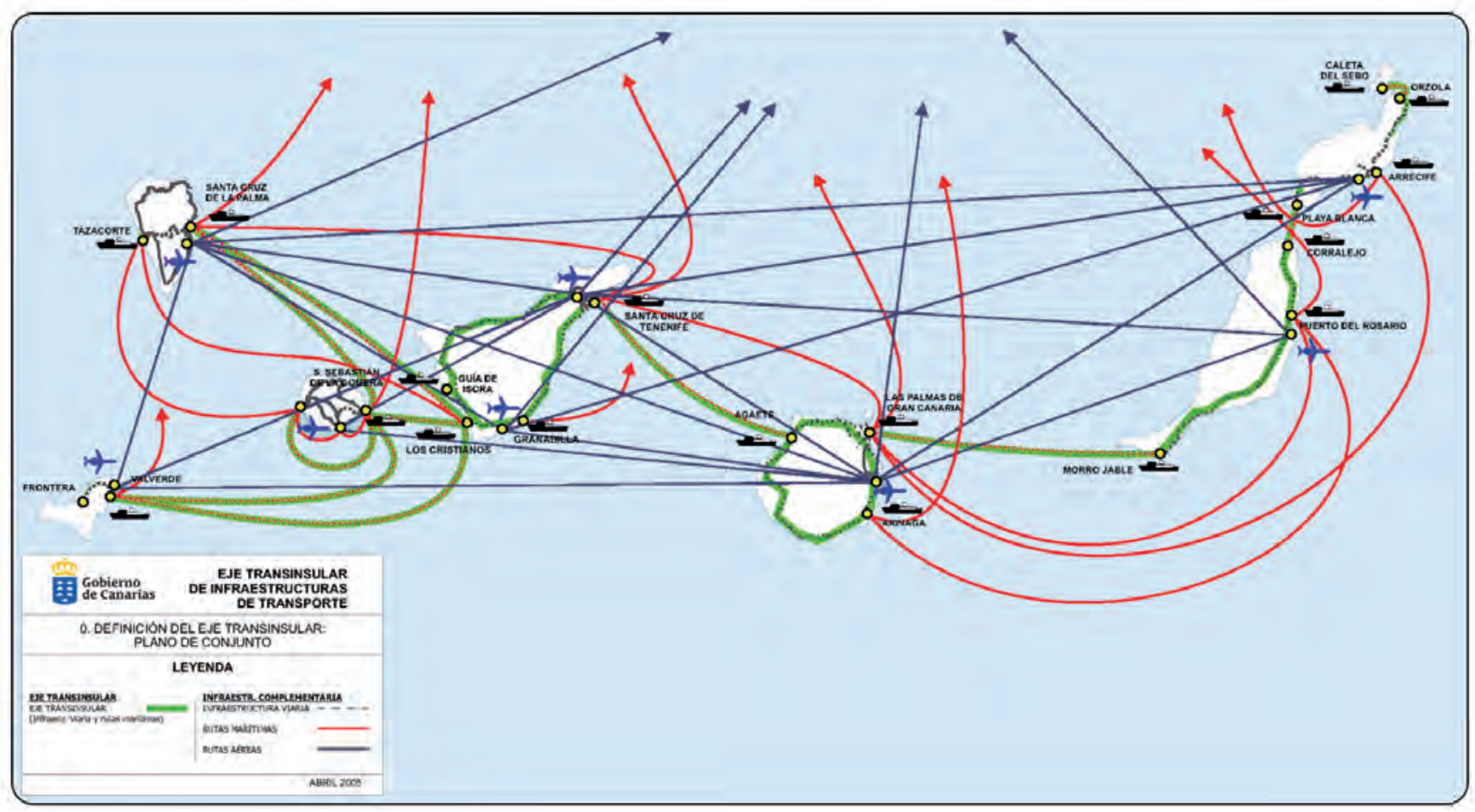

Figura 11. El Eje Transinsular de Infraestructuras de Transporte de Canarias. Fuente: Gobierno de Canarias, 2005.

el caso de Lanzarote y Fuerteventura, los puertos capitalinos de Arrecife y de Puerto del Rosario, apenas tienen significación para el tráfico entre islas en relación con los puertos comarcales de Órzola, Playa Blanca, Corralejo y Morro Jable.

Pues bien, partiendo de la base de que el transporte marítimo es fundamental para el desarrollo socioeconómico y la integración territorial como ya se ha apuntado en las páginas anteriores, analizamos aquí -y en especial-, algunas cuestiones que afectan al mencionado desarrollo de los hinterland insulares, como es el caso del factor tiempo y la accesibilidad económica, elementos de vital importancia para una óptima accesibilidad. En suma, esta filosofía que trasciende de los análisis de la accesibilidad, se corresponde con los postulados que defiende la Red Transeuropea de Transportes (RTET). Es más, el Eje Transinsular de Transportes (ETIT) de Canarias, plantea conectar con dicha red, por lo que a continuación se aborda esta última política de transportes y sus implicaciones de desarrollo para el territorio canario.

\subsection{El Eje Transinsular de Transportes de Canarias como motor de desarrollo del Archipiélago}

El Eje Transinsular de Transportes de Canarias se basa en el cambio modal y, en especial, el terrestre con el marítimo de corta distancia (véase la figura 11). De este modo, esta política de transportes tiene como finalidad el que una mercancía rodada partiendo desde cualquier isla pueda llegar a otra en la misma jornada, incluyendo además el retorno a la isla de origen (Gobierno de Canarias, 2005; Hernández, 2007). No obstante, queda condicionado a los enganches de los horarios marítimos que se producen entre la isla anterior y la siguiente, siendo mayor el riesgo de que ni siquiera la ida se pueda realizar en una misma jornada conforme los tiempos de tránsito en otras islas van aumentando, por ejemplo, entre Lanzarote y El Hierro, vía Fuerteventura, Gran Canaria y Tenerife.

Así pues, el ETIT (figura 11) es un nuevo concepto de movilidad basado en la mejora de la accesibilidad entre islas, además de en el interior de cada una de ellas. Su objetivo principal es facilitar la cohesión territorial, social y económica de Canarias a través de la intermodalidad entre los transportes terrestres, marítimos 
y aéreos, teniendo como soporte tanto la mejora de las infraestructuras, como de los medios de transporte. Es óbice que en este apartado tienen especial incidencia los puertos y aeropuertos, pero especialmente los primeros como reconoce el Gobierno de Canarias (Gobierno de Canarias, 2005).

Algunos factores como el tiempo y la disponibilidad de cupo son fundamentales para una óptima accesibilidad, cimentado en la propia política de transportes de la Unión Europea a través de la RTET. Esta red surge a finales de los años ochenta con la propuesta de creación de un gran mercado único, pues se pensaba que, para potenciar la circulación de mercancías, personas y servicios, se hacía necesaria la mejora de la accesibilidad en el territorio. En este sentido, el Tratado de la Unión Europea recoge, en el capítulo XV, artículos 154, 155 y 156, la necesidad de que la UE desarrolle la citada red en aras de fomentar el mercado interior, así como la integración socioeconómica de las distintas regiones. De hecho, el Libro Blanco del Transporte de la Unión Europea argumenta que "conviene mantener el apoyo a la Red Transeuropea, ya que representa un elemento importante de la competitividad europea y permite conectar mejor las regiones periféricas a los mercados centrales de la Unión Europea" (CEC, 2001).

En este contexto, el ETIT se propone enlazar con dicha red tanto a través del transporte marítimo como del aéreo. De hecho, la Decisión 1692/96/CE del Parlamento Europeo y del Consejo, de 23 de Julio de 1996, sobre la RTET, definía con carácter indicativo aquellos proyectos que, por su trascendencia, debían ser considerados de especial importancia por la Unión Europea. Entre dichos proyectos la Decisión resalta los relacionados con el transporte multimodal. En concreto, encaja dentro del artículo 18 de dicha Decisión, pues da la posibilidad de que los estados miembros aporten sus propuestas de redes integradas entre sí y con el resto de la Unión.

El ETIT se apoya tanto en las infraestructuras como en el transporte en sí. Particularmente en materia de infraestructuras, los Convenios de colaboración entre el Ministerio de Fomento y el Gobierno de Canarias en materia de carreteras, que datan de 1997, 2006 y 2018, han programado una serie de obras, con preferencia en el eje que, sin duda, han favorecido la mejora, de forma ostensible, de la accesibilidad dentro de las propias islas, pero también con el exterior.

Si bien es cierto que son fundamentales las infraestructuras para el ETIT, también lo es la conectividad. Así, un factor clave es la coordinación de horarios cuando se hace uso de las travesías cortas, de tal modo que se permita el flujo continuo de pasajeros y mercancías entre islas (Hernández, 2002; Neutens, 2012). En particular, estos autores incluso conceden a los horarios una relevancia aún mayor en relación con la conectividad física en si, las tarifas o el estado de las infraestructuras portuarias, por lo que los horarios de operatividad de las navieras se convierten en el eje vertebrador de una red de transporte eficiente y que estimula la integración territorial. Otro aspecto importante son los tiempos de travesía marítima y terrestres, en tanto que también contribuyen a una mejora de los horarios de operatividad. No obstante, estos últimos pueden oscilar ligeramente en función del estado del mar y del tráfico viario en cada hora; aunque lo cierto es que para que se cumpla la filosofía central del eje transcanario se hace necesaria la utilización de fast ferrys en el mar y la mejora de las condiciones viales, de tal manera que se alcancen velocidades medias aceptables dentro de los parámetros de seguridad.

Así pues, la clave en la actualidad se centra sobre todo en el grado de accesibilidad marítima que puedan aportar las navieras, así como la mejora de las carreteras, pues como veremos, no puede justificarse un eje transinsular cuando una mercancía rodada cuenta incluso con más de seis horas de espera en un puerto de tránsito. Esta demostración también ha sido desarrollada por otros autores, como es el caso de la accesibilidad temporal del transporte terrestre en Auckland (Nueva Zelanda), donde se ha demostrado que los viajeros estarían más interesados en una reducción de los tiempos de viaje, antes que en un descenso de las tarifas (Chowdhury, 2015).

\subsection{Situación de las infraestructuras portuarias}

Los puertos han sido una pieza clave en el desarrollo de las relaciones comerciales entre las Islas, tanto de mercancías como pasajeros. Si bien es cierto que, en gran medida en relación con el potencial de cada hinterland 
insular, las infraestructuras portuarias presentan en la actualidad características bien diferenciadas, la docena de puertos que sirven de soporte para la potenciación del Eje Transinsular, han posibilitado un movimiento importante a pesar de algunas limitaciones, en especial por falta de espacio, congestión viaria en su entorno, etc.

Específicamente, entre las limitaciones podemos señalar el escaso calado o la limitada explanada comercial de algunos puertos como el de Órzola y el de Caleta del Sebo que, sin embargo, posibilitaron el tránsito de más de 300 mil pasajeros en 2016. Por el contrario, el puerto de Las Palmas de Gran Canaria, además en expansión en la actualidad, cuenta con cuatro rampas para ferry en trayectos interinsulares, además de una extensa explanada comercial y de línea de atraque.

Pero quizá más importante es la congestión viaria que tiene lugar en algunos puertos tan importantes para el Eje, como son los de Agaete y el de Los Cristianos, donde las actuales cifras de movimiento de pasajeros y de vehículos, dejan en entredicho la escasa capacidad infraestructural de estos puertos y, por tanto y como decimos, un obstáculo para el tránsito rápido de las unidades de tráfico. Es precisamente en estos últimos puertos donde están proyectadas las mayores actuaciones en los próximos años, duplicando la superficie de atraque en el primer caso y sustituyendo el puerto de Los Cristianos en el segundo caso, por el de Fonsalía (Guía de Isora, Tenerife), incrementando notablemente la línea de atraque.

Por tanto, aun existiendo en la actualidad algunas limitaciones relacionadas con las infraestructuras portuarias, éstas no han impedido a priori los intercambios y, por ende, el desarrollo económico de las Islas, aunque los propios proyectos de expansión, reconocen la inviabilidad de las infraestructuras actuales para un mayor desarrollo de las relaciones comerciales entre las Islas.

\subsection{Características de las infraestructuras viarias que conectan con los puertos}

Si bien es cierto que todas las islas cuentan con algún tramo considerado dentro del eje transinsular (figura 12), existen al menos tres que son vitales para los objetivos que se persiguen con esta política, como es el que una unidad de tráfico pueda atravesar el Archipiélago en una misma jornada e incluso que el vehículo que transportó esa mercancía pueda regresar al punto de retorno dentro del mismo día. Esas tres vías son las que conectan Corralejo con Morro Jable en Fuerteventura (de 121 kilómetros); Las Palmas de Gran Canaria y Agaete en Gran Canaria (34 kilómetros); y Santa Cruz de Tenerife y Los Cristianos en Tenerife (76 kilómetros).

Por tanto, haciendo especial énfasis en estos tres tramos, habría que comentar que el primero, es decir, entre Corralejo y Morro Jable, presenta en la actualidad un buen estado y, en general, no existen problemas de congestión. Sin embargo, y como principales debilidades para una movilidad de ida y vuelta en el día, la vía presenta una distancia importante, además de que varios tramos en proyecto de desdoblamiento actualmente, se encuentran sin ejecutar.

En cuanto a la segunda vía, es decir, Las Palmas de Gran Canaria y Agaete, presenta como fortaleza una distancia aceptable, además de un buen estado en general de la vía, mientras que, como principales debilidades, el tramo urbano San Andrés - Pagador sin ejecutar, además de los problemas de concentración horaria de vehículos, en especial de las primeras horas de las mañanas cuando confluye el tráfico portuario con el pendular por motivos de trabajo y escolar.

Por su parte, el tramo Santa Cruz de Tenerife a Los Cristianos presenta un buen estado en general y, aunque existen atascos, son de carácter puntual. Como principales debilidades tendríamos que señalar la importante distancia para un round trip en la misma jornada, pero sobre todo hacer hincapié que el acceso al puerto de Los Cristianos es en la actualidad bastante deficitario, siendo muy complicadas las operaciones fluidas en este puerto en determinadas fechas del año cuando se incrementa de modo notable el tráfico, así como en horas muy puntuales del día.

\subsection{Los horarios como grandes condicionantes de la movilidad}

Quizá más importante que las condiciones de las infraestructuras portuarias y viarias, es la accesibilidad horaria, es decir, los tiempos de viaje (Chowdhury, 2015), pues de nada sirve disponer del mayor número 

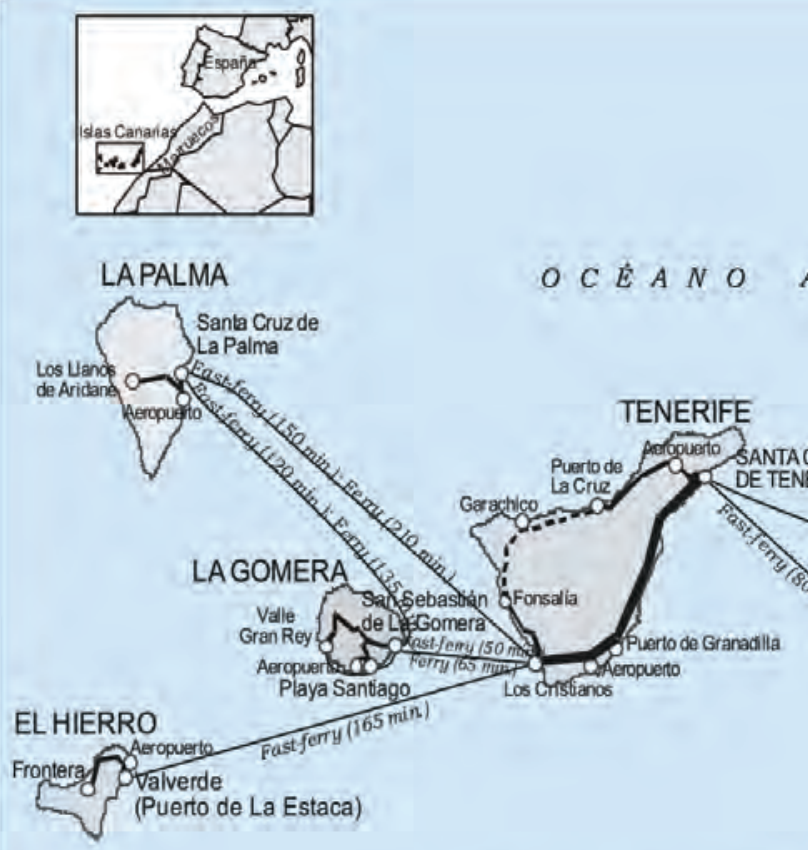

A $T L A N T I C O$
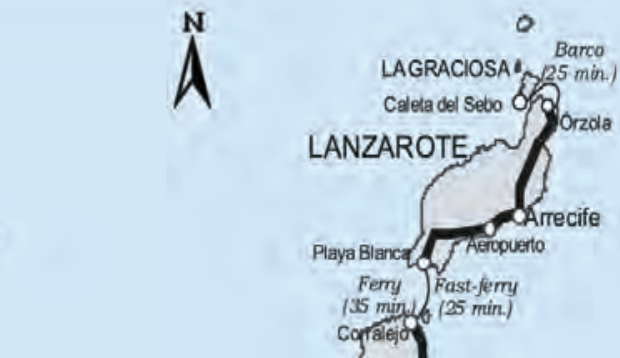
Cuadro 3. Mercancía rodada en una jornada laboral entre Lanzarote y las islas occidentales a través del Eje Transinsular de Transportes en diciembre de 2017.

\begin{tabular}{|c|c|c|}
\hline Tramos del transporte & Horario actual & Horario ideal \\
\hline Salida Puerto de Playa Blanca (Lanzarote) & 07.00 (N.A.) & 07.00 \\
\hline Llegada Puerto de Corralejo (Fuerteventura) & 07.35 & 07.35 \\
\hline Tiempo de desembarco en Corralejo (Fuerteventura) & 07.40 & 07.40 \\
\hline Tramo terrestre Corralejo - Morro Jable (Fuerteventura) & 09.30 & 09.30 \\
\hline Salida Puerto de Morro Jable (Fuerteventura) & 16.00 (N.A.) & 10.00 \\
\hline Llegada Puerto de Las Palmas de G.C. (Gran Canaria) & 19.20 & 12.30 \\
\hline Tiempo de desembarco en Las Palmas de Gran Canaria & 19.30 & 12.40 \\
\hline Tramo terrestre Las Palmas G.C. - Agaete (Gran Canaria) & 20.10 & 13.20 \\
\hline Salida del Puerto de Agaete (Gran Canaria) & - & 14.00 \\
\hline Llegada Puerto de S/C de Tenerife & - & 15.20 \\
\hline Tiempo de desembarco en S/C de Tenerife & - & 15.30 \\
\hline Tramo terrestre S/C de Tenerife - Los Cristianos (Tenerife) & - & 16.30 \\
\hline Salida Puerto de Los Cristianos (Tenerife) - La Gomera & - & 17.00 \\
\hline Llegada Puerto de San Sebastián La Gomera & - & 17.50 \\
\hline Salida Puerto de Los Cristianos (Tenerife) - La Palma & - & 17.00 \\
\hline Llegada Puerto de Santa Cruz de La Palma & - & 19.30 \\
\hline Salida Puerto de Los Cristianos (Tenerife) - El Hierro & - & 17.00 \\
\hline Llegada Puerto de Valverde (EI Hierro) & - & 19.30 \\
\hline
\end{tabular}

Fuente: Departamentos comerciales de Naviera Armas y Fred. Olsen. Elaboración propia.

En el cuadro 3 se considera la situación actual o real, aunque, a todos los efectos, se debería incentivar conectividades horarias próximas a la situación ideal -especificada en la metodología-, que también exponemos, empleando la tecnología fast ferry, es decir, velocidades de crucero en torno a los 40 nudos. Tomamos la salida más inmediata, independientemente de la naviera, aunque no termina siendo del todo viable, ya que las navieras priman económicamente el viaje en su propia compañía cuando se transborda de una isla a otra, por ejemplo, La Gomera y Gran Canaria (vía Tenerife), hecho que, casi siempre, obliga a la unidad de tráfico a desplazarse en una frecuencia no óptima, más tardía, por ejemplo, si la mercancía -o urgencia del pasajero-, no indican lo contrario.

Como vemos, la conexión desde Lanzarote hasta las islas más occidentales podríamos calificarla actualmente como muy mala, pues solo es posible alcanzar Gran Canaria tras hacer escala en los puertos de Corralejo y Morro Jable en Fuerteventura, después de permanecer más de seis horas en este último puerto a la espera de la siguiente frecuencia con Gran Canaria. Debido a ello, no es posible que el transporte pueda enganchar con la frecuencia de las 20.00 horas en Agaete que, al menos, lo transporte a Tenerife, isla ésta que si tiene un ostensible movimiento de unidades de tráfico con las islas periféricas orientales. La situación ideal que también modelamos en cuadro anterior, donde los tiempos de tránsito en los puertos son los mínimos, alrededor de 30 minutos, demostramos que se pueden alcanzar perfectamente las islas 
Cuadro 4. Tarifa marítima de ida de una mercancía rodada entre Lanzarote y La Palma en diciembre de 2017.

\begin{tabular}{|c|c|c|}
\hline \multirow{2}{*}{ Tramos del transporte } & \multicolumn{2}{|c|}{ Tarifas $(€)$} \\
\hline & Fred. Olsen & Armas \\
\hline Coste medio combustible del transporte terrestre en Lanzarote & 3,00 & 3,00 \\
\hline Playa Blanca - Corralejo & 75,76 & 47,65 \\
\hline Coste medio combustible del transporte terrestre en Fuerteventura & 6,00 & 6,00 \\
\hline Morro Jable - Las Palmas de Gran Canaria & 197,70 & 188,46 \\
\hline Coste medio combustible del transporte terrestre en Gran Canaria & 3,00 & 0,00 \\
\hline Agaete - Santa Cruz de Tenerife & 192,24 & $159,35 * *$ \\
\hline Coste medio combustible del transporte terrestre en Tenerife & 5,00 & 5,00 \\
\hline Los Cristianos - Santa Cruz de La Palma & 250,93 & 170,56 \\
\hline Coste medio combustible del transporte terrestre en La Palma & 3,00 & 3,00 \\
\hline $\begin{array}{l}\text { Subtotal (incluyendo } 20 \% \text { de bonificación con la naviera Fred. Olsen por } \\
\text { utilización de más de una línea) }\end{array}$ & 573,30 & 566,02 \\
\hline Total, incluyendo coste del combustible del transporte terrestre & 593,30 & 583,02 \\
\hline $\begin{array}{l}\text { Total, incluyendo amortización del vehículo, reparaciones, coste del conduc- } \\
\text { tor, etc. (entre un } 20 \text { y } 40 \% \text { más) }\end{array}$ & $711,96-830,62$ & $699,62-816,23$ \\
\hline
\end{tabular}

Fuente: Departamentos comerciales de Naviera Armas y Fred. Olsen, y Observatorio del Transporte del Gobierno de Canarias. Elaboración propia.

periféricas occidentales en la misma jornada, si bien no es posible realizar el retorno por completo en la misma jornada.

\subsection{La accesibilidad económica}

La movilidad en función de los costes que presenta ésta para los usuarios, es otro factor esencial que mide la integración territorial de un espacio (Hernández, 2010), al tiempo que deja entrever también el nivel de desarrollo (Tindemans, 2005).

Habría que señalar, no obstante, que el desembolso económico de un ciudadano o empresa al hacer uso de un servicio de transporte no es exacto, pues el sistema de tarifas puede cambiar de modo notable, incluso con un mismo operador, día y horario.

De esta manera, las tarifas se convierten en un entramado donde si es difícil entrar, más lo es salir con resultados fiables, sobre todo si nos atenemos a las particularidades de cada unidad de tráfico. Por todo ello, y para homogeneizar los datos, hemos optado por un análisis metodológico tomando las tarifas base partiendo de un transporte estándar en furgoneta con mercancía entre islas.

Pues bien, hemos calculado (cuadro 4) que el coste en diciembre de 2017 de un transporte en un furgón grande se aproximaba a los 600 euros de ida entre Lanzarote y La Palma, incluyendo solo el combustible terrestre y las tarifas marítimas. Se excluyen los costes imputables al alquiler o amortización del vehículo, el coste del conductor, las reparaciones y los seguros entre otros, pudiendo éstos significar entre un $20 \%$ y un $40 \%$ más sobre los costes señalados.

En suma, el coste global que, como comentamos, puede superar incluso los 800 euros de ida en un trayecto de 540 kilómetros, incluyendo los itinerarios terrestres y marítimos entre el puerto de Santa Cruz 
de La Palma y el de Playa Blanca en Lanzarote (vía Tenerife, Gran Canaria y Fuerteventura), suponen unos costes entre 1,30 y 1,54 euros por kilómetro, frente a los 1,05 en la Península Ibérica (Ministerio de Fomento, 2011) ${ }^{2}$, esto es, unos 570 euros para el mismo trayecto en territorio continental. En suma, desplazar una mercancía en Canarias en un furgón grande supone como mínimo un 35\% más oneroso en relación con el territorio continental, hecho que, evidentemente, supone una pérdida de competitividad de las empresas de las Islas frente al territorio continental, traduciéndose en un serio hándicap para su desarrollo.

\section{CONCLUSIONES}

El marco teórico-conceptual en el que se ha insertado la propuesta específica del ETIT de Canarias expresa la realidad territorial y de fuerzas sociales y económicas activas que operan en el transporte y sus infraestructuras. El sistema de transporte no es el resultado de una situación azarosa, por el contrario, es el producto de las relaciones sociales de producción y de la globalización progresiva e invasiva del capitalismo mundial. Este proceso tiene repercusiones directas sobre los espacios regionales y subregionales, de modo que determinan su posicionamiento y el desarrollo socioeconómico. En estos espacios los transportes tienen un rol asignado por la red transnacional, nacional o regional. Su desempeño y su fortalecimiento tendrá consecuencias directas sobre la jerarquización territorial y la transformación de sus diferentes espacios productivos, con incidencias de grado diverso en las infraestructuras de transportes, la conectividad y la movilidad.

En el ejemplo práctico, se ha expuesto la incidencia que el ETIT de Canarias tiene en el desarrollo insular. Desde este punto de vista, se analizan el estado de las infraestructuras marítimas y viarias, los horarios y las tarifas marítimas, pues condicionan el grado de conectividad.

Así pues, como se ha constatado, la posibilidad de disponer de una óptima infraestructura no garantiza una verdadera integración de los espacios insulares. En particular, la política tarifaria y horaria de las navieras presenta una gran parte del problema, de ahí que la desregulación de los transportes haya sido una buena política estratégica, en tanto que ha facilitado una oferta más amplia de tarifas y horarios.

Del mismo modo, los espacios con menor potencial demográfico y económico -que en el caso de Canarias se corresponderían sobre todo con islas como El Hierro-, no son un atractivo para las operaciones de las navieras privadas, de ahí que las conexiones con esa isla hayan tenido que salir a concurso público varias veces, para así cumplir con un servicio mínimo, dentro de la política de las obligaciones de servicio público (OSP), en aras de favorecer la mencionada integración territorial.

En consecuencia, se debe considerar que parece más importante disponer de unas buenas conexiones que estimulen una mínima movilidad y sostenible por parte de los operadores, antes que centrar todos los esfuerzos en monumentales construcciones portuarias. De ahí que hayamos realizado especial hincapié en los horarios, en tanto que en la estructura del mercado actual los tiempos de las operaciones de las flotas de camiones se miden en costes y en integración territorial y, por esto, en posibilidades de desarrollo social y económico del territorio que, en suma, es uno de los objetivos finales.

\section{REFERENCIAS}

Alisch, M.W. (2007). East West Transport Corridor Strategy and Action Plan Final, Karlskrona: Region Blekinge. Recuperado de https://goo.gl/RpweYo Último acceso: 15 de abril de 2018.

Banister, D. y Berechman, J. (2000). Transportation Investment and Economic Development. London: University College London.

Brown, L. R. (2000). Paving the Planet: Cars and Crops Competing for Land. Recuperado de https://goo.gl/2jDPCe Último acceso: 20 de junio de 2018.

2. El dato que nos ofrece la fuente es de exactamente 1,01 euros por kilómetro para 2011, aunque lo hemos corregido en función de la inflación hasta los 1,05 euros por kilómetro de 2017 (Ministerio de Fomento, 2011). 
Chowdhury, S. (2015). The effects of travel time and cost savings on commuters' decision to travel on public transport routes involving transfers. Journal of Transport Geography, 43, 151-159. doi: https://doi.org/10.1016/j.jtrangeo.2015.01.009.

Coe, N. M., Hess, M., et al. (2015). Globalizing regional development: a global production networks perspective. Transactions of the Institute of British Geographers, 29, 468-484. doi: https://doi.org/10.1111/j.0020-2754.2004.00142.x

CEC (2001). La política europea de transportes de cara a 2010: la hora de la verdad. Luxemburgo: Comisión de las Comunidades Europeas. Recuperado de https://bit.ly/2Wqdx50 Último acceso: 10 de septiembre de 2018.

CEC (2007). Ampliación de los principales ejes de transporte transeuropeos a los países vecinos. Orientaciones sobre el transporte en Europa y las regiones vecinas. Comunicación de la Comisión al Consejo y al Parlamento Europeo. Recuperado de https://goo.gl/Si2TLn Último acceso: 10 de septiembre de 2018.

De Jong, G., Gunn, H.F., Y Walker, W. (2004). National and international freight transport models: an overview and ideas for further development. Transport Reviews, 24 (1), 103-124. doi: https://doi.org/10.1080/0144164032000080494

Deakin, E. (2007). Equity and environmental justice in sustainable transportation: toward a research agenda. California University: Transport Center.

Fundación Tomillo (2001). Los costes de ultraperiferia de la economía canaria. Santa Cruz de Tenerife: Consejería de Economía Hacienda y Comercio. Recuperado de http://hdl.handle.net/10234/55362 Último acceso: 10 de septiembre de 2018.

Gobierno De Canarias (2005). Eje Transinsular de Infraestructuras del Transporte de Canarias. Las Palmas de Gran Canaria: Consejería de Obras Públicas, Vivienda y Aguas. Recuperado de https://bit.ly/2vtqnoi Último acceso: 10 de septiembre de 2018.

Hernández Luis, J. Á. (2002). Temporal accessibility in archipelagos: inter-island shipping in the Canary Islands. Journal of Transport Geography, 10, 231-239. doi: https://doi.org/10.1016/S0966-6923(02)00014-5

Hernández Luis, J. Á. (2007). Repercusiones territoriales del transporte marítimo y aéreo en la isla de La Gomera. Estudios Geográficos, LXVII, 260, 79-104. doi: https://doi.org/10.3989/egeogr.2006.i260.44

Hernández Luis, J. Á. (2010). El transporte aéreo interinsular como factor de cohesión territorial en las Islas Canarias. Transporte y Territorio, 2, 38-67.

Hoyle, B. S., Knowles, R. D. (1998). Modern transport geography. London: Belhaven Press.

ITMMA (2009). Economic analysis of the European seaport system, Report serving as input for the discussion on the TEN-T policy. Amberes: Universidad de Antwerp.

Laffel, N. (2206). Promoting Public Transport for Sustainable Transport. Recuperado de https://goo.gl/RpweYo Último acceso: 3 de abril de 2018.

Lavissière, A. Y Rodrigue, J-P. (2017). Free ports: towards a network of trade gateways. Journal of Shipping and Trade, 2 (7), 1-17. doi: https://doi.org/10.1186/s41072-017-0026-6

Ministerio de Fomento (2011). Observatorio del transporte intermodal terrestre y marítimo. Madrid: Secretaría de Estado de Transporte. Recuperado de https://bit.ly/2ZOxyoT Último acceso: 20 de junio de 2018.

Neutens, T. et al. (2012). The relationship between opening hours and accessibility of public service delivery. Journal of Transport Geography, 25, 128-140. doi: https://doi.org/10.1016/j.jtrangeo.2011.03.004

Newman, M. E. J. (2003). The structure and function of complex networks. SIAM Review, Vol. 45, 2, 167-256. doi: https:// doi.org/10.1137/S003614450342480

Notteboom, T. (2018). Growth Q1 2018 for top 20 container ports in Europe. Recuperado de https://bit.ly/2JgxkBr Último acceso: 3 de junio de 2018.

Petrus Bey, J. M. y Seguí Pons, J. M. (1991). Geografía y redes de sistemas de transporte. Madrid: Síntesis.

Potrykowski, M. y Taylor, Z. (1984). Geografía del transporte, Barcelona: Ariel.

Ramos Pérez, D. (2001). Transporte aéreo, territorio e insularidad en Canarias. Una aproximación en el umbral del siglo XXI. Santa Cruz de La Palma: Tauro Producciones.

Rodrigue, J. P. (2006). Intermodal Transportation and Integrated Transport Systems: Spaces, Networks and Flows. Flowpolis: The Form of Nodal Space conference. Las Palmas de Gran Canaria. Recuperado de https://goo.gl/NZ2kcj Último acceso: 18 de mayo de 2018.

Rodrigue, J.P., Comtois, C., y Slack, B. (2013). The Geography of Transport Systems, New York: Routledge. Recuperado de https://bit.ly/2uGQ6ZO Último acceso: 18 de mayo de 2018. 
Rodríguez Dapena, A. (2013). Tendencias del transporte marítimo y los puertos, Madrid: Puertos del Estado. Recuperado de https://goo.gl/ocHcdb Último acceso: 18 de mayo de 2018.

Sánchez, J. E. (1981). La geografía y el espacio social del poder. Barcelona: Los Libros de la Frontera.

Tindemans, H. (2005). Spatial analysis and modelling based on activities: a pilot study for Antwerpen and Gent. En WiIliams, K. (Ed), Spatial Planning, urban form and sustainable transport. Aldershot: Ed. Ashgate.

Unión Europea (2007). Extension of the major trans-European transport axes to the neighbouring countries. Guidelines for transport in Europe and neighbouring regions. Bruselas: Directorate-General Energy and Transport.

Unión Europea (2007). The Northern Transport Axis. Pilot for the analytical support framework to monitor the implementation of the infrastructure and soft. Finland: High Level Group of European Commission, WSP.

UNCTAD (2018). Review of maritime transport. Nueva York: United Nations Publications. Recuperado de https://bit.ly/2NIUvZ5 Último acceso: 23 de enero de 2018.

Vallega, A. (1995). La regione, sistema territoriale sostenibile. Milán: Mursia.

Yamaguchi, K. (2007). Inter-regional air transport accessibility and macro-economic performance in Japan. Transportation Research Part E: Logistics and Transportation Review, 43 (3), 247-258. doi: https://doi.org/10.1016/j.tre.2006.10.004 


\section{La Importancia de la Articulación Territorial de Escala Intermedia en la Recuperación de la Memoria del Trabajo. El Caso de Barbate}

\section{The Importance of the Territorial Articulation of the Intermediate Scale in the Recovery of the Work Memory. The Case of Barbate}

Virginia Arnet-Callealta

virginia.arnet@mayor.cl @ https://orcid.org/0000-0001-8068-8383

Universidad Mayor (Chile). Av. Portugal N³51, Santiago, Chile, Código Postal 8330231

\section{INFO ARTÍCULO}

Recibido: 6/3/2019

Revisado: 2/5/2019

Aceptado: 8/5/2019

\section{PALABRAS CLAVE}

\section{Identidad}

Industria

Memoria

Paisaje

Recuperación urbana

\section{KEYWORDS}

Identity

Industry

Memory

Landscape

Urban recovery

\begin{abstract}
RESUMEN
El presente artículo indaga en la recuperación de entornos industriales para constatar la influencia que tanto el paisaje litoral como la actividad productiva tienen en la configuración de la imagen identitaria de municipios de escala media.

Para ello, se profundiza en la importancia de la escala intermedia en la organización territorial para adentrarse en su incidencia en la articulación del tejido productivo del litoral. Posteriormente, se aborda la aplicación metodológica de un instrumento de recuperación urbana contemporánea, reconociendo cuáles son los desafíos concretos del caso de estudio, Barbate, y fijando líneas estratégicas que contribuyan a dar respuesta al trabajo planteado. Finalmente, se disponen una serie de reflexiones que confirman el enriquecimiento de las identidades locales dentro del panorama global gracias a la memoria del trabajo.
\end{abstract}

\begin{abstract}
This article explores the recovery of industrial environments to verify the influence that both the coastal landscape and productive activity have on the configuration of the identity image of medium-scale cities.

For this, it deepens in the importance of the intermediate scale in the territorial organization to delve into its impact on the articulation of the productive fabric of the seacoast. Subsequently, the methodological application of a contemporary urban recovery instrument is approached, recognizing the specific challenges of the case of study, Barbate, and establishing strategic lines that contribute to respond to the work proposed. Finally, there are a series of thoughts that confirm the development of local identities within the global panorama thanks to the memory of work.
\end{abstract}




\section{INTRODUCCIÓN}

La actividad productiva de Andalucía occidental, predominantemente marcada por los parajes agrestes fértiles de las Béticas que han propiciado una industria agroalimentaria de gran riqueza comercial, han perfilado la realidad territorial del sur de la península ibérica, proporcionando un nuevo sistema de redes de ciudades de escala intermedia, a caballo entre los grandes centros regionales y los pequeños asentamientos rurales que "son una de las expresiones más acabadas del nuevo orden [...] y una forma eficiente de actualizar la realidad de las redes urbanas andaluzas al siglo XXI" (Sánchez, L. M., et al., 2010b, 287).

Debido a la trascendencia que han ido adquiriendo como objeto de investigación en las últimas décadas, las ciudades medias se han visto posicionadas como elementos fundamentales dentro del marco geográfico de referencia y establecidas como piezas esenciales en la conservación, ordenamiento y gestión del territorio. Por lo tanto, se hace imperante la necesidad de esbozar líneas estratégicas que se ocupen de una realidad patrimonial concreta, desde una perspectiva integradora que contemple los elementos arquitectónicos del pasado industrial para sumarlos a la trama urbana a la que pertenecen y, así, reconfigurar la identidad colectiva de la sociedad que lo habita desde la comprensión lógica de la relación entre paisaje, industria y sociedad.

Para ello, se profundiza en la importancia de la naturaleza y el paisaje en la articulación del territorio del litoral andaluz, para distinguir las actividades productivas que históricamente han organizado su actividad económica y que han legado espacios de oportunidad para la construcción de la ciudad actual. Todo ello, se contextualiza mediante la aplicación metodológica de un instrumento de recuperación urbana diseñado desde estándares contemporáneos que contribuye a la perdurabilidad de la memoria industrial del caso de estudio, el municipio de Barbate, a través de la definición de estrategias de intervención que consideran la influencia del paisaje en su territorio, la memoria industrial del lugar y el sentido de pertenencia derivado de ello. Finalmente, se concluye con una discusión final que alude a la perdurabilidad de las identidades locales a través de acciones que las refuercen dentro del panorama global.

\section{LA ORGANIZACIÓN TERRITORIAL DE LA FRANJA COSTERA ANDALUZA A TRAVÉS DE LA ESCALA INTERMEDIA}

En las últimas décadas, Andalucía ha experimentado cambios considerables en numerosos aspectos como el económico, el social, el cultural y el territorial (Feria, J. M., 2008). El crecimiento económico de este territorio, unido a la consolidación del sector servicios, lo han posicionado en el contexto del mercado global (García, E., 2000), siendo el turismo litoral "el elemento económico estratégico de Andalucía" (Junta de Andalucía, 2007, art. 37.1.14). Un claro ejemplo de esto último es el desarrollo obtenido por los municipios costeros de Benalmádena o Marbella desde la década de los noventa del siglo pasado hasta la actualidad; por ello, "el turismo empieza a verse como un sector productivo con mucha capacidad de generar riqueza a partir de la alusión a determinados núcleos de 'instalación' de los extranjeros en las costas" (Conde F., 2007, 39), pero también capaz de distorsionar su imagen por un crecimiento desmesurado del litoral.

Su posición geográfica, que lo ubica como nodo de conexiones con Latinoamérica, África y Europa, permite que la mirada con relación a la planificación y articulación territorial se vuelva indispensable hacia las estructuras de crecimiento y difusión integral, unidas a la progresiva apertura de los mercados y a los nuevos modos de comunicación que han propiciado una cantidad ingente de intercambios, sin responder a una localización concreta, sino todo lo contrario, perteneciendo a un territorio común y global (Delgado, M., 1999, 2002).

Se plantea la configuración de las ciudades medias andaluzas como importantes elementos en la definición del nuevo panorama territorial mediante la constitución de un sistema de redes que equilibran y unifican el territorio además de dinamizar la economía mediante sistemas de flujos de personas, mercancías, capital, conocimiento o información (Caravaca, I., 1999). Los núcleos urbanos de escala intermedia adquieren una creciente importancia como lugares de asentamiento de su población y así lo demuestran los diversos estudios realizados en la última década sobre ellos (Mosquera, E., et al., 2003a, 2003b; Bonet, A., 2007; Cano, 
G., 2008; Caravaca, I., 2008; Sánchez, L. M., et al., 2010a, 2010b). Sin embargo, y a pesar de las disimilitudes que puedan presentar estos estudios, existe un punto de encuentro en el ámbito normativo: el Plan de Ordenación Territorial de Andalucía - POTA en adelante - (Junta de Andalucía, 2006). Este documento incluye la definición de un modelo territorial para Andalucía que se sustenta en unas bases a partir de las cuales es posible progresar en la conformación de esta región como un espacio común, articulado y cohesionado, donde conviene resaltar la trascendencia de las ciudades medias en la realidad autonómica, ya que suponen el sustento del tejido productivo, empresarial, turístico,... como centros económicos con potencial de desarrollo y, a la vez, depositarias de un valioso patrimonio histórico. Además, y debido al extenso volumen de estas urbes, el POTA establece una jerarquía de las mismas según su ubicación en el entorno. Así se destacan las redes de ciudades medias interiores y las redes de ciudades medias litorales (ver Figura 1), aunque los límites entre estas distinciones sean difusos y colaboren con el enriquecimiento del conjunto global de la región. Tradicionalmente han sido las ciudades medias del interior las que han respondido a esta categoría, debido a su ubicación centralizada en el territorio, $y$, por ello, los estudios versados en la materia son mucho más numerosos (Díaz, J. L., 2007), incorporando la marca 'Tu Historia' del Plan Turístico de Ciudades Medias del Centro de Andalucía (Muñoz, A., 2007).

No obstante, ha sido en el litoral "donde se han sumado los procesos de crecimiento urbano [... ya que] presentan una fuerte especialización funcional (turismo y nuevas agriculturas)" (Junta de Andalucía, 2006, 28-56). De esta manera, la costa andaluza conforma ocho redes policéntricas de ciudades medias que comparten funciones y aparecen, dentro del paisaje andaluz como elementos estructuradores del mediterráneo (Sánchez, L. M., 2016; Rodríguez, F. et al., 2016) y del atlántico (ver Figura 2).

Estos espacios generan distintos flujos que se convierten en referentes para lecturas e interpretaciones sobre la emergencia y consolidación de las nuevas dinámicas del litoral andaluz. Las relaciones flujos-lugares, territorio-redes, territorio-superficie, se vuelven elementos claves para la interpretación de la arti-

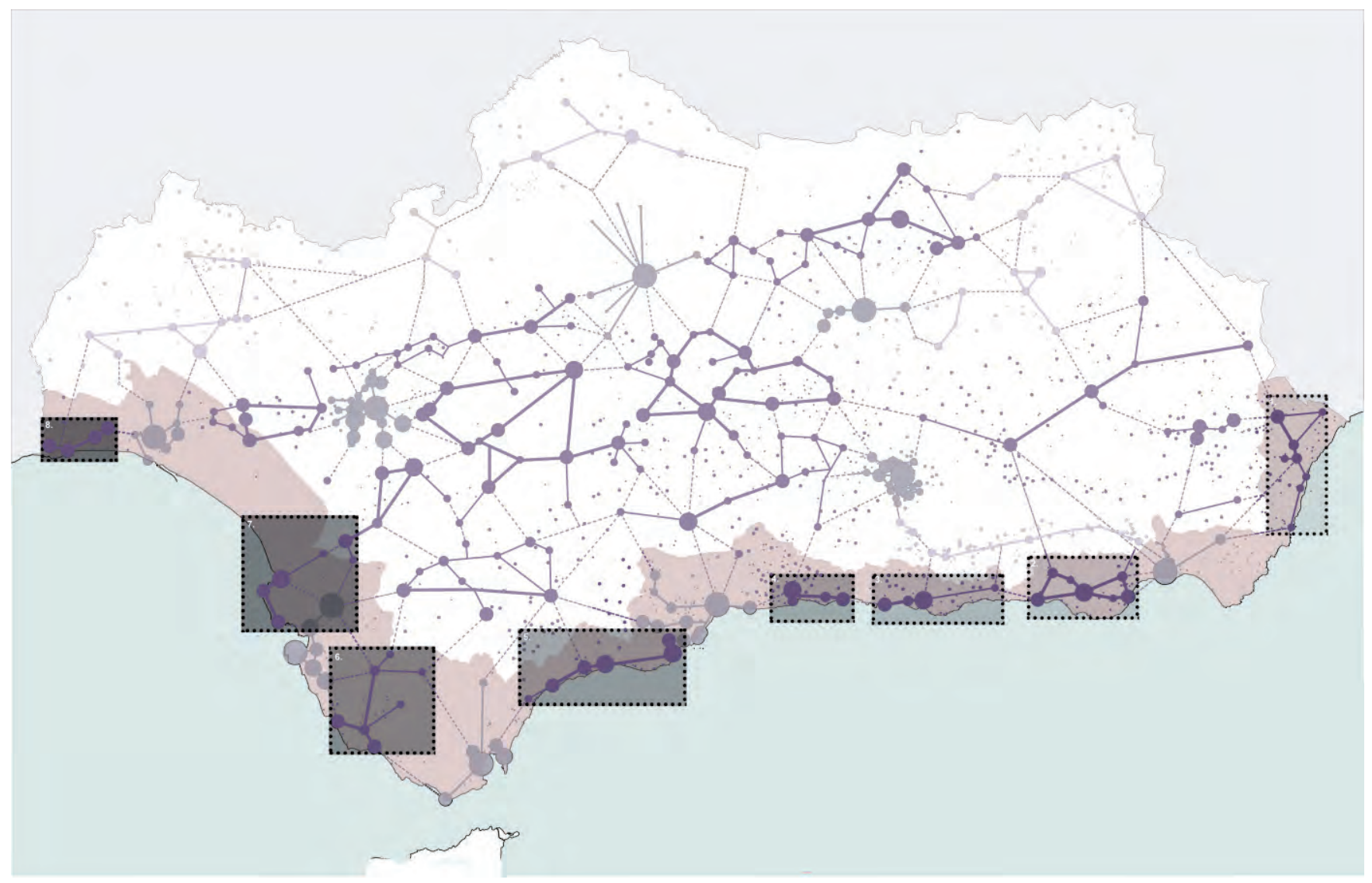

Figura 1. Redes de ciudades medias de Andalucía presentes en el litoral.

Fuente: Elaboración propia a partir de Plan de Ordenación Territorial de Andalucía (Junta de Andalucía, 2006). 


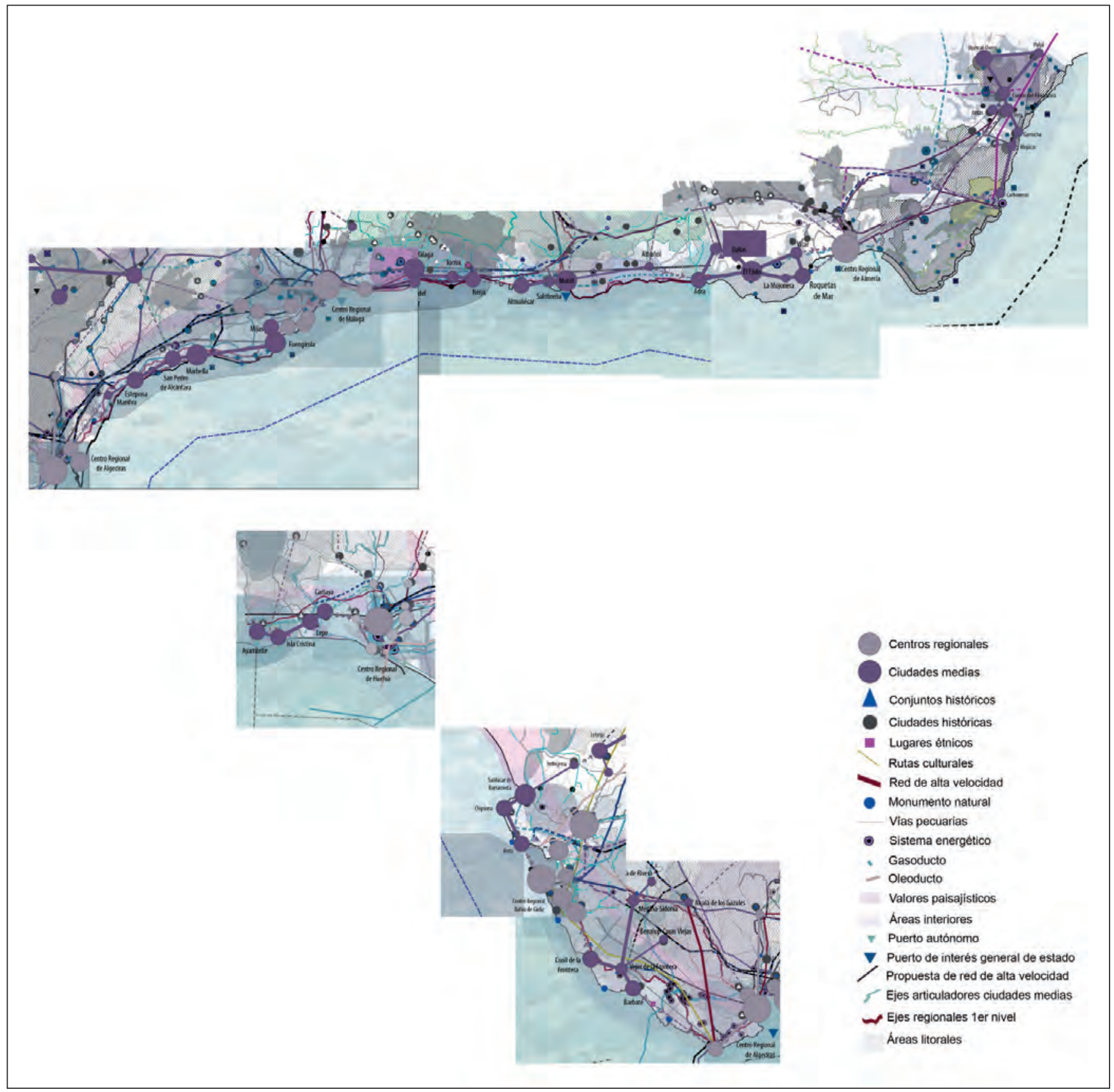

Figura 2. Esquemas de las redes de ciudades medias del litoral mediterráneo (arriba) y atlántico (abajo) de Andalucía. Fuente: Elaboración propia a partir de Plan de Ordenación Territorial de Andalucía (Junta de Andalucía, 2006).

culación territorial de Andalucía donde las ciudades medias que lo colonizan son espacios relevantes para las actividades económicas más dinámicas y, por tanto, factores imprescindibles para la comprensión de la evolución urbana de la región (De Aguilera, M., 2000). Asimismo, las modificaciones surgidas en estos enclaves como respuesta a los procesos de desindustrialización, descentralización productiva y especialización, constituyen nuevas posiciones mediadoras entre la industria y el territorio, "que aumenten la calidad de vida de una comunidad humana sin destrozar su hábitat y sin necesidad de hacerla depender excesivamente de elementos extraños a ella misma" (Ojeda, J., 1988, 43), ya sea bajo nuevas formas arquitectónicas o con la reutilización del legado productivo que aún perdura en sus tejidos urbanos. Por ello, las ciudades de escala intermedia que constituyen el litoral andaluz son piezas fundamentales para establecer dinámicas de desarrollo endógeno que impactan en la organización territorial y en la articulación de sus flujos de desarrollo (Sánchez, L. M., 2018). 


\section{LA INCIDENCIA DEL TERRITORIO EN LA CONFIGURACIÓN DEL TEJIDO PRODUCTIVO LITORAL DE ANDALUCÍA}

Este apartado recupera la inserción de la noción de industria y territorio, y el desarrollo de las acciones en torno a ella desde sus orígenes hasta la fecha. Si bien es cierto, diversos estudios sobre la industrialización andaluza (González, A., 1984; Monlau, P. F., et al., 1984; Garrabou, R., 1988; Nadal, J., et al., 1994; Morales, M., 1999; Del Río, C., 2000; Parejo, A., 2001; Nadal, J., 2009) afirman la diferenciación de todo el proceso en cinco etapas:

- Antecedentes (hasta 1850): se inicia con la radicación de los tartessos en la zona occidental andaluza debido a la riqueza que tiene este territorio para la extracción de mineral con el que confeccionar joyas, además de perfumes, tejidos, vinos y aceites, con los que comerciar con las otras civilizaciones del Mediterráneo.

- Etapa de implantación (1850 - 1880): el crecimiento económico en esta etapa favorece la relación industria-sociedad influyendo notablemente en el borde litoral con la aparición de distintos núcleos urbanos en torno a una importante actividad industrial en primera línea de playa que atraen capitales extranjeros a la región.

- Etapa de crecimiento (1880 - 1950): frente al colapso económico con la crisis agraria de finales del siglo XIX al finalizar la etapa anterior que agota toda posibilidad de producción y comercialización, la actividad productiva retorna al carácter exportador agroalimentario anterior dedicando su actividad a la producción de vino, aceite, azúcar o conservas de pescado.

- Etapa de desarrollo (1950 - 1970): a mediados del siglo XX se suavizan las políticas económicas de carácter internacional, favoreciendo proyectos de promoción turística que marcan el germen del cambio paradigmático de la economía andaluza basada en un nuevo modelo de consumo territorial que afecta al paisaje y a su territorio.

- Etapa de producción turística (1970-actualidad): la escasa capacidad de adaptabilidad tecnológica y ambiental en el desarrollo económico del entorno andaluz, unida a la favorable condición geográfica facilitan la terciarización de la actividad productiva, provocando un auge de la economía andaluza centrada en propiciar destinos atractivos al turismo como la Costa del Sol malagueña o en la Costa de la Luz gaditana.

Si bien es cierto que la costa andaluza a todo lo largo de su territorio concentra un extenso número de elementos industriales, y que la gran mayoría de ellos se definen por una industria dependiente de la agricultura, la pesca y la ganadería (Sobrino, J., 1997, 1998), la posición estratégica, de fácil acceso y comunicación, unida a la tradición industrializadora desde época fenicia, además del vínculo inmediato de estas actividades con la presencia de dos redes importantes de ciudades medias en la costa de esta provincia, hacen de la provincia de Cádiz un elemento relevante para esta investigación. Sin embargo, la red de ciudades medias de la costa oriental gaditana tiene una larga tradición pesquera como podemos observar en las ciudades de Conil y Barbate, frente a la actividad vinícola presente en el poniente gaditano. A pesar de que en el litoral gaditano aparecen dos sectores industriales fuertemente diferenciados de los demás, la actividad pesquera y de salazón y la actividad vitivinícola, este estudio se centrará en su condición de metrópolis marina originada con el comercio de indias, la relevancia del mar para el territorio y la fuerte dependencia de él en todos los ámbitos.

\section{FUNDAMENTOS METODOLÓGICOS PARA LA REALIDAD BARBATEÑA}

El análisis y diagnósticos de las variables territoriales, paisajísticas, productivas y sociales se constituyen en patrones esenciales de confrontación ante los modelos tradicionales y las pautas contemporáneas de recuperación de espacios del trabajo para definir novedosas perspectivas exploratorias y propositivas que enaltezcan los valores presentes en el tejido productivo de las ciudades medias litorales por medio de acciones que redefinan usos contemporáneos para antiguos entornos productivos, además de mejorar la rentabili- 
zación social del patrimonio industrial. Para ello, la metodología planteada se configura en tres etapas que constantemente se hallan en un proceso de reformulación permanente.

- Posicionamiento epistemológico ante la realidad territorial e industrial barbateña: en esta etapa se apunta a la aproximación epistemológica del marco de estudio para, con ello, lograr abordar la realidad territorial, urbana, productiva y social del objeto de estudio con el oportuno grado de madurez. Para ello, se considera el levantamiento bibliográfico a partir de herramientas esenciales como bases de datos, repositorios virtuales, publicaciones científicas, documentos de trabajo, así como noticias de actualidad, además del levantamiento planimétrico apoyado en normativas y documentos de ordenación territorial y urbana que contribuyan a la elaboración de una síntesis analítica y planimétrica al respecto.

- Profundización en la percepción de agentes locales respecto a la importancia del patrimonio industrial de carácter urbano: para esta segunda etapa, es necesario encuadrar el entorno industrial a analizar para determinar las demandas reales de los habitantes actuales. Para ello, y con el fin de ahondar en los requerimientos de las personas que están inmersas en la realidad de estudio, se brinda la oportunidad de recoger mediante entrevistas las opiniones de algunos agentes locales que contribuyen a ampliar, profundizar y complejizar la mirada del caso de estudio.

- Contextualización propositiva: finalmente, se determinan los valores que prevalecen en el inconsciente colectivo de los ciudadanos locales, atendiendo al legado productivo para definir líneas de intervención que contribuyan a confirmar la hipótesis planteada y que, asimismo, entregue resultados comunes a la importancia de la articulación territorial en la recuperación de la memoria del trabajo en las ciudades medias del litoral andaluz.

\section{LA CHANCA: PRAXIS RESISTENTE ANTE EL OLVIDO DE LA PRODUCCIÓN ALMADRABERA}

Las investigaciones aportadas al respecto (Fernández, C., 1866; Bellón, L., 1926; Ríos, S., 2005; Bernal, D., 2012) remontan la actividad pesquera en el sector oriente de la costa de Cádiz desde el siglo V a.C con la aparición de una factoría de salazones prerromana en Las Redes en el Puerto de Santa María o el núcleo urbano costero de Baelo Claudia en Bolonia, cuya "existencia y explotación de dichas factorías parece ser la razón primordial de su fundación y desarrollo" (López, J. A., et al., 2012, 141). Estas fábricas de salazones permitieron dar a conocer el producto gaditano a lo largo del Mediterráneo en época romana, lo que generó unas dinámicas de comercio intensas y una gran actividad industrial en las costas de Cádiz, además de caracterizar un paisaje que le es propio y que no es entendible sin el mar, las embarcaciones, las redes, el atún, la sal y la marisma. A pesar de ciertos derechos señoriales adquiridos que benefició al proceso de la almadraba tras la reconquista, no es hasta finales del siglo XVIII cuando comienza una verdadera industrialización en torno a la pesca de almadraba, con la implantación de un nuevo sistema de pesca, la almadraba de buche y la liberación del sistema monopolístico pesquero en 1817 (Florido, D., 2005, 2006). De forma paralela a la industria almadrabera, a partir del siglo XVI se construyen a lo largo de la costa gaditana distintas chancas como las de Conil o Zahara con fábricas de salazones, de conservas y almacén de barcos de almadraba, consolidándose esta relación durante el siglo XVIII (Ríos, S., 2005) y transformando la actividad productiva de los siglos XIX y XX con el fortalecimiento de la industria conservera (Ríos, S., 2006) que se conoce en la actualidad gracias al papel fundamental del Consorcio Nacional Almadrabero en la costa atlántica de Andalucía quedando su sede principal en Barbate desde su origen en 1928 (Florido, D., 2013).

\subsection{La importancia del municipio de Barbate en la articulación del territorio andaluz}

El modelo territorial definido en el Plan de Ordenación del Territorio de Andalucía (Junta de Andalucía, 2006), enmarca a Barbate dentro del sistema de ciudades medias como una ciudad media de segundo nivel, perteneciente a las redes de ciudades medias litorales $y$, a su vez, incluida en la unidad territorial denominada 
'Unidades organizadas por redes de ciudades medias litorales', dentro del dominio territorial definido por dicho Plan como Litoral (ver Figura 3).

Es por eso que el entendimiento de este municipio no ha de hacerse de forma aislada sino como parte integrante de una de las redes de ciudades medias que articulan el litoral gaditano. En base a esta posición dentro del contexto geográfico, el municipio se categoriza como 'Nodo Urbano de $2^{\circ}$ Nivel', actuando como centro de intersección de redes de transporte de primer nivel y adquiriendo una posición idónea para actuar como punto de intercambio modal (incluyéndose, junto a Conil y Vejer de la Frontera, en una de las 'Áreas Litorales de Ordenación del Transporte', vinculadas con los centros regionales de la Bahía de Cádiz y Algeciras). Asimismo, y debido a su posición estratégica entre estos dos grandes centros regionales de la provincia, el Plan condiciona a esta ciudad como ámbito de múltiples potencialidades donde desarrollar los sistemas de infraestructuras a escala global.

Además, la inclusión del municipio como parte integrante del Plan de Ordenación del Territorio de La Janda (Junta de Andalucía, 2011), pone de manifiesto su importancia natural y paisajística, poniendo en valor la influencia que han tenido las actividades pesqueras en la definición de la imagen de esta parte de la costa gaditana. Con relación a esto, el Plan de la Janda (Junta de Andalucía, 2011) establece que los futuros crecimientos del municipio habrán de ser respetuosos con los condicionantes del territorio en el que se emplacen y desarrollarse de forma compacta, además de presentar una distribución equilibrada de los equipamientos, evitar una dispersión de usos globales y presentar un sistema de comunicaciones y transportes que faciliten las conexiones y la articulación de toda la comarca (ver Figura 4).

\subsection{La pesca como inicio de la actividad industrial}

- Antecedentes: de garum y vasijas. Los fenicios fueron los primeros pobladores de la costa andaluza, pero no es hasta el período romano cuando aparecen las primeras fábricas de salazones en la zona de estudio gracias a la existencia de las salinas de Barbate - elementos reconocibles en la desembocadura del río Barbate, en la isla de San Paulino, en el Parque Natural de La Breña y Marismas del
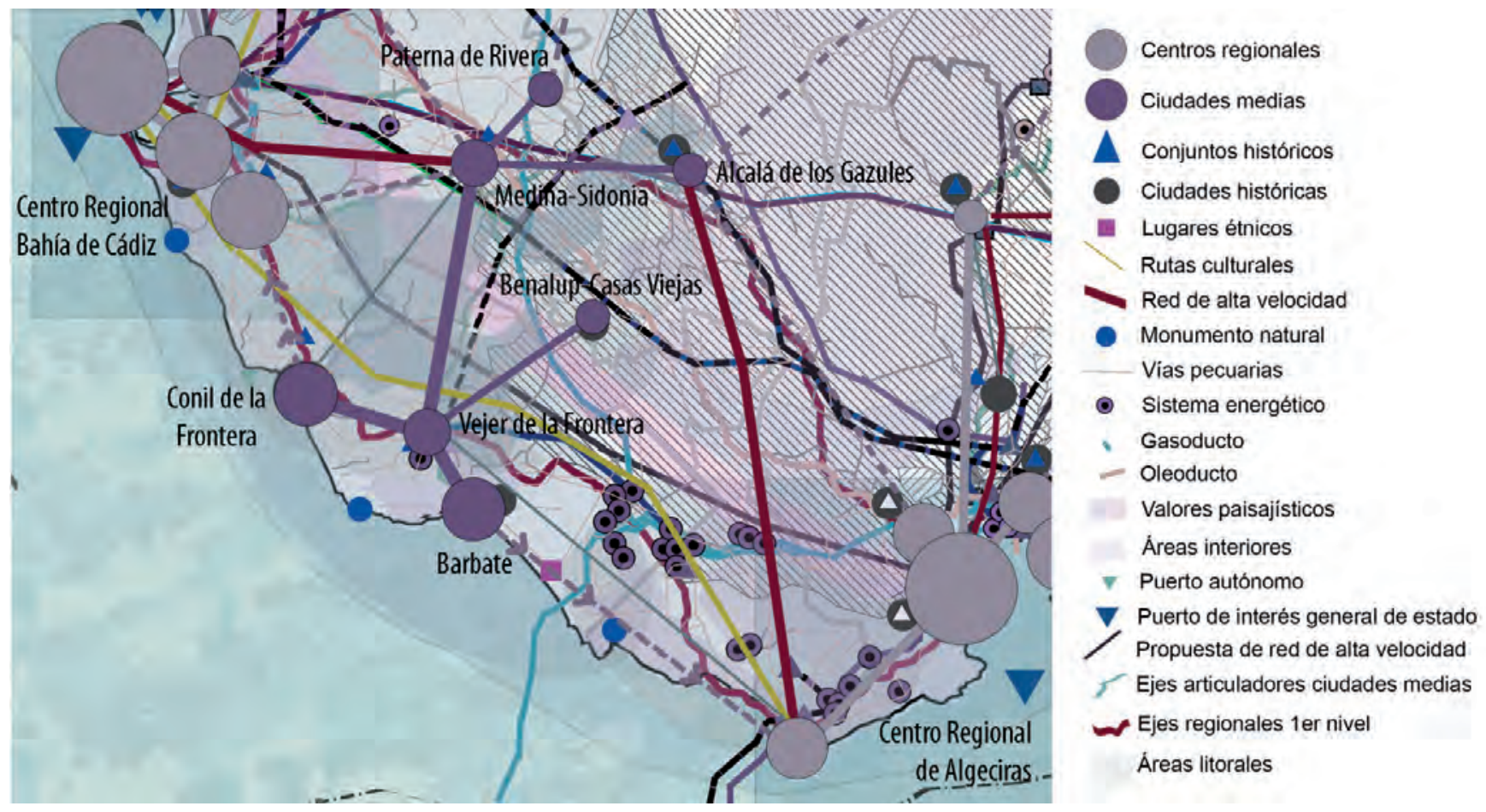

Figura 3. Detalle de la red de ciudades medias que engloba a Barbate.

Fuente: Elaboración propia a partir de Plan de Ordenación Territorial de Andalucía (Junta de Andalucía, 2006). 

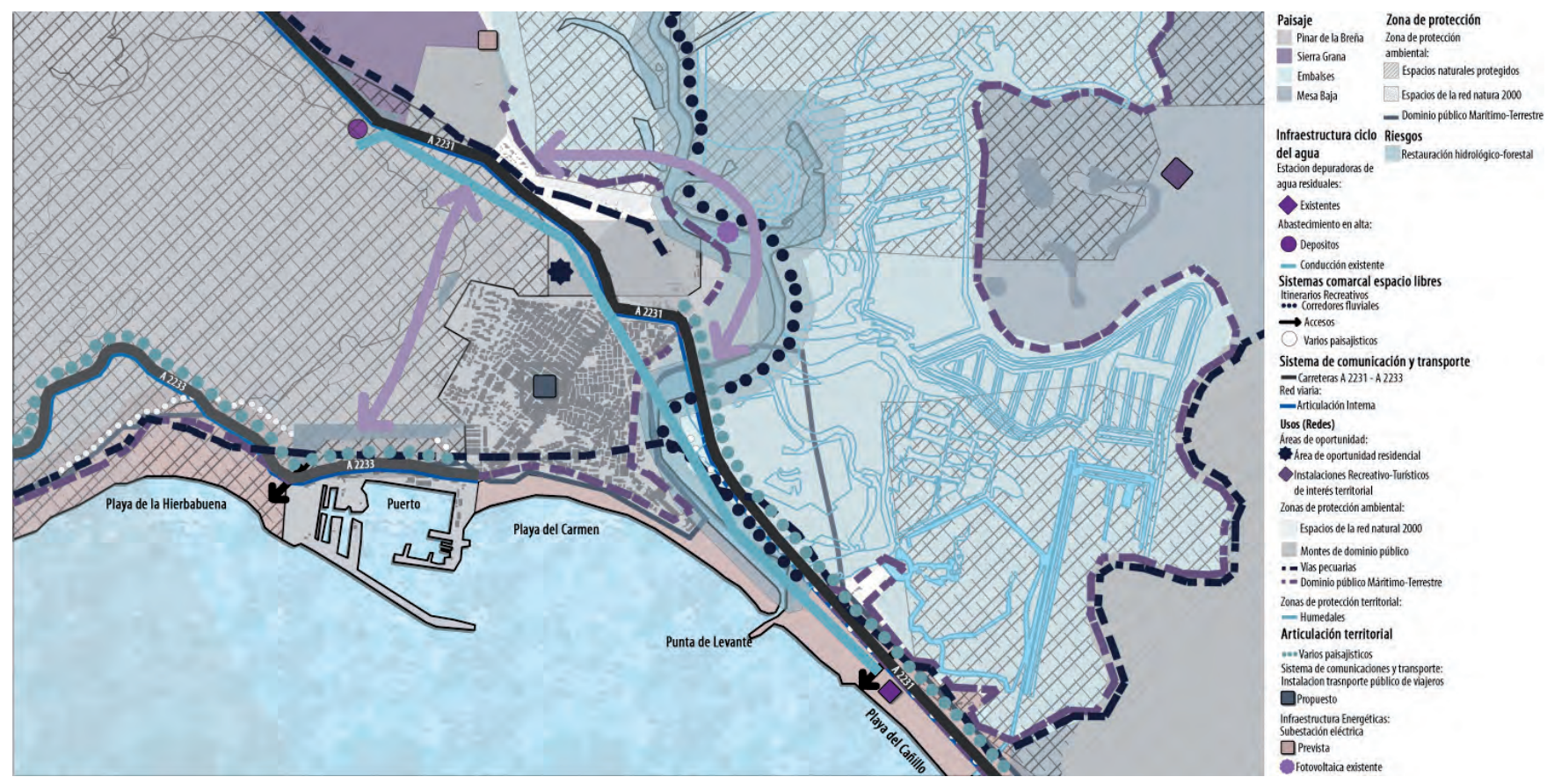

Figura 4. Área territorial de intervención.

Fuente: Elaboración propia a partir de información del Plan de Ordenación del Territorio de La (Junta de Andalucía, 2011).

Barbate, que se encargaban de estructurar de un modo reconocible en el paisaje, el litoral atlántico gaditano - que prosiguió su actividad hasta el siglo XX, facilitando el elemento principal de conservación a las pequeñas empresas locales que dirigían su actividad productiva a las conservas de salazones, además de contribuir al ciclo productivo del municipio que incorporaba a la pesca, la salazón y la conserva, la fabricación de envases ${ }^{1}$ en los que transportar el pescado, la fabricación de redes o la construcción y reparación naval (Lagóstena, L., 2001; Santos, A., 2001, 2006; Conde, F. G., 2007).

- Etapa de implantación: las primeras conservas. Tras la reconsquista castellana, la pesca resurge en aguas barbateñas, generando una actividad productiva importante ligada al mundo marítimo y la conservación de estos elementos (Conde, F. G., 2007). La necesidad de dar respuesta a las demandas existentes en torno al atún, pero siempre bajo el monopolio de los duques de Medina Sidonia hasta que en 1817 se abolieran definitivamente los derechos de la casa ducal sobre la almadraba, genera una gran actividad industrial en la costa barbateña, ligada a la conservación de salazones - notablemente influenciado por la presencia de un paisaje marismeño y salinero en la costa del municipio -; no obstante, la fuerte competencia del mercado valenciano que contribuye a la sobreproducción conservera unida a su escaso consumo, unida a la competencia portuguesa en el rubro y el elevado precio que alcanza la sal en este momento, concatenan una gran crisis al final de esta etapa (Ríos, S., 2005, 2006). - Etapa de crecimiento: italianos en las costas. Esta etapa se inicia con dos detonantes: el primero, la bifurcación del mercado portugués hacia la conserva en escabeche (Lacomba, J. A., 2006) y, el segundo, el arribo de numerosos italianos a las costas gaditanas en 1879 , que llegaron con conocimientos de conservación de atunes, melvas y bonitos en aceite y salmuera desde su Italia natal, lo que supuso un cambio notable en los modos, los tiempos y el público objetivo la producción conservera que posteriormente retomaron trabajadores y empresarios locales cuando los italianos regresaron a su país de origen tras el fin del tratado hispano-italiano en 1888 (Ríos, S., 2005, 2006; Florido, D., 2006). Con este clima propicio que aunaba pesca e industria entendido como un único conjunto, favoreció la nacionalización de la explotación y su posterior consolidación con la aparición del Consorcio Nacional

1. En la huerta de Luis Santos se encuentran vestigios productivos que permiten identificar un horno de planta circular datado de época romana donde se fabricaban piezas cerámicas para el envasado del atún para su comercialización (Lagóstena, 2001). 
Almadrabero de Barbate en 1929, sólo un año después de la configuración nacional, formando parte de él empresarios locales como Serafín Romeu i Fagés, Demófilo Vitorique, Aniceto Ramírez, Roberto Osborne, Braulio Crespo y Manuel Gallardo (AA. VV., 1988, 2006). En este complejo, conocido como la chanca de Barbate, no sólo se aúnan fábricas de conservas como el Rey de Oros, Conservas Sur, Los Crespo y Los Gallardo, sino que además se disponen viviendas, talleres, la lonja y el puerto de interior (CNA, 1929; Ríos, S., 2006; Florido, D., 2013). Todo ello, configura un paisaje característico de Barbate en la margen derecha del río, mediante un conjunto industrial separado del resto de la población, pero unido al centro urbano. Lamentablemente, el ímpetu con el que se crean las dependencias almadraberas barbateñas no perdura en el tiempo (AA. VV., 1988).

- Etapa de desarrollo: el florecimiento conservero. La caída de los rendimientos de las almadrabas suratlánticas no afectaron a Barbate, sino todo lo contrario, se produjo un esplendor durante la década de 1950 que llevó a localizar ocho grandes fábricas conserveras en el sector: el Consorcio Nacional Almadrabero, el Rey de Oros, Conservas Sur, Los Crespo, Pérez y Feu, Los Gallardo, el Estanquero y Los Masones. A éstas hay que añadir pequeñas fábricas de conservas como la fábrica de sardinas arenques de Antonio Soler y Pepe Aragón, ubicadas en la actual avenida El Faro; saladeros como el de Juan Quintana o el de Troyano; la construcción de la Lonja Vieja que facilitaba el ronqueo y la distribución del atún, en las proximidades de la chanca; talleres para la reparación de barcos; y almacenes para arreglo de las cajas de pescado o para la fabricación de tabales para las sardinas arenques, junto a salones donde se estibaban los pescados provenientes de la almadraba (Florido, D., 2013) hasta que la bonanza de las dos décadas anteriores decae en 1970 comenzando un paulatino deterioro desde entonces. Asimismo, destaca la importancia de una nueva trama urbana dedicada por completo a la actividad productiva con la proliferación de barrios almadraberos como la Chanca o el Zapal, constituido este último por chabolas en el núcleo de actividad del municipio y que estuvo activo hasta que en 1974 fuera demolido, desplazando a todos los residentes del lugar a otras zonas de Barbate como el barrio de La Paz, Fátima, Blas Infante, Serafín Romeu, San José, Rafael Alberti,... que acogieron a los antiguos trabajadores de la producción barbateña (Florido, D., 2006).

- Etapa de producción turística: japoneses en el copo. Durante la década de 1970, debido a las limitaciones impuestas en las políticas marítimas de Marruecos para la captura de atunes, se produce un declive en la flota barbateña que deciden emigrar a las costas de levante, Cataluña y Canarias, abandonando la pesca en Barbate y produciendo un descenso notable en los niveles de pesca y conservas en el litoral gaditano, repercutiendo en el sucesivo cierre de fábricas, como la fábrica de conservas Massó (Bohórquez, D., 2000). No obstante, la crisis del sector pesquero del municipio vuelve a resurgir en los años ochenta, con el interés de comerciantes japoneses en el atún rojo que se captura en estas almadrabas. La mayor parte de la producción es adquirida por empresas japonesas que trasladan hasta su país de origen las especies en cámaras frigoríficas que atracan en las proximidades del puerto de La Albufera, previamente trabajadas por ronqueadores barbateños (Florido, D., 2006). Todo ello, ha facilitado en los últimos años, la creación de empresas que se dedican a la preparación del atún rojo en el puerto de Barbate y que obligan a convivir, durante la época de ronqueo, en un mismo lugar las técnicas tradicionales barbateñas con los cortes japoneses (Florido, D., 2013). A pesar del alto beneficio que las empresas japonesas han proporcionado al municipio de Barbate, se producen dos inconvenientes notables: el natural y el patrimonial. Por un lado, la transformación de los ciclos tradicionales de la actividad almadrabera que dejan de adaptarse a los ciclos migratorios de los atunes, alterando las condiciones naturales de desove del atún rojo obligando a la instalación de piscinas a mar abierto donde se crían, engordan y reproducen múltiples especies (Florido, D., 2006). Todo ello, conlleva consecuencias graves que afectan a la flota pesquera y a la actividad conservera que de ella depende 2 . Por otro, la pérdida notable de tejido industrial debido a la transformación radical que la economía almadrabera ha soportado en los últimos años y que ha concatenado el

2. En el año 2010, el Ministerio de Medio Ambiente y Medio Rural y Marino tuvo que proceder al cierre de la almadraba de la Ensenada de Barbate debido a que ya habían superado el volumen de capturas de atún rojo establecido para esa campaña. 
cierre paulatino de conserveras tradicionales como la del Rey de Oros para favorecer la creación de grandes empresas que se adaptan al mercado global como Salpesca o Herpac. También, en su afán de producción rápida, otras empresas extranjeras intentan emplazar almadrabas propias en la costa gaditana poniendo en peligro la almadraba tradicional junto con el posterior tratamiento del atún.

\subsection{Ciudadanos: Protagonistas en la recuperación de la memoria industrial}

A raíz de las visitas realizadas al lugar, se puede comprobar el escaso funcionamiento que obtiene este entorno tras la rehabilitación de la antigua lonja; por ello, se proponen nuevas pautas que dirijan su reutilización a generar un elemento que sea capaz de revitalizar esta área, sólo así se conseguirá favorecer la permanencia en buen estado de los elementos industriales. La intencionalidad gobernable es consolidar este fragmento urbano a través del uso hotelero como define el Plan Especial de Reforma Interior (Ayuntamiento de Barbate, 2013a)3. Este hecho servirá, asimismo, para la recuperación ambiental de la zona mediante amplios espacios libres que circundarán la zona y permitirá la conexión peatonal con el borde marítimo de Barbate y la playa del Carmen. Sin embargo, el planeamiento se presenta como una necesidad ligada a la promoción económica y a la mejora de la calidad de vida del área escogida.

La disponibilidad de nuevos espacios económicos, áreas de vivienda, distintas opciones de transporte, la reducción temporal de las distancias o la seguridad viaria responden a una propuesta realizada desde la lejanía institucional; por ello, se vuelve imperante la necesidad de establecer contacto con agentes locales que ayude al entendimiento de la situación y la cooperación en el resultado final.

Las distintas entrevistas realizadas se pueden clasificar en tres grandes grupos de estudio de ciudadanos: grupo 1 (familiares de trabajadores en activo de actividad pesquera en la actualidad), grupo 2 (antiguos trabajadores de almadraba barbateña que continúan vinculados a la actividad de La Chanca), grupo 3 (antiguos pescadores que han reconvertido sus labores en claves culturales).

El primer grupo de entrevistas son testimonios representativos de un colectivo muy arraigado al área urbana que se estudia debido a las experiencias personales de todos ellos con el mar y el atún. Uno de los entrevistados, durante el recorrido por las casas del Consorcio Nacional Almadrabero, relata sus vivencias en este lugar y cómo el hecho de depender económicamente de la pesca influye en las relaciones sociales de todos los que allí habitan, para continuar hablando de la importancia del mar para ellos, sobre todo en la primera mitad del siglo XX, ya que les proporcionaba todo lo necesario para su subsistencia, evitándoles tener que emigrar a otras poblaciones en busca de trabajo. Los integrantes del segundo grupo de estudio han vivido de primera mano las últimas dos décadas de esplendor de este lugar con lo que la sensación de arraigo al lugar se hace más presente conforme avanza la conversación. Uno de los entrevistados, al ser cuestionado sobre las ideas plasmadas en el Plan General de Ordenación Urbanística para la zona responde de manera irónica: "soy más viejo, cuando usted tenga mi edad aún no habrán destruido este lugar. No pueden. Esto es Barbate". Estas palabras tan temperamentales responden a las acciones llevadas a cabo en 1961 con la construcción del nuevo puerto exterior de La Albufera y el distanciamiento de las fábricas del núcleo urbano consolidado. Finalmente, las entrevistas realizadas al tercer grupo de estudio muestran la 'nueva' cara de la Lonja Vieja que en la actualidad apuesta por una funcionalidad cultural. Sin embargo, a pesar de los esfuerzos realizados para su reconversión laboral, los integrantes de este sector poblacional reclaman ante el paulatino abandono de los últimos años y las múltiples modificaciones funcionales que están sufriendo que los obliga a desvincularse del mar y de sus tradicionales modos de vida.

Por ello, la obligación de recuperar la centralidad demográfica y económica que la actividad pesquera de almadraba y las industrias de procesamiento de atún y otras especies otorgaron a la desembocadura del río Barbate, desde parámetros locales inclusivos con los habitantes actuales se vuelve indispensable. De este modo se logrará una solución de carácter global para la preservación del entorno que manifieste que

3. La aprobación definitiva del Plan Especial de Reforma Interior de la Unidad de Ejecución B06 'El Consorcio', que alberga el área de estudio, realizada a fecha de 28 de julio de 2010, dará respuesta a la demanda turística que está sufriendo el municipio en los últimos años. 
la identidad, las relaciones y la historia de quienes lo habitan se inscribe allí, en un entorno determinado, combatiendo con la 'modernidad' y los procesos de globalización.

\subsection{Nuevos resultados para la recuperación de la memoria almadrabera en Barbate}

Los vestigios industriales escogidos se localizan en la zona de La Chanca, semiaislada del resto del municipio debido a su ubicación en una península de tierra que se encuentra rodeada del océano y el río Barbate, aún hoy una zona residual dentro del tejido urbano de la ciudad. Sin embargo, la importancia que el paisaje tiene en la conformación de la identidad territorial propicia un intercambio permanente entre lo natural y lo artificial (Nogué, J., 2007) que ha definido su imagen característica. Dicha imagen es la que confiere fuerza a la relación atún, sal y marisma que configura la identidad cultural barbateña a partir de elementos intangibles de un mismo lugar (González, I., 1999; Castells, M., 2005).

La desaparición de toda memoria de actividad industrial debido al traslado de las principales fábricas conserveras al polígono industrial de La Oliva ha condicionado que el Plan General Ordenación Urbanística de Barbate (Ayuntamiento de Barbate, 2013b) delimite el área dentro del sector 'Ensanche Sur' con un uso predominante residencial que, además, contempla la apertura de un nuevo viario fragmentando una de las manzanas posibilita una mejor comunicación por tráfico rodado de la zona, ya que los accesos están muy reducidos y la zona mal conectada. Asimismo, la intención de colmatar esta vía con un frente destinado a equipamientos públicos enriquece una futura integración de los vestigios fabriles, posibilitando la mezcolanza de usos en el área, lo que conllevará a un mayor enriquecimiento del tejido urbano que aunará equipamientos, nuevos y existentes, con un sistema de espacios libres contundente y una zona residencial de vivienda plurifamiliar cerrada de $\mathrm{B}+3$.

La preservación y el rescate de los elementos arquitectónicos que constituyen el antiguo conjunto industrial almadrabero sintetizan de forma clara la interacción industria, territorio y sociedad. Por ello, La Chanca se presenta como un lugar idóneo donde impera la heterogeneidad con funciones diversas que históricamente estaban unidas bajo un objetivo común, la producción almadrabera, y que, por ello, se constituye como un espacio clave para la recuperación del patrimonio industrial de las ciudades medias del litoral andaluz, mediante la puesta en escena de intervenciones que evidencien "la apropiación del sitio vaciando su contenido simbólico y cambiando su significado [impidiendo] la sistemática destrucción de la memoria social" (Montaner, J. M., 2004, 59-60). Además, en el caso de Barbate, la percepción, la apreciación, el análisis y el conocimiento de la naturaleza juega un papel fundamental en la concreción de su identidad. Por ello, se plantea una propuesta que se articule en las tres líneas estratégicas, profundizando en el diálogo territorio, industria y patrimonio:

a. Reestablecer la relación perdida entre la ciudad y el territorio. En primer lugar, se detecta la relevancia que el río Barbate ha tenido como elemento estructurador de la actividad productiva de La Chanca, por tanto, la consideración del Parque Natural de La Breña y Marismas del Barbate como un elemento fundamental en la organización y articulación de la vida cotidiana de los ciudadanos de este sector de Barbate, favorece el contacto directo de los mismos con los elementos naturales de su entorno. Con el fin de reestablecer la identidad perdida entre la ciudad y su territorio y, además, favorecer el vínculo inmediato con el territorio y el paisaje que éste regala al área de estudio, se propone un entramado de paseos, plazas, jardines y calles peatonales producto de la reutilización de los espacios industriales intersticiales que fomentan la permeabilidad y la relación inmediata con el entorno de la propuesta, recuperando la relación perdida del núcleo urbano con el río y la marisma. Asimismo, para que esta conexión traspase la barrera de lo visual y se transforme en tangible se propone la apertura de un nuevo sistema viario que facilite la comunicación interna de todo el ámbito, de éste con el resto del municipio, $y$, además, con el resto del territorio andaluz reforzando el carácter intermediador y articulador de las ciudades medias.

b. Recuperar la memoria industrial. Por otro lado, para profundizar en la recuperación del pasado productivo se propone un nuevo espacio que armonice pasado y futuro mediante la reutilización del 
conjunto industrial de La Chanca al considerar la reconversión funcional mediante nuevos usos que sean sensibles con el territorio y contribuyan a redefinir la desembocadura del río Barbate y su paisaje marismeño.

c. Considerar la reconversión programática del caso de estudio a través de usos contemporáneos sensibles con el entorno. El complejo industrial del Consorcio Nacional Almadrabero, formado por la fábrica almadrabera, las viviendas de los trabajadores y la antigua lonja de Barbate, se convierte en un espacio de oportunidad desde el que consolidar usos contemporáneos para recuperar sus estructuras fabriles y, con ello, devolver su seña de identidad originaria al ámbito de estudio.

No obstante, el turismo ligado a la actividad industrial, es un fenómeno ya explotado en otros países como el Reino Unido, Alemania, Bélgica, Francia,... en las que antiguos conjuntos industriales se han reconvertido para albergar usos turísticos como sucede con las intervenciones realizadas en la Tate Modern de Londres, el Zollverein de Essen, el puerto de Génova, el Matadero de Madrid, entre otros, para vincular el turismo y el patrimonio industrial, como dos elementos indispensables en la lectura transversal que el planeamiento de las ciudades del siglo XXI demanda.

Para ello, se establecen ocho sectores programáticos de intervención (ver Figura 5) a través de los cuales alcanzar las líneas estratégicas planteadas (Arnet,V., 2015, 519-521):

Sector barrial. Puesto que tanto las viviendas dispuestas en torno al patio interior, como las ubicadas en el ángulo norte del conjunto residencial, se encuentran en excelente estado de conservación, no es necesario implementar actuaciones de ninguna índole en este sector; sin embargo, las viviendas distribuidas en hilera, así como aquellas que se encuentran enfrentadas a la calle Pez Espada, a causa del notable deterioro que presentan, requieren de la puesta en práctica de acciones que le devuelvan su estado original, además de incrementar el tejido residencial de la zona. Asimismo, estas intervenciones deberán incorporar la renovación de los espacios intersticiales dispersos en el sector, para consolidar el entramado viario interno que facilita la unión vecinal y la conexión con el resto del municipio. Todo ello quedará reforzado con la incorporación de locales comerciales de carácter barrial (fruterías, pescaderías, mercerías,...) en los antiguos talleres de lavado de pescado, consolidando el nuevo sector barrial.

- Sector de negocios pesqueros. Para asegurar la permanencia de la actividad almadrabera originaria en el ámbito de estudio, se plantea reforzar la actividad pesquera a través del establecimiento de un pequeño sector de negocios relacionado con el mundo de la pesca en las antiguas dependencias administrativas del Consorcio Nacional Almadrabero.

- Sector industrial. La necesidad de incorporar el municipio de estudio a las dinámicas económicas contemporáneas exige integrar un modesto sector industrial, adaptado a la escala barrial de la intervención, que incorpore PYMES e industrias limpias que contribuyan a consolidar la economía local dentro del panorama global de la región; para ello, se reutilizarán las naves de menor tamaño ubicadas en el área norte en torno al patio de ronqueo del conjunto industrial original.

- Sector turístico. Asimismo, para evitar la reconversión 'tematizada' del pasado fabril del conjunto industrial se plantea en su punto neurálgico, un sector cuya funcionalidad sea acorde a la demanda contemporánea del litoral andaluz: el turismo. Este escenario urbano ofrece condiciones óptimas para ensayar algunas propuestas con el fin de acceder al disfrute del mar y la actividad pesquera, y convertir la zona en un foco de atracción. Sin embargo, las estructuras fabriles existentes, a pesar de ser los dos cuerpos de mayor volumen del conjunto estudiado, no han de entenderse bajo el concepto tradicional de turismo en exclusiva; por ello, se proponen dos subprogramas dispares en cuanto al usuario que acogen: un espacio hotelero de gran envergadura y un pequeño sector de albergue. De este modo, se plantea un nuevo espacio turístico, más diverso y complejo, que reactive sincrónicamente la economía, la arquitectura, el paisaje y la cultura.

- Sector dotacional. La necesidad de originar relaciones entre la ciudad existente y la nueva recuperada requiere de la incorporación de equipamientos que optimicen la integración de la nueva ordenación con el tejido urbano existente, el territorio y la sociedad, mediante la reinterpretación funcional de los antiguos contenedores productivos. De este modo, se propone la incorporación de un equipamiento 


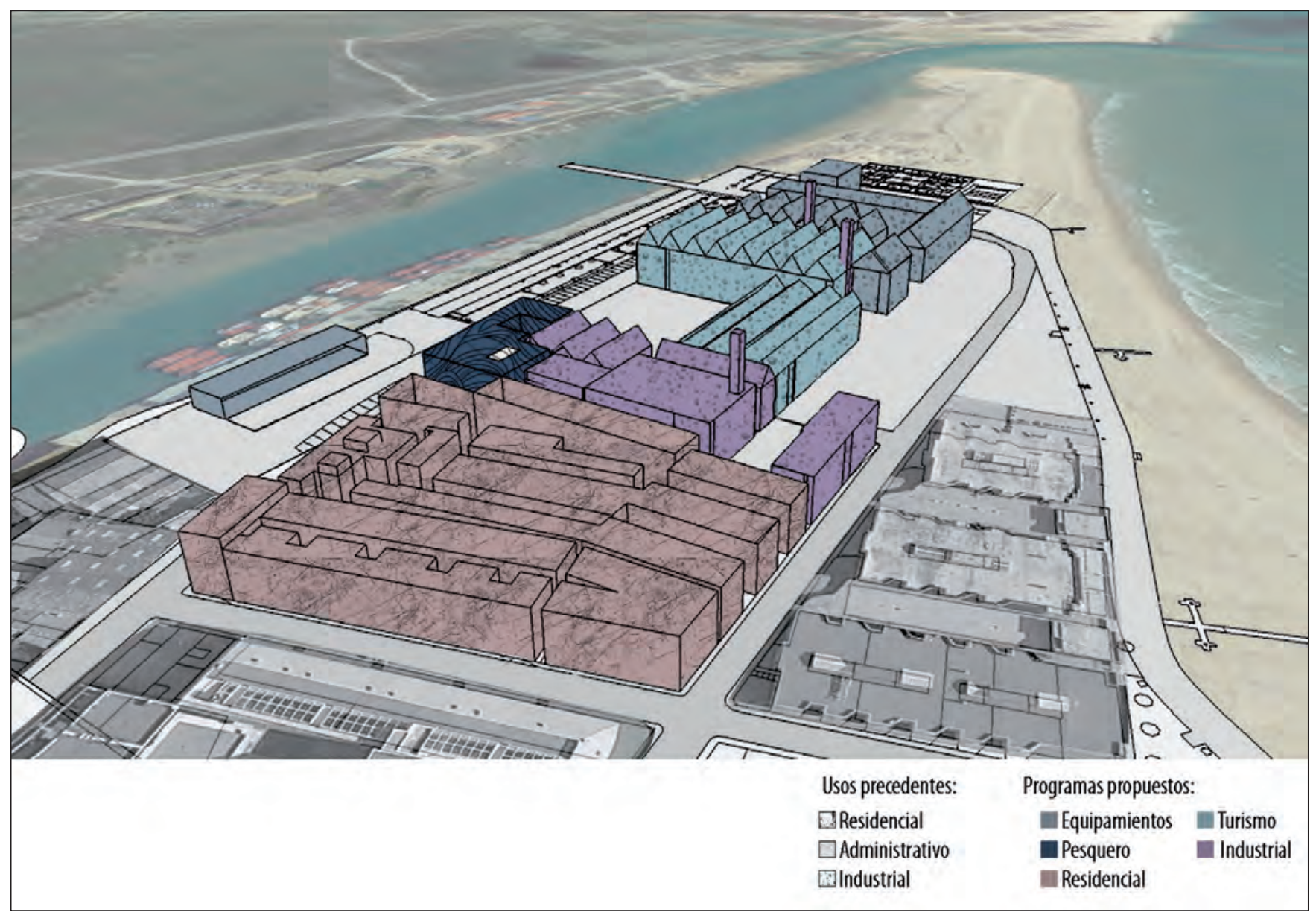

Figura 5. Propuesta planteada tras la aplicación de la metodología. Fuente: Elaboración propia.

social que, apoyado en la la compartimentación de las naves menores presentes en el área meridional del antiguo conjunto industrial, facilite la implantación de usos complementarios como pequeños talleres de cocina de atún de almadraba, de apoyo educativo o actividades culturales y sociales, que servirán de contenedor de relaciones sociales entre una población heterogénea. Igualmente, el carácter longitudinal de las naves que cierran este sector, enfrentadas estratégicamente al borde litoral, entregan la posibilidad de reinvención comercial de la zona a partir de estándares locales y artesanales que dan respuesta a las insuficiencias de ocio de este ámbito y, con ello, consolidan un nuevo hito en la cotidianeidad barbateña. Además, se formula un área cultural que se sirva de las sinergias entregadas por las construcciones fabriles del pasado para consolidar nuevas identidades colectivas en los vecinos. Por último, se crea un espacio destinado al deporte que dé respuesta a las carencias deportivas del municipio además de mantenerlo activo y evitar que el remate territorial de La Chanca sea un espacio abocado al abandono y deterioro.

\section{DISCUSIONES Y REFLEXIONES AL FINAL DEL PROCESO}

La contingencia actual patrimonial reafirma la necesidad de construir instrumentos de intervención actualizados que contemplen condicionantes contemporáneos en materia de paisaje, industria y territorio. La capacidad inconmensurable de resiliencia que presentan las ciudades medias define la idoneidad territorial dentro del marco completo del litoral andaluz para soportar cambios estructurales y, aun así, conservar sus características fundamentales tras estas alteraciones donde el "devenir en el tiempo reúne la violencia 
traumática del cambio con la resistencia perezosa a la mudanza" (Fernández, L., 2006). Por otro lado, las directrices de reutilización de las piezas industriales de estos enclaves sirven de desarrollo socioeconómico, además de aproximarse al concepto configurador de ciudad media al implementar nuevas dinámicas de intervención que logran revitalizar las zonas intervenidas, a partir de estrategias que concilien los edificios productivos y los entornos naturales en los que se insertan, otorgando resultados positivos a mayor escala.

La revalorización del patrimonio almadrabero de Barbate tiene una trascendencia inmediata en la estructuración del territorio andaluz, ya que permite redefinir paisajes de gran contenido histórico, económico y social como es el Parque Natural de La Breña y Marismas del Barbate, posibilitando que las distintas ciudades que conforman la red de ciudades medias de la costa suroeste gaditana implementen su atractivo cultural y paisajístico con nuevos focos de atracción al reutilizar antiguos edificios con nuevos usos que se adapten al contexto actual (Mayoral, E., 2011).

Estas nuevas funcionalidades responden a tres alternativas de recuperación de la memoria del trabajo:

- La reinterpretación contemporánea del uso original mediante la reactivación de la actividad productiva presente en el tejido urbano.

- El reaprovechamiento de los espacios y edificios productivos del conjunto industrial mediante la integración de nuevos usos contemporáneos que divergen sustancialmente de la actividad fabril original.

- La transformación radical de la zona industrial mediante la incorporación de diferentes funcionalidades que se adaptan a las demandas contemporáneas reales de los diferentes casos de estudio para que, entregando nuevos espacios urbanos a las ciudades que se convierten en los escenarios idóneos en los que ensayar prácticas complejas contemporáneas de recuperación donde converjan distintas visiones para profundizar en el conocimiento local y, con ello, entregar soluciones multidisciplinares que mejoren la organización territorial del litoral andaluz.

Esta última opción, apoyada en los planteamientos de De Gracia (1992) es la preferida para la contextualización de la metodología planteada en el municipio de estudio debido a las capacidades que la complejidad territorial ofrece en relación a la reinterpretación de un entorno natural protegido, la recuperación de un entorno degradado tras la desindustrialización ubicado en un lugar excepcional de la costa gaditana y la incorporación del municipio como centro de intersección de redes de transporte de primer nivel debido a su posición idónea dentro de la región andaluza.

La conformación del turismo como foco de atracción para la economía como impulsor de la sostenibilidad local (Sánchez, D., 2003), permite proteger la memoria industrial barbateña al reinterpretar su funcionalidad desde nuevos paradigmas que se adaptan a las demandas contemporáneas del municipio mediante la puesta en práctica de dinámicas diversas que contemplan espacios residenciales, empresariales, industriales, turísticos, de ocio, comerciales, sociales, culturales y deportivos. "Así, la búsqueda de sol y playa se combina con los valores culturales y las señas de identidad de esta ciudad media, cuyo patrimonio, y la preservación de éste, son aspectos fundamentales para mantener activa la memoria de la industrialización y sus relaciones con el paisaje en el que se implanta" (Arnet, V., 2015, 521). Sin embargo, la propuesta planteada no tendría los resultados deseables si no se consigue implicar y comprometer a la ciudadanía (Castro, F., 2001), elemento indispensable a la hora de diseñar la nueva configuración de este entorno. Por ello, sin una verdadera experiencia local, sería difícil plantear una propuesta que, finalmente, reactive el tejido urbano de estudio, por lo que el desarrollo endógeno es imprescindible para llevar a cabo dinámicas de reutilización y reciclaje.

Por último, la integración de este conjunto industrial como parte fundamental de un modelo de planificación integral que se aleje del modelo tradicional de zonificación de usos para aproximarse a la reutilización del legado de la actividad productiva almadrabera como recurso para el ocio y el turismo mediante la aplicación de nuevos usos combinados, posibilita un novedoso ámbito de investigación donde la recuperación de la arquitectura, el paisaje, el tejido urbano y las relaciones sociales se convierten en el motivo recurrente de estas intervenciones en el contexto urbano, además de reafirmar sentimientos de pertenencia a la comunidad local, aprovechando la coyuntura que ofrece un entorno como Barbate. 


\section{REFERENCIAS}

AA.VV. (1988). Barbate. Cádiz, España: Diputación de Cádiz.

AA.VV. (2006). Patrimonio industrial de Andalucía: portfolio fotográfico. Sevilla, España: Consejería de obras Públicas y Transportes.

Arnet, V. (2015). Almadraba al sol: construyendo el futuro de la costa gaditana. En M. García y K. Pino (Coords.), El turismo y su relación con la comunidad local. El desafío de la sustentabilidad. Experiencias de investigación, desarrollo e innovación. Anales del VIII Congreso de la Sociedad de Investigadores en Turismo (pp. 509-524). Santiago, Chile: Instituto del Patrimonio Turístico, Universidad Central de Chile.

Ayuntamiento de Barbate (2013a). Plan Especial de Reforma Interior, Unidad de Ejecución B06 'El Consorcio'.

Ayuntamiento de Barbate (2013b). Plan General de Ordenación Urbanística de Barbate, Aprobación Provisional III.

Bellón, L. (1926). La industria del atún en España. Madrid, España: Mateu artes e Industrias Gráficas.

Bernal, D. (2012). El paisaje cultural evanescente de la pesca y la salazón antiguas. El caso de la Bahía de Cádiz. PH: Boletín del Instituto Andaluz del Patrimonio Histórico, 20 (83), 24-28.

Bohórquez, D. (2000). Sancti Petri, de ayer a hoy. Cádiz, España: Fundación Vipren.

Bonet, A. (2007). Las ciudades de tamaño medio y óptimo en Andalucía. PH: Boletín del Instituto Andaluz del Patrimonio Histórico, 15 (63), 62-68.

Cano, G. (2008). Clasificaciones Urbanas en Andalucía. Las Ciudades Medias. Revista de Estudios Andaluces, (27), $115-153$. doi: https://doi.org/10.12795/rea.2008.i27.05

Caravaca, I. (1999). Efectos de la globalización en el sistema urbano andaluz. Revista de Estudios Regionales, (54), $291-307$.

Caravaca, I. (2008). Dinamismo, innovación y desarrollo en ciudades pequeñas y medias de Andalucía. Sevilla, España: Consejo Económico y Social de Andalucía.

Castells, M. (5 de noviembre de 2005). La importancia de la identidad. La Vanguardia. Recuperado de http://www.iceta. org/mc061105.pdf Último acceso: 6 de marzo de 2019.

Castro, F. (2001). Memoria, ocio y cultura: nuevos usos en España para el patrimonio industrial. En AA.VV., Preservación de la arquitectura industrial en Iberoamérica y España (pp. 204-212). Sevilla, España: Junta de Andalucía, Instituto Andaluz de Patrimonio Histórico.

Conde, F. (2007). Metropolización, territorio y vivienda en Andalucía. Culturas e identidades urbanas. Sevilla, España: Junta de Andalucía, Consejería de Obras Públicas y Transportes, Empresa Pública de Suelo de Andalucía.

Conde, F. G. (2007). Patrimonio Cultural de Barbate (vol. I). Vejer de la Frontera, España: G.D.R. Litoral de La Janda.

CNA - Consorcio Nacional Almadrabero (1929). Legislación y Estatutos. Madrid, España: Gráficas Reunidas.

De Aguilera, M. (2000). Las industrias culturales en Andalucía: una apuesta de futuro. En M. De Aguilera et al. (Coords.). La industria audiovisual y publicitaria en Andalucía. Estudios sobre un sector estratégico (7-33). Málaga, España: Servicio de Publicaciones e Intercambio Científico de la Universidad de Málaga.

De Gracia, F. (2000). Construir en lo construido: la arquitectura como modificación. San Sebastián, España: Editorial Nerea.

Delgado, M. (1999). Globalización, agricultura y ordenación del territorio de Andalucía. Revista de Estudios Regionales, 54, 183-202.

Delgado, M. (2002). Andalucía en el siglo XXI. Una economía crecientemente extractiva. Revista de Estudios Regionales, $63,65-83$.

Del Río, C. (2000). El sector de los servicios en la moderna evolución de la economía española. ICE Sector Servicios, 797, $11-30$.

Díaz, J. L. (2007). Las ciudades medias interiores en el Plan de Ordenación del Territorio de Andalucía. PH: Boletín del Instituto Andaluz del Patrimonio Histórico, 12 (47), 44-53.

Feria, J. M. (2008). Comportamiento del sistema urbano. En AA.VV., Andalucía 2020. Escenarios previsibles (128-139). SeviIla, España: Fundación Centro de Estudios Andaluces, Consejería de la Presidencia, Junta de Andalucía.

Fernández, C. (1866). Almadrabas. Reseña histórica de su empleo en las costas de España y Reglamento para su régimen. Madrid, España: Imp. De Estrada, Díaz y López.

Fernández, L. (2006). Una Historia de Violencia. Arquitectura Viva, (110), 3.

Florido, D. (2005). Evolución histórica y cultural de las almadrabas en el litoral atlántico meridional (s. XVI-XX). Girona, España: Cátedra d’Estudis Marítims (Universidad de Girona), Ayuntamiento de Palamós y Museo de la pesca de Palamós. 
Florido, D. (2006). Las almadrabas andaluzas: entre el prestigio y el mercado. En G. Chic (Dir.), Economía de prestigio vs. Economía de mercado, vol. 1, 193-214. Sevilla, España: Padilla Libros.

Florido, D. (2013). Las almadrabas andaluzas bajo el Consorcio Nacional Almadrabero (1928-1971): aspectos socio-culturales y políticos. SEMATA, Ciencias Sociais e Humanidades, 25 (25), 1-35.

García, E. (2000). Los espacios turísticos del litoral andaluz. Cuadernos Geográficos, 30, 43-76.

Garrabou, R. (Coord.). (1988). La crisis agraria de finales del siglo XIX. Barcelona, España: Crítica.

González, A. (1984). La protoindustrialización en España. Revista de Historia Económica, II 1, 11-44. doi: https://doi. org/10.1017/S021261090001288X

González, I. (1999). Conservación de Bienes Culturales. Madrid, España: Ediciones Cátedra.

Junta de Andalucía (2006). Decreto 129/2006, de 27 de junio, por el que se aprueba el Plan de Ordenación del Territorio de Andalucía.

Junta de Andalucía (2007). Ley Orgánica 2/2007, de 19 de marzo, de reforma del Estatuto de Andalucía.

Junta de Andalucía (2011). Decreto 358/2011, de 8 de noviembre, por el que se aprueba el Plan de Ordenación del Territorio de La Janda (Cádiz).

Lacomba, J. A. (2006). El sector pesquero andaluz en el último cuarto del XIX: una fase de cambios y transformaciones. Una aproximación. Revista de Estudios Regionales, 75, 129-150.

Lagóstena, L. (2001). La producción de salsas y conservas de pescado en la Hispania romana (s. II a.C. - VI d.C.). Barcelona, España: Universidad de Barcelona, Real Academia de la Historia.

López, J. A. y Ruiz, J. M. (2012). Series históricas de capturas del atún rojo en las almadrabas del Golfo de Cádiz. Colección Documentos Científicos ICCT, 1 (67), 139-174.

Mayoral, E. (2011). Monumento o Instalación. El proyecto como teoría de intervención en el patrimonio. En P. Diañez y et al. (Coords.), Objetos Patrimoniales, Metodologías Alternativas en Intervención en el Patrimonio (pp. 33-44). Sevilla, España: Universidad de Sevilla.

Monlau, P. F. y Salarich, J. (1984). Condiciones de vida y trabajo obrero en España a mediados del siglo XIX. Barcelona, España: Anthropos, Editorial del Hombre.

Montaner, J. M. (Julio de 2004). Traumas urbanos: la pérdida de la memoria [En línea]. En AA.VV., Jornadas Traumas urbanos. La ciudad y los desastres (pp. 59-64). Recuperado de https://www.cccb.org/rcs_gene/josepmariamontaner.pdf Último acceso: 6 de marzo de 2019.

Morales, M. (1999). El papel de las élites en la industrialización andaluza. Baética: Estudios de arte, geografía e historia, 21, 431-450.

Mosquera, E. y Pérez, M. T. (2003a). El desencanto de la ciudad, la arquitectura como refugio. Siglo que viene: Revista de cultura, 51-52, 38-41.

Mosquera, E. y Pérez, M. T. (2003b). La excepción como norma. La devaluación de la gran escala en la arquitectura andaluza. Neutra: revista del Colegio Oficial de Arquitectos de Andalucía Occidental, 9-10, 14.

Muñoz, A. (2007). El Plan Turístico de Ciudades Medias: el interior avanza. PH: Boletín del Instituto Andaluz del Patrimonio Histórico, 15 (63), 42-91.

Nadal, J. (Ed.) et al. (1994). La cara oculta de la industrialización española: la modernización de los sectores no líderes (siglo XIX y XX). Madrid, España: Alianza.

Nadal, J. (2009). El fracaso de la Revolución industrial en España, 1814-1913. Barcelona, España: Crítica editorial.

Nogué, J. (2007). La construcción social del paisaje. Madrid, España: Editorial Biblioteca Nueva.

Ojeda, J. (1988). Desarrollo económico, transformación de paisajes y protección de la naturaleza en Andalucía. Revista de Estudios Andaluces, 10, 43-52. doi: https://doi.org/10.12795/rea.1988.i10.03

Parejo, A. (2001). Industrialización, desindustrialización y nueva industrialización de las regiones españolas (1950-2000). Un enfoque desde la historia económica [En línea]. Revista de Historia Industrial, (19-20), 15-75. Recuperado de: http://www.raco.cat/index. php/HistoriaIndustrial/article/viewFile/62485/84796 Último acceso: 26 de abril de 2015

Ríos, S. (2005). Origen y desarrollo de la industria de conservas de pescado en Andalucía (1879-1936). Revista de Historia Industrial, 14 (29), 55-84.

Ríos, S. (2006). La gran empresa almadrabero-conservera andaluza entre 1919 y 1936: el nacimiento del Consorcio Nacional Almadrabero. Historia agraria: Revista de agricultura e historia rural, (41), 57-82. 
Rodríguez, F. y Sánchez, L. M. (2016). Ciudades medias y nuevas perspectivas de desarrollo regional en el litoral mediterráneo andaluz. Boletín de la Real Sociedad Geográfica, CLI, 181-214.

Sánchez, D. (2003). Turismo y Sostenibilidad. En AA.VV. I Jornadas sobre Naturaleza, Cultura y Tecnología para un Desarrollo Urbano Territorial Sostenible. Sevilla, España: FETE-UGT-Universidad de Sevilla.

Sánchez, L. M. (2016). Ciudades medias y articulación territorial en el litoral mediterráneo andaluz (1950-2014). Nuevas tipologías urbanas para el diagnóstico y el desarrollo territorial. Granada, España: Universidad de Granada.

Sánchez, L.M. (2018). Ciudades intermedias y redes territoriales en Andalucía. Potencialidades para el desarrollo regional. En Cebrián, F. (Coord.). Ciudades medias y áreas metropolitanas: de la dispersión a la regeneración (pp. 161-173). Cuenca, España: Universidad de Castilla-La Mancha.

Sánchez, L. M. y Rodríguez, L. (2010a). La planificación y el sistema urbano de Andalucía. Notas para una reflexión desde la geografía. Cuadernos Geográficos, (47), 223-245.

Sánchez, L. M. y Rodríguez, L. (2010b). Sobre la nueva dimensión territorial de las ciudades medias en Andalucía. En C. Cornejo, J. Morán y J. Prada (Coords.), Ciudad, territorio y paisaje: Reflexiones para un debate multidisciplinar (pp. 272287). Madrid, España: CSIC.

Santos, A. (2001). La chanca de Conil. Almadrabas, industria de salazones y sociedad durante el Antiguo Régimen. Janda. Anuario de Estudios Vejeriegos (Vejer), 4, 71-116.

Santos, A. (2006). Las almadrabas gaditanas entre el señorío y el liberalismo, 1800-1850. Boletín La Laja, 7, 38-57.

Sobrino, J. (1997). Balance de la situación del Patrimonio Industrial Andaluz. PH: Boletín del Instituto Andaluz del Patrimonio Histórico, 5 (21), 130-136.

Sobrino, J. (1998). Arquitectura de la industria en Andalucía. Sevilla, España: Instituto de fomento de Andalucía. 


\title{
Delimitación de los Conjuntos Poblacionales Rurales de la Comarca del Altiplano en la Región de Murcia
}

\author{
Delimitation of the Rural Population Sets of the Region of Altiplano \\ in the Region of Murcia \\ Miguel Ángel Sánchez-Sánchez \\ miguelangel.sanchez2@um.es @ https://orcid.org/0000-0003-0774-2560 \\ Universidad de Murcia. Departamento de Geografía. Campus de La Merced. Calle Santo Cristo, 1, 30001
}

\section{INFO ARTÍCULO}

Recibido: 20/12/2018

Revisado: 4/5/2019

Aceptado: 10/5/2019

\section{PALABRAS CLAVE}

Medio rural

Asentamientos humanos

Núcleo de población

Yecla

Jumilla

Altiplano

Región de Murcia

\section{KEYWORDS}

Rural environment

Human settlements

Population center

Yecla

Jumilla

Altiplano

Region of Murcia

\section{RESUMEN}

El objetivo de este trabajo ha sido el determinar que asentamientos humanos de la comarca del Altiplano Jumilla-Yecla de la Región de Murcia pueden ser calificados como conjuntos poblacionales rurales. Esta cuestión es de interés en el ámbito de las Directrices de Ordenación Territorial de la comarca. Para ello se idearon unos diagramas de flujo, con condicionantes tales como: ser núcleo de población y estar localizados en el medio rural, que debían cumplir los asentamientos humanos estudiados -excepción de los yacimientos arqueológicos-.Tan sólo nueve elementos fueron calificados como aldeas, de entre los cincuenta casos estudiados. Este trabajo ha permitido una primera aproximación a la definición-determinación de aldea en el área de estudio.

\begin{abstract}
The objective of this work has been to determine that human settlements in the Jumilla-Yecla Altiplano region of the Murcia Region can be classified as rural population groups. This question is of interest within the scope of the Territorial Ordinance Guidelines of the region. To do this, flow diagrams were devised, with conditions such as: being a population nucleus and being located in rural areas, which had to comply with the human settlements studied -exception of the archaeological sites-. Only nine elements were qualified as villages, among the forty-nine cases studied. This work has allowed a first approximation to the definition-determination of rural population in the study area.
\end{abstract}




\section{INTRODUCCIÓN}

Para comenzar, hay que decir, que entre los años 50 y 90 del siglo XIX, Yecla, se ve inmersa en un período expansivo. Durante tal período se afianza su carácter agrario, y especialmente vitivinícola, por lo que será conocida por la actividad relacionada con el vino de manera exclusiva, hasta fechas muy recientes. Será, a partir de los 70 -del referido siglo-, con el desarrollo de la industria alcoholera, cuando se da el primer desarrollo de la actividad industrial en la ciudad.

Entorno a la mitad de los años 20 del siglo XX, se producirá un segundo impulso hacia la industrialización del municipio yeclano. Esto será consecuencia del paulatino, pero constante, abandono de la actividad tonelera -con carácter artesanal-, y de la carpintería; para reconvertirse a la fabricación y producción de muebles. Entre las décadas de los cincuenta y los sesenta se da, lo que bien podría ser considerado como un primer despegue de la industria del mueble, con origen en la creación Cooperativa Obrera del Mueble y la posterior creación de la Feria del Mueble (Ayuntamiento de Yecla, 2019).

En lo que respecta, al otro municipio comarcal -Jumilla-, hay que hacer referencia a que entre los años cincuenta del siglo XIX y los años treinta del XX, se producirá un fuerte desarrollo económico. La producción de vino fue uno de los aspectos más influyentes en el aludido desarrollo. La expansión del viñedo, condicionante del significativo desarrollo, estuvo relacionada con la plaga de la Filoxera, que en Francia había afectado a buena parte de los sus viñedos, por lo que las producciones españolas, y por ende la jumilla, se vieron favorecidas en los mercados europeos por la demanda. Tras la finalización de la Guerra Civil Española, se inicia un nuevo auge económico, basado en el cultivo y posterior explotación del esparto, al citado auge contribuyeron también la industria del vino y la abundante producción cerealista. En la actualidad, la economía jumillana sigue teniendo como una de las actividades económicas principales el cultivo del viñedo y la producción de vinos. Toda la actividad vitivinícola desembocó en la creación la Denominación de Origen Jumilla, en la década de los sesenta (regmurcia.com, 2019).

Como colofón a esta sucinta historia comarcal de los municipios del Altiplano, hay que decir que en la actualidad las ciudades de Yecla y Jumilla son, respectivamente, claro ejemplos de ciudad industrial y de agrociudad. Habiendo influido de alguna manera en la organización territorial de sus municipios, y distribución del poblamiento. Siento esta una cuestión de interés académico, cultural y de ordenación del territorio.

Por otro lado, cabe decir, que las Directrices de Ordenación Territorial [DOT] de la Comarca del Altiplano de Jumilla-Yecla en la Región de Murcia recogen propuestas de acción dirigidas a los conjuntos rurales, en referencia a los asentamientos humanos de carácter rural localizados en dicho territorio. Puesto que, en tales directrices no quedan claramente definidos o delimitados los conjuntos poblacionales rurales; surge la siguiente pregunta: ¿Qué asentamientos humanos, existentes en la comarca del Altiplano de la Región de Murcia, pueden ser considerados como conjuntos poblacionales rurales? Es por esto que, se tiene como objetivo: determinar que asentamientos humanos de la comarca pueden ser calificados como conjuntos poblacionales rurales. Máxime cuando se tienen previstas actuaciones territoriales de índole socio-económica sobre tales conjuntos.

Las DOT de la Comarca del Altiplano de Jumilla-Yecla en la Región de Murcia, aprobadas en 2010 (Orden, 2010), recogen propuestas de acción, y por tanto de gestión, dirigidas a estos asentamientos rurales. Entre los objetivos generales recogidos en su "normativa" (Art.7.4) se contempla: "Mejorar la calidad de vida de la población mediante el favorecimiento del desarrollo económico endógeno en las zonas rurales, la mejora de dotación en equipamientos y servicios básicos, y la promoción de los sectores económicos generadores de empleo". Como parte de esta normativa se plantea una jerarquización de los asentamientos comarcales, divididos en tres niveles funcionales siendo incluidos en el tercero los "conjuntos rurales o caseríos" (Art. 12.1). En su artículo 16, dedicado a la definición de "Área Funcional Rural", en su punto segundo, se citan los núcleos rurales y pedanías, dando la impresión de tratarse de entes distintos. En el marco de las "Actuaciones Estratégicas" se vuelve a citar las pedanías y núcleos rurales, como si de dos hechos diferentes se tratara (Art. 31). El capítulo dedicado a la "ordenación de los núcleos de población", en su artículo 82, hace referencia a los "núcleos de población tradicionales" donde a su vez se incluyen como integrantes de los mismos los "núcleos de $2^{\circ}$ y $3 e r$ Orden" de la clasificación funcional, anteriormente citada. En este mismo capítulo, 
en lo que respecta al fomento de los núcleos rurales, califica los núcleos poblacionales de $2^{\circ}$ Orden como núcleos rurales (Art. 83.1). Por último, cabe hacer referencia a lo recogido en el artículo 82.3, de donde se deduce que núcleo de población y pedanía no es lo mismo, al estar los primeros incluidos en estas últimas (DPOT-Altiplano, 2010).

Además, la Ley 13/2015, de 30 de marzo, de ordenación territorial y urbanística de la Región de Murcia, en su artículo 81.4 (Categorías de suelo urbano) hace referencia tangencialmente a los "núcleos rurales". Al definir suelo urbano de núcleo rural nos da pistas de lo que pude ser considerado como núcleo rural. Estos núcleos son: "agrupaciones de viviendas con viario e infraestructura común y relaciones propias de la vida comunitaria, constituyen un asentamiento de población tradicional reconocido oficialmente por un topónimo y especialmente vinculado a las actividades del sector primario" (Ley 13/2015).

Por otro lado, es común hacer referencia al "pueblo", la "aldea", el "caserío", la "cortijada", etc., en distintos ámbitos: coloquial, prensa, documentos institucionales, etc. Todos ellos nos llevan a la idea intuitiva de "núcleo de población", de "núcleo tradicional", "de conjunto de pequeño tamaño compuesto por viviendas", de "asentamiento humano de pequeño tamaño", incardinado en un medio alejado de lo urbano. Y, porque no, de "núcleo rural". Para Barbosa-Brandão, V., et al. $(2018,108)$ “... una de las tareas más importantes y complicadas dentro de la planificación territorial" es la "delimitación de los núcleos rurales".

Ante tal situación, se hace necesario -inicialmente- dar respuesta a preguntas tales como: ¿Qué es un conjunto poblacional rural?, ¿Cómo se define este?, ¿Cuáles son sus rasgos y/o características?, etc. Las definiciones y caracterizaciones de asentamientos humanos tales como: caserío, aldea, pueblo, cortijada, etc., pueden permitir una mejor caracterización y definición de conjunto poblacional rural o, en su defecto, enriquecerla, todo ello justificado por las aparentes similitudes entre tales asentamientos humanos.

Así, los caseríos son definidos como el "conjunto de casas de una población" o "el conjunto formado por un número reducido de casas". La cortijada como el "conjunto de varios cortijos", y a su vez el cortijo como la "finca rústica con vivienda y dependencias adecuadas" siendo "típica de amplias zonas de la España Meridional". Los rasgos de las aldeas son los propios de un "pueblo de escaso vecindario y, por lo común, sin jurisdicción propia" entendiéndose por pueblo una "población de menor categoría" (RAE, 2018). También, la aldea, puede ser "... una unidad pequeña de población agrupada rural...", desde una concepción sociológica sería aquella definida por "... las características que afectan a la comunidad que vive en ella, que presenta formas de organización económica y social individualista..." (Larousse2000, 1998). Puede ser vista como: la "unidad más elemental del hábitat, formada por un reducido grupo de casas, con pocos habitantes (a menudo menos de 50 habitantes, a veces unos cientos), con funciones exclusivamente rurales y rodeadas por terrazgos agrícolas" (Armas, P., 1997,113). Esta última definición vincula la posible actividad económica, existente, a las actividades agrarias. Al erigirse, esta, en la actividad económica principal -en su área circundante-, nos sitúa ante la "aldea agrícola" (SALVAT-UNIVERSAL, 1981).

Cabe observar, que lo pequeño -tanto en lo que respecta a edificaciones como a población-, así como lo rural -en el ámbito de la actividad económica-; constituyen aspectos definitorios básicos comunes de las definiciones expuestas.

Teniendo en cuenta que, los asentamientos poblacionales a estudiar son hechos geográficos localizados en un contexto territorial mucho más amplio que el ocupado por los mismos, y para comprender mejor estos hechos, resulta de interés conocer ese medio en el que se incardinan, aunque sea de manera sucinta. Si aceptamos que, una aldea lo es: por sus "funciones exclusivamente rurales" y por estar "rodeada por terrazgos agrícolas" (Armas, P., 1997, 113), que la cortijada tiene como base una "finca rústica", que el núcleo rural se encuentra vinculado a la "actividad primaria" -entiéndase agraria, para este caso-, y los núcleos rurales o caseríos se inscriben en un área funcional de carácter rural (DPOT-Altiplano, 2010), si todo esto, es así, queda justificado acudir directamente a la definición de medio rural, recogida en la Ley 45/2007 para el Desarrollo Sostenible del Medio Rural.

Así, la citada ley, considera como medio rural: "el espacio geográfico formado por la agregación de municipios o entidades locales menores definido por las administraciones competentes que posean una población inferior a 30.000 habitantes y una densidad inferior a los 100 habitantes por km²" (art.3.a). Además, es de interés aludir a la definición de "municipio rural de pequeño tamaño", recogida en la ley, "siendo aquel 
que posea una población residente inferior a los 5.000 habitantes y esté integrado en el medio rural" (art. 3.c) (Ley 45/2007). En este mismo sentido, la Organización para la Cooperación y el Desarrollo Económicos [OCDE], utiliza la densidad de población como criterio para delimitar zonas rurales, para el caso de los municipios, define a estos como rurales cuando su densidad de población es inferior a 150 habitantes $/ \mathrm{km}^{2}$ (OCDE, 1994). También, hay que decir que el medio rural bien puede ser asimilado a las "zonas poco pobladas" definidas por la Comisión Europea para el territorio de la Unión Europea, siendo aquellas con una densidad de población de menos de 100 habitantes $/ \mathrm{km}^{2}$ y su población inferior a 50.000 habitantes (UE-Comisión Europea, 1997). Por añadidura, cabe citar el trabajo de Nieto, et al. $(2018,231)$, respecto al índice de ruralidad para los municipios españoles en 2011, en donde al de Yecla se le asigna una ruralidad media y el de Jumilla baja.

Volviendo a la definición de aldea, cabe enfatizar su carácter como: "unidad pequeña de población agrupada rural" (Larousse2000, 1998) y “...reducido grupo de casas..." (Armas, P., 1997,113). Se deja entrever que la aldea bien puede ser vista como: "núcleo de población". Lo nuclear, está también presente en otras de las definiciones citadas en párrafos anteriores: núcleos rurales, núcleos de población tradicionales, etc. Tal y como se ha podido observar, parte de los conceptos, aludidos hasta aquí -referidos a los asentamientos humanos-, hacen referencia a la existencia de conjunto de viviendas. Dicho lo anterior, es adecuado tener en cuenta afirmaciones tales como aquella que define como núcleo de población al "entramado de viviendas conformando calles y plazas con un mínimo demográfico" (López, L., 2015, 489). Por otra parte, el INE (2018) atribuye tal denominación al "conjunto de al menos diez edificaciones, que estén formando calles, plazas y otras vías urbanas". Asimismo, de manera excepcional, el número de edificaciones podrá ser inferior a 10, siempre que la población que habita las mismas supere los 50 habitantes. También, se incluyen las edificaciones aisladas, que distan menos de 200 metros de los límites exteriores del conjunto, excluidas infraestructuras que no sean propiamente viviendas.

Además, Flores, O. (2016), en su tesis doctoral, al analizar la problemática de la ordenación territorial y urbanística de los "núcleos rurales" admite el reconocimiento jurídico de estos como la "huella del asentamiento tradicional de la población sobre el territorio...". En relación a este mismo ámbito, el de la ordenación territorial y urbanística, y conectando con la anterior apreciación sobre los núcleos rurales como:... asentamiento tradicional..., a este respecto cabe sacar a colación que para la Ley de Ordenación Territorial y Urbanística de la Región de Murcia, los núcleos rurales “...constituyen un asentamiento de población tradicional..." (Ley 13/2015, art. 81.4). Otros autores, seleccionaron criterios sociales y ambientales para la delimitación de núcleos rurales en Galicia (Barbosa-Brandão, V., et al., 2018,109). También, Sánchez-Sánchez, M.A., et al., $(2016,862-863)$ en su trabajo sobre los aspectos patrimoniales y culturales de las aldeas del Altiplano, establecen como criterios que este tipo de núcleos de población "estén habitados y conformen un mínimo núcleo de viviendas, con una posible trama urbana"; aunque no entrando en una delimitación precisa de todas las existentes en la comarca.

Finalmente, hay que decir que, ante las preguntas relativas a la caracterización de los conjuntos poblacionales rurales de la comarca del Altiplano de Jumilla-Yecla, se plantea la siguiente hipótesis de trabajo: Todos los asentamientos humanos de la Comarca del Altiplano Jumilla-Yecla en la Región de Murcia, excepto aquellos que constituyen yacimientos arqueológicos, pueden ser calificados como conjuntos poblacionales rurales. Por lo que, se tiene como objetivo: determinar que asentamientos humanos de la comarca del Altiplano, en la Región de Murcia, pueden ser calificados como conjuntos poblacionales rurales.

\section{METODOLOGÍA}

En relación a, la estrategia o plan para confirmar la certeza de la hipótesis planteada -diseño de la investigación-, hay que hacer constar que se trata del tipo cuantitativo no experimental. Mediante esta se observó y midió el fenómeno "tal como se da en su contexto natural, para posteriormente analizarlo, siguiendo siempre el planteamiento del problema". Respecto a esta cuestión, cabe decir que el diseño de la investigación, además de cuantitativo no experimental, es de los denominados "transeccional o transversal", caracterizado 
por: la recolección de datos en un "momento o período único" con la intención de "describir variables y analizar su incidencia en interrelación con un momento dado" (Hernández, R., et al., 2017, 97, 107, 109).

Se actuó sobre toda la población, por lo que no se tomaron muestras. Los individuos estudiados debían cumplir: el ser asentamientos humanos con edificaciones en pie y/o ruinas, excluyendo los yacimientos arqueológicos definidos y/o calificados. La exclusión de los yacimientos quedó justificada, por la inferencia observada tras la lectura de las DOT (DPOT-Altiplano, 2010). El parámetro - "característica o valor poblacional, objeto de investigación"- (García, A., 2010, 40) estudiado fue: ¿Qué asentamientos humanos, sitos en la comarca del Altiplano de Jumilla-Yecla, pueden ser calificados como núcleo poblacional rural?, determinándose una serie de variables.

La referencias al núcleo poblacional rural: como lo pequeño, tanto en edificaciones como en habitantes (Armas, P., 1997; Larousse 2000; RAE, 2018), no permite avanzar hacia una posible matematización, y por ende hacia una mayor objetividad en lo tocante al fenómeno. Armas, P., $(1997,113)$ afirma, en relación al número de habitantes, que si este es igual o inferior a 50, aunque a veces podrían ser unos cientos, estaríamos ante una aldea. Simultáneamente, se dedujo de las citadas definiciones, la connotación nuclear asociada a las edificaciones existentes en los núcleos poblaciones rurales. A este respecto, la consideración de López, L., (2015), sobre la aldea como un entramado de viviendas conformando calles y plazas resulta de interés. La existencia de "calles, plazas y otras vías de comunicación" son, también, contempladas como aspectos definitorios de un núcleo de población (INE, 2018).

Por lo que, los elementos: calles y plazas, fueron tomados como indicador de las variables "-propiedad o característica del fenómeno"- (Hernández, R., 2017, 82). Para estas variables las "modalidades de los caracteres", entendidas como: "posibilidades, tipos o clases que pueden presentar los caracteres" (García, 2010, 42) fueron: existencia o no existencia de calles y plazas.

Al respecto, puede considerarse la calle como: vía pública que discurre entre edificaciones, sirviendo para el desplazamiento por el núcleo de población de las personas. Así, la plaza sería el espacio, sitio o lugar, ancho y espacioso existente en el interior del núcleo de población, en el que en ocasiones suelen afluir varias calles (RAE, 2018). Ochoa de la Torre, J.M., cree que la plaza puede ser la "primera creación humana de un espacio urbano" por tanto "el nivel más primitivo" (2007, 3.10-3.14). Ahora bien, hay asentamientos humanos denominados: "pueblo calle", donde no se evidencia la existencia de una plaza. De ahí que, en este trabajo se trate en primer lugar de identificar la presencia o no de calles y posteriormente de plazas.

No obstante las consideraciones sobre los conceptos de calle y plaza, vertidas por Ochoa de la Torre, J.M., en su trabajo, resultan de interés para la presente investigación. Estas perfectamente pueden contribuir a una mejor identificación de tales elementos. En palabras del citado autor, "una calle es un camino relativamente ancho, dentro de la ciudad o un pueblo, que discurre entre dos hileras de casas por lo general dispone de aceras y calzadas» también son incluidos carreteras y casas adyacentes". La calle es "un sistema cerrado y delimitado" por las edificaciones. La plaza "resulta de la agrupación de casas alrededor de una zona libre, es un espacio cerrado" (2007, 3.10-3.15).

Además, el INE (2018) establece la existencia de un núcleo de población cuando: el conjunto de las edificaciones es igual o superior a 10 edificaciones, incluyendo aquellas aisladas, que disten a $200 \mathrm{~m}$. , o menos del límite exterior del conjunto, excluidas infraestructuras que no sean propiamente viviendas.

Por otro lado, teniendo en cuenta el carácter rural de los núcleos poblacionales rurales (Armas, P., 1997; Larousse 2000, 1998) la variable que se determinó, fue la referida a la ruralidad del entorno de los asentamientos. Para esta variable las "modalidades de los caracteres" fueron: sí rural o no rural. Siendo utilizados como indicador de las variables, conceptos recogidos en la Ley para el Desarrollo Sostenible del Medio Rural, tales como: medio rural y municipio rural de pequeño tamaño.

En esta Ley el medio rural se define: como aquel cuya población es igual o inferior a 30.000 habitantes, y una densidad de población igual o inferior a 100 habitantes $/ \mathrm{km}^{2}$.Y, el municipio rural de pequeño tamaño es: aquel que cuenta con una población igual o inferior a los 5.000 habitantes y está integrado en el medio rural (Ley 45/2007).

Las fuentes donde se obtuvo la información fueron: INE, CREM, EDUSI-Yecla, Catastro, plataforma SITMURCIA y Google Earth. En relación al INE, los datos manejados fueron los derivados de las tablas de 
población referidas a las distintas unidades territoriales municipales e inframunicipales. Lo mismo ocurrió para el caso del CREM, y EDUSI-Yecla. El Catastro permitió la obtención de información referida a edificaciones, permitiendo diferenciar las dedicadas a viviendas y otros usos. La plataforma SITMURCIA, junto con Google Earth facilitó la localización y contabilización de los distintos asentamientos humanos estudiados.

Para determinar si un asentamiento humano es una conjunto poblacional rural se ideo un algoritmo, el cual quedó representado por tres diagramas de flujo, mediante los cuales se determina si el asentamiento es: núcleo de población, si está en un medio rural y finalmente si es un núcleo poblacional rural (figura 1, 2, 3).

Tras haber localizado los asentamientos humanos, a estudiar, se les aplicó el primer diagrama de flujo (figura 1). El objetivo era determinar si los asentamientos humanos constituían un "núcleo de población". Tal y como se aprecia en el diagrama, el primer paso fue determinar la existencia o no de diez o más edificaciones, si la respuesta era afirmativa se pasaba a los siguientes indicadores: existencia de calles y plazas. Para el primer caso, se tomó como referencia la definición de la misma como: vía pública que discurre entre edificaciones o hileras de casas que por lo general dispone de aceras y calzadas, sirviendo para el desplazamiento de las personas por el núcleo de población, siendo un sistema cerrado y delimitado. En el caso de la plaza, se consideró aquella parte del territorio que "resulta de la agrupación de casas alrededor de una zona libre, erigiéndose como un espacio cerrado". Pero, que, a diferencia de la calle se caracteriza, además, de por un espacio, sitio o lugar, por su amplitud y ser espacioso. Este espacio se localiza en el interior del núcleo de población, y, en ocasiones, suelen afluir varias calles.

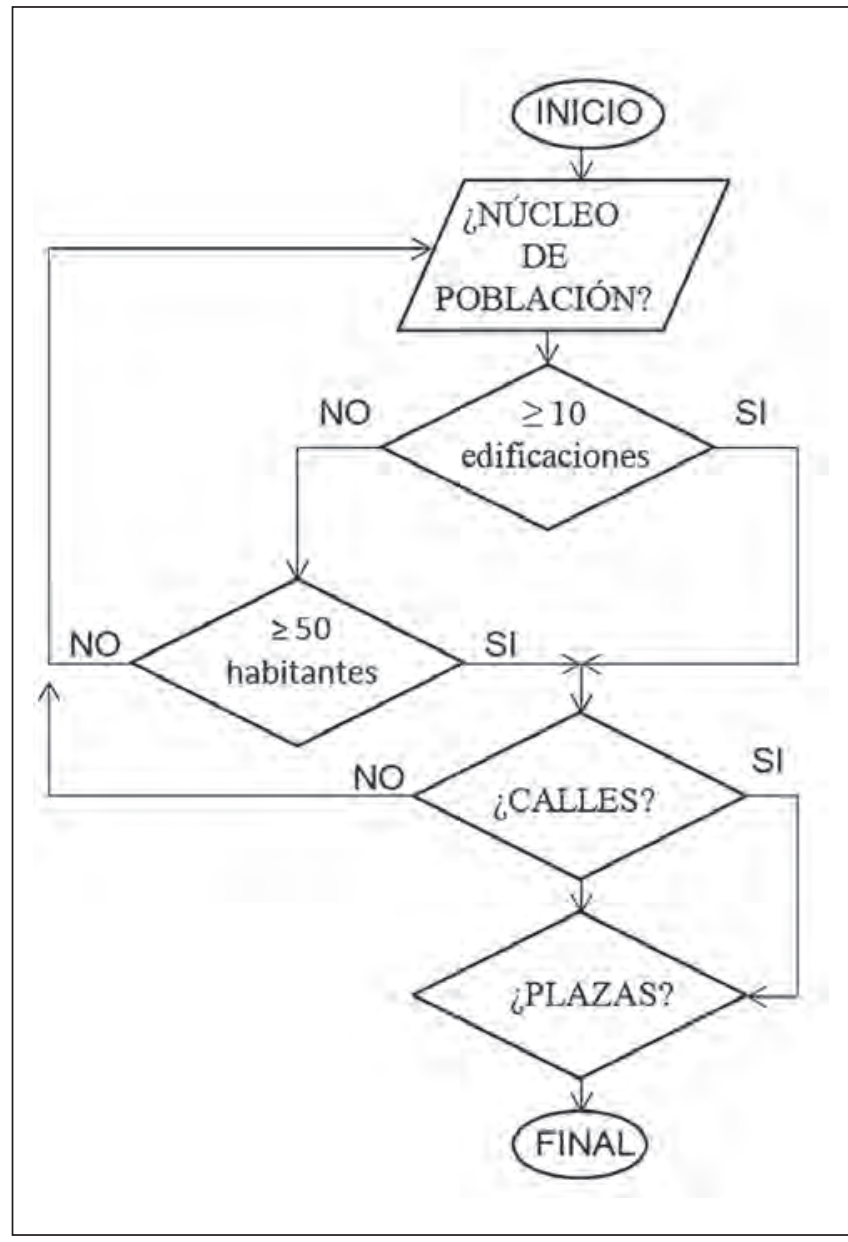

Figura 1. Diagrama de flujo.

Determinación de núcleo de población.

Fuente: Elaboración propia.

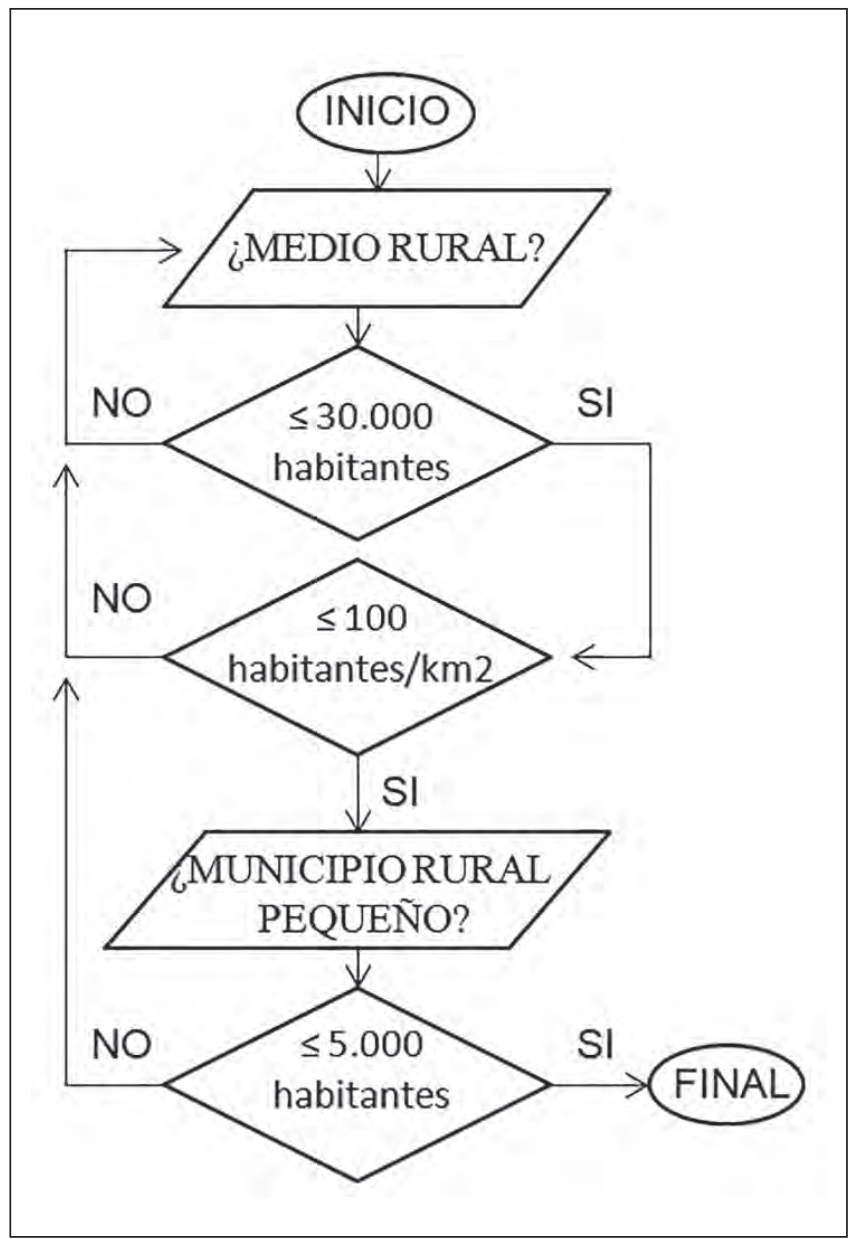

Figura 2. Diagrama de flujo. Determinación de la existencia de medio rural y municipio rural pequeño. Fuente: Elaboración propia. 
De modo que, si todos los pasos eran afirmativos, nos encontrábamos ante un asentamiento humano que constituía un núcleo de población. Si en el indicador de edificaciones, la respuesta era negativa se constataba la existencia de cincuenta o más habitantes; en caso afirmativo se avanzaba hacia los siguientes indicadores (calles y plazas). En caso negativo quedaba desechada la posibilidad de constituir un núcleo de población. La misma suerte corrían aquellos asentamientos que no disponían de calles, ni plazas.

En paralelo, al diagrama de flujo para la determinación de los distintos asentamientos como posibles "núcleos de población", se trató de determinar el grado de ruralidad del medio donde se encuentran los asentamientos humanos estudiados. Para ello, de entre las distintas concepciones de medio rural (OCDE, UE-Comisión Europea, y Ley de Desarrollo Rural), se utilizaron los indicadores más restrictivos: Tener un número de habitantes igual o inferior a 30.000 y una densidad de población igual o inferior a 100 habitantes $/ \mathrm{km}^{2}$. También, fue utilizado el concepto de municipio rural pequeño, aplicándose a los municipios y a las unidades inframunicipales. Se debían cumplir dos condiciones: estar en un medio rural y tener una población igual o menor de 5.000 habitantes.

La última fase del proceso, basado en diagramas de flujo, fue la que permitió averiguar si los asentamientos humanos estudiados eran o no núcleo de poblacional rural.

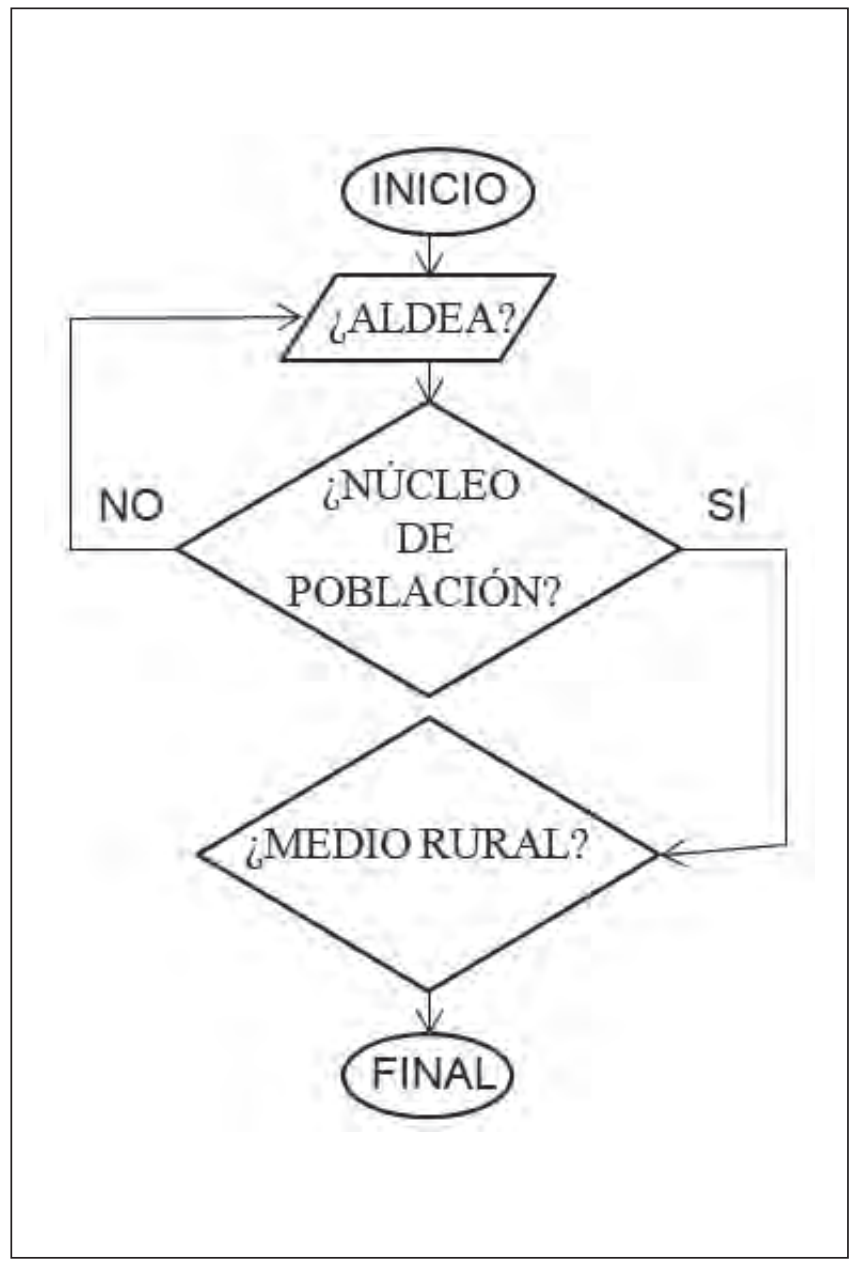

Figura 3. Diagrama de flujo.

Determinación de núcleo poblacional rural.

Fuente: Elaboración propia.

Por último, cabe decir que el área de estudio se localiza en la zona norte de la Región de Murcia, en el Sureste de España, en la denominada comarca del Altiplano, compuesta esta por los municipios de Jumilla y Yecla, a los cuales ya se ha hecho referencia anteriormente (figura 4).

\section{RESULTADOS}

Inicialmente, al seguir los pasos indicados en el diagrama de flujo de la figura 1, se contabilizan un total de 49 asentamientos humanos comarcales que cumplen con el primer requisito: tener un número igual o superior a 10 edificaciones, incluyendo las situadas en un radio de 200 metros. De los cuales 28 se encuentran el municipio de Jumilla y 21 en el de Yecla (cuadro 1) todo estos datos son referidos al casi centenar de asentamientos que componen el universo de estudio.

Los asentamientos que no cumplen la anterior condición, tampoco cumplen con la alternativa de contar con una población igual o superior a los 50 habitantes. Tan sólo cumplen, también, esta condición: La Alquería, Cañada del Trigo, La Estacada, Fuente del Pino, Torre del Rico, Raspay y las ciudades de Yecla y Jumilla (Cuadro 2 y 3 ).

Con respecto a la división inframunicipal recogida por INE, hay que decir que esta muestra un total de 14 unidades poblacionales en el municipio de Jumilla y 4 en el de Yecla, siendo subdivididas en algunos casos en distribución concentrada y diseminada. Así, hay que hacer notar que algunas de estas entidades singulares llegan a carecer de habitantes en la distribución concentrada, como es el caso de Barahonda Vieja y 
Peña Roja, que por el contrario si cuentan con habitantes en la distribución correspondiente al diseminado. Además las capitales municipales albergan la práctica totalidad de los habitantes del municipio, Jumilla el $95,5 \%$ y Yecla el 93,17\% (Cuadro 2 y 3 ).

En otro orden de cosas, los resultados obtenidos referidos a aquellos asentamientos que contienen en su estructura, al menos una calle, son, en el municipio de Jumilla: Jumilla, La Estacada, Cañada del Trigo, Fuente del Pino, La Alquería, Torre del Rico, Las Cebolletas-Las Encebras, El Carche, Las Casícas-Las Encebras, Casas de Juan Marcos-La Raja, Los Capitos, La AmacoIla o Macolla, Santa Ana del Monte, Casas de la Caña-Las Encebras, Casas de Los Algíbes-Estrecho de Marín, Casas de Castilla, Casas del Conejo, La Alberquilla y Casas del Café-Las Encebras. En el caso de Yecla: Yecla, Raspay, La Bronquina, Casas de Pinillos, Casas del Demonio y Casa Ortega. En lo que respecta, aquellos asentamientos que cuenta con plaza, aunque en algunos casos no

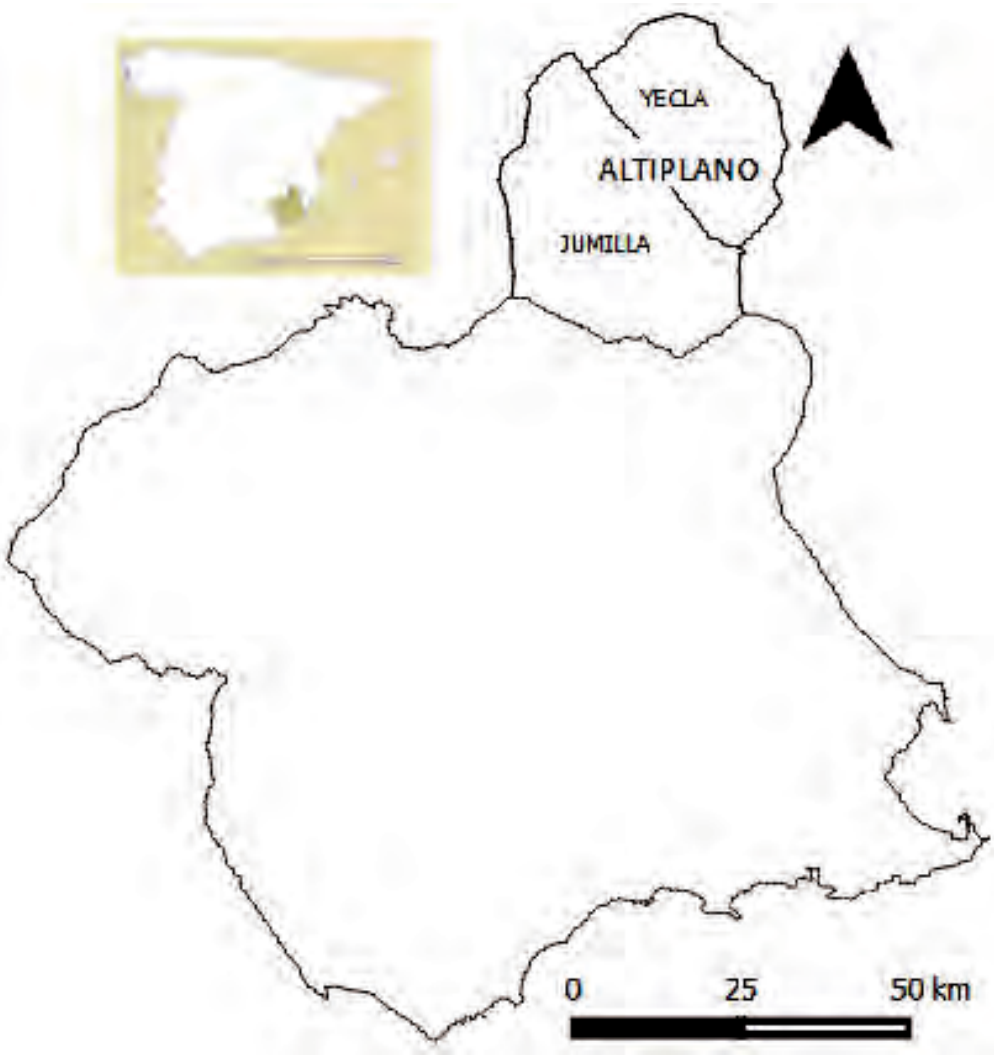

Figura 4. Localización del área de estudio. Fuente: Elaboración propia. claramente definida, se encontraron en el municipio de Jumilla: Jumilla, La Estacada, Cañada del Trigo, Fuente del Pino, La Alquería, Torre del Rico, Casas de Juan Marcos-La Raja, La Zarza y Santa Ana del Monte. En el municipio yeclano los asentamientos con plaza son: Yecla, Raspay, Casas de Palao y Casas de Pinillos. En vista de lo anterior, los asentamientos que cumplen con las dos condiciones son: JumiIla, Yecla, Raspay, La Estacada, Cañada del Trigo, Fuente del Pino, La Alquería, Torre del Rico, Casas de Juan Marcos-La Raja, Casas de Pinillos y Santa Ana del Monte.

Resulta que, de la aplicación del diagrama de flujo para la determinación de la existencia de núcleos de población (figura 1) en la comarca del Altiplano, tan sólo fueron considerados como tal: Jumilla, Yecla, Raspay, La Estacada, Cañada del Trigo, Fuente del Pino, La Alquería, Torre del Rico, Casas de Juan Marcos-La Raja, Casas de Pinillos y Santa Ana del Monte.

A continuación, se llevaron a cabo las acciones pertinentes para saber si los asentamientos se encontraban en un medio rural o no. Para ello, se utilizó el diagrama de flujo ideado para la determinar si el área de estudio estaba inserta en un medio rural (figura 2). Se comenzó por un nivel comarcal, para ir descendiendo al mayor detalle posible, pasando por la escala municipal previamente.

El territorio comarcal, con un total de 59.764 habitantes, no albergaría un medio rural. En la escala del ámbito municipal, los datos obtenidos muestran que el territorio del municipio de Jumilla tendría el aspecto de un medio rural. Por el contrario, no sería así para los territorios municipales de Yecla. Al utilizar el indicador referido a la variable densidad de población, tanto la comarca como ambos municipios quedarían encuadrados en el ámbito del medio rural: Comarca $(37,95)$, Jumilla $(26,49)$ y Yecla $(56,29)$. Recordemos, que estos municipios cuenta con una considerable superficie municipal: Jumilla $\left(969,00 \mathrm{~km}^{2}\right)$ y Yecla $\left(605,64 \mathrm{~km}^{2}\right)$ (Cuadro 2 y 3). 
Cuadro 1. Criterio 10 edificaciones y 200 metros.

\begin{tabular}{|c|c|c|c|c|c|}
\hline Municipio & Asentamiento & $\begin{array}{c}\mathrm{N}^{\circ} \\
\text { viviendas }\end{array}$ & Municipio & Asentamiento & $\begin{array}{l}\mathrm{N}^{\circ} \\
\text { viviendas }\end{array}$ \\
\hline \multirow{30}{*}{ Jumilla } & Jumilla & 5.410 & \multirow{24}{*}{ Yecla } & Yecla & $5.561 * *$ \\
\hline & La Estacada & 60 & & Raspay & 150 \\
\hline & Cañada del Trigo & 147 & & Casa de la Balsa & 25 \\
\hline & Fuente del Pino & 180 & & Casas de la Ceja & 23 \\
\hline & La Alquería & 130 & & Caserío Carrascalejo & 20 \\
\hline & Torre del Rico & 110 & & Boquera del Carche & 19 \\
\hline & La Estacada & 60 & & Venta de Los Hitos & 16 \\
\hline & Las Cebolletas-Las Encebras & 50 & & Casas de Ibañez & 15 \\
\hline & El Carche & 40 & & La Bronquina & 15 \\
\hline & Las Casicas-Las Encebras & 25 & & Las Gamellejas & 15 \\
\hline & Casas de Los Harineros & 18 & & Casas de Quintana-El Pulpillo-Ca- & 14 \\
\hline & Casas de Juan Marcos-La Raja & \multirow{2}{*}{17} & & sa del Huerto & \\
\hline & \multirow{2}{*}{ Los Capitos } & & & Casas de Los Marañones & 13 \\
\hline & & 17 & & Casas de Palao & 13 \\
\hline & La Zarza & 16 & & \multirow{2}{*}{$\begin{array}{l}\text { Casas de Palao/u-Cañada del } \\
\text { Pulpillo }\end{array}$} & \multirow{2}{*}{12} \\
\hline & Amacolla o Macolla & 15 & & & \\
\hline & La Celia & 15 & & Casas de La Alberca & 12 \\
\hline & Santa Ana del Monte & 15 & & Casas de Pinillos & 12 \\
\hline & $\begin{array}{l}\text { Varahonda o Barahonda o Los } \\
\text { Casucos del Coto }\end{array}$ & 15 & & $\begin{array}{l}\text { Casas de Almansa/Casa San } \\
\text { Antonio }\end{array}$ & 10 \\
\hline & Casas de La Caña-Las Encebras & 13 & & Casas del Demonio & 10 \\
\hline & Los Ferreles & 13 & & Casas Igarza & 10 \\
\hline & Casas de La Rosa & 13 & & Casas La Sin Puerta & 10 \\
\hline & Casas de Los Algibes-Estrecho de & 12 & & Casa del Olivar & 10 \\
\hline & Marín & & & Casa de Ortega & 10 \\
\hline & Casas de Castilla & 12 & \multirow{6}{*}{\multicolumn{3}{|c|}{$\begin{array}{l}\text { Fuente: Elaboración propia a partir del Catrastro, Google } \\
\text { Earth, ** EDUSI-Yecla. (2018). }\end{array}$}} \\
\hline & Varahonda o Barahonda La Vieja & 11 & & & \\
\hline & Casas del Conejo & 11 & & & \\
\hline & La Alberquilla & 10 & & & \\
\hline & Casa Díaz-La Raja & 10 & & & \\
\hline & Casas del Café-Las Encebras & 8 & & & \\
\hline
\end{tabular}


Cuadro 2. Unidades poblacionales del municipio de Jumilla (2017).

\begin{tabular}{|c|c|c|c|}
\hline \multicolumn{4}{|c|}{ Unidades Poblacionales y número de habitantes. Jumilla. 2017.} \\
\hline Unidad Poblacional & Población total & Unidad Poblacional & Población total \\
\hline 000000 JUMILLA & 25.672 & 000799 *DISEMINADO* & 38 \\
\hline 000100 ALBERQUILLA (LA) & 22 & 000800 JUMILLA & 24.518 \\
\hline 000199 *DISEMINADO* & 22 & 000801 JUMILLA & 24.518 \\
\hline 000200 ALQUERÍA (LA) & 161 & 000900 RAJA (LA) & 60 \\
\hline 000201 ALQUERÍA (LA) & 79 & 000901 PEÑA ROJA & 0 \\
\hline 000299 *DISEMINADO* & 82 & 000999 *DISEMINADO* & 60 \\
\hline 000300 CAÑADA DEL TRIGO & 117 & 001000 SANTA ANA & 109 \\
\hline 000301 CAÑADA DEL TRIGO & 95 & 001001 SANTA ANA & 4 \\
\hline 000399 *DISEMINADO* & 22 & 001099 *DISEMINADO* & 105 \\
\hline 000400 CARCHE (EL) & 82 & 001100 TÉRMINO DE ARRIBA & 6 \\
\hline 000499 *DISEMINADO* & 82 & 001101 BARAHONDA VIEJA & 0 \\
\hline 000500 ENCEBRAS (LAS) & 53 & 001199 *DISEMINADO* & 6 \\
\hline 000501 CAÑAS (CASAS DE LAS) & 4 & 001200 TORRE DEL RICO & 90 \\
\hline 000502 CEBOLLETAS (CASAS) & 8 & 001201 CASAS DE DÍAZ & 7 \\
\hline 000503 CONEJO (CASAS) & 6 & 001202 TORRE DEL RICO & 54 \\
\hline 000599 *DISEMINADO* & 35 & 001299 *DISEMINADO* & 29 \\
\hline 000600 ESTACADA (LA) & 287 & 001300 ZARZA (LA) & 22 \\
\hline 000601 ESTACADA (LA) & 174 & 001302 ZARZA (LA) & 15 \\
\hline 000699 *DISEMINADO* & 113 & 001399 *DISEMINADO* & 7 \\
\hline 000700 FUENTE DEL PINO & 132 & 001400 ROMÁN & 13 \\
\hline 000701 FUENTE DEL PINO & 94 & 001499 *DISEMINADO* & 13 \\
\hline
\end{tabular}

Fuente: INE 2018.

Cuadro 3. Unidades poblacionales del municipio de Yecla (2017).

\begin{tabular}{|l|c||c|c|}
\hline \multicolumn{2}{|c|}{ Año 2017} \\
\hline Unidad Poblacional & Población total & Unidad Poblacional & Población total \\
\hline 000000 YECLA & 34.092 & 000300 RASPAY & 100 \\
\hline 000100 CAMPO ABAJO & 758 & 000301 RASPAY & 100 \\
\hline 000199 *DISEMINADO* & 758 & 000400 YECLA & 31.764 \\
\hline 000200 CAMPO ARRIBA & 1.470 & 000401 YECLA & 31.764 \\
\hline 000299 *DISEMINADO* & 1.470 & Fuente: INE, 2018. & \\
\hline
\end{tabular}




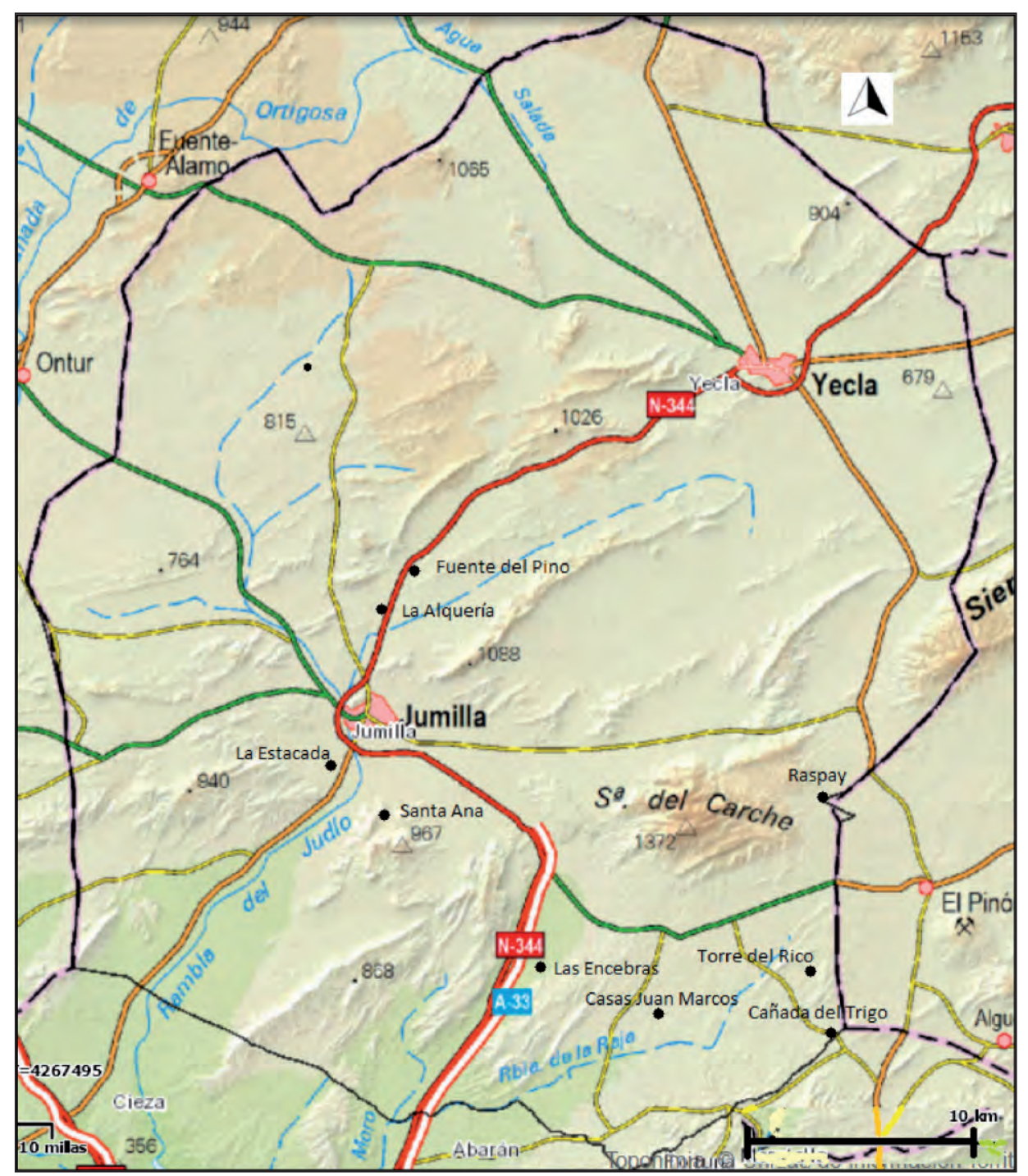

Figura 5. Mapa comarcal. Fuente: SITMUR (2019).

Asimismo, mediante el uso de los datos asociados a la figura administrativa de "entidad menor" -de carácter inframunicipal- (Gráfico 1), todos los asentamientos humanos, con la excepción de Yecla y Jumilla, estarían localizados en un medio rural (cuadro 4). Habría que decir también, que asimilando la entidad menor al concepto de municipio rural pequeño, todas las entidades menores -excepto las correspondientes a Yecla y Jumilla- tendrían un perfil propio del tipo de municipio citado.

Asimismo, para determinar que asentamientos humanos, de entre los analizados, se les puede calificar de conjuntos poblacionales rurales, fue utilizado el diagrama de flujo creado para tal determinación (figura 3). El primer filtro, recogido en el mencionado diagrama -¿núcleo de población? sí o no-, tan sólo lo pasaron: Jumilla, Yecla, Raspay, La Estacada, Cañada del Trigo, Fuente del Pino, La Alquería, Torre del Rico, Casas de Juan Marcos-La Raja, Casas de Pinillos y Santa Ana del Monte. Sin embargo, al aplicar el filtro referido a la presencia de un medio rural sobre los distintos territorios -reforzado con el concepto de municipio rural pequeño-, del listado anterior los asentamientos humanos correspondientes a las ciudades de Jumilla y Yecla decaerían. Quedando adjetivados como núcleos poblacionales rurales tan sólo Raspay y Casas de Pinillos en el término municipal de Yecla, y La Estacada, Cañada del Trigo, Fuente del Pino, La Alquería, Torre del Rico, Casas de Juan Marcos-La Raja y Santa Ana del Monte en el municipio de Jumilla.

Finalmente, cabe decir que los núcleos poblacionales rurales quedan repartidas por el territorio tal y como se muestra en la figura 5. La distribución gráfica permite observar como el mayor número de ellos se 


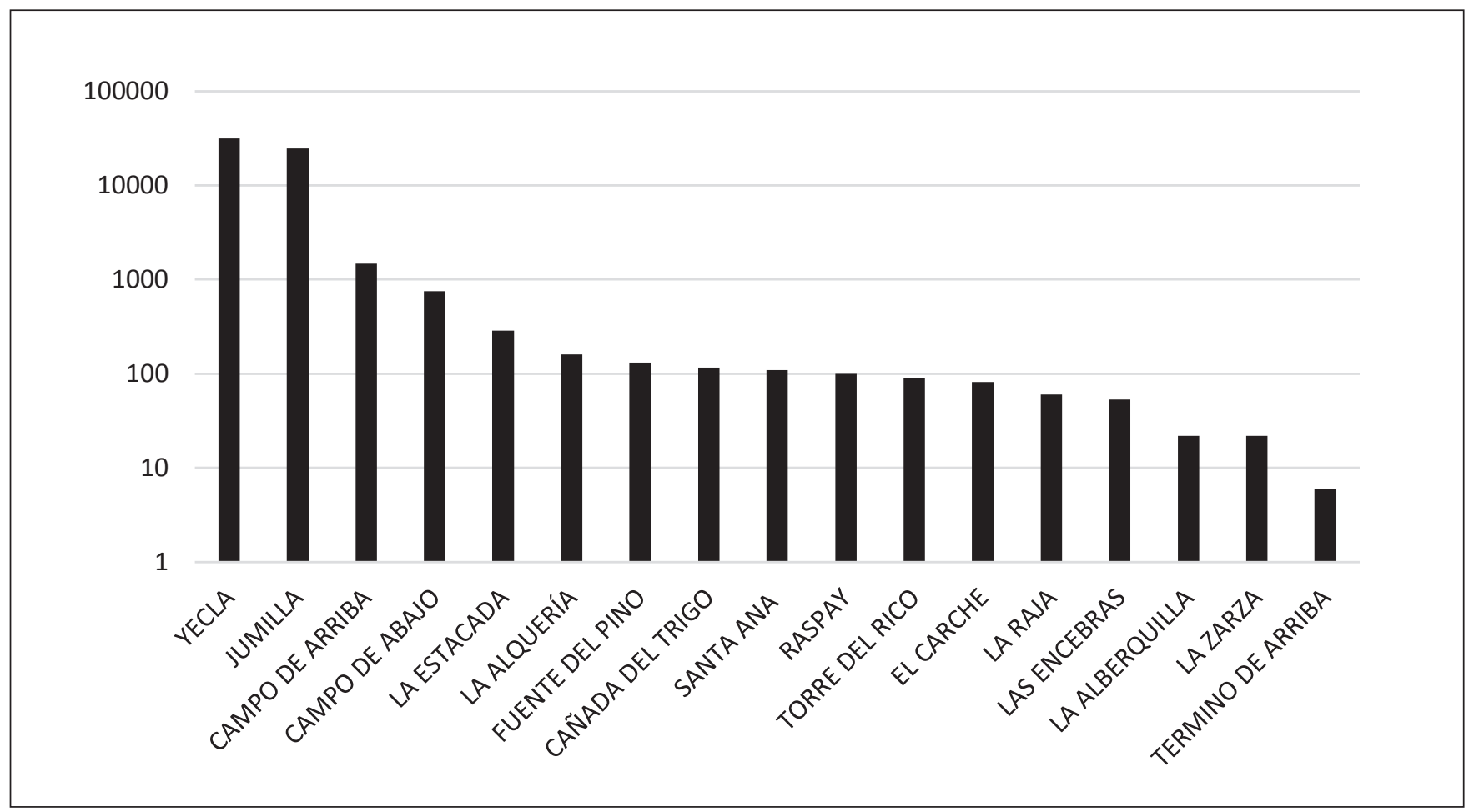

Gráfico 1. Distribución de la población por entidades menores (2018). Fuente: INE (2018).

Cuadro 4. Superficie, población y densidad de las entidades menores de Yecla y Jumilla

\begin{tabular}{|c|c|c|c|}
\hline ENTIDAD MENOR & $\mathrm{Km}^{2}$ & POBLACIÓN & DENSIDAD \\
\hline \multicolumn{4}{|c|}{ YECLA } \\
\hline CAMPO ARRIBA & 313,95 & 1.470 & 5 \\
\hline YECLA & 5,21 & 31.764 & 6.097 \\
\hline CAMPO ABAJO & 286,29 & 858 & 3 \\
\hline \multicolumn{4}{|c|}{ JUMILLA } \\
\hline TERMINO DE ARRIBA & 173,55 & 6 & 0 \\
\hline LA ALQUERÍA & 86,15 & 161 & 2 \\
\hline FUENTE DEL PINO & 69,52 & 132 & 2 \\
\hline LA ESTACADA & 55,01 & 287 & 5 \\
\hline JUMILLA & 11,82 & 24.518 & 2.074 \\
\hline EL CARCHE & 154,66 & 82 & 1 \\
\hline SANTA ANA & 232,28 & 106 & 0 \\
\hline ROMÁN & 25,79 & 13 & 1 \\
\hline LAS ENCEBRAS & 26,72 & 53 & 2 \\
\hline LA ALBERQUILLA & 33,21 & 22 & 1 \\
\hline LA RAJA & 43,12 & 60 & 1 \\
\hline TORRE DEL RICO & 39,02 & 90 & 2 \\
\hline LA ZARZA & 12,21 & 22 & 2 \\
\hline CAÑADA DEL TRIGO & 5,69 & 117 & 21 \\
\hline
\end{tabular}

Fuente: INE y CREM [Centro Regional de Estadística de Murcia], 2018. 
encuentra en el municipio de Jumilla, así como que todas se reparten por la zona centro-sur de la comarca. Mostrando un vaciado poblacional en oeste, noroeste y norte del municipio jumillano. En el caso de Yecla la ausencia de núcleos poblacionales rurales, tal y como han sido definidos en este trabajo, son inexistentes, al igual que los asentamientos humanos habitados. Salvo la excepción de las localidades de Yecla y Raspay.

\section{DISCUSIÓN}

Hay que comenzar, resaltando como principal hallazgo que: del casi centenar de asentamientos humanos presentes en el área de estudio, tan sólo nueve son calificados como conjuntos poblacionales rurales. Recordemos, que el universo de estudio está compuesto por todos los asentamientos humanos de la comarca, salvo los yacimientos arqueológicos. Todo ello, supone que tan sólo, entorno al $9 \%$ de los asentamientos, son conjuntos poblacionales rurales (Raspay, Casas de Pinillos, La Estacada, Cañada del Trigo, Fuente del Pino, La Alquería, Torre del Rico, Casas de Juan Marcos-La Raja y Santa Ana del Monte). Sirva como ejemplo, que tras la aplicación del primer criterio, recogido en el diagrama de flujo -referido a la catalogación de los asentamientos como núcleos de población-, se contabilizan un total de 49 asentamientos comarcales que cumplen con tal criterio: tener un número igual o superior a 10 edificaciones, incluyendo las situadas en un radio de 200 metros.

En lo que respecta, al objetivo planteado consistente este en: determinar que asentamientos humanos de la comarca del Altiplano, en la Región de Murcia, pueden ser calificados como conjuntos poblacionales rurales, puede decirse que este se ha cumplido. Para esto, se sigue la metodología propuesta y utilizada en esta investigación; no cerrándose la puerta a otras metodologías existentes, o, que puedan surgir en el futuro, y que por tanto puedan enriquecer el estudio de los conjuntos poblacionales rurales, en cuanto a su delimitación se refiere. En relación a, la hipótesis está no se cumple, ya que no es conforme a la realidad obtenida y recogida en los resultados, pues tan sólo nueve asentamientos pueden ser calificados como conjuntos poblacionales rurales a la luz de los datos obtenidos, tras pasar todos los asentamientos humanos por los tres diagramas de flujo. No obstante, estamos ante una hipótesis que puede ser calificada de científica al poder ser falsable, como en este caso ocurre.

En lo concerniente a, la metodología de investigación, diversos autores: Barbosa-Brandao et al., para el caso de Galicia, han utilizado otros enfoques basados en aspectos: sociales, ambientales y paisajísticos, para delimitar los "núcleos rurales" (2018). Así, Flores, O. (2016) trata la cuestión de los núcleos rurales o aldeas, en, su tesis doctoral: "núcleos rurales y organización inframunicipal", desde un análisis jurídico-social, evolutivo, y por tanto con cierta connotación histórica. Todo ello, permite enriquecer el abordaje de la delimitación de los asentamientos humanos que pueden ser considerados como conjuntos poblacionales rurales. No obstante, con la metodología utilizada para este trabajo, se trata de explorar nuevas vías de aproximación a la delimitación de los conjuntos poblacionales rurales de la comarca del Altiplano murciano.

Además, la metodología propuesta, en esta investigación, tiene como fin el agilizar y clarificar la calificación de los asentamientos humanos, no entrando en conflicto con otras. Presentándose, como complementaria y enriquecedora de otras propuestas actuales y/o futuras. Se aporta como novedad la utilización de algoritmos, representados mediante diagramas de flujos. Así, toda la metodología queda enmarcada en diseño de investigación denominado: cuantitativo no experimental y transeccional o transversal. Mediante el primero, tan sólo, se observa y mide el fenómeno, tal y como se muestra, de modo natural, sin plantear ningún experimento, y sólo recogiendo datos de carácter cuantitativo. En el marco del segundo tipo de diseños, los datos recogidos, lo son en un momento o período único (Hernández, R., et al., 2017).

Acerca de los diagramas de flujo, hay que hacer notar que, de no haber utilizado los criterios recogidos en estos, del modo que se plantea, los resultados variarían. Sirva como ejemplo, que para comprobar: si el territorio incluido en el área de estudio tiene visos de medio rural. Se utilizara como primer criterio tener $\leq$ 30.000 habitantes, y partiendo de la escala comarca, no se podría haber continuado con el presente trabajo. Ya que al contar la comarca con 59.764 habitantes, nos situamos en un medio considerado como no rural. 
Siempre que, nos atengamos a la propuesta metodológica seguida en este trabajo. Sin embargo, se optó por seguir el procedimiento establecido en los diagramas recogidos en este trabajo.

Asimismo, se ha derivado -indirectamente de esta investigación-, que los conjuntos poblacionales rurales se localizan en el municipio de Jumilla, salvo el caso de Raspay -en el término municipal de Yecla-. También, hay que decir que la distribución territorial de los mismos sigue ciertos patrones: situarse en la zona sur-sureste de la comarca (Raspay, Torre del Rico Cañada del Trigo y Casas de Juan Marcos); que los tres primeros se encuentran próximos a los límites territoriales-administrativos entre la Comunidad Autónoma de la Región de Murcia y la Comunitat Valenciana; y que Las Encebras, La Alquería y Fuente del Pino se encuentran en las proximidades de una de las vías de comunicación más importantes, la primera junto a la Ctra. Nacional N-344 y la Autopista A-33, y las dos últimas junto a la N-344; y La Estacada y Santa Ana en el área de influencia de la ciudad de Jumilla (Figura 5).

Para el caso de la Región de Murcia, no se ha encontrado definición contundente y clarificadora de conjunto poblacional rural, donde esta sea definida de un modo claro y objetivo, aparecen referencias a los núcleos rurales en la Ley de Ordenación Territorial y Urbanista de la Región de Murcia, con referencias vagas de los mismos, y circunscritas a los núcleos rurales sitos en las zona de huerta tradicional. En síntesis, se puede decir que no se da un tratamiento extenso y profundo a los asentamientos de corte rural que forman núcleos, aun siendo estos un gran número en la Región de Murcia. En las Directrices de Ordenación Territorial de la Comarca del Altiplano, no quedan suficientemente definidos los conjuntos poblacionales rurales.

Por lo que, es de suponer que, en posteriores desarrollos de estas directrices, tendrían que ser definidos este tipo de asentamientos humanos, para llevar a cabo las acciones contempladas en el marco de las citadas directrices. Es por tanto, que este trabajo adelanta, al tiempo que sirve de referencia, una definición más extensa y completa de conjunto poblacional rural para el caso concreto de la comarca. No obstante, esta debe ser enriquecida con otros puntos de vista, ya aludidos anteriormente (socio-económicos, ambientales, etc.).

Por último, cabe decir que la metodología ideada para este trabajo puede ser extrapolable a otros territorios, con las correcciones pertinentes si fuera necesario. Siendo de este modo el método adecuado para la definición de los conjuntos poblacionales rurales en el caso concreto de la comarca murciana del Altiplano, en el norte de la Región de Murcia.

\section{CONCLUSIÓN}

En principio, se tiene como primera conclusión: la conveniencia de definir el concepto de conjunto poblacional rural, en la comarca del Altiplano en la Región de Murcia, para poder llevar a cabo las acciones contempladas en el marco de las Directrices de Ordenación Territorial de dicha comarca. Esto, es así, ya que las acciones se ubican en el marco de futuros programas de acción, que normalmente van asociados a una dotación económica: como formando parte de los Presupuestos Generales de la Comunidad Autónoma de la Región de Murcia, y/o mediante financiación externa: Estado y/o Unión Europea. Por lo que, es necesario conocer sobre los conjuntos poblacionales rurales, para poder aplicar el recurso económico del modo más certero y rentable posible.

En lo tocante, a la metodología, mediante esta se contribuye a mejorar y enriquecer el camino a seguir para definir que es un conjunto poblacional rural. Al tiempo, que mejora la objetividad en la definición, y agiliza esta. Si bien, podrían omitirse otros rasgos singulares de los conjuntos poblacionales rurales, mediante los que se puede enriquecer, y realizar una definición más certera, mediante la complementariedad de la propuesta metodológica de este trabajo y otras metodologías. Aunque, se detecta cierta vaguedad en la definición/delimitación de los conjuntos poblacionales rurales mediante el uso de otras técnicas, con toda seguridad todas contribuyen a una mejor definición.

De todo lo anterior, se deriva la pertinencia de avanzar en una metodología, donde se contemplen criterios, índices, indicadores, etc., con los que llevar a cabo una más apta delimitación y definición de los núcleos poblacionales rurales. En concreto, para el territorio de la comarca del Altiplano, en aplicación de las Directri- 
ces de Ordenación Territorial relativas a la misma, y de modo general para el resto de comarcas murcianas. Quizás, habría que introducir algún modulador por las diferencias -vinculadas a la idiosincrasia propia de los distintos asentamientos- presentes entre las áreas costeras e interiores - áreas de montaña, altiplanos, vegas, etc.- de la Región de Murcia.

Asimismo, la metodología ideada para esta investigación podría ser extrapolable a otros territorios, más concretamente a los: surestinos y/o manchegos, por la similitud con la comarca. Al tomar esta caracteres tanto de uno y otro entorno.

Por lo que se refiere, al área de estudio, destaca que a pesar del casi centenar de asentamientos detectados, y visitados, y habiendo pasado el primer criterio: hasta 49; tan sólo 9 pueden ser considerados como aldeas o núcleos rurales, tras la aplicación de los algoritmos plasmados mediante los distintos diagramas de flujo. De este modo, cabe preguntarse: ¿si de haber aplicado otros criterios -junto a los utilizados- se hubieran obtenido otros resultados? Sólo podemos responder: que no lo sabemos. Pudiendo plantearse a partir de aquí otros temas de trabajo, planteados a modo de hipótesis. Donde los aspectos socio-culturales e históricos podrían modificar en buena medida los resultados. Pero, como ya se ha dicho, esta podría ser otra hipótesis a contrastar, a comprobar. Además, se desprende de estos datos la escasa dispersión de la población municipal, que tiende a concentrarse en las capitales comarcales, siendo más significativa esta situación en el caso del municipio yeclano.

También, hay que hacer nota que, a la hora de definir los conjuntos poblacionales rurales, puede resultar conveniente tener en cuenta los valores culturales e históricos que puedan albergar. Siempre y cuando, mediantes los programas de actuación de las Directrices de Ordenación Territorial, se pretenda llevar a cabo una puesta en valor de las singularidades de las mismas. O bien, porque estas sean vistas como representación patrimonial y cultural de los pueblos de la comarca, siendo adecuada su ordenación para posteriores actuaciones patrimoniales de recuperación, puesta en valor, etc. Ya que podrían contribuir al bien estar socio-económico de la comarca. Pues, recordemos que la filosofía de la ordenación territorial puede conllevar, la organización territorial que de cómo producto una mejora económica de los habitantes del territorio. Puesto que en ocasiones los valores culturales con interés patrimonial, pueden ser un recurso turístico de atracción de inversiones y/o visitantes.

De vuelta a los asentamientos humanos de la comarca, los conjuntos poblacionales rurales que fueron calificados como tal, se localizan en el municipio de Jumilla, salvo Raspay en el de Yecla. Todos tienen en común que se distribuyen hacía el sur del eje que formarían las ciudades de Jumilla y Yecla. Se observan varios patrones: los conjuntos poblacionales rurales localizados junto a los ejes de comunicación más importantes -carretera nacional y autovía-, entorno próximo a Jumilla y junto a los límites con la provincia de Alicante -en la vecina Comunitat Valenciana-. Todos estos patrones de distribución territorial tienen en común el encontrarse en las zonas más dinámicas socioeconómicamente de la comarca. Donde además, en el caso de Jumilla -en lo que respecta a su entorno próximo-, puede verse influenciado por la prestación de servicios por parte de la propia ciudad de Jumilla, junto a la existencia de un polígono industrial entre esta y las pedanías de: La Alquería y Fuente del Pino.

\section{REFERENCIAS}

Armas, P. (1997). Aldea y paisaje, patria y patrimonio. Aulas no Camiño (2a , 1997. Ferrol). Universidade Da Coruña. pp. 105-139.

Ayuntamiento de Yecla (2019). Historia de Yecla. Recuperado de http://www.yecla.es/CIUDAD/Historia.aspx Último acceso: 3/5/2019.

Barbosa-Brandão, V., Pérez-Rodríguez, F., Rojo-Alboreca, A. y Ferreira-Neto, J. (2018). Selección de criterios sociales y ambientales para la delimitación de núcleos rurales en Galicia, España. Rev. Fac. Agron. (LUZ), 35 (Enero-Marzo), 08-126.

CREM (2017). Centro Regional de Estadística de Murcia [CREM]. Recuperado de: http://econet.carm.es Último acceso:18/04/2018. 
DPOT-Altiplano (2010). Directrices y Plan de Ordenación Territorial de la Comarca del Altiplano, en la Región de Murcia [DPOT-Altiplano], Modelo Territorial. Tomo II. Consejería de Obras Públicas y Ordenación del Territorio de la Región de Murcia.

EDUSI-Yecla (2017). Estrategia de Desarrollo Urbano Sostenible e Integrado [EDUSI] Yecla-2020. Ayuntamiento de Yecla. Recuperado de http://www.yecla.es/Portals/0/Transpariencia/estrategias/estrategia_edusi_2017.pdf Último acceso: 21/11/2018.

Flores, O. (2016). Núcleos rurales y organización inframunicipal (Tesis Doctoral, s.p.). Universidad de Oviedo.

García, A. (2010). Estadística básica con R. Madrid: Universidad Nacional de Educación a Distancia. pp. 322.

Hernández, R., Méndez, S; Mendoza, C.P. y Cuevas, A. (2017). Fundamentos de investigación. Mexico: McGRAW-HILL/INTERNATIONAL EDITORES, S.A. DE C.V. pp. 265.

INE [Instituto Nacional de Estadística de España] (2018). Glosario de términos, 18 abril de 2018. Recuperado de http:// www.ine.es/censo_accesible/es/glosario.html

Larousse 2000 (1998). Diccionario Enciclopédico. Temáticos Larousse, S.A. Barcelona.

Ley 45/2007, de 13 de diciembre, para el desarrollo sostenible del medio rural. Boletín Oficial del Estado [BOE], núm. 299, de 14 de diciembre de 2007.

Ley 13/2015, de 30 de marzo, de ordenación territorial y urbanística de la Región de Murcia. Boletín Oficial de la Región de Murcia [BORM], Núm. 77, de 6 de abril de 2015.

López, L. (Dir.) (2015). Diccionario de Geografía aplicada y profesional: terminología de análisis, planificación y gestión del territorio. Universidad de León. pp. 676.

Nieto, A., Engelmo, A., Cárdenas, G. y Mora, J. (2018). Índice de ruralidad para los municipios españoles (Censo del 2011). En Cejudo, E.; Navarro, F.A. y Cañete, J.A.: Nuevas realidades rurales en tiempos de crisis: territorios, actores, procesos y políticas. Ed. Universidad de Granada, pp. 223-234.

OCDE (1994). Creating rural indicators for shaping territorial policy. París, Organización para la Cooperación y Desarrollo Económico [OCDE].

Ochoa de la Torre, J.M. (2007). La vegetación como instrumento para el control microclimático. Tesis Doctoral s.p. Universitat Politécnica de Catalunya (UPC).

Orden (2010). Orden del Excmo. Sr. Consejero de Obras Públicas y Ordenación del Territorio de 18 de mayo de 2010 , de aprobación inicial de las Directrices y Plan de Ordenación Territorial de la Comarca del Altiplano de la Región de Murcia. Boletín Oficial de la Región de Murcia [BORM], número 128, de 5 de junio.

RAE (2018). Diccionario de la Real Academia de la Lengua [RAE]. Madrid.

SALVAT-UNIVERSAL (1981). Diccionario Enciclopédico Salvat Universal. Barcelona, Salvat Editores, S.A.

Regmurcia.com (2019). Historia de Jumilla. Edad Contemporánea. Recuperado de https://www.regmurcia.com Último acceso: 3/5/2019.

Sánchez-Sánchez, M.A., Belmonte, F. y García, R. (2016). Aldeas de la comarca del Altiplano Jumilla-Yecla (Región de Murcia): Paisaje y patrimonio cultural y rural. En Ruiz Pulpón, Ángel Raúl, Serrano de la Cruz Santos-Olmo Manuel Antonio y Julio Plaza Tabasco, Julio (Ed.). TREINTA años de Política Agraria Común en España. Agricultura y multifuncionalidad en el contexto de la nueva ruralidad. Edita Asociación de Geógrafos Españoles, Grupo de Geografía Rural, pp. $860-867$.

SITMURCIA (2019). Plataforma. Sistema de Información Territorial de la Región de Murcia [SITMURCIA]. Recuperado de http://sitmurcia.carm.es/ Último acceso: 3/5/2019.

UE-Comisión Europea (1997). Rural Developments, CAP 2000. Working Document, Euroestat. Unión Europea-Comisión Europea. 


\title{
Vulnerabilidad Territorial y Accesibilidad a los Servicios de Proximidad para las Personas Mayores en la Ciudad de Valencia*
}

\section{Territorial Vulnerability and Accessibility to Proximity Services for Older People in the City of Valencia}

\author{
María Dolores Pitarch-Garrido \\ maria.pitarch@uv.es @ https://orcid.org/0000-0001-9109-4687 \\ Félix Fajardo-Magraner \\ felix.fajardo@uv.es @ https://orcid.org/0000-0003-1516-6655
}

Departamento de Geografía. Instituto Interuniversitario de Desarrollo Local. Universitat de València

Av. Blasco Ibañez, 28. 46010 Valencia

\section{INFO ARTÍCULO}

Enviado: $21 / 3 / 2019$

Revisado: 21/5/2019

Aceptado: 22/5/2019

\section{PALABRAS CLAVE}

Servicios públicos

Movilidad sostenible

Accesibilidad

Pobreza senior

Población mayor

Valencia

\section{KEYWORDS}

Public services

Sustainable mobility

Accessibility

Senior poverty

Elderly population

Valencia

\section{RESUMEN}

El aumento de la edad media de la población en las sociedades occidentales es una realidad que define nuevos parámetros de convivencia a la vez que nuevas demandas sociales. En el caso de los mayores, los servicios garantizan no sólo el cuidado, en particular a los dependientes, sino también la compañía (soledad). En este artículo se analiza la localización y accesibilidad a dichos servicios, concretamente centros de día, centros municipales de actividad y residencias, en la ciudad de Valencia, lo cual resulta de gran interés también para la planificación y gestión pública. Se hace hincapié en el contexto de los barrios más vulnerables. Los resultados nos indican que existen claras diferencias según el lugar de residencia de las personas, el modelo público o privado de la oferta y el tipo de transporte, todo lo cual resta cohesión social y espacial, a pesar de la buena situación general de la ciudad.

* Este artículo se ha elaborado en el marco del proyecto "Sostenibilidad social, conectividad global y economía creativa como estrategias de desarrollo en el Área metropolitana de Valencia" (CSO2016-74888-C4-1-R), financiado por la Agencia Estatal de Investigación (AEI) y al Fondo Europeo de Desarrollo Regional (FEDER) dentro del Programa Estatal de Investigación, Desarrollo e Innovación Orientada a los Retos de la Sociedad, en el marco del Plan Estatal de Investigación Científica y Técnica y de Innovación 2013-2016, convocatoria de 2016.Uno de los autores, Félix Fajardo, cuenta con una ayuda para contratos predoctorales para la formación de profesorado universitario, convocatoria 2014 (FPU14/05550), financiada por el Ministerio de Educación, Cultura y Deporte. 


\section{INTRODUCCIÓN}

Una de las características indiscutibles de la sociedad occidental actual es la elevada edad media de la población, originada por una bajísima tasa de natalidad y una mayor esperanza de vida. Esta situación, que ya tiene poco de coyuntural, determina algunas de las actuaciones públicas (sobre todo en lo que tiene que ver con la fiscalidad y las pensiones) y muchas de las acciones privadas, en particular en aquellos países o regiones donde la familia sigue siendo el sustento fundamental de la sociedad.

Según la Organización Mundial de la Salud (OMS) (2012)' el envejecimiento de la población es más rápido que nunca antes en la historia. Entre 2015 y 2050 el aumento de la población mayor de 60 años a nivel mundial pasará del 12 al 22\%, rebasando los 2.000 millones de personas, y no hay pruebas que indiquen que las personas mayores gocen ahora de mejor salud que sus padres, es decir que las limitaciones vitales son prácticamente las mismas. Además, según este mismo estudio, se empieza a detectar un aumento de la discriminación por razones de edad, incluso superior a la discriminación por sexo o raza, en forma de prejuicios, actitudes y prácticas o políticas, lo que puede suponer, según la OMS, una desvalorización y menoscabo de la calidad de la atención sanitaria y social a las personas mayores.

A nivel local, en concreto a escala urbana, el envejecimiento de la población supone un reto importantísimo para cuestiones prácticas básicas, tanto a nivel público como privado: desde el transporte hasta los servicios a domicilio, y, por supuesto, los cuidados, cuando son necesarios. La calidad de vida de las personas no debe disminuir cuando éstas aumentan en edad $y$, aunque las situaciones personales son muy diferentes, sus derechos siguen siendo los mismos.

Como indica la OMS (2012), las personas mayores, cuyo número y proporción en los entornos urbanos aumentará de forma considerable, presentan unos elevados índices de exclusión, problema que se une a otros como la soledad y la mala salud, la dificultad (por precio o por lejanía) para acceder a los mecanismos de protección social, entre ellos, los servicios públicos básicos. Son problemas que las políticas de austeridad en tiempos de crisis no han hecho sino acrecentar (OCDE, 2009, Doyle et al., 2009, Falkingham et al., 2012, OMS, 2012, OMS, 2015, Abellán y Pujol, 2016, Nieto-Masot et al., 2019).

El siglo XXI ha visto aparecer el término "envejecimiento activo". Para la OMS (2001) el envejecimiento activo es "el proceso de aprovechar al máximo las oportunidades para tener un bienestar físico, psíquico y social durante toda la vida. El objetivo es extender la calidad y esperanza de vida a edades avanzadas. Además de continuar siendo activo físicamente, es importante permanecer activo social y mentalmente participando en: actividades recreativas, actividades con carácter voluntario o remuneradas, actividades culturales y sociales, actividades educativas, vida diaria en familia y en la comunidad." (p.2) y añade: "El envejecimiento activo es positivo para todos, sin consideración alguna de las facultades psíquicas o físicas ni del estado socioeconómico o ubicación geográfica de la persona." (p.2). En este sentido, resulta relevante que las condiciones materiales faciliten y, en cierta medida, garanticen el envejecimiento activo. Una parte significativa es la que tiene que ver con la autonomía de las personas mayores. Dicha autonomía puede conseguirse mediante la modificación del entorno directo que habita, el hogar, pero también mediante la generación de mecanismos de apoyo que contribuyan a satisfacer las necesidades básicas (OMS, 2015).

En resumen, en una sociedad envejecida la calidad de vida de los mayores, tanto desde el punto de vista físico como psicológico, es un valor a preservar y mejorar no sólo porque involucra a un número cada vez mayor de personas, sino porque en un Estado de Bienestar es objetivo y responsabilidad de la política pública. Así pues, un envejecimiento activo, como se ha señalado, supone protección contra la pobreza, el aislamiento y la enfermedad. En las ciudades, la oferta de servicios y la protección social presentan un determinado patrón espacial que puede marcar diferencias entre las personas según el barrio en el que residan.

Con este convencimiento, acometemos esta investigación cuyo objetivo es identificar las áreas vulnerables en la ciudad de Valencia en términos de capacidad socioeconómica de sus residentes y de la accesibilidad a la oferta de servicios a la tercera edad. Nuestra hipótesis es que, a pesar de los esfuerzos de inversión

1. OMS: https://www.who.int/topics/ageing/es/ 
y de mejora de la red de servicios, todavía existen diferencias de acceso a los mismos según el lugar de residencia, siendo las áreas centrales de la ciudad las mejor servidas, tanto desde el punto de vista de la oferta pública como privada. Para ello se aplica una metodología ya contrastada (Pitarch-Garrido, Salom y Fajardo, 2018). La finalidad del análisis es conocer, con la información disponible, qué zonas de la ciudad son más vulnerables para las personas mayores que allí residen y facilitar la identificación de los principales problemas sobre los que debe incidir la planificación pública (oferta, tipología, transporte, etc.). Todo ello se detallará en los apartados que siguen a continuación.

\section{ESTADO DEL ARTE}

\subsection{Marco teórico}

Como ya se ha señalado, el proceso de envejecimiento afecta a todas las sociedades actuales, sin embargo, éste es un fenómeno espacialmente diferenciado. En las ciudades de más de 100.000 habitantes, la media de edad de la población urbana difiere 21 años en EE.UU., 12 años en China y 10 años en España (OCDE, 2015a). Existen grandes diferencias en cuanto a la edad media de la población en el interior de las ciudades, por ejemplo, en los países del norte de Europa los centros de las ciudades albergan más población joven que la periferia, mientras que, en los países del sur y este europeo, la población mayor es más abundante en el centro que en la corona metropolitana (OCDE, 2012).

Por otra parte, es necesario hablar del fenómeno del sobreenvejecimiento, es decir, del aumento del número de personas en las edades más avanzadas. Campelo et al. (2014) utilizan el índice de envejecimiento y sobreenvejecimiento como parte del proceso de vulnerabilización en las ciudades, entendido como "aquellas transformaciones en la estructura sociodemográfica, socioeconómica o sociocultural de una ciudad o área urbana que, al modificar situaciones o tendencias características de momentos temporales anteriores, afectan a las prácticas sociales e institucionales existentes..." (p. 121). En el mundo², la población mayor de 65 años (envejecimiento) supone en la actualidad el 9\% del total, y los mayores de 80 (sobreenvejecimiento) el 1,7\%. La previsión para el 2050 es que sean el 15,8 y el 4,3\% respectivamente. En los países más desarrollados se prevé que los mayores de 80 años supongan en 2050 el 10\% de la población. En España, la previsión de la ONU para 2050 es que el 14,1\% de la población sea mayor de 80 años y el 7,9\% mayor de 85 . Las cifras son relevantes por sí mismas y evidencian la necesidad de planificar para transformar esta situación en una oportunidad y no en un problema. Un elevado número de estas personas residen en las ciudades, aunque el índice de envejecimiento y de sobreenvejecimiento en las mismas sea menor que en el entorno rural ${ }^{3}$ (Nieto-Masot et al., 2019).

La OCDE (2015b) realiza una serie de recomendaciones estratégicas para la acción política en las ciudades, de cara a su desarrollo sostenible y equitativo, y dos de ellas están directamente relacionadas con el envejecimiento de la población: la ordenación de las infraestructuras y servicios urbanos para responder a las necesidades de la población mayor, y la promoción de la inclusión social y la participación de la población mayor en el diseño y gestión del entorno urbano.

Según Iglesias Souto et al. (2018), las instituciones públicas deben asumir mayor responsabilidad en la atención a las personas mayores, facilitando servicios que respondan a sus necesidades. Estos autores identifican, a partir de publicaciones científicas ${ }^{4}$, las variables predictoras del uso de los servicios a la tercera

2. ONU: https://population.un.org/wpp/Download/Standard/Population/

3. Siguiendo a Sancho Comins y Moreno Reinoso (2012), la delimitación de rural según EUROSTAT “utiliza dos criterios para cuantificar la población residente en zonas urbanas: uno relativo a la densidad y otro al tamaño demográfico mínimo. En primer lugar, las «celdas» del territorio de 1 kilómetro cuadrado han de tener una densidad de población superior a 300 hab/km2 para ser consideradas urbanas; en segundo lugar, el conjunto de celdas adyacentes que superen ese umbral de densidad han de tener una población mínima de 5.000 habitantes." (p. 614).

4. Los autores realizan una revisión sistemática a través de Psyinfo, Web of Science, Dialnet, CSIC y Teseo, seleccionando 44 artículos científicos utilizando como estrategia de búsqueda palabras clave relacionadas con personas mayores, cuidados, provisión de servicios, etc. Todos los artículos seleccionados tratan sobre el perfil o los factores que predicen el uso de los servicios sociales para mayores. 
edad. Dichas variables son: la dependencia funcional, el deterioro cognitivo, la ausencia o escasez de apoyo social y la precariedad de la vivienda. Estas dos últimas, ligadas a los temas de soledad y calidad material del barrio, justifican, en cierta medida, la necesidad de una distribución equilibrada de los servicios, al menos los de carácter público (Roberts y Chapman, 2017).

La soledad en la vejez es un problema cuando ésta no es deseada. La escasez o falta de relaciones sociales en el caso de las personas mayores tiene consecuencias en la salud física y psicológica (Yanguas et al. 2018). A ello añaden Silva et al. (2017) que es fundamental promover la independencia y la autonomía de las personas mayores. Se les debe facilitar la información necesaria y adecuada para apoyar sus decisiones diarias y estar alerta ante situaciones de desventaja y desigualdad. En definitiva, que la edad no sea causa de pérdida de capacidad de decisión y de actuación, por una inadecuada visión social de la vejez.

Tras lo señalado anteriormente, se prevé que las ciudades de los países occidentales, en particular las europeas, serán crecientemente vulnerables, precisamente debido al aumento de la población mayor, así como de la población dependiente, y al declive poblacional. Sin embargo, en Europa se le ha prestado menos atención a este tema que en otros contextos (OCDE, Japón, Corea). McCann (2017) señala la importancia de un enfoque urbano, o regional, del declive poblacional o envejecimiento por la importancia que tiene en términos de política pública, en especial en cuanto a la capacidad a largo plazo que tienen los gobiernos locales para proveer de servicios a la población mayor.

En esta línea, y focalizando la atención en el nivel local, cabe destacar lo que Amin (2002) llama la "micropolítica del contacto y el encuentro" (p. 959), es decir, las relaciones con las personas y con el entorno más cercano, el lugar en el que se vive, se trabaja y se siente como propio. Ese entorno es fundamental para la acción política de cercanía, sobre todo en cuanto a la política social se refiere.

La estructura espacial de la oferta de los servicios públicos y privados, pero sobre todo los primeros, determina las pautas de movilidad de la población y el hecho de que ésta sea más o menos sostenible. Además, por lo que respecta a la oferta de servicios públicos, uno de los condicionantes de su eficacia y eficiencia es la elección de un buen emplazamiento, lo cual se encuentra implícitamente vinculado a una buena accesibilidad. Los servicios de proximidad, los más frecuentemente demandados por la población, suponen un determinado uso del tiempo con implicaciones en la calidad de vida. Las altas densidades de población unidas a una extensa oferta de transporte público y a un espacio urbano caracterizado por una determinada mezcla de usos, son factores que contribuyen de manera trascendente a la configuración de un espacio urbano equilibrado y menos proclive a la aparición de espacios de exclusión.

Diferentes estudios (Andreotti et al., 2012, Marquet y Miralles, 2014, Blockland et al., 2016, Pitarch-Garrido, Salom y Fajardo, 2018) señalan que la movilidad más sostenible es aquella que se realiza a pie o en bicicleta, evitando el uso de cualquier medio de transporte motorizado. Si a ello añadimos que una buena accesibilidad supone cercanía a la demanda, y que la población tiene derecho (capítulo tercero de la Constitución Española) a una serie de servicios públicos considerados como de proximidad (servicios de salud, educativos y sociales básicos, así como de la administración del Estado provistos por las corporaciones locales), resulta relevante el estudio de los mismos -y los equipamientos a ellos asociados- por sus dos características fundamentales: en primer lugar, son una vía directa para la redistribución espacial y social de las rentas públicas; $y$, en segundo lugar, como consecuencia de lo anterior, su oferta por parte de la administración pública los convierte en instrumentos de las políticas de desarrollo económico, social y territorial (Nieto-Masot et al., 2019).

\subsection{Situación en la ciudad de Valencia}

Siguiendo el argumento del apartado anterior, cabe señalar que, en 2018, en la ciudad de Valencia, el índice de envejecimiento es del 20,58\% y el de sobreenvejecimiento del 11,5\% (según definición del INE, es decir, con los mayores de 85 años como porcentaje de los mayores de 65). Este último, por comparar, en la Comunidad Valenciana asciende a 14,12\%, en España es de 15,4\% y en el mundo del 8,84\%. 
La población mayor de 64 años asciende a 164.341 personas, de los que 25.177 tienen más de 85 años. La población total de la ciudad es, en 2018, de 798.538 habitantes, por lo que, como ya hemos señalado, una quinta parte de la población es mayor de 65 años, y en crecimiento. Como indican Pinazo y Berjano (2003), la cohorte de personas mayores de 65 años ha experimentado un enorme crecimiento en la ciudad de Valencia, mientras que la población total apenas ha experimentado incremento alguno. Es una ciudad envejecida y con una importante representación de la mujer, como es habitual en las edades más avanzadas. A estos datos hay que añadir el número de personas mayores que viven solas. En este sentido, los autores anteriormente citados (Pinazo y Berjano, 2003) estiman que, en 2001, el 27,5\% de los mayores de 65 años viven solos, un total de 32.468 personas. Esta cifra alcanza el 29,5\% (43.124 personas) en 2018, según información de la Oficina de Estadística del Ayuntamiento de Valencia.

La distribución de la población mayor en la ciudad no es homogénea. Los distintos barrios presentan situaciones muy diferentes, y lo mismo ocurre con la población mayor de 65 años que vive sola. Los barrios más envejecidos (mayor índice de envejecimiento) son Mahuella, Ciutat Jardí, El Palmar, Cases de Bàrcena y Marxalenes. Son barrios de la periferia urbana, de antigua tradición agrícola y que hoy se encuentran vinculados a la ciudad, pero con escasa población residente. Sin embargo, la mayor concentración de personas de la tercera edad en números absolutos, se da en la primera periferia, es decir, en los barrios del segundo ensanche y Russafa, Orriols, Aiora, Nou Moles y Mont-Olivet, zonas de nueva construcción en los años 60, entonces ocupadas por familias jóvenes, hoy población anciana. Los barrios del primer ensanche y de Ciutat Vella (centro histórico) son los que han experimentado renovaciones urbanísticas más recientes, desde finales de los 90, experimentando dos procesos paralelos: gentrificación y reemplazo generacional, lo que supone en la actualidad una estructura de edades algo más rejuvenecida y menos hogares unifamiliares de personas mayores (mapa 1).

Los barrios que albergan un mayor número de personas mayores que viven solas son Faitanar, Els Orriols, Ciutat de les Arts, El Saler, La Carrasca, El Perellonet, El Mercat y Ciutat Universitaria. En todos ellos el porcentaje de mayores de 65 años solos sobre el total de mayores de esa edad supera el 35\%, siendo elevadísimo en el primer caso, por encima del 87\%, y especialmente relevante en el segundo, pues supone un total de 944 personas, mientras que en el resto de barrios señalados la población mayor en términos absolutos es más reducida. Como podemos observar en el mapa 2, son los barrios centrales, junto a los de la periferia oriental los que concentran más población mayor que vive sola. Se trata de barrios de antigua ocupación, tradicionales, con un parque de viviendas antiguo y una oferta de servicios, en general, consolidada y amplia.

La oferta de centros de servicios (cuadro 1) para las personas mayores tampoco se encuentra equitativamente repartida entre los distintos barrios de la ciudad. Es cierto que los Centros Municipales de Actividad, todos ellos de carácter público y gestionados por el Ayuntamiento, presentan una distribución más equilibrada. Sin embargo, las residencias, en su abrumadora mayoría privadas, presentan una mayor concentración en los barrios de la primera periferia o el ensanche, siendo inexistentes en las zonas norte y sur de la ciudad. Los centros de día presentan una distribución algo más equilibrada, siendo en su mayoría privados, todos los cuales se encuentran en la zona central, más poblada, de la ciudad.

La oferta de servicios dirigida a las personas mayores es más amplia que la presentada en el cuadro 1. Existe una serie de recursos dirigidos a las personas mayores en situación de dependencia que se ofertan en el domicilio, tales como el servicio de ayuda a domicilio y el servicio de teleasistencia. En ambos casos, en la ciudad de Valencia se oferta a través de contratos o de ONGs, como Cruz Roja. Además, existen otras posibilidades como las viviendas tuteladas (sólo una en Valencia) y la oferta de transporte adaptado, también brindadas por entidades del tercer sector social. Por otra parte, consta oferta de Centros de Atención Preventiva para Personas Mayores, centros públicos dependientes de Generalitat Valenciana, de los cuales en la Comunidad Valenciana hay 7, y en la ciudad de Valencia hay sólo 2, una oferta claramente mejorable. Por último, en la ciudad hay una Oficina de Atención al Mayor y un Defensor del mayor, este último sustentado por voluntariado.

Teniendo en cuenta que el impacto social y económico de la dependencia es creciente y, previsiblemente, se incrementará en las próximas décadas, la oferta pública de centros de día y residencias resulta estratégica. El número de personas mayores en situación de dependencia en la ciudad de Valencia en 2001 ascendía 


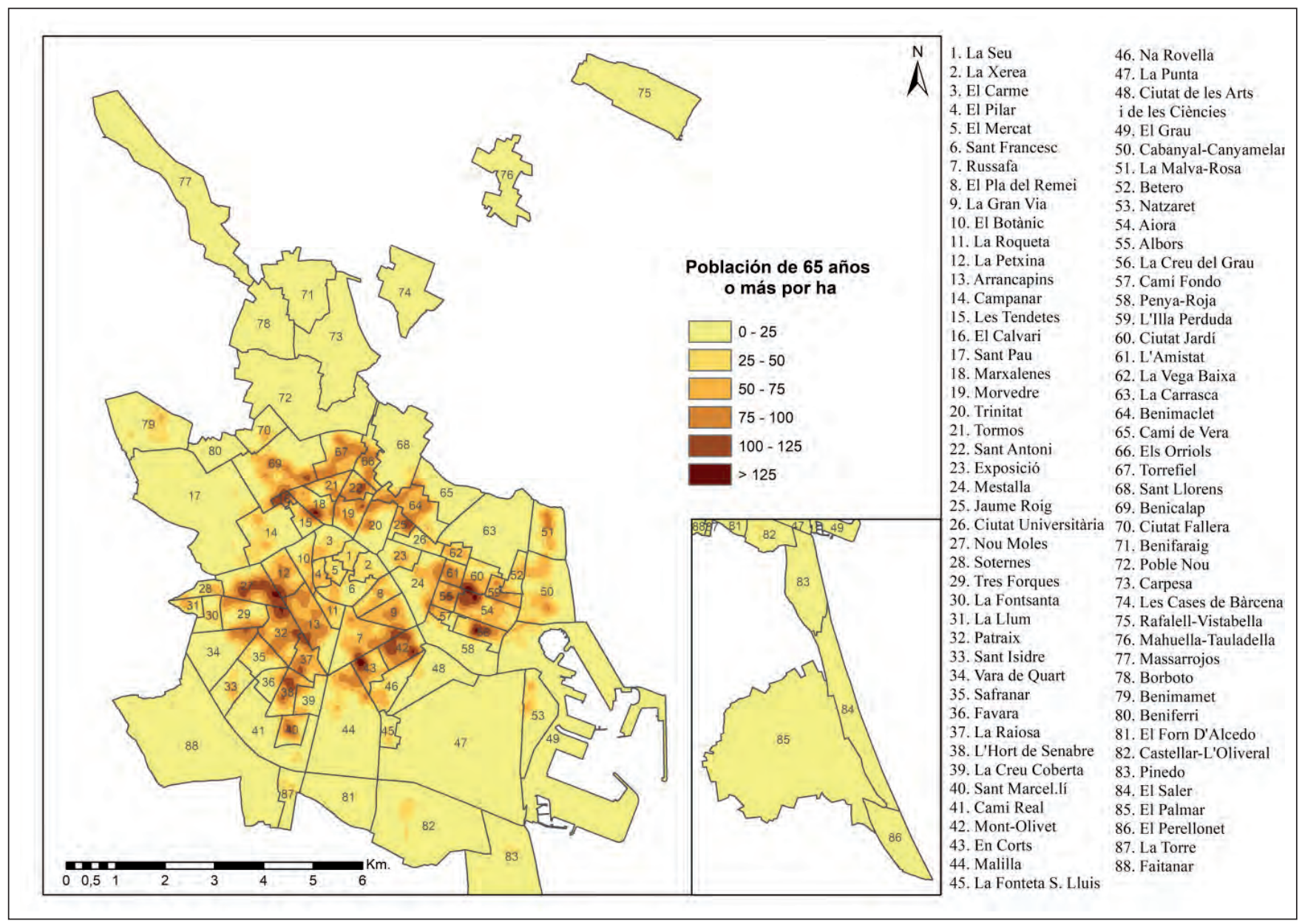

Mapa 1. Distribución de los mayores de 65 años en la ciudad de Valencia. 2018. Fuente: Elaboración propia a partir de datos de Padrón Municipal.

Oficina de Estadística del Ayuntamiento de Valencia (datos por portales).

Cuadro 1. Total de oferta de servicios (número de centros) en Valencia destinados a personas mayores.

\begin{tabular}{|l|c|c|c|}
\hline \multicolumn{1}{|c|}{ Tipo } & Total & Públicos & Privados \\
\hline Centros Municipales de Actividad & 49 & 49 & 0 \\
\hline Centros de día & 19 & 6 & 13 \\
\hline Residencias & 22 & 2 & 20 \\
\hline
\end{tabular}

Fuente: Oficina de Estadística del Ayuntamiento de Valencia.

a 23.308 (Berjano y Pinazo, 2003), mientras que, en 2018, según el Ayuntamiento de Valencia, el número de personas mayores de 65 años que tienen certificado de discapacidad es de 68.389, de las cuales, 17.643 presentan un grado de discapacidad severo, superior al 74\%. Además, en la actualidad, 2.783 personas mayores de 65 son atendidas por los servicios de Ayuda a Domicilio, 6.677 personas (de todas las edades, pero principalmente mayores) son atendidas en el Programa de Teleasistencia Domiciliaria, y 662 por el programa Menjar a Casa de los Servicios Sociales Municipales, que facilitan la comida a domicilio (Oficina Estadística del Ajuntament de València).

Las cifras expuestas confirman, por un lado, el reto que supone para la sociedad el aumento de la población mayor, y, por otro, el avance que en la última década se ha dado en la ciudad en cuanto a ofrecer respuesta a dicha demanda creciente. Cabe añadir que desde 2016 Valencia forma parte de la Red Interna- 


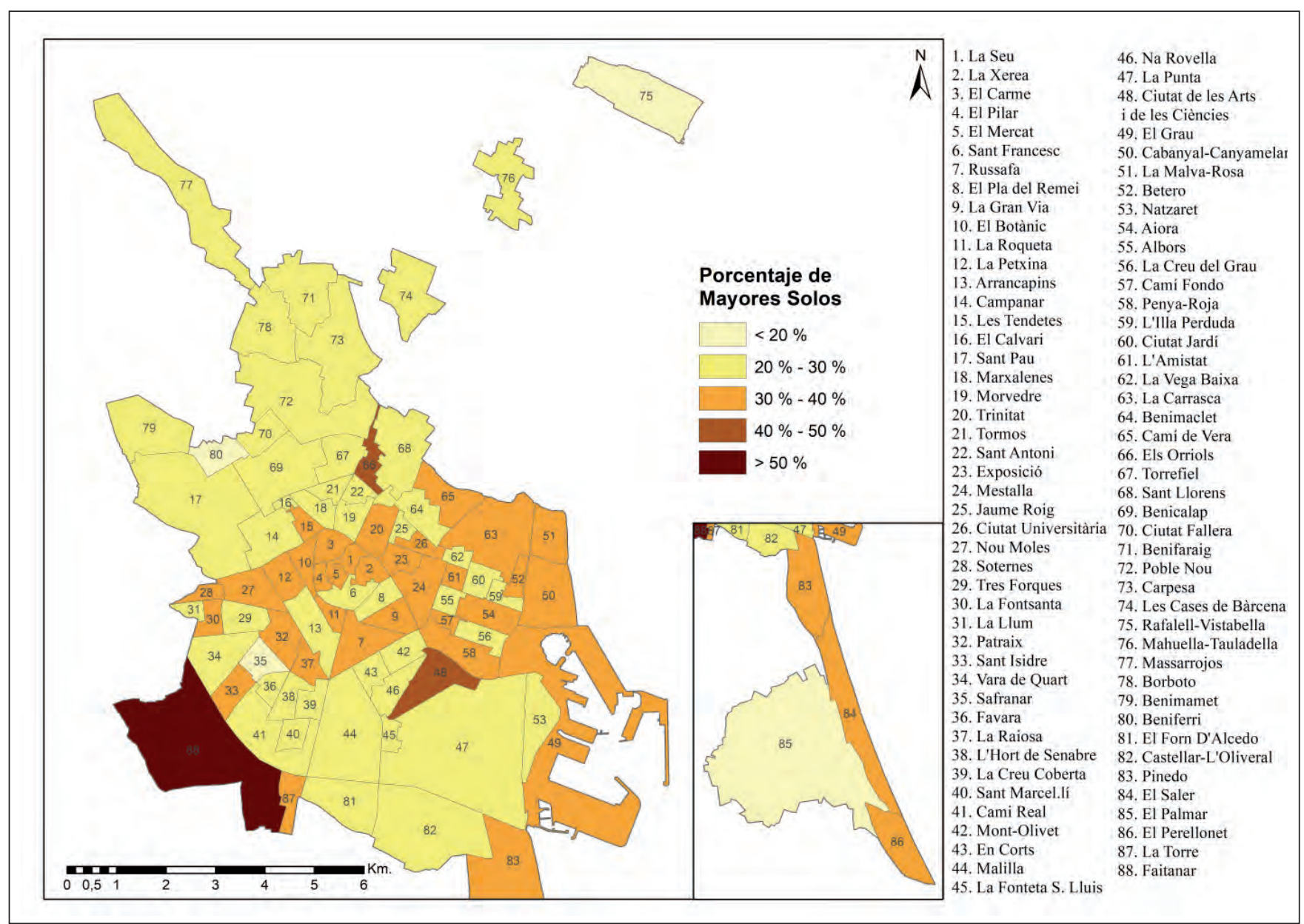

Mapa 2. Porcentaje de mayores de 65 años (sobre el total de mayores de 65) que viven solos por barrios en Valencia. 2018. Fuente: Elaboración propia a partir de datos de Oficina de Estadística del Ayuntamiento de Valencia.

cional de Ciudades Amigables con las Personas Mayores, auspiciada por la OMS, lo cual supone un primer paso, aunque sea simbólico, por hacer de la ciudad un entorno más amable para las personas mayores.

A esta situación de mejora se suma que, recientemente, en febrero de 2019, se ha aprobado la Ley 3/2019, de 18 de febrero, de servicios sociales inclusivos de la Comunitat Valenciana ${ }^{5}$, la cual supone un avance de calidad en la oferta y una reestructuración del sistema público de servicios sociales Valenciano. La puesta en marcha de esta ley supondrá una racionalización de los recursos y de la oferta, con efectos positivos para las personas mayores, pero sus efectos sólo serán detectables a largo plazo.

En nuestra investigación hemos considerado los servicios dirigidos a la población mayor con localización fija que se ofertan en la ciudad de Valencia, tanto desde el ámbito público como privado. Desde finales del siglo pasado y, sobre todo, a raíz de la crisis económico-financiera de 2008, la política que el gobierno regional y local en la Comunidad Valenciana y en su capital ha tendido hacia la restricción del gasto público, en particular en este tipo de servicios (Centros de actividades, Centros de día y Residencias), privatizando su oferta y reduciendo el número de plazas públicas. Esta política, neoliberal y de austeridad, ha supuesto recortes en las inversiones dirigidas a aumentar los recursos y equipamientos públicos para mayores.

Proponemos un nuevo vocablo para definir pobreza o exclusión que aparece, sobre todo a partir de la crisis, en este entorno urbano y social: la pobreza senior. Se trata de personas mayores, en particular muy mayores (con más de 85 años, sobreenvejecimiento), en situación de dependencia, escasa movilidad, con 
ingresos bajos (pensiones mínimas o no contributivas), que viven solas y sin entorno familiar, residentes en barrios con una baja dotación de servicios sociales públicos u obligadas a desplazarse fuera de su lugar habitual de residencia para poder acceder a servicios de cuidado. Una parte importante de esta situación de vulnerabilidad es la que nos proponemos analizar en este artículo para el caso de la ciudad de Valencia: la relacionada con el lugar, es decir, la parte que afectaría a la equidad espacial de la pobreza senior. A continuación, expondremos brevemente la metodología utilizada para pasar al análisis de la situación y las conclusiones.

\section{METODOLOGÍA}

Proponemos a continuación un estudio de caso, la ciudad de Valencia. La metodología desarrollada puede ser replicable en cualquier otro contexto urbano y ha sido ya aplicada a otro tipo de servicios públicos, por lo que no abundaremos ahora en los detalles de la misma que se pueden consultar en Pitarch-Garrido, Salom y Fajardo (2018).

Los elementos que consideramos son: la movilidad a pie (la más adecuada y sostenible para este grupo de población), la accesibilidad-cercanía, la calificación de dichos servicios como de proximidad, y, por tanto, el derecho de los usuarios a que se localice su oferta en un área dentro de su espacio vital. Los servicios considerados son: los centros municipales de actividad (conocidos como asociaciones de jubilados), los centros de día y las residencias de la tercera edad. Para el análisis se ha diferenciado entre servicios públicos, privados y el total.

En pro de la sostenibilidad de la movilidad, se ha calculado el índice de accesibilidad a los distintos centros de oferta de servicios para mayores públicos y privados a pie ${ }^{6}$ y en transporte público. Por otra parte, se analiza la cantidad de personas que suponen demanda potencial, considerando el total de la población mayor, aunque no todos sean usuarios del servicio, y se calcula el área de influencia de cada uno de los centros de oferta, comparándola con los límites de los barrios. Para cada una de las áreas resultantes, tanto las calculadas, como los barrios, se consideran las variables socioeconómicas de la población residente.

La localización de la población (según edades) en su lugar de residencia (portal o número de policía) es la base para el cálculo de la accesibilidad a los servicios. La información facilitada por el Padrón de Habitantes y cedida por la Oficina de Estadística del Ayuntamiento de Valencia ha sido de gran utilidad para la exactitud espacial de los cálculos. La medida de la accesibilidad utilizada ha sido el índice de separación espacial ${ }^{7}$ (Garrocho y Campos, 2006), en minutos. El índice se ha calculado desde cada portal al punto de oferta más cercano mediante el uso del software Arc-SIG 10.2 de ESRI.

La transformación de los datos puntuales en superficies se ha realizado a partir de la interpolación mediante el método IDW (Inverse Distance Weighting), utilizando la herramienta correspondiente del módulo Spatial Analysis de ARCINFO 10.0. El exponente de distancia utilizado ha sido de 2 aplicado a los puntos del ISE, a partir de los cuales se define un radio de búsqueda de los 12 puntos más cercanos entre sí (separados por una distancia máxima de 500 metros), y un tamaño de celda de $25 \times 25$ metros. Con estas premisas se han delimitado áreas con niveles significativos en relación con la accesibilidad.

Desde el punto de vista espacial, se ha sumado la información sociodemográfica a nivel de portal, a partir de una malla de polígonos cuadrados de 100 metros de lado dibujada sobre la ciudad de Valencia. De esta manera es posible obtener la información a una escala intermedia, entre el barrio (excesivamente amplio) y

6. La velocidad media a la que se ha considerado que se desplaza un peatón es de 4,5 km/h. Estimamos que en 10 minutos se recorren 600 metros. Las condiciones de salud de las personas mayores pueden suponer una ralentización de esta velocidad, con lo que los resultados deben ser considerados como límites de distancia máxima, es decir, para algunos mayores los 20 minutos de desplazamiento pueden convertirse en 30.

7. El Índice de Separación Espacial de la unidad espacial $i\left(I S E_{i}\right)$ es igual a: ISE $=\sum D_{i} / n$. Donde $i$ es el lugar de origen (portales) para el que se calcula el índice, $j$ es cada uno de los potenciales lugares de destino de los desplazamientos (equipamientos). Sólo se utiliza el más cercano al lugar de origen. $D_{i j}$ es la distancia en minutos, -obtenida a partir de las matrices calculadas-, entre el lugar de origen $\mathrm{i}$ y el lugar de destino j. $Y n$ es el número de posibles lugares de destino. 
el portal (difícil de representar por la multitud de puntos). A cada celda se le ha asignado el valor medio de los puntos de las residencias y el del barrio. Para la caracterización de las diversas zonas de la ciudad, junto a la información a nivel de portal (Padrón), se han considerado distintos indicadores de la situación económica del barrio en que se ubican ${ }^{8}$. Con estos datos se ha realizado un Análisis Factorial de Componentes Principales (ACP) que nos ha permitido reducir la cantidad de datos, siendo posible establecer los elementos comunes a las variables asociadas (Pitarch, Salom y Fajardo, 2018). El tratamiento estadístico se ha llevado a cabo con el programa IBM SPSS Statistics, Versión 22. Se ha utilizado el método propuesto por López-Roldán et al (2016), por tanto, se ha seleccionado el primer componente, que explica por sí mismo el 32,6\% de la varianza. El valor de este componente en sentido negativo nos da una idea muy ajustada de la localización de la población con menor nivel de renta, menor calidad funcional y del entorno, bajos precios del suelo (y de la vivienda) y escasez o ausencia de funciones superiores. Así, ha sido posible cartografiar las áreas (espacios inferiores al nivel de barrio) de la ciudad de Valencia donde se dan al mismo tiempo un nivel socioeconómico bajo con una lejanía relativa a los servicios públicos considerados.

\section{RESULTADOS Y DISCUSIÓN}

El análisis de la situación de la accesibilidad de las personas mayores a los servicios a ellas destinados en Valencia presenta algunos resultados destacables. En términos de distancias medias recorrida, medidas en tiempo, en Valencia resulta evidente que el transporte público es más competitivo (Cuadro 2). Esto no resulta siempre tan evidente, ya que la cercanía del servicio a la demanda pudiera hacerlo más accesible a pie, evitando los inconvenientes de las esperas, trasbordos, etc. del transporte público. Sin embargo, en todos los casos, es menor el tiempo medio usado por los usuarios para acceder al servicio en transporte público.

Cuadro 2. Tiempo medio en la ciudad de acceso a los diferentes servicios analizados tanto a pie como en transporte público (promedio de ISE).

\begin{tabular}{|l|l|c|c|}
\hline \multicolumn{1}{|c}{ Tipología } & \multicolumn{1}{c|}{ Titularidad } & \multicolumn{2}{c|}{ Minutos } \\
\cline { 2 - 4 } & \multicolumn{1}{|c|}{ A Pie } & En Transporte Público \\
\hline \multirow{2}{*}{ Centro Municipal de Actividad } & Total (todos públicos) & 8,09 & 5,96 \\
\hline \multirow{2}{*}{ Centro de Día } & Total (públicos y privados) & 20,60 & 10,35 \\
\cline { 2 - 4 } & Público & 29,42 & 13,54 \\
\cline { 2 - 4 } & Privado & 22,70 & 11,18 \\
\hline \multirow{2}{*}{ Residencia } & Total (públicas y privadas) & 17,79 & 9,32 \\
\cline { 2 - 4 } & Pública & 41,10 & 16,41 \\
\cline { 2 - 4 } & Privada & 17,94 & 9,45 \\
\hline
\end{tabular}

Fuente: Elaboración propia.

8. Los indicadores utilizados proceden del Padrón, del Catastro y de la Oficina de Estadísticas del Ayuntamiento de Valencia. Son los siguientes: porcentaje menores de 16 años, porcentaje 65 y más años, porcentaje de población de 24 y más años con nivel educativo inferior a Bachiller, Edad media de las viviendas, valor por $\mathrm{m}^{2} \mathrm{de}$ la vivienda, porcentaje de vehículos con menos de $80 \mathrm{CV}$ sobre el total de vehículos del barrio, porcentaje de vehículos con más de 200 CV sobre el total de vehículos del barrio, porcentaje de empresas e instituciones financieras y seguros sobre el total de empresas del barrio, porcentaje de empresas de comercio, restaurantes, hostelería y reparaciones sobre el total de empresas del barrio, porcentaje de empresas profesionales sobre el total de empresas del barrio, porcentaje ocupados en comercio, hostelería y transportes sobre el total de ocupados residentes en el barrio, porcentaje de ocupados en finanzas, derecho y seguros sobre el total de ocupados residentes en el barrio, y porcentaje de nacionalidad extranjera extracomunitario. 
El cuadro 2 nos indica la situación media en la ciudad en cuanto a accesibilidad a los centros de actividad, los centros de día y las residencias. Los datos medios ocultan realidades particulares para cada barrio, sin embargo, nos dan una visión general bastante fiable. Cabe destacar, la elevada distancia media que existe entre el lugar donde viven los ciudadanos y las residencias públicas para mayores. Llama la atención el caso de las residencias, en particular las públicas, que, al ser tan escasas -sólo dos-, en comparación con la red de residencias privadas, la accesibilidad a pie es bastante negativa, el doble de tiempo que en transporte público.

Dada la importancia de la cercanía física y la localización en el entorno habitual de vida de las personas usuarias de las residencias, estos minutos pueden suponer una barrera para el acceso, dado que, además, la oferta es mayoritariamente privada, la decisión familiar de sacar a la persona mayor de su contexto es casi una necesidad. Por lo que respecta a los centros de día públicos, la distancia media en la ciudad es de unos treinta minutos a pie y algo más de trece minutos con transporte público, lo que supone también una difícil decisión familiar que obliga, en muchas ocasiones al traslado de los usuarios en transporte privado, estando, en tal caso, la decisión menos vinculada al espacio de vida y más a la facilidad de acceso por carretera y/o disponibilidad familiar. Los centros municipales de actividades son los que presentan una mejor accesibilidad, con una media de ocho minutos a pie, apenas rebajada a seis minutos en transporte público, lo que no supone diferencia real.

Las cifras generales de la ciudad en cuanto a número de personas y de personas mayores de 65 años afectadas por la lejanía a un centro de servicios de los analizados (cuadros 3 y 4) nos dan información sobre el impacto social que tiene la localización de los mismos. Hemos considerado dos umbrales a partir de los cuales los usuarios reales y potenciales se encuentran lejos del área de cercanía al servicio que hemos establecido (este umbral puede variar): veinte minutos a pie y cuarenta en transporte público. En Valencia, 12.820 residentes se localizan a más de veinte minutos de un centro municipal de actividades para personas mayores, de ellos, 2.765 son mayores de 65 años. Tan sólo supone un 1,89\% de la población total. Si incorporamos el transporte público, sólo 24 personas mayores de 65 años se encuentran a más de cuarenta minutos de uno de estos centros. Las cifras son muy bajas, lo que indica una distribución bastante equitativa desde el punto de vista espacial.

Cuadro 3. Población en relación con la distancia a los centros municipales de actividad para personas mayores.

\begin{tabular}{|c|c|c|c|c|c|}
\hline & \multirow{3}{*}{ Población afectada } & \multicolumn{4}{|c|}{ CENTROS MUNICIPALES DE ACTIVIDAD PARA PERSONAS MAYORES } \\
\hline & & \multicolumn{2}{|c|}{ A pie (a más de 20 minutos) } & \multicolumn{2}{|c|}{$\begin{array}{c}\text { Transporte Público (a más de } 40 \\
\text { minutos) }\end{array}$} \\
\hline & & Número & $\begin{array}{c}\text { Porcentaje (\%) } \\
\text { sobre el Total } \\
\text { de población } \\
\text { Valencia }\end{array}$ & Número & $\begin{array}{c}\text { Porcentaje (\%) } \\
\text { sobre el Total de } \\
\text { población } \\
\text { Valencia }\end{array}$ \\
\hline \multirow{2}{*}{ Total Centros } & Residentes & 12.820 & 1,71 & 73 & 0,01 \\
\hline & Mayores de 65 años & 2.765 & 1,89 & 24 & 0,02 \\
\hline
\end{tabular}

Fuente: Elaboración propia.

En el caso de los Centros de día (cuadro 4), los mayores de 65 años a más de veinte minutos a pie ascienden a 26.411. Si consideramos sólo los centros públicos, el número de potenciales usuarios, es decir, de personas mayores de 65 años, a más de veinte minutos asciende a 69.560. Estos últimos suponen un 47,6\% de la población mayor de la ciudad, cifra elevada, sobre todo si consideramos que, en el caso de los centros privados, se reduce a la mitad. En este servicio, la oferta pública es claramente deficitaria.

La distancia media a las residencias para la tercera edad, como ya se ha adelantado a partir de las cifras generales, es mayor (cuadro 5). En el caso de los centros públicos, los resultados son preocupantes, pues 114.780 mayores de 65 años residentes en la ciudad de Valencia necesitan más de veinte minutos para 
trasladarse a un servicio de este tipo, aunque en el caso de las residencias privadas, la cifra se reduce a 13.912. Los barrios más perjudicados por la distancia a residencias públicas son El Perellonet, El Palmar, El Sales, Mahuella-Tauladella, Massarrojos y Pinedo, todos ellos de la periferia de la ciudad, incluidos en los denominados Pobles del Sud y Pobles del Nord. Dentro del casco urbano consolidado, destacan por su peor posición Nazaret, Malvarrosa, Cabanyal-Canyamelar, Carpesa y la Torre, a los que se unen también otros barrios periféricos como Benimamet y Cases de Bárcena. Son barrios como El Pilar, El Carme, El Mercat, El Botànic, La Seu y Sant Francesc, todos ellos en Ciutat Vella, el distrito central de la ciudad, los que se encuentran mejor servidos en el sentido de una mayor oferta y dispersión, por lo que la cercanía al usuario es más clara. Se trata, como es sabido, de barrios de alta densidad, con una población residente muy abundante y también envejecida, lo que hace que la situación media de la ciudad no sea excesivamente mala, sino que, por el contrario, un elevado porcentaje de población se encuentre bien servida, aunque por oferta privada.

Cuadro 4. Población en relación con la distancia a los centros de día (total, públicos y privados).

\begin{tabular}{|c|c|c|c|c|c|}
\hline & \multirow{3}{*}{ Población afectada } & \multicolumn{4}{|c|}{ CENTROS DE DÍA } \\
\hline & & \multicolumn{2}{|c|}{ A pie (a más de 20 minutos) } & \multicolumn{2}{|c|}{$\begin{array}{l}\text { Transporte Público (a más de } 40 \\
\text { minutos) }\end{array}$} \\
\hline & & Número & $\begin{array}{c}\text { Porcentaje sobre } \\
\text { el Total de Va- } \\
\text { lencia }\end{array}$ & Número & $\begin{array}{c}\text { Porcentaje sobre } \\
\text { el Total de Va- } \\
\text { lencia }\end{array}$ \\
\hline \multirow{2}{*}{ Total Centros } & Residentes & 149.396 & 19,94 & 3.763 & 0,50 \\
\hline & Mayores de 65 años & 26.411 & 18,02 & 630 & 0,43 \\
\hline \multirow{2}{*}{ Centros públicos } & Residentes & 380.140 & 50,75 & 5.158 & 0,69 \\
\hline & Mayores de 65 años & 69.560 & 47,46 & 890 & 0,61 \\
\hline \multirow{2}{*}{$\begin{array}{l}\text { Centros priva- } \\
\text { dos }\end{array}$} & Residentes & 193.571 & 25,84 & 3.763 & 0,50 \\
\hline & Mayores de 65 años & 33.929 & 23,15 & 630 & 0,43 \\
\hline
\end{tabular}

Fuente: Elaboración propia.

Por la naturaleza del servicio, es evidente que las residencias para la tercera edad no implican un desplazamiento diario del usuario. Sin embargo, exponemos aquí los resultados de accesibilidad por un doble motivo: en primer lugar, para poder compararlos con el resto de servicios considerados en el estudio y conocer su patrón espacial, y en segundo lugar, por enfatizar el aspecto relacionado con la cercanía y el espacio vital, es decir, con el entorno habitual del usuario del servicio. Es cierto que en el caso de las residencias son muchas veces las familias las que deciden, pero dicha decisión puede verse afectada por una estructura de la oferta fundamentalmente privada que dificulta que los familiares puedan seleccionar una residencia en función de su ubicación, sino que son otros aspectos (coste, calidad, variedad en el servicio, cercanía a la residencia de los hijos, etc.) los que determinan la decisión.

Por otra parte, el acceso a una plaza en residencia pública supone el desplazamiento del usuario fuera de la ciudad, donde éstas son más abundantes, con los consecuentes problemas de lejanía, aislamiento y dificultad de acceso por parte de familiares y amigos. Con una estructura de oferta pública equilibrada en el territorio, la localización de residencias y centros de día, es decir, la cercanía al usuario, o a su familia, sería un elemento clave para la decisión y facilitaría que los mayores residentes pudieran seguir vinculados a su entorno, a su barrio (muchas veces también es el barrio en el que reside la familia), y ejercitar el verdadero envejecimiento activo, sin discriminación, siempre contando con que la calidad de la oferta del servicio fuera elevada y de similares características.

A continuación, cabe analizar los mismos resultados, pero únicamente en el caso de las áreas de la ciudad que han sido calificadas como más vulnerables. En dichas áreas, de escala inferior al barrio, el bajo nivel so- 
Cuadro 5. Población en relación con la distancia a las residencias para mayores (total, públicos y privados).

\begin{tabular}{|c|c|c|c|c|c|}
\hline & \multirow{3}{*}{ Población afectada } & \multicolumn{4}{|c|}{ RESIDENCIAS } \\
\hline & & \multicolumn{2}{|c|}{ A pie (a más de 20 minutos) } & \multicolumn{2}{|c|}{$\begin{array}{l}\text { Transporte Público (a más de } 40 \\
\text { minutos) }\end{array}$} \\
\hline & & Número & $\begin{array}{c}\text { Porcentaje sobre } \\
\text { el Total de Va- } \\
\text { lencia }\end{array}$ & Número & $\begin{array}{c}\text { Porcentaje sobre } \\
\text { el Total de Va- } \\
\text { lencia }\end{array}$ \\
\hline \multirow{2}{*}{ Total Centros } & Residentes & 82.751 & 11,05 & 3.816 & 0,51 \\
\hline & Mayores de 65 años & 13.912 & 9,49 & 626 & 0,43 \\
\hline \multirow{2}{*}{ Centros públicos } & Residentes & 612.970 & 81,83 & 5.288 & 0,71 \\
\hline & Mayores de 65 años & 114.780 & 78,32 & 932 & 0,64 \\
\hline \multirow{2}{*}{$\begin{array}{l}\text { Centros priva- } \\
\text { dos }\end{array}$} & Residentes & 82.751 & 11,05 & 5.288 & 0,71 \\
\hline & Mayores de 65 años & 13.912 & 9,49 & 932 & 0,64 \\
\hline
\end{tabular}

Fuente: Elaboración propia.

cio económico coincide con una mala accesibilidad a los servicios destinados a la población mayor. Hemos destacado aquí sólo la accesibilidad a pie, poniendo el mismo umbral que en el análisis anterior: veinte minutos. Se ha cartografiado, pues, la localización del servicio, las áreas con un componente principal 1 negativo (a distintos niveles que indican diferente grado de vulnerabilidad) y la accesibilidad a pie por encima de los veinte minutos señalados. Aquellas más vulnerables (por encima de 2,5 desviaciones estándar) y a más de veinte minutos a pie al servicio más cercano (sea público o privado) se señalan en rojo (mapas 3, 4 y 5). Se ha trabajado con el total, aunque, como se ha señalado, en el caso de los Centros Municipales de Actividades todos son públicos, mientras que, en el caso de las residencias, casi todas son privadas. Se ha decidido así, en esta primera aproximación, porque esta es la estructura general actual y real en la ciudad y porque es posible desarrollar diferentes políticas de apoyo a las personas que superen la dicotomía público-privado, como subvenciones, conciertos, ayudas personales a las situaciones de dependencia, etc. La mejora de la oferta pública es una cuestión de decisión política que supone considerar aspectos como inversiones en equipamientos y en personal a medio y largo plazo.

Como resultado concluyente, cabe señalar que la oferta de servicios a los mayores sigue diferentes modelos de localización según tipología y, por tanto, la población residente en las áreas más vulnerables de la ciudad se ve afectada de diferente forma según el servicio de que se trate.

Los mapas resultantes muestran la localización de las zonas vulnerables o de intervención prioritaria, es decir, la localización de la mayor parte de la anteriormente denominada pobreza senior. En ellas, la población mayor afectada por una lejanía a alguno de los servicios considerados asciende a 191.775 personas, de los cuales, 36.537 son mayores de 65 años.

En el caso de los Centros Municipales de Actividades, 842 residentes en áreas vulnerables se encuentran a más de 20 minutos a pie (cuadro 6). Ello supone menos del $2 \%$ de la población total residente en estas áreas, aunque si consideramos sólo a los mayores de 65 años, el porcentaje asciende ligeramente, hasta el $2,3 \%$, lo que indica que una parte del territorio vulnerable está especialmente envejecido.

Si consideramos los centros de día, tanto públicos como privados, el porcentaje de residentes mayores en áreas vulnerables a más de 20 minutos andando es del 50,37\%. La mitad de los residentes en estas zonas tendrían dificultades para acudir a pie a este tipo de centros, pues les quedan demasiado lejos. Las cifran de acceso a los Centros de Día públicos aún son mayores: el 78,9\% de los mayores de 65 años residentes en las áreas vulnerables se encuentran a más de 20 minutos a pie del Centro de Día público más cercano (cua- 

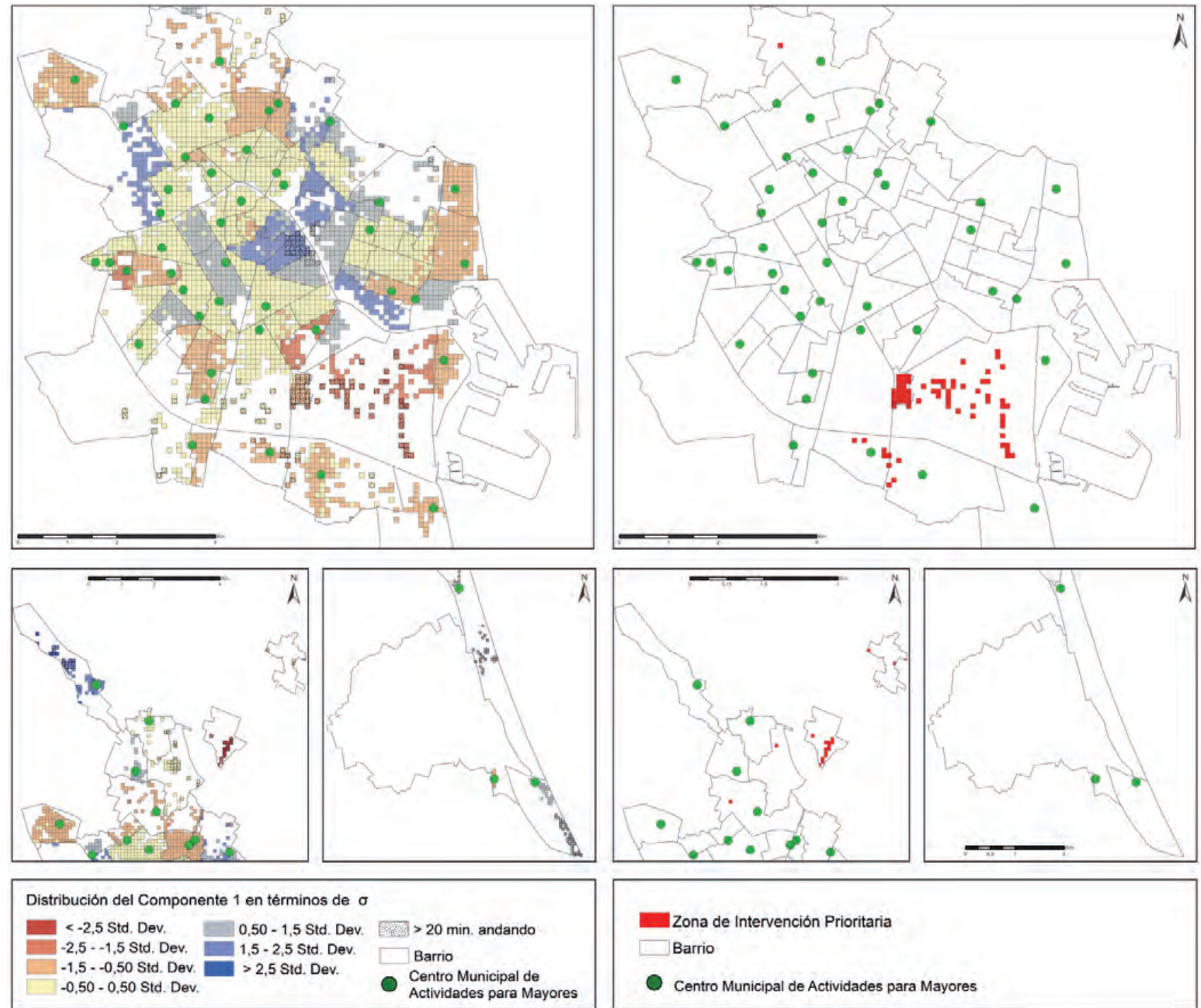

Mapa 3. Nivel socioeconómico (Componente $1 \mathrm{ACP}$ ) y accesibilidad a pie a los Centros Municipales de Actividades para Mayores y zonas de intervención prioritaria en Valencia.

Fuente: Elaboración propia.

dro 6). En el caso de las residencias (total) es del 19,21\%. La diferencia fundamental está en la oferta pública y privada. En este último caso, el de las residencias, si consideramos la distancia en minutos a los centros públicos, las cifras se multiplican: más de 36.000 residentes se ven afectados, lo que supone la práctica totalidad de los mayores de 65 años empadronados en estas zonas vulnerables: el 98,8\% (cuadro 6).

Dado los resultados obtenidos con la aplicación de la metodología propuesta, podemos afirmar que se trata de una herramienta con gran potencial y sencilla de aplicar, siempre que se cuente con la información sociodemográfica detallada a nivel de portal (detalle de escala), tanto de la oferta del servicio como de la demanda. El Padrón Municipal proporciona dicha información, aunque su elaboración puede resultar costosa y generar resistencias en la administración competente dada la necesidad de cumplir con la ley de protección de datos. En el caso de la ciudad de Valencia, los resultados generales son muy positivos, aunque siempre es posible detectar espacios donde las necesidades, reales o potenciales, aún no están completamente cubiertas. Se trata de detectar estos barrios o áreas para calificarlos como prioritarios en cuanto a provisión de servicios o de transporte público específico.

En definitiva, el trabajo aquí presentado versa en la combinación entre la delimitación de las áreas (barrios o parte de los mismos) de menor nivel socioeconómico con las necesidades de cercanía a los servicios 

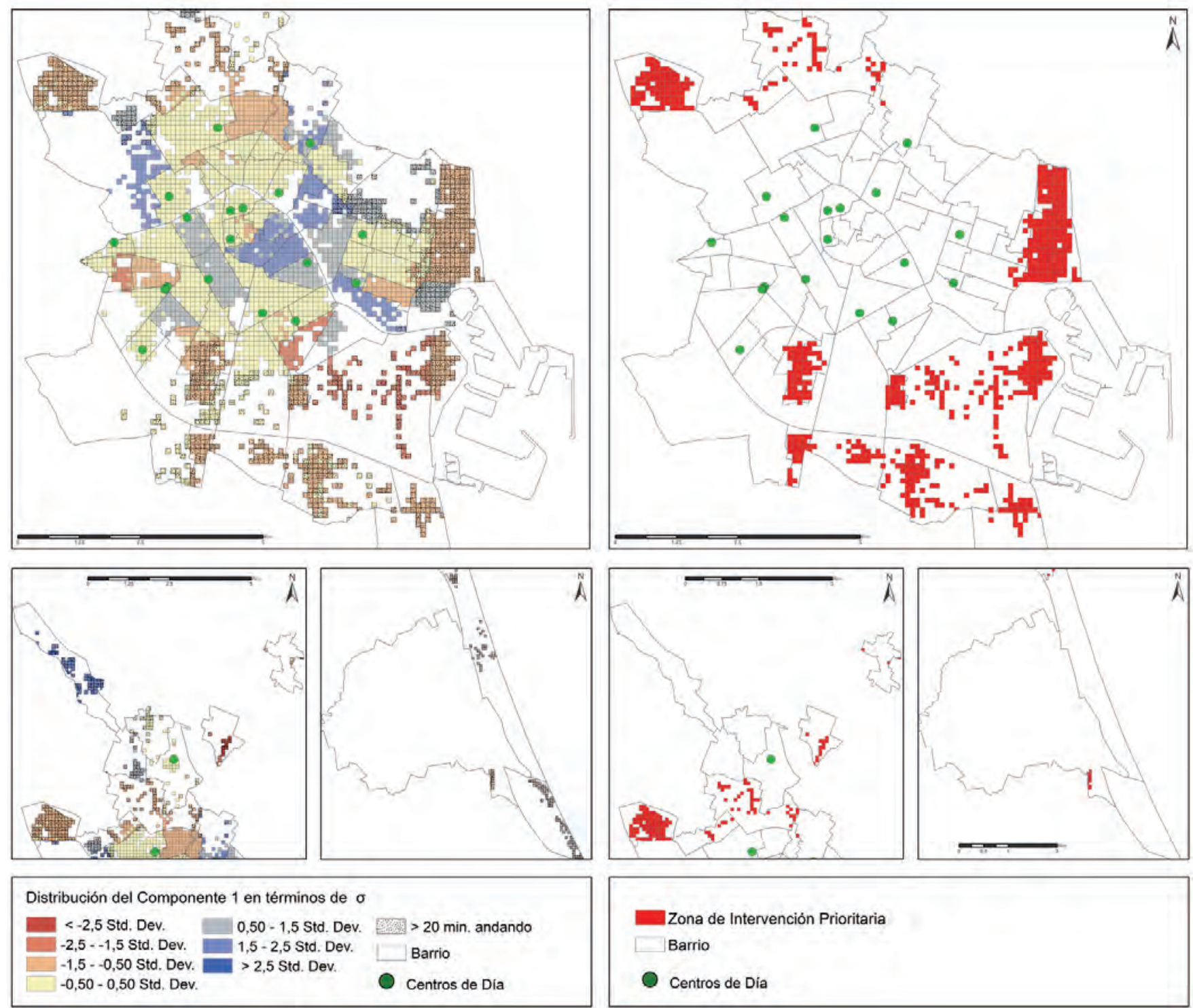

Mapa 4. Nivel socioeconómico (Componente $1 \mathrm{ACP}$ ) y accesibilidad a pie a los Centros de Día para Mayores y zonas de intervención prioritaria en Valencia. Fuente: Elaboración propia.

especializados por parte de la población mayor. El estudio de caso no es más que un ejemplo de las posibilidades que esta metodología presenta para poder ser aplicada a otros espacios, ciudades o regiones, en las que se cuente con la información estadística detallada de las personas a nivel de portal. La potencialidad del SIG depende de la calidad (exactitud locacional) de la información, por lo que la metodología propuesta podría modificarse dependiendo de la disponibilidad de datos más precisos.

Por último, cabe señalar que ciertamente existen estudios de accesibilidad a otro tipo de servicios (Calvo et al., 2001, Alfonso et al., 2016, Cazacu et al., 2016, Rode et al., 2017, Pitarch et al., 2018, Pitarch-Garrido, 2018, Zazzi et al. 2018,), la mayor parte centrados en las formas de transporte; sin embargo, son relativamente escasos los artículos científicos centrados en la accesibilidad a los servicios y equipamientos dirigidos a las personas mayores (Nieto-Masot, et al., 2019), a pesar del reto que supone el envejecimiento de la población en las sociedades actuales más avanzadas, en particular en los espacios urbanos. Cabe destacar algunas de las aportaciones recientes puntuales como el análisis del caso de Bangkok (Srichuae et al., 2016), la accesibilidad a los espacios verdes y espacios públicos para la población mayor (Artmann, et al., 2017, Yung et al., 2016) y el estudio de la demanda de los servicios de salud en las ciudades canadienses (Shah, et al., 2016). Todos ellos estudios de interés, sin embargo, no en la línea del que exponemos en el presente artículo. 

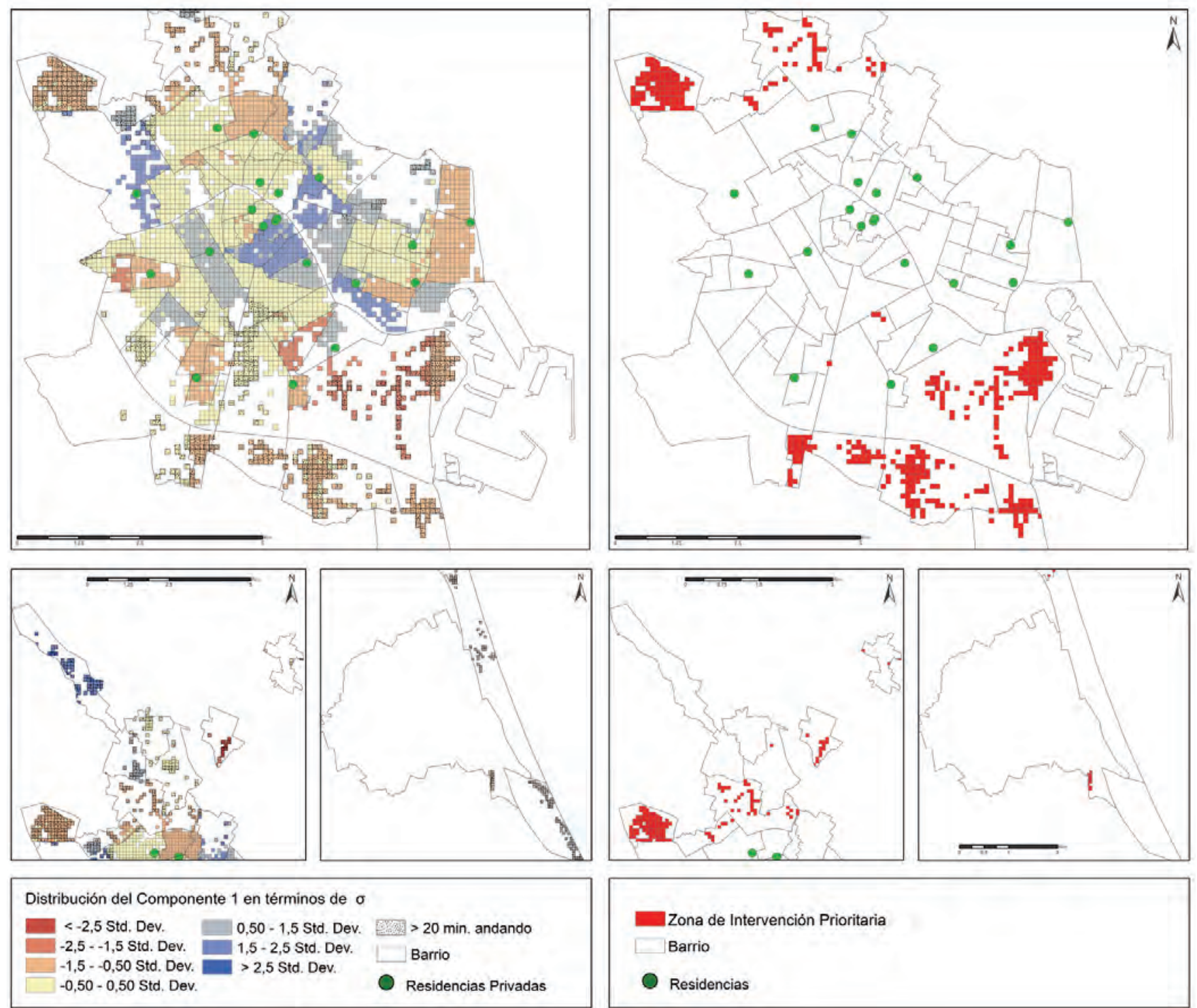

Mapa 5. Nivel socioeconómico (Componente 1 ACP) y accesibilidad a pie a las Residencias y zonas de intervención prioritaria en Valencia. Fuente: Elaboración propia.

Cuadro 6. Población mayor de 65 años residente en las áreas vulnerables de Valencia a más de 20 minutos a pie del centro de servicios más cercano.

\begin{tabular}{|l|l|c|c|}
\hline \multirow{2}{*}{$\begin{array}{l}\text { Centros Municipales de } \\
\text { Actividades }\end{array}$} & \multicolumn{1}{|c|}{ Titularidad } & Mayores de 65 años & $\begin{array}{c}\text { Porcentaje sobre el Total de Población ma- } \\
\text { yor de 65 años en Zonas Vulnerables }\end{array}$ \\
\cline { 2 - 4 } & Total & 842 & 2,30 \\
\hline \multirow{2}{*}{ Centros De Día } & Total & 18.403 & 50,37 \\
\cline { 2 - 4 } & Públicos & 28.809 & 78,85 \\
\hline & Privados & 19.326 & 52,89 \\
\hline \multirow{3}{*}{ Residencias } & Total & 7.017 & 19,21 \\
\cline { 2 - 4 } & Públicos & 36.118 & 98,85 \\
\cline { 2 - 4 } & Privados & 7.017 & 19,21 \\
\hline
\end{tabular}

Fuente: Elaboración propia a partir de datos del Padrón Municipal. 


\section{CONCLUSIONES}

La investigación presentada permite aplicar una metodología de análisis espacial para contribuir al conocimiento de una realidad, la accesibilidad de las personas mayores en situación económica vulnerable, a los servicios a ellas destinados, con el mayor detalle que permiten las estadísticas y la tecnología SIG. Se trata de un análisis que no por ser un clásico de la Geografía, deja de tener interés en la actualidad. La percepción de los tomadores de decisiones no es suficiente para responder de la manera más adecuada a las necesidades sociales, pues precisan de herramientas y metodologías que, con la información disponible a nivel local, corroboren o no dichas percepciones.

En Valencia son escasas las áreas o barrios que necesitan una intervención integral con el fin de acercar la oferta de servicios a los mayores, sin embargo, un análisis en detalle permite detectar los servicios que son menos accesibles por parte de la población en general, pero de la población más directamente afectada en particular. La búsqueda de la equidad espacial y social, ambas vinculadas estrechamente, en un espacio urbano dinámico y densamente poblado, ha de considerar a toda la población, sea cual sea su nivel de renta y también la localización de su residencia, pues todos deben disfrutar de una buena accesibilidad a los servicios. La aparición de nuevas formas de vulnerabilidad, en este caso, asociadas a la llamada pobreza senior, suponen un reto para las políticas públicas y de planificación que hay que acometer antes de que se conviertan en problema.

Es preciso, en este punto, tener en consideración dos cuestiones: por una parte, la diferencia entre la oferta pública y la privada, y por otra, la necesaria proximidad a los servicios, la vinculación con el barrio. La oferta privada no responde a patrones relacionados con la equidad, sino con el mercado, y, aun así, en la ciudad de Valencia, algunos servicios privados para la tercera edad, como son las residencias, están localizadas de manera que se reparten el mercado potencial de manera bastante equilibrada. En este caso, el principal problema de la oferta pública es su escasez. Sin embargo, la oferta pública de servicios debería garantizar plazas a todos los posibles usuarios, sin importar sus características personales. La segunda cuestión tiene que ver con el entorno habitual de las personas, que no deben verse obligadas a abandonar su barrio en especial a una edad en la que la cotidianeidad es importante para anclarse en el presente y mantener una vida larga y de calidad, es decir, un envejecimiento activo. En este sentido, la acción pública en forma de oferta de servicios de calidad para las personas mayores, en su entorno del barrio, en particular si estas son dependientes, es capital.

En conclusión, y aunque es evidente que toda la población mayor, sea cual sea su nivel de renta, debe disfrutar de una buena accesibilidad (cercanía) a los servicios públicos de proximidad, la realidad es que, en una situación de recesión económica y contención del gasto, es necesario priorizar las inversiones y orientarlas allí donde éstas son más urgentes o necesarias, en particular cuando estamos hablando de un segmento de la población con necesidades muy específicas y crecientemente afectado por nuevas formas de pobreza y exclusión, como la que hemos venido denominando aquí pobreza senior. El análisis realizado ayuda, en este sentido, a la toma de decisiones públicas, favorece la movilidad sostenible (a pie) y genera bienestar en la población. En el caso analizado, la ciudad de Valencia, se ha desarrollado una metodología que permite avanzar en estudios de geografía aplicada y que puede transferirse a otros entornos urbanos. Los umbrales de tiempo pueden variar dependiendo de las necesidades de la investigación, y la demanda puede proyectarse para trabajar sobre escenarios a más largo plazo. La detección de las áreas en riesgo de exclusión facilita herramientas para el diseño de políticas de planificación urbana que luchen contra la exclusión, tanto social como espacial, en pro de una mejora de la calidad de vida de toda la ciudadanía.

\section{REFERENCIAS}

Abellán García, A. y Pujol Rodríguez, R. (2016). Un perfil de las personas mayores en España, 2016. Indicadores estadísticos básicos. Madrid, Informes Envejecimiento en red, n. 14. Recuperado de http://envejecimiento.csic.es/documentos/ documentos/enred-indicadoresbasicos16.pdf 
Ajuntament de València (2018). Població major de 64 anys a la ciutat de València. Valencia: Oficina de Estadística del Ajuntament de València. Recuperado de: file://F:/PUBLICAR/TERCERA\%20EDAD\%20para\%20REA/Majors64_2018.pdf

Alfonso, J., Duquesne, C., Sánchez, N., Menéndez, J. M., Blanco, N. \& Melero, T. (2016). Urban mobility data managementthe OPTICITIES project and the Madrid standardization proposal. Transportation Research Procedia, 14, 1260-1269. doi: https://doi.org/10.1016/j.trpro.2016.05.198

Amin, A, (2002). Ethnicity and the multicultural city: living with diversity. Environment and Planning A, 34, 959-980. doi: https://doi.org/10.1068/a3537

Andreotti, A., Mingione, E. \& Polizzi, E. (2012). Local welfare systems: a challenge for social cohesion. Urban studies, 49 (9), 1925-1940. doi: https://doi.org/10.1177/0042098012444884

Artmann, M., Chen, X., Iojă, C., Hof, A., Onose, D., Poniży, L., ... \& Breuste, J. (2017). The role of urban green spaces in care facilities for elderly people across European cities. Urban Forestry \& Urban Greening, 27, 203-213. doi: https://doi. org/10.1016/j.ufug.2017.08.007

Berjano, E. y Pinazo, S. (2003). ¿Están preparadas las grandes ciudades para atender a los ancianos dependientes? Revista multidisciplinar de gerontología, 13 (4), 252-266.

Blockland, T. et al. (eds.) (2016). Creating the unequal city. The exclusion consequences of everyday routines in Berlin. Nueva York: Routledge. doi: https://doi.org/10.4324/9781315574639

Calvo, J.L. et al. (2001). Análisis, diagnóstico y ordenación de equipamientos mediante formulaciones cartografiables: valoración de la accesibilidad y requerimientos de la asistencia hospitalaria en la CC.AA. de la Rioja mediante la técnica de potenciales. Berceo, 141, 247-268.

Campelo, P., Izaola, A., Urrutia, V. y Zubero, (2014). Vulnerabilidades sociodemográficas en las ciudades, en I. Subirats, J. y Martí.Costa, M. (eds) Ciudades, vulnerabilidades y crisis en España. Centro de Estudios Andaluces, Consejería de Presidencia, Junta de Andalucía, 109-145.

Cazacu, V. A., Ionescu, B. G., y Tudora, D. (2016). Analyze of the population accesibility to the essential services of general interest in the historical region of moldavia. International Multidisciplinary Scientific GeoConference: SGEM: Surveying Geology \& mining Ecology Management, 3, 51-56. doi: https://doi.org/10.5593/SGEM2016/B23/S11.007

Doyle, Y., McKee, M., Rechel, B. \& Grundy, E. (2009). Meeting the challenge of population ageing. BMJ (Clinical research ed). Recuperado de http://researchonline.Ishtm.ac.uk/4658/1/Meeting\%20the\%20challenge\%20of\%20population\%20ageing_1_\%20The\%20BMJ.pdf

Falkingham, J.C., Héran, F. \& Vaupel, J.W. (2011). Europe's citizens should have a choice. Toward a new policy of life-course flexibility. Population Policy Compact. Recuperado de file:///C:/Users/usuario/Downloads/population_policy_compact_01-2011.pdf

Garrocho, C. y Campos J. (2006). Un indicador de accesibilidad a unidades de servicios clave para ciudades mexicanas: fundamentos, diseño y aplicación, Economía, Sociedad y Territorio. VI (22), 1-60.

Iglesias Souto, M.I., Real Deus, J.E., Dosil Maceira, A., Mayo Pais, M.E. y Taboada Ares, E.M. (2018). Asignación de servicios sociales a personas mayores: revisión y modelo de toma de decisiones. Cuadernos de Trabajo Social, 31 (2), $417-430$. doi: https://doi.org/10.5209/CUTS.55454

López-Roldán, P., Fachelli, S. (2016). Análisis factorial. En P. López-Roldán y S. Fachelli, Metodología de la Investigación Social Cuantitativa. Bellaterra (Cerdanyola del Vallès): Dipòsit Digital de Documents, Universitat Autònoma de Barcelona. $1^{a}$ edición, versión 3. Recuperado de http://ddd.uab.cat/record/142928

Marquet, S. y Miralles, C. (2014). La proximidad en Barcelona. Un análisis desde los tiempos de desplazamiento cotidianos. Ciudades, $17,99-120$

McCann, P. (2017). Urban futures, population ageing and demographic decline. Cambridge Journal of Regions, Economics and Society, 10, 543-557. doi: https://doi.org/10.1093/cjres/rsx009

Nieto-Masot, A., Engelmo-Moriche, A. y Cárdena-Alonso, G. (2019). La Distribución Territorial de Recursos Sanitarios y Socio-Sanitarios Públicos para Población Mayor en Extremadura. Revista de Estudios Andaluces, 37, 141-160. doi: https://doi.org/10.12795/rea.2019.i37.07

OCDE (2009). Policies for Healthy Ageing: An Overview. OECD Health Working Papers, $\mathrm{n}^{\circ} 42,32$. Recuperado de https:// www.oecd-ilibrary.org/docserver/226757488706.pdf?expires=1556653672\&id=id\&accname=guest\&checksum=2624BF4EF969EE29FC676809247F32B8 
OCDE (2012). Compact cities policies: A comparative Assessment. Paris: OCDE. Recuperado de http://www.oecd.org/ greengrowth/compact-city-policies-9789264167865-en.htm Último acceso: 21 de diciembre de 2018.

OCDE (2015a). Ageing in cities. Paris: OCDE. Recuperado de http://www.oecd.org/regional/ageing-in-cities9789264231160-en.htm Último acceso: 21 de diciembre de 2018.

OCDE (2015b). Sustainable Urban Development Policies in Ageing Societies. Paris: OCDE. Recuperado de http://www. oecd.org/governance/regional-policy/sustainable-urban-development-policies-in-ageing-societies.htm Último acceso: 21 de diciembre de 2018.

OMS (2001). Campaña de la OMS por un envejecimiento activo. OMS. Recuperado de https://www.who.int/ageing/publications/alc_elmanual.pdf?ua=1 Último acceso: 20 de diciembre de 2018.

OMS (2012). La buena salud añade vida a los años. Información general para el día mundial de la salud 2012. OMS. Recuperado de http://apps.who.int/iris/bitstream/handle/10665/75254/WHO_DCO_WHD_2012.2_spa.pdf;jsessionid=BOF995F38336DD389AE16C686DA0126B?sequence=1 Último acceso: 20 de diciembre de 2018.

OMS (2015). Informe mundial sobre el envejecimiento y la salud. OMS. Recuperado de http://apps.who.int/iris/bitstream/handle/10665/186466/9789240694873_spa.pdf?sequence=1 Último acceso: 20 de diciembre de 2018.

Pitarch-Garrido, M.D., Salom, J. y Fajardo, F. (2018). Detección de barrios vulnerables a partir de la accesibilidad a los servicios públicos de proximidad. El caso de la ciudad de Valencia. Anales de Geografía de la Universidad Complutense, 38 (1), 61-85. doi: https://doi.org/10.5209/AGUC.60469

Pitarch-Garrido, M.D. (2018). Social Sustainability in Metropolitan Areas: accessibility and Equity in the Case of the Metropolitan Area of Valencia (Spain). Sustainability, 10, 371. doi: https://doi.org/10.3390/su10020371

Roberts, K. \& Chapman, T. (2017). Elderly people as active users of health and social care. Londres: Routledge.

Rode, P., Floater, G., Thomopoulos, N., Docherty, J., Schwinger, P., Mahendra, A., \& Fang, W. (2017). Accessibility in cities: transport and urban form. In Disrupting mobility (pp. 239-273). Springer, Cham. doi: https://doi.org/10.1007/978-3319-51602-8_15

Shah, T. I., Bell, S., \& Wilson, K. (2016). Spatial accessibility to health care services: identifying under-serviced Neighbourhoods in Canadian urban areas. PloS one, 11(12). Recuperado de https://journals.plos.org/plosone/article?id=10.1371/journal.pone.0168208. https://doi.org/10.1371/journal.pone.0168208

Sancho Comíns, J. y Reinoso Moreno, D. (2012). La delimitación del ámbito rural: una cuestión clave en los programas de desarrollo rural. Estudios Geográficos, Vol. LXXIII, 273, 599-624. doi: https://doi.org/10.3989/estgeogr.201221

Silva, T., Caravau, H. \& Campelo, D. (2017). Information needs about public and social services of Portuguese elderly. En 3rd International Conference on Information and Communication Technologies for Ageing Well and e-Health. doi: 10.5220/0006284900460057.

Srichuae, S., Nitivattananon, V., \& Perera, R. (2016). Aging society in Bangkok and the factors affecting mobility of elderly in urban public spaces and transportation facilities. Iatss Research, 40 (1), 26-34. doi: https://doi.org/10.1016/j. iatssr.2015.12.004

Yanguas, J.J., Cilveti, A., Hernández, S., Pinazo, S., Roig, S. y Segura, C. (2018). El reto de la soledad en la vejez. Zerbitzuan: Gizarte zerbitzuetarako aldizkaria. Revista de servicios sociales, 66, 61-75. doi: https://doi.org/10.5569/11347147.66 .05

Yung, E. H., Conejos, S., \& Chan, E. H. (2016). Social needs of the elderly and active aging in public open spaces in urban renewal. Cities, 52, 114-122. doi: https://doi.org/10.1016/j.cities.2015.11.022

Zazzi, M., Ventura, P., Caselli, B. y Carra, M. (2018). GIS-based monitoring and evaluation system as an urban planning tool to enhance the quality of pedestrian mobility in Parma. In Town and Infrastructure Planning for Safety and Urban Quality: Proceedings of the XXIII International Conference on Living and Walking in Cities (LWC 2017). June 15-16, 2017. Brescia, Italy: CRC Press (p. 87). doi: https://doi.org/10.1201/9781351173360-14 


\title{
El Transporte Aéreo de Mercancías en los Aeropuertos Españoles: Hacia una Concentración e Internacionalización Selectivas
}

\section{The Air Freight Transport at Spanish Airports: Towards Selective Concentration and Internationalization}

\author{
Carlos López-Escolano \\ cle@unizar.es @ https://orcid.org/0000-0002-1653-7780 \\ Daniel Cruz-Alonso \\ 684072@unizar.es @ https://orcid.org/0000-0001-8264-1263 \\ Ángel Pueyo-Campos \\ apueyo@unizar.es 10 https://orcid.org/0000-0003-4103-2116 \\ Universidad de Zaragoza. Edficio Residencia de Profesores, $5^{\circ}$ Izquierda. Ciudad Universitaria \\ Campus San Francisco. C/Pedro Cerbuna 12. 50009 Zaragoza
}

\section{INFO ARTÍCULO}

Recibido: 22/12/2019

Revisado: 21/5/2019

Aceptado: 24/5/2019

PALABRAS CLAVE

Mercancías

Carga aérea

Aeropuertos

Globalización

España

\section{KEYWORDS}

Freight

Air cargo

Airports

Globalization

Spain

\section{RESUMEN}

El proceso de globalización requiere que los actores locales y regionales se incorporen en las redes y flujos económicos internacionales para lograr la competitividad y el desarrollo económico. Ello supone cambios que modifican los impactos y alcance de las infraestructuras de transporte. En el caso de la distribución de mercancías, el transporte aéreo supone un volumen reducido sobre el total de la carga internacional, donde solo unos cuantos aeropuertos centralizan la mayor parte del mismo. En España únicamente cuatro son relevantes en la gestión de carga aérea, en especial de la internacional. Esta investigación caracteriza los principales patrones de la carga aérea en los aeropuertos españoles mediante el análisis de su evolución reciente en torno a diferentes variables, evaluando algunos cambios notables que están modificando la jerarquía aérea. 


\section{INTRODUCCIÓN}

La aceleración de los procesos de globalización económica ha modificado de manera fundamental la organización de la economía global, intensificando la integración e interdependencia de la actividad económica transfronteriza (Coe, N. M., y Yeung, H. W. -C., 2015). Por ello, el transporte es un elemento fundamental para el desarrollo de la globalización a todas las escalas y en todos los ámbitos. Productores y consumidores de todo el mundo están ahora conectados mediante sistemas de transportes, logística y telecomunicaciones rápidos y eficaces que están reconfigurando las redes tradicionales de suministro y distribución (Dilian, C. D., y White, C. L., 2010). La globalización requiere así de complejos, robustos y eficaces sistemas de transporte necesarios para el intercambio global, rápido y masivo de personas y mercancías (Gago García, 2002); así como para facilitar el rápido crecimiento de algunas economías; asegurar los modelos productivos descentralizados, externalizados y deslocalizados; concentrar rentas; desarrollar la logística o fomentar el comercio electrónico (Rodrigue, J. P. et al., 2017; Sales, M., 2017).

Estas transformaciones conllevan importantes efectos en la escena internacional, pero también en espacios locales y, lógicamente, en las políticas de transporte. En este contexto, el transporte como factor de competitividad obliga a ciudades y territorios a buscar estrategias para incorporarse en las redes globales de distribución y suministro. Aunque factores tradicionales como la situación siguen siendo fundamentales (Savy, M., 2004) para la nueva red mundial de transporte de mercancías, la seguridad jurídica, la agilidad aduanera, la accesibilidad y la conectividad que otorgan los actuales medios de gestión y de transporte son determinantes importantes para mantener bajo control los costes del transporte internacional (Tovar B., et al., 2015). Ubicaciones centrales e intermedias se identifican como cualidades espaciales que mejoran los niveles de tráfico de los centros de transporte y, por lo tanto, indican qué lugares se ubican estratégicamente dentro de los sistemas de transporte globales o regionales (Fleming, D. K., y Hayuth, Y., 1994). Por lo tanto, interesa analizar y comprender la organización de los nodos y conexiones del sistema de transporte para desarrollar una adecuada planificación de las actividades económicas y de las infraestructuras.

Las grandes distancias que la globalización impone entre espacios productores y espacios consumidores suponen que los principales flujos internacionales de mercancías sean asumidos por el transporte marítimo gracias a su elevada capacidad y bajo coste. La jerarquía portuaria tradicional mundial se está modificando sin embargo aceleradamente por el rápido crecimiento de los puertos asiáticos (Akhavan, M., 2017), relegando a los puertos europeos y norteamericanos a posiciones intermedias, aunque fundamentales. Por su parte, el transporte terrestre es esencial y predomina la distribución en escalas regionales y de proximidad, en especial el modo carretero sobre el ferroviario. Además, en los próximos años cabrá prestar especial atención al impacto del reparto de "última milla" en los entornos urbanos (Lim, S. F. W. T., et al., 2018). Mientras, el transporte aéreo de carga supone una parte poco significativa sobre el total de los desplazamientos de mercancías a pesar de su papel estratégico en el comercio internacional (Yamaguchi, K., 2008), por ser determinante en sectores con alto valor añadido (Morrell, P. S., 2011; Sales, M., 2017) y/o que requieren una distribución inmediata (Lotti, R., y Caetano, M., 2018). Impulsado por el auge del comercio electrónico (Boeing, 2017), se prevén durante los próximos veinte años crecimientos anuales medios del volumen de mercancías transportadas por avión de un 4,2\% y un aumento del número de aviones de carga del $70 \%$.

De este modo, el transporte aéreo puede entenderse como una práctica que permite valorar los procesos de interconectividad que acontecen en el orden global (Córdoba Ordóñez, J. A., y Gago García, C., 2012; Gago García, C., y Córdoba Ordóñez, J. A., 2013). A pesar de su interés estratégico, las investigaciones realizadas sobre este último modo a nivel internacional se centran mayoritariamente en el análisis de la estructura y flujos de las redes de transporte aéreo de mercancías (Hui, G. W. L., et al., 2004; Matsumoto, H., 2004; Fung, M. K. Y., et al., 2005; Derudder, B. et al., 2008; Dang, Y. R., y Peng, L. N., 2012; Mayer, R., 2016; Sales, M., 2017; Gong, Q. et al., 2018; Suwanwong, T. et al., 2018); así como en el estudio de casos para las terminales aeroportuarias (Zhang, A., 2003; Hwang, C. C., y Shiao, G. C., 2011; Hesse, M., 2014; Walcott, S. M., y Fan, Z., 2017), 
en especial para determinados productos y mercancías (Lotti, R., y Caetano, M., 2018) o empresas (Bowen Jr., J. T., 2012; Balliauw, M. et al., 2018).

En el caso español, la literatura existente sobre esta temática es ciertamente reducida (López, C., et al., 2015), contrastando con la mayor variedad de las investigaciones que abordan los desplazamientos aéreos de pasajeros y los que analizan las terminales aeroportuarias (Antón, F. J. et al., 1994; Rey, M. B., 2003; Martí-Henneberg, J. et al., 2007; Tapiador, F. J. et al., 2008; Escalona, A. I., y Ramos, D., 2010; Suau-Sánchez, P., y Burghouwt, G., 2011; Jiménez, J. L., y Betancor, O., 2012; Ramos, D. et al., 2013; Martín, J. C. et al., 2014; Díez, R. et al., 2016).

Por su interés para el desarrollo económico es importante que planificadores y otros actores involucrados comprendan los cambios en las redes aéreas globales ante el papel que estas pueden desempeñar para una ciudad o región en cuanto a su integración y gestión de la capacidad aérea (Wong, W. H. et al., 2019), así como por su posicionamiento y jerarquía (Derudder, B. et al., 2008; Matsumoto, H., 2004), o el impulso a las actividades logísticas y económicas de sus entornos. De este modo, determinados lugares están configurando una red que concentra actividades y que cada vez se encuentra más desconectada de sus entornos inmediatos (Gago García, C., y Córdoba Ordóñez, J. A., 2013) por la nueva concepción flexidimensional de los espacios geográficos (Pueyo, Á. et al., 2018) que refuerza los lazos de los territorios en distintas escalas y temporalidades.

En este contexto, este trabajo avanza en la interpretación de los flujos de transporte aéreo de mercancías con el objetivo de valorar la inserción de los aeropuertos españoles en las redes globales de distribución. Para ello, se caracteriza la evolución reciente y las especificidades de las conexiones de las redes de carga aérea reflexionando, a su vez, sobre su interés estratégico por las implicaciones socioeconómicas y territoriales en la planificación de infraestructuras. Aun considerando el enfoque de tipo descriptivo de este trabajo, se valora sin embargo el interés de una aportación que contextualice este ámbito en España por la importancia para la competitividad económica actual y futura de muchos de sus territorios.

Revisado el contexto e interés de la investigación, el resto del trabajo se organiza del siguiente modo: el apartado segundo expone las características y la jerarquía global actual del sistema de carga aérea; la sección tercera describe las características de la zona de estudio, los datos y métodos empleados; la sección cuarta muestra los resultados obtenidos; la sección quinta sirve como discusión del trabajo; y por último la sección sexta recoge las principales conclusiones.

\section{JERARQUÍA GLOBAL DE LA CARGA AÉREA}

Como se ha comentado en el apartado anterior, el transporte aéreo de mercancías supone un modo minoritario sobre el volumen total de la carga transportada en el mundo, si bien su valor económico hace que sea un modo estratégico. El volumen de mercancías transportadas por avión muestra un incremento constante durante los últimos años (figura 1) aunque ralentizado desde 2011 por el exiguo crecimiento del comercio mundial, pero con previsiones que apuntan a un crecimiento medio anual del 4,2\% (Boeing, 2017). En 2016 se transportaron por vía aérea un total de 54.932 .000 t, un 4,4\% más que el año anterior (IATA, 2017). Este crecimiento va a conllevar importantes efectos sobre la industria aeronáutica, como el aumento previsto del número de aviones de carga en torno al $70 \%$ durante los próximos veinte años, ayudado por el empuje del comercio electrónico (Boeing, 2017), pero también en las terminales aeroportuarias y en las zonas de actividades logísticas asociadas (Verhetsel, A. et al., 2015).

La distribución aérea de mercancías se concentra en una selección de flujos principales donde un número reducido de aeropuertos actúa como nodos centrales del sistema (Guimerà, R., y Amaral, L. A. N., 2004). En este sentido, el $86,3 \%$ de las mercancías globales transportadas por vía aérea en 2016 pasó por los veinte principales aeropuertos (tabla 1), mostrando la elevada concentración del sector.

Estos aeropuertos (tabla 1) actúan como hubs conectores y redistribuidores de mercancías al igual que sucede con los tráficos de pasajeros (O’Kelly, 1998; Bryan, D. L., y O’Kelly, M. E., 1999). Su localización, bien sea 


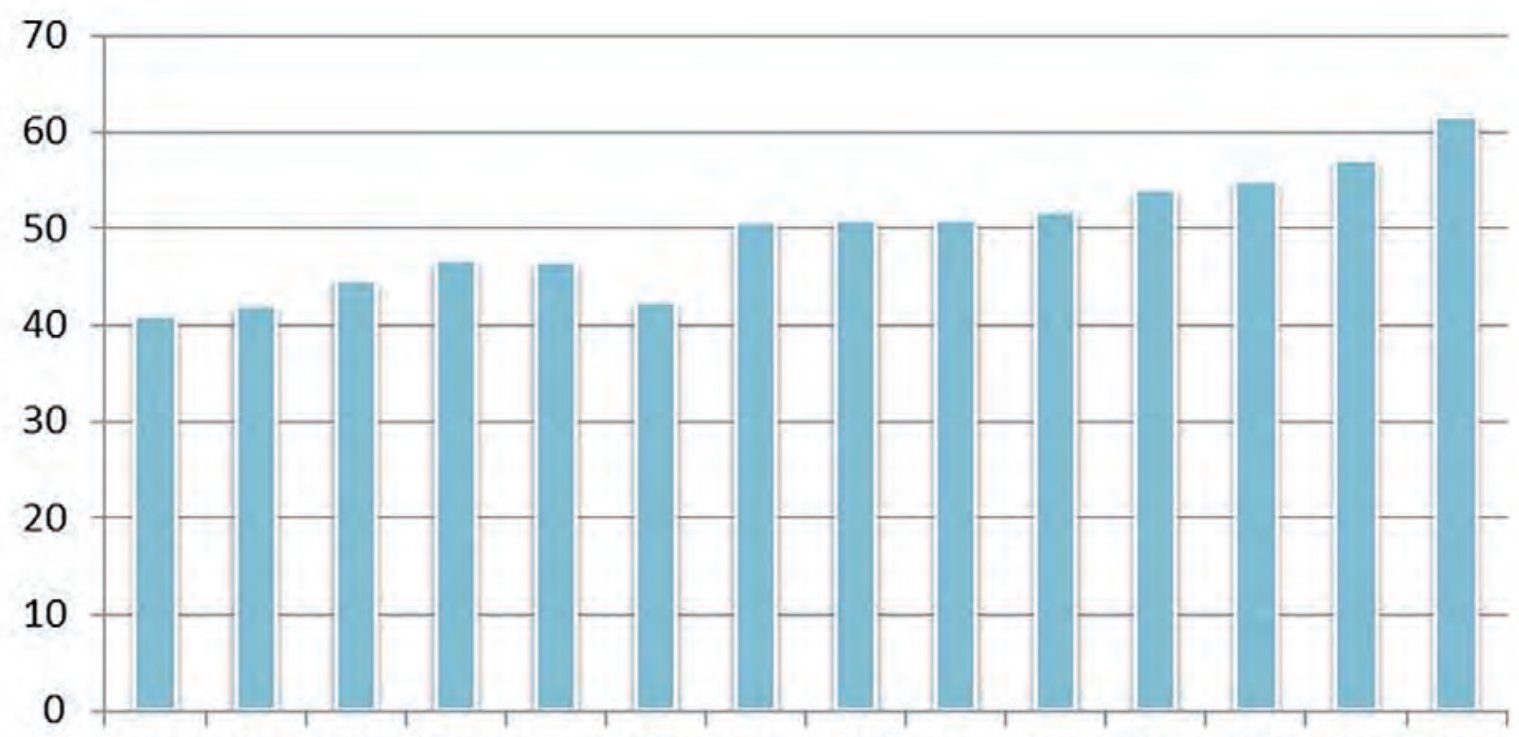

20042005200620072008200920102011201220132014201520162017

Volumen (millones t métricas)

Figura 1. Evolución de la carga aérea global, 2004-2017.

Fuente: Statista, 2018. Elaboración propia, 2018.

central o intermedia en el sistema global (Fleming, D. K., y Hayuth, Y., 1994), coincide con espacios estratégicos ubicados dentro de la cadena global de producción, suministro, logística e intermodalidad (Savy, M., 2004). La mayor parte de estos aeropuertos son a su vez hubs globales para el tráfico de pasajeros, como Hong Kong, Shanghai, Dubai, Tokyo-Narita o París-Charles de Gaulle, entre otros; aunque sin embargo las necesidades especiales que requiere el transporte de carga aérea (Mayer, R., 2016) supone que algunos aeropuertos que no presentan especial interés para el tráfico de pasajeros y no se encuentren en áreas geográficas centrales se están configurando como nodos óptimos para el transporte de mercancías (Behrens, K., 2007) en un papel de terminales intermediarias. Así, destacan los aeropuertos de Memphis, Anchorage o Louisville.

Por su parte, los aeropuertos de la Unión Europea (UE-28) gestionaron un total de 15.179.000 de toneladas de mercancías en 2016 (Eurostat, 2018), de las cuales un 94,1\% pasaron por alguno de los veinte principales aeropuertos europeos (tabla 2). Estas terminales presentan un papel global para la cadena de distribución de mercancías atendiendo al tipo de conexión de sus flujos y al volumen gestionado. La mayor parte de estos aeropuertos son también importantes hubs para el tráfico de pasajeros, como París-Charles de Gaulle, Frankfurt, Ámsterdam-Schipol, Londres-Heathrow, Bruselas, Madrid-Barajas o Munich, entre otros. Otra categoría de aeropuertos la conforman aquellos especializados en mercancías y que, en cambio, no son tan relevantes respecto al tráfico de pasajeros, como Leipzig-Halle, Luxemburgo o Colonia-Bonn. Una tercera categoría sería la de aquellos aeropuertos que están altamente especializados en el tráfico de mercancías, como Lieja o East Midlands.

La gestión del transporte de carga aérea se concentra también en unas cuantas empresas o aerolíneas, como se muestra en la tabla 3. En general, las bases centrales de estas operadoras coinciden con los principales aeropuertos de carga aérea, exceptuando United Parcel Service (UPS) que tiene su sede en Atlanta, ciudad cuyo aeropuerto no figura entre los principales para el manejo de mercancías pero que sin embargo ocupa el primer puesto global en número de pasajeros. 
Tabla 1. Principales aeropuertos de carga aérea en el mundo en 2016.

\begin{tabular}{|c|c|c|c|}
\hline Puesto & Aeropuerto (Código) & Estado & Volumen (t) \\
\hline 1 & Hong Kong (HKG) & China (Hong Kong) & 4.615 .241 \\
\hline 2 & Memphis (MEM) & Estados Unidos & 4.322 .071 \\
\hline 3 & Shanghai (PVG) & China & 3.440 .280 \\
\hline 4 & Incheon (ICN) & Corea del Sur & 2.714 .341 \\
\hline 5 & Dubai (DXB) & Emiratos Árabes Unidos & 2.592 .454 \\
\hline 6 & Anchorage (ANC) & Estados Unidos & 2.542 .526 \\
\hline 7 & Louisville (SDF) & Estados Unidos & 2.437 .010 \\
\hline 8 & Tokyo-Narita (NRT) & Japón & 2.165 .427 \\
\hline 9 & Paris-Charles de Gaulle (CDG) & Francia & 2.135 .172 \\
\hline 10 & Frankfurt-Main (FRA) & Alemania & 2.113 .594 \\
\hline 11 & Taipei (TPE) & Taiwán & 2.097 .228 \\
\hline 12 & Miami (MIA) & Estados Unidos & 2.014 .205 \\
\hline 13 & Singapore (SIN) & Singapur & 2.006 .300 \\
\hline 14 & Los Angeles (LAX) & Estados Unidos & 1.993 .308 \\
\hline 15 & Beijing (PEK) & China & 1.943 .159 \\
\hline 16 & Doha (DOH) & Qatar & 1.758 .074 \\
\hline 17 & Amsterdam-Schipol (AMS) & Países Bajos & 1.694 .729 \\
\hline 18 & Guangzhou (CAN) & China & 1.652 .215 \\
\hline 19 & London-Heathrow (LHR) & Reino Unido & 1.640 .400 \\
\hline 20 & Chicago-O'Hare (ORD) & Estados Unidos & 1.528 .136 \\
\hline
\end{tabular}

Fuente: Airports Council International, 2018. Elaboración propia, 2018.

Tabla 2. Principales aeropuertos de carga aérea en la Unión Europea en 2016.

\begin{tabular}{|c|l|l|c|}
\hline Puesto & \multicolumn{1}{|c|}{ Aeropuerto (CODIGO) } & Estado & Volumen (t) \\
\hline 1 & Paris-Charles de Gaulle (CDG) & Francia & 2.211 .265 \\
\hline 2 & Frankfurt-Main (FRA) & Alemania & 2.111 .358 \\
\hline 3 & Ámsterdam-Schipol (AMS) & Países Bajos & 1.771 .106 \\
\hline 4 & London-Heathrow (LHR) & Reino Unido & 1.637 .582 \\
\hline 5 & Leipzig-Halle & Alemania & 1.044 .952 \\
\hline 6 & Luxembourg & Luxemburgo & 801.058 \\
\hline 7 & Köln-Bonn & Alemania & 768.138 \\
\hline 8 & Liège & Bélgica & 592.146 \\
\hline
\end{tabular}




\begin{tabular}{|c|l|l|c|}
\hline Puesto & \multicolumn{1}{|c|}{ Aeropuerto (CODIGO) } & Estado & Volumen (t) \\
\hline 9 & Milano-Malpensa & Italia & 548.765 \\
\hline 10 & Brussels & Bélgica & 472.710 \\
\hline 11 & Madrid-Barajas & España & 404.284 \\
\hline 12 & München & Alemania & 353.495 \\
\hline 13 & East Midlands & Reino Unido & 319.609 \\
\hline 14 & London-Stansted & Reino Unido & 245.658 \\
\hline 15 & Wien-Schwechat & Austria & 216.382 \\
\hline 16 & Kobnehavn-Kastrup & Dinamarca & 185.691 \\
\hline 17 & Helsinki-Vantaa & Finlandia & 182.198 \\
\hline 18 & Roma-Fiumicino & Italia & 160.904 \\
\hline 19 & Dublin & Irlanda & 134.207 \\
\hline 20 & Bergamo-Orio al Serio & Italia & 117.660 \\
\hline
\end{tabular}

Fuente: Eurostat. Elaboración propia, 2018.

Tabla 3. Liderazgo de líneas aéreas en la carga aérea global en 2017. Movimientos nacionales e internacionales.

\begin{tabular}{|c|c|c|c|c|}
\hline Puesto empresa & Empresa & $\begin{array}{c}\text { Volumen } \\
\text { (millones t por km) }\end{array}$ & Sede (Estado) & Puesto aeropuerto \\
\hline 1 & FedEx & 16.851 & $\begin{array}{l}\text { Memphis } \\
\text { (Estados Unidos) }\end{array}$ & $2^{\circ}$ (global) \\
\hline 2 & Emirates & 12.715 & $\begin{array}{l}\text { Dubai } \\
\text { (Emiratos Árabes } \\
\text { Unidos) }\end{array}$ & $5^{\circ}$ (global) \\
\hline 3 & UPS & 11.940 & $\begin{array}{l}\text { Atlanta (Estados } \\
\text { Unidos) }\end{array}$ & $\begin{array}{l}1^{\circ} \text { pasajeros } \\
\text { (global) }\end{array}$ \\
\hline 4 & Qatar Airways & 10.999 & Doha (Qatar) & $16^{\circ}$ (global) \\
\hline 5 & Cathay Pacific Airways & 10.772 & $\begin{array}{l}\text { Hong Kong } \\
\text { (China, Hong Kong) }\end{array}$ & $1^{\circ}$ (global) \\
\hline 6 & Korean Air & 8.015 & $\begin{array}{l}\text { Seúl -Incheon- } \\
\text { (Corea del Sur) }\end{array}$ & $4^{\circ}$ (global) \\
\hline 7 & Cargolux & 7.322 & Luxemburgo & $6^{\circ}(\mathrm{EU}-28)$ \\
\hline 8 & Lufthansa & 7.317 & $\begin{array}{l}\text { Colonia/Frankfurt } \\
\text { (Alemania) }\end{array}$ & $\begin{array}{l}7^{\circ} \text { (UE-28)/ } \\
10^{\circ} \text { (global) } \\
\text { y } 2^{\circ}(\text { EU-28) }\end{array}$ \\
\hline 9 & Air Chine & 6.701 & Beijing (China) & $15^{\circ}$ (global) \\
\hline 10 & Singapore Airlines & 6.592 & Singapore (Singapur) & $13^{\circ}$ (global) \\
\hline
\end{tabular}

Fuente: Statista, 2018. Elaboración propia, 2018. 


\section{DATOS Y MÉTODOS}

Extrapolando este análisis a las características básicas del sistema aeroportuario español, en primer lugar, cabe destacar que el sistema aeroportuario español está configurado por una red de 52 aeropuertos de muy diferxentes características (figura 2). La mayor parte de se engloba en la empresa pública Aeropuertos Españoles y Navegación Aérea (Aena)' ${ }^{1}$ que gestiona 46 terminales y dos helipuertos, y que suponen la mayor parte del tráfico de pasajeros y mercancías. Aunque todas las Comunidades Autónomas disponen al menos de alguna terminal aérea, no todos los aeropuertos mantienen vuelos regulares o estacionales para viajeros y/o carga aérea (Pueyo, Á., et al., 2017). Por su parte, doce provincias no disponen de instalaciones aeroportuarias.

La red de Aena se complementa con otros aeropuertos gestionados por otras administraciones o sociedades, que no han sido considerados en este estudio. Se trata de los aeropuertos de Lleida-Alguaire y Andorra-la Seu d'Urgell (gestionados por Aeroports de Catalunya), Castellón (Aerocas), y Teruel (Consorcio del Aeropuerto de Teruel). Por su parte, el aeropuerto de Ciudad Real (Ciudad Real International Airport) no presta actualmente ningún servicio aéreo, si bien se espera que lo haga próximamente orientado al mantenimiento de aeronaves y a la carga aérea.

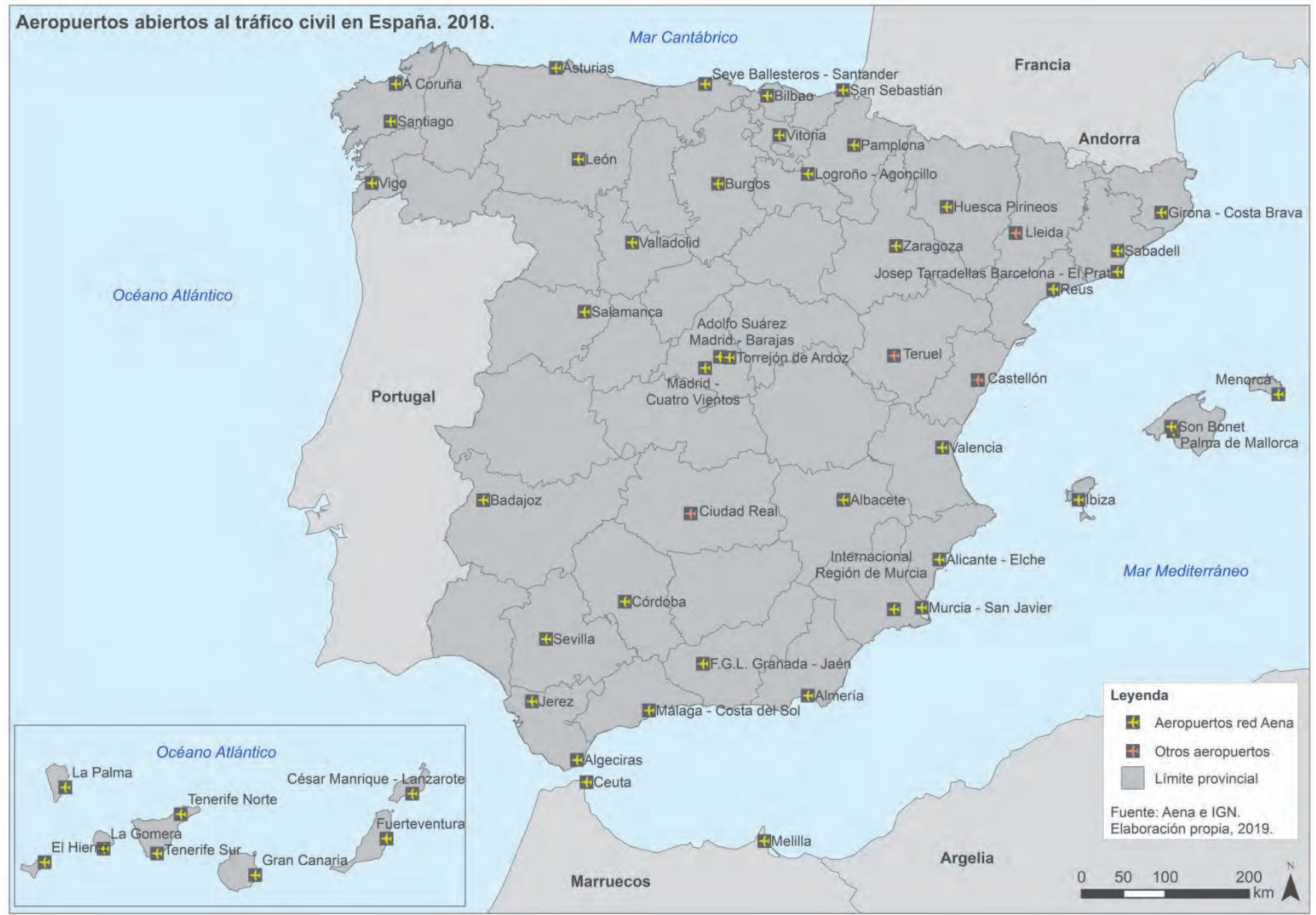

Figura 2. Mapa de aeropuertos abiertos al tráfico civil en España. Fuente: Instituto Geográfico Nacional, 2016. 
Para analizar la situación y evolución de la carga aérea en el sistema de aeropuertos españoles se ha obtenido información del servicio estadístico de Aena $^{2}$. Se han considerado como variables el volumen total de carga gestionada (2000-2017) y el número de conexiones internacionales (a nivel de país) existentes (20042017). Con esta información se ha creado una base de datos que facilita el análisis de:

1. La evolución del volumen de carga aérea total gestionada por la red Aena para el periodo 2000-2017.

2. La variación en el número de conexiones internacionales atendiendo al número de países con origen/ destino de carga aérea en cada aeropuerto de la red Aena para el periodo 2004-2017.

3. La evolución de la carga según el origen/destino por volumen: nacional, Unión Europea, resto de Europa, internacional (excluyendo a los países de la Unión Europea y del resto de Europa).

\section{RESULTADOS}

\subsection{Evolución del volumen de carga aérea}

Para ilustrar la evolución del sector de la carga aérea en España en los últimos años cabe mencionar que el incremento en el volumen gestionado por el conjunto de aeropuertos de la red Aena entre los años 2000 y 2017 ha sido de un 48,6\%, pasando de 617.808 t en el año 2000 a 918.305 t en 2017 (figura 3). A pesar de esta tendencia positiva, se observa como entre los años 2000 y 2008 la situación se mostró estable, apreciándose en 2009 el mayor descenso de la serie consecuencia de la Gran Recesión. Desde este año, el volumen de carga se recupera, con especial intensidad a partir de 2014. Por su parte, el peso de las mercancías transportadas entre aeropuertos españoles y otros países aumenta de forma considerable impulsado por la internacionalización de la economía española, mientras que desciende el total del volumen intercambiado entre aeropuertos españoles.

En este contexto, debe mencionarse que el número de aeropuertos que operan mercancías se ha reducido de 39 en el año 2000 a 34 en 2017, aunque en el mismo periodo el número de aeropuertos operados por Aena aumentó de 42 a 48 (incluidos los helipuertos de Ceuta y Algeciras). En la figura 4 se aprecia la evolución de los cuatro principales aeropuertos de carga aérea (base 2017) que en el transcurso del periodo de estudio han pasado de gestionar el 71,1\% en el año 2000 al 90,3\% en 2017. Esta jerarquía la componen los aeropuertos de Madrid, Barcelona, Zaragoza y Vitoria en 2017, aunque en los años iniciales Gran Canaria ocupaba el lugar de Zaragoza.

El aeropuerto que mayor peso tiene en el conjunto del sistema es Adolfo Suárez-Madrid Barajas, con el $51,3 \%$ del total del volumen de carga en 2017, cifra que mantiene sin grandes cambios desde el año 2000 (50,3\%). A cierta distancia se sitúa Barcelona-El Prat, aeropuerto que ha aumento su peso en el sistema al pasar del 14,4\% en el año 2000 al 17\% del volumen total en 2017. Ambos aeropuertos se benefician de ser los principales hubs nacionales e internacionales para el tráfico de pasajeros, lo que supone poder aprovechar determinados vuelos, como los de largo radio, para la carga simultánea de mercancías. Además, ambas ciudades son plataformas naturales para la actividad logística y de distribución de mercancías para el resto del Estado, además de atender amplios hinterlands, zonas industriales y espacios densamente poblados. El aeropuerto de El Prat se encuentra junto al puerto de Barcelona y la Zona Franca; mientras que Barajas se ubica en el corredor del Henares, espacio industrial y especializado en empresas de servicios logísticos y de transporte.

A continuación, se ubican dos aeropuertos del valle del Ebro, Zaragoza con el 15,5\% del volumen total, y Vitoria-Gasteiz con el 6,6\%. En el caso de Zaragoza la evolución ha sido muy significativa, pues en el año 2000 apenas pasaba por su terminal el $0,6 \%$ de la carga total. Por su parte, Vitoria-Gasteiz ha mejorado modestamente sus datos en este periodo. Se trata de dos aeropuertos con escasa relevancia en el tráfico de pasajeros, pero especializados en la operación de vuelos de carga gracias a su situación estratégica y a la excelente accesibilidad terrestre. En las inmediaciones de ambos aeropuertos han surgido en los últimos años espacios e instalaciones dedicadas a la actividad logística, como PlaZa en Zaragoza o Arasur en Vitoria-Gasteiz, que aprovechan las excelentes instalaciones de intercambio modal tren-avión-carretera en áreas

2. Aena estadísticas: <http://www.aena.es/csee/Satellite?pagename=Estadisticas/Home>. 


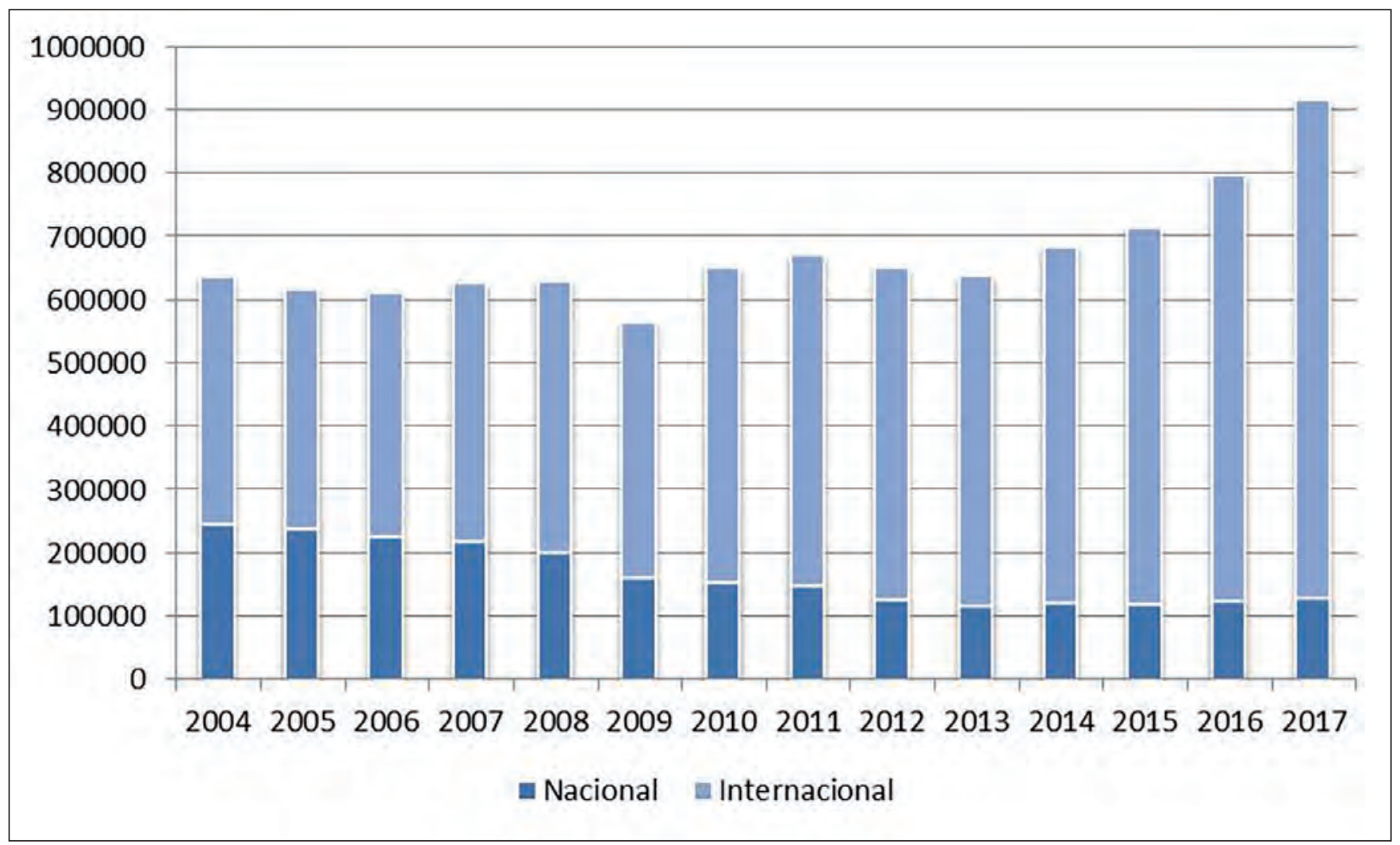

Figura 3. Evolución de las mercancías aéreas en España según tráfico nacional e internacional, 2000-2017. Fuente: Aena, 2018. Elaboración propia, 2018.

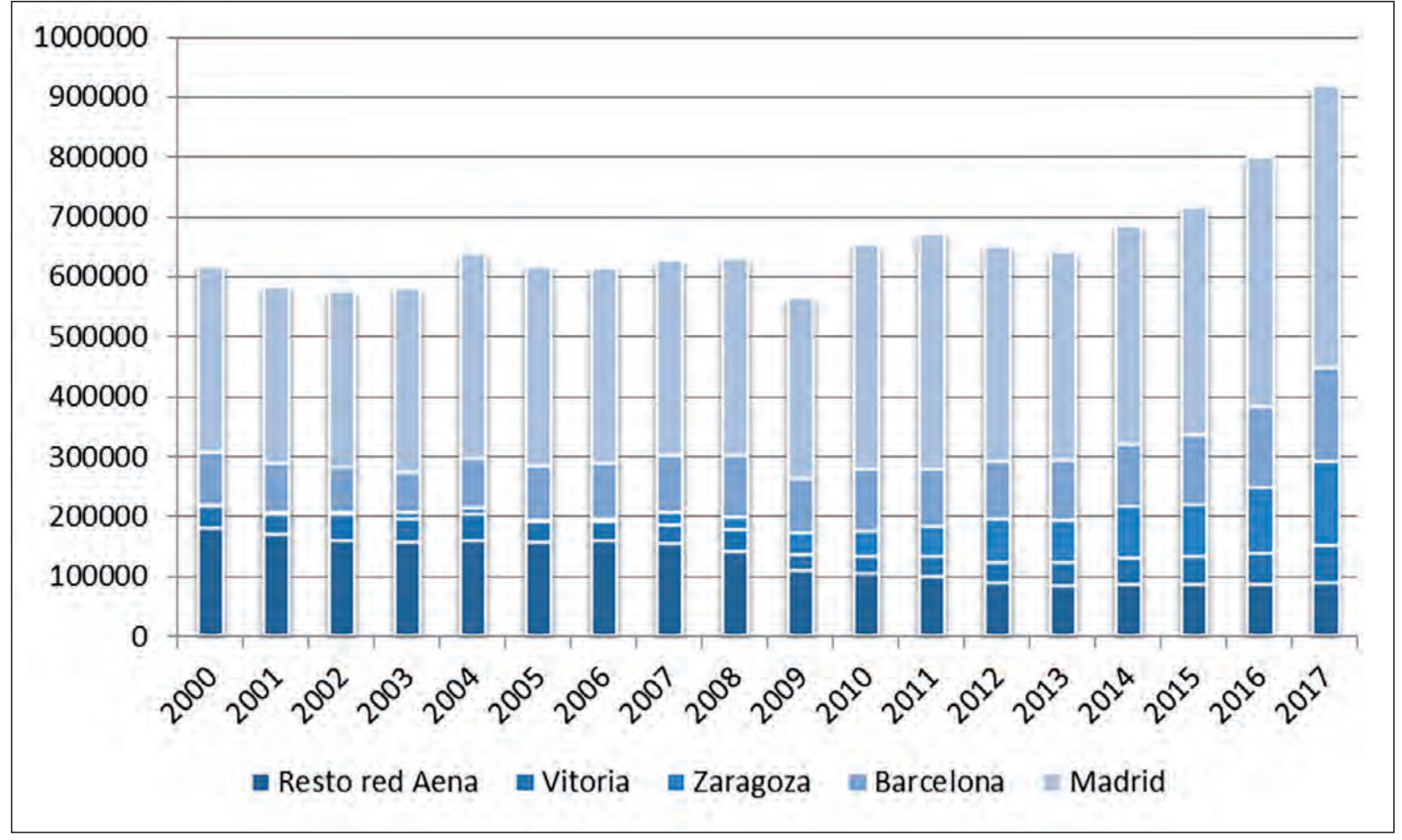

Figura 4. Evolución de las mercancías aéreas en España por aeropuertos, 2000-2017. Fuente: Aena, 2018. Elaboración propia, 2018. 
poco congestionadas. Además, Zaragoza aprovecha su renta de situación en el cuadrante nororiental de la península Ibérica, mientras Vitoria-Gasteiz lo hace en el norte peninsular.

Como se observa en la tabla 4, los veinte principales aeropuertos para la carga aérea de mercancías (que suponen el 99,5\% del total el volumen en 2004 y el 99,9\% en 2017) se mantienen sin la irrupción de otros que escalen posiciones durante el periodo analizado. Sin embargo, sí se aprecian variaciones internas, en especial en la parte media-alta de la clasificación. Madrid $\left(1^{\circ}\right)$ y Barcelona $\left(2^{\circ}\right)$ no han variado sus posiciones en la jerarquía, mientras que Vitoria-Gasteiz ha perdido una ( $3^{\circ}$ en 2004 y $4^{\circ}$ en 2017). En 2004 eran los principales aeropuertos insulares los que ocupaban las siguientes posiciones (Gran Canaria, Tenerife-Norte, Palma de Mallorca, Lanzarote, Ibiza, Menorca, Fuerteventura, La Palma) y otros en ciudades principales (Valencia, Zaragoza, Málaga, Alicante-Elche, Sevilla, Santiago, Bilbao, Vigo). Su evolución hasta 2017 muestra que todos ellos pierden un volumen significativo respecto a 2004, exceptuando Zaragoza, Valencia y Sevilla. Se territorializa de este modo el cambio del modelo de transporte aéreo en España motivado por el aumento de las exportaciones en los últimos años ${ }^{3}$ que beneficia especialmente a espacios como Zaragoza o Vitoria-Gasteiz.

De este modo, Adolfo Suárez-Madrid Barajas y Barcelona-El Prat mantienen su jerarquía y peso, mostrando cierta falta de capacidad para crecer en el segmento del transporte de mercancías, lo cual conlleva a una desconcentración de las operaciones mediante una diversificación hacia instalaciones intermedias (especialmente Zaragoza y en menor grado Vitoria-Gasteiz), provocada por los efectos de falta de espacio logístico en las inmediaciones de Barajas y El Prat así como por la mayor saturación de sus instalaciones por vuelos de pasajeros. Además de estos cuatro aeropuertos principales, destaca el comportamiento del aeropuerto de Sevilla que, aunque operó tan solo el 1,2\% del total en 2017, ha duplicado el volumen de carga, mejorando cinco puestos en la jerarquía y erigiéndose como el principal aeropuerto de carga del sur peninsular por delante de Málaga-Costa del Sol (principal aeropuerto andaluz para el tráfico de pasajeros).

En la situación opuesta (pérdida de volumen gestionado, de representatividad y de jerarquía) destacan los aeropuertos insulares, tanto del archipiélago canario como del balear. En conjunto, los aeropuertos de Canarias (Gran Canaria, Tenerife-Norte, Tenerife-Sur, Lanzarote, Fuerteventura y La Palma -los de El Hierro y La Gomera no entran en los veinte primeros puestos-) han pasado de operar conjuntamente el 13,7\% de las mercancías al 4,1\% en 2017. Por su parte, los aeropuertos de Baleares (Palma de Mallorca, Menorca e Ibiza -se excluye Son Bonet-) operaban en 2004 el 4,5\% del total, mientras que han gestionado un 1,5\% en 2017. Aunque el auge de algunos aeropuertos peninsulares, por su vocación exportadora, esté provocando la pérdida de representatividad de los aeropuertos insulares, cabe profundizar en el futuro sobre las causas del importante descenso en el volumen gestionado por estas terminales ante las necesidades específicas de suministro propias a su condición de insularidad.

\subsection{Variación del número de conexiones internacionales}

La organización de la carga aérea presenta una diversidad de orígenes y destinos que ha evolucionado de distinta manera e intensidad (figura 5 y tabla 6). Entre 2004 y 2017 no hubo variaciones significativas ya que el número de países con intercambio de mercancías ha aumentado de 93 a 103, y el número de aeropuertos ha disminuido de 382 a 374 en el conjunto de la red Aena. Se observa así una tendencia positiva a la internacionalización de los destinos con un leve aumento que, no obstante, es variable entre cada año, pero sin que ello implique la existencia de una red más amplia de aeropuertos conectados. Ello constataría por lo tanto un proceso de optimización y especialización de las terminales aeroportuarias de carga, respondiendo a los cambios en los modelos de organización y gestión de las aerolíneas y empresas logísticas siguiendo los patrones de la red global, así como de la mayor apertura de la economía española tras la Gran Recesión mediante la búsqueda de mercados fuera de su espacio habitual.

Existen sin embargo matices entre los cuatro aeropuertos principales. Por países, todos excepto Vitoria-Gasteiz han incrementado el número de orígenes/destinos, destacando especialmente el aumento de

3. ICEX: <https://www.icex.es/icex/es/Navegacion-zona-contacto/revista-el-exportador/en-cifras/index.html\#seccion3> 
Tabla 4. Principales aeropuertos de carga aérea en España en 2004 y 2017 según volumen gestionado. Base 2017.

\begin{tabular}{|c|c|c|c|c|c|}
\hline \multirow{2}{*}{ Aeropuerto } & \multicolumn{2}{|c|}{2004} & \multicolumn{2}{|c|}{2017} & \multirow{2}{*}{$\begin{array}{l}\text { Diferencia volumen (\%) } \\
\text { 2004-2017 }\end{array}$} \\
\hline & Volumen (t) & Puesto & Volumen (t) & Puesto & \\
\hline Adolfo Suárez-Madrid Barajas & 341.177 & 1 & 470.796 & 1 & $38,0 \%$ \\
\hline Barcelona-El Prat & 84.985 & 2 & 156.105 & 2 & $83,7 \%$ \\
\hline Vitoria-Gasteiz & 43.683 & 3 & 60.484 & 4 & $38,7 \%$ \\
\hline Gran Canaria & 40.935 & 4 & 18.045 & 5 & $-55,9 \%$ \\
\hline Tenerife-Norte & 23.647 & 5 & 13.044 & 7 & $-44,8 \%$ \\
\hline Palma de Mallorca & 20.408 & 6 & 10.191 & 9 & $-50,1 \%$ \\
\hline Valencia & 12.169 & 7 & 13.126 & 6 & $7,9 \%$ \\
\hline Tenerife Sur & 9.218 & 8 & 2.797 & 12 & $-69,7 \%$ \\
\hline Zaragoza & 9.160 & 9 & 142.185 & 3 & $1.452,2 \%$ \\
\hline Lanzarote & 7.997 & 10 & 1.825 & 15 & $-77,2 \%$ \\
\hline Málaga-Costa del Sol & 6.811 & 11 & 2.867 & 11 & $-57,9 \%$ \\
\hline Alicante-Elche & 6.037 & 12 & 5.366 & 10 & $-11,1 \%$ \\
\hline Sevilla-San Pablo & 5.053 & 13 & 10.709 & 8 & $111,9 \%$ \\
\hline Santiago de Compostela & 4.939 & 14 & 2.693 & 13 & $-45,5 \%$ \\
\hline Ibiza & 4.510 & 15 & 1.747 & 16 & $-61,3 \%$ \\
\hline Bilbao & 4.153 & 16 & 1.956 & 14 & $-52,9 \%$ \\
\hline Menorca & 3.975 & 17 & 1.474 & 17 & $-62,9 \%$ \\
\hline Fuerteventura & 3.640 & 18 & 947 & 18 & $-74,0 \%$ \\
\hline La Palma & 1.502 & 19 & 617 & 20 & $-58,9 \%$ \\
\hline Vigo-Peinador & 1.030 & 20 & 771 & 19 & $-25,1 \%$ \\
\hline
\end{tabular}

Fuente: Aena, 2018. Elaboración propia.

Zaragoza. Madrid ostenta el mayor nivel de internacionalización, seguido de Barcelona, Zaragoza y Vitoria-Gasteiz.

Respecto al número de aeropuertos en conexión (tabla 5) destaca Madrid, que muestra una estabilidad en esta variable donde decrece el número de conexiones nacionales y aumentan las internacionales; Barcelona pierde conexiones nacionales; Zaragoza casi triplica el número de aeropuertos internacionales conectados; y Vitoria-Gasteiz pierde de forma evidente conexiones nacionales e internacionales por su alta especialización en torno a una serie de destinos específicos. 


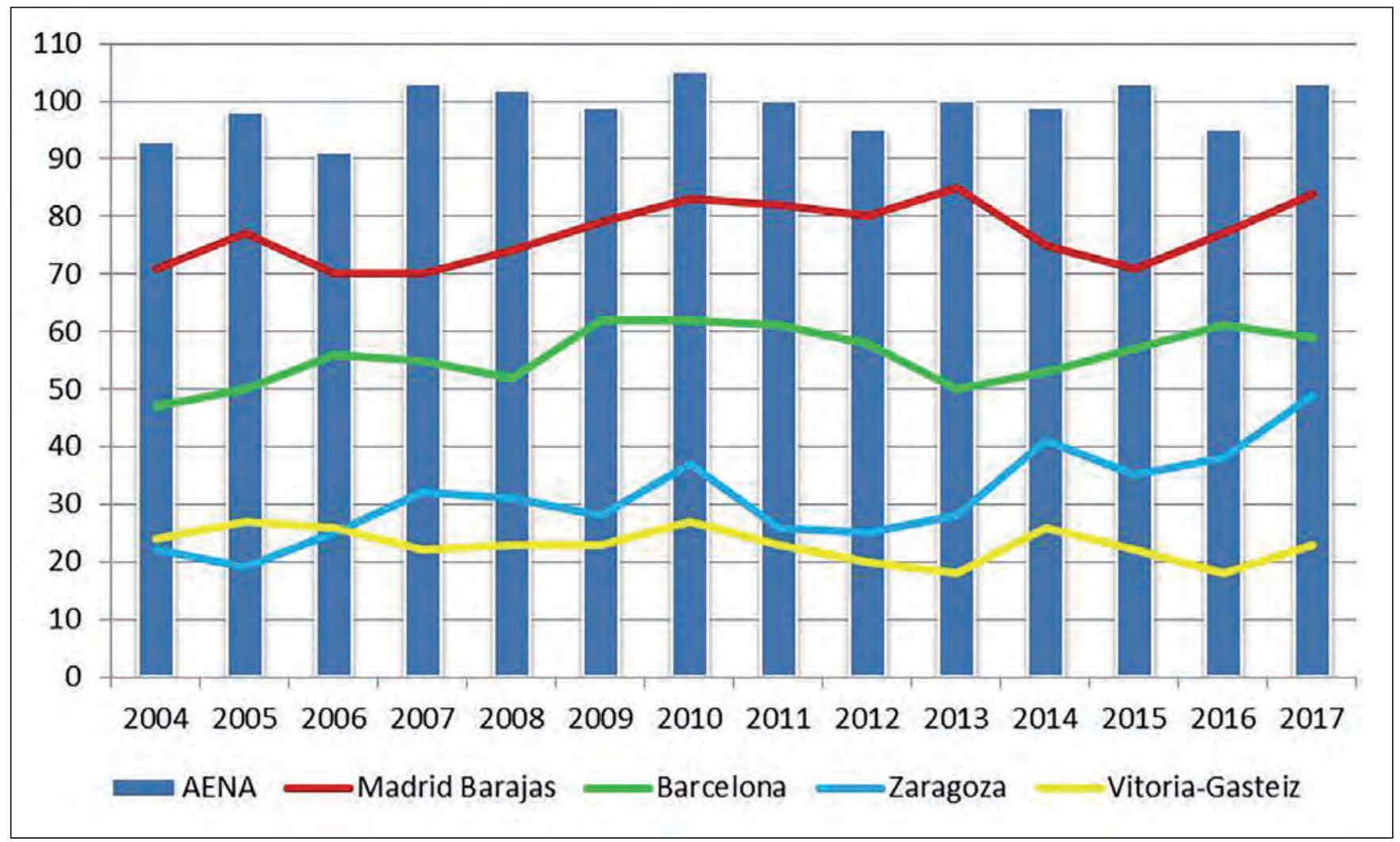

Figura 5. Evolución del número de conexiones internacionales (países) en los cuatro principales aeropuertos de carga aérea por volumen, y en el conjunto de la red Aena, 2004-2017.

Fuente: Aena, 2018. Elaboración propia.

Tabla 5. Evolución del número de conexiones internacionales (aeropuertos) en los cuatro principales aeropuertos de carga aérea por volumen, 2004-2017. Base 2017.

\begin{tabular}{|l|c|c|c|c|c|c|c|}
\hline \multicolumn{1}{|c|}{ Aeropuerto } & \multicolumn{3}{|c|}{2004} & \multicolumn{2}{c|}{$\begin{array}{c}2017 \\
\text { Diferencia número de } \\
\text { conexiones totales (\%) } \\
2004-2017\end{array}$} \\
\cline { 2 - 8 } & Nacional & Internacional & Total & Nacional & Internacional & Total & \\
\hline $\begin{array}{l}\text { Adolfo Suárez-Madrid } \\
\text { Barajas }\end{array}$ & 36 & 166 & 202 & 30 & 174 & 204 & $1,0 \%$ \\
\hline Barcelona-El Prat & 33 & 137 & 170 & 27 & 138 & 165 & $-2,9 \%$ \\
\hline Zaragoza & 9 & 38 & 47 & 7 & 100 & 107 & $127,7 \%$ \\
\hline Vitoria-Gasteiz & 12 & 68 & 80 & 7 & 41 & 48 & $-40,0 \%$ \\
\hline $\begin{array}{l}\text { Conjunto de la red } \\
\text { Aena }\end{array}$ & 45 & 337 & 382 & 39 & 335 & 374 & $-2,1 \%$ \\
\hline
\end{tabular}

Fuente: Aena, 2018. Elaboración propia.

\subsection{Evolución de la carga según origen/destino}

Por último, se presentan los resultados atendiendo al origen/destino de la carga de acuerdo a su ámbito geográfico: nacional, países de la Unión Europea, resto de países europeos, resto de países (internacional). En el conjunto del sistema, y como se ha visto en la figura 3, aumenta de forma importante el volumen, así como el porcentaje de la carga internacional en detrimento de la nacional. El análisis de estas tendencias muestra la orientación y especialización tomada por cada uno de los aeropuertos que priman la red (figuras 6, 7, 8 y 9): 


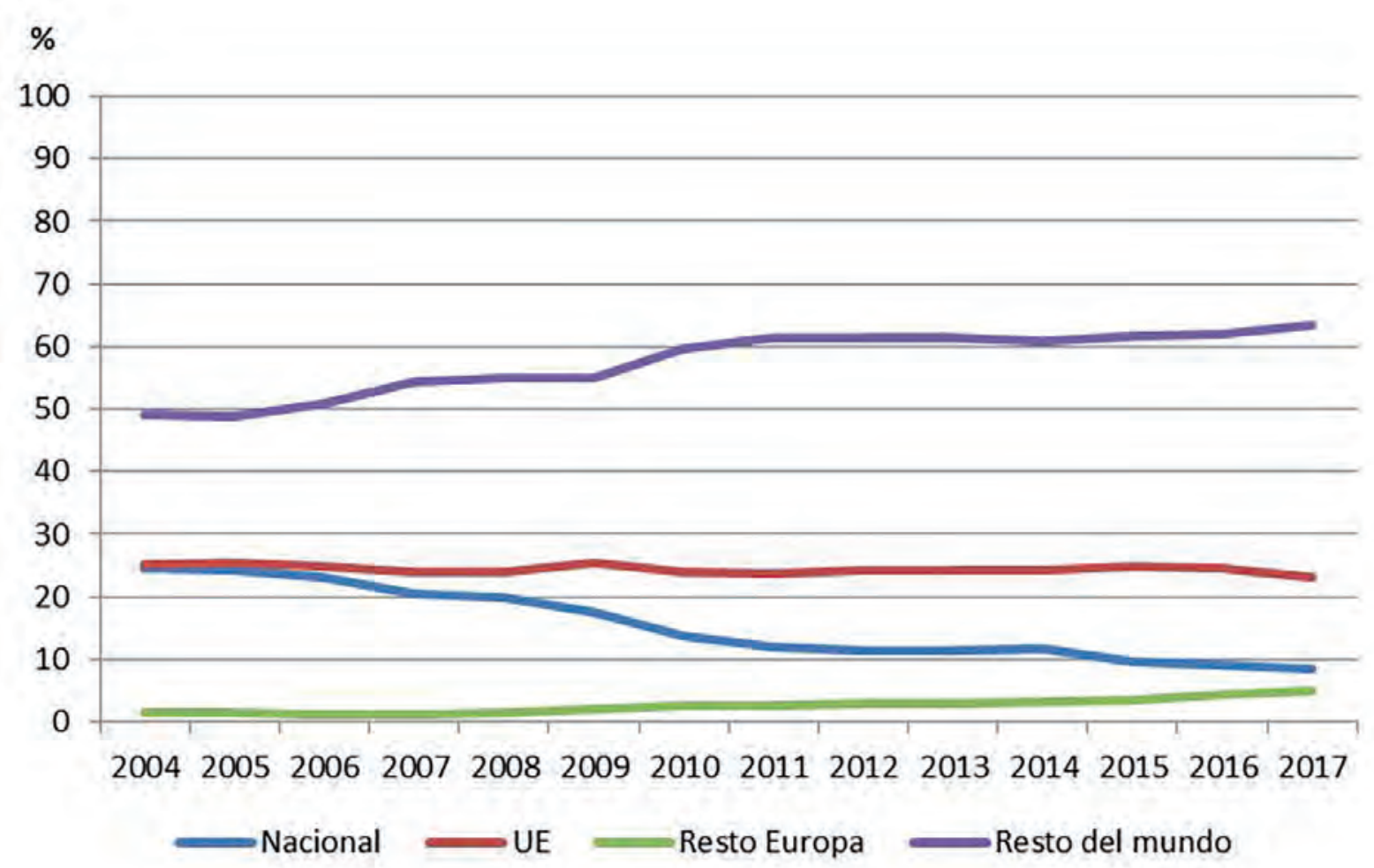

Figura 6. Evolución del tráfico por orígenes/destinos de Adolfo Suárez-Madrid Barajas, 2004-2017. Fuente: Aena, 2018. Elaboración propia.

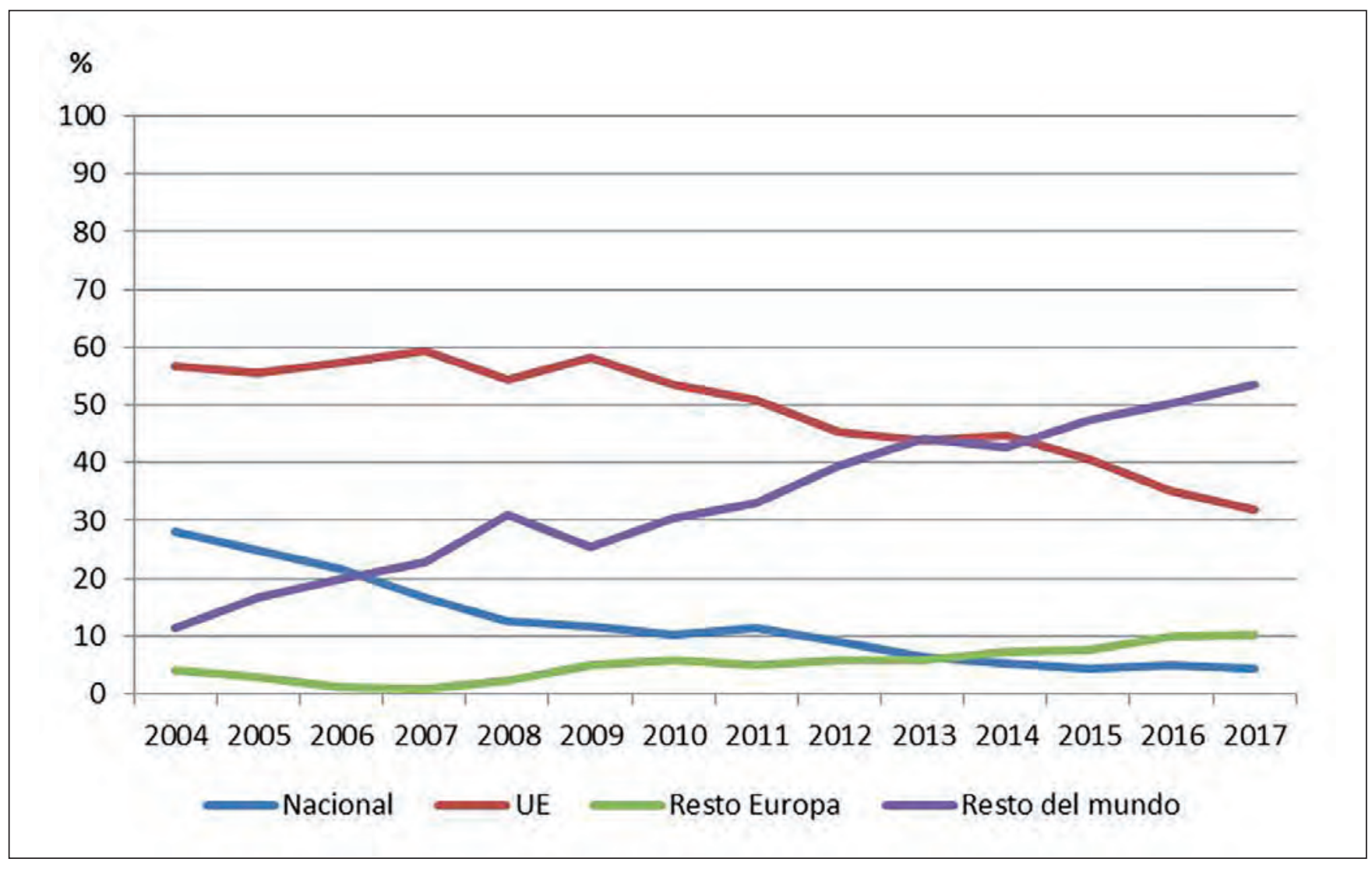

Figura 7. Evolución del tráfico por orígenes/destinos de Barcelona-El Prat, 2004-2017. Fuente: Aena, 2018. Elaboración propia. 


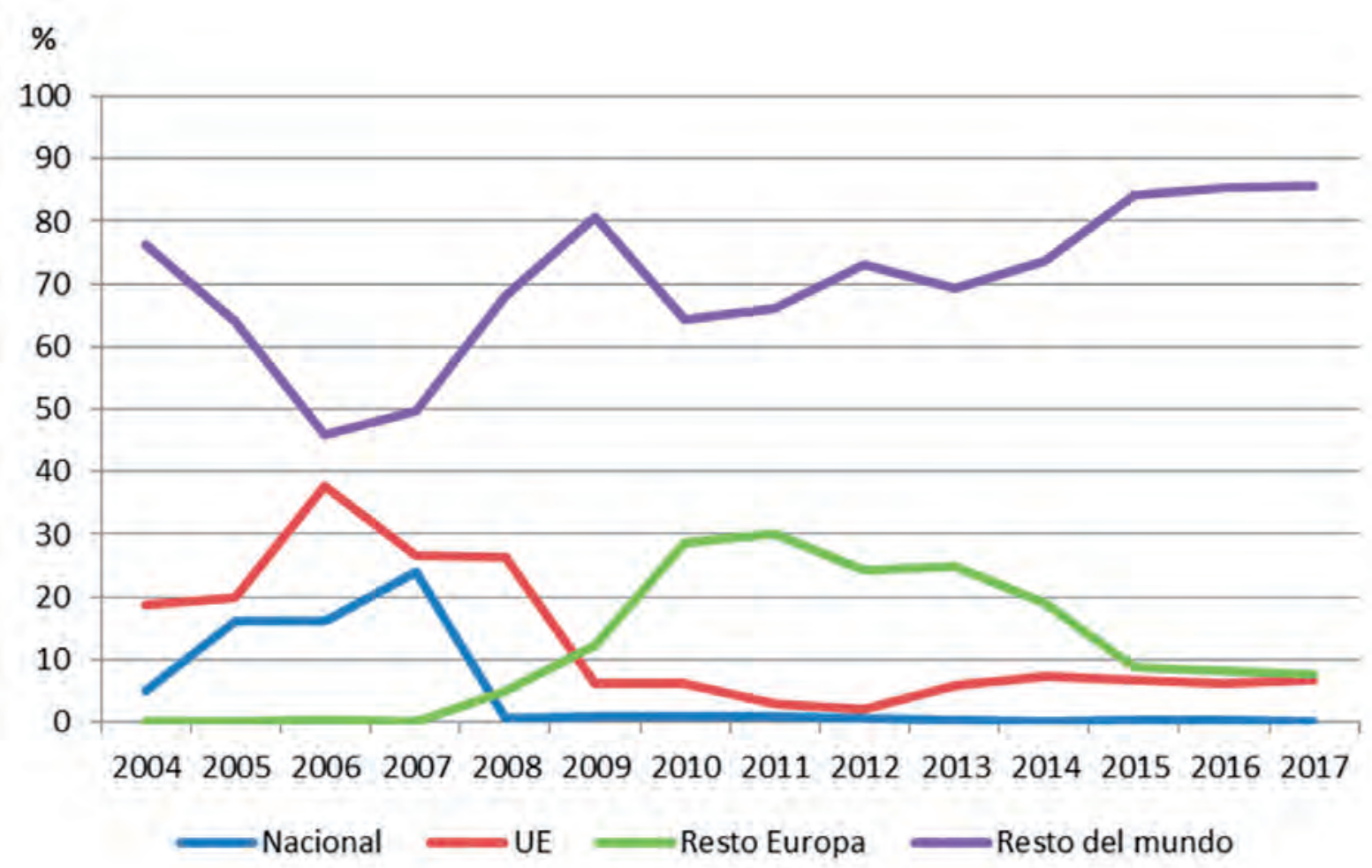

Figura 8. Evolución del tráfico por orígenes/destinos de Zaragoza, 2004-2017. Fuente: Aena, 2018. Elaboración propia.

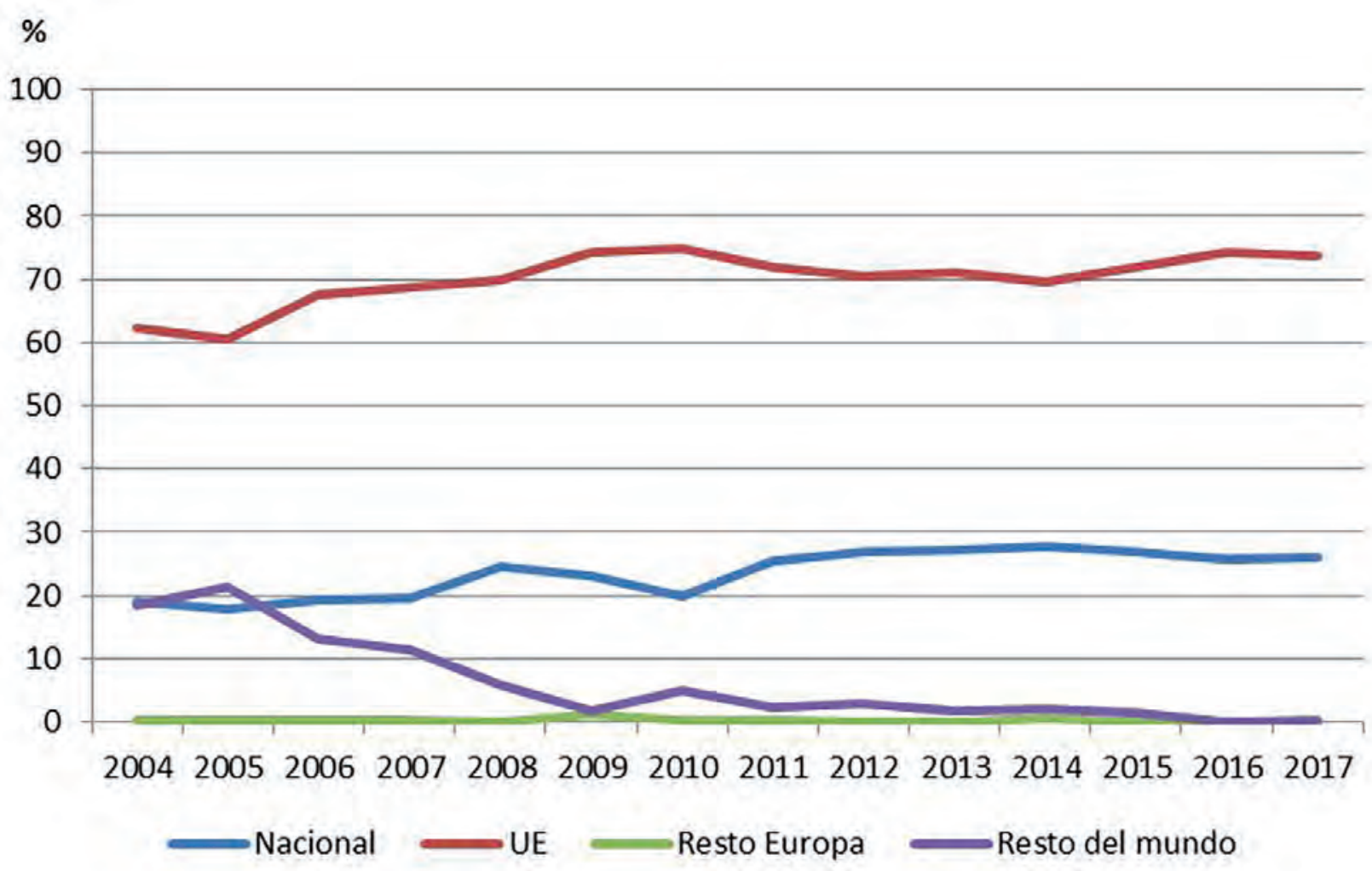

Figura 9. Evolución del tráfico por orígenes/destinos de Vitoria-Gasteiz, 2004-2017. Fuente: Aena, 2018. Elaboración propia. 
1. La carga entre aeropuertos españoles decrece de forma significativa, siendo representativos Madrid, Barcelona y Vitoria-Gasteiz. En los dos primeros la pérdida es relevante, mientras que Vitoria-Gasteiz aumenta levemente su porcentaje de carga destino a otros aeropuertos de la red Aena. Zaragoza pierde prácticamente todas las conexiones nacionales.

2. El intercambio con los países de la Unión Europea se mantiene estable en Madrid y Vitoria-Gasteiz, mientras que pierde peso en Barcelona y Zaragoza.

3. En los desplazamientos con otros aeropuertos europeos que no pertenecen a países de la Unión Europea Madrid y Barcelona aumentan levemente mientras que en Vitoria-Gasteiz son muy poco significativos, y Zaragoza pierde este tipo de conexiones a pesar de que suponían casi una tercera parte de sus conexiones.

4. Por último, los intercambios con aeropuertos de otros continentes crecen en Madrid, aumentan de forma muy significativa en Zaragoza y Barcelona, y desaparecen en Vitoria-Gasteiz.

\section{DISCUSIÓN}

De acuerdo a los resultados obtenidos, y aun considerando su carácter descriptivo, es posible deducir diferentes patrones en los aeropuertos españoles de especial interés para la planificación de sus infraestructuras y de los impactos espaciales y económicos en los próximos años. Se deduce así que los aeropuertos españoles están siguiendo un proceso de concentración en la gestión de la carga aérea paralelo al esquema global, como sugieren otras investigaciones (Sales, M., 2017; Wong, W. H. et al., 2019) donde determinadas ciudades o regiones jerarquizan los flujos globales (Smith, D. A. y Timberlake, M. F., 2001) y se especializan en una economía de logística compleja que responde a los nuevos modelos de la economía mundial.

Además, esta tendencia se ha acentuado tras la Gran Recesión, momento a partir del cual los procesos económicos globales se han reconfigurado afectando especialmente al sector del transporte (Pueyo, Á. y Hernández, M. L., 2013). Cabe destacar además que, a pesar del incremento de la carga total gestionada, las mercancías transportadas entre aeropuertos españoles mantienen una tendencia negativa mientras que aumentan de forma importante los volúmenes hacia y desde el exterior, en especial con países fuera de la Unión Europea, lo que constata el incremento de los flujos de comercio internacional más allá del espacio económico europeo. Para ello, Madrid y Barcelona se presentan como principales nodos entre el sistema global y el internacional al aprovechar su infraestructura y las conexiones de largo radio de pasajeros.

Sin embargo, y a partir de la análisis realizado, cabe reflexionar sobre el papel que están adquiriendo otros nodos intermedios, a los cuales se les puede dar tráfico adicional si son favorecidos por los transportistas como centros de conexión o puntos de retransmisión en el sistema (Fleming, D. K. y Hayuth, Y., 1994). Así, si bien la mayoría de los estudios existentes en este campo incluyen solo las características geoeconómicas de los aeropuertos y sus zonas de influencia como variables explicativas, algunos estudios desarrollan modelos que incorporan más factores que podrían influir en los flujos internacionales de carga aérea operados en los aeropuertos (Hwang, C. C. y Shiao, G. C., 2011; Gong, Q. et al., 2018), evidenciando el papel de los operadores y aerolíneas en sus sistemas de optimización de costes (Bowen Jr., J. T., 2012; Balliauw, M. et al., 2018), en la ubicación de empresas intermediadoras (empresas logísticas, espacios para actividades de transportes, operadores y empresas de provisión de servicios mediante redes digitales, etc.), y en la accesibilidad e intermodalidad con otros medios de transporte más competitivos para la distribución final. Además, esta lógica refuerza el papel de ciertos espacios que ya cuentan con modelos maduros, con fuertes inversiones, con posibilidades de capitalización y jurídicamente seguros para el comercio internacional, lo que restringe y potencia algunos de los espacios ya conocidos e impide su desarrollo en otras zonas de Asia o África.

Asimismo, en la escena internacional se está valorando el papel de los grandes aeropuertos de pasajeros, en muchas ocasiones saturados. En este sentido, son evidentes los casos de éxito de Vitoria-Gasteiz y de 
Zaragoza en España (frente a las instalaciones más concurridas de Madrid y Barcelona), replicando modelos internacionales (a distinta escala e intensidad) como Sharjah y Al-Maktoum en Emiratos Árabes Unidos; Damman en Arabia Saudí; Navoi en Uzbekistán; Zengzhou en China; o Memphis, Louisville y Anchorage en Estados Unidos, entre otros.

La creciente demanda global y las necesidades de especialización e integración de la actividad logística ha llevado, por ejemplo, a posicionar el aeropuerto de Zaragoza como nodo prioritario para el intercambio de mercancías en España, incorporado ahora dentro la cadena global de suministro gracias al desarrollo de una estrategia que combina factores de accesibilidad, logística, calidad, costes ajustados, telecomunicaciones y especialización en la gestión de mercancías textiles (Escalona, A. I., y Ramos, D., 2014). Sobre estas características, cabe añadir su posición intermedia entre Madrid y Barcelona, y en el corredor Cantábrico-Mediterráneo, lo que le otorga un gran potencial para determinados sectores que han de redistribuirse posteriormente. De igual manera, Vitoria aprovecha unas características semejantes, aunque su desarrollo ha sido más débil en los últimos años ya que su especialización en los intercambios nacionales y con otros países europeos le ha restado el potencial de crecimiento que los intercambios internacionales ofrecen, como sucede con el caso de Zaragoza.

De este modo, se constata un desarrollo interesante en los últimos años para determinados sectores y terminales que aprovechan la mejora y expansión de las infraestructuras aeroportuarias (Serrano, J. M., y García, R., 2015), posible gracias a la fuerte inversión en los años previos a la crisis (Pueyo, Á. et al., 2017), así como a la paulatina conversión de la península Ibérica en un hub estratégico para las relaciones entre Europa y América Latina que aprovecha los crecientes lazos con África y Asia.

Por su parte, el aumento del volumen total transportado desde o hacia España contrasta con un incremente mínimo del número de países y un descenso de los aeropuertos con intercambios aéreos en vuelos directos de mercancías, lo cual mostraría la configuración de una red internacional de hubs especializados en carga aérea siguiendo el patrón de los flujos de pasajeros (Bryan, D. L. y O'Kelly, M. E., 1999). Asimismo, a nivel interno el número de instalaciones que gestionaban carga en el año 2000 era mayor al actual a pesar de aumentar el número de aeropuertos integrados en la red Aena. Ambas situaciones sugieren una respuesta del modelo socioeconómico a los procesos globales eficaz para demandas cada vez más diversificadas y ubicuas, que exigen un aumento de la movilidad auspiciado en gran medida por el auge del comercio electrónico, una logística de último kilómetro muy eficiente, y las nuevas pautas de consumo rápidas y flexibles. Por ello, la especialización y el crecimiento de estas terminales de carga sólo es posible si existe una mejora de accesibilidad con el resto de modos de transporte para dar una salida o suministro rápido a las mercancías operadas en los aeropuertos. En ello, el desarrollo de la actividad logística como pieza fundamental para el intercambio global de flujos (Verhetsel, A. et al., 2015) está incidiendo en estos cambios, lo que lleva a la reflexión sobre cómo la configuración de las redes aéreas globales está imponiendo un nuevo modelo de accesibilidad y reorganización territorial que recompone el esquema tradicional de dependencia derivada de localización y distancia (Antón, F. J., 2013).

Todo ello está conllevando importantes impactos territoriales como el desarrollo de espacios logísticos, industriales y terciarios que, sin embargo, todavía no han alcanzado en España el desarrollo de otros espacios globales (Hesse, M., 2014; Al-Mehairi, J. M., 2016). Así, el factor de localización sigue siendo determinante para alcanzar grandes volúmenes de operaciones (Hesse, M., 2014; Al-Mehairi, J. M., 2016), por lo que es necesario dotarse de infraestructuras y servicios, profundizando asimismo en la investigación de las interrelaciones socioeconómicas e impactos territoriales que genera el transporte aéreo de mercancías (Graham, A., 2005; Escalona, A. I., y Ramos, D., 2010; Mayer, R., 2016). Específicamente, en el caso de España el desarrollo de la actividad logística requiere una planificación integrada entre las infraestructuras de transporte y el desarrollo de los usos del suelo que solucione eficientemente las nuevas demandas y necesidades (López, C., 2017). En especial, respecto a los retos que supone el auge del comercio electrónico, que está conllevando una reordenación de las cadenas y modos de gestión de distribución de las mercancías que presenta sus propios efectos locales, como la multiplicación de áreas destinadas a la gestión logística (Hesse, M. y Rodrigue, J. P., 2004). 


\section{CONCLUSIONES}

Este trabajo ha presentado un análisis sobre la evolución reciente de la gestión de carga aérea en los aeropuertos españoles. Los resultados han permitido vislumbrar cómo el volumen de carga aérea en España ha aumentado de forma importante tras la crisis económica en 2008 y, al mismo tiempo, cómo la actividad se ha concentrado en un número menor de aeropuertos. Ello muestra la especialización de determinadas instalaciones que se apoya en la reconfiguración en el modelo logístico y de distribución de las mercancías transportadas por vía aérea, replicando el modelo existente en el conjunto del sistema aéreo global y europeo.

De este modo, la organización internacional actual de la carga aérea ha influido sobre el sistema aeroportuario español, reconfigurando la jerarquía aeroportuaria. En la actualidad, la funcionalidad del sistema de carga aérea se encuentra extremadamente polarizada en cuatro aeropuertos que concentraron en 2017 más del 90\% del volumen total. Estos son Madrid, Barcelona, Zaragoza y Vitoria-Gasteiz. Específicamente, Adolfo Suárez-Madrid-Barajas se ha consolidado como nodo global de carga aérea con origen/destino nacional e internacional, mientras que Barcelona-El Prat mantiene una segunda posición con un papel menos relevante con una orientación internacional. Ambos tienen pendiente la ampliación y mejora de capacidad mediante nuevos planes directores que incluyen la creación de espacio logístico y de servicios, por lo que cabe estar atentos a si estas inversiones conducirán más si cabe a una concentración mayor en torno a ambos aeropuertos. Además, debe destacarse la irrupción del aeropuerto de Zaragoza hasta la tercera posición (con unos valores muy próximos a Barcelona en 2017), gracias al desarrollo de un modelo de gestión logística, especialización sectorial en distribución de carga aérea textil, y aprovechando su estratégica situación en el centro del cuadrante nororiental de la península Ibérica donde se concentra la mayor parte del PIB y del tejido industrial y de servicios; apoyado en una excelente accesibilidad con otros modos de transporte. Vitoria-Gasteiz mantiene un peso todavía relevante sobre el conjunto, aunque su orientación hacia conexiones de medio alcance le está restando posibilidades para alcanzar los grandes volúmenes propios de la carga aérea intercontinental.

Consecuentemente, en los próximos años la previsión de crecimiento de la demanda de transporte aéreo de mercancías va a requerir la ampliación de terminales y la construcción de nuevas instalaciones especializadas, la presencia de plataformas multimodales, modelos automatizados, sistemas de distribución mediante inteligencia artificial y el desarrollo de sistemas de gestión en tiempo real que permitan ubicuidad, adaptabilidad y flexibilidad total. Ello muestra un desafío para gobiernos y empresas en un momento en el que la hibridación físico-digital y la automatización de todos los procesos de las cadenas productivas y de distribución supondrán nuevos escenarios y retos para los territorios tanto en las escalas globales como locales en un escenario flexidimensional en el que la mano de obra clásica será suplantada por otras formas de cooperación hombre-máquina-sistemas inteligentes. Sin embargo, estos procesos mejorarán y optimizarán el modelo de organización de las grandes empresas de transporte, complementando un modelo de hubs globales reducidos sobre los que pivotan el grueso de la distribución de mercancías en el contexto de un sistema de distribución sumamente flexible.

\section{REFERENCIAS}

Aeropuertos Españoles y Navegación Aérea (2018). Recuperado de http://www.aena.es/csee/Satellite?pagename=Estadisticas/Home Último acceso: 10 de octubre de 2018.

Akhavan, M. (2017). Evolution of hub port-cities into global logistics centres. International Journal of Transport Economics, 44 (1), 25-47. doi: 10.19272/201706701002

Al-Mehairi, J. M. (2016). Dubai's geographic location and its advantages for the air transportation industry. Arab World Geographer, 19 (3-4), 352-367. doi: https://doi.org/10.5555/i1480-6800.19.3.352

Antón Burgos, F. J., y Córdoba y Ordóñez, J. A. (1994). La liberalización del transporte aéreo en España. Boletín de la Asociación de Geógrafos Españoles, 19, 113-132. 
Antón Burgos, F. J. (2013). Redes de transporte, articulación territorial y desarrollo regional. Revista de Estudios Andaluces 30, 27-47. doi: http://dx.doi.org/10.12795/rea.2013.i30.02

Balliauw, M., Meersman, H., Onghena, E. \& Van de Voorde, E. (2018). "US all-cargo carriers" cost structure and efficiency: A stochastic frontier analysis. Transportation Research Part A: Policy and Practice, 112, 29-45. doi: https://doi. org/10.1016/j.tra.2018.01.005

Behrens, K. (2007). On the location and lock-in of cities: Geography vs transportation technology. Regional Science and Urban Economics, 37, 22-45. doi: https://doi.org/10.1016/j.regsciurbeco.2006.04.003

Boeing (2017). World Air Cargo Forecast 2016-2017. Recuperado de http://www.boeing.com/resources/boeingdotcom/ commercial/about-our-market/cargo-market-detail-wacf/download-report/assets/pdfs/wacf.pdf Último acceso: 05 de octubre de 2018.

Bowen Jr., J. T. (2012). A spatial analysis of FedEx and UPS: Hubs, spokes, and network structure. Journal of Transport Geography, 24, 419-431. doi: https://doi.org/10.1016/j.jtrangeo.2012.04.017

Bryan, D. L. \& O'Kelly, M. E. (1999). Hub-and-spoke networks in air transportation: An analytical review. Journal of Regional Science, 39 (2), 275-295. doi: https://doi.org/10.1111/1467-9787.00134

Coe, N. M. \& Yeung, H. W. -c. (2015). Global production networks: Theorizing economic development in an interconnected world. Oxford: Oxford University Press. doi: https://doi.org/10.1093/acprof:oso/9780198703907.001.0001

Córdoba Ordóñez, J. A. y Gago García, C. (2012). Globalización, movilidad y análisis de conectividad aérea: Una herramienta para la práctica interdisciplinar. Revista de Antropología Social, 21 (1), 117-146. doi: http://dx.doi.org/10.5209/ rev_RASO.2012.v21.40052

Dang, Y. R. \& Peng, L. N. (2012). Hierarchy of air freight transportation network based on centrality measure of complex networks. Jiaotong Yunshu Xitong Gongcheng Yu Xinxi/ Journal of Transportation Systems Engineering and Information Technology, 12 (3), 109-114. doi: https://doi.org/10.1016/S1570-6672(11)60207-9

Derudder, B., Witlox, F., Faulconbridge, J. \& Beaverstock, J. (2008). Airline networks and urban systems (Editorial). GeoJournal 71 (1), 1-3. doi: https://doi.org/10.1007/s10708-008-9151-y

Díez Pisonero, R., Gago García, C., y Córdoba Ordóñez, J. A. (2016). Los aeropuertos de la globalización. Espectacularización y teatralización de la infraestructura como herramienta de citymarketing. Boletín de la Asociación de Geógrafos Españoles 72, 221-247. doi: http://dx.doi.org/10.21138/bage.2338

Dilian, C. D. \& White C. L. (eds.) (2010). Trade and Exchange: Archaeological Studies from History and Prehistory. Springer.

Escalona Orcao, A. I. y Ramos Pérez, D. (2010). Geografía productiva y flujos internacionales de transporte: el crecimiento de la carga aérea en el aeropuerto de Zaragoza. Anales de Geografía de la Universidad Complutense, 30 (2), $59-80$. Recuperado de http://revistas.ucm.es/index.php/AGUC/article/view/AGUC1010220059A/30703

Escalona Orcao, A. I. y Ramos Pérez, D. (2014). Global production chains in the fast fashion sector, transports and logistics: the case of the Spanish retailer Inditex. Investigaciones Geográficas, Boletín del Instituto de Geografía, 85, 113127. doi: https://doi.org/10.14350/rig.40002

Eurostat (2016). Recuperado de http://ec.europa.eu/eurostat/statistics-explained/index.php?title=File:Top-20_airports_ in_the_EU-28_in_terms_of_total_freight_and_mail_loaded_unloaded_in_2016.png Último acceso: 20 de octubre de 2018.

Fleming, D. K. \& Hayuth, Y. (1994). Spatial characteristics of transportation hubs: centrality and intermediacy. Journal of Transport Geography, 2 (1), 3-18. doi: https://doi.org/10.1016/0966-6923(94)90030-2

Fung, M. K. Y., Zhang, A., Leung, L. C. K. \& Law, J. S. (2005). The air cargo industry in China: Implications of globalization and WTO accession. Transportation Journal, 44 (4), 44-62.

Gago García, C. (2002). Estructura geo-económica mundial, globalización y flujos comerciales. Estudios geográficos, 63 (246), 143-153. Recuperado de http://estudiosgeograficos.revistas.csic.es/index.php/estudiosgeograficos/article/ view/264/263

Gago García, C. y Córdoba Ordóñez, J.A. (2013). Sistemas urbanos en América Latina: Roles y advenimientos de nuevos centros desde la perspectiva del transporte aéreo. Anales de Geografía de la Universidad Complutense, 33 (2), 9-39. doi: http://dx.doi.org/10.5209/rev_AGUC.2013.v33.n2.43000

Graham, A. (2005). Airport benchmarking: a review of the current situation. Benchmarking: An International Journal, 12 (2), 99-111. doi: https://doi.org/10.1108/14635770510593059 
Gong, Q., Wang, K., Fan, X., Fu, X. \& Xiao, Y. B. (2018). International trade drivers and freight network analysis - The case of the Chinese air cargo sector. Journal of Transport Geography, 71, 253-262. doi: https://doi.org/10.1016/j.jtrangeo.2017.02.009

Guimerà, R. \& Amaral, L. A. N. (2004). Modeling the world-wide airport network. European Physical Journal B, vol. 38 (2), 381-385. doi: 10.1140/epjb/e2004-00131-0

Hesse, M. \& Rodrigue, J. P., (2004). The transport geography of logistics and freight distribution. Journal of Transport Geography 12,171-184. doi: https://doi.org/10.1016/j.jtrangeo.2003.12.004

Hesse, M. (2014). International hubs as a factor of local development: evidence from Luxembourg City, Luxembourg, and Leipzig, Germany. Urban Research and Practice, 7 (3), 337-353. doi: https://doi.org/10.1080/17535069.2014.966508

Hui, G. W. L., Hui, Y. V. \& Zhang, A. (2004). Analyzing China's air cargo flows and data. Journal of Air Transport Management, 10 (2), 125-135. doi: https://doi.org/10.1016/j.jairtraman.2003.08.003

Hwang, C. C. \& Shiao, G. C. (2011). Analyzing air cargo flows of international routes: an empirical study of Taiwan Taoyuan International Airport. Journal of Transport Geography, 19 (4), 738-744. doi: https://doi.org/10.1016/j.jtrangeo.2010.09.001

IATA (2017). World Air Transport Statistics. [En línea]. International Air Transport Association. Recuperado de http://www. iata.org/pressroom/media-kit/Documents/WATS-2017-mediakit-summary.pd Último acceso: 25 de enero de 2013.

Jiménez, J. L. \& Betancor, O. (2012). When trains go faster than planes: The strategic reaction of airlines in Spain. Transport Policy 23, 34-41. doi: https://doi.org/10.1016/j.tranpol.2012.06.003

Lim, S. F. W. T., Jin, X. \& Srai, J. S. (2018). Consumer-driven e-commerce: A literature review, design framework, and research agenda on last-mile logistics models. International Journal of Physical Distribution and Logistics Management, 48 (3), 308-332. doi: https://doi.org/10.1108/IJPDLM-02-2017-0081

López Escolano, C., Pueyo Campos, A., Valdivielso Pardos, S., y Hernández Navarro, M. L. (2015). Transformaciones espaciales y de actividad frente a las dinámicas globales en el entorno metropolitano de Zaragoza. En A. Espinosa Seguí, F. J. Antón Burgos (Eds), El papel de los servicios en la construcción del territorio: redes y actores (vol. 1, pp. 285-302). Alicante: Asociación de Geógrafos Españoles.

López Escolano, C. (2017). Valoración de las transformaciones territoriales de la España peninsular mediante el estudio de la red viaria, indicadores de accesibilidad y de potencial de población. Tesis doctoral, Universidad de Zaragoza. Consejo Económico y Social de Aragón. Recuperado de http://www.aragon.es/estaticos/GobiernoAragon/OrganosConsultivos/ConsejoEconomicoSocialAragon/Areas/Publicaciones/TESIS/2018/TESIS_RED_VIARIA.pdf Último acceso: 30 de octubre de 2018.

Lotti, R. \& Caetano, M. (2018). The airport choice of exporters for fruit from Brazil. Journal of Air Transport Management 70 , 104-112. doi: https://doi.org/10.1016/j.jairtraman.2018.05.003

Martí-Henneberg, J., Tapiador, F. J., y Pueyo, A. (2007). La eclosión de los aeropuertos regionales españoles. Universidad de Lleida, Universidad de Castilla-La Mancha y Universidad de Zaragoza.

Martín, J. C., Román, C., García-Palomares, J. C. \& Gutiérrez, J. (2014). Spatial analysis of the competitiveness of the high-speed train and air transport: The role of access to terminals in the Madrid-Barcelona corridor. Transportation Research Part A, 69, 392-408. doi: https://doi.org/10.1016/j.tra.2014.09.010

Matsumoto, H. (2004). International urban systems and air passenger and cargo flows: Some calculations. Journal of Air Transport Management, 10 (4), 241-249. doi: https://doi.org/10.1016/j.jairtraman.2004.02.003

Mayer, R. (2016). Airport classification based on cargo characteristics. Journal of Transport Geography, 54, 53-65. doi: https://doi.org/10.1016/j.jtrangeo.2016.05.011

Ministerio de Fomento (2018). Recuperado de https://www.fomento.gob.es/MFOM/LANG_CASTELLANO/DIRECCIONES_GENERALES/AVIACION_CIVIL/POLITICAS_AEROPORTUARIAS/ITA/PLANES_DIRECTORES/ Último acceso: 02 de noviembre de 2018.

Morrell, P. S. (2011). Moving Boxes by Air: The Economics of International Air Cargo. Abingdon: Routledge.

O'Kelly, M. E. (1998). A geographer's analysis of hub-and-spoke networks. Journal of Transport Geography, 6 (3), $171-186$. doi: https://doi.org/10.1016/S0966-6923(98)00010-6

Pueyo Campos, A. y Hernández Navarro, M. L. (2013). L’Espagne face à la Grande Récession depuis 2008. M@ppemonde, 111 (3). Recuperado de https://mappemonde-archive.mgm.fr/num39/articles/art13301_fr.pdf 
Pueyo Campos, A., López Escolano, C., y Hernández Navarro, M. L. (2017). La tensión entre las dinámicas productivas y residenciales. El papel de las infraestructuras. En J. Farinós Dasí, J. Olcina Cantos (eds. y coords.) Geografía Regional de España: Espacio y comunidades (pp. 371-425). Valencia: Tirant lo Blanch.

Pueyo Campos, A., López Escolano, C., y Hernández Navarro, M. L. (2018). Nuevos espacios y realidades a partir del análisis espacial: un territorio distinto de ideas preconcebidas. En J. Farinós Dasí, J. (coord.) y J. Farinós y E. Peiró (eds.) Territorio y Estados. Elementos para la coordinación de las políticas de ordenación del territorio en el siglo XXI (pp. 785-828). Valencia: Tirant lo Blanch.

Ramos Pérez, D., Gámir Orueta, A., y Escalona Orcao, A. I. (2013). Ayudas públicas y oferta de servicios aéreos en los aeropuertos españoles. Boletín de la Asociación de Geógrafos Españoles, 61, 25-46. doi: http://dx.doi.org/10.21138/ bage. 1534

Rey, M. B. (2003). Structural changes in the Spanish scheduled flights market as a result of air transport deregulation in Europe. Journal of Air Transport Management, 9 (3), 195-200. doi: https://doi.org/10.1016/S0969-6997(02)00097-2

Rodrigue, J. P., Comtois, C. \& Slack, B. (2017). The Geography of Transport Systems. Abingdon: Routledge. doi: https://doi. org/10.4324/9781315618159

Sales, M. (2017). Air Cargo Management: Air Freight and the Global Supply Chain. Abingdon: Routledge. doi: https://doi. org/10.4324/9781315620169

Savy, M. (2004). Croissance économique et transports des marchandises: le découplage en débat. Les Sens du movement. París: Belin.

Serrano Martínez, J. M. y García Marín, R. (2015). Aeropuertos locales y de reducido tráfico en España: dificultades y necesaria reordenación de la red aeroportuaria territorial. Boletín de la Asociación de Geógrafos Españoles, 67, 497-505. doi: http://dx.doi.org/10.21138/bage.1832

Smith, D. A. y Timberlake, M. F. (2001). World city networks and hierarchies, 1977-1997: an empirical analysis of global air travel links. American Behavioral Scientist, 44 (10), 1656-1678. doi: https://doi.org/10.1177/00027640121958104

Suau-Sánchez, P. \& Burghouwt, G. (2011). The geography of the Spanish airport system: Spatial concentration and deconcentration patterns in seat capacity distribution, 2001-2008. Journal of Transport Geography, 19 (2), $244-254$. https://doi.org/10.1016/j.jtrangeo.2010.03.019

Suwanwong, T., Sopadang, A., Hanaoka, S. \& Rodbundith, T. (2018). Evaluation of air cargo connectivity and policy in Thailand. Transport Policy, 72, 24-33. doi: https://doi.org/10.1016/j.tranpol.2018.09.005

Tapiador, F.J., Mateos, A. \& Martí-Henneberg, J. (2008). The geographical efficiency of Spain's regional airports: A quantitative analyses. Journal of Air Transport Management, 14, 205-212. doi: https://doi.org/10.1016/j.jairtraman.2008.04.007

Tovar, B., Hernández, R. \& Rodríguez-Déniz, H. (2015). Container port competitiveness and connectivity: The Canary Islands main ports case. Transport Policy, 38, 40-51. doi: https://doi.org/10.1016/j.tranpol.2014.11.001

Verhetsel, A., Kessels, R., Goos, P., Zijlstra, T., Blomme, N. \& Cant, J. (2015). Location of logistics companies: a stated preference study to disentangle the impact of accessibility. Journal of Transport Geography, 42, 110-121. doi: https:// doi.org/10.1016/j.jtrangeo.2014.12.002

Walcott, S. M. y Fan, Z. (2017). Comparison of major air freight network hubs in the U.S. and China. Journal of Air Transport Management, 61, 64-72. https://doi.org/10.1016/j.jairtraman.2016.06.006

Wong, W. H., Cheung, T., Zhang, A. \& Wang, Y. (2019). Is spatial dispersal the dominant trend in air transport development? A global analysis for 2006-2015. Journal of Air Transport Management, 74, 1-12. doi: https://doi.org/10.1016/j.jairtraman.2018.09.011

Yamaguchi, K. (2008). International trade and air cargo: Analysis of US export and air transport policy. Transportation Research Part E: Logistics and Transportation Review, 44 (4), 653-663. doi: https://doi.org/10.1016/j.tre.2007.05.006

Zhang, A. (2003). Analysis of an international air-cargo hub: The case of Hong Kong. Journal of Air Transport Management, 9 (2), 123-138. doi: https://doi.org/10.1016/S0969-6997(02)00066-2 


\title{
De Concesiones Lineales a Contratos de Gestión Zonales: Una Propuesta para el Transporte Público Interurbano de Viajeros por Carretera en Aragón
}

\author{
From Linear to Zonal Management Contracts: A Proposal for the Public \\ Inter-Urban Transportation of Travelers by Road in Aragón \\ Ricardo Badía-Lázaro \\ rbadia@unizar.es@ https://orcid.org/0000-0003-0572-3681 \\ Eugenio Climent-López \\ ecliment@unizar.es @ https://orcid.org/0000-0001-6788-4873 \\ Grupo de Estudios de Ordenación del Territorio (GEOT). Universidad de Zaragoza \\ Departamento de Geografía y Ordenación del Territorio \\ Universidad de Zaragoza. C/ San Juan Bosco, $n^{\circ}$ 7. 50009 - Zaragoza
}

\section{INFO ARTÍCULO}

Recibido: 10/4/2019

Revisado: 21/5/2019

Aceptado: 24/5/2019

\section{PALABRAS CLAVE}

Transporte público

Autobús

Interurbano

Accesibilidad rural

Contrato de gestión

\section{KEYWORDS}

Public transportation

Bus

Inter-urban

Rural accessibility

Management contract

\section{RESUMEN}

El objetivo del artículo es presentar una propuesta de reestructuración del sistema de transporte interurbano de viajeros por carretera en Aragón, a partir del diagnóstico previo. Para ello se recurre a diversas fuentes de información y se utilizan técnicas de análisis espacial. Se constata la dificultad de prestar un servicio de transporte de calidad en regiones de baja densidad demográfica y dispersión del poblamiento y se identifican las ineficiencias del actual sistema de concesiones lineales. Se propone un nuevo sistema de concesiones zonales, que permite mayor coordinación e integra transporte regular y escolar. La propuesta se valora económicamente y se contrasta con los planes de la administración regional.

\begin{abstract}
The objective of the article is to present a proposal for the restructuring of the interurban transportation system of travellers by road in Aragón, based on a previous diagnosis. Several sources of information and spatial analysis methods are used. The difficulty of providing a quality transport service in regions of low population density and settlements dispersion is noted and the inefficiencies of the current system of linear concessions are identified. A new system of zonal concessions is proposed, which allows for greater coordination and integrates general and school transportation. The proposal is valued economically and compared with the plans of the regional administration.
\end{abstract}




\section{INTRODUCCIÓN}

Dentro del amplio campo de investigación de la geografía del transporte, este trabajo se ubica en una parcela a la que se ha prestado poca atención, en comparación con otras: el transporte público interurbano de personas por carretera.

El transporte público de viajeros hace posible y garantiza un derecho ciudadano fundamental: la libre circulación de personas (Belintxon, U., 2016, 20). Todos los modos de transporte contribuyen a ello, teniendo cada cual su funcionalidad propia. El transporte interurbano por carretera posibilita la movilidad de los ciudadanos a diferentes escalas espacio-temporales, pero es en las distancias cortas o medias donde tiene una ventaja insuperable respecto a los demás modos: la capilaridad, es decir, la posibilidad de llegar a todas partes, pues los vehículos gozan de una amplia autonomía de movimientos y las redes de carreteras son las de mayor longitud y densidad, con notable ventaja respecto al ferrocarril.

Además de ser la garantía de un derecho ciudadano, el transporte de pasajeros juega un papel fundamental en el funcionamiento de una sociedad cohesionada: "una mayor justicia social no puede ser alcanzada sin una mayor inclusión social, la cual requiere que la gente tenga acceso a un conjunto de actividades consideradas como típicas de su sociedad; una mayor inclusión social requiere una mayor accesibilidad que a menudo implica movilidad y uso de transporte" (Farrington, J. y Farrington, C., 2005, 2).

La Estrategia Territorial Europea (ETE) parte de tres principios de desarrollo territorial, el segundo de los cuales es el acceso equivalente a las infraestructuras y al conocimiento. Dicho principio se desarrolla en los siguientes términos: "Las ciudades y áreas metropolitanas deben conectarse de manera eficaz no sólo a la economía mundial, sino también entre sí y con sus zonas de influencia. Además, el buen funcionamiento de los transportes y un acceso suficiente a las telecomunicaciones son condiciones básicas para el refuerzo de la competitividad de las regiones periféricas o las menos favorecidas y, por lo tanto, de la cohesión económica y social de la UE" (Comisión Europea, 1999, 28). Si bien la ETE se centra principalmente en las infraestructuras, de interés preferente siempre para las administraciones públicas (Garrido, 2002), también propugna el uso eficaz y sostenible de las mismas, mostrando preocupación por la contaminación atmosférica y la congestión del tráfico. Una de las medidas propuestas para aliviar ambos es la mejora del transporte público.

En la misma línea que la ETE, la Estrategia de Ordenación Territorial de Aragón (EOTA) establece como objetivo cuarto "facilitar las condiciones de movilidad y accesibilidad de las personas y bienes" (Gobierno de Aragón, 2014, 39110). Las estrategias y normas formuladas para alcanzar dicho objetivo se centran de manera destacada en las infraestructuras, confirmando que "en la mayoría de las ocasiones, los esfuerzos de las administraciones públicas para mejorar la accesibilidad entre los asentamientos centran su atención casi exclusivamente en la creación y mantenimiento de las infraestructuras viarias, tratando de disminuir el tiempo y los riesgos asociados a la movilidad" (Pons, J. y Betelu, A., 2004, 217). Pero la EOTA no olvida los servicios de transporte, recomendando la redacción de una directriz, que debería tener en cuenta diversos factores, entre ellos "la mejora del sistema de transporte colectivo por carretera de Aragón mediante una nueva propuesta de Concesiones Administrativas de la Gestión del Servicio de Autobús" (Gobierno de Aragón, 2014, 39115).

En tanto que garante de un derecho y favorecedor de una sociedad cohesionada, el transporte de pasajeros puede considerarse un servicio público, respecto al cual el Estado tiene la última responsabilidad. Lo habitual es que el transporte interurbano de viajeros en autobús lo presten empresas privadas en régimen de concesión, según la terminología tradicional, o contrato de gestión, en su denominación actual. Esto significa que las administraciones públicas, por una parte, establecen las rutas que deben seguir los autobuses y las condiciones generales en que debe prestarse el servicio y, por otra, conceden la explotación comercial de dichas líneas a empresas privadas, mediante concurso competitivo. En España las competencias administrativas recaen en el Gobierno central, para el transporte entre comunidades autónomas, y en los Gobiernos regionales, para el transporte interior comunitario.

El transporte interurbano de viajeros en autobús debe planificarse en función de las necesidades de la población, buscando ante todo la rentabilidad social. Por ello la planificación debe prever una "oferta equilibrada de transporte público, adecuada a las necesidades de desplazamiento de todos los individuos y que 
permita, en primer lugar, el acceso a la educación, al empleo y a los servicios y, seguidamente, al desarrollo de actividades recreativas y sociales" (Ruiz, M. et al., 2016, 621). Las necesidades de transporte pueden satisfacerse por medios privados, pero "no todos los hogares disponen de vehículo privado, y mucho menos todos los miembros del hogar. Las causas de esta falta de acceso universal al automóvil son muy diversas y abarcan desde la imposibilidad física o mental para conducir, a motivaciones económicas" (Pons, J. y Betelu, A., 2004, 217-218). En aras de la cohesión social, el Estado está obligado a atender especialmente las necesidades de los colectivos menos favorecidos económicamente, así como de los niños, ancianos y demás personas que no disponen de vehículo privado (alrededor de un tercio de la población total). Pero no debe olvidarse tampoco que, en tanto que este tipo de transporte lo prestan empresas privadas, su planificación debe tener en cuenta también la rentabilidad económica (López, E., 1989).

Esa necesidad de atender a los colectivos menos favorecidos se plantea tanto en los espacios urbanos, donde los contrastes sociales son muy marcados (Ruiz, M. et al, 2016; Guirao, B. y Briceño, D., 2006), como en el ámbito rural, donde los principales servicios tienden a concentrarse en un reducido número de lugares centrales (Bachiller, J.M. y Molina, I., 2014), a los que la población tiene que desplazarse necesariamente. En este sentido, "la accesibilidad física y geográfica de los servicios puede ser descrita como el factor primario que condiciona la capacidad de la gente para acceder a ellos" (Smith, N. et al., 2012, 93) y esa capacidad viene dada por la existencia de transporte. Por eso el transporte público de viajeros por carretera es fundamental para que todos los habitantes del medio rural puedan acudir al colegio, al centro de salud, al trabajo, al comercio y a los demás servicios.

\section{1. Ámbito territorial y objetivos}

El ámbito territorial de este trabajo es la Comunidad Autónoma de Aragón. Las concesiones de líneas regulares de autobús, resultado de un cúmulo de decisiones sucesivas tomadas y revisadas a lo largo del último medio siglo, caducaron en el año 2017, abriéndose así la posibilidad de diseñar un mapa totalmente nuevo, con visión de conjunto y adaptado a las necesidades actuales. Los empresarios del sector, anticipándose a dicha fecha, patrocinaron la realización de un estudio para hacer una propuesta de reordenación, partiendo del diagnóstico de la situación vigente. ${ }^{1}$ Los criterios del diagnóstico se establecieron a partir de la condición de servicio público de dicho transporte, según las consideraciones realizadas previamente. La propuesta se basó en la doble premisa de la rentabilidad social y económica: el nuevo sistema de contratos de gestión, por una parte, debe garantizar la movilidad de todos los habitantes de Aragón, sea cual sea su lugar de residencia, permitiéndoles acceder en condiciones adecuadas a los servicios necesarios; por otra parte, debe garantizar unos beneficios razonables a las empresas prestatarias del servicio.

El objetivo de este artículo es dar a conocer la metodología empleada y los resultados más relevantes de dicho estudio, con el deseo de que pueda ser útil para trabajos de similar índole planteados en otros contextos espaciales.

El estudio se estructuró en dos fases: diagnóstico y propuesta. En la primera se analizaron los contratos de gestión y las rutas de autobús existentes, en relación con la distribución espacial de la población, la estructura comarcal y la localización de los principales servicios, especialmente los educativos y sanitarios; asimismo se cuantificaron el coste económico del sistema, los ingresos obtenidos por la venta de billetes y las subvenciones de la administración pública. En la segunda fase se diseñó un sistema de contratos de gestión de carácter zonal. A partir de los resultados del diagnóstico se hizo una delimitación de zonas de transporte, en cada una de las cuales se planificaron rutas de autobús para solucionar los problemas detectados sin incurrir en incremento de costes y procurando llegar a todos los núcleos de población.

1. Se trata del contrato de $I+D+i$ "Análisis y propuestas para la remodelación de las concesiones del transporte de viajeros por carretera en la comunidad autónoma de Aragón", firmado por la Asociación Empresarial de Transportes Interurbanos de Viajeros en Autobuses de Aragón (AETIVA) y la Universidad de Zaragoza en junio de 2014. 


\section{METODOLOGÍA}

El proceso metodológico consta de dos etapas: 1) diagnóstico del sistema actual de transporte y 2) evaluación de propuestas de mejora. La primera etapa se subdivide en dos fases: a) obtención y tratamiento de datos y b) análisis de datos.

La fase de obtención y tratamiento de datos engloba la recopilación y edición de una base de datos espacial con información tanto de la oferta como de la demanda de transporte público. Los datos referidos a la oferta están integrados por dos niveles. El primero lo constituye una tabla referida a todas las rutas de transporte del área, tanto regular como escolar, que recoge su tipología, kilómetros recorridos, coste, número de alumnos y viajeros. Se trata de datos que las empresas contratistas están obligadas a suministrar periódicamente a la Administración y que ha sido utilizada también como fuente de información en otros trabajos sobre las concesiones de transporte (Sánchez, S., 2015, sobre Andalucía; Rojo, M., 2011, sobre Castilla y León). Esta tabla queda integrada en una capa de líneas que permite caracterizar la red de transporte público. Un segundo nivel, más desagregado, es la tabla de servicios, que relaciona los horarios de parada de cada una de las expediciones de estas rutas con los núcleos de población, integrándose en una capa de núcleos, a la que se asignan también los datos referidos a la demanda de transporte, que son las características demográficas de los núcleos de población, su nivel de centralidad y la disponibilidad de servicios escolares y sanitarios.

La segunda fase del diagnóstico consistió en el análisis de estos datos. Por un lado, se hicieron consultas espaciales a la capa de rutas para clasificarlas en función del rango jerárquico de los núcleos que conectan. Por otro lado, se calculó el tiempo de recorrido desde cada localidad a su capital comarcal y cabecera de sector sanitario, utilizando los horarios de paso de cada expedición, y se obtuvo el total de expediciones en cada sentido; estos dos últimos datos (tiempo de recorrido y número de expediciones) se sintetizaron para establecer rangos de calidad del servicio en cada uno de los núcleos. La metodología de esta fase es la habitual en los estudios sobre servicios de transporte, que consideran la accesibilidad en referencia a los núcleos en que se ubican los principales servicios y toman el tiempo como medida de la fricción de la distancia (Gutiérrez, J., 1988 y 2001). En este caso, el tiempo ha sido calculado a partir de los horarios oficiales, no de la velocidad estimada en función de las características de las carreteras, lo cual suele hacerse al estudiar el transporte en vehículo privado o al valorar la importancia de las infraestructuras (Martínez, H. S., 2012, para el caso de Castilla La Mancha; Mora, J. et al., 2003, para el de Extremadura).

La segunda etapa del proceso metodológico es la propuesta de mejora del servicio, mediante la delimitación de zonas de transporte. A la propuesta final se ha llegado de forma iterativa mediante un proceso que consta de las siguientes fases:

En primer lugar, se ha realizado una delimitación apriorística de zonas de transporte atendiendo a los siguientes criterios derivados del diagnóstico:

a. Existencia de líneas estructurantes que canalizan la mayor parte de los flujos de transporte interno en la zona, articulando un eje que debe actuar como la columna vertebral de cada zona de transporte.

b. Existencia a lo largo de dichos ejes de núcleos de población que funcionan como lugares centrales de áreas de influencia bien definidas.

c. Existencia de áreas funcionales definidas según criterios de prestación de servicios, principalmente sanitarios y educativos.

En segundo lugar, se ha diseñado la reordenación del transporte de viajeros en cada una de las zonas; esto permite establecer, por un lado, una valoración cualitativa de las características y la estructura del transporte de viajeros y, por otro, una cuantificación de las principales variables e indicadores del sistema de transporte. En tercer lugar, se ha hecho el ajuste y propuesta definitiva de zonas de transporte. Finalmente, la valoración económica de cada una, comparando la situación actual y la resultante de la reordenación. 


\section{DIAGNÓSTICO DEL TRANSPORTE REGULAR INTERURBANO DE VIAJEROS EN AUTOBÚS DE ARAGÓN}

El diagnóstico del transporte regular interurbano de viajeros en autobús de Aragón se expone en tres pasos: en primer lugar, la distribución espacial de la población, en términos de densidad demográfica y modelo de poblamiento. A continuación, la estructura del sistema actual de transporte, identificando y caracterizando las concesiones y líneas regulares existentes. En tercer lugar, la valoración de la calidad del servicio prestado a los usuarios y su valoración económica.

\subsection{Distribución espacial de la población y modelo de poblamiento}

La organización del servicio público de transporte de viajeros por carretera está condicionada por la distribución espacial de la población, es decir, por la densidad demográfica y la estructura del sistema de poblamiento.

En el territorio aragonés viven 1.308.728 habitantes -según el padrón municipal a 1 de enero de 2018sobre una superficie de $47.720 \mathrm{~km}^{2}$. Esto da lugar a una densidad de 27 habitantes por $\mathrm{km}^{2}$, una de las más bajas de España. Pero a la vez presenta fuertes desequilibrios territoriales: por una parte, en 480 de sus 731 municipios la densidad es inferior a diez habitantes por $\mathrm{km}^{2}$, considerado como "límite de despoblación severa" (Delgado, J. M., 2018, 269). Por otra, en el área metropolitana de Zaragoza se concentran 744.579 personas, el $57 \%$ de la población regional, en sólo el $5 \%$ del territorio. Esta situación de concentración y a la vez despoblación, típica del interior de España, dificulta la prestación de un transporte público de calidad, afectando principalmente a la movilidad de la población rural, como ha sido puesto en evidencia, por ejemplo, en el caso de la provincia de Albacete (Fernández, F., 1999).

El sistema de poblamiento condiciona la demanda de transporte público de viajeros. En aquellas áreas donde la densidad de asentamientos es alta, se necesitan más rutas de transporte para poder atender a la población. Combinando densidad de población y densidad de núcleos se identifican cuatro tipos de zonas, cada una de las cuales demanda servicios de transporte de diferentes características (mapa 1).

- Densidad de población baja, sea cual sea la densidad de núcleos: son las zonas que plantean las mayores dificultades para asegurar un servicio de transporte de calidad, por la limitación de la demanda. En ellas habita el 3\% de la población aragonesa, pero se ubica el $40 \%$ de los núcleos de población. Representadas en el mapa con tonos amarillos y anaranjados, se extienden especialmente por el norte de la provincia de Huesca y la práctica totalidad de la de Teruel.

- Densidad de población media y densidad de núcleos media-alta: se trata de espacios en los que la población se asienta en muchos núcleos relativamente pequeños y dispersos, por lo que las distancias entre ellos son cortas. Esto obliga a diseñar un elevado número de rutas, con muchas paradas, aunque la demanda es baja, lo que hace muy difícil que las frecuencias sean altas. En ellas habita el $8 \%$ de la población aragonesa y se localiza el 33\% de los núcleos. Se corresponden con las zonas rosadas del mapa, que engloban buena parte del somontano pirenaico y la Comunidad de Calatayud.

- Densidad de población media-alta y densidad de núcleos baja: en estos espacios encontramos mayor población, concentrada en pocos núcleos. La demanda de transporte es moderada, pero puede ser satisfecha con un número de rutas relativamente bajo, posibilitando la existencia de un servicio de transporte adecuado. Estos espacios, muy poco extendidos en Aragón, aparecen con tonalidades verdes en el mapa; en ellos vive el 7\% de la población y se localiza el 5\% de los núcleos.

- Densidad de población alta y densidad de núcleos media-alta: Implica una alta demanda de transporte de viajeros, creándose un escenario parecido al de los espacios urbanos, con muchas rutas, numerosas paradas y frecuencias altas. En estas zonas habita el $82 \%$ de la población regional y en ellas se ubica el $21 \%$ de los núcleos. Están representadas con colores azulados y se extienden principalmente por las vías de entrada a la ciudad de Zaragoza, englobando también el resto de núcleos de cierto tamaño. 


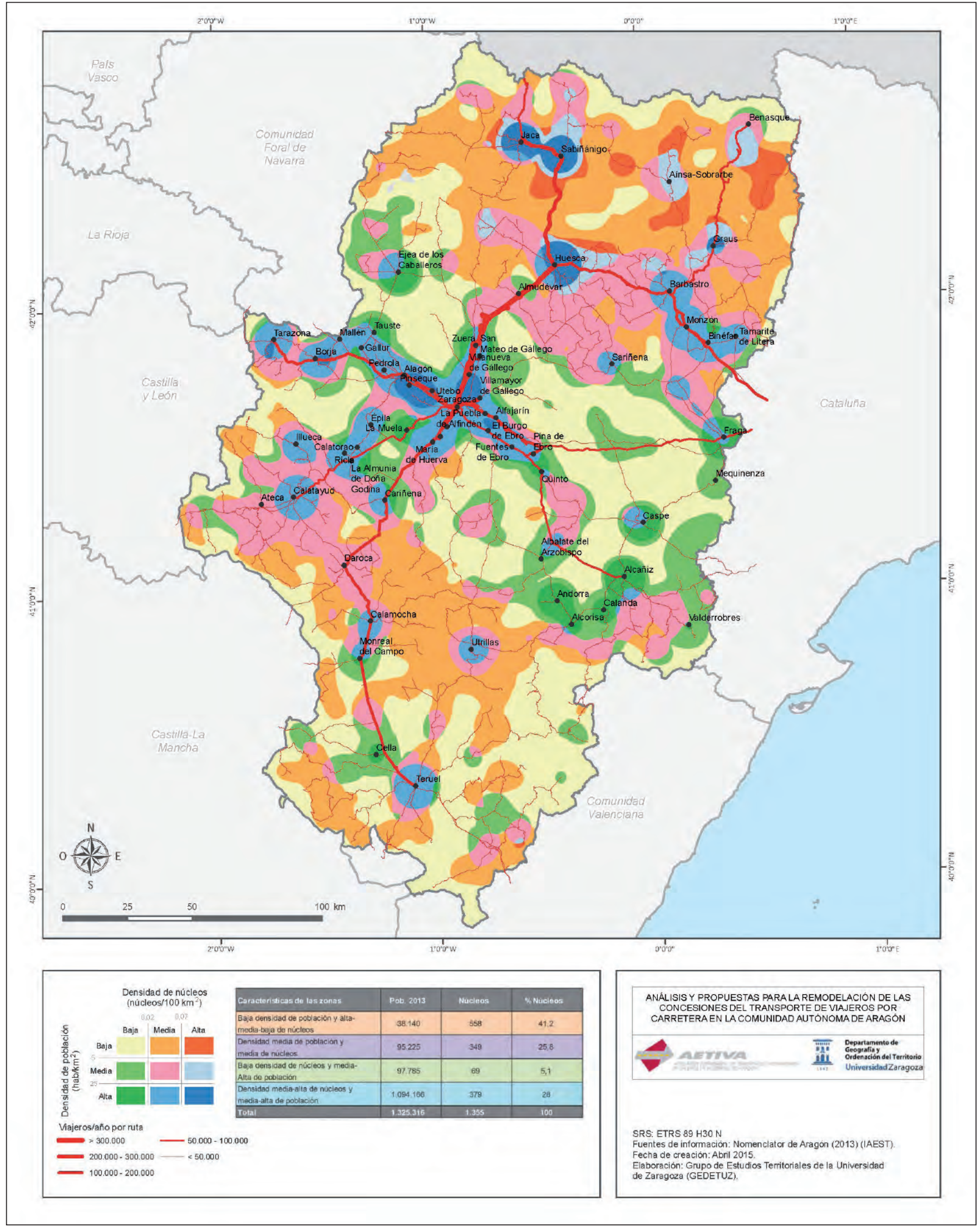

Mapa 1. Densidad de población y densidad de núcleos de población.

Fuente: Nomenclátor y elaboración propia. El procedimiento seguido para la confección del mapa es el utilizado por Escolano, S. y de la Riva, J. (2003, 12). 
La proyección demográfica del Instituto Nacional de Estadística para el período 2018-2033 prevé un ligerísimo crecimiento de la población aragonesa hasta 2024; a partir de ahí se espera un decrecimiento, debido a un saldo vegetativo negativo, compensado sólo parcialmente por un flujo migratorio positivo. Se acentuará el envejecimiento demográfico, es decir, el aumento en la edad media de la población, provocado por el cambio en la estructura por edades (Pérez, J. y Abellán, A., 2018). El decrecimiento se centrará en las provincias de Huesca y, sobre todo, Teruel, previéndose que continúe la concentración progresiva de la población en las capitales provinciales y otros núcleos de cierto tamaño. Estas tendencias influirán en la demanda de usuarios de transporte público, sobre todo en el medio rural, incrementando la extensión de las áreas que presentan una mayor dificultad de prestación del servicio.

\subsection{Estructura de la red}

La red de transporte público interurbano de viajeros en Aragón está compuesta por dos modos de transporte: autobús y ferrocarril. El transporte por carretera es, con amplia diferencia, el más importante con un total de 283.000 expediciones y 15 millones de kilómetros recorridos en el año 2013, frente al ferrocarril con 19.000 expediciones y 3,3 millones de kilómetros. En paralelo existe una importante red de transporte escolar con un escaso nivel de integración con el resto.

El servicio de autobuses interurbanos se organiza en 288 rutas. A causa de la baja densidad de población la mayoría de ellas cuenta con una frecuencia inferior a la diaria, operando únicamente en días alternos o incluso un solo día a la semana. En el lado opuesto el $9 \%$ de las rutas supera los cuatro viajes diarios por sentido.

El sistema es operado por 46 empresas diferentes, 7 de las cuales concentran más del 75\% de los kilómetros recorridos. Los contratos de gestión lineales aseguran a las empresas que una relación entre un origen y un destino determinados sólo puede ser cubierta por esa misma empresa, evitando así situaciones de competencia. Como la red de concesiones ha sido fruto de un proceso no planificado y dilatado en el tiempo se producen numerosos solapamientos entre líneas de diferentes empresas, por lo que existen restricciones de tráfico que segmentan la escasa demanda existente y disminuyen el número de oportunidades de viaje.

Las rutas existentes se han clasificado en dos tipos, atendiendo a la función que desempeñan en el territorio:

a. Rutas estructurantes: son las que conectan entre sí las localidades de mayor centralidad, es decir, la capital regional, las otras dos capitales provinciales y las nueve pequeñas ciudades que funcionan como cabeceras supra-comarcales. Este último rango jerárquico está definido en la Estrategia de Ordenación Territorial de Aragón (EOTA) y lo integran las localidades de entre 10.000 y 25.000 habitantes (excluidas las del área metropolitana de Zaragoza), todas las cuales disponen de servicios para atender a la población de varias comarcas: institutos con una amplia oferta de educación secundaria no obligatoria (tanto modalidades de bachillerato como ciclos de formación profesional) y hospitales o centros de especialidades médicas. ${ }^{2}$ Téngase en cuenta que la Comunidad Autónoma de Aragón está organizada administrativamente en comarcas, creadas por ley y constituidas como entidades locales dotadas de organismos y competencias específicas. Estas rutas estructurantes son pocas, pero forman una malla en el territorio que facilita los desplazamientos de tipo regional. Se caracterizan por ser relativamente largas, circular por los principales ejes de transporte, poseer una velocidad comercial elevada y superar el umbral de 4 expediciones por sentido en día laborable. Son las que tienen mayores volúmenes de tráfico, con un gran número de expediciones y de viajeros (mapa 2).

b. Rutas de centralidad: su función es la de conectar los núcleos de población menores con los núcleos dotados de centralidad, que son aquéllos donde se localizan los principales servicios básicos a la población: educativos, sanitarios, comerciales, administrativos y lúdicos. Forman el conjunto más numeroso (mapa 3). La cantidad de rutas, el área atendida y el número de expediciones es mayor cuan-

2. El Gobierno de Aragón considera que Calamocha es una cabecera supra-comarcal (mapa 2), a pesar de no llegar a 5.000 habitantes y no disponer de servicios sanitarios supra-comarcales. Con ello pretende cubrir parcialmente la falta de ciudades pequeñas que se aprecia en la mitad meridional de Aragón. 


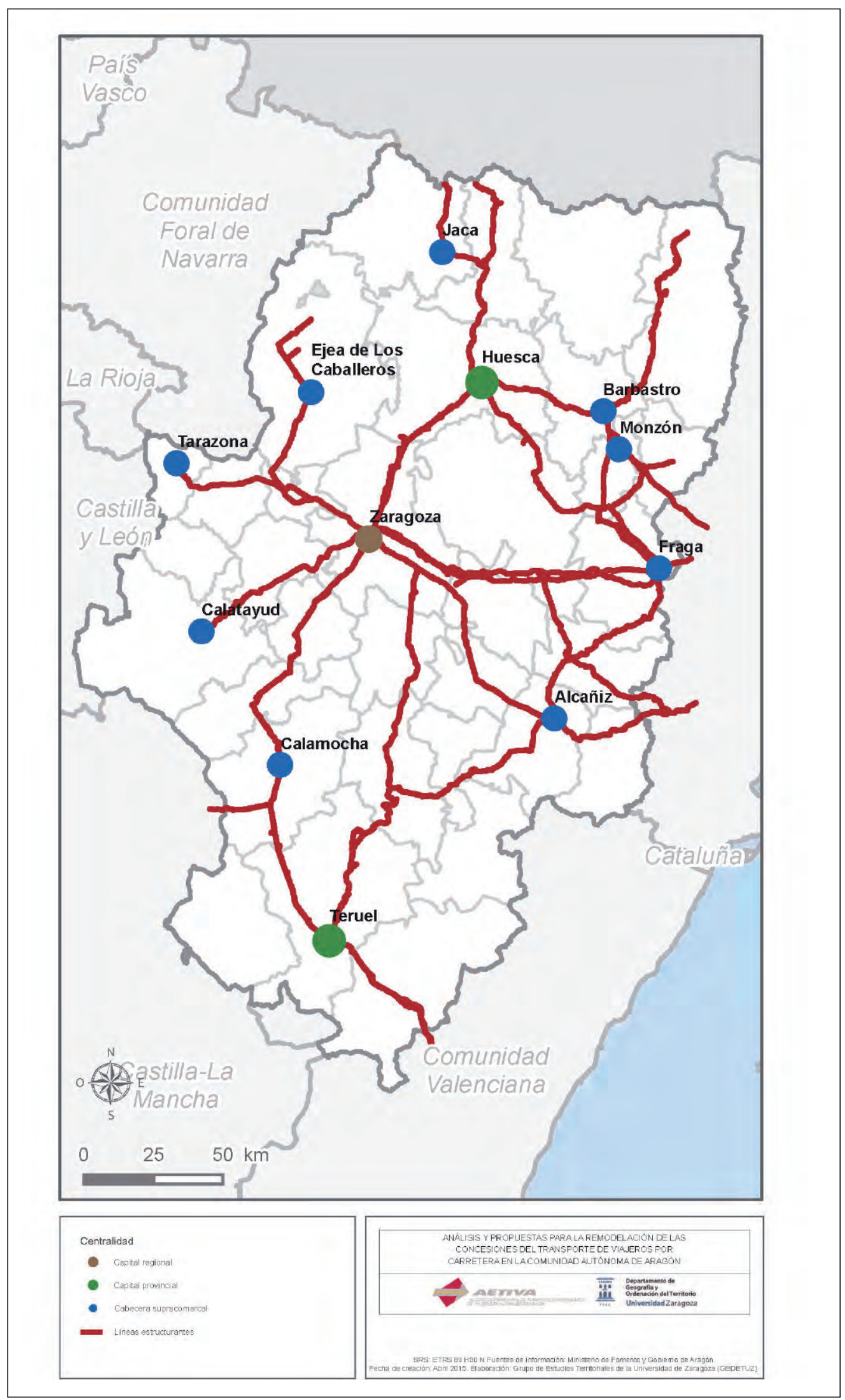

Mapa 2. Rutas estructurantes.

Fuente: Ministerio de Fomento, Gobierno de Aragón y elaboración propia. 


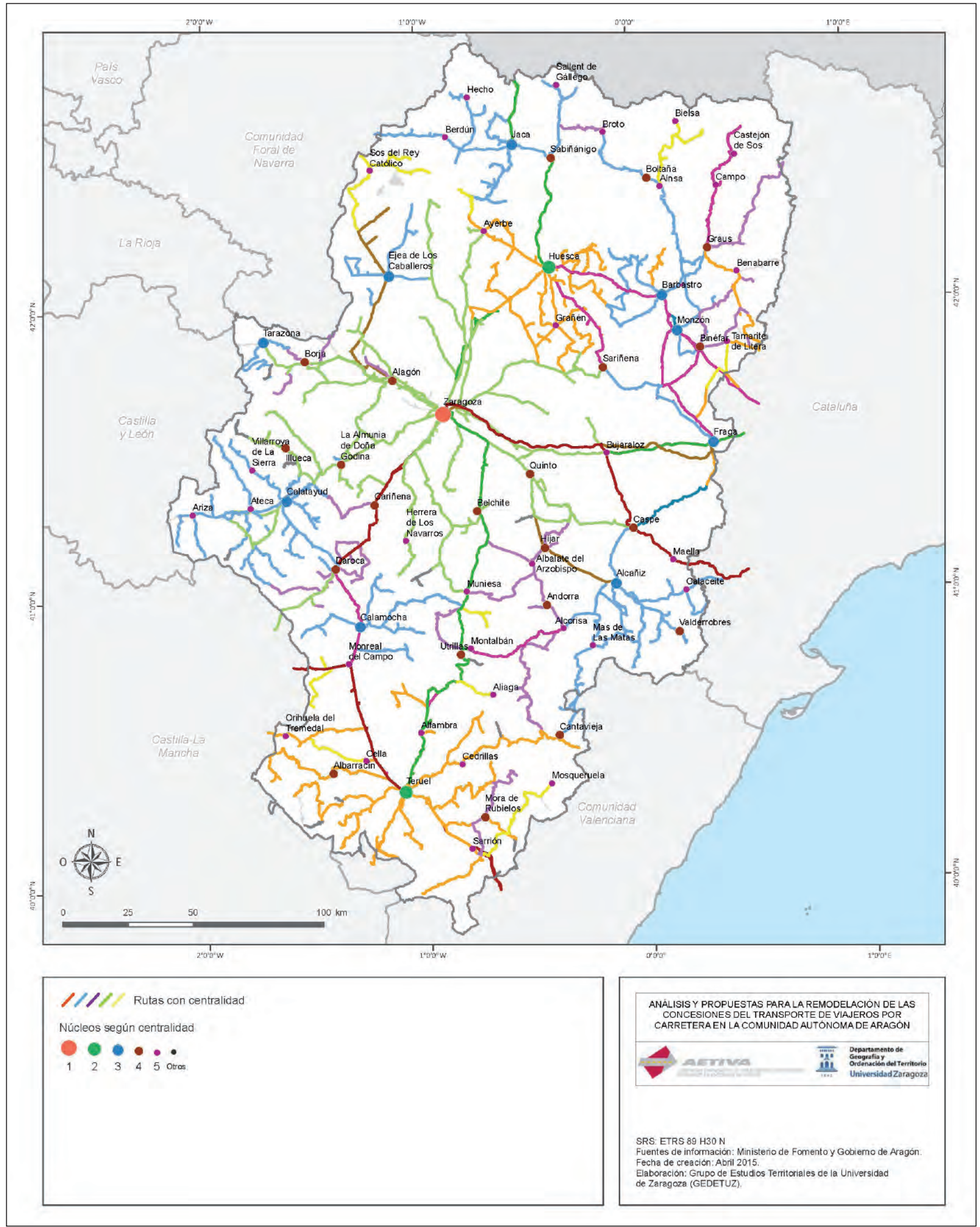

Mapa 3. Rutas de centralidad.

Fuente: Ministerio de Fomento, Gobierno de Aragón y elaboración propia. 
to mayor es el rango de dicho núcleo central. De esta forma, en el entorno de Zaragoza encontramos mayor proporción de rutas con más de 4 frecuencias por sentido, mientras que en las cabeceras de comarca y otros núcleos centrales de carácter sub-comarcal el número de rutas con una única expedición por sentido al día o incluso con expediciones en días alternos es mayor.

En las rutas de centralidad se han observado algunas disfunciones similares a las puestas de manifiesto en trabajos sobre otras regiones: así, en el caso de Murcia "los centros comarcales, con mayor grado de centralidad, son también quienes consiguen un número de líneas y viajes diarios más alto; aunque, en conjunto, el total de los que se dirigen hacia y desde la capital es proporcionalmente superior a su valor en centralidad" (Serrano, J.M., 1987, 633); en Valencia las áreas de influencia delimitadas por las líneas regulares de autobuses no coinciden con las comarcas establecidas para la prestación de determinados servicios (Sanchis, M.C., 1987). En Aragón muchas de las cabeceras comarcales no cuentan con rutas de centralidad en su entorno, dominando claramente las que tienen como destino las capitales de provincia.

En paralelo al servicio general de viajeros encontramos el transporte escolar: Aragón cuenta con 529 rutas y 5,2 millones de viajeros al año, se atiende a 889 núcleos, predominando aquellos de menor volumen demográfico, y supone un coste de 15,8 millones de euros, que es enteramente financiado por las administraciones públicas. Se trata de una red independiente, aunque se ha iniciado un proceso de integración del transporte escolar y regular, que ya afecta al 30\% de las rutas, atendiendo a dos modelos diferentes:

- Las rutas en integración: son rutas escolares que se incorporan a la red de transporte público ofertando las plazas vacías al resto de usuarios. En la actualidad, un $20 \%$ de las rutas escolares se encuentran bajo este sistema. Su principal ventaja es la creación de nuevas expediciones de transporte para el público general en áreas de baja densidad de población.

- Las rutas en reserva de plaza: son rutas en las que los alumnos usan el sistema de transporte público regular junto con el resto de usuarios, mediante reserva previa de sus asientos para todo el curso escolar. Afecta sólo a los alumnos de educación secundaria, que de hecho son más del $80 \%$ de los usuarios del transporte escolar, pues los de infantil y primaria deben viajar siempre en vehículos acompañados de monitores. En la actualidad el modelo de reserva de plaza supone el $10 \%$ del total de servicios escolares y su principal ventaja es la reducción de costes.

La fusión de transporte regular y escolar se da también en otras regiones españolas y en algunos casos ha generado controversia. Por ejemplo, en Galicia ha suscitado críticas, entre otras razones, por la supeditación de los horarios de los centros educativos a la conveniencia de las empresas de transporte (Boquete, D., 2018). En el caso de Aragón el $52 \%$ de los usuarios de autobús afectados se manifiesta indiferente y el $39 \%$ lo considera adecuado; los que no están de acuerdo son sólo el $9 \%$ y sus quejas apuntan en sentido contrario al de Galicia, pues los horarios de los autobuses siempre se supeditan a los horarios escolares; eso perjudica a otros usuarios, como los que se desplazan para hacer compras u otras gestiones, pues la apertura de los comercios se hace sensiblemente más tarde que la de los institutos. ${ }^{3}$

\subsection{Calidad y rentabilidad económica del sistema}

La evaluación de la calidad del servicio de transporte de viajeros por carretera se ha sintetizado mediante la combinación de dos variables: la frecuencia, medida por el número de servicios diarios, y la accesibilidad, expresada en términos de duración del viaje desde cada núcleo de población hasta un municipio dotado de centralidad. Se ha considerado que la calidad del servicio es excelente cuando se dispone de diez o más servicios diarios y el viaje dura menos de 30 minutos; en la medida en que va disminuyendo el número de servicios y aumentando la duración del viaje la calidad va evolucionando a peor (mapa 4).

3. Resultados de la encuesta realizada a los usuarios de autobús en el contexto del contrato de I+D+i mencionado en la nota 1. 


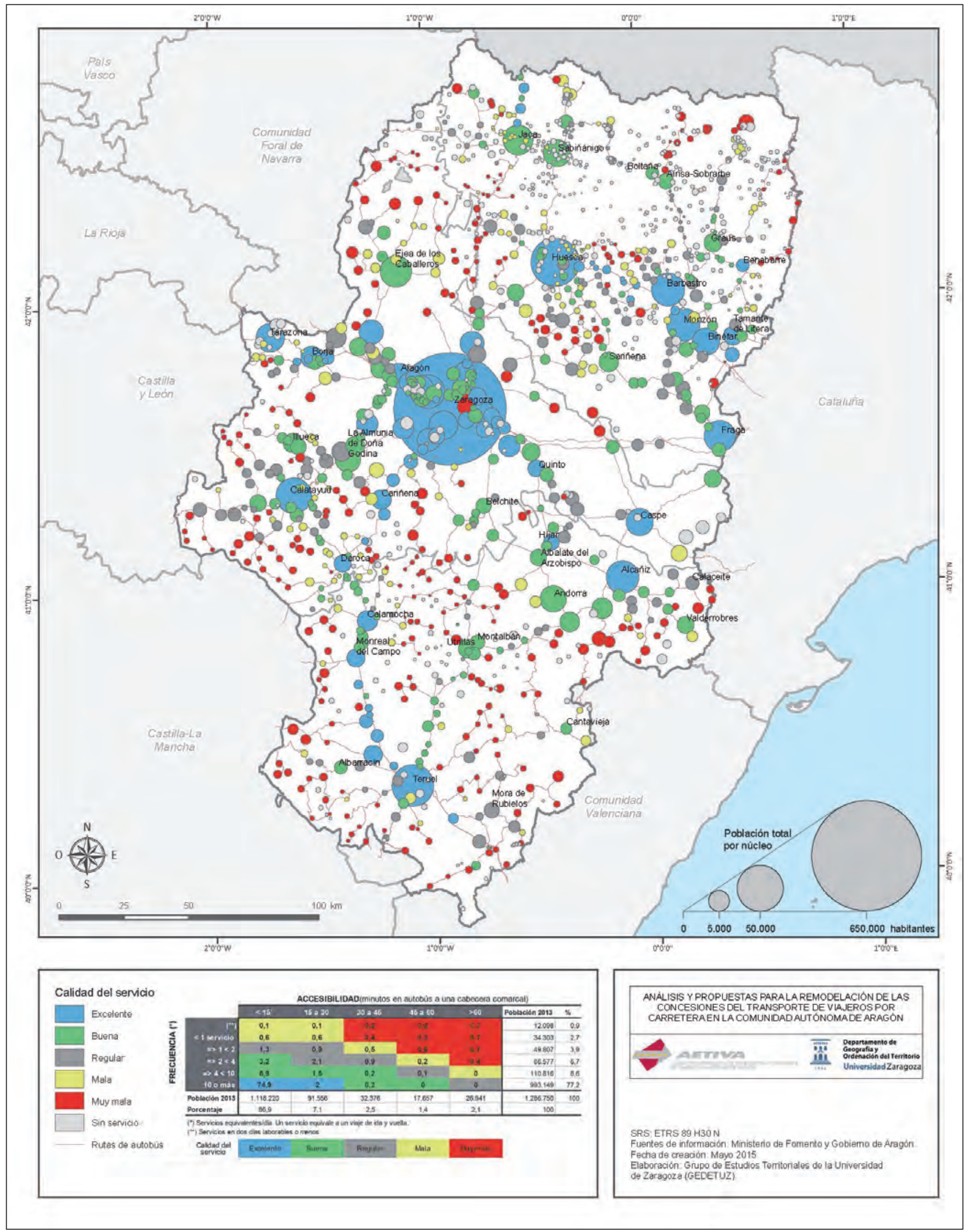

Mapa 4. Calidad del servicio.

Fuente: Ministerio de Fomento, Gobierno de Aragón y elaboración propia. 
Combinando los valores correspondientes a cada núcleo, se concluye que el 77\% de la población aragonesa disfruta de una calidad excelente; se trata mayoritariamente de la que habita en los principales núcleos de población, incluyendo Zaragoza, que por sí sola concentra el 51\% de los habitantes de Aragón. Otro 12\% disfruta de una calidad buena, un $5 \%$ regular, un $2 \%$ mala y un $4 \%$ muy mala. En las dos últimas situaciones se encuentra el $50 \%$ de los núcleos habitados, aunque la población afectada sea reducida.

En cuanto a la rentabilidad, el sistema de transporte regular en autobús moviliza a unos 4 millones de viajeros al año y presenta un coste anual de 20,8 millones de euros. Los ingresos anuales por venta de billetes ascienden a 13 millones de euros, lo que equivale al $63 \%$ de los costes de explotación. Como la recaudación es insuficiente para cubrir los costes y dado que se trata de un servicio público la administración aporta subvenciones a las empresas por valor de 4,2 millones de euros, el 90\% de las cuales procede del Gobierno de Aragón y el $10 \%$ restante de las administraciones locales. Estas subvenciones públicas no cubren totalmente la diferencia entre recaudación y costes, generando un déficit de 3,5 millones de euros, que recae sobre las empresas.

\subsection{Síntesis del diagnóstico}

El diagnóstico realizado pone de manifiesto que el sistema de transporte público de viajeros por carretera de Aragón satisface, en condiciones de calidad, las necesidades básicas de movilidad de una elevada proporción de la población aragonesa, aunque no de toda ni en todas las circunstancias.

Se han puesto de relieve también algunas disfunciones importantes: el estar basado en un número elevado de contratos de gestión lineales da lugar a solapamientos de rutas, con las consiguientes restricciones de tráfico; ello implica un aprovechamiento ineficiente de los recursos disponibles, lo cual repercute en un peor servicio a la población y un mayor coste económico, que en buena medida se ve obligada a asumir la administración pública. Si a ello se añade que el transporte escolar se gestiona de manera independiente, aunque existe cierta coordinación, la ineficiencia se acentúa.

Los mayores problemas se dan en las áreas poco pobladas, con muchos núcleos de población pequeños (mapas 1 y 4); es ahí donde más difícil resulta garantizar la movilidad de las personas en condiciones razonables de calidad. En el resto de las zonas los esfuerzos han de dirigirse a racionalizar al máximo las rutas, evitando duplicidades; ello sería suficiente para mejorar la calidad del servicio y reducir costes.

\section{PROPUESTA PARA EL TRANSPORTE REGULAR INTERURBANO DE VIAJEROS EN AUTOBÚS DE ARAGÓN}

El sistema actual de transporte regular interurbano de viajeros en autobús de Aragón se acomoda con fidelidad, aunque con algunos desajustes, a la jerarquía regional de asentamientos. Como se ha visto, las rutas estructurantes conectan entre sí de forma satisfactoria los núcleos urbanos y la mayor parte de las cabeceras comarcales, mientras que en torno a estos núcleos centrales se organizan rutas de centralidad, que garantizan a los habitantes del área el acceso a los servicios básicos, siendo en ellas donde se aprecian los principales déficits de calidad. Una buena forma de mejorar el sistema es coordinar de forma eficiente las rutas estructurantes y las de centralidad.

La legislación vigente ofrece un instrumento adecuado para realizar esa coordinación: la concesión zonal, prevista en la Ley 16/1987 de Ordenación de los Transportes Terrestres (LOTT). El artículo 78 de la LOTT establece: “Como regla general, las concesiones se otorgarán, únicamente, para servicios predeterminados de carácter lineal; no obstante, la Administración podrá otorgar concesiones zonales que comprenderán todos los servicios regulares permanentes o temporales y de uso general o especial que hayan de prestarse en una determinada zona, salvo los que expresamente se exceptúen". En coherencia con dicha redacción las concesiones lineales son la norma y las zonales la excepción. La ley además indica que al establecer una concesión zonal deben respetarse los derechos económicos de las concesiones lineales ya establecidas. Esta salvaguarda de derechos restringe las posibilidades de su implantación, pero en el caso de Aragón todas las concesiones autonómicas caducaron en el año 2017, estando actualmente en situación de prórroga hasta 
que se publique el nuevo mapa concesional. Esto constituye una gran oportunidad para la realización de un diseño global de contratos de gestión zonales.

Una concesión de este tipo incluye todos los servicios de uso general o especial, aunque se pueden exceptuar algunos expresamente; entre los de uso especial ocupa un papel destacado el transporte escolar, por lo que la coordinación de ambos en la misma zona aseguraría el uso más eficiente de los recursos disponibles. Existen precedentes de concesiones zonales en el País Vasco y en Asturias. ${ }^{4}$

\subsection{Sistema de concesiones zonales}

La propuesta concreta para Aragón consiste en establecer zonas de transporte a partir de las rutas estructurantes (mapa 2), que son las que conectan entre sí las ciudades, es decir, la capital regional, las capitales provinciales y las cabeceras supra-comarcales, donde se localizan los servicios de ámbito supra-comarcal, como ya se ha indicado (apartado 3.2.). Cada zona se articula en torno a un eje, con varios nodos, que en su mayor parte coinciden con las cabeceras de las rutas de centralidad. En estos nodos los núcleos de las áreas de influencia respectivas se conectan a la ruta axial mediante transbordos coordinados y así sus habitantes pueden acceder a los núcleos urbanos. Dentro de cada zona el transporte escolar se coordina con el regular, ampliando todo lo posible el número de rutas mixtas en régimen de reserva de plaza.

La propuesta final de zonas de transporte, resultado del proceso iterativo descrito en el apartado de metodología, se recoge en el mapa 5. Puede apreciarse un marcado componente radial, con centro en Zaragoza, la capital regional, como corresponde a la estructura primacial del sistema aragonés de asentamientos. Las dos zonas radiales más importantes son las que tienen como ejes los tramos de autovía que conectan Zaragoza con las otras dos capitales de provincia: Teruel, al sur, y Huesca, al norte, prolongándose este hasta Jaca.

Otras cuatro zonas radiales conectan Zaragoza con cinco de las cabeceras supra-comarcales. Al oeste hay dos: la más meridional conecta Zaragoza y Calatayud, siguiendo la autovía nacional II; la más septentrional se articula desde Zaragoza en torno al eje de la autopista A-68, que se bifurca en dirección a Tarazona y Ejea de los Caballeros. Al este hay otras dos, estructuradas en torno a los ejes que conectan Zaragoza con Fraga y Alcañiz, pequeñas ciudades que aun perteneciendo a las provincias de Huesca y Teruel, respectivamente, tienen más vinculación con la capital regional que con las de su provincia; el primer eje sigue la carretera radial II y el segundo la carretera nacional 232.

Las dos zonas restantes no se vinculan directamente a Zaragoza, sino a las ciudades de Huesca y Teruel. La primera se articula en torno al eje del somontano pirenaico, que dispone de autovía, aunque algunos tramos están sin terminar; conecta Huesca con las cabeceras supra-comarcales de Barbastro y Monzón. La última zona no tiene un eje claramente definido: Teruel es la única ciudad de la misma, a la que sólo acompañan algunas pequeñas cabeceras comarcales; es el área más despoblada y más aislada de Aragón. Se barajaron distintas opciones para esta zona, como integrarla en el eje radial Zaragoza-Teruel, pero resultaba un espacio demasiado extenso y difícil de articular teniendo en cuenta las infraestructuras viarias, o conformar un eje secundario entre Zaragoza y Teruel por Utrillas y Belchite, pero el análisis reveló su escasa viabilidad.

Un principio general aplicado en la propuesta de organización de cada una de las zonas ha sido que todo núcleo de población debería, como mínimo, mantener el mismo nivel de calidad de que ya dispone en servicios de transporte, mejorándolo en todo lo posible. Como ejemplo concreto de propuesta se presenta la de la zona Zaragoza-Calatayud-Valle del Jalón.

4. Orden de la Diputación Foral de Guipúzcoa, de 2 de agosto de 2002, publicada en el Boletín Oficial de Guipúzcoa del 30 de agosto de 2002. Resolución de 30 de noviembre de 2009, del Director General del Consorcio de Transportes de Asturias, publicada en el Boletín Oficial del Principado de Asturias del 4 de enero de 2010. 


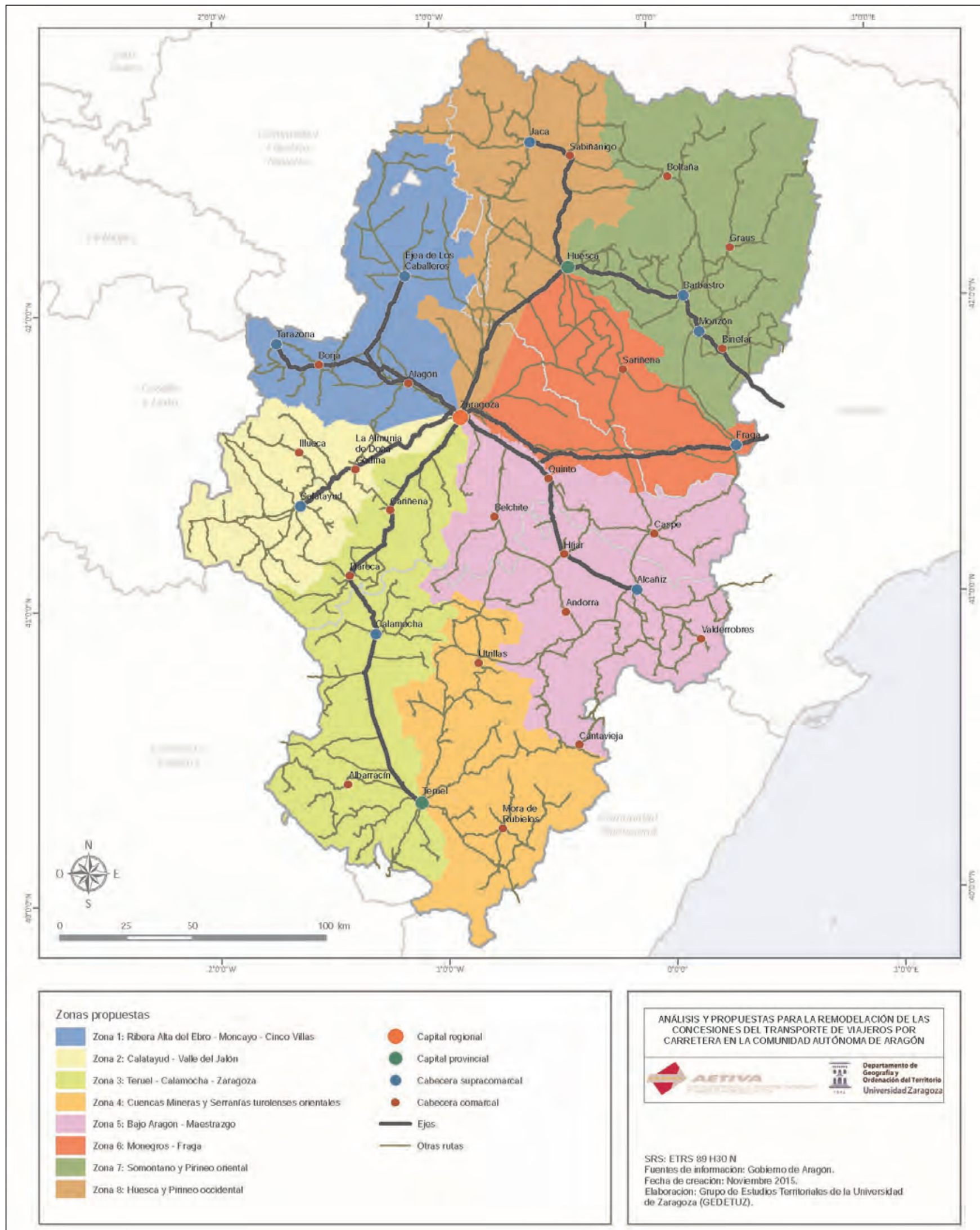

Mapa 5. Propuesta de zonas de transporte para Aragón.

Fuente: Elaboración propia. 
El mapa 6 muestra la estructura básica de la zona con su jerarquía de líneas y de nodos. En cuanto a estos últimos encontramos tres niveles jerárquicos:

a. Nodos principales, que se corresponden con las cabeceras comarcales: Calatayud, La Almunia de Doña Godina e Illueca. En el caso de Aragón se trata de capitales administrativas, como se ha indicado en el apartado 3.2, en las que se ubican los servicios públicos de base. Además, la concentración en ellas de equipamientos comerciales y servicios a la población privados les confiere centralidad y los convierte en lugares atractivos para los habitantes de los núcleos de su entorno.

b. Nodos de trasbordo: Ariza, Alhama de Aragón, El Frasno y Épila. Son lugares situados en cruces de carreteras, cuya posición estratégica en relación con el eje principal los hace idóneos para organizar en ellos transbordos coordinados.

c. Otros nodos, que son los núcleos rurales donde finalizan las rutas escolares, con lo que se abre la posibilidad de trasbordo a líneas regulares. En una buena parte de los casos estos núcleos disponen también de centro de salud.

La estructura de las rutas o líneas es la siguiente:

a. Una línea principal o línea estructurante: Zaragoza-Calatayud

b. Tres líneas secundarias: Illueca-Calatayud, Ariza-Calatayud y Calatayud-Daroca

c. 19 rutas de centralidad, con destino en los nodos principales o de trasbordo.

d. 24 rutas integradas de transporte escolar que finalizan en otros núcleos.

Como ya se ha adelantado, la ruta principal une las ciudades de Zaragoza y Calatayud, pasando por una cabecera comarcal importante, La Almunia de Doña Godina. Esta ruta presta servicio a 32.612 habitantes y para ella se propone una frecuencia de 10 expediciones por sentido en día laborable. En las rutas principales o estructurantes de cada zona se propone un aumento de frecuencias, que se fundamenta en una mayor afluencia de viajeros derivada de una mejor coordinación horaria con las rutas de menor rango. Además, en este caso concreto, el aumento de frecuencias también se sustenta en la eliminación de una importante restricción, pues el tráfico actual entre Calatayud y Zaragoza es operado por una empresa diferente a la de la línea entre La Almunia y Zaragoza.

Las líneas secundarias son de dos tipos. El primero incluye rutas de centralidad que atienden los flujos de mayor importancia; son dos, que discurren íntegramente por la zona, afluyendo al eje en determinados nodos: Ariza-Ateca-Calatayud, por la parte occidental, siguiendo la autovía nacional II, y la que recorre la comarca del Aranda, pasando por su capital Illueca, hasta Calatayud. El segundo tipo de rutas secundarias incluye las que conectan con nodos principales situados en zonas de transporte vecinas, como la Calatayud-Daroca, pasando por Morata de Jiloca, cuya necesidad deriva del hecho de que la comarca de Daroca está incluida en el sector sanitario de Calatayud, donde se ubica el hospital de referencia, con los servicios anejos de especialidades médicas en consulta externa. La mejora de las líneas secundarias se fundamenta en el ahorro de kilómetros realizado por la eliminación de restricciones de tráfico, la creación de puntos de trasbordo o la eliminación de solapes con las líneas principales. La ruta entre Illueca y Calatayud es un buen ejemplo de la propuesta planteada, ya que gracias a la instauración del nodo de trasbordo de El Frasno, los viajeros de la línea pueden trasbordar en dirección a Zaragoza. Esto ha permitido eliminar la única expedición por sentido de esta zona con Zaragoza, sin perder oportunidades de viaje.

El mapa se completa con otras rutas de menor jerarquía, cuya función es acercar a los viajeros a alguno de los nodos, donde podrán terminar viaje si el motivo del mismo es utilizar los servicios que en él se ofrecen, o continuar, mediante transbordo coordinado, hacia un núcleo de población de mayor rango jerárquico. Este tipo de rutas adolece de dos problemas que se retroalimentan: un bajo número de viajeros, y un bajo número de expediciones. Para paliar el primero se propone movilizar un mayor número de escolares mediante el uso de la reserva de plaza. En cuanto al segundo, estas rutas de centralidad ven mejorado su nivel de frecuencia gracias a la integración del transporte escolar.

Así las rutas escolares en integración amplían durante el curso escolar el sistema de transporte regular sin coste alguno, mejorando la calidad del servicio en aquellas áreas de mayor carácter rural, que es preci- 


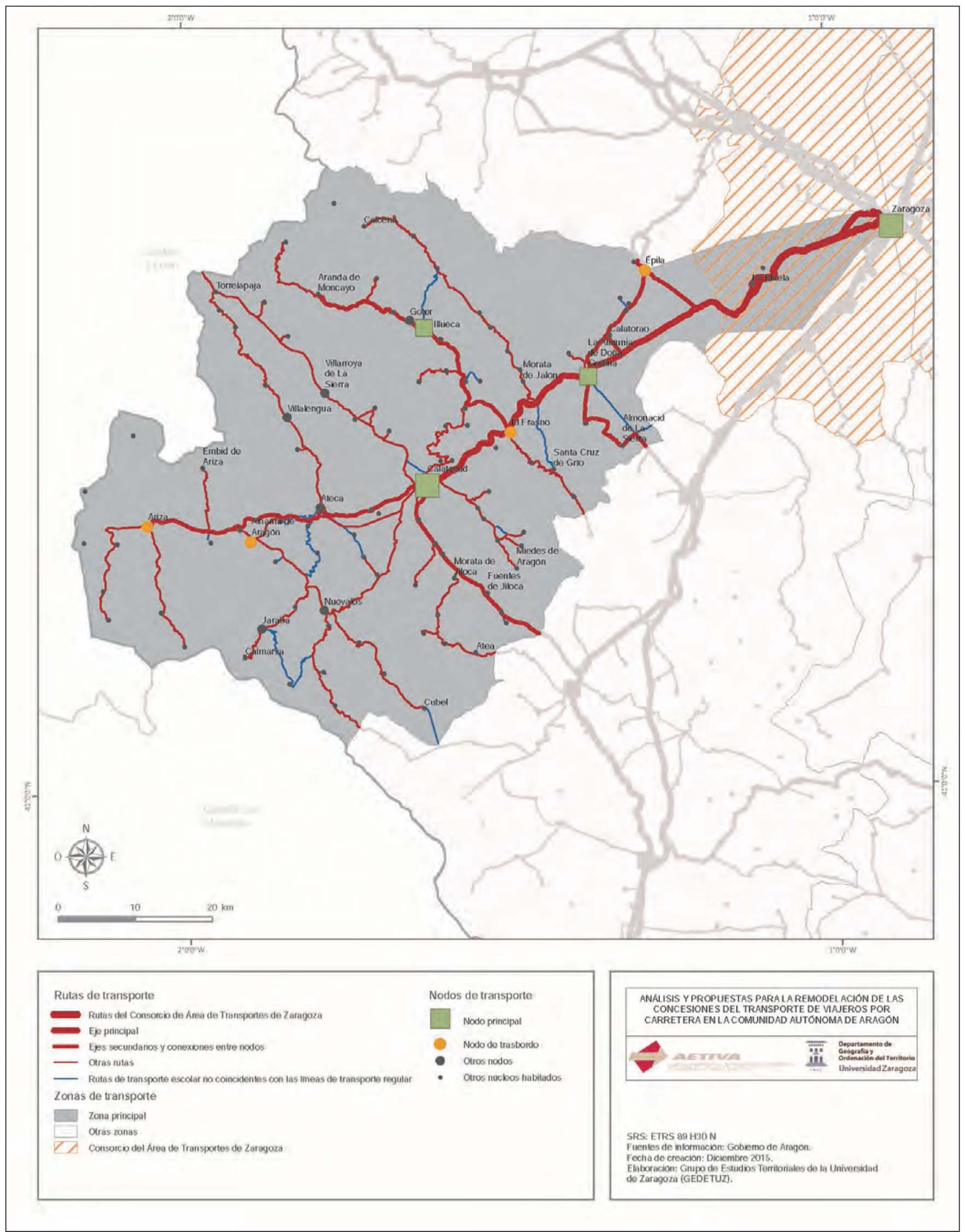

Mapa 6. Nodos y rutas planificados para la zona Zaragoza-Calatayud-Valle del Jalón. Fuente: Elaboración propia. 
samente donde más se necesita. Estas rutas suponen, por un lado, un aumento de la frecuencia hacia los núcleos de destino del transporte escolar, donde existen otros servicios de transporte regular y, por otro, la creación de nuevos itinerarios que atienden a núcleos muy pequeños que carecen de servicio regular en la actualidad, con lo que garantizarían unos servicios mínimos de lunes a viernes durante todo el curso escolar. A escala de toda la comunidad autónoma, estas rutas mejoran las oportunidades de viaje para más de 50.000 personas que residen en pequeños núcleos, dando servicio además a 157 núcleos que ahora no tienen transporte regular, en los que en 2018 vivían 8.265 personas.

Las rutas programadas cubren la práctica totalidad de la zona, pero aún quedan algunos pequeños núcleos de población sin servicio. La solución que se propone para ellos es la implantación de un sistema de transporte a la demanda, término que "ha sido crecientemente aplicado en los últimos diez años a un nicho de mercado que sustituye y complementa el transporte convencional allá donde la demanda es pequeña y a menudo está dispersa por una extensa área" (Brake, J. et al, 2004, 324). El transporte a la demanda está ampliamente extendido por diversos países, como el Reino Unido (Laws, R. et al, 2009), y se ha implementado también en regiones españolas, como Castilla y León (Delgado, J.M. y Martínez, L.C., 2016), semejante a Aragón en cuanto a densidad demográfica y estructura territorial. El transporte a la demanda en esencia consiste en que el demandante comunica a la empresa su necesidad de viajar y ésta le ofrece la mejor opción dentro de su oferta, normalmente alargando hasta la localidad del viajero una de las expediciones que llega o parte de alguna localidad vecina. El aviso debe hacerse con una antelación razonable, mayor o menor en función del sistema que se implemente: los centros coordinadores disponen de un servicio de atención telefónica; además, una buena aplicación informática puede transmitir en tiempo real la demanda al autobús, junto con las instrucciones para el conductor.

Recapitulando, tal como se ha visto en el caso de Calatayud-Zaragoza, cada zona se estructura en torno a una ruta principal que conecta entre sí las ciudades. A esa ruta principal afluyen las demás en determinados nodos, donde se efectúan transbordos coordinados que permiten continuar viaje hasta los destinos principales. Dentro de cada zona el transporte escolar se coordina con el regular, ampliando todo lo posible el número de rutas mixtas: la reserva de plaza permite suprimir numerosas rutas escolares normales, sin disminuir las oportunidades de viaje de los usuarios de transporte regular ni de los alumnos. La integración, por su parte, amplía durante el curso escolar el sistema de transporte regular sin coste alguno. La implementación de sistemas de transporte a la demanda permite conectar al resto de núcleos en condiciones satisfactorias para usuarios y empresas.

Al estimar los parámetros de la propuesta, para compararlos con los de la situación actual, se ha partido de los siguientes supuestos: el primero de ellos, teniendo en cuenta las proyecciones demográficas recogidas en el apartado 3.1., es que el número de viajeros apenas variará, experimentando sólo un ligero crecimiento del 1,4\%, efecto esperable de la coordinación de horarios, la eliminación de restricciones, la creación de nuevos servicios y la puesta en marcha del transporte a la demanda. El segundo supuesto es que los costes unitarios se van a mantener constantes, si bien se trata de una hipótesis conservadora, pues las economías de escala derivadas de la organización zonal previsiblemente producirán una reducción de los mismos. El tercero es que el precio de los billetes se mantendrá también constante. En el cuadro 1 se recogen los resultados de la comparación de dicha estimación con la situación actual.

El número de viajeros apenas crecerá, pero se producirá un trasvase importante del transporte escolar al regular, gracias a la expansión de la reserva de plaza para estudiantes de secundaria en los autobuses de línea; ello permitirá aprovechar mejor los recursos disponibles, con la consiguiente reducción de costes. El número de kilómetros recorridos en un año por los autobuses disminuirá en una octava parte, gracias a la sustitución de líneas de transporte escolar específicas por la reserva de plaza; se trata de un ahorro considerable, que además no repercutirá negativamente en la calidad, pues en la propuesta no se ha suprimido -sólo reorganizado- ninguno de los servicios existentes. Los costes de explotación del sistema se reducirán en la misma proporción, teniendo en cuenta el supuesto de partida de costes unitarios invariables.

La recaudación por tarifa disminuirá casi un 5\%, como efecto combinado del ligero incremento del número de viajeros, la fuerte reducción de los kilómetros recorridos y el supuesto de precios constantes. Conviene destacar en este aspecto que la recaudación subirá un $25 \%$ en el transporte regular, pero se reducirá un 
Cuadro 1. Variación de los principales parámetros entre la situación actual y la propuesta zonal (\%).

\begin{tabular}{|c|c|c|c|c|c|c|c|}
\hline & $\begin{array}{l}\text { Tipo de } \\
\text { transporte }\end{array}$ & Viajeros & Kilómetros & $\begin{array}{l}\text { Costes de } \\
\text { explotación } \\
(€)\end{array}$ & $\begin{array}{l}\text { Recaudación } \\
\text { por tarifa }(€)\end{array}$ & Déficit (€) & $\begin{array}{c}\text { Recaudación } \\
\text { sobre costes } \\
\text { (\%) }\end{array}$ \\
\hline \multirow{3}{*}{$\begin{array}{l}\text { Situación } \\
\text { de partida } \\
\text { (2013) }\end{array}$} & Regular & 3.974 .506 & 12.734 .106 & 20.796 .382 & 13.033 .084 & -7.763 .297 & 62,67 \\
\hline & Escolar & 4.581 .846 & 8.454 .248 & 13.436 .042 & 13.436 .042 & 0 & 100 \\
\hline & Total & 8.556 .352 & 21.188 .354 & 34.232 .424 & 26.469 .127 & -7.763 .297 & 77,32 \\
\hline \multirow{3}{*}{$\begin{array}{l}\text { Propuesta } \\
\text { (2017) }\end{array}$} & Regular & 5.900 .030 & 12.780 .939 & 21.016 .234 & 16.289 .001 & -4.727 .233 & 77,51 \\
\hline & Escolar & 2.778 .556 & 5.711 .032 & 8.929 .079 & 8.929 .079 & 0 & 100 \\
\hline & Total & 8.678 .586 & 18.491 .970 & 29.945 .313 & 25.218 .080 & -4.727 .233 & 84,21 \\
\hline \multirow{3}{*}{$\begin{array}{l}\text { Tasa de } \\
\text { variación (\%) }\end{array}$} & Regular & 48,45 & 0,37 & 1,06 & 24,98 & $-39,11$ & 23,68 \\
\hline & Escolar & $-39,36$ & $-32,45$ & $-33,54$ & $-33,54$ & - & 0 \\
\hline & Total & 1,43 & $-12,73$ & $-12,52$ & $-4,73$ & $-39,11$ & 8,91 \\
\hline
\end{tabular}

Fuente: Gobierno de Aragón: Transporte público interurbano de viajeros por carretera en Aragón [https://opendata. aragon.es/datos/catalogo/dataset/transporte-regular-de-viajeros-por-carretera-en-aragon] y elaboración propia.

33,5\% en el escolar. Téngase en cuenta a este respecto que la administración pública sufraga íntegramente los billetes de los escolares, sea cual sea el sistema en que viajen, pero el sistema de reserva de plaza es más económico (Badía, R., 2016), por lo que su expansión supone un ahorro para el erario público. ${ }^{5}$

Combinando costes y recaudación resulta una caída del déficit de explotación estimada en un 39\%, pues la reducción de costes será superior a la de la recaudación. Esta caída afectará al transporte regular, pues en el escolar no tiene sentido hablar de déficit, dado que el coste lo sufraga íntegramente la administración pública. Con ello la proporción de los costes cubierta por la recaudación pasaría del 63 al 78\% en el transporte regular o, considerando las cifras globales, del 77 al $84 \%$.

Con los supuestos de partida, especialmente el de garantizar unos servicios con al menos la misma calidad que los actuales, no es posible eliminar por completo el déficit de explotación, aunque sí reducirlo considerablemente. En la situación de partida las administraciones públicas regionales aportan 4,2 millones de euros en subvenciones a las empresas, pero éstas aún tienen que cubrir un déficit de 3,5 millones. El déficit estimado en la propuesta zonal es de 4,7 millones de euros, que se podría cubrir casi íntegramente manteniendo el volumen actual de las aportaciones públicas.

\subsection{La propuesta zonal y el plan del gobierno de aragón}

Como ya se ha indicado (nota 1), la propuesta aquí presentada es el producto final de un contrato de I+D+i firmado por la asociación de empresarios AETIVA y la Universidad de Zaragoza. Una vez redactado el informe por parte del equipo investigador, los empresarios lo pusieron a disposición del Gobierno regional. Este realizó su propio estudio, pero no pudo tener elaborado a tiempo el nuevo mapa de concesiones, prorrogando las vigentes, que caducaban en 2017. En octubre de 2018 publicó una resolución en la que sometía al trámite de información pública el nuevo mapa concesional, desglosado en 19 anteproyectos de explotación del servicio (Gobierno de Aragón, 2018), no habiéndose dado ningún otro paso desde entonces hasta las

5. En el diagnóstico, utilizando datos del Gobierno de Aragón, pudo determinarse que el coste medio por alumno de secundaria y día en régimen de reserva de plaza ascendía a 3,39 euros, frente a 4,76 en una ruta escolar normal. 
elecciones autonómicas de 26 de mayo de 2019; la formación del nuevo Gobierno seguramente retrasará en varios meses el desarrollo del proceso.

En la citada resolución se asume el modelo de concesión zonal, pues cada uno de los 19 anteproyectos corresponde a un "área" claramente delimitada. Estas áreas se dividen en dos grandes grupos: 4 de carácter metropolitano, ubicadas en el entorno de Zaragoza, y 15 interurbanas, que se reparten el resto del territorio regional. Algunas de estas últimas coinciden en alto grado con las de nuestra propuesta (mapa 7), siendo la principal diferencia la forma de considerar el área metropolitana de Zaragoza, que nosotros no hemos segregado de cada una de las zonas radiales en torno a la ciudad. Se aprecian coincidencias sustanciales en las zonas 1 (Jaca-Huesca-Zaragoza), 11 (Teruel-Calamocha-Zaragoza) y 13 (Calatayud-Zaragoza), si bien en la segunda no se incluye la comarca de Albarracín y la última incorpora el bajo valle del Jalón. Las restantes zonas de nuestra propuesta aparecen en la del Gobierno fragmentadas en dos o más, aunque grosso modo coinciden los límites agregados.

La justificación del modelo zonal que hace el Gobierno de Aragón se fundamenta en la generación de economías de escala derivadas de la concentración de contratos y la eliminación de las duplicidades de

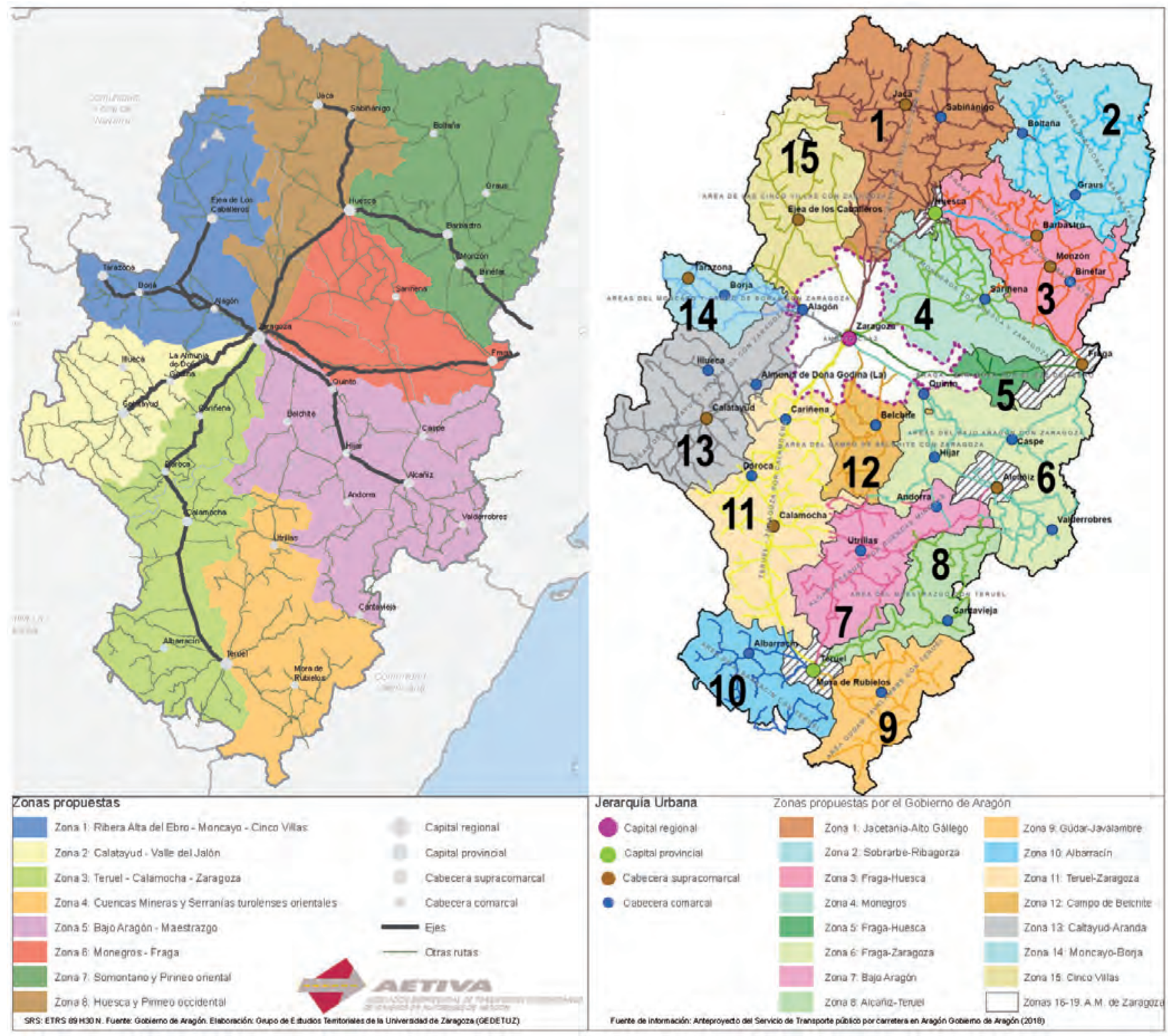

Mapa 7. Zonas de transporte propuestas y futuro mapa concesional de Aragón. Fuente: Gobierno de Aragón (2018) y elaboración propia. 
tráfico. Es una línea argumental plenamente coincidente con la desarrollada en este artículo. No obstante, el Gobierno regional ha optado por una concentración menor que la propuesta por nosotros, lo que traerá consigo que la generación de economías de escala será más modesta y, sobre todo, que no se podrán eliminar muchas duplicidades de tráfico. Esta afirmación puede ilustrarse con los dos ejemplos siguientes:

En primer lugar, la delimitación de las zonas 2 y 3 parte en dos un mismo espacio funcional, dando lugar a una fuerte asimetría: en la zona 3 es donde se localizan el eje viario principal y las centralidades de mayor rango (Huesca, Barbastro y Monzón); la zona 2 es un área de montaña de baja densidad demográfica y pequeños núcleos de población, por lo que resulta muy difícil generar en ella economías de escala significativas. Por otra parte, esta zona depende funcionalmente de Barbastro, donde se localiza, entre otros servicios importantes, el hospital de referencia, por lo que lo más lógico sería que se integrase en la misma zona de transporte que la ciudad de la que depende, tal como nosotros hemos propuesto.

El segundo ejemplo es el de las zonas 14 y 15. Con esa división no se podrán evitar duplicidades de tráfico, porque las líneas de Tarazona a Zaragoza y de Ejea de los Caballeros a Zaragoza coinciden en una buena parte de su recorrido, aunque en el anteproyecto se suprimen las restricciones de tráfico. Esa es la razón de que nosotros propusiéramos integrarlas en una sola zona, porque de esa manera se podrían organizar las rutas con una mayor coordinación, recurriendo a transbordos que mejorarían las posibilidades de viaje con la capital regional y entre las dos cabeceras supra-comarcales.

La zonificación de la propuesta del Gobierno de Aragón hace que las situaciones descritas en los ejemplos anteriores se repitan en otras zonas: la generación de economías de escala significativas queda en entredicho en las zonas 4, 7, 8, 9, 10 y 12, donde la densidad de población es muy baja (mapa 1).

La duplicidad de tráficos afectará claramente a todas las zonas que rodean el espacio metropolitano de Zaragoza. Consciente de este problema, la resolución del Gobierno establece lo siguiente: "en el ámbito del Consorcio de Transportes del Área de Zaragoza se planificarán las líneas pasantes interurbanas de tal manera que complementen los servicios consorciales planificados por el propio CTAZ, alcanzando conjuntamente por ambos tipos de líneas, e incluso mejorando, los objetivos definidos en las Directrices Metropolitanas de Movilidad de Zaragoza" (Gobierno de Aragón, 2018). De donde se desprende que la coordinación estará orientada a la consecución de los objetivos del espacio metropolitano, lo cual parece implicar la subordinación de los espacios no metropolitanos.

Por otra parte, y esta es una diferencia radical respecto a nuestra propuesta, no se plantea la gestión conjunta de transporte regular y escolar, que sólo se menciona como una mera posibilidad para un futuro indeterminado: "Todo esto sin perjuicio de que en un futuro pudieran integrarse los servicios regulares de uso especial (transporte escolar de titularidad pública)" (Gobierno de Aragón, 2018). Sí se hace mención de las líneas en reserva de plaza existentes, que continuarán como tales.

Al margen de las observaciones críticas previas, la propuesta del Gobierno de Aragón va a suponer una mejora significativa en cuanto a la población y los núcleos atendidos por el transporte público, cuyo número se incrementará hasta el punto de que todos los núcleos de más de 10 habitantes tendrán al menos un servicio por semana. Para estos casos se prevé el establecimiento de sistemas de transporte a la demanda.

Como elemento final queda la valoración económica. Es difícil hacer una comparación precisa y rigurosa entre nuestra propuesta y la del Gobierno de Aragón, habida cuenta de que los supuestos de partida son diferentes: el Gobierno ha calculado los costes al momento presente y fijado las tarifas que considera adecuadas, mientras que en nuestra propuesta asumíamos costes y tarifas constantes respecto a la situación de partida. No obstante, vale la pena tomar en consideración, a modo de ejemplo, la zona de Calatayud, que es una de las más parecidas en ambos casos (cuadro 2).

El Gobierno de Aragón asume que el sistema de transporte va a generar déficit, que se compromete a sufragar íntegramente. Esto contrasta con el planteamiento tradicional de las concesiones de líneas de autobús, que se llevaban a cabo "a riesgo y ventura", planteamiento que ha cambiado últimamente al afianzarse la consideración del transporte como un derecho que la administración pública debía garantizar y, en caso necesario, sufragar. El déficit que está dispuesto a asumir en este caso es superior a la mitad de los costes de explotación. Nuestra propuesta arroja un déficit y, en consecuencia, una necesidad de financiación pública inferior. Aunque las cifras no sean estrictamente comparables, como ya se ha indicado, la diferencia resulta 
Cuadro 2. Valoración económica anual de la zona de transporte de Calatayud.

\begin{tabular}{|c|c|c|c|}
\hline & \multirow{2}{*}{ Gobierno de Aragón } & \multicolumn{2}{|c|}{ Propuesta propia } \\
\hline & & Transporte regular & Transporte total* \\
\hline Costes de explotación & 2.272 .559 & 1.961 .035 & 2.720 .207 \\
\hline Ingresos tarifarios & 1.006 .793 & 1.667 .788 & 2.426 .960 \\
\hline Déficit = Subvención & 1.265 .766 & 293.247 & 293.247 \\
\hline Ingresos sobre costes (\%) & 44,3 & 85,0 & 89,2 \\
\hline Subvención sobre costes (\%) & 55,7 & 15,0 & 10,8 \\
\hline
\end{tabular}

*Incluye transporte regular y transporte escolar; este último no se contempla en la propuesta del Gobierno de Aragón. Fuente: Gobierno de Aragón (2018) y elaboración propia.

coherente con las observaciones previamente realizadas sobre las economías de escala, las duplicidades de tráficos, la menor utilización de trasbordos y, sobre todo, la no integración de transporte escolar y regular. Al final todo se traduce en unos costes más elevados, que repercutirán en el erario público.

\section{CONCLUSIONES}

La movilidad es un derecho ciudadano, cuya garantía es responsabilidad de la administración pública, que debe diseñar un sistema de transporte colectivo que satisfaga las necesidades de la población, especialmente la de quienes no tienen posibilidades de acceso a medios de transporte privados (Belintxon, U., 2016; Farrington, J. y Farrington, C., 2005). El Gobierno de Aragón, ante la caducidad simultánea de todas las concesiones de tráfico interno, trabaja en su remodelación, contando con un estudio previo de los empresarios.

Este estudio ha confirmado la dificultad de organizar un buen servicio de transporte en zonas de baja densidad demográfica (Gutiérrez, J., 1988). Como revela el diagnóstico, la calidad del servicio es buena para la mayor parte de la población aragonesa, pero claramente insuficiente en casi la mitad del territorio, precisamente el menos densamente poblado. Otros trabajos han llegado a conclusiones similares para el caso de otras áreas españolas, como Castilla y León (Delgado, J.M. y Martínez, L.C., 2016), Navarra (Pons, J.J. y Betelu, A., 2004) o la provincia de Albacete (Fernández, F., 1999).

Se ha demostrado que es posible mejorar la calidad del sistema reduciendo a la vez los costes de explotación. Los sistemas basados en concesiones lineales presentan disfunciones importantes, lo que implica un aprovechamiento ineficiente de los recursos disponibles, que repercute en un peor servicio a la población y un mayor coste económico. La clave está en un sistema basado en contratos de gestión zonales, que permite organizar de forma flexible y coordinada las líneas de autobús. La jerarquización de rutas, la elección de nodos estratégicos y el recurso sistemático a transbordos con horarios coordinados crea nuevas oportunidades de viaje para las personas (Carbonell, M., 2018), reforzando destinos ya existentes y creando otros nuevos, con un ahorro considerable de kilómetros y costes de explotación.

La gestión conjunta del transporte regular y el escolar evita duplicidad de rutas de autobús: la generalización de la reserva de plazas escolares en el transporte regular permite ahorrar muchos kilómetros, con la consiguiente reducción de costes. La admisión de pasajeros regulares en líneas de transporte escolar crea nuevas oportunidades de viaje precisamente en los espacios rurales de menor densidad de población, sin generar costes adicionales (Badía, R., 2016; Carbonell, M., 2018). El sistema se completa con la implantación del transporte a la demanda, que permite llegar prácticamente a todas partes cuando es necesario, en condiciones razonables para usuarios y empresas (Delgado, J.M. y Martínez, L.C., 2016; Laws, R. et al., 2009).

El sistema de contratos de gestión zonales ha sido asumido por el Gobierno de Aragón, que se incorpora así a otros que ya lo han hecho, como el de Asturias. El proyecto de nuevo mapa concesional supone una 
mejora respecto a la situación actual, pero nace con poca ambición, pudiendo pronosticarse que no resolverá bien los problemas, sobre todo porque no incorpora el transporte escolar, que seguirá siendo una red paralela.

Esa falta de ambición tiene efectos económicos, que el Gobierno reconoce en forma de déficit de explotación en las zonas, aceptando que ese déficit no debe recaer sobre las empresas, como sucede ahora parcialmente, sino que debe ser cubierto por el erario público, pues se trata de un servicio que garantiza un derecho ciudadano. Este es el verdadero sentido del contrato de gestión, frente al tradicional de prestación de servicio a riesgo y ventura. Constituye una garantía para las empresas y obliga a la administración a ser rigurosa en el manejo del dinero de todos. Nuestro estudio concluye también que es imposible acabar con el déficit, pero nuestros cálculos apuntan a una reducción importante respecto a la situación actual, con unas cifras muy inferiores a las del proyecto del Gobierno. La causa es que la integración del transporte escolar con el regular y la delimitación de zonas de mayor extensión y coherencia interna tienen como resultado una notable reducción de costes. Este mayor ahorro de recursos podría utilizarse para reforzar el sistema aquí propuesto bajo los principios anteriormente expuestos, lo que mejoraría la accesibilidad rural.

\section{REFERENCIAS}

Badía R. (2016). Las posibilidades de integración del transporte regular y escolar en Aragón. Geographicalia, 68, 1-24. doi: https://doi.org/10.26754/ojs_geoph/geoph.2016681579

Bachiller-Martínez, J.M. y Molina de la Torre, I. (2014). La localización de servicios y equipamientos en el medio rural: claves para la articulación territorial de Castilla y León. Ería, 93, 77-100.

Belintxon-Martin, U. (2016). Derecho internacional privado y transporte de viajeros por carretera: algunas cuestiones sobre jurisdicción y ley aplicable. Cuadernos de Derecho Transnacional, 8(1), 17-35.

Boquete-Sánchez, D. (2018). Transporte escolar en Galiza. Outra oportunidade perdida. Revista galega de educación, 72, 40-42.

Brake, J., Nelson, J.D. \& Wright, S. (2004). Demand responsive transport: towards the emergence of a new market segment. Journal of Transport Geography, 12, 323-337. doi: https://doi.org/10.1016/j.jtrangeo.2004.08.011

Carbonell-Alemany, M. (2018). Estudio y diseño de una red de transporte público interurbano en las comarcas de “L'Alcoià” y "El Comtat". 3C Tecnología: glosas de innovación aplicadas a la pyme, 7(1), 20-42. doi: https://doi.org/10.17993/3ctecno.2018.v7n1e25.20-42

Comisión Europea (1999). Estrategia territorial europea. Hacia un desarrollo equilibrado y sostenible del territorio de la UE. Luxemburgo: Oficina de Publicaciones de la Unión Europea.

Delgado-Urrecho, J. M. y Martínez Fernández, L.C. (2016). El transporte a la demanda como sistema de movilidad alternativo en áreas rurales de baja densidad demográfica: el caso de Castilla y León. Boletín de la Asociación de Geógrafos Españoles, 72, 195-220. doi: https://doi.org/10.21138/bage.2337

Delgado-Urrecho, J. M. (2018). Más allá del tópico de la España vacía: una geografía de la despoblación. En Informe España 2018 (pp. 232-295). Madrid: Universidad Pontificia Comillas, Catedra J.M. Martin Patino.

Escolano-Utrilla, S. y De la Riva-Fernández, J. (2003). Marco conceptual y metodológico del estudio de los procesos de despoblación. En Escolano Utrilla, S. y De la Riva Fernández, J. (Ed), Despoblación y ordenación del territorio (pp. 7-14). Zaragoza: Institución Fernando el Católico.

Farrington, J., Farrington, C. (2005). Rural accessibility, social inclusion and social justice: towards conceptualisation. Journal of Transport Geography, 13, 1-12. doi: https://doi.org/10.1016/j.jtrangeo.2004.10.002

Fernández-Santamaría, F. (1999). Transporte público de viajeros por carretera y accesibilidad en la provincia de Albacete. Ensayos. Revista de Estudios de la Escuela Universitaria de Magisterio de Albacete, 14, 27-41.

Garrido-Palacios, J. (2002). Política de transporte y accesibilidad en Europa. Estudios Geográficos, 63 (246), 49-67. doi: https://doi.org/10.3989/egeogr.2002.i246.260

Gobierno de Aragón (2014). Estrategia de Ordenación Territorial de Aragón. Boletín Oficial de Aragón, 243 (12/12/2014).

Gobierno de Aragón (2018). Resolución de 29 de octubre de 2018, de la Dirección General de Movilidad e Infraestructuras, por la que se aprueban y someten al trámite de información pública los diecinueve anteproyectos de explota- 
ción del servicio de Transporte Público Regular de Viajeros por Carreteras de Aragón. Boletín Oficial de Aragón, 213 (05/11/2018).

Guirao, B. y Briceño, D. (2006). First study on mobility for a medium size town: Ciudad Real, a Spanish experience. WIT Transactions on Ecology and the Environment, 93. Recuperado de https://www.witpress.com/elibrary/wit-transactions-on-ecology-and-the-environment/93/16893 Último acceso: 12 de marzo de 2019. doi: https://doi.org/10.2495/ SC060621

Gutiérrez-Puebla, J. (1988). Accesibilidad y transporte rural. Una perspectiva social. Revista del Ministerio de Transportes, Turismo y Comunicaciones, 34, 27-40. doi: https://doi.org/10.3989/egeogr.2001.i242.295

Gutiérrez-Puebla, J. (2001). Escalas espaciales, escalas temporales. Estudios Geográficos, 62 (242), 92-97.

Laws, R., Enoch, M. \& Ison, S. (2009). Demand Responsive Transport: a Review of Schemes in England and Wales. Journal of Public Transportation, 12 (1), 19-37. doi: https://doi.org/10.5038/2375-0901.12.1.2

Lopez-Lara, E. (1989). Sobre la articulación a escala intermedia en Andalucía. Análisis de la estructura empresarial y territorial de las líneas de transporte público de pasajeros por carretera. Revista de Estudios Andaluces, 13, 79-101. https://doi.org/10.12795/rea.1989.i13.05

Martínez Sánchez-Mateos, H. S. (2012). La accesibilidad regional y el efecto territorial de las infraestructuras de transporte. Aplicación en Castilla-La Mancha. Boletín de la Asociación de Geógrafos Españoles, 59, 79-103.

Mora-Aliseda, J., Nogales-Galán, J. M., Gutiérrez-Gallego, J. A. y Cortés-Ruiz, T. (2003). Aplicación de técnicas SIG en la planificación del transporte por carretera en Extremadura (España). Finisterra, 38 (75), 67-83. doi: https://doi. org/10.18055/Finis1580

Pérez-Díaz, J., Abellán-García, A. (2018). Envejecimiento demográfico y vejez en España. Panorama Social, 28, 11-47.

Pons-Izquierdo, J.J. y Betelu-Corcuera, A. (2004). Accesibilidad territorial al transporte público interurbano de viajeros en Navarra. En Quinto Congreso de Economía de Navarra (pp. 216-234). Pamplona: Gobierno de Navarra.

Rojo-Arce, M. (2011). Modelización de la interrelación entre las variables de servicio y la demanda de viajeros de autobuses de tipo interurbano. Burgos: Universidad de Burgos. Recuperado de http://riubu.ubu.es/handle/10259/162 Último acceso: 17 de mayo de 2019.

Ruiz, M., Seguí-Pons, J. M., Mateu-Lladó, J., y Martínez-Reynés, M. R. (2016). Evaluación de la equidad del servicio de transporte público: el caso de Palma de Mallorca. Estudios Geográficos, 77(281), 619-646. doi: https://doi.org/10.3989/ estgeogr.201621

Sánchez-Portales, S. (2015). El sistema concesional de transporte público regular de viajeros de uso general por carretera en Andalucía. Presente y futuro. Málaga: Universidad de Málaga. Recuperado de http://orcid.org/0000-0001-9604-8858 Último acceso: 17 de mayo de 2019

Sanchis-Deusa, M. C. (1987). Redes de transporte público de viajeros por carretera y delimitación comarcal en el país valenciano. Cuadernos de Geografía, 42, 181-192.

Serrano-Martínez, J. M. (1987). Comunicaciones terrestres y sistema urbano en la región de Murcia. Anales de Geografía de la Universidad Complutense 7, 625-633.

Smith, N., Hirsch, D. \& Davis, A. (2012). Accessibility and capability: the minimum transport needs and costs of rural households. Journal of Transport Geography, 21, 93-101. doi: https://doi.org/10.1016/j.jtrangeo.2012.01.004 


\title{
Sectores Estratégicos en la Economía del Conocimiento y Desarrollo en la Ciudad de Madrid y su Región*
}

\section{Strategic Sectors in the Knowledge Economy and Development in the City of Madrid and its Region}

\author{
Simón Sánchez-Moral \\ simon.sanchez@ghis.ucm.es @ https://orcid.org/0000-0001-6381-2653 \\ Roberto Díez-Pisonero \\ rdpisonero@ghis.ucm.es @ https://orcid.org/0000-0002-7817-628X \\ Cándida Gago-García \\ cgago@ucm.es@ https://orcid.org/0000-0003-2315-7943 \\ Universidad Complutense de Madrid. Facultad de Geografía e Historia. \\ c/ Profesor Aranguren s/n. Madrid-28040
}

Alfonso Arellano-Espinar

alfonso.arellano@pdi.ucm.es @ https://orcid.org/0000-0002-1464-8751

Universidad Complutense de Madrid. Facultad de Ciencias Económicas y Empresariales.

Campus de Somosaguas 28223 - Pozuelo de Alarcón (MADRID)

\section{INFO ARTÍCULO}

Recibido: $1 / 5 / 2019$

Revisado: 6/6/2019

Aceptado: 7/6/2019

\section{PALABRAS CLAVE}

Sectores estratégicos

Innovación

Redes empresariales

Estrategias urbanas

\section{KEYWORDS}

Strategic sectors

Innovation

Firm networks

Urban strategies

\begin{abstract}
RESUMEN
Diversas agendas internacionales (OCDE, Europa 2020) recogen la apuesta por las actividades intensivas en conocimiento e innovación. El objetivo de esta investigación es analizar el carácter estratégico de las industrias de alta intensidad tecnológi$\mathrm{ca}$, los servicios intensivos en conocimiento y las industrias culturales en Madrid. Se comienza revisando el planteamiento de los sectores estratégicos en grandes capitales europeas. El análisis de las redes empresariales confirma la importancia de estos sectores en la conexión global de Madrid y en la articulación de sus flujos económicos, pero también lo heterogéneo de las dinámicas temporales y espaciales del empleo. Sin perder de vista la tendencia a replicar la selección sectores estratégicos similares entre las grandes ciudades, su protagonismo en las estrategias de desarrollo urbano y regional estaría sólidamente fundamentado en el caso de Madrid.
\end{abstract}

\begin{abstract}
Different international agendas (OECD, Europe 2020) consider the promotion of knowledge based activities and innovation. The objective of this research is to analyze the strategic role of high technology-intensive industries, knowledge-intensive services and the cultural industries in Madrid. The paper begins by reviewing the approaches to strategic sectors in large European capitals. The analysis of firm networks in the region confirms the importance of these sectors in Madrid's global connections and the articulation of their economic flows, but also the heterogeneous nature of the temporal and spatial trends of employment. Without losing sight of the tendency by large cities to replicate the selection of similar strategic sectors, their role in urban and regional development strategies would have a solid base in the case of Madrid.
\end{abstract}

* Este trabajo se enmarca dentro del proyecto “ Atracción de talento, innovación y creatividad para el desarrollo inteligente de la ciudad-región de Madrid" Ref. CSO2016-74888- C4-4-R (AEI/ FEDER, UE). 


\section{INTRODUCCIÓN: HACIA UN MARCO INTERPRETATIVO SOBRE SECTORES ESTRATÉGICOS Y COMPETITIVIDAD URBANA}

El proceso de globalización y la creciente integración de la economía mundial han favorecido niveles crecientes de competencia entre empresas y entre territorios. En este contexto, las ciudades buscan asegurar la generación de ventajas competitivas dinámicas, las cuales se fundamentarían en una dotación muy destacada de recursos específicos de calidad, más o menos tangibles, como empleo cualificado, servicios avanzados y las infraestructuras de comunicación; pero sobre todo a través de redes de colaboración empresariales y socio-institucionales que impulsan los procesos de innovación (Salom, J. y Albertos, J.M., 2009; Musterd, S. y Murie, A., 2010). Las grandes ciudades verían así reforzada su posición a la cabeza del sistema urbano, especializándose en sectores y funciones de mayor rango, destacando aquellas más intensivas en el uso de tecnología y conocimiento (Scott, A.J., 2008 y 2009; Méndez, R. y Sánchez Moral, S., 2011).

Muchas de estas actividades forman parte de lo que hace décadas Machlup ya identificó como sectores con alta intensidad de conocimiento, relacionados con las tecnologías y los servicios de información, la educación, el I+D, la creación artística o los medios de comunicación (Machlup, F., 1962). También se relaciona con las propuestas de K. Pavitt (1984), quien añadió la perspectiva de la intensidad tecnológica y el tipo de innovaciones predominantes en las distintas actividades. A partir de aquí, distintos organismos internacionales, como UNCTAD, OCDE o Eurostat, han tratado de acotar los límites sectoriales de la llamada "economía del conocimiento", a partir de las clasificaciones de actividades económicas vigentes, como punto de partida para valorar el nivel de implantación y su contribución en el desarrollo de los territorios. Con todo, actualmente suele identificarse un conjunto de clusters innovadores o estratégicos en el contexto del capitalismo cultural- cognitivo (Scott, A.J., 2008) y que aparecerían especialmente desarrollados en las grandes metrópolis: industrias de alta intensidad tecnológica, servicios intensivos en conocimiento, dentro de estos los servicios avanzados a las empresas, así como las industrias culturales (Wu, W., 2005).

En relación con estas propuestas conviene no perder de vista algunas cuestiones importantes. Por un lado, dentro del debate existente se reconoce igualmente la existencia de zonas de solapamiento donde emergen otras actividades y funciones urbanas que podrían considerarse igualmente estratégicas para las grandes ciudades, en relación por ejemplo con el ocio, el consumo o el turismo (Glaeser, E.L., 2011). De hecho, en una aproximación más transversal a la economía del conocimiento, se entiende que el conocimiento (como recurso) y la innovación económica y social (como estrategia) son susceptibles de mejorar el desempeño de cualquier tipo de actividad, favoreciendo en último término el desarrollo urbano (Widen, W., et al., 2007; Méndez, R., 2013).

Por otro lado, desde diferentes foros de pensamiento económico se advierte un interés renovado por la identificación de sectores estratégicos, sabedores del importante papel que estos juegan en la resiliencia territorial y la competitividad urbana y regional, así como de la necesidad de priorizar las acciones de política económica. Dicha identificación está presente en los diferentes enfoques existentes dentro de las políticas de corte sectorial y que algunos autores como W. Warwick (2013) contraponen a otras políticas más horizontales y que persiguen resolver problemas generales, como por ejemplo las políticas de convergencia ("catch-up policies"), destinadas a que los países o regiones alcancen el nivel óptimo y competitivo respecto a otros países. En concreto, dentro de las aproximaciones sectoriales cabría diferenciar entre aquellas que persiguen el conservar una ventaja ya adquirida con respecto a competidores (en relación por ejemplo con sectores maduros) y las que buscan crear "ex novo" fortalezas, afianzando nuevos sectores económicos o sectores de vanguardia ("frontier industrial policies"). En relación con esto último, cabe destacar igualmente el papel de las estrategias de especialización inteligente de la Unión Europea que, aunque con un planteamiento horizontal, también persiguen efectos sobre sectores concretos, relacionados con la innovación y el avance tecnológico a escala regional (Comisión Europea, 2010a y 2010b; Foray, D., et al., 2011).

En este contexto, el objetivo de esta investigación es contrastar el carácter estratégico de las actividades de la economía del conocimiento en el caso de la ciudad-región de Madrid y actualizar el diagnóstico sobre su marcha reciente, ofreciendo con ello un marco de reflexión para orientar las prioridades de la ciudad en 
materia de promoción y ordenación de estas actividades². Esta reflexión parte de una serie de interrogantes iniciales que emanan de la propia revisión de la literatura:

En primer lugar, resulta evidente la apuesta a escala internacional por una economía más intensiva en innovación y conocimiento, con vistas a hacer frente al reto de la competitividad, unido al de la equidad y la sostenibilidad ambiental, lo que exige de nuevas estrategias que mejoren la resiliencia territorial en esta etapa postcrisis (OCDE, 2010a; Comisión Europea, 2010a; Sánchez-Moral, S., 2015). Nuestra hipótesis de trabajo es que esta visión estratégica ha penetrado en las capitales europeas, incluida Madrid. Esto es algo que queremos contrastar en relación con la posible apuesta por otro tipo sectores, que igualmente serían considerados estratégicos.

En segundo lugar, queremos confirmar que efectivamente las estrategias empresariales que dan forma, junto con otros procesos espaciales, a la reestructuración metropolitana en curso (Scott, A.J., 2008; Paddison, R. y Hutton, T., 2015), como por ejemplo las estrategias de descentralización productiva, de internacionalización o de innovación tecnológica, han reforzado el carácter estratégico de las actividades de la economía del conocimiento para Madrid. En particular, nos proponemos analizar el papel de las relaciones input-output que ligan a las actividades de la economía del conocimiento con el resto de la economía regional, contribuyendo a la articulación interna de esta y a mejorar su competitividad en un contexto cada vez más globalizado.

Por último, queremos verificar el grado de implantación de este tipo de actividades en la economía y el territorio de Madrid, que podría estar reforzando su posición dentro del bicéfalo sistema urbano español, al menos desde el punto de vista de la localización de sedes de empresas, servicios avanzados a las empresas o actividades financieras (Taylor, P.J., 2013); al tiempo que Barcelona se posiciona como hub cultural- creativo internacional (Boix, 2011). En todo caso, Madrid se sitúa en principio alejado de los principales centros europeos líderes en la economía del conocimiento (ESPON, 2013). Además, desde el punto de vista del dinamismo reciente, cabe preguntarse por esa capacidad de las actividades intensivas en conocimiento para proteger a las economías regionales ante las crisis económicas y convertirse en un "refugio" para el empleo (Comisión Europea, 2013; Perlo, M., 2011). Al respecto, conviene no perder de vista algunas tendencias no tan positivas, como la segmentación y precarización del empleo, el impacto de la crisis sobre los sistemas regionales de innovación o de las políticas de austeridad sobre las estrategias de innovación e investigación (Jordá, R., et al., 2014). Con todo, cabe relacionar la marcha de la economía del conocimiento con la propia trayectoria y especificidad de los territorios urbanos, comenzando por sus recursos materiales y humanos, la calidad institucional y la gobernanza local (Pratt, A.C., 2012; Méndez, R., 2013; Méndez, R., et al., 2016).

\section{METODOLOGÍA}

La investigación se fundamenta en la siguiente definición de los clusters innovadores de la economía del conocimiento (Wu, W., 2005), obtenida de la revisión de la literatura:

1. Industrias de alta intensidad tecnológica. De acuerdo con la OCDE se trata de actividades con un gasto en I+D por encima del $4 \%$ de su facturación y, además, con una proporción mayor de trabajadores cualificados. Entre las principales actividades cabe mencionar la industria farmacéutica, el material electrónico e informático y la construcción aeronáutica. Estas quedan incluidas dentro de las clasificaciones recientes de EUROSTAT sobre "knowledge intensive industries".

2. Servicios intensivos en conocimiento. La estrecha relación de algunos servicios con esos sectores industriales de alta intensidad tecnológica sirve como punto de partida para la definición de EUROSTAT de servicios intensivos en conocimiento (servicios financieros, telecomunicaciones, educación, sanidad...). La delimitación no está exenta de ciertos problemas relacionados, sobre todo, con su elevada

2. Una primera versión de este diagnóstico tuvo su origen en el contrato "Bases para la identificación de sectores estratégicos en la ciudad de Madrid" (Ayuntamiento de Madrid, 2016). 
heterogeneidad interna y la presencia de algunas ramas con elevado peso de empleo público (Musterd, S., et al., 2007).

3. Dentro del grupo anterior suele identificarse el subconjunto de los Servicios avanzados a las empresas (como consultoría, contabilidad, publicidad, arquitectura,...). Todos ellos tendrían una importancia estratégica desde el punto de vista del valor añadido, la generación y el consumo de innovaciones y la creación de empleo de calidad. Surgidas con frecuencia de procesos de externalización de empresas industriales, estas actividades son también fundamentales desde la perspectiva de la articulación interna y competitividad de las economías urbanas, contribuyendo a generar un continuo de actividades servindustriales. Su elevada productividad les permitiría resistir mejor las tendencias deslocalizadoras hacia territorios con menores costes.

4. Industrias culturales. Por un lado, se alude a aquellas industrias que combinan la creación, producción y comercialización de contenidos que son por su naturaleza intangibles y culturales (UNESCO, 2006). Se parte de la idea que actualmente el capitalismo se sitúa en una fase donde la generación de productos culturales es crucial en la estrategia productiva (Scott, A.J., 2008). El concepto se relaciona también con las llamadas "industrias creativas", que suman a las actividades culturales tradicionales (edición de libros, música, artes escénicas,...), otras como el software de videojuegos, las actividades de arquitectura, el diseño o la publicidad. Estas actividades son importantes impulsoras de la innovación económica y social en otros muchos sectores, siendo con frecuencia el origen de soluciones imaginativas relacionadas, por ejemplo, con la creación de marcas, el desarrollo de capacidades tecnológicas, el aprendizaje permanente o el estímulo a la investigación (Comisión Europea, 2010c).

A partir de aquí, el estudio plantea tres aproximaciones metodológicas complementarias. En primer lugar, se comienza haciendo un repaso a las estrategias emprendidas en los diferentes niveles escalares de la intervención, en relación con la selección y promoción de sectores económicos estratégicos. En concreto, se han analizado nueve ciudades europeas, seleccionadas por ocupar los primeros puestos en rankings de ciudades de carácter económico. Lógicamente, todas ellas son potenciales competidoras de Madrid. La información analizada es de naturaleza diversa, incluyendo: (i) estrategias de desarrollo económico elaboradas por ayuntamientos, gobiernos regionales o ambos, dependiendo del ámbito de competencias que tengan atribuido las diferentes administraciones; (ii) el papel que se otorga en webs institucionales o en documentos de citimarketing de aquellos sectores considerados claves por las oficinas $u$ organismos regionales de promoción económica y de inversión. La principal dificultad a la hora de analizar esta documentación es la variación en la propia denominación de los sectores. En ocasiones estos aparecen agrupados en denominaciones muy genéricas, mientras que en otros casos se especifican subsectores de forma detallada. En este sentido, de forma intencionada no se ha acotado el ámbito sectorial de esta identificación para poder valorar la importancia otorgada a los sectores intensivos en tecnología y conocimiento en el marco de las respectivas economías locales.

En segundo lugar, el estudio se adentra en la importancia de las actividades estratégicas en la articulación del sistema productivo regional y de investigación. Concretamente, de forma complementaria a los estudios de caso habitualmente empleados en investigaciones monográficas que parten de la construcción ad- hoc de indicadores (Navarro Arancegui, M. y Gibaja Martins, J.J., 2009), se propone aquí un sistema de análisis sistemático de los vínculos input-output. En concreto, buscamos evaluar la capacidad de las actividades seleccionadas para inducir dos tipos de efectos. En primer lugar, nos fijamos en los llamados efectos de arrastre entre una actividad económica y aquellas otras que le sirven de proveedor, de tal forma que si el sector económico se reactiva gracias a un shock, sus proveedores experimentan sinergias positivas derivadas de un aumento de la demanda de ese sector. También este efecto se asocia al concepto de eslabonamiento hacia atrás. En segundo lugar, nos fijamos en el llamado efecto impulso entre esa actividad económica y aquellas otras que constituyen sus clientes, de modo que un impacto positivo en el sector económico de estudio repercute favorablemente en su provisión de productos, beneficiando a los compradores de dicho producto. También este efecto se asocia al concepto de eslabonamiento hacia delante. 
Para obtener una cuantificación de estos efectos se ha utilizado la última tabla input-output disponible para la Comunidad de Madrid (TIOCM-2010). En este sentido, el desglose a 66 ramas de actividad no coincide exactamente con la CNAE-2009, por lo que no siempre es posible ajustarse a la definición inicial sobre clusters innovadores. Pese a estas limitaciones técnicas, la tabla input-output permite generar diversos indicadores de interés, siendo necesario hacer tres apuntes sobre la metodología desarrollada, basada en los trabajos de Collado, J.C., et al. (2003):

1. La tabla input-output pone énfasis en las transacciones que tienen lugar entre las diferentes ramas de actividad, ofreciendo una imagen nítida de la economía de un territorio como un sistema de flujos interdependientes, incluyendo sus relaciones con otros territorios (exportaciones e importaciones). Permite registrar el origen (dentro de la economía o exterior a través de la importación) de cada consumo, sea éste de carácter intermedio o final.

2. Los coeficientes técnicos expresan la utilización que cada rama hace de productos de otra rama por unidad de producción. Estos coeficientes miden el impacto directo de una rama sobre otra cuando se produce un aumento de la demanda final de la primera cifrado en una unidad. Los coeficientes técnicos constituyen la base de las interconexiones existentes entre las distintas actividades económicas que constituyen el tejido productivo. Así, sirven de instrumento para medir las interrelaciones sectoriales directas, tanto el eslabonamiento directo hacia atrás como el eslabonamiento directo hacia delante.

3. Por otro lado, los elementos de la matriz inversa de Leontief expresan la cuantía en que debe variar la producción total de una rama de actividad si se desea aumentar en una unidad la demanda final de otra rama de actividad. De esta forma, para captar los efectos directos de empuje y arrastre que una rama genera en otra se utilizan los coeficientes técnicos, mientras que si se quiere captar los efectos directos e indirectos (generando un efecto multiplicador en la economía) se emplean los coeficientes de la matriz inversa de Leontief.

Este análisis se completa con una valoración del papel de las actividades intensivas en tecnología y conocimiento desde la perspectiva de otras interacciones generadas con las instituciones de educación superior e investigación de la región, a través de fuentes indirectas.

Finalmente, se plantea el análisis de las dinámicas temporales y espaciales del empleo afiliado, por medio de los microdatos de la Seguridad Social (2011-2016), obtenido ex profeso para esta investigación. El análisis a nivel de dos dígitos de la CNAE2009 y para los distritos de la ciudad y de los municipios de la región de Madrid (según disponibilidad estadística), permite obtener una imagen detallada tanto del dinamismo reciente, como de las tendencias espaciales, analizadas mediante cartografía basada en el cálculo de los cocientes de localización del empleo.

\section{RESULTADOS Y DISCUSIÓN}

\subsection{Sectores estratégicos en ciudades europeas}

El repaso a las propuestas de aquellos organismos cuya misión fundamental es el diseño de las políticas (OCDE y Unión Europea) confirma que las políticas económicas sectoriales que emanan de su reflexión estratégica tienden a replicarse en los diferentes ámbitos de aplicación; desde la propia Unión Europea, pasando por los Estados miembros y las Administraciones locales. Ello suele llevar a una identificación ciertamente similar de sectores estratégicos intensivos en tecnología y conocimiento.

Por lo que respecta a las nueve capitales europeas analizadas (Londres, París, Berlín, Ámsterdam, Bruselas, Zúrich, Barcelona, Viena, Estocolmo), todas comparten la misión de la promoción económica en las respectivas ciudades, considerando como premisa básica un contexto altamente competitivo entre las grandes ciudades del mundo.

Se observa, no obstante, diferentes planteamientos estratégicos a la hora de identificar los sectores. Así, por ejemplo, algunas estrategias inciden en el concepto de la ventaja tecnológica competitiva ("revealed te- 
chnology advantage"), lo que permitiría a la ciudad continuar especializándose y potenciar determinadas actividades por encima de otras; beneficiándose en primer lugar de las capacidades locales y en segundo lugar de una posición relevante frente a territorios competidores. Otras estrategias inciden en la importancia de las condiciones concretas del entorno empresarial, necesarias para el desarrollo de las actividades productivas. En cuanto a los sectores concretos que se consideran estratégicos, estos están en clara relación con las directrices marcadas por los organismos internacionales. En concreto, cuatro son comunes a las nueve ciudades analizadas, esto es, industrias de la salud y de la vida, industrias creativas y culturales, tecnologías de la información y telecomunicaciones (estos dos últimos deben considerarse en estrecha relación temática y, de hecho, algunos documentos analizados los consideran conjuntamente). Otros cuatro sectores más, el sector financiero, las industrias verdes (fundamentalmente aquellas relacionadas con la producción de energías renovables), la educación superior y el turismo aparecen consideradas también en la mayor parte de los casos analizados (Tabla 1).

En este punto cabe destacar la coherencia en la selección de sectores estratégicos en las ciudades del entorno europeo con el planteamiento observado en las últimas décadas en el caso de Madrid. Habitualmente, los ejercicios de identificación de sectores estratégicos de este tipo han partido del gobierno de la Comunidad de Madrid; por ejemplo, a través de la política de clusters productivos de los años noventa del pasado siglo; o, de forma más reciente, a través de la formulación de su Estrategia de Especialización Inteligente: "Estrategia Regional de Investigación e Innovación 2014-2020 (RIS3)" (Comunidad de Madrid, 2013). En este sentido, RIS3- Madrid plantea cuatro áreas prioritarias en torno a Nanociencia, Materiales Avanzados, Tecnologías Industriales y del Espacio; Energía, Medio ambiente y Transporte (incluida la Aeronáutica); Salud, Biotecnología Agua y Agroalimentación; Tecnologías de la información y comunicaciones (TIC) y Servicios de alto valor añadido. Por su parte, el Ayuntamiento de Madrid propuso en la década pasada una selección de "sectores servindustriales estratégicos", donde además de algunas industrias de alta intensidad tecnológica, como la aeronáutica o la farmacéutica, se ponía el énfasis en las tecnologías de la información y comunicaciones, así como en los servicios avanzados a las empresas (Sánchez Moral, S., 2006).

En suma, la identificación de sectores o clusters estratégicos en ciudades europeas parece responder, por un lado, al planteamiento de las estrategias territoriales de innovación, basado en diagnostico sistemático de las capacidades locales y los nichos de oportunidad, como en el caso de las estrategias de especialización inteligente (Foray, D., et al., 2011). No obstante, se observa al mismo tiempo el impacto de esas "vehicular ideas" o "políticas móviles" que viajan entre regiones, tal como se ha señalado en la literatura especializada (Peck, J., 2012). En este sentido, la tarea de identificación de los sectores estratégicos es crucial teniendo en cuenta la similitud de opciones que consideran los responsables de la Administración. Más aún, la mayor parte de las estrategias analizadas se acompañan de una cohorte de medidas para facilitar las condiciones de instalación y desarrollo de los distintos clusters (dotación de suelo e infraestructura, ventanillas únicas, exenciones fiscales y ayudas a las startups de componente innovador, entre otras). Dichas medidas, que influyen directamente sobre el desempeño final de los mismos (junto con otros factores como la atracción de flujos de capital y de talento, la formación o capacitación del capital humano, muy presentes también en las políticas), tienden igualmente a ser replicadas entre las ciudades analizadas.

\subsection{El papel de los sectores estratégicos en la articulación del sistema productivo y de innovación de la región}

La Tabla 2 sintetiza los resultados obtenidos siguiendo la metodología Collado, J.C., et al. (2003) descrita anteriormente. Esta distingue entre valores por encima y por debajo de la media en los eslabonamientos directos y los efectos totales, tanto para los valores de Madrid como para los valores totales, incluyendo la parte correspondiente a las importaciones. Dado que nuestro objetivo es valorar el papel de las actividades 
Tabla 1. Sectores considerados estratégicos en una selección de ciudades europeas.

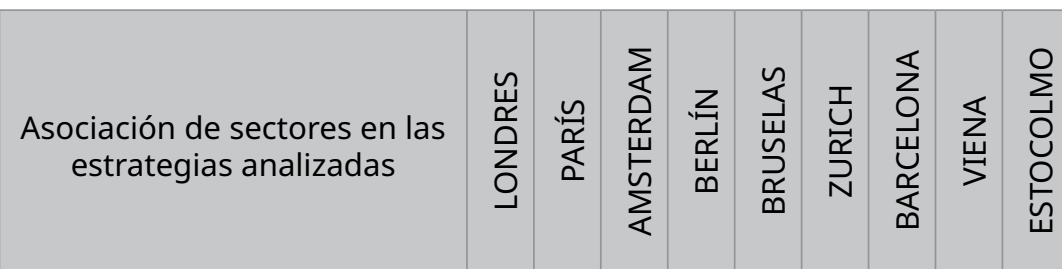

\begin{tabular}{|c|c|c|c|c|c|c|c|c|c|c|}
\hline Industrias de la salud y de la vida & - & & & & & & & & & \\
\hline Industrias creativas y culturales & \multirow{2}{*}{ Mencionados conjuntamente } & & & & & & & & & \\
\hline Turismo & & & & & & & & & & \\
\hline Tecnologías de la información & \multirow{2}{*}{ Mencionados conjuntamente } & & & & & & & & & \\
\hline Telecomunicaciones & & & & & & & & & & \\
\hline Financiero & \multirow{2}{*}{ Mencionados conjuntamente } & & & & & & & & & \\
\hline Servicios avanzados a las empresas & & & & & & & & & & \\
\hline Educación superior & \multirow{2}{*}{ Mencionados conjuntamente } & & & & & & & & & \\
\hline Investigación y desarrollo & & & & & & & & & & \\
\hline Industrias verdes (incl. energías renovables) & \multirow{3}{*}{ Mencionados conjuntamente } & & & & & & & & & \\
\hline Movilidad (sostenible) & & & & & & & & & & \\
\hline Automóviles & & & & & & & & & & \\
\hline Agricultura y alimentación & - & & & & & & & & & \\
\hline Logística & \multirow{2}{*}{ Mencionados conjuntamente } & & & & & & & & & \\
\hline Aeronáutica/ espacial & & & & & & & & & & \\
\hline Comercio & - & & & & & & & & & \\
\hline Comercio al por menor & - & & & & & & & & & \\
\hline Micro y nanotecnología & - & & & & & & & & & \\
\hline Electrónica & - & & & & & & & & & \\
\hline Energía & - & & & & & & & & & \\
\hline Óptica (fotónica entre ellas) & - & & & & & & & & & \\
\hline Metal & - & & & & & & & & & \\
\hline Instrumentos & - & & & & & & & & & \\
\hline Materiales de alta tecnología & - & & & & & & & & & \\
\hline Industrias químicas y del plástico & - & & & & & & & & & \\
\hline Mecatrónica & - & & & & & & & & & \\
\hline Número de sectores estratégicos: & - & 10 & 13 & 13 & 17 & 15 & 9 & 13 & 9 & 8 \\
\hline
\end{tabular}

Fuente: Elaboración propia, procedente y adaptado de Ayuntamiento de Madrid (2016). 
Tabla 2. Descomposición de los efectos de las actividades de la economía del conocimiento y del resto de la economía.

\begin{tabular}{|c|c|c|c|c|}
\hline & $A(T)$ & $\mathrm{B}(\mathrm{T})$ & $C(T)$ & $\mathrm{D}(\mathrm{T})$ \\
\hline$\sum_{\bar{\Sigma}}$ & & $\begin{array}{l}\text { - Agua, saneamiento y } \\
\text { residuos } \\
\text { - Cine, video, TV, radio } \\
\text { y sonido } \\
\text { - Construcción general } \\
\text { - Informática } \\
\text { - Productos metálicos } \\
\text { - Publicidad y estudios } \\
\text { de mercado } \\
\text { - Sedes centrales y } \\
\text { gestión empresarial } \\
\text { - Serv. anexos al trans- } \\
\text { porte } \\
\text { - Serv. técnicos }\end{array}$ & $\begin{array}{l}\text { - Actividades jurídicas } \\
\text { y de contabilidad } \\
\text { - Alquileres } \\
\text { - Transporte terrestre } \\
\text { de mercancías }\end{array}$ & - Artes gráficas \\
\hline$\sum_{\infty}$ & - Metálicas básicas & $\begin{array}{l}\text { - Act. postales y de } \\
\text { correos } \\
\text { - Cemento y derivados } \\
\text { - Cuero y calzado } \\
\text { - Edición } \\
\text { - Ordenadores y ma- } \\
\text { quinaria de precisión } \\
\text { - Otra química final } \\
\text { - Servicios de informa- } \\
\text { ción } \\
\text { - Transporte no terres- } \\
\text { tre }\end{array}$ & - Madera & $\begin{array}{l}\text { - Alojamientos } \\
\text { - Ind. mueble } \\
\text { - Otras act. profesio- } \\
\text { nales } \\
\text { - Restaurantes y bares } \\
\text { - Seguros y fondos de } \\
\text { pensiones } \\
\text { - Serv. recreativos } \\
\text { Serv. personales } \\
\text { - Transp. terrestre de } \\
\text { viajeros }\end{array}$ \\
\hline$\underset{\sum}{U}$ & $\begin{array}{l}\text { - Caucho y plástico } \\
\text { Industria del papel }\end{array}$ & $\begin{array}{l}\text { - Comercio y reparación } \\
\text { de vehículos } \\
\text { - Industrias cárnicas } \\
\text { - Maquinaria indus- } \\
\text { trial } \\
\text { - Otras alimenticias } \\
\text { - Otras manufacturas } \\
\text { - Vidrio e industrias no } \\
\text { metálicas } \\
\text { - (Telecomunicaciones) }\end{array}$ & $\begin{array}{l}\text { - Act. Inmobiliarias } \\
\text { - Aux. a construcción } \\
\text { - Comercio mayorista } \\
\text { - Energía eléctrica y gas } \\
\text { - Industrias extractivas } \\
\text { - Intermediación finan- } \\
\text { ciera } \\
\text { - Otras act. administra- } \\
\text { tivas } \\
\text { - (Telecomuniciones) }\end{array}$ & $\begin{array}{l}\text { - Auxiliares financie- } \\
\text { ros y de seguros } \\
\text { - Otro comercio mino- } \\
\text { rista }\end{array}$ \\
\hline$\sum_{\Delta}$ & $\begin{array}{l}\text { - Coquerías y refino de } \\
\text { petróleo } \\
\text { - Química de base e } \\
\text { industrial }\end{array}$ & $\begin{array}{l}\text { - Bebidas y tabaco } \\
\text { - Confección } \\
\text { - Material electrónico } \\
\text { - Material eléctrico } \\
\text { - Otro material de } \\
\text { transporte } \\
\text { - Productos farmacéu- } \\
\text { ticos } \\
\text { - Vehículos y sus } \\
\text { piezas }\end{array}$ & $\begin{array}{l}\text { - Agricultura y gana- } \\
\text { dería } \\
\text { - Industria textil }\end{array}$ & $\begin{array}{l}\text { - Act. asociativas } \\
\text { - Act. hogares } \\
\text { - Admon. públicas } \\
\text { - Educación } \\
\text { - Ind. lácteas } \\
\text { - Sanidad y Servicios } \\
\text { Sociales }\end{array}$ \\
\hline
\end{tabular}

Nota grupos: A: Niveles por encima de media en eslabonamientos directos y efectos totales; B: Niveles por encima de media en eslabonamiento directo hacia atrás y/o el efecto arrastre; C: Niveles por encima de media en eslabonamiento directo hacia delante y/o efecto impulso; D: Niveles por debajo de media en eslabonamientos directos y efectos totales; (T): Datos totales; (M): Datos para la región de Madrid Fuente: Elaboración propia, procedente y adaptado de Ayuntamiento de Madrid (2016). 
intensivas en tecnología y conocimiento en el contexto de la economía regional, el análisis incluye las 66 ramas de las TIO (2010) organizadas en cuatro grupos de sectores ${ }^{3}$ :

- Grupo A: constituido por aquellas ramas de actividad que tienen valores por encima de la media en los eslabonamientos directos hacia atrás y hacia delante, así como en los efectos arrastre e impulso.

- Grupo B: formado por las actividades que presentan niveles por encima de la media en el eslabonamiento directo hacia atrás y/o el efecto arrastre.

- Grupo C: incluye los sectores económicos que disponen de niveles por encima de la media en el eslabonamiento directo hacia delante y/o el efecto impulso.

- Grupo D: incorpora a las ramas de actividad que tienen valores por debajo de la media en los eslabonamientos directos hacia atrás y hacia delante, así como en los efectos arrastre e impulso.

Haciendo referencia a las actividades pertenecientes a los clusters innovadores identificados al comienzo, cabe señalar que las industrias de alta intensidad tecnológica presentan una capacidad de arrastre a nivel global considerable, como consumidoras de inputs intermedios de otras muchas actividades. Esta influencia se extiende hacia delante en el caso concreto de la industria química de base e industrial. Sin embargo, las industrias de alta intensidad tecnológica muestran un papel mucho más discreto cuando se consideran los datos del interior de la región de Madrid, salvo para los ordenadores y maquinaria de precisión, así como la maquinaria industrial, en este caso por generar impulsos hacia delante. En otras palabras, estas actividades sí estarían generando cierto efecto multiplicador sobre empresas de la región. En el resto de actividades el importante grado de internacionalización e integración de las actividades en grupos multinacionales, unido a la tendencia a la reducción de algunos clusters regionales en las últimas décadas (Méndez, R., et al., 2007), explicaría que los principales efectos se dirijan, sobre todo, hacia el exterior de la región.

Frente a esto, la mayoría de servicios avanzados a las empresas (como informática, sedes centrales y gestión empresarial, servicios técnicos, publicidad y estudios de mercado, así como actividades jurídicas y de contabilidad) se posicionan como actividades estratégicas para el funcionamiento y la generación de valor de las empresas de la región. Más aún, la mayor parte de ellas presentan a su vez efectos de arrastre directos o indirectos igualmente notables fuera del territorio regional, salvo algunas excepciones como las actividades jurídicas y de contabilidad (con mayor importancia en los efectos de impulso), así como otras actividades profesionales.

Cabe relacionar todo ello con la mencionada concentración de funciones terciarias avanzadas en Madrid, como núcleo rector del sistema urbano español, a través del que se canalizan y articulan el grueso de los flujos productivos nacionales e internacionales. En efecto, como señala la abundante literatura internacional sobre Knowledge Intensive Business Services (KIBS), la gestión de esos flujos en un contexto de incertidumbre y creciente integración de las regiones y empresas en la globalización sitúa en una posición nuclear a los servicios avanzados a las empresas (Cuadrado Roura, J.R., 2013). Ello queda plenamente confirmado en el caso de la región madrileña.

Por lo que respecta a otras actividades de servicios intensivas en conocimiento, como telecomunicaciones, intermediación financiera o servicios auxiliares financieros y de seguros, estas se perfilan como actividades fundamentales para la expansión del tejido productivo regional. En este sentido, mención especial merece el caso de las telecomunicaciones, que forma parte del Grupo C para el caso de los datos del interior de Madrid. Sin embargo, obtiene resultados diferentes entre los eslabonamientos directos y los efectos totales para los valores globales, registrando un valor por encima de la media en el eslabonamiento directo hacia atrás y también en el efecto impulso.

Por último, las industrias culturales presentan efectos multiplicadores domésticos por encima de la media. En el caso de actividades como cine, video, televisión, radio y sonido estos efectos incluyen además el impulso hacia delante. Salvo en el caso de los servicios recreativos, una parte importante de ese arrastre vía el consumo de inputs intermedios alcanza a actividades fuera de la región. El resultado viene a confirmar el

3. El Anexo I recoge los coeficientes técnicos que fundamentan esta clasificación por grupos (por motivos de espacio se incluye solo el detalle de las actividades relacionadas con la economía del conocimiento). 
carácter estratégico de estas actividades que, junto con otras como publicidad, software, etc., suelen agruparse bajo el epígrafe de la "economía creativa" (DCMS, 1998). Tal como señala la propia Comisión Europea "Ias industrias culturales y creativas representan un conjunto de empresas altamente innovadoras, con un gran potencial económico, y constituyen uno de los sectores más dinámicos en Europa" (Comisión Europea, 2010c, p. 2). Por lo tanto, junto con la contribución al crecimiento y al empleo regional, el caso de Madrid confirma su importante papel de cara a la generación de efectos multiplicadores sobre otras actividades o el impulso a la innovación, económica y social, dentro de los clusters creativos (Cooke, P. y Lazzeretti, L., 2008).

Obviamente existen otros vínculos y formas de interacción de los sectores de la economía del conocimiento con el resto del sector productivo (incluidas otras relaciones de colaboración no de mercado). Profundizar en estos aspectos exige de un estudio monográfico, fuera de los objetivos de esta investigación. Sin embargo, sí parece oportuno mencionar, al menos, la existencia de vínculos que se establecerían dentro del sistema regional de innovación y, en concreto, entre las empresas de las actividades identificadas y los grupos de investigación pertenecientes a instituciones de educación superior y centros de investigación de la región. Para ello nos basamos en los resultados del diagnóstico previo de RIS3- Madrid (Comunidad de Madrid, 2013). De los 333 grupos de investigación entrevistados durante el proceso de diagnóstico, hasta 295 declararon colaborar en proyectos con empresas de sectores relacionados con los aquí seleccionados. Destaca el caso de I+D (113 colaboraciones en proyecto) y los productos farmacéuticos (80), muy por delante del resto de sectores de la economía madrileña; además de la industria química (36), los productos informáticos y electrónicos (30), las telecomunicaciones (20), otras actividades profesionales científicas y técnicas (18), la programación y consultaría informática (12), el transporte aéreo (7) o la arquitectura, ingeniería y ensayos (7). En definitiva, muchas de estas actividades se erigen como elementos fundamentales dentro del Sistema Regional de Innovación de Madrid, caracterizado ya por R. Jordá et al. (2014) como un SRI de excelencia centrados en la alta tecnología.

\subsection{Nivel de desarrollo de los sectores estratégicos en la economía y el territorio madrileño}

La última dimensión del análisis considera el carácter estratégico de las actividades desde el punto de vista de las dinámicas del empleo. Sin perder de vista las diferencias metodológicas entre los estudios y las dificultades a la hora de adscribir las actividades de innovación, creatividad o I+D+i, cabe recordar, en primer lugar, que el empleo en la ciudad de Madrid podría rondar la cuarta parte del empleo total en economía del conocimiento del país (Méndez, 2013). No obstante, el análisis de los datos de empleo y su evolución reciente arroja resultados contrastados por clusters innovadores (por razones de disponibilidad estadística el análisis está limitado a la ciudad de Madrid). En primer lugar, es evidente el desigual peso de estos, destacando por orden de importancia los servicios avanzados a las empresas, con 269.150 empleos en 2016, por delante de otros servicios intensivos en conocimiento, que contaban con 114.894 empleos, las industrias culturales, con 39.484 empleos y las industrias de alta intensidad tecnológica, cuyo volumen se ve reducido hasta los 19.865 empleos. Desde el punto de vista de la importancia en la economía local, cabe señalar que el peso en el empleo local de las industrias de alta intensidad tecnológica resulta muy reducido (ligeramente superior al 1\%). Limitado resulta también el desarrollo del cluster de actividades culturales, siendo su peso en el empleo local del $2,15 \%$. Otros servicios intensivos en conocimiento se mueven en torno al $6 \%$ del total del empleo de la ciudad, mientras que los servicios avanzados a las empresas alcanzan valores del 14,68\% (Tabla 3).

En relación con la capacidad de resiliencia de los clusters innovadores, cabe señalar que el descenso más acusado entre 2011 y 2016 correspondió a la industria de alta intensidad tecnológica (-17,31\%), afectada por los ajustes de capacidad durante la crisis y las decisiones de (des)localización de las multinacionales del sector (Méndez, R., 2013). Igualmente negativo resultó el comportamiento del empleo en las industrias culturales (-13,79\%), en relación sobre todo con el sector de la edición (precisamente la actividad de naturaleza más industrial del cluster). Por el contrario, otros sectores que vivieron un ajuste importante en la fase de la austeridad, como fue el caso de la creación artística, los espectáculos o las actividades de museos y 
archivos, salen en cambio mejor parados en el global del periodo. Por su parte, otros servicios intensivos en conocimiento, que experimentaron una caída menor $(-2,90 \%)$, parecen recuperarse una vez superada la reestructuración del sector financiero y muy especial de la entidad Bankia y de los agentes financieros de su antigua red comercial. Frente a esto, los servicios avanzados a las empresas presentan una tasa de variación positiva del $14 \%$. En este sentido, se confirma su capacidad de recuperación en la salida de la crisis, ya observada en la segunda fase de la misma por R. Méndez et al. (2015), una vez se recupera la demanda por parte del tejido productivo madrileño y la contratación del sector público. En definitiva, las evidencias apuntan a una recuperación del dinamismo del empleo, al menos en parte de la economía del conocimiento.

Tabla 3. Evolución del empleo en clusters estratégicos en la ciudad de Madrid.

\begin{tabular}{|c|c|c|c|c|}
\hline Cod. CNAE-2009 & Actividad & Empleo (2016) & $\begin{array}{l}\text { \% Empleo } \\
\text { Local }\end{array}$ & $\begin{array}{c}\text { Tasa de variación } \\
2011 / 16\end{array}$ \\
\hline 20 & Industria química & 1.895 & 0,10 & $-16,19$ \\
\hline 21 & Fabr. de productos farmacéuticos & 3.747 & 0,20 & $-19,32$ \\
\hline 26 & Prod. informáticos, electrónicos, ópticos & 880 & 0,05 & $-15,79$ \\
\hline 28 & Fabr. de maquinaria y equipo N.C.O.P & 4.238 & 0,23 & $-28,68$ \\
\hline 29 & Fabr. vehículos de motor, remolques... & 6.573 & 0,36 & $-10,49$ \\
\hline \multirow[t]{2}{*}{30} & Fabr. otro material de transporte & 2.532 & 0,14 & $-9,21$ \\
\hline & Total cluster 1 & 19.865 & 1,08 & $-17,31$ \\
\hline 62 & Programación, consultoría informática... & 73.408 & 4,00 & 40,96 \\
\hline 63 & Servicios de información & 7.568 & 0,41 & 5,23 \\
\hline 69 & Actividades jurídicas y de contabilidad & 55.649 & 3,03 & 6,41 \\
\hline 70 & Act. sedes centrales; gestión empresarial & 19.767 & 1,08 & 18,20 \\
\hline 71 & Servicios técnicos de arquitectura... & 47.036 & 2,57 & 1,12 \\
\hline 72 & Investigación y desarrollo & 15.313 & 0,84 & $-2,48$ \\
\hline 73 & Publicidad y estudios de mercado & 32.972 & 1,80 & 1,59 \\
\hline \multirow[t]{2}{*}{74} & Otras act. profesionales, científicas... & 17.437 & 0,95 & 32,85 \\
\hline & Total cluster 2 & 269.150 & 14,68 & 14,00 \\
\hline 61 & Telecomunicaciones & 31.014 & 1,69 & 4,09 \\
\hline 64 & Servicios financieros, exc. seguros... & 48.645 & 2,65 & $-14,17$ \\
\hline 65 & Seguros, reaseguros y fond. pensiones & 18.218 & 0,99 & 6,68 \\
\hline \multirow[t]{2}{*}{66} & Act. auxiliares servicios financieros... & 17.017 & 0,93 & 15,14 \\
\hline & Total cluster 3 & 114.894 & 6,27 & $-2,90$ \\
\hline 58 & Edición & 15.954 & 0,87 & $-29,31$ \\
\hline 59 & Act. cinematográficas, vídeo, prog. TV... & 8.201 & 0,45 & $-5,14$ \\
\hline 60 & Act. programación, emisión radio y TV & 2.406 & 0,13 & $-2,20$ \\
\hline 90 & Act. creación, artísticas y espectáculos & 10.367 & 0,57 & 7,92 \\
\hline \multirow[t]{2}{*}{91} & Act. bibliotecas, archivos, museos... & 2.556 & 0,14 & 1,51 \\
\hline & Total cluster 4 & 39.484 & 2,15 & $-13,79$ \\
\hline
\end{tabular}

Fuente: Elaboración propia, procedente y adaptado de Ayuntamiento de Madrid (2016). 
Para evaluar el grado de implantación de las actividades estratégicas en el territorio de la Comunidad de Madrid se han analizado las tendencias de localización del empleo, agregadas por clusters innovadores. Los municipios que acogen un mayor número de trabajadores en industrias de alta intensidad tecnológica son: Madrid (19.034 empleos, 30,9\% del total), cuyo poder de atracción sobre estas actividades es algo mayor al que tiene sobre la industria manufacturera en general. Junto con ello, destaca el caso de Alcobendas (11.287 empleos, 18,3\%), Getafe (6.407 empleos, 10,4\%), Alcalá de Henares (3.047 empleos, 4,9\%) y Tres Cantos (2.597 empleos, 4,2\%), localizaciones tradicionales todas ellas para este tipo de actividades industriales. Dentro del municipio de Madrid, los distritos con mayor número de empleos en estas actividades son San Blas-Canillejas y Villaverde, ámbitos donde la actividad industrial en general mantiene presencia en algunas de las áreas industriales más consolidadas de la ciudad (Méndez, R., Ondátegui, J. y Sánchez Moral, S., 2007). Estas tendencias quedan perfectamente reflejadas en los niveles de especialización a nivel de municipios de la región y distritos de la capital, que dibujan el conocido arco por el este de la ciudad; desde Colmenar Viejo, Tres Cantos y Alcobendas al norte; pasando por Ajalvir y varios municipios del corredor del Henares, con Alcalá a la cabeza; hasta el sur metropolitano, donde destacan Getafe, Pinto y Fuenlabrada, en conexión con el tejido del sector sur de la ciudad (Figura 1).

En cuanto a los servicios avanzados a las empresas, Madrid es el municipio de la región que acoge el mayor volumen de trabajadores en servicios avanzados a las empresas ( 239.758 empleos, $70,8 \%$ del total), seguido de otros municipios del Norte y Oeste metropolitano, como Alcobendas (16.439 empleos, 4,8\%), Las Rozas de Madrid (12.466 empleos, 3,7\%), Pozuelo de Alarcón (11.725 empleos, 3,4\%) o Tres Cantos (8.514 empleos, 2\%). Todos estos ámbitos aparecen especializados a nivel regional, evidenciándose la importancia que adquiere el norte metropolitano, así como la difusión hacia el oeste metropolitano. En la ciudad destaca el peso y nivel de especialización que se alcanza en varios distritos, como Salamanca, Chamartín, Centro, o San Blas-Canillejas, entre otros. En definitiva, se confirma el fuerte arraigo del terciario avanzado en la mitad norte de la ciudad y en la periferia metropolitana, conformando un tejido económico continuo, al que contribuyen tanto la localización en los espacios de oficinas más centrales de la ciudad, como en los numerosos parques empresariales desarrollados en las últimas décadas en un entorno metropolitano de elevada calidad ambiental y nivel socioeconómico (Méndez, R. y Sánchez Moral, S., 2011).

Por lo que respecta a otras actividades intensivas en conocimiento, estas se concentran preferentemente en la ciudad central (especialmente en el caso de los servicios financieros y las telecomunicaciones). En concreto, Madrid registra el mayor número de trabajadores (94.656 empleos, 73,7\% del total), seguido de otros municipios de nuevo del norte y oeste metropolitano, como Boadilla del Monte (11.071 empleos, 8,58\%), Pozuelo de Alarcón (4.465 empleos, 3,4\%), Majadahonda (3.781 empleos, 2,9\%) o Tres Cantos (3.462 empleos, $2,6 \%$ ), entre otros. Todos ellos presentan una elevada especialización a nivel regional (salvo en el caso de Alcobendas), destacando muy por encima del resto el caso de Boadilla del Monte, sede de la ciudad financiera del Banco Santander y, a bastante distancia, el de Tres Cantos, en relación con su Parque Tecnológico. Los niveles de empleo y especialización por distritos no difieren mucho del cluster anterior, salvo por el aumento de la importancia de las actividades en el entorno de Barajas. Igualmente, cabe aludir a la localización en el distrito de Fuencarral- El Pardo de la ciudad financiera del BBVA o del Distrito C de Telefónica.

Por último, el mayor volumen de trabajadores en industrias culturales se localiza en Madrid (34.563 empleos, $64,5 \%$ del total). No obstante, un notable volumen de empleo se distribuye por el resto de la región metropolitana, donde en este caso destacan Pozuelo de Alarcón (7.930 empleos, 14,81\%), San Sebastián de los Reyes (1.585 empleos, 4,6\%) y las Rozas de Madrid (1.475 empleos, 2,7\%). En todo caso, el nivel de especialización del empleo en las industrias culturales resulta especialmente elevado en algunos núcleos, como por ejemplo Pozuelo de Alarcón o San Sebastián de los Reyes, en relación con la Ciudad de la Imagen o los estudios de Atresmedia respectivamente; pero también en buena parte del resto de la región metropolitana, incluidos sectores de la sierra madrileña. Por otro lado, dentro del municipio de Madrid, destacan especialmente los distritos de Centro, Hortaleza, San Blas-Canillejas y Fuencarral-El Pardo, con niveles superiores a 3.000 empleos en industrias culturales y elevados niveles de especialización en el contexto regional.

En definitiva, nuestros resultados apuntan a la desigual importancia de los clusters innovadores en la economía de la región de Madrid. Por un lado, se confirma el papel de la ciudad como localización prefe- 
Cluster 1,

de Industrias de alta intensidad tecnológica

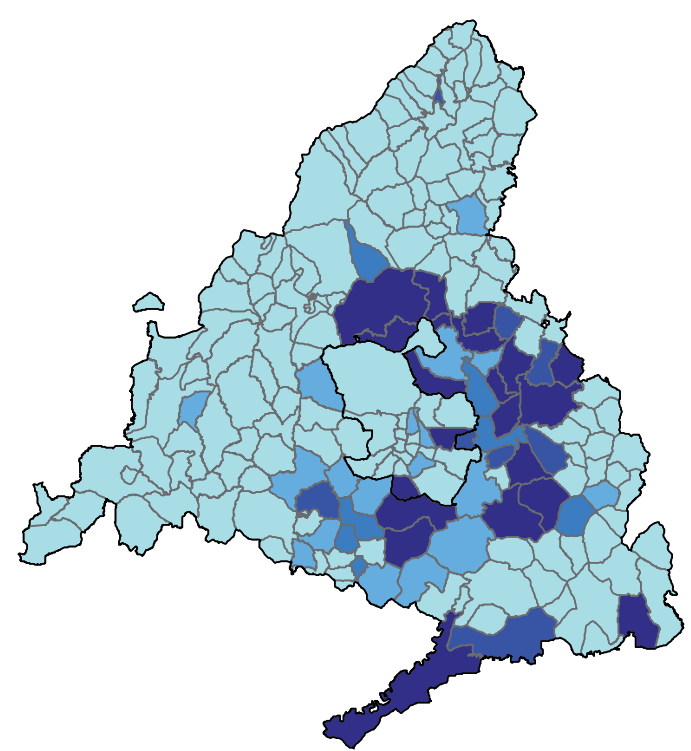

Cluster 3,

de Otros servicios intensivos en conocimiento

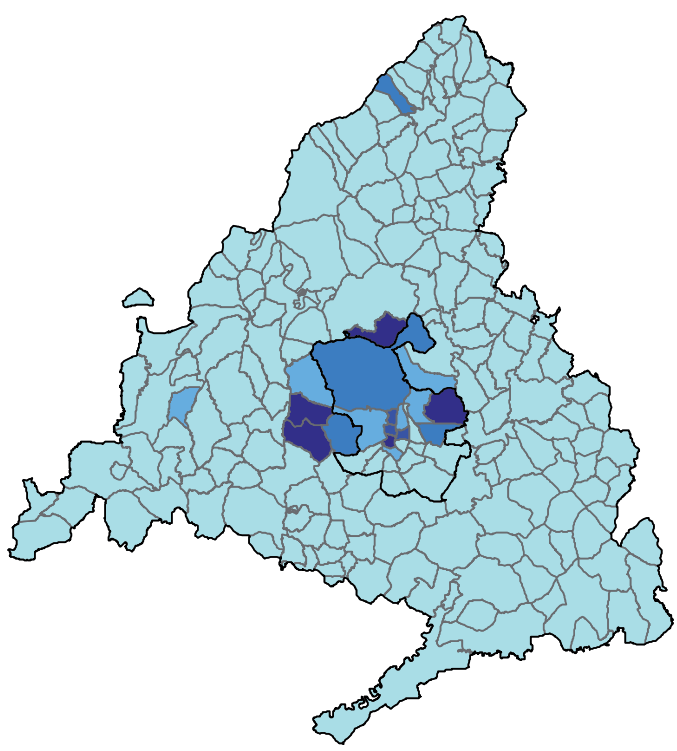

Cluster 2,

de Servicios avanzados a las empresas

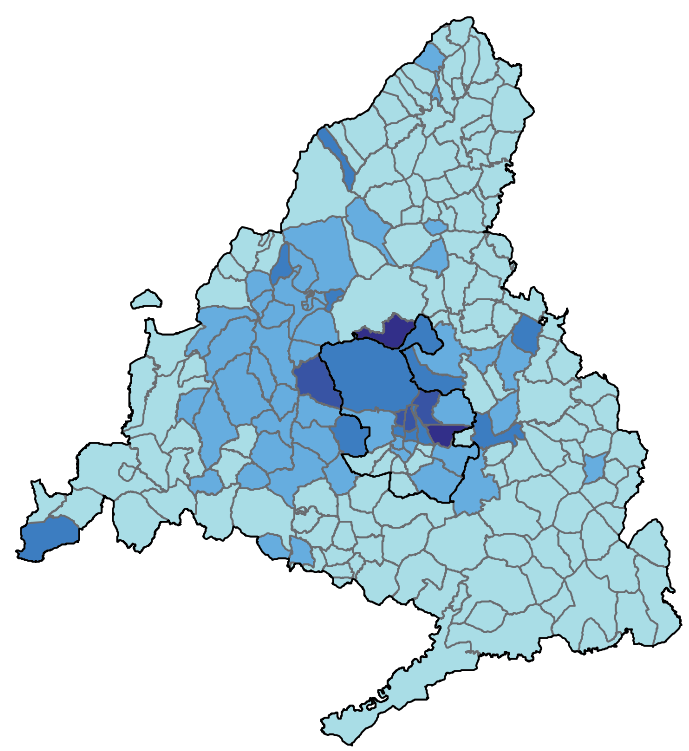

Cluster 4, de Industrias culturales

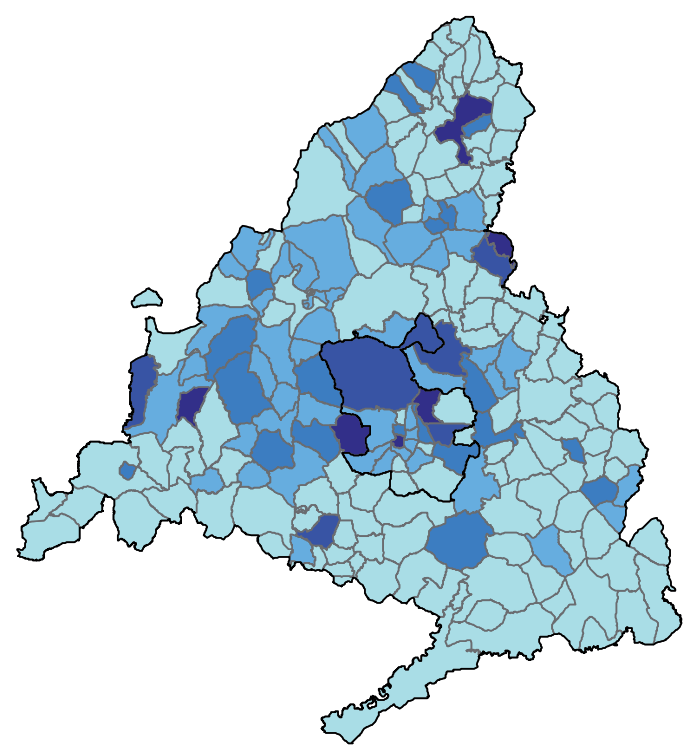

$\underline{156}$

Cociente de localización
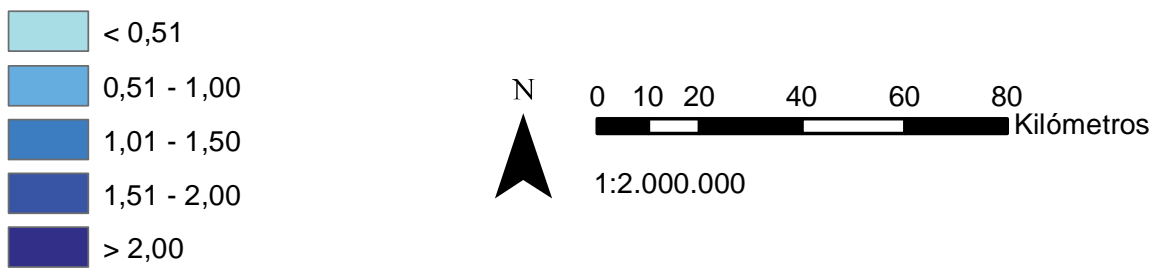

Figura 1. Localización del empleo según clusters innovadores en la Comunidad de Madrid (2016). Fuente: Elaboración propia a partir de Seguridad Social (2016). 
rente de las actividades del terciario avanzado. Destaca así el volumen de actividad en servicios avanzados y empresas financieras nacionales e internacionales, que aportarían al resto del tejido empresarial un conocimiento estratégico para la inserción de Madrid en la globalización y que encuentran en la ciudad ventajas de localización relacionadas con la generación de economías de urbanización y de red, sin olvidar otros factores relacionados con la localización en zonas de prestigio (Taylor, P.J., 2015; Sánchez Moral, S. et al., 2008). No obstante, como hemos comprobado, la influencia de algunos de estos factores no se limita a la ciudad central. Por otro lado, se confirma el atractivo de esta última para las industrias culturales, en relación sobre todo con la densidad de redes empresariales del sector o el valor simbólico de su centro histórico-cultural (Méndez, R. et al., 2010). Frente a esto, resulta evidente el impacto en las últimas décadas de los procesos de descentralización productiva y deslocalización de la industria de alta intensidad tecnológica hacia el resto de la región metropolitana (Sánchez Moral, S., 2009; Rama, R., 2007).

\section{CONCLUSIONES}

Los resultados obtenidos permiten orientar la discusión sobre el carácter estratégico de los clústeres innovadores para la región de Madrid, incluida la ciudad central. En ese sentido, cabe recordar que de acuerdo con autores como W. Wu (2005), A.J. Scott (2009) o S. Musterd y A. Murie (2010) la desigual dotación de los inputs necesarios para el desarrollo de las actividades intensivas en conocimiento, incluidas las economías de aglomeración, junto con otros factores más relacionados con el atractivo urbano que influirían sobre las localización de los trabajadores, explicarían la tendencia a la concentración de estas actividades en los principales núcleos urbanos. Las estrategias y políticas pueden jugar un papel importante en el impulso de estos procesos.

De este modo, estas tendencias (visibles en el caso de Madrid) se ven hoy en día reforzadas por las directrices planteadas desde diferentes instituciones internacionales y organismos multilaterales de cooperación económica (UNCTAD, Banco Mundial, UE, OCDE). Muchos de ellos aluden constantemente a la necesidad de favorecer una economía más intensiva en conocimiento e innovación, como vehículo para hacer frente no sólo al reto de la competitividad (resuelto con frecuencia a favor de aquellas regiones capaces de asegurar ventajas competitivas dinámicas, es decir, basadas en la innovación), sino también de la sostenibilidad y la equidad. De este modo, se entiende que con ello se puede ayudar a mitigar cuestiones socioeconómicas muy acuciantes como el envejecimiento, la desigualdad o la transición hacia una economía eficiente en el uso de recursos y baja en carbono (Comisión Europea, 2010a).

En la presente investigación hemos podido comprobar cómo esta visión se repite a escala regional, donde es bien conocido el esfuerzo realizado en la última década en relación con las estrategias de especialización inteligente desarrolladas en el marco de la nueva Política Regional y de Cohesión de la UE, pero también entre las grandes ciudades europeas competidoras de Madrid. Resulta así común la identificación de un núcleo de actividades intensivas en tecnología y conocimiento, incluidas algunas de naturaleza servindustrial, como pueden ser las TIC, las telecomunicaciones o las industrias creativas. No obstante, cabe recordar la frecuente consideración de otras actividades como el turismo, la educación y la energía (algunas con importantes implicaciones para la competitividad urbana). Todo ello plantea una primera reflexión sobre el alcance de esas visiones complementarias de la economía del conocimiento -sectorial y transversal-y su reflejo en las políticas y estrategias de promoción económica o de innovación.

En ese sentido, pese a tratarse de sectores de opción preferente a la hora de desarrollar políticas productivas de orden sectorial, los clusters innovadores tienen un comportamiento muy heterogéneo en el caso de Madrid, desde el punto de vista de sus dinámicas temporales y espaciales. Como hemos comprado, las estrategias desplegadas por las empresas en un mundo cada vez más globalizado han tenido un impacto desigual en Madrid, reforzando en algunos casos los procesos deslocalización en la región iniciados hace décadas. También ha sido desigual el impacto de la crisis internacional y las políticas de ajuste posteriores (Méndez, R., et al., 2015). Al respecto, algunos autores ya han señalado los impactos dentro del sistema regional de innovación, en términos por ejemplo del desempeño innovador de las empresas o del esfuerzo en ciencia y tecnología (ver por ejemplo Jordá, R., et al., 2014). 
Nuestra aproximación a través del empleo confirma que los clusters innovadores juegan hoy un papel importante desde el punto de vista de su provisión en la región de Madrid y, especialmente, en la ciudad central, donde su peso supera ya la cuarta parte del total del empleo. Son además fundamentales para la articulación interna del sistema productivo y del sistema regional de innovación, asegurando además la conexión con la economía global. Todo ello, junto con la capacidad de resiliencia exhibida por varias de estas actividades (muy especialmente de los servicios avanzados a las empresas y las industrias culturales y creativas), hace que puedan ser consideradas estratégicas de cara a articular nuevos programas de desarrollo urbano y regional. En cualquier caso, cabe concluir que la opción política y de planificación de una determinada ciudad o región para potenciar económicamente los territorios, no puede solo circunscribirse a decisiones tomadas desde una perspectiva sectorial. Como se viene señalando, ello requiere también de aproximaciones transversales, siendo importante mejorar la gobernanza y asegurar una política coherente, garantizando la coordinación entre los actores regionales, nacionales e internacionales además de proporcionar condiciones adecuadas a las personas e instituciones para innovar. Al mismo tiempo, todo ello debe conducir a resolver los retos sociales que se presentan en la actualidad (OCDE, 2010b, p3).

\section{REFERENCIAS}

Boix, R. (2012). Facing globalization and increased trade: Catalonia's evolution from industrial region to knowledge and creative economy. Regional Science Policy and Practice, 4, 97-112. doi: https://doi.org/10.1111/j.17577802.2011.01057.x

Collado, J.C., et al. (2003). La economía de Madrid según la tabla input-output de 2000. Madrid: Comunidad de Madrid.

Comisión Europea (2010a). Europa 2020: Una estrategia para un crecimiento inteligente, sostenible e integrador. Bruselas: COM, Comisión Europea.

Comisión Europea (2010b). Contribución de la Política Regional al crecimiento inteligente en el marco de Europa 2020. Bruselas: COM, Comisión Europea.

Comisión Europea (2010c). Libro Verde. Liberar el potencial de las industrias culturales y creativas. Bruselas: COM, Comisión Europea.

Comisión Europea (2013): Octavo informe de situación sobre la cohesión económica, social y territorial. La dimensión regional y urbana de la crisis. Bruselas: Comisión Europea. Recuperado de http://eur-lex.europa.eu/LexUriServ/LexUriServ. do?uri=COM:2013:0463:FIN:ES:PDF. Último acceso: 1 de junio de 2014.

Comunidad de Madrid (2013): Estrategia Regional de Investigación e Innovación 2014-2020 (RIS3). Madrid: Comunidad de Madrid. [En línea]. Recuperado de http://www.comunidad.madrid/sites/default/files/estrategia_ris_3_madrid_ v21.2.pdf. Último acceso: 1 de enero de 2016.

Cooke, P. \& Lazzeretti, L. (2008). Creative Cities, Cultural Clusters and Local Economic Development. Cheltenham: Edward Elgar. doi: https://doi.org/10.4337/9781847209948

Cuadrado-Roura, J.R. (2013). Service Industries and Regions - Growth, Location and Regional Effects. Berlin-Heidelberg: Springer-Verlag. https://doi.org/10.1007/978-3-642-35801-2

DCMS (1998). Creative Industries Mapping Document. London: DCMS (Department for Culture, Media and Sport).

ESPON- Politécnico de Milano (2013). KIT ESPON: Knowledge, Innovation and Territory. Recuperado de https://www.espon. eu/sites/default/files/attachments/KIT_Interim-Report.pdf Último acceso: 26 de abril de 2019].

Foray, D.; David, P.A. \& Hall, B.H. (2011). Smart specialization. From academic idea to political instrument, the surprising career of a concept and the difficulties involved in its implementation, MTEI-Working Paper, Lausanne: Management of Technology \& Entrepreneurship Institute. Recuperado de https://pdfs.semanticscholar.org/29ad/6773ef30f362d7d3937c483003d974bc91c5.pdf. Último acceso: 1 de enero de 2016.

Glaeser, E.L. (2011). Triumph of the city: how our greatest invention makes us richer, smarter, greener, healthier, and happier. New York: Penguin Press.

Jordá, R., Ruiz, F., González, R. y Contreras, G. (2014). Caracterización del Sistema Nacional de Innovación español (SNI) y de los SRIs durante la crisis. En Albertos J. M. y Sánchez, J. L. (Coords.) Geografía de la crisis económica en España (pp. 263-304). Valencia: Universidad de Valencia. 
Machlup, F. (1962). The production and distribution of knowledge in the United States. Princeton: Princeton University Press. Méndez, R. (2013a). Economía del conocimiento y nuevos contrastes territoriales en España: una perspectiva multiescalar. Boletín de la Asociación de Geógrafos Españoles, 63, 7-32.

Méndez, R., Ondátegui, J. y Sánchez Moral, S. (2007): La estructura territorial de las actividades económicas y la renta. En J.L. García Delgado (Dir.). Estructura económica de Madrid. (pp. 137-183). Madrid: Thomson Civitas.

Méndez, R., y Sánchez, S. (2011). Spanish cities in the knowledge economy: Theoretical debates and empirical evidence. European Urban and Regional Studies, 18 (2), 136-155. doi: https://doi.org/10.1177/0969776410381039

Méndez, R., Sánchez-Moral, S., y Malfeito, J. (2016). Employment changes in knowledge-based industries in large urban areas of Spain: Impact of the economic crisis and austerity policies. Environment and Planning C: Government and Policy, 34 (5), 963-980. doi: https://doi.org/10.1177/0263774X15614698

Musterd, S., Bontje, M., Chapain, C., Kovács, Z. \& Murie, A. (2007). Accomodating creative knowledge. A literature review from a European perspective. ACRE Report 1. Amsterdam. Netherlands: University of Amsterdam. Recuperado de http:// acre.socsci.uva.nl/results/documents/WP1StateoftheArtversion15mrt2007.pdf Último acceso: 26 de abril de 2019.

Musterd, S. \& Murie, A. (2010). Making competitive cities. Pathways, actors and policies. London, UK: Blackwell.

Navarro Arancegui, M. y Gibaja Martins, J.J. (2009). Las tipologías en los sistemas regionales de innovación. El caso de España. Ekonomiaz, 70, 241-281.

OCDE (2010a). The OCDE Innovation Strategy. Getting a head start on tomorrow. Recuperado de https://read.oecd-ilibrary. org/science-and-technology/the-oecd-innovation-strategy_9789264083479-en\#page1 Último acceso: 26 de abril de 2019]. ISBN 978-92-64-08347-9.

OCDE (2010b). The OCDE Innovation Strategy. Ministerial report on the OECD Innovation Strategy. Innovation to strengthen growth and address global and social challenges. Recuperado de https://www.oecd.org/sti/45326349.pdf Último acceso: 20 de mayo de 2019.

OCDE (2011). Regions and Innovation Policy, OECD Reviews of Regional Innovation. París: OCDE. doi: https://doi.org/10.1787/9789264097803-27-en

Paddison, R. \& Hutton, T. (Eds) (2015). Cities and economic change. Restructuring and dislocation in the global metropolis. London: SAGE Publications.

Pavitt, K. (1984). Sectorial patterns of technical change: Towards a taxonomy and a theory. Research Policy, 13, $343-373$. doi: https://doi.org/10.1016/0048-7333(84)90018-0

Peck, J. (2012). Recreative city: Amsterdam, vehicular ideas and the adaptive spaces of creativity policy. International Journal of Urban and Regional Research, 36 (3), 462-485. doi: https://doi.org/10.1111/j.1468-2427.2011.01071.x

Perlo, M. (2011). Cities in times of crisis. The response of local governments in light to the global economic crisis: the role of the formation of human capital, urban innovation and strategic planning. IURD Working Papers. Berkeley: University of California. Recuperado de https://iurd.berkeley.edu/wp/2011-01.pdf Último acceso: 1 de abril de 2019.

Pratt, A. C. (2012). A world turned upside down: the cultural economy, cities and the new austerity. En Smart, creative, sustainable, inclusive: territorial development strategies in the age of austerity. London, UK: Regional Studies Association.

Rama, R. (2007). Emerging districts facing structural reform: The Madrid electronics district and the reshaping of the Spanish telecom monopoly. Environment and Planning A, 39 (9), 2207-2231. doi: https://doi.org/10.1068/a38270

Salom, J. y Albertos, J. (2009). Redes socioinstitucionales, estrategias de innovación y desarrollo territorial en España. Valencia: Universitat de València.

Sánchez Moral, S., Calatrava, A., Melero, A., Méndez, R., Michelini, J.J. y Tébar, J. (2008): Sectores servindustriales estratégicos. Observatorio Industrial de Ayuntamiento de Madrid. Madrid: Ayuntamiento de Madrid. doi: https://doi. org/10.1080/00343400801932326

Sánchez Moral, S. (2009) Industrial Clusters and New Firm Creation in the Manufacturing Sector of Madrid's Metropolitan Region. Regional Studies, 43 (7), 949-965. doi: http://dx.doi.org/10.1080/00343400801932326

Sánchez-Moral, S. (2015). Transformación productiva, equidad y redes. Revista de Estudios Andaluces 32, 49-75. doi: http:// dx.doi.org/10.12795/rea.2015.i32.03

Scott, A.J. (2008). Social Economy of the Metropolis: Cognitive-Cultural Capitalism and the Global Resurgence of Cities. Oxford: Oxford University Press. doi: https://doi.org/10.1093/acprof:oso/9780199549306.001.0001

Scott, A.J. (2009). Human capital resources and requirements across the metropolitan hierarchy of the USA. Journal of Economic Geography, 9, 207-226. doi: https://doi.org/10.1093/jeg/lbn051 
Taylor, P.J., Hoyler, M. y Sánchez Moral, S. (2013). European cities in globalization: a comparative analysis based on the location strategies of advanced producer services. En Cuadrado Roura, J.R. (Ed.): Service Industries and Regions: Growth, Location and Regional Effects. (pp. 285-304). Berlín: Springer-Verlag. doi: https://doi.org/10.1007/978-3-64235801-2_12

UNESCO (2006). Understanding creative industries: cultural statistics for public-policy making. Paris: UNESCO.

Vanhove, N. (2011). The Economics of Tourism Destinations. London: Elsevier. doi: https://doi.org/10.4324/9780080969978 Warwick, K. (2013). Beyond Industrial Policy. Emerging issues and new trends. Paris: OCDE.

Winden, W., Berg, L., Van D. \& Pol, P. (2007). European cities in the knowledge economy: towards a typology. Urban Studies, 44 (3), 525-549. doi: https://doi.org/10.1080/00420980601131886

Wu, W. (2005). Dynamic Cities and Creative Clusters. World Bank Policy Research Working Paper 3509, 1-35. doi: https://doi. org/10.1596/1813-9450-3509 
Anexo I. Coeficientes técnicos y de la matriz inversa de Leontief de las actividades relacionadas con la economía del conocimiento.

\begin{tabular}{|c|c|c|c|c|c|c|c|c|}
\hline & \multicolumn{2}{|c|}{$\begin{array}{c}\text { Eslabona-mien- } \\
\text { to directo hacia } \\
\text { atrás }\end{array}$} & \multicolumn{2}{|c|}{$\begin{array}{l}\text { Eslabona-mien- } \\
\text { to directo hacia } \\
\text { delante }\end{array}$} & \multicolumn{2}{|c|}{ Efecto de arrastre } & \multicolumn{2}{|c|}{ Efecto empuje } \\
\hline & Int. & Total & Int. & Total & Int. & Total & Int. & Total \\
\hline Maquinaria industrial & 0,170 & 0,630 & 0,315 & 2,007 & 1,228 & 2,692 & 1,137 & 2,331 \\
\hline Material electrónico & 0,140 & 0,813 & 0,001 & 1,292 & 1,180 & 3,115 & 1,000 & 2,217 \\
\hline $\begin{array}{l}\text { Ordenadores y maquinaria de } \\
\text { precisión }\end{array}$ & 0,291 & 0,700 & 0,011 & 0,781 & 1,407 & 2,802 & 1,006 & 1,504 \\
\hline Vehículos y sus piezas & 0,098 & 0,823 & 0,079 & 0,592 & 1,122 & 3,421 & 1,096 & 2,220 \\
\hline Otro material de transporte & 0,134 & 0,642 & 0,266 & 0,728 & 1,180 & 2,731 & 1,145 & 1,795 \\
\hline Productos farmacéuticos & 0,133 & 0,598 & 0,111 & 0,876 & 1,184 & 2,539 & 1,055 & 1,628 \\
\hline Química de base e industrial & 0,185 & 0,712 & 0,145 & 1,670 & 1,256 & 2,842 & 1,135 & 4,432 \\
\hline Informática & 0,412 & 0,632 & 0,353 & 0,378 & 1,629 & 2,531 & 1,904 & 2,398 \\
\hline Servicios de información & 0,412 & 0,613 & 0,422 & 0,525 & 1,629 & 2,455 & 1,251 & 1,404 \\
\hline $\begin{array}{l}\text { Actividades jurídicas y de } \\
\text { contabilidad }\end{array}$ & 0,367 & 0,449 & 0,483 & 0,723 & 1,560 & 1,955 & 1,879 & 2,850 \\
\hline $\begin{array}{l}\text { Sedes centrales y gestión } \\
\text { empresarial }\end{array}$ & 0,453 & 0,600 & 0,460 & 0,543 & 1,733 & 2,373 & 1,757 & 2,214 \\
\hline Servicios técnicos & 0,310 & 0,571 & 0,305 & 0,405 & 1,434 & 2,365 & 1,547 & 2,103 \\
\hline Publicidad y estudios de mercado & 0,423 & 0,651 & 0,667 & 0,865 & 1,648 & 2,732 & 2,239 & 3,347 \\
\hline Otras actividades profesionales & 0,280 & 0,517 & 0,056 & 0,517 & 1,402 & 2,246 & 1,082 & 2,224 \\
\hline Telecomunicaciones & 0,268 & 0,577 & 0,228 & 0,382 & 1,383 & 2,381 & 1,967 & 3,330 \\
\hline Intermediación financiera & 0,100 & 0,145 & 0,440 & 0,674 & 1,137 & 1,283 & 1,823 & 2,751 \\
\hline Seguros y fondos de pensiones & 0,327 & 0,640 & 0,271 & 0,387 & 1,412 & 1,853 & 1,213 & 1,507 \\
\hline Auxiliares financieros y de seguros & 0,112 & 0,172 & 0,483 & 0,767 & 1,150 & 1,318 & 1,314 & 1,655 \\
\hline Edición & 0,472 & 0,701 & 0,364 & 0,832 & 1,689 & 2,780 & 1,248 & 1,778 \\
\hline Cine, video, TV, radio y sonido & 0,422 & 0,765 & 0,619 & 1,057 & 1,709 & 3,463 & 2,038 & 4,296 \\
\hline Servicios recreativos & 0,410 & 0,483 & 0,080 & 0,166 & 1,589 & 2,055 & 1,088 & 1,305 \\
\hline
\end{tabular}

Nota: Int.: Valores interiores; Total: valores totales (incluye importación).

Fuente: Elaboración propia, procedente y adaptado de Ayuntamiento de Madrid (2016). 


\title{
Zonas con Potencial para el Pago de Servicios Ambientales en el Valle del Mezquital, Hidalgo
}

\section{Zones with Potential for the Payment of Environmental Services in the Valle del Mezquital, Hidalgo}

\author{
Genaro Aguilar-Sánchez \\ g_aguila@correo.chapingo.mx @ https://orcid.org/0000-0003-1518-0801 \\ Reynol González-Vizcarra \\ canas_X@hotmail.com @ https://orcid.org/0000-0002-4983-3164 \\ Universidad Autónoma Chapingo (México) \\ Carretera México-Texcoco, Km 38.5, Chapingo, municipio de Texcoco, Estado de México,
} México. 56230

\section{INFO ARTÍCULO}

Recibido: $21 / 3 / 2018$

Revisado:13/6/2019

Aceptado: 25/6/2019

\section{PALABRAS CLAVE}

Servicios ambientales

Valle del Mezquital

SIG

Facetas

\section{KEYWORDS}

Environmental services

Mezquital Valley

SIG

Facets

\section{RESUMEN}

Las regiones áridas en México, están excluidas de los beneficios del esquema de Pago por Servicios Ambientales (PSA), de la Comisión Nacional Forestal, debido a la poca cubierta forestal que estas tienen. El objetivo del trabajo es realizar una identificación a nivel regional de aquellas zonas potenciales de pago por servicios ambientales en el Valle de Mezquital, estado de Hidalgo. La limitante de zona árida es la principal justificación para que se generen propuestas como alternativas para tratar de incluir dichas regiones en el PSA. La identificación de zonas elegibles o prioritarias para el PSA se basó en las metodologías del Levantamiento Fisiográfico, para delimitar las áreas o unidades ambientales y, para el análisis de la toma de decisiones el Multicriterio. Se identificaron las áreas prioritarias para el pago por servicios ambientales equivalentes a 911 ha, con características de riesgo alto y muy alto de perder los servicios ecosistémicos provistos por la conservación de la biodiversidad.

\begin{abstract}
The arid regions in Mexico are excluded from the benefits of the Payment for Environmental Services (PES) scheme of the National Forestry Commission, due to the low forest cover they have. The objective of the work is to carry out an identification at the regional level of those potential payment zones for environmental services in the Mezquital Valley, Hidalgo State. The limitation of the arid zone is the main justification for generating proposals as alternatives to try to include these regions in the PSA. The identification of eligible or priority areas for the PSA was based on the methodologies of the Physiographic Survey, to delimit the environmental areas or units and, for the analysis of decision-making, the Multicriteria. Priority areas for payment for environmental services equivalent to 911 ha were identified, with high and very high risk characteristics of losing the ecosystem services provided by the conservation of biodiversity.
\end{abstract}




\section{INTRODUCCIÓN}

De acuerdo con la Ley General de Desarrollo Forestal Sustentable de México, los servicios ambientales están definidos como los que brindan los ecosistemas forestales de manera natural o por medio del manejo sustentable de los recursos forestales, tales como: la provisión del agua en calidad cantidad; la captura de carbono, de contaminantes y componentes naturales; la generación de oxígeno; el amortiguamiento del impacto de los fenómenos naturales; la modulación o regulación climática; la protección de la biodiversidad, de los ecosistemas y formas de vida; la protección y recuperación de suelos; el paisaje y la recreación, entre otros (DOF, 2009).

La relación que existe entre los bosques, la sociedad y la provisión ecosistémica que éstos proporcionan han pasado por varias modificaciones a lo largo del tiempo. Se habla, de la incorporación de nuevos conceptos para valorar a los bosques. Lo anterior ha dado la pauta para brindar alternativas y nuevos conocimientos en el campo de la ciencia y la tecnología, aplicadas por las ciencias forestales (Gómez J., Monterroso A., y Espejel de la Rosa, S. 2007).

Se estima que más del $30 \%$ de la superficie del planeta está cubierta por bosque (FAO, 2005), aunado a esto se agrega el alto valor de importancia para la vida en todo el globo. Sin duda existe un alto valor asociado a la conservación de la mega diversidad florística y faunística que estos albergan, más estrechamente a los bosques de las regiones tropicales del continente americano. Por otro lado, se ha estimado que los ecosistemas forestales albergan más del $70 \%$ de las especies a nivel mundial (Groombridge, B., 1992). Derivado de lo anterior, es imposible prescindir de la cubierta forestal que los bosques nos proporcionan, dado que son el motor de vida de los seres humanos. Sin embargo, no solo los ecosistemas forestales son los únicos que existen en nuestro planeta, las regiones áridas y semiáridas albergan una proporción menor, pero no menos importante de las especies animales y vegetales del mundo.

En México los servicios ambientales han recibido cada vez mayor atención, tal es el caso de los esquemas de pago para la protección de los mismos. Derivado de esto, desde el año 2003, se implementó el programa de Pago por Servicios Ambientales (PSA) el cual funciona dentro de un esquema a nivel nacional que brinda el financiamiento para dicho propósito. Para el caso de México, el órgano de gobierno encargado de llevar a cabo la dirección y ejecución de éste es la Comisión Nacional Forestal (Diario Oficial de la Federación 2009). En algunos casos, con el pago se busca que los usuarios del suelo adopten prácticas de uso que garanticen la provisión de un servicio en particular, por ejemplo, plantar árboles con fines de secuestro de carbono, entre otros (CIFOR, 2007).

Los esquemas de pago tratan que los beneficiarios directos o indirectos de los Servicios Ambientales, $\mathrm{SA}$, paguen de manera directa, contractual y condicionada a los propietarios proveedores de SA locales por adoptar prácticas que aseguren la conservación, protección y restauración de ecosistemas y los SA que estos generan (Wunder, S., 2006). Sin embargo, los criterios metodológicos que rigen la selección de los ecosistemas o regiones que son propensas a entrar en dichos esquemas de pago son iguales para todo el territorio. Estos están muy por debajo de los criterios de selección definidos por las reglas de operación que para este fin promueve la Comisión Nacional Forestal, (CONAFOR 2012), entre lo que destaca que serán zonas elegibles aquellas superficies propuestas que su cubierta forestal sea mayor al $50 \%$.

En este sentido, se debe comprender que las nuevas propuestas metodológicas que solo atañen a las zonas áridas, son para que las identificaciones de zonas elegibles sean exclusivas de estas características climáticas, y su definición y delimitación territorial abarquen la diversidad de flora y fauna que en ellas se encuentran. De este modo, se debe hacer énfasis en que la correcta evaluación de los servicios ecosistémicos debe producir mejores resultados en la identificación de los sitios donde estos residen, cuantificar si existe cambio de uso del suelo y su probable impacto en la provisión de los servicios y así valorar los beneficios derivados de estos servicios a las poblaciones humanas cercanas y distantes (Naidu, et al., 2006).

En este contexto, el objetivo del presente trabajo es realizar una identificación, a nivel regional, de aqueIlas zonas potenciales de pago por servicios ambientales en el Valle de Mezquital, estado de Hidalgo (México). 


\section{2. ÁREA DE ESTUDIO}

La Unidad de Manejo Forestal (UMAFOR) "1304-Valle del Mezquital", la cual por extensión territorial ocupa el primer lugar dentro del estado de Hidalgo, por relación con las otras cuatro unidades de manejo que lo conforman, y tiene una superficie total de 642.654 hectáreas. Se localiza al suroeste del estado de Hidalgo, entre las coordenadas extremas $20^{\circ} 42^{\prime} 19,98^{\prime \prime}$ y $19^{\circ} 46^{\prime} 09,81^{\prime \prime}$ de latitud norte, y $99^{\circ} 51^{\prime} 06^{\prime \prime}$ y $98^{\circ} 46^{\prime} 44.48^{\prime \prime}$ de longitud oeste (mapa 1).

El valle del Mezquital, Hidalgo, abarca 28 municipios (INEGI, 2005) lo que representa aproximadamente el $34 \%$ de la superficie del estado de Hidalgo y constituye un área de gran importancia ecológica, económica, social, histórica y cultural, que se caracteriza por sus diversas condiciones ambientales lo que ocasiona que se presenten gradientes ecológicos que favorecen la presencia de diversos hábitats. Las variantes altitudinales, fisiográficas, de geología y suelo influyen de manera decisiva en el establecimiento de varias formas de vida y en el desarrollo de una gran riqueza específica, lo que genera diversidad de vegetación con un amplio potencial de recursos para la zona.

\subsection{Aspectos Físicos}

- Clima. En el territorio de esta unidad se ubican dos grandes grupos de climas, los templados con menor proporción, y en mayor proporción los semisecos, BS, con precipitación de 400 a 600 mm anuales

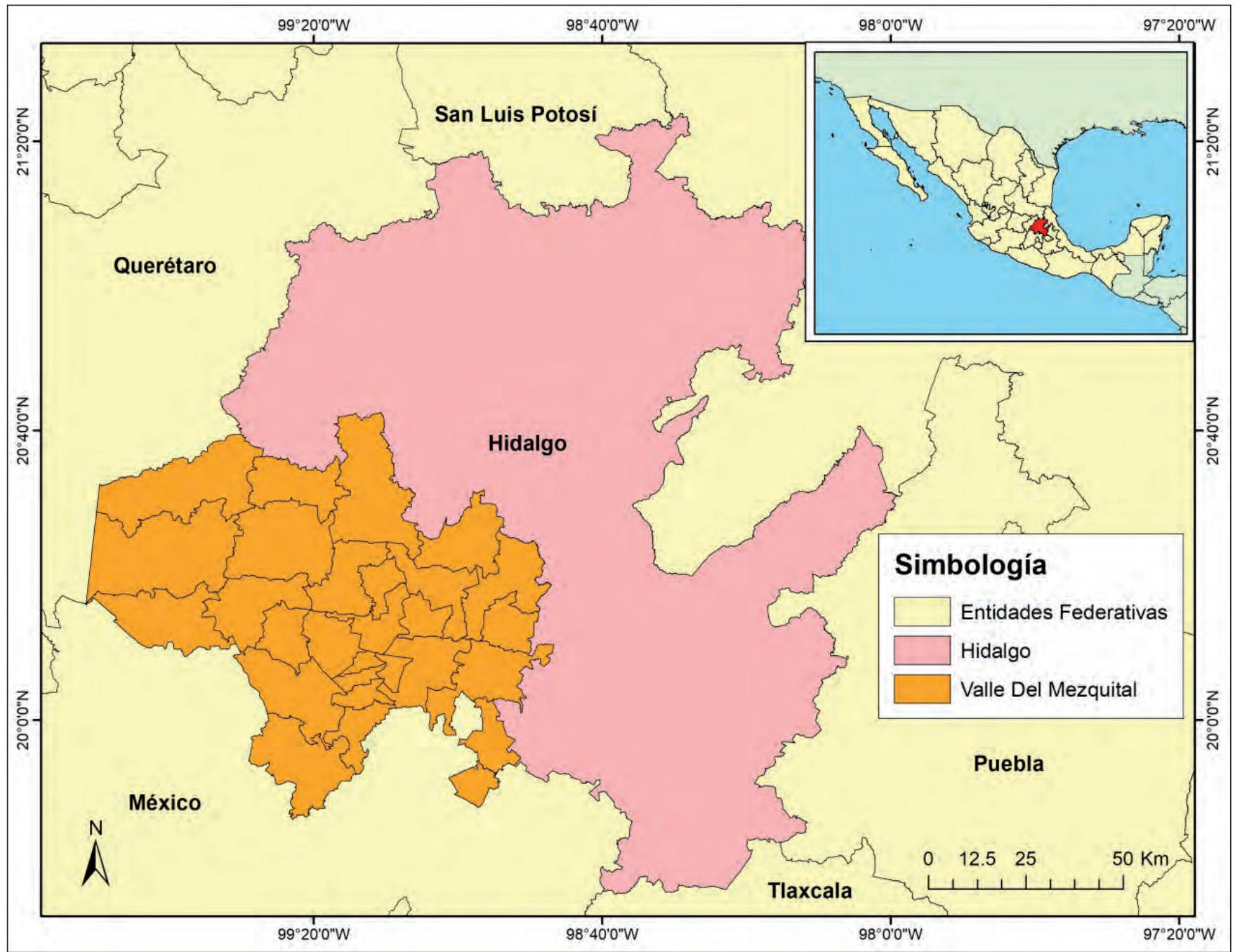

Mapa 1. Ubicación del Valle del Mezquital, estado de Hidalgo. Fuente: Elaboración propia. INEGI, 2005. 
y temperatura media de $18^{\circ} \mathrm{C}$. El clima semiseco es el más común en la mayoría de los municipios. Dada la condición climática de la Unidad se pueden prever también las condiciones de vegetación, tomando el clima como el principal factor para el desarrollo de los niveles de vegetación.

- Geología y geomorfología. La Unidad de manejo forestal se ubica en el Altiplano Mexicano, dentro de la provincia fisiográfica denominada Eje Neovolcánico, en donde forma un amplio valle dividido por serranías y cerros separados. En el área afloran rocas de tipo sedimentario e ígneo que varían en edad y composición.

- Suelos. En la UMAFOR inciden ocho diferentes unidades de suelo de acuerdo con la clasificación FAO - UNESCO. Los tipos de suelo son: cambisol (B), Feozem (H), Litosol (I), Luvisol (L), Planosol (W), Rendzina (E), Vertisol (V) (INEGI, 1992).

- Hidrología. El área de estudio pertenece en su generalidad a la Región Hidrológica No. 26, Parcial, Alto Pánuco, Cuenca del río Tula. Desde el punto de vista administrativo, tanto la Cuenca del Valle de México como la de Tula, quedaron integradas al Consejo de Cuenca del Valle de México. (CONAGUA, 2015) - Vegetación. La vegetación está descrita de acuerdo con la clasificación de Rzedowsky (2006) como Matorral Xerófilo. Entre las principales características fisonómicas y estructurales abarca comunidades de fisonomías muy diversas, características de las zonas áridas y semiáridas. Incluye comunidades, en las que predominan arbustos altos o árboles bajos de 3 a $5 \mathrm{~m}$ de altura, caducifolios (generalmente por un periodo breve durante la época de secas), con hojas o foliolos de tamaño pequeño. Los matorrales crasicaules son comunidades arbustivas dominadas por plantas de tallo suculento (cactáceas grandes); la altura depende de la especie que lo conforma y puede ser hasta de $10 \mathrm{~m}$. En los matorrales rosetófilos predominan especies arbustivas o subarbustivas de hojas alargadas y angostas agrupadas en forma de roseta; el estrato subarbustivo espinoso y perennifolio a menudo es muy denso. Los bosques de Yucca (izotales) llegan a medir de 2 a $4 \mathrm{~m}$ de alto.

En el matorral micrófilo predominan elementos arbustivos de hoja o foliolo pequeño; de altura variable ( 1 a $3 \mathrm{~m}$, con eminencias aisladas de hasta $6 \mathrm{~m}$ ) de acuerdo a su composición florística y las condiciones ambientales.

El pastizal está formado por comunidades vegetales en las que el papel preponderante corresponde a las gramíneas (i.e. estrato herbáceo dominante). Comprende las comunidades denominadas zacatonales, páramos de altura y sabanas. La altura media es de 20 a $70 \mathrm{~cm}$, aunque se mantienen casi siempre mucho más bajos a causa del pastoreo. La cobertura frecuentemente es menor del 50\% y rara vez supera el $80 \%$. Las sabanas están constituidas por praderas de gramíneas sin árboles o con árboles esparcidos. En general las gramíneas son amacolladas, ásperas y resistentes a las quemas periódicas.

A fin de simplificar el análisis de la distribución de las especies en los tipos de vegetación, se agruparon éstos de la siguiente manera: como Matorrales, el Matorral crasicaule, Matorral desértico, y el Matorral submontano; y como Bosques templados mixtos, el Bosque de encino, el Bosque de junípero, el Bosque de encino junípero y el Bosque de pino-encino. Se consideraron los registros de zonas agrícolas o campos de cultivo y de pastizales como registros de áreas perturbadas por igual, ya que se consideró que el pastizal es inducido en la mayoría de los casos.

\section{MARCO CONCEPTUAL}

\subsection{La provisión de los servicios ecosistémicos y la estimación de valor}

Los servicios ecosistémicos son los que integran beneficios, tangibles e intangibles, que proporciona el medio natural para que sean aprovechados por el ser humano y de acuerdo a ciertos criterios, pueden ser valorados en términos económicos a fin de equipararlos con actividades económicas que implican cambios en los usos de suelo y de esta manera contar con argumentos adicionales para su conservación y manejo (Camacho, 2011). Se puede definir y clasificar a los servicios ecosistémicos de acuerdo a su importancia y valor de provisión: 
- Funciones de regulación: Son los que están relacionados con la capacidad de regular procesos ecológicos esenciales y sostener sistemas vitales a través de ciclos biogeoquímicos y otros procesos biológicos.

- Funciones de hábitat: De forma natural los ecosistemas proporcionan hábitat de refugio y reproducción para flora y fauna contribuyendo a la conservación biológica y diversidad genética. Estas funciones proporcionan servicios como mantenimiento de la diversidad biológica y genética, y de especies comercialmente aprovechables.

- Funciones de producción: Son los que intervienen en los procesos fotosintéticos y autótrofos en general, a partir de los cuales los organismos autoabastecen sus requerimientos orgánicos a partir de compuestos inorgánicos y que también son sustento de consumidores de distinto orden, para generar una mayor variedad de biomasa. Esta variedad de estructuras proporciona una variedad de bienes y servicios para consumo humano, que van desde alimento y materia prima hasta recursos energéticos y medicinales.

- Funciones de información: Los ecosistemas proporcionan funciones de referencia y contribuyen al mantenimiento de la salud humana, proporcionando oportunidades de enriquecimiento espiritual, desarrollo cognitivo, recreación y experiencias estéticas (paisaje).

- Desde hace mucho tiempo, los ecologistas siempre han manifestado como la naturaleza provee los servicios que mantienen la vida en la tierra a cualquier escala, a su vez muchos servicios no tienen un precio en el mercado y muchos de estos servicios son irremplazables por la tecnología (Constanza et al. 1997). Por tanto, un servicio ambiental es utilizado para entender que la estructura y función de la naturaleza tiene un valor y que las funciones de los ecosistemas pueden redefinirse como servicios y bienes ambientales, cuando se considera el valor que tienen para los seres humanos.

Por otro lado, es bien sabido que las relaciones que existen entre las políticas ambientales y la obtención de satisfactores no es completamente compatible, deriva en que la relación entre el manejo de la tierra y los servicios ambientales no es completamente conocida y muy poco estudiada (Campos, 2005). En este sentido, tratar de dar valor a los servicios ambientales es un problema grave dado que no son procesos definidos con principio y fin establecidos, sin embargo, es necesario tratar de hacerlo para poder determinar los esquemas de PSA.

En el intento por valorar los servicios ambientales, los desarrollos de las políticas solo consideran valores mixtos (Faber, 2005), sin considerar las externalidades que se generan en la obtención y aprovechamiento de los satisfactores que estos proporcionan.

\subsection{Los esquemas de pago por Servicios Ambientales}

De acuerdo con la Ley General de Desarrollo Forestal Sustentable de México, los servicios ambientales están definidos como los que brindan los ecosistemas forestales de manera natural o por medio del manejo sustentable de los recursos forestales, tales como: la provisión del agua en calidad y cantidad; la captura de carbono, de contaminantes y componentes naturales; la generación de oxígeno; el amortiguamiento del impacto de los fenómenos naturales; la modulación o regulación climática; la protección de la biodiversidad, de los ecosistemas y formas de vida; la protección y recuperación de suelos; el paisaje y la recreación, entre otros (DOF, 2011).

En este sentido, el pago por servicios ambientales (PSA) es una clase de instrumento económico diseñado para dar incentivos a los usuarios del suelo, de manera que continúen ofreciendo un servicio ambiental (ecológico) que beneficia a la sociedad como un todo. En algunos casos, con el pago se busca que los usuarios del suelo adopten prácticas de uso que garanticen la provisión de un servicio en particular, por ejemplo, plantar árboles con fines de almacenar carbono, entre otros (CIFOR, 2006).

Otra definición de esquema de pago por servicios ambientales es que se trata de un mecanismo flexible y adaptable a diferentes condiciones, que apunta a un pago o compensación directa por el mantenimiento o 
provisión de un servicio ambiental por parte de los usuarios del servicio del cual se destina a los proveedores (Pagiola et al. 2006).

Si bien es cierto que los esquemas de pago por servicios ambientales están tomando un lugar importante en las políticas públicas orientadas a la protección de recursos naturales, es importante mencionar que la definición de la misma toma en cuenta criterios que son por lo general verticales y generalizan la aplicación de los recursos. En este mismo sentido, la definición de las políticas toma un sentido estructural un tanto complicada, ya que existen sectores de la sociedad que ven un tanto irreverente poner un precio a los componentes de la naturaleza, ya que esto ha provocado serios problemas de carácter técnico y hasta cierto punto ha levantado críticas que son de origen cultural (Pagiola, 2006).

De esta manera, en el diseño de la estrategia de política pública para proteger los servicios ambientales, encontramos tres opciones:

1. Apoyar el surgimiento de mercados privados, un ejemplo de este enfoque es el ecoturismo, el café de sombra certificado, proyectos de bonos de captura de carbono, los contratos de servidumbres ecológicas, comprar los derechos a cambiar la vegetación natural, etc.

2. Recibir transferencias de los beneficiarios globales, por ejemplo los apoyos del Fondo para el Medio Ambiente Mundial.

3. Actuar como intermediarios, cobrando a los beneficiarios locales y pagando a los propietarios de los bosques. El esquema de Pago por Servicios Ambientales (PSA) en México, ha sido un esfuerzo llevado a cabo por la Comisión Nacional Forestal (CONAFOR) y diversos Socios importantes como la Comisión Nacional de Áreas Naturales Protegidas (CONANP). Este programa, tiene como finalidad impulsar el reconocimiento del valor de los servicios ambientales que proporcionan los ecosistemas forestales, agroforestales y recursos naturales, además de apoyar la creación de mercados de estos servicios. Estos programas apoyan a comunidades, ejidos, Asociaciones Regionales de Silvicultores y a propietarios de terrenos forestales. El Programa y las reglas de operación de ProÁrbol de México, han pasado por una serie de modificaciones y actualmente los conceptos de apoyo se agrupan en cinco categorías siendo (CONAMP, 2010): Hidrológicos, Biodiversidad, Sistemas agroforestales, Captura de carbono y Elaboración de proyectos.

En el año 2003 la CONAFOR creó el Programa de Pago de Servicios Ambientales Hidrológicos (PSAH) y un año después, en 2004 se creó el Programa para Desarrollar el Mercado de Servicios Ambientales por Captura de Carbono y los Derivados de la Biodiversidad y para Fomentar el Establecimiento y Mejoramiento de Sistemas Agroforestales (PSA-CABSA) (Diario Oficial de la Federación 2009). Aunque a partir del año 2010, la CONAFOR retiró la modalidad de Pago por servicios ambientales por Captura de Carbono, quedando únicamente las modalidades para: 1) Servicios ambientales hidrológicos y 2) Derivados de la Biodiversidad (incluyendo el establecimiento y mejoramiento de Sistemas Agroforestales). (Diario Oficial de la Federación, 2009).

El esquema de PSA mexicano, lo que trata es obtener el máximo beneficio ambiental en la selección de predios a través de una serie de criterios (Pagiola, 2008). Entre los criterios que tiene CONAFOR para seleccionar los predios (terrenos) beneficiados para PSA en ambas modalidades (Hidrológicos y Biodiversidad) se encuentran (Diario Oficial de la Federación 2009): estar dentro de un Área Natural Protegida; estar incluido dentro de las 60 montañas prioritarias para CONAFOR; ubicarse dentro de la microcuenca donde haya una zona elegible para PSA; estar conformado por un comité de vigilancia acreditado por la Procuraduría Federal de Protección al Ambiente (PROFEPA), si el predio se une con otros predios para formar corredores biológicos, si bien si se demuestra que es un usuario el propietario de los servicios ambientales pagará por estos; tener un predio con Ordenamiento Territorial Aprobado; encontrarse en una zona con riesgo de deforestación y contener alta densidad de biomasa. 


\subsection{Experiencias del Pago de Servicios ambientales, PSA}

El tema del PSA, tiene antecedentes en diversos países del mundo, por ejemplo, en Ecuador Chafa P. y Cerón P (2016), en su trabajo sobre PSA para conservar el agua, obtuvieron buenos resultados en la construcción de un fondo para protección del agua.

Por otra parte, Macip-Ríos R. y Macip R. F. (2013), investigaron sobre pago por servicios ambientales (ecosistémicos) en México y al interrogarse sobre si estos son eran una alternativa para la conservación de la biodiversidad y el desarrollo, observaron preliminarmente como entre el índice de desarrollo humano (IDH) y el PSA, a escala nacional y estatal (Estados de Puebla, Veracruz y Oaxaca, entre otros), se evidencia una relación negativa. Sin embargo, indican que a nivel local es necesario para generar conclusiones más precisas e insisten en el hecho de que los esquemas de PSA en México deben considerarse aún en proceso experimental y no como herramienta para la conservación de referencia.

También, Rojas-López O., González- Guillen M., Gómez-Guerrero M. y Romo Lozano. J., (2012) indagaron sobre la renta de la tierra y el pago de servicios ambientales en la Sierra norte de Puebla. En este caso, los estudios realizados mostraron que el Pago por Servicios Ambientales Hidrológicos (PSAH) no había sido exitoso dentro del área de estudio. Se entiende así que para que este sistema hubiese resultado atractivo a los propietarios forestales se les debería haber compensado con al menos $\$ 1.516,50$ ha/año, cantidad que representa el costo de oportunidad (CO) de los terrenos con uso potencial forestal que pueda obtenerse por el uso pecuario; mientras que el CO para los usos agrícola y pecuario correspondió a $\$ 1,829.50$ ha/año que pudiera obtenerse por el uso forestal. El estudio reveló que los suelos con un bajo uso potencial forestal presentan características de productividad superior y son más aptos para brindar mayor diversidad de servicios ambientales, en contraste con aquellos terrenos que sustentan usos agrícolas y pecuarios. Por tanto, además de la renta de la tierra forestal y de los beneficios derivados de alguna actividad que soporte, es importante que el PSAH considere los costos de los impactos ambientales que se pueden producir ante un cambio de uso potencial de la tierra.

Otros investigadores han realizado trabajos en México. Así, Gómez J., Monterroso A. y Espejel de la Rosa, S. (2007) investigaron sobre la captura de carbono como servicio ambiental en la comunidad "Lobos y Pescadores"del Municipio de Tepehuanes, Durango. Este trabajo concluye que las áreas de mayor potencial de contenido de carbono son las que son manejadas por el Programa del Manejo Forestal de la Comunidad, ya que ahí se tienen las mejores características naturales, para el crecimiento de los árboles. Dentro del conjunto de la vegetación, el género que tiene más contenido de carbono es el Pinus con un tallo de 30 centímetros de grosor.

Por último, referir los trabajos de Sánchez, A., García, R. Ma y Palma, A. (2007). Estos hicieron análisis de algunas experiencias relacionadas con el Pago de Servicios Ambientales Hidrológicos en México. Ellos evidenciaron como el valor total de los pagos de SAH en las áreas analizadas es modesto, pero significativo para los productores forestales de bajos ingresos. Además, indican la necesidad de establecer tarifas equitativas, para lograr una mayor equidad.

Con todo, cabe resaltar como el PSA, y el PSAH, aunque en diferentes espacios, han sido importantes al contribuir tanto a la preservación y conservación de los recursos naturales, como del suelo, vegetación y el agua. Sin embargo, se pone de manifiesto como para conseguir una compensación económica suficiente por estos servicios, es necesario incrementar el pago, a los ejidatarios, comuneros y pequeños propietarios, en tanto contribuiría en gran medida lograr ese otro gran reto que no es otro sino conseguir a mejorar el nivel de vida de la población local de estos ámbitos.

\subsection{Alcances del PSA en México}

Según cifras derivadas del Inventario Nacional Forestal y de Suelos 2004-2009 (CONAFOR, 2012) México cuenta con una superficie de bosques y selvas de aproximadamente unas 63, 411,754.04 ha, mientras que de zonas áridas y semiáridas tiene unas 56.929.256,33 ha. La superficie destinada total de zonas elegibles para el PSA asciende a unas 48.64 .000 ha, divididas en seis áreas de Pago. 
De acuerdo con las reglas de operación del programa denominado ProÁrbol, las áreas de PSA diferenciado se dividen en seis áreas; correspondiendo al área I, II y III, los apoyos para Servicios Ambientales Hidrológicos, mientras las áreas IV, V y VI los apoyos para Servicios ambientales derivados de la Conservación de la Biodiversidad. De este modo y de acuerdo con las superficies, las áreas destinadas a protección de la Biodiversidad suman un total de 28.826 .712 hectáreas, consideradas solo dentro de zonas con cubierta forestal, siendo en este sentido insuficiente para cubrir el resto de la superficie que no cuenta con características necesarias para su integración.

Los criterios de selección y determinación de las áreas, son de aplicación general para todas las regiones del país, sin embargo, esto afecta directamente a las zonas que no cuentan con características de selección aplicables. Aun con este argumento existen expertos, quienes piensan que los criterios de decisión para la delimitación de las áreas elegibles no deben cambiar, sino que deberían ser un tanto más rigurosos y exactos en su aplicación, es decir, que estén en acordes a su conexión directa con la definición de mecanismo de PSA y que se apliquen según la lógica de su funcionamiento, pues a pesar de contar con dichos criterios, en nuestro país se tiende a emplear este tipo de apoyos como un mecanismo político de combate a la pobreza y desigualdad de género, ya que las áreas manejadas por mujeres tienen prioridad. Aunado a esto se tiene que en el esquema de PSA, ni la directriz firme de sus objetivos, está garantizada debido a la deficiencia en su legislación y las fluctuaciones en las corrientes políticas sexenales (COLPOS, 2007).

\section{METODOLOGÍA}

En el presente trabajo se considera que el uso de metodologías combinadas derivadas de la observación simple y la ayuda de los Sistemas de Información Geográfica (SIG) ayudan a definir mejor las áreas importantes, para PSA, de las regiones semiáridas y áridas. Ancira (2015) y Valdez (2011) respaldan la veracidad de los resultados al usar imágenes satelitales combinado con los SIG.

La identificación de zonas elegibles o prioritarias para el PSA se basó en gran medida en la combinación de la metodología utilizada por Imbach, I., (2005) y Chuvieco, E. (2000). En la que se explica mediante la utilización de un Sistema de Información Geográfica (SIG) y el Multicriterio propuesta por Malczewski, J. (1999) para el análisis de propuestas. Dicha metodología también fue usada por Paneque (2006) y Paegelow, M., Et al (2003) en estudios sobre gobernanza del agua y para modelación del paisaje.

Para delimitar las unidades cartográficas se usó la metodología del Levantamiento Fisiográfico (Ortíz, C., y Cuanalo, H., 1984), en la que se explica de manera puntal los pasos a seguir para generar los sistemas terrestres $\mathrm{y}$, facetas o unidades ambientales que delimitan espacialmente el área de estudio. Donde se trabaja con imágenes de satélite y fotografías aéreas, para delimitar sistemas terrestres a escalas menores y facetas con escalas más detalladas.

La metodología consiste de dos componentes principales cuya integración permite dar prioridades para el PSA; esto se refiere a que un mapa de provisión de servicios ecosistémicos es combinado con un mapa de la amenaza o riesgo a perder estos servicios. En esta metodología se le da prioridad a las diferentes actividades elegibles bajo los actuales esquemas de servicios ambientales de CONAFOR (que serían la conservación del bosque y los Servicios Ambientales Forestales, pero cada una es evaluada de forma diferente (González, B., 2011).

Dado que la información utilizada es un tanto heterogénea se debió utilizar un método que estandarizara u homogeneizara los criterios y escalas ya que estos toman valores muy diferentes entre sí. Este problema se resolvió mediante la estandarización de los criterios (Malczewski, J., 1999). En la cual todos los criterios son transformados en una escala común de medida y también el significado de los valores es evaluado en términos del objetivo a obtener. 


\subsection{Información Cartográfica}

Se utilizaron Imágenes de satélite del sensor SPOT XS, cada una abarcando una superficie de $3.600 \mathrm{~km}^{2}$ con 3 bandas del espectro electromagnético (cuadro 1). Las imágenes cubren el 100\% de la superficie abarcada por la UMAFOR 1304 que corresponde a la región del Valle del Mezquital.

Cuadro 1. Relación de imágenes utilizadas en el proceso.

\begin{tabular}{|l|l|l|}
\hline \multicolumn{1}{|c|}{ Nombre de la Imagén } & Cobertura & Fuente \\
\hline s5_586309_20080414_3a」 & $60 \times 60 \mathrm{~km}$ & CONAFOR \\
\hline s5_586310_20080409_3a」 & $60 \times 60 \mathrm{~km}$ & CONAFOR \\
\hline s5_588309_20070228_3a」 & $60 \times 60 \mathrm{~km}$ & CONAFOR \\
\hline s5_588310_20070213_3a」 & $60 \times 60 \mathrm{~km}$ & CONAFOR \\
\hline s5_589309_20071207_3a」 & $60 \times 60 \mathrm{~km}$ & CONAFOR \\
\hline s5_589310_20080404_3a」 & $60 \times 60 \mathrm{~km}$ & CONAFOR \\
\hline
\end{tabular}

Fuente: CONAFOR -Comisión Nacional Forestal-, 2012.

La cartografía temática digital es obtenida para atender las diversas variables y, se trabaja mediante el uso de Sistemas de Información Geográfica (SIG) ArcGis@ 9.2. La identificación de las áreas, del Valle del Mezquital, se llevó a cabo mediante geoprocesamientos y análisis espaciales de las coberturas cartográficas que se muestran en el Cuadro 2 . En el presente trabajo la unidad mínima cartografiable es de $10 \times 10 \mathrm{~m}$.

Cuadro 2. Relación de capas vectores utilizadas en el proceso.

\begin{tabular}{|c|c|c|}
\hline Nombre de la capa/ Estudio & Fuente & Escala \\
\hline Áreas naturales protegidas & $\begin{array}{l}\text { INEGI (conjunto de datos topográficos de Hidalgo escala } \\
\text { 1:50000) }\end{array}$ & $1: 50000$ \\
\hline Localidades & $\begin{array}{l}\text { INEGI (conjunto de datos topográficos de Hidalgo escala } \\
1: 50000)\end{array}$ & $1: 50000$ \\
\hline Curvas de nivel & $\begin{array}{l}\text { INEGI (conjunto de datos topográficos de Hidalgo escala } \\
1: 50000)\end{array}$ & $1: 50000$ \\
\hline $\begin{array}{l}\text { Uso de Suelo y Vegetación Estado de } \\
\text { Hidalgo }\end{array}$ & Gobierno del estado de Hidalgo & $1: 50000$ \\
\hline $\begin{array}{l}\text { Diseño de muestreo del Inventario } \\
\text { Estatal Forestal }\end{array}$ & Gobierno del estado de Hidalgo & $1: 50000$ \\
\hline Microcuencas UMAFOR 1304 & ERF 2010 & $1: 250000$ \\
\hline $\begin{array}{l}\text { Unidades de gestión ambiental } \\
\text { UMAFOR } 1304\end{array}$ & ERF 2010 & $1: 250000$ \\
\hline Climas Hidalgo & ERF 2010 & $1: 250000$ \\
\hline $\begin{array}{l}\text { Índice de Deforestación para el } \\
\text { Estado de Hidalgo }\end{array}$ & INE & $1: 250000$ \\
\hline
\end{tabular}

Fuente: Elaboración propia. 
La zonificación ecológica, contiene los elementos del medio natural como el relieve, clima, suelo, hidrología, vegetación, uso de la tierra, y la población. Es decir, comprende el análisis del territorio de manera integral, paso definitivo en la elaboración del diagnóstico ambiental territorial. En la zonificación se considera el paisaje como una entidad espacio temporal integrada, contribuyendo a presentar la dinámica de los procesos ecológicos y funcionamiento del paisaje; logrando así una planificación prospectiva del uso de la tierra que garantice la conservación y uso sostenido de los recursos naturales.

Para realizar una conservación correcta de la diversidad biológica es necesario ubicar las áreas más ricas, las que contienen una mayor diversidad, aquellas con altos niveles de endemismos en los grupos biológicos y aquellas que contienen especies que se encuentran en la NOM 059 que proporciona los listados de especies con estatus de protección especial. La identificación de las áreas críticas para la conservación de la biodiversidad, es urgente dadas las elevadas tasas de deforestación y cambios en el uso de suelo que ocurren en la actualidad, lo que conlleva a la perdida de importantes números de especies, así como de hábitats particulares y perdida de la funcionalidad de los ecosistemas (SEMARNAT, 2010). Asimismo, se puede perder biodiversidad de manera importante debido en parte a la falta de estrategias que permitan identificar lo que es realmente prioritario conservar.

En este estudio se consideró como información alfanumérica las tablas obtenidas de la NOM 059 (SEMARNAT, 2010), específicamente la riqueza de la fauna encontrada en la región de estudio, haciendo hincapié que por el tipo de región ambiental-climática solo se considera a la avifauna y anfibios

\subsection{Asignación de valores a criterios e indicadores}

El presente estudio retoma las propuestas de González, B. (2011), requirió de la integración de un esquema jerárquico que mediante el uso de conceptos ambientales fuera integrando criterios. Se debe señalar que para el caso de la demanda para los servicios derivados de la conservación de la biodiversidad, no se considera una demanda como tal por los usuarios dado que estos servicios son importantes únicamente por el hecho de existir de la misma, que en este caso se remite únicamente a la conservación de los ecosistemas que la proveen y ciertos usos de la tierra que no alteran significativamente la función de los mismos.

Mediante la consulta de literatura y a través de expertos en los diferentes temas, que laboran en la UMAFOR 1304, fue posible obtener el peso asignado a cada criterio e indicador, los cuales permitieron identificar espacialmente las áreas elegibles para PSA derivados de la Biodiversidad. Mediante el método de comparación "pair wise comparision" (comparación por partes) fue posible dar un peso (P) o valor a los criterios, mientras que para los indicadores se utilizó el método de "Ratio estimation procedure" (Procedimiento de estimación de porcentajes). Para ambos métodos se utilizó una escala de 0 a 100. (Aron, A.,y Aron E. 2002), ( Atil H., y Unver Y. 2001). La descripción de las variables, criterios, y peso de variables se describen en la figura 4, y los cuadros 3, 4 y 5.

De esta forma, el método Pair wise comparison se utiliza para el nivel jerárquico de más arriba porque es más preciso cuando se necesita comparar cada criterio con el restante e implica el cálculo de una proporción de consistencia de los resultados para evaluar la coherencia de comparaciones. En cambio, el Ratio estimation procedure es más fácil (simple y rápido) de utilizar por lo que se aplicó únicamente en el nivel jerárquico menor que corresponde a los indicadores de cada criterio.

Por otra parte, se utilizó el "procedimiento de rangos record" para obtener los criterios e indicadores favorables, se usó la Ecuación 1, mientras que para los criterios e indicadores de costos se utilizó la Ecuación 2. (Bechhofer, E. 1954) y (Einot, I., and Gabriel, R. 1975).

La interpretación de estas ecuaciones muestra que cuando el criterio o indicador benéfico es el más alto, el valor es más atractivo y el criterio tiene que ser maximizado; y cuando el criterio o indicador de costos es mayor, el valor es menos atractivo y el criterio tiene que minimizarse (González, B., 2011). Así pues los criterios (Figura 4) que se utilizaron para evaluar las zonas con prioridad por su importancia para la provisión de los servicios ambientales, su demanda y el riesgo o amenaza de perderlos, fueron elegidos acorde a la literatura consultada y la información disponible para la zona de estudio. 
Ecuación 1:

$$
\mathrm{x}_{\mathrm{ij}}^{\prime}=\left(\frac{\mathrm{x}_{\mathrm{ij}}-\mathrm{x}_{\mathrm{j} \text { min }}}{\mathrm{x}_{\mathrm{j} \max }-\mathrm{x}_{\mathrm{j} \min }}\right) * 100
$$

Ecuación 2:

$$
x_{i j}^{\prime}=\left(\frac{x_{j \max }-x_{i j}}{x_{j \max }-x_{j \min }}\right) * 100
$$

donde:

$X_{i j}=$ Valor del pixel estandarizado

$X_{i j}=$ Valor de todos los pixeles en el mapa

$X_{\text {jmax }}=$ Valor máximo del pixel en el mapa

$\mathrm{X}_{\mathrm{jmin}}=$ Valor mínimo del pixel en el mapa

En el caso de variables cualitativas y categóricas se utilizó la Ecuación 3, mediante la cual se le asigna un valor con rango equivalente (de forma ascendente o descendente) a cada clase o categoría.

Ecuación3:

$$
V=\left(\frac{x_{i j \max }}{n}\right)
$$

donde:

$\mathrm{V}=$ valor

Xjmax = Valor máximo del pixel en el mapa

$\mathrm{n}=$ Número de clases o categoría

\section{RESULTADOS Y DISCUSIÓN}

\subsection{Delimitación de Sistemas terrestres y facetas}

La delimitación fisiográfica de las unidades cartográficas denominadas Sistemas Terrestres y facetas, se realizó mediante la utilización de imágenes aéreas específicamente de satélite del sensor SPOT XS con tres bandas de color, se delimitaron linderos en forma de polígonos que a simple vista tuvieran características similares en su toponimia y clima, considerando en gran medida que el clima es el factor principal para la creación de zonas bióticamente homogéneas. Dichos linderos fueron hechos sobre un mosaico de imágenes de los años 2007 y 2008, con una resolución espacial de $3.600 \mathrm{~km}^{2}$ cada una. Estas imágenes permitieron, mediante el uso del sistema de Información Geográfica (SIG) antes indicado, delimitar los linderos.

En la Figura 1, se muestra el mosaico de imágenes de satélite utilizado para la UMAFOR 1304 en cobertura completa y en la Figura 2 se muestra solo el recorte que atañe específicamente al límite geopolítico de la Unidad, proceso elaborado mediante la herramienta: spatial analyst tools>extraction>extract by mask. Para realizar el proceso de unión de las imágenes se utilizó la herramienta que viene integrada en la caja de herramientas del propio ArcGis 9.2 la ruta es la siguiente: arctoolbox $>$ data management tools $>$ raster $>$ raster dataset>mosaic to new raster.

Dadas las condiciones climáticas de la Unidad de manejo, se determinó que se usaran como Sistemas Terrestres los polígonos generados por los tipos de clima, templados y semisecos, que convergen en la UMAFOR 1304, esto debido a que por defecto las características biológicas flora y fauna se ven afectadas por el factor clima. De tal modo que para el presente trabajo se ubicaron según la capa de vectores de clima del Estudio Regional Forestal con escala 1: 250.000, nueve polígonos con características climáticas propias, lo que nos da un total de nueve Sistemas Terrestres a describir. Cabe mencionar que de acuerdo a los datos 


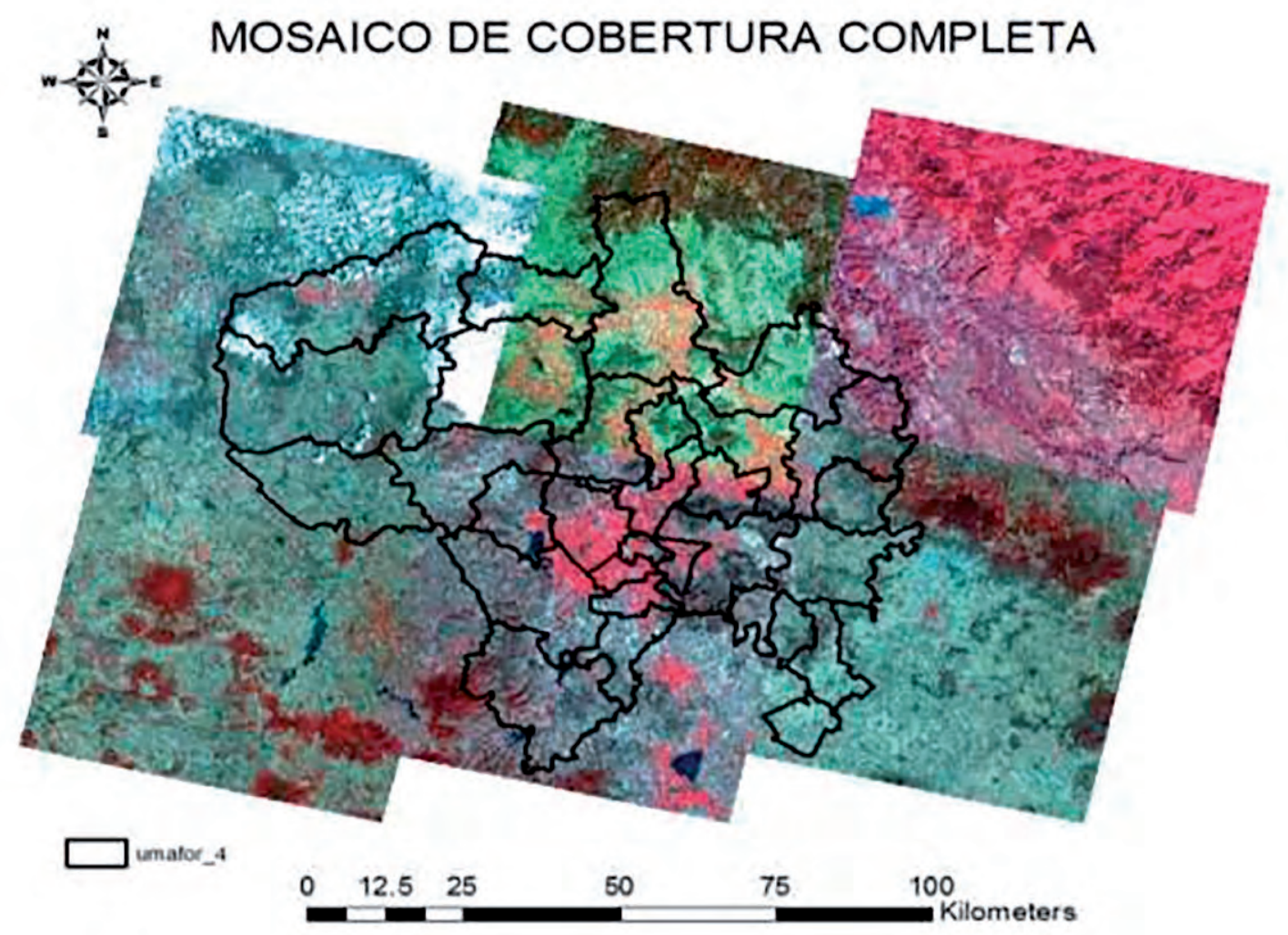

Figura 1. Mosaico de imágenes de cobertura de la UMAFOR 1304. Fuente: Elaboración propia.

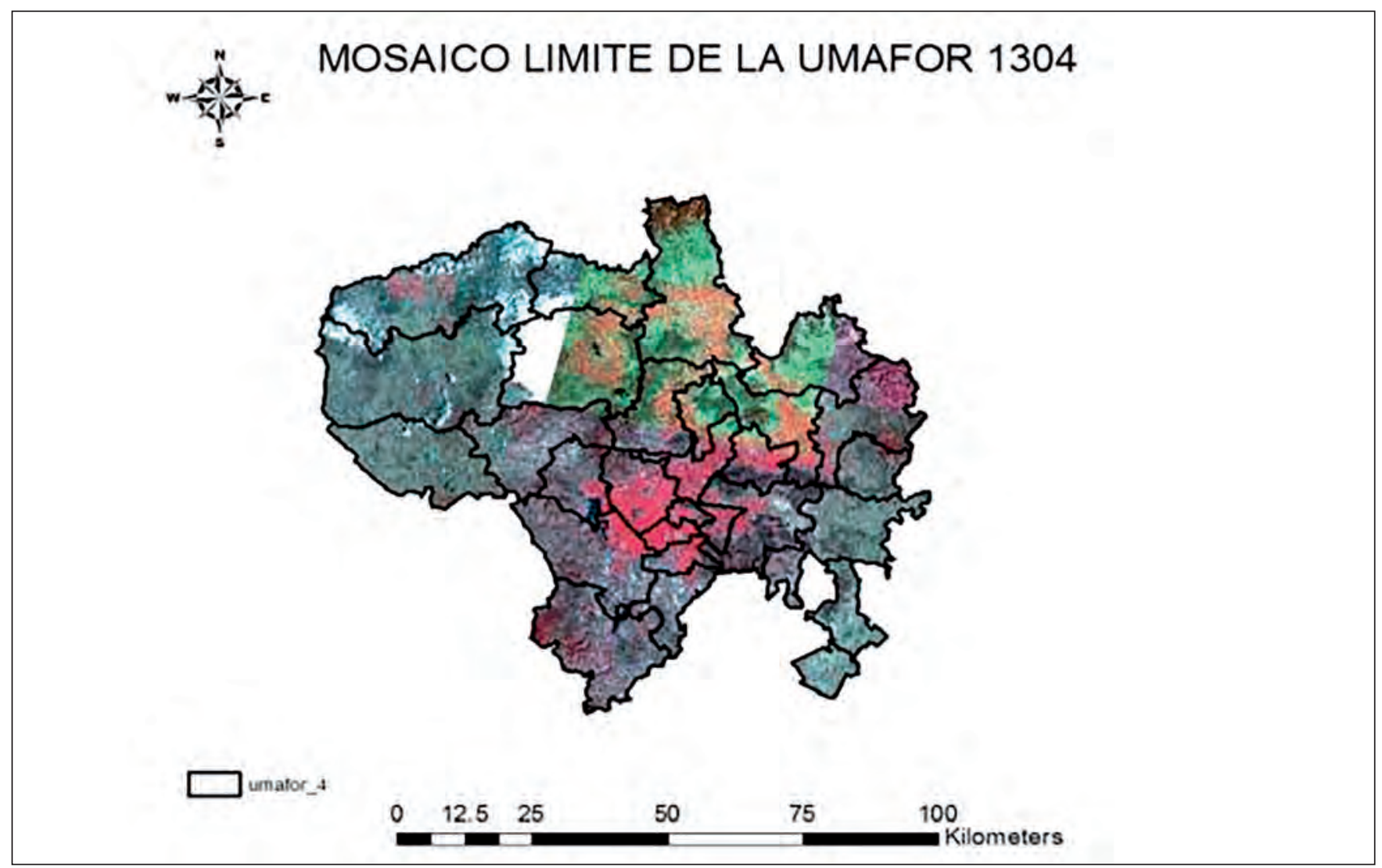

Figura 2. Recorte del mosaico de imágenes para la delimitación de la UMAFOR 1304. Fuente: Elaboración propia. 
obtenidos en cuanto a espacios naturales sólo se hace una descripción del tipo de vegetación de cada una de los 9 sistemas terrestres. También se obtuvieron 20 facetas en toda el área de la IMAFOR 1304 (Figura 3). Trabajos donde se usa la metodología del Levantamiento fisiográfico indican que ese método es adecuado para la delimitación de porciones fisiográficas, como lo indican López, F., Muñoz, D., et al (2003) usan la toposecuencia clima, suelo y vegetación para delimitar sus sistemas terrestres. En el trabajo que hicieron en la subcuenca de Zapototitlan de Salinas en el estado de puebla, México. Así mismo, Aguilar, G., y Sánchez, D. (2018) corroboran la utilidad del levantamiento fisiográfico, para la delimitación de espacios por el paisaje del relieve y la ubicación de especies vegetales en el municipio de Acámbaro, Guanajuato (México).

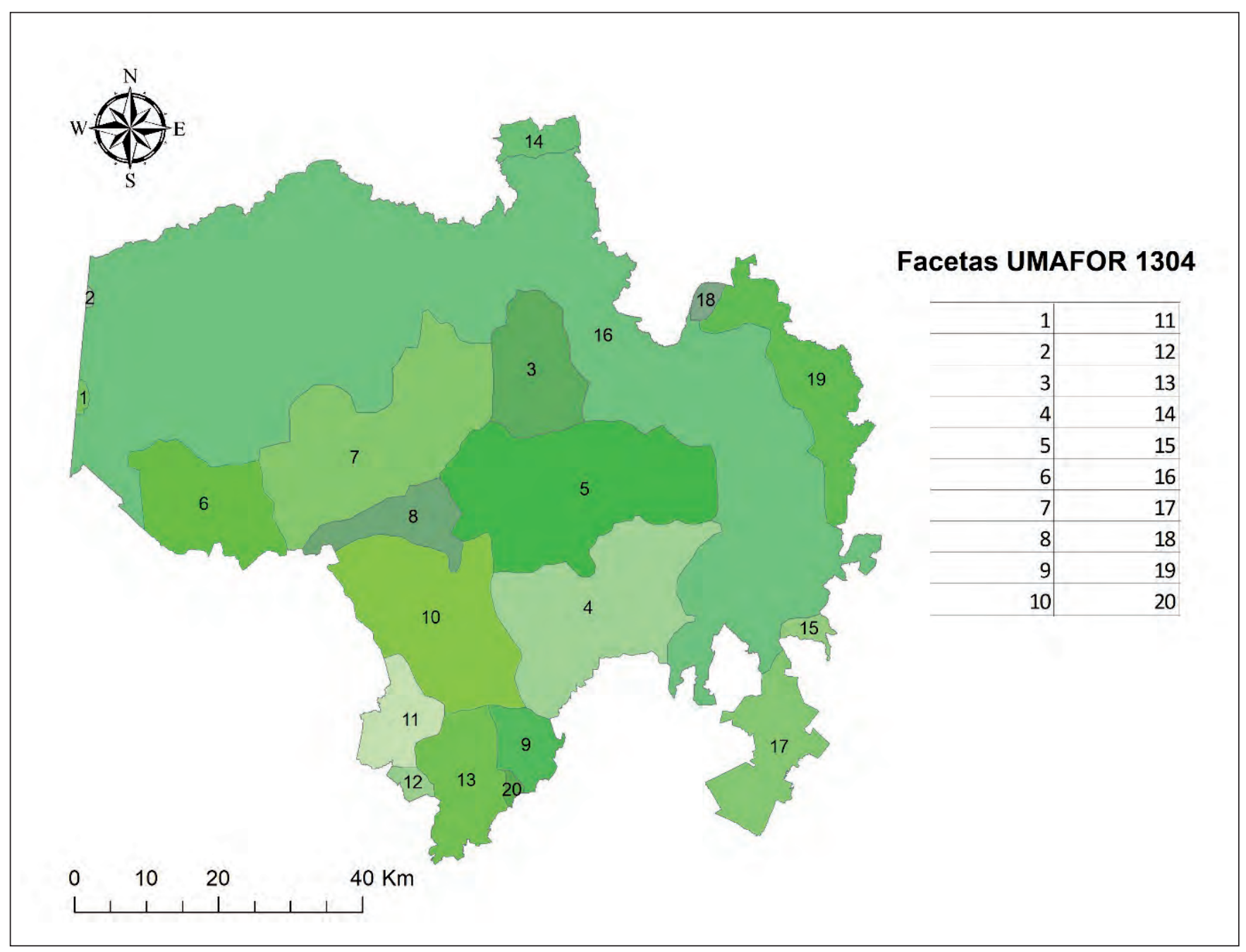

Figura 3. Facetas encontradas en la UMAFOR 1304.

Fuente: Elaboración propia.

\subsection{Determinación de áreas por la provisión de Servicios Ambientales derivados de la conservación de la biodiversidad}

La conservación de la biodiversidad corresponde a la protección de especies de flora y fauna, esta puede ser de especies en específico o desde un ámbito más generoso, es decir, la conservación de las funciones de los mismos ecosistemas (González, B., 2011). 


\subsubsection{Criterios, y pesos para priorizar áreas para el PSA por conservación de la biodiversidad}

En el esquema de la figura 4, se aprecia de forma estructural la disposición de los criterios y pesos utilizados para la priorización de áreas, por amenaza de perder los servicios eco-sistémicos, para el PSA por la conservación de la biodiversidad (González, B,2011).

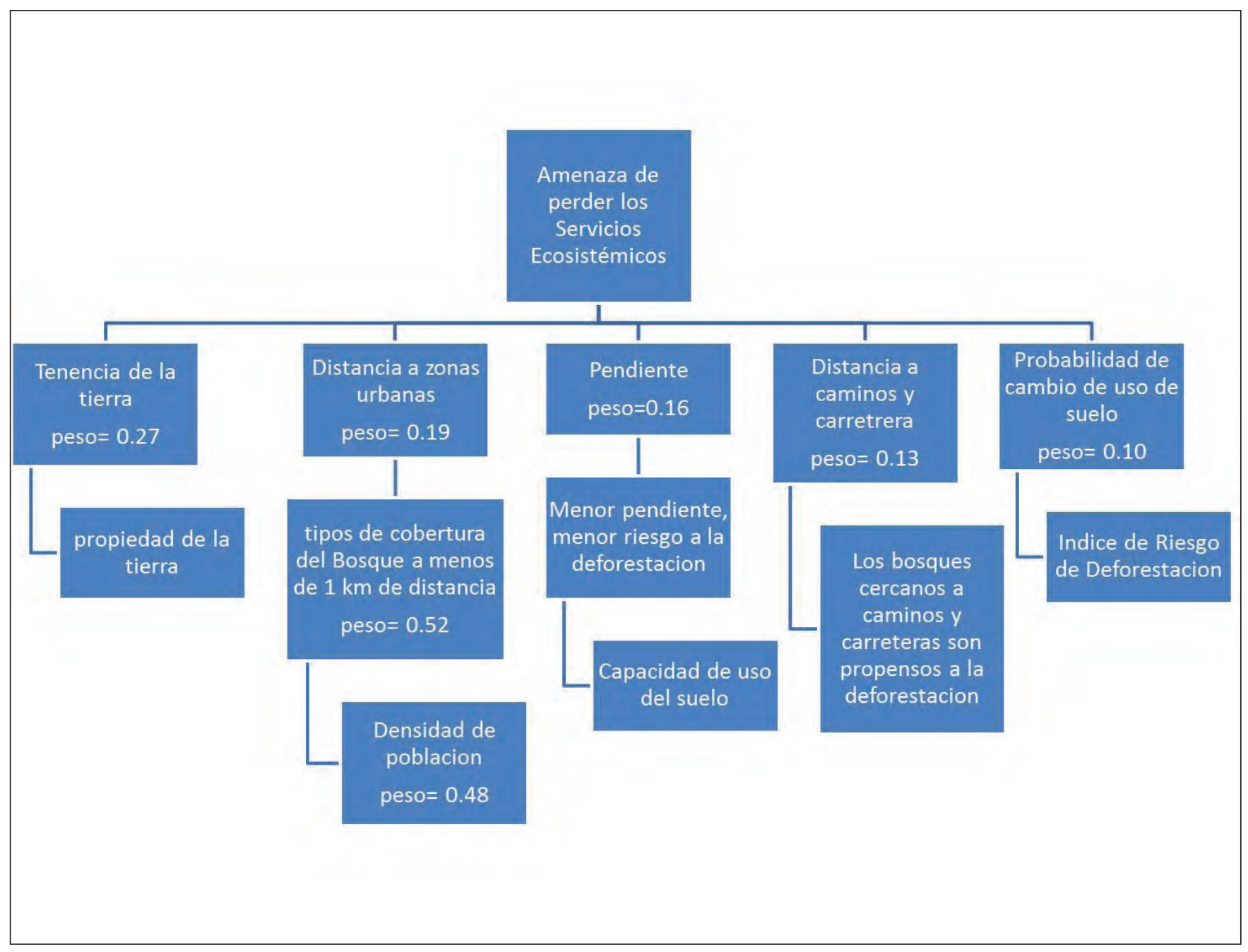

Figura 4. Esquema de criterios y pesos usados en el cálculo de la amenaza de perder los servicios ecos-sistémico. Fuente: Gonzales, B. 2011.

\subsection{Importancia para la conservación de ecosistemas en la Región}

En concordancia con el mapa de Uso de suelo y vegetación del estado de Hidalgo el cual es derivado del Inventario Estatal Forestal escala 1:50000, se reportaron 23 categorías o coberturas, de las cuales 19 son de importancia forestal (Cuadro 3, Figura 5), porque las unidades de bosque de abies, bosque de encino y selva baja caducifolia, no tienen porcentajes altos. 
Cuadro 3. Superficie de Uso de Suelo y Vegetación UMAFOR 1304 en Has.

\begin{tabular}{|c|c|c|}
\hline Agrupación & Superficie en has & $\%$ \\
\hline Área sin vegetación aparente & 832,43 & 0,13 \\
\hline Bosque de abies & 0,45 & 0 \\
\hline Bosque de abies-pino-encino & $1.008,96$ & 0,16 \\
\hline Bosque de encino & $12.621,64$ & 1,97 \\
\hline Bosque de encino-pino con vegetación secundaria & $2.446,09$ & 0,38 \\
\hline Bosque de encino con vegetación secundaria & $23.064,38$ & 3,60 \\
\hline Bosque de pino & $2.423,59$ & 0,38 \\
\hline Bosque de pino - encino (incluye encino - pino) & $3.672,20$ & 0,57 \\
\hline Bosque de pino con vegetación secundaria & 624,35 & 0,10 \\
\hline Bosque de táscate & $15.859,34$ & 2.48 \\
\hline Bosque mesofilo de montaña & 4,07 & 0 \\
\hline Cuerpo de agua & $4.313,96$ & 0,67 \\
\hline Matorral crasicaule & $118.580,31$ & 18,50 \\
\hline Matorral desértico microfilo & $1.646,67$ & 0,26 \\
\hline Matorral desértico rosetofilo & $22.949,72$ & 3,59 \\
\hline Matorral submontano & $2.874,08$ & 0,45 \\
\hline Mezquital & 510,26 & 0,08 \\
\hline Otros usos & $3.212,18$ & 0,50 \\
\hline Pastizal del alta montaña & $1.548,94$ & 0,24 \\
\hline Pastizal inducido y/o cultivado & $67.112,79$ & 10,50 \\
\hline Selva baja caducifolia & 34,34 & 0,01 \\
\hline Uso agrícola & $328.158,82$ & 51,30 \\
\hline Uso urbano & $26,516.53$ & 4,14 \\
\hline
\end{tabular}

Fuente: Elaboración propia. 


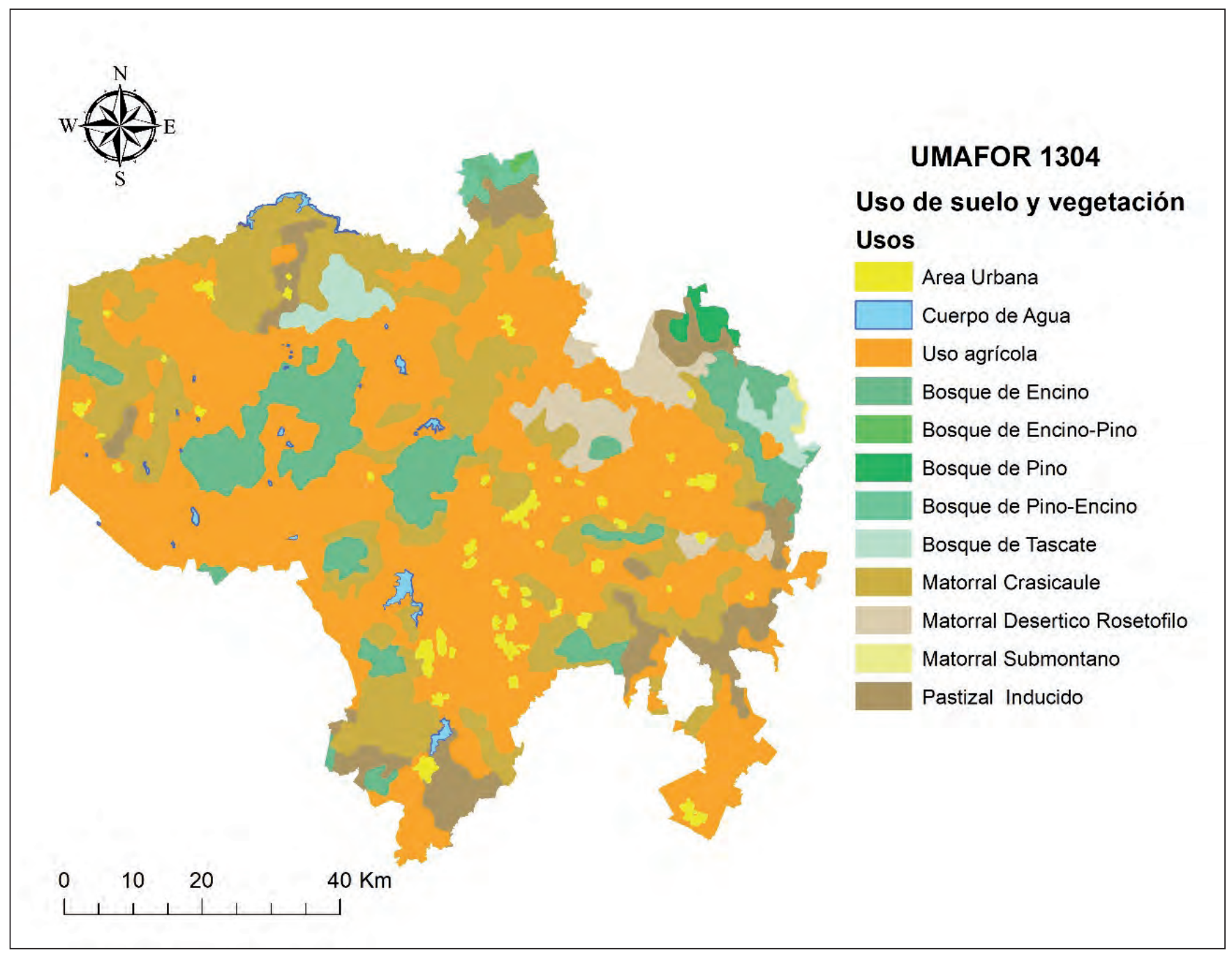

Figura 5. Uso de suelo y Vegetación. Fuente: Elaboración propia.

\subsection{Valor de los ecosistemas por su riqueza y endemismo de especies}

Flores, J., y Gérez, A. (1994) nos proporcionan una idea del número de especies endémicas y estatus de peligro de acuerdo a la NOM 059, esto con respecto a las especies que existen en el país. Trabajando bajo el supuesto de que los tipos de vegetación con mayor número de especies y endemismo son los más importantes para la protección de la Biodiversidad, entonces y mediante el uso de la Ecuación 1, se asigna a cada ecosistema un valor por la riqueza de especies y un valor por la cantidad de endemismos que se tienen, considerando que 100 es el valor más alto (Cuadro 4 y Figura 4).

En el cuadro 4, se observa que los mayores valores por endemismo son: Matorral desértico microfilo, bosque de encino, bosque mixto de pino-encino, abies, y selva baja caducifolia. Por extensión destacan: matorral desértico microfilo, bosque de pino, pastizal inducido, cuerpos de agua y uso urbano.

Al relacionar el cuadro 4 con la figura 6 , se puede destacar que por endemismo el MDM, tiene valor de 100, el BMM con valor de 94, BQ con 87, B Mixto con valor de 74 y SBC, con 59, los otros tipos de vegetación tienen valores menores de 50. La importancia y valoración de estudios sobre especies endémicas es mencionado por León, B., Pitman, N., y Roque, J. (2006) al realizar un estudio de plantas endémicas en Perú, que está influenciado por la cordillera de los Andes, con sus variaciones de altitud y, en consecuencia, de clima. Asimismo, López, F., Muñoz,D., et al. (2003) en la investigación que hicieron en la subcuenca de Zapotitlan, Puebla (México) indican como la interacción entre la geomorfología, geología, edafología y clima influyen en 
Cuadro 4. Valor de asignación de acuerdo al número de endemismos y riqueza de especies.

\begin{tabular}{|c|c|c|c|c|c|c|}
\hline $\begin{array}{l}\text { Categoría de acuerdo al inventa- } \\
\text { rio estatal forestal }\end{array}$ & $\begin{array}{l}\text { Sub-agru- } \\
\text { pación }\end{array}$ & $\begin{array}{c}\text { Agrupación final (Flores y } \\
\text { Gerez, 1994) }\end{array}$ & $\begin{array}{l}\text { Valor por } \\
\text { su No. de } \\
\text { especies }\end{array}$ & $\begin{array}{l}\text { Valor por } \\
\text { su No. de } \\
\text { endemis- } \\
\text { mos }\end{array}$ & $\begin{array}{l}\text { Valor final } \\
\text { No de sp/ } \\
\text { No de en- } \\
\text { demis-mo }\end{array}$ & $\begin{array}{l}\text { Superficie } \\
\text { (ha) }\end{array}$ \\
\hline Bosque de encino & $\mathrm{BQ}$ & bosque de encino encino & 100 & 53 & 87 & 12.622 \\
\hline Bosque mesofilo de montaña & BMM & $\begin{array}{l}\text { bosque mesofilo } \\
\text { de montaña }\end{array}$ & 90 & 75 & 94 & 4 \\
\hline Bosque de abies & $\mathrm{BC}$ & \multirow{5}{*}{ bosque de coníferas } & \multirow{5}{*}{89} & \multirow{5}{*}{40} & \multirow{5}{*}{74} & \multirow{5}{*}{22.965} \\
\hline Bosque de abies-pino-encino & $\mathrm{BC}$ & & & & & \\
\hline Bosque de pino & $\mathrm{BC}$ & & & & & \\
\hline $\begin{array}{l}\text { Bosque de pino - encino (in- } \\
\text { cluye encino - pino) }\end{array}$ & $\mathrm{BC}$ & & & & & \\
\hline Bosque de táscate & $\mathrm{BC}$ & & & & & \\
\hline Selva baja caducifolia & BT & bosque tropical & 67 & 37 & 59 & 34 \\
\hline Matorral crasicaule & MTC & \multirow{4}{*}{ matorrales } & \multirow{4}{*}{75} & \multirow{4}{*}{100} & \multirow{4}{*}{100} & \multirow{4}{*}{146.051} \\
\hline Matorral desértico microfilo & MTDM & & & & & \\
\hline Matorral desértico rosetofilo & MTDR & & & & & \\
\hline Matorral submontano & MTS & & & & & \\
\hline $\begin{array}{l}\text { Bosque de encino-pino con } \\
\text { vegetacion secundaria }\end{array}$ & BVS & \multirow{3}{*}{$\begin{array}{l}\text { bosques con vegetación } \\
\text { secundaria }\end{array}$} & \multirow{3}{*}{61} & \multirow{3}{*}{0} & \multirow{3}{*}{35} & \multirow{3}{*}{26.135} \\
\hline $\begin{array}{l}\text { Bosque de encino con vegeta- } \\
\text { ción secundaria }\end{array}$ & BVS & & & & & \\
\hline $\begin{array}{l}\text { Bosque de pino con vegeta- } \\
\text { ción Secundaria }\end{array}$ & BVS & & & & & \\
\hline Mezquital & $\mathrm{BE}$ & bosque espinoso & 44 & 10 & 31 & 510 \\
\hline Pastizal del alta montaña & PA & \multirow{2}{*}{ pastizales } & \multirow{2}{*}{34} & \multirow{2}{*}{8} & \multirow{2}{*}{24} & \multirow{2}{*}{68.662} \\
\hline Pastizal inducido y/o cultivado & PA & & & & & \\
\hline Cuerpo de agua & VA & vegetación subacuática & & & & 4.314 \\
\hline Uso agrícola & Resto & \multirow{4}{*}{ resto de ecosistemas } & \multirow{4}{*}{ * } & \multirow{4}{*}{ * } & \multirow{4}{*}{1} & \multirow{4}{*}{358.720} \\
\hline Uso urbano & Resto & & & & & \\
\hline Otros usos & Resto & & & & & \\
\hline Área sin vegetación aparente & Resto & & & & & \\
\hline
\end{tabular}

Fuente: Elaboración propia. No= número , $s p=$ especies 


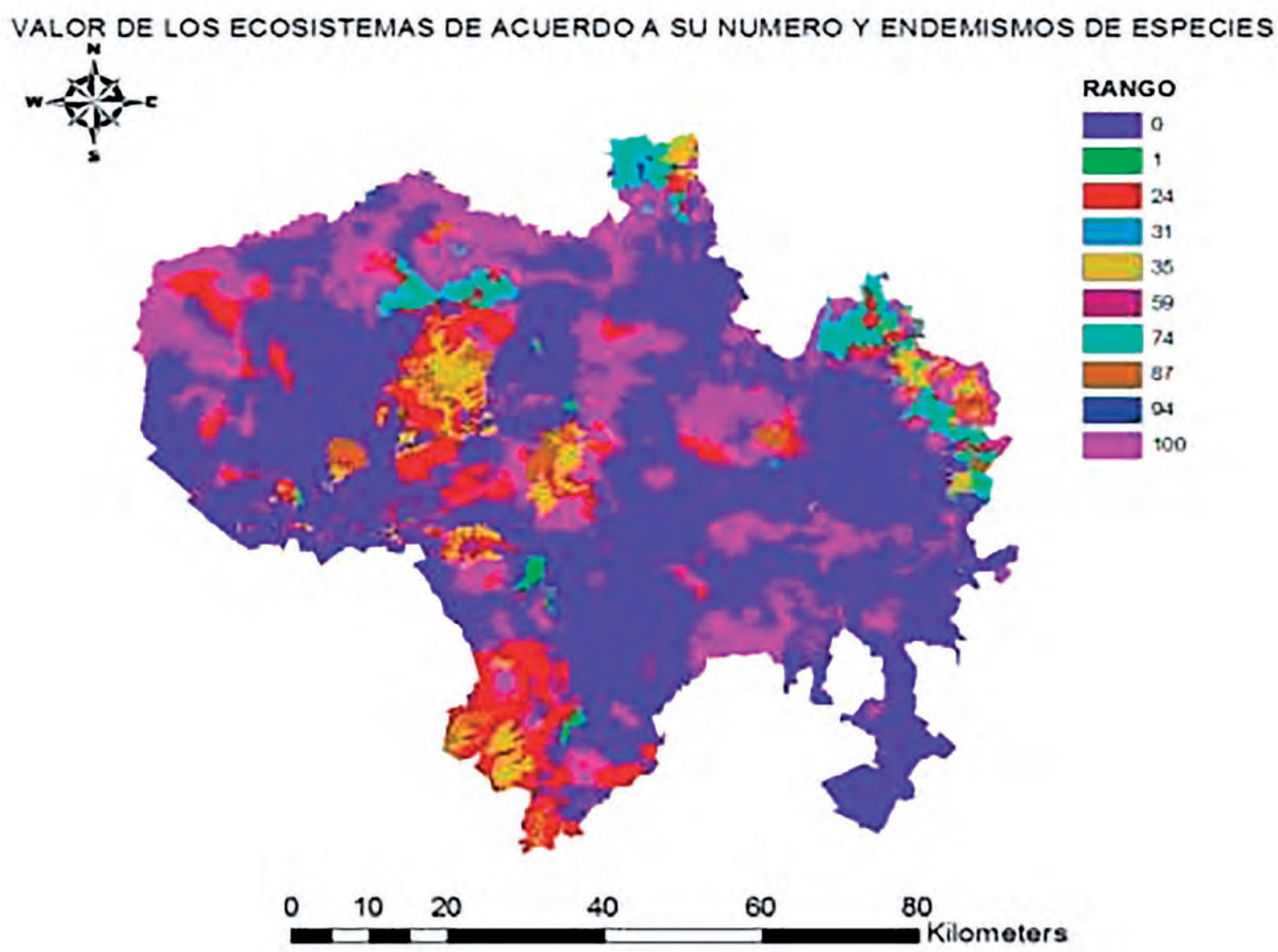

Figura 6. Valor de los ecosistemas de acuerdo a su número de especies y endemismos. Fuente: Elaboración propia.

la distribución de la vegetación endémica en cada faceta de la subcuenca estudiada. En general, la importancia del endemismo radica en el origen nativo de cada especie vegetal, ligado con su espacio geográfico a través del tiempo (Noguera, E.A., 2017).

\subsection{Superficie perdida a nivel regional}

El estado de Hidalgo pertenece a la depresión principal de la Sierra Madre Oriental. Reyes, H., et al. (2009) establece los ecosistemas de mayor pérdida de superficie en dicha depresión, en un estudio realizado que ofrece datos que van desde el año 1989 al año 2005. Tomando en cuenta esta consideración y suponiendo que los ecosistemas de mayor pérdida de superficie son prioridad en la decisión de conservación, resulta que mediante el uso de la Ecuación 1 propuesta anteriormente, los ecosistemas de mayor pérdida de superficie son los de mayor valor, para este caso se asigna el valor más alto según la escala utilizada por la metodología, es decir, 100 y este valor es el referente para definir los valores menores, los cuales serán en proporción de la pérdida de superficie y serán menores (Cuadro 5 y Figura 7). La figura 7 indica que los ecosistemas bosque tropical, bosque templado y matorral xerófilo, tienes valores de 36 a 100 , con pérdidas de vegetación importantes, y el resto de los ecosistemas también tienen un decremento importante. 
Cuadro 5. Superficie perdida de ecosistema en la UMAFOR 1304.

\begin{tabular}{|l|c|c|c|c|}
\hline \multicolumn{1}{|c|}{ Nombre de ecosistema } & $\begin{array}{c}\text { Superficie en } \\
1989, \mathrm{~km} 2\end{array}$ & $\begin{array}{c}\text { Superficie en } \\
2005, \mathrm{~km} 2\end{array}$ & \% de perdida & Valor asignado según su pérdida100 \\
\hline Bosque Tropical & 244 & 223 & 8.6 & 100 \\
\hline Matorral Xerófilo & 194 & 188 & 3.1 & 36 \\
\hline Bosque Templado & 119 & 115 & 3.4 & 40 \\
\hline Demás ecosistemas & 0 & 0 & 0 & 1 \\
\hline
\end{tabular}

Fuente: Elaboración propia.

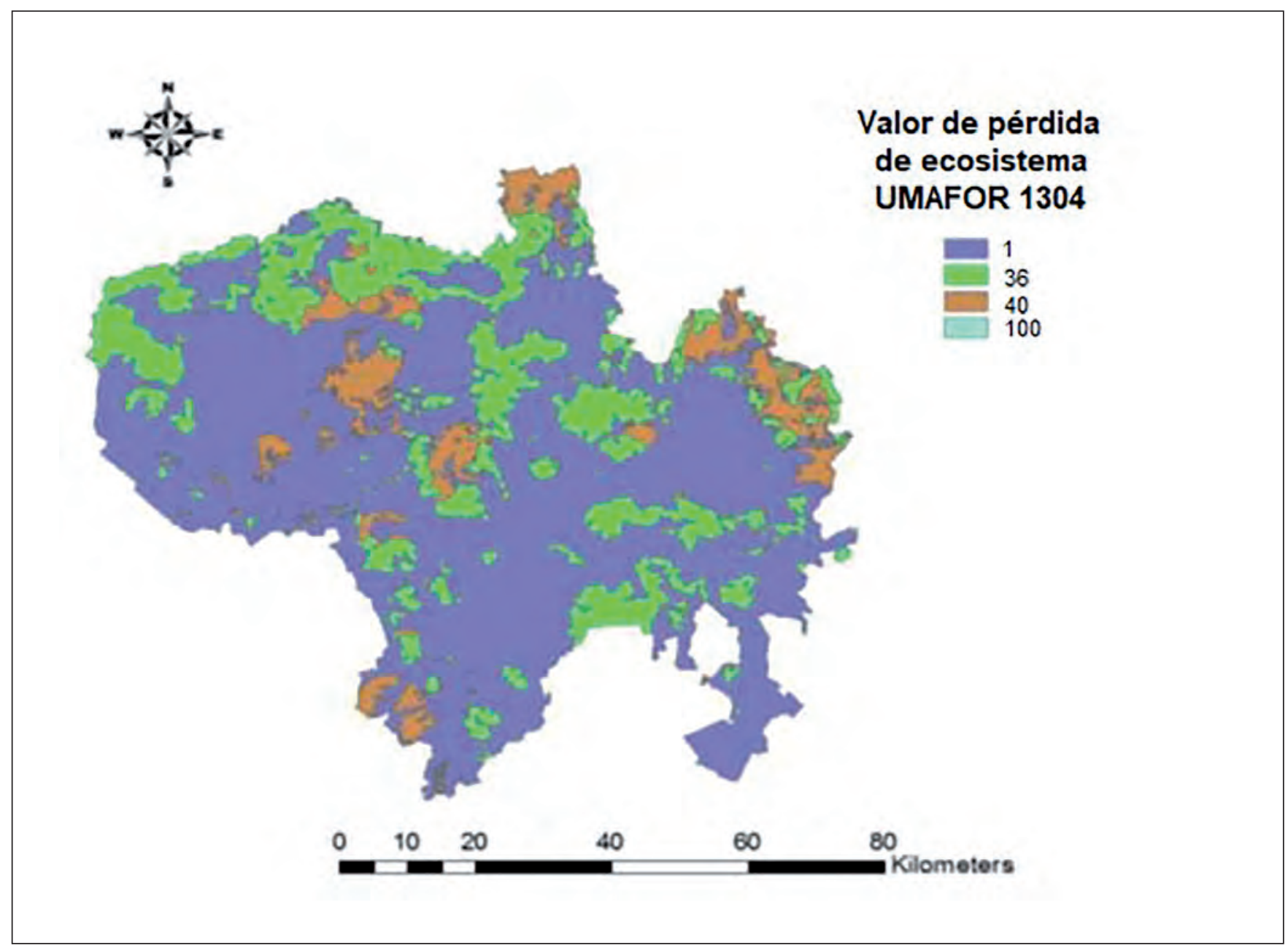

Figura 7. Mapa de valor de los ecosistemas de acuerdo a la superficie pérdida a nivel regional. Fuente: Elaboración propia.

Como resultado de la metodología propuesta se identificaron las zonas elegibles para el Pago por Servicios Ambientales dentro de la UMAFOR 1304. El mapa de la Figura 8, nos muestra gráficamente como quedaron dispuestos los polígonos que se proponen para la inclusión en el PSA dentro de UMAFOR 1304.

En el cual el rango de valor de 0-100 es significativo de que el valor más alto corresponde a zonas que tienen más valor para su conservación, esto según la metodología y la combinación de las figuras 7 y 8 con el mapa de facetas. 
Con el uso de esta metodología se identificaron las áreas elegibles de ser propuestas para el PSA de mayor prioridad, demanda y riesgo de perder los SE. Los resultados muestran que solo 911 ha de toda la superficie en la UMAFOR son áreas de alta a muy alta prioridad por la oferta y el riesgo de perder los SE derivados de la conservación de la biodiversidad (Figura 8).

La figura 8, indica que el área para el pago por servicios ambientales en toda la UMAFOR 1304, es pequeña en comparación con el espacio total, sin embargo, si se implementara el PSA con la cantidad de dinero suficiente para ayudar a los propietarios de bajos recursos, se contribuiría a preservar el ambiente y mejorar el ingreso de los dueños de los predios, como lo mencionan Sánchez A., García Rosa María, y Palma A. (2007). Así mismo se contribuiría a preservar las especies endémicas y, proteger la diversidad ecológica de las especies nativas.

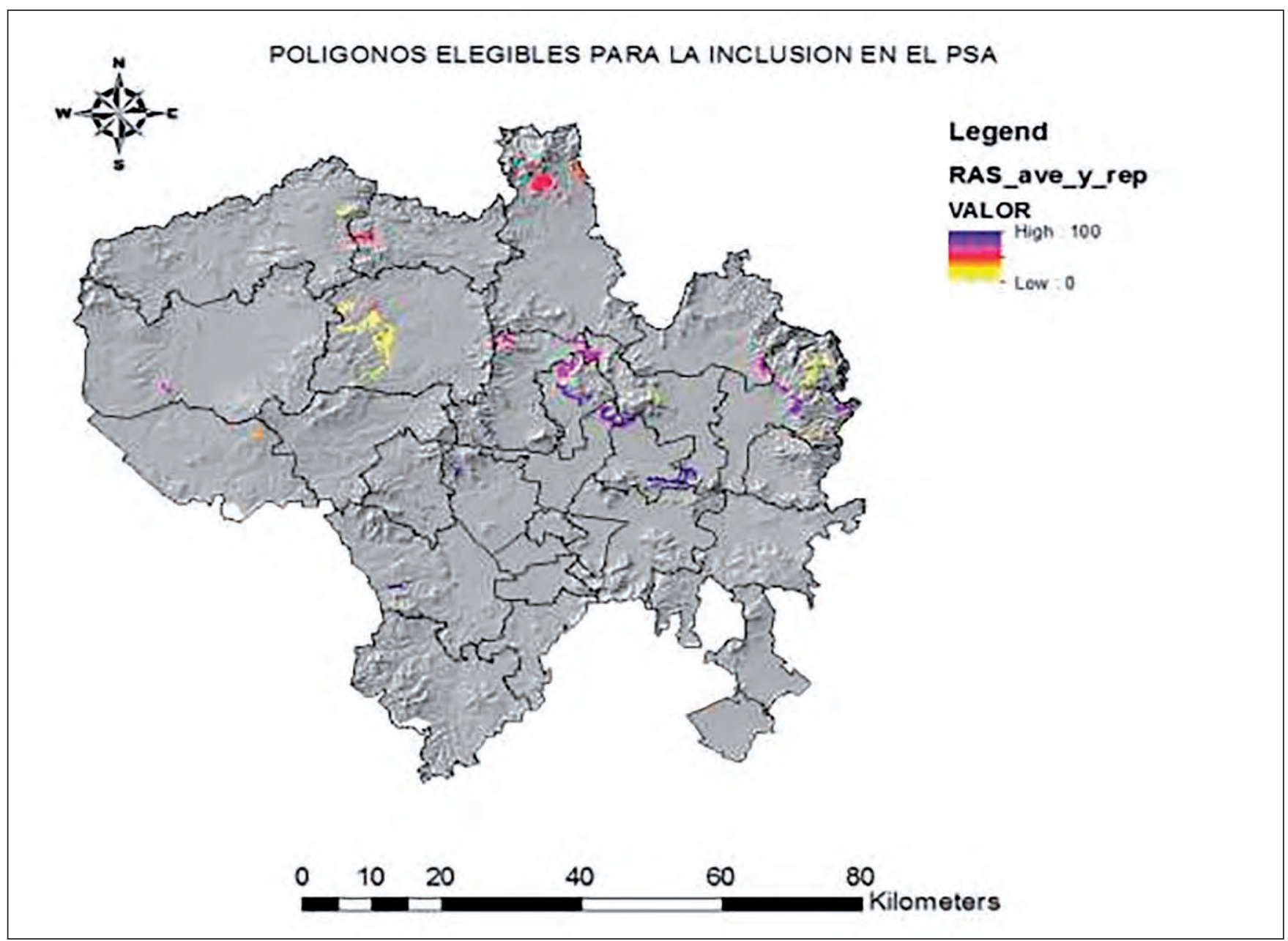

Figura 8. Mapa correspondiente a los polígonos elegibles para el PSA en la UMAFOR 1304. Fuente: Elaboración propia.

\section{CONCLUSIONES}

La metodología junto con la información técnica disponible en la UMAFOR 1304 permite ayudar a los encargados de tomar decisiones sobre la priorización de áreas para el PSA. Aunque, el procedimiento se basa únicamente en datos técnicos, se han considerado las opiniones de las partes interesadas, como los productores locales, que han sido tenidas en cuenta a través de los contactos mantenidos con técnicos de la 
UMAFOR 1304. A su vez, la metodología utilizada tiene la flexibilidad necesaria para adaptarse a cambios en las políticas institucionales y gubernamentales.

Como resultado de este trabajo, puede estimarse que en 6 de las 20 facetas es factible implementar el pago por servicios ambientales. A este respecto cabe precisar que es necesario compensar a los habitantes que viven en estos espacios con el dinero necesario como para que estos puedan al menos vivir dignamente durante el tiempo que sean utilizados sus territorios a efectos de la preservación de los ecosistemas.

Las diversas metodologías y procedimientos que usamos en este trabajo pueden ser implementadas por las gerencias estatales de CONAFOR, con el objetivo de que la toma de decisiones sobre la elección de Áreas prioritarias para el PSA se realice de una forma descentralizada y que todos los dueños de predios localizados en áreas importantes para el PSA, tengan las mismas oportunidades de participar y ser elegidos. Aunque el mecanismo con el cual la CONAFOR podría implementar esta metodología en la toma de decisiones, implicaría una modificación de sus procedimientos administrativos actuales.

Los estudios sobre los servicios ambientales que proporcionan los bosques es relativamente reciente. Domínguez, O., Betancourt, Y. y Rodríguez, G. (2007) indican que, en Cuba en 2004, las instituciones y el pueblo en general desconocen la importancia de los SA, que proporciona el bosque y que se han venido proporcionando de manera espontánea. Además, mencionan que no hay trabajos sobre su valoración económica. Por lo anterior, es relevante lo que se hace en México. Sin embargo, para no perder los SE, es necesario que el PSA, sea mayor a lo autorizado por la CONAFOR, como lo indican Sánchez A., García R M., y Palma A. (2007) ya que tanto el PSA, como el PSAH, son importantes para conservar y preservar los ecosistemas de México.

\section{REFERENCIAS}

Aguilar, G., \& Sánchez, D. (2018). Regionalización del paisaje para el ordenamiento del territorio en el municipio de Acámbaro, Gunajuato. En J. M. Rodriguez, y V. M. Ortega, El Ordenamiento Territorial y Ecológico: Hacia una Visión Integradora (págs. 394-411). Guanajuato: Universidad de Guanajuato.

Ancira-Sánchez, L. (2015). Utilización de imágenes de satélite en el manejo forestal del noreste de México. Madera y Bosques, 21(1), 77-91. doi: https://doi.org/10.21829/myb.2015.211434

Aron, A., \& Aron, E. (2002). Statistics for the Behavioral and Social Sciences. New York: Prentice Hall.

Ayala, F., Espejel, I., Eaton, R., \& Daessle, W. (2011). Propuesta de evaluaciòn ràpida de servicios ambientales hidrològicos en zonas aridas.

Bechhofer, E. (1954). A single-sample multiple decision procedure for ranking means of normal populations with known variances. Ann. Math. Stat. 25, 16-39. doi: https://doi.org/10.1214/aoms/1177728845

Camacho, I. (2011). Ecologia y medio ambiente. Mèxico D F.: S.T.

Campos, J., Alpízar, F., Louman, B., \& Parrotta, J. (2005). An Integrated Approach to Forest Ecosystem Services. En G. A. Mery.

Chafla, P., \& Cerón, P. (2016). Pago por servicios ambientales en el sector del agua: el Fondo para la Protección de Agua. Tecnología y Ciencias del Agua, 21-40.

CIFOR. (2006). Los principios básicos del pago por servicios ambientales, policy research proyects, reports. Los principios básicos del pago por servicios ambientales. Indonecia: Research Institutes Bogor.

CIFOR. (2007). Annual Report: forest management,forest policy,research projects, reports, research institutes. Indonencia: Bogor.

Colegio de posgraduados. (2008). Evaluación Externa de los Apoyos de los Servicios Ambientales ejercicio fiscal 2007. Montecillos: Conafor-SAGARPA.

CONAFOR. (2003). "documento de Posición Institucional- PROÁRBOL- Programa de Pago por Servicios Ambientales HidrológiCOS (PSAH) y Programa para Desarrollar el Mercado de Servicios Ambientales por Captura de Carbono y los Derivados de la Biodiversidad y para fomentar el es. Mèxico DF: SAGARPA.

CONAFOR. (2012). Descripción técnica de la clasificación de la Zona Elegible en áreas de pago diferenciado, para el Concepto de Apoyo B2. Servicios Ambientales de ProÁrbol, correspondiente a la Convocatoria 2012. Mèxico DF: SAGARPA.

CONAFOR. (2012). Inventario Nacional Forestal 2004-2009. Zapopan Jalisco: SAGARPA. 
CONAGUA. (15 de Enero de 2015). Sistema Nacional de Información del Agua (SINA)" - Estadísticas del agua en Mèxico 2008. Recuperado de: http://www.conagua.gob.mx

CONANP. (2010). Pago Por Servicios Ambientales en Áreas Naturales Protegidas. Dirección General de Operación Regional Comisión Nacional de Áreas Naturales Protegidas". Mèxico DF: SEMARNAP.

Costanza, R., d'Arge, R., de Groot, R., Farber, S., Grasso, M., Hannon, B., Van den Belt, M. (1997). The value of the world's ecosystem services and natural capital. Nature, 387, 253-260. doi: https://doi.org/10.1038/387253a0

Diario Oficial de la Federación, (DOF). (1988). Ley General del Equilibrio Ecológico y la Protección al Ambiente. Última reforma publicada DOF 16-05-2008. Mèxico DF: Congreso de la Uniòn.

DOF. (2011). Ley sobre la compensación ambiental por el cambio de uso de suelo en terrenos forestales. Mèxico DF: Congreso de la uniòn.

Domínguez, O., Betancourt, Y., \& y Rodríguez, G. (2007). Metodología para la elaboración de un sistema de pagos por servicios ambientales forestales. En M. de Agricultura: Cuarto Congreso forestal de Cuba (págs. 75-76). La Habana: Ministerio de la agricultura de Cuba.

Einot, I., \& and Gabriel, R. (1975). A study of the powers of several methods of multiple comparisons. Am. Stat. Assoc, 574583. doi: https://doi.org/10.1080/01621459.1975.10482474

FAO. (2005). State of the World Forest 2005. Roma: ONU.

Farber, S., Costanza, R., \& Wilson, M. (2002). Economic and ecological concepts for valuing Ecosystem services. Ecological Economics, 375-392. doi: https://doi.org/10.1016/S0921-8009(02)00088-5

Flores, J., \& y Gerez, A. (1994). Anfibios, reptiles, aves y mamíferos. Especies endémicas restringidas al tipo de vegetación. Mèxico DF: Semarnap.

Francisco, F., Muñoz, D., Hernández, M., Alfonso Soler, A., \& Castillo, M. y. (2003). Análisis integral de la toposecuencia y su influencia en la distribución de la vegetación y la degradación del suelo en la Subcuenca de Zapotitlán Salinas, Puebla. Boletín de la Sociedad Geologíca Mexicana, 19-41. doi: https://doi.org/10.18268/BSGM2003v56n1a3

Gobierno de los Estados Unidos Mexicanos. (2009). Diario Oficial de la Federación. DOF. Mèxico DF: DOF.

Gómez, J. M. (2007). La captura de carbono como servicio ambiental en la comunidad Los y Pescadores del Municipio de Tepehuanes, Durango. En A. S. (Editor), Manejo de los Recursos Naturales en México, UACh., México (pp. 67-92). Texcoco, México: UACh.

González, B. (2011). Identificación espacial de áreas prioritarias para el pago por servicios ambientales (PSA) hidrológicos y derivados de la conservación de la biodiversidad en la Sierra Madre Oriental. San Luis Potosì: UASLP.

Groombridge, B. (1992). Biological diversity; Species diversity; Biological diversity conservation. doi: https://doi. org/10.1007/978-94-011-2282-5_15

Imbach, P. (2005). Priority areas for payment for environmental services (PES) in Costa Rica. Turrialba: UNA-Costa Rica.

INEGI. (1992). Síntesis Geográfica del estado de Hidalgo. México, DF: SPP.

INEGI. (2005). Anuario Estadístico de Hidalgo. Aguascalientes Ags: SPP.

León, B., \& P. N. (2006). Introducción a las plantas endémicas de Perú. Perú. Biología, 9-22.

Macip-Ríos R, y. R. (2013). Payment for environmental services in mexico. an alternative for biodiversity conservation and development. Biocyt, 89-107.

Malczewski, J. (1999). GIS and Multicriteria decision analysis. New York: John Wiley \& Sons.

Naidu, R. S. (2006). "Managing Arsenic in the Environment: From soil to human health. Victoria: CSIRO Publishing. doi: https://doi.org/10.1071/9780643093515

Noguera, E. A. (2017). El endemismo: diferenciación del término, métodos y aplicaciones. Acta Zoológica Mexicana, 89107.

Ortiz, C., \& Cuanalo, H. (1984). Metodología del Levantamiento Fisiográfico, un sistema de clasificación de tierra. Texcoco, México: COLPOS.

Paegelow, M., \& Camacho, M. y. (2003). Cadenas de markov, evaluación multicriterio y evaluación multiobjetivo para la modelización prospectiva del paisaje. Geo Focus, 22-24.

Pagiola, S. (2008). Payments for environmental services in Costa Rica. Ecological Economics. Elsevier, 712-724. doi: https://doi.org/10.1016/j.ecolecon.2007.07.033

Paneque, P., Corral, S. G., \& Del Moral (2006). Participative multi-criteria analysis for the evaluation of water governance alternatives. A case in the Costa del Sol (Málaga). Ecological Economics, 990-1005. 
Rojas-López, O., M, G. G., Gómez-Guerrero, M., \& Romo Lozano, J. (2012). La renta de la tierra y el pago de servicios ambientales en la Sierra norte de Puebla. Revista Mexicana de Ciencias Forestales, 41-56. doi: https://doi.org/10.29298/ rmcf.v3i11.516

Rzedowski, J. (2006). Vegetación de México. México, DF: Limusa.

Sánchez, A., G. R., \& y Palma, A. (2007). Producción de agua en bosques de montaña: balance hidríco, PSAH, y su valoración económica. En A.S.G (Coord.) Manejo de los Recursos Naturales en México (pp. 41-66). Texcoco, México: UACh.

SEMARNAT. (2010). Norma Oficial Mexicana NOM-059-SEMARNAT-2010, Protección ambiental-Especies nativas de México de flora y fauna silvestres-categorías de riesgo y especificaciones para su inclusión, exclusión o cambio de lista de especies. México, DF: SEMANRNAT.

Valdez-Lazalde, J., Aguirre-Salado, C., \& Ángeles-Pérez, G. (2011). Análisis de los cambios en el uso del suelo en la cuenca del río metztitlán (México) usando imágenes de satélite: 1985-2007. Revista Chapingo. Serie Ciencias Forestales y del Ambiente, 313-322. doi: https://doi.org/10.5154/r.rchscfa.2010.06.041

Wunder, S. (2006). Pagos por servicios ambientales: Principios básicos esenciales. Centro de Investigación Forestal (CIFOR. Indonesia: CIFOR. 


\title{
Aproximación Metodológica a los Itinerarios no Motorizados de Mayor Potencialidad para la Intermodalidad "Tren+Bici" en Andalucía
}

\author{
A Methodological Approach to Non-Motorized Itineraries with Greater \\ Potentiality for the "Train+Bike" Intermodality in Andalusia \\ Isabel Aránzazu García-Bello \\ jargarbel@alum.us.es @ https://orcid.org/0000-0001-9239-4331 \\ Universidad de Sevilla, SigTam Consultores. C/ Gonzalo Bilbao 33, bajo 241003 Sevilla
}

Jesús Ventura-Fernández

jventura@us.es $\bigcirc$ https://orcid.org/0000-0002-8271-1011

Universidad de Sevilla. Dpto. de Geografía Física y Análisis Geográfico Regional.

C/ María de Padilla s/n. 41004 Sevilla

\section{INFO ARTÍCULO}

Recibido: 27/5/2019

Revisado: 28/6/2019

Aceptado: 29/6/2019

\section{PALABRAS CLAVE}

Movilidad sostenible

Intermodalidad "tren+bici"

Cicloturismo

Vías verdes

Sistemas de Información Geográfica

\section{KEYWORDS}

Sustainable Mobility

Intermodality "train+bike"

Cycle tourism

Greenways

Geographic Information Systems

\section{RESUMEN}

El auge del cicloturismo se apoya en el uso de itinerarios no motorizados, lo que favorece una nueva tipología turística que posibilita la dinamización de zonas rurales y periféricas. En la actualidad los estudios de movilidad sostenible contemplan, en gran medida, la intermodalidad, sobre todo entre medios de transporte de carácter público, poco contaminantes y colectivos, como es el caso del ferroviario.

Andalucía dispone de una enorme variedad de itinerarios no motorizados (vías pecuarias, caminos rurales, vías verdes...) asociados a espacios de gran valor paisajístico y patrimonial. El objetivo principal de esta investigación es el establecimiento de una metodología que permita identificar los vínculos existentes entre líneas férreas en uso y estos itinerarios.

Para ello, a nivel metodológico, se ha realizado primero un estudio de proximidad mediante la herramienta Buffer Geoprocessing, y posteriormente un análisis de redes para medir la accesibilidad a través de la extensión Network Analyst, en ambos casos del programa ArcGIS, aplicados al Sistema de Información Geográfica que se ha implementado.

Sus resultados principales están en relación con la determinación de rutas propicias para los potenciales usuarios de la intermodalidad "tren+bici" en Andalucía. Y sus conclusiones son, por consiguiente, indicativas de cara a posteriores estudios de detalle.

\begin{abstract}
The rise of cycle tourism is based on the use of non-motorized itineraries, which favours a new tourist typology that makes possible the revitalization of rural and peripheral areas. At present, studies of sustainable mobility consider, to a large extent, intermodality, especially among public transportation means, which are not very polluting and collective, as in the case of railways.

Andalusia has a huge variety of non-motorized itineraries (livestock trails, rural roads, greenways ...) associated with areas of great scenic and heritage value. The main objective of this research is the establishment of a methodology that allows to identify the existing links between railway lines in use and these itineraries.

To do this, at the methodological level, a proximity study was carried out first using the Buffer Geoprocessing tool, and subsequently a Network Analysis to measure accessibility through this extension, in both cases of the ArcGIS program, applied to the Geographic Information System that has been implemented.

Its main results are related to the determination of favourable routes for potential users of the "train+bike" intermodality in Andalusia. In addition, its conclusions are, therefore, indicative for further studies of detail.
\end{abstract}




\section{INTRODUCCIÓN}

En la actualidad, el auge del cicloturismo y de las actividades recreativas en la naturaleza a través del uso de itinerarios no motorizados combinados con transportes públicos ha favorecido una nueva tipología turística que hace posible la dinamización de zonas rurales, dando lugar a un modelo económico sostenible, sobre todo en países europeos como Francia, Alemania y Suiza.

Los estudios de movilidad contemplan, como parte esencial, la intermodalidad entre distintos tipos de transporte, especialmente aquéllos de carácter público, poco contaminantes y colectivos. Así podemos encontrar países que se sitúan próximos a nuestro entorno que ya tienen un largo bagaje con respecto a la intermodalidad del tren con estos itinerarios no motorizados y las actividades ecoturísticas, como queda reflejado en el informe Impacto económico del cicloturismo en Europa. Síntesis de los principales estudios realizados, de Emili Mató y Xandra Troyano (2014).

En Andalucía existe una gran variedad de itinerarios no motorizados asociados a espacios de gran valor paisajístico y patrimonial, quedando patente la gran potencialidad de estos itinerarios para el desarrollo de estas actividades. Así, el Plan Andaluz de la Bicicleta 2014-2020 (Consejería de Fomento y Vivienda, 2014), propone, para esta Comunidad Autónoma, una red ciclista básica, donde la distribución de sus espacios naturales y la red urbana son determinantes en el trazado de la misma, y, por tanto, dando soporte a estos itinerarios y a las actividades turísticas, deportivas y de ocio que puedan realizarse en ellos.

La elección y potencialidad de estos itinerarios no motorizados dependerá, en gran medida, de la distancia que exista a los núcleos intermodales, principalmente estaciones de tren, por ser éste considerado un transporte público y sostenible. Como decíamos, la oferta de itinerarios no motorizados en Andalucía es muy amplia, teniendo gran potencialidad la rehabilitación de las antiguas vías de ferrocarril que hoy en día se encuentran en desuso, y que conocemos como vías verdes (Aycart, C., 2001), aunque también se dispone de caminos rurales, senderos y vías pecuarias.

Con esta aportación se pretende, por medio de su metodología, estableciendo un procedimiento que sirva para identificar los vínculos existentes entre líneas férreas en uso e itinerarios no motorizados. En este sentido los Sistemas de Información Geográfica (SIG) determinarán los potenciales núcleos intermodales a partir de una serie de requisitos y variables que establecerán cuáles serán, más adelante, los casos de estudio.

La identificación de los núcleos potencialmente óptimos de intermodalidad entre líneas férreas e itinerarios no motorizados servirá para poder realizar posteriores estudios de mayor detalle sobre los ámbitos seleccionados. En todo caso, este primer momento de la investigación que ahora se inicia permite obtener un diagnóstico básico de la situación actual, que facilite la toma decisiones a la hora de impulsar estos espacios intermodales. Se trata de generar ejes articuladores que interconectan medio rural y espacios periféricos, y que tengan como premisa fundamental una movilidad intermodal colectiva y sostenible, que coadyuve a un desarrollo socio-económico adecuado, basado en actividades cicloturísticas, recreativas y de ocio.

Según Martín Cejas y Martínez Hernández (2017), la relación entre el turismo y los transportes no sólo se limita a la posibilidad de llegar al destino, sino que se mantiene y se amplía una vez que el turista se dispone a disfrutar de su tiempo en dicho destino, pudiéndose apreciar ejemplos en estados europeos como Francia, Alemania y Suiza que cuentan con larga trayectoria en el uso de la bicicleta como modelo turístico y dinamizador económico del territorio, siendo nuestros competidores para atraer hacia sus itinerarios a usuarios de la actividad ecoturística y ciclista.

En este sentido EuroVelo es una red ciclista extensa, compuesta por 15 rutas de larga distancia, implantada y coordinada por la Federación Europea de Ciclistas (ECF) que se pretende que esté finalizada en 2020, pasando varias rutas importantes por los diferentes países europeos y contando con estructuras modernizadas y de fácil accesibilidad e información detallada de estos itinerarios (Freire, J., 2018).

Otro factor importante a destacar es la combinación intermodal de la utilización del "tren+bici" como algo muy habitual en Centroeuropa, donde los trenes están adaptados al desplazamiento de cicloturistas. También, en Francia, se ha creado un sello de calidad para las actividades comerciales y turísticas que se desarrollan alrededor de las estaciones de tren y de estos itinerarios no motorizados, generando una red 
de desarrollo económico ligada a los usuarios de la bicicleta y disfrute de la naturaleza, como potenciadores turísticos de ámbitos rurales y creadores de corredores que combinan sinergias diferentes, enlazando asentamientos con diferente patrimonio geomorfológico, industrial, etnográfico y cultural, que dan singularidad a cada itinerario.

En el caso andaluz, en la actualidad, se están habilitando muchos itinerarios para la actividad cicloturística por el potencial que tienen, tanto paisajístico como desde su vertiente económica, pero presentan un difícil acceso y falta de infraestructuras adaptadas a las actividades relacionadas con la naturaleza. Además de esto, hay escasa información sobre estos itinerarios no motorizados, la accesibilidad a los mismos (Ventura, J. et al. 2017) y los diferentes servicios que se encuentran a su alrededor, resultando aún poco atractivos para el ciclista extranjero, e incluso para el nacional, que prefiere otros destinos con mejores infraestructuras.

Todos estos factores, junto con la escasa intermodalidad del "tren+bici" entre las estaciones de tren y los itinerarios no motorizados, hacen que Andalucía pierda oportunidades para desarrollar una economía sostenible vinculada a la bicicleta, debido, en cierto modo, a la normativa existente, que condiciona el acceso al tren, y el hecho de que este medio no se encuentre todavía adaptado para los desplazamientos de cicloturistas. En definitiva, este contexto fomenta la necesidad de aplicar una metodología capaz de determinar la potencialidad en Andalucía de aquellos itinerarios que favorezcan la intermodalidad entre las estaciones ferroviarias y su proximidad a estos itinerarios, creando un modelo de interpretación científica de los datos, siendo éstos obtenidos de una combinación de fuentes de distinta procedencia, junto con un soporte cartográfico que proporcione alternativas y ayude a la toma de decisiones estratégicas en cualquier parte del territorio andaluz.

\section{AUGE DEL CICLOTURISMO Y MARCO TEÓRICO}

Según se ha dicho, en las últimas décadas, el cicloturismo ha experimentado un fuerte auge como nueva modalidad turística, ya que es capaz de integrar, y por lo tanto de potenciar, diferentes elementos territoriales, abordando una visión global del espacio y desconcentrando la presión turística en puntos concretos, para diversificarla a lo largo de itinerarios de gran valor patrimonial, paisajístico y singularidad.

Países de Europa Occidental, como Bélgica y Holanda, comenzaron a fomentar el uso de la bicicleta en los años setenta del pasado siglo XX, originando una fuerte demanda del uso de ésta para la realización de desplazamientos, tanto de uso cotidiano como de carácter integrador entre naturaleza y actividades recreativas (Pucher, J. et al., 2008). Este hecho hace que, en la actualidad, sean éstos los países que cuentan con más ciclistas dentro de la Unión Europea (Serra, M., 2016), destacando por fomentar el uso de vías ciclistas como motor turístico, y favoreciendo la intermodalidad con transportes públicos colectivos, como es el tren fundamentalmente.

En los últimos años Francia y Alemania están incrementando sustancialmente su atracción para cicloturistas, pues, aunque empezaron con posterioridad en la creación de rutas y redes para la realización de actividades relacionadas con la bicicleta, han sido capaces de atraer a un turismo respetuoso con la naturaleza, y han creado una serie de servicios e infraestructuras de alta calidad alrededor de éstas, donde el usuario encuentra itinerarios con buena accesibilidad, así como un alto valor paisajístico y etnográfico, con una notable información del recorrido. Se trata de itinerarios bien señalizados, que conectan poblaciones con servicios. De esta forma relacionamos conceptos como capital territorial con cicloturismo y economía sostenible, y, como indica Fernández Latorre (2015): "confirmamos que hay mayores infraestructuras y aspectos económicos que se encuentran en regiones turísticas más maduras".

Una parte del éxito de estos itinerarios no motorizados en estos países se debe a que han sabido conectar el transporte público con estos destinos, es decir, la intermodalidad entre el tren, sobre todo, y el uso de la bicicleta. Así, en asociaciones ciclistas de los mismos, se puede encontrar información sobre el transporte ferroviario, la normativa existente sobre el desplazamiento de bicicletas en los vagones, estaciones, frecuencias de paso y precios.

Los ferrocarriles nacionales franceses presentan un volumen de trenes y frecuencia bastante altos, por lo que la oferta de los que admiten bicicletas es grande, evitándose así incertidumbres a la hora de realizar des- 
plazamientos, donde el transporte de bicicletas está permitido no sólo en los trenes regionales y de cercanías de la Región de París, donde no se paga por ello, sino que se admite bajo tres modalidades distintas en los de Grandes Líneas (Corail en sus diferentes variantes) e incluso Alta Velocidad. Algunos de estos trenes de larga distancia admiten gratuitamente bicicletas desmontadas y embaladas y otros (Corail Intercités) sin embalar.

En Alemania se pueden llevar bicicletas en los trenes locales y la mayoría de los trenes interurbanos, pero no se pueden transportar en trenes de Alta Velocidad. La Deutsche Bahn (DB), en la región alemana de Waden Wurtenberg, funciona, sobre todo, en la zona de la Selva Negra, cerca de Freiburg. Por otro lado, en algunas ciudades, como en la suiza Basilea, los tranvías tienen soportes para bicicletas. Así, en la Confederación Helvética, la compañía de Ferrocarriles Federales Suizos (en alemán, Schweizerische BundesBahnen) ofrece servicios de transporte de bicicletas, y los autobuses de la compañía postal y barcos, así como los transportes de montaña, están bien conectados con el ferrocarril.

En otros estados miembros de la Unión Europea, como es Reino Unido, encontramos la National Cycle Network, que es una red de itinerarios no motorizados con una longitud de unos 16.000 km (Insall, P., 2004), y que la organización Sustrans cifraba ya en 16.755 millas (unos 26.520 km) en 2018, para el desarrollo de actividades recreativas, donde cualquier núcleo de población se localiza a menos de dos kilómetros de distancia de una ruta con muy buena accesibilidad, incluso para Personas con Movilidad Reducida (PMR; niños, embarazadas, personas mayores, discapacitados físicos...; Stehlíková y Řezník, 2018).

Las asociaciones ciclistas británicas tienen un fuerte poder, ya que han impulsado la creación de miles de kilómetros de itinerarios no motorizados, y, junto con las administraciones públicas, se encargan de la gestión y el mantenimiento de estos itinerarios. Estas asociaciones tienen una larga trayectoria en el fomento y promoción de estas rutas dentro de su sociedad, al igual que intentan dotarlas de calidad mejorando la oferta turística. Asociaciones ciclistas, como la mencionada Sustrans, fomenta la movilidad sostenible, siendo capaz de diseñar y mantener tramos con la ayuda de fondos públicos y voluntariado, además de implicar a las administraciones locales para que se comprometan en el desarrollo y mantenimiento de los tramos de itinerarios que les afecten.

Este caso de fuerte implicación de las asociaciones es muy parecido al de la Rails to trails conservancy de Estados Unidos, la cual es una asociación que reconvierte las antiguas vías férreas que están en desuso en itinerarios multifuncionales para actividades cicloturísticas y otras no motorizadas. Esta asociación presenta iniciativas a nivel local para la creación y gestión de nuevas rutas, pero en estos momentos esta red de itinerarios y vías verdes tiene poca continuidad en el territorio al igual que sucede aún en España, mermando por tanto la oferta cicloturística y las posibilidades de movilidad sostenible. No obstante, esta organización estadounidense ha anunciado, recientemente, una gran ruta para bicicleta de montaña (MTB) que cruzará el país de costa a costa.

Por otro lado, cabe también señalar que en Europa se están desarrollando itinerarios no motorizados que conectan el conjunto del territorio. Son los conocidos como senderos europeos transnacionales, de larga distancia, y que están compuestos por 12 rutas que atraviesan el conjunto del continente, las cuales aprovechan las antiguas infraestructuras existentes. Para que esta red de caminos se desarrolle en Europa ha sido necesaria la colaboración entre entes diferentes, tanto gubernamentales como asociaciones de senderismo y ciclismo de distintos países, que han colaborado para impulsar un turismo sostenible, combinando el capital territorial con estrategias específicas (Camagni y Capello, 2013). Así encontramos la asociación ERA, o Asociación Europea de Senderistas, que ha contribuido a que las rutas presenten un balizado único y homogéneo, encargándose de su mantenimiento, propuesta de nuevos recorridos, e información y divulgación a través de webs y de otras fuentes.

Por su parte la referida red EuroVelo, promovida por la Federación Europea de Ciclistas (European Cyclists' Federation, ECF), está compuesta por 15 rutas de larga distancia que conectan todo el territorio europeo para desarrollar actividades cicloturísticas y recreativas en el medio natural. EuroVelo tiene como objetivo conectar todos los países que forman la Unión Europea mediante itinerarios no motorizados de alta calidad y que sean seguros para los usuarios de estas grandes rutas (Weston, R. et al., 2012). Para ello existen parámetros que se tienen que cumplir para incorporar las rutas a la red. Estas especificaciones van desde aspectos generales sobre distancias mínimas de la ruta, pendientes máximas, señalización, y que 
impliquen como mínimo a dos estados; pero también existen requisitos en cuanto a estructuras y servicios que son clave para garantizar la seguridad y el bienestar de los usuarios de estos itinerarios.

España se ve afectada por 3 de estos itinerarios cicloturistas paneuropeos, en concreto, por la Ruta de los Peregrinos (la $n^{\circ} .3$ ), en la práctica el Camino francés a Santiago de Compostela, y por la 1 y la 8. Estas dos últimas discurren en concreto por la Comunidad andaluza: la Ruta de la Costa Atlántica ( $n^{\circ}$. 1), que debe recorrer de Norte a Sur la provincia de Huelva y enlazar con el Algarve portugués salvando la frontera que supone el río Guadiana; y la Ruta Mediterránea $\left(n^{\circ}\right.$. 8), que transita próxima al litoral mediterráneo andaluz (provincias de Almería, Granada, Málaga y Cádiz), hasta concluir en la milenaria capital gaditana.

Por su parte debemos señalar, en relación con estos itinerarios, que disponemos ya de estudios muy recientes sobre el impacto económico de las actividades cicloturísticas en los territorios que se ven afectados por estas grandes rutas, y que indican que son un proyecto con gran futuro, como bien enfatiza Nicolas Mercat (2018), destacando tanto los impactos económicos directos, la importancia de la bicicleta como modelo turístico, y también sus repercusiones en salud y seguridad.

Otros países externos a la Unión Europea, como Australia, cuentan con estudios sobre el tamaño y alcance de la actividad cicloturística como motor turístico sostenible, poniendo de manifiesto el creciente interés del uso de la bicicleta y el potencial impacto económico que supone, sobre todo para las zonas rurales. Así, en el trabajo Cycle Tourism in Australia: An investigation into its size and scope (Faulks, P. et al., 2006), se realiza un diagnóstico sobre el alcance del turismo en bicicleta, y se cuantifica su potencial en función de su escala nacional, regional o local, en el que los resultados obtenidos sobre patrones de uso y gastos en estos itinerarios proporcionan información de gran importancia para valorar sus potencialidades, pero también las debilidades a corregir, para mejorar las infraestructuras existentes y la oferta cicloturística, así como su repercusión económica en el territorio, ya que con ello se podrán identificar mejor qué inversiones serán más adecuadas. En el cuadro 1, procedente de dicho informe, se pone de manifiesto, a modo de resumen, cuáles son los factores que fomentan el cicloturismo.

En Andalucía contamos con diversos estudios sobre el potencial del cicloturismo como sector emergente (Rebollo, S., 2003; Luque, P., 2012; y Fernández, F., 2015), destacándose a las vías verdes como las infraestructuras deportivas del futuro. Otros autores, como Aycart Luengo (2006), también pone en valor estos soportes, que tienen como objetivo "la reutilización de trazados ferroviarios en desuso como itinerarios no motorizados que conecten las poblaciones, los espacios naturales y los puntos de interés histórico-artístico, acercando a ellos de forma sostenible al ciudadano".

Así pues, las sinergias entre cicloturismo, vías verdes y otros tipos de itinerarios no motorizados, junto con una buena accesibilidad desde el transporte público ferroviario, son un ejemplo de desarrollo sostenible (Ventura, J. y Gavira, A., 2016), con muy buenos resultados tanto en Europa como en aquellos otros lugares donde se han implantado.

Por su parte el Plan Andaluz de la Bicicleta (PAB, 2014-2020) pretende implantar una red de vías ciclistas en Andalucía que sea motor para la creación de un nuevo modelo de desarrollo turístico y de movilidad sostenible, y se ha tenido en consideración para la elaboración del Plan General de Turismo Sostenible de Andalucía Horizonte 2020, aprobado en 2016 por parte de la Consejería de Turismo y Deporte.

Dentro del PAB se pueden diferenciar objetivos desde el punto de vista del conjunto de la Comunidad Autonómica, pero también a escala metropolitana e incluso urbana, donde se consolidan rutas cicloturísticas existentes y además se integran y conectan los diferentes territorios con los nuevos itinerarios propuestos, potenciándose la capacidad de atracción de sus recursos naturales, gastronómicos, artísticos y etnográficos.

Así pues, el Plan Andaluz de la Bicicleta (PAB) tiene como uno de sus objetivos difundir la oferta de la red cicloturística. Para ello es necesario crear una red amplia y darla a conocer a las empresas del sector $y$, de esta manera, adaptar su oferta a los servicios necesarios para el cicloturismo, diversificando diferentes productos alrededor del sector de la bicicleta.

Se procura, en definitiva, consolidar e integrar las iniciativas existentes con las nuevas propuestas turísticas, creando itinerarios ciclistas temáticos, en los que se ponga en valor el patrimonio interior de las áreas rurales y periféricas, como por ejemplo rutas de carácter monumental, industrial o natural, entre otras. 
Cuadro 1. Factores que facilitan las experiencias cicloturísticas.

\begin{tabular}{|c|c|c|}
\hline \multirow{7}{*}{ Atracciones } & \multirow{4}{*}{ Atracciones construidas } & Pueblos \\
\hline & & Restaurantes \\
\hline & & Sitios históricos \\
\hline & & Alojamientos \\
\hline & \multirow{3}{*}{ Atracciones naturales } & Paisajes \\
\hline & & Bosques \\
\hline & & Lagos \\
\hline \multirow{7}{*}{ Información } & \multirow{6}{*}{ Mapas } & Folletos y dispositivos electrónicos \\
\hline & & Debe informarse sobre: \\
\hline & & Alojamientos \\
\hline & & $\begin{array}{l}\text { Localización de baños, tiendas y almacenamiento de } \\
\text { bicicletas }\end{array}$ \\
\hline & & Descripción del terreno y clasificación de las pistas \\
\hline & & Atracciones clave \\
\hline & Señalización de rutas & \\
\hline \multirow{6}{*}{ Rutas } & \multirow{5}{*}{ Variedad de longitudes } & Rutas circulares de ida y vuelta en recorridos tranquilos \\
\hline & & $\begin{array}{l}\text { Rutas de una noche con varios alojamientos a lo largo del } \\
\text { recorrido }\end{array}$ \\
\hline & & $\begin{array}{l}\text { Rutas largas con alojamientos y comodidades para el } \\
\text { usuario }\end{array}$ \\
\hline & & $\begin{array}{l}\text { Rutas que enlazan sitios de interés geográfico, histórico o } \\
\text { cultural }\end{array}$ \\
\hline & & Rutas que conectan pueblos y aldeas. \\
\hline & Variedad de terrenos & \\
\hline \multirow{3}{*}{ Transporte público } & \multirow{3}{*}{$\begin{array}{l}\text { Que permitan el } \\
\text { transporte de bicicletas }\end{array}$} & Trenes \\
\hline & & Autobuses \\
\hline & & Aviones \\
\hline \multirow{4}{*}{ Compañías turísticas } & & Pueden proporcionar: \\
\hline & & Guías turísticos \\
\hline & & Transporte de equipos y equipaje \\
\hline & & Apoyo de servicios, alojamiento y comida \\
\hline Alquiler de bicicletas & & Deberían estar disponibles cerca de las rutas \\
\hline Alojamiento & $\begin{array}{l}\text { Alojamiento amigable } \\
\text { para ciclistas }\end{array}$ & Pueden estar identificados para promover el cicloturismo \\
\hline \multirow[t]{2}{*}{$\begin{array}{l}\text { Comodidades en tiendas y } \\
\text { aparcamientos }\end{array}$} & $\begin{array}{l}\text { Almacenamiento seguro } \\
\text { de bicicletas y equipos }\end{array}$ & $\begin{array}{l}\text { En cafés, restaurantes y alojamientos (incluidos campings } \\
\text { y hoteles) }\end{array}$ \\
\hline & $\begin{array}{l}\text { Aparcamiento seguro de } \\
\text { vehículos }\end{array}$ & $\begin{array}{l}\text { En cafés, restaurantes y alojamientos (incluidos campings } \\
\text { y hoteles) }\end{array}$ \\
\hline
\end{tabular}

Fuente: Hunter Cycling Network (2005), recogido por Faulks, P. et al., 2006. 
De esta forma el programa turístico del PAB propone recorridos en bicicleta con distinta temática a diferentes escalas territoriales, así como la creación del distintivo de calidad que presentan otros países como Francia, tanto para los destinos turísticos como para la red de empresas e infraestructuras que dan cobertura a los itinerarios no motorizados.

Ahora bien, no deja de ser sumamente significativo que a fecha del primer trimestre de 2019 sólo se hayan construido 142,2 km de carriles-bici para una red que, en su conjunto, se establecía en 4.392 km; o que a unos 18 meses de su finalización cronológica sólo se hayan ejecutado 261,9 millones de euros de los 446,2 contemplados en el capítulo de inversiones. El nuevo Ejecutivo andaluz (desde enero de 2019) ha indicado, no obstante, su voluntad de reactivar este Plan.

\section{OBJETIVOS Y METODOLOGÍA DEL ESTUDIO REALIZADO}

La hipótesis de partida consiste en que para entender la potencialidad de la intermodalidad de las líneas férreas con los itinerarios no motorizados para la práctica del cicloturismo, todo dependerá, en gran medida, de la distancia de desplazamiento o proximidad entre las estaciones de tren y el acceso a estos itinerarios. Emili Mató y Xandra Troyano, en el ya referido informe de Impacto Económico del cicloturismo en Europa. Síntesis de los principales estudios realizados, consideran que la distancia recorrida en diez minutos por el cicloturista es el límite aceptable para llegar desde una estación de transporte público al inicio de un itinerario, de manera que más allá de ese tiempo, el recorrido comienza a convertirse en disuasorio. Es por ello que consideran que, para el usuario de la bicicleta, la distancia máxima a recorrer antes de empezar el itinerario propiamente dicho sería de 3,2 km, lo que implica una velocidad media de desplazamiento de 19,2 km/h.

El estudio por proximidad se va a completar aquí con otro de accesibilidad mediante un análisis de redes, a través de la extensión Network Analyst de ArcGIS, que permite establecer distintas isócronas a partir de la estación ferroviaria en uso según su tipología de interés para este trabajo (cercanías, circulación y mixta). En este caso se ha reducido la velocidad media a un valor más cercano al de un cicloturista novel o con posible carga en sus alforjas, esto es, a $15 \mathrm{~km} / \mathrm{h}$, si bien se ha incrementado el tiempo crítico hasta los 15 minutos, según es habitual en diferentes estudios sobre accesibilidad ideal en general (Escalona y Díez, 2005) y ferroviaria en particular (Gavira y Ventura, 2003).

En suma, mediante la presente investigación se pretende alcanzar dos objetivos fundamentales:

a. Identificar los núcleos intermodales con mayores oportunidades para el desarrollo de actividades cicloturísticas, así como los itinerarios no motorizados que se encuentran en las proximidades de estaciones ferroviarias, para poderlos abordar a posteriori en profundidad.

b. Determinar qué rutas podrían ser las más atractivas, al permitir el desarrollo de actividades recreativas en contacto con la naturaleza, pudiéndose diseñar itinerarios tanto de un día como otros que impliquen varias pernoctaciones.

Andalucía presenta una superficie de $87.286 \mathrm{~km}^{2}$, y posee una gran variedad de paisajes y estructuras geomorfológicas diferenciadas, junto con unos rasgos climáticos en general benignos para las actividades al aire libre. Estas características, unidas a la gran diversidad de itinerarios no motorizados que se interconectan, dotan a la región de un enorme potencial para el establecimiento de núcleos intermodales entre líneas férreas en funcionamiento y rutas dedicadas al desarrollo de actividades cicloturísticas y recreativas.

De este modo contamos con una densísima red de vías pecuarias (entra las que destacan por su anchura las cañadas reales), senderos (algunos de ellos calificados como de Gran Recorrido) y líneas férreas en desuso, conocidas como vías verdes cuando están debidamente acondicionadas; lo que representa un gran potencial para la mencionada práctica del cicloturismo, en muchos casos con longitudes importantes para el desarrollo de actividades recreativas en la naturaleza (ocio activo), bien de un solo día o, cuando son de mayor recorrido, con las consiguientes pernoctaciones.

Así pues estudiaremos y seleccionaremos aquellas estaciones de tren para el transporte de pasajeros que se encuentren a una distancia de menos de $3 \mathrm{~km}$ de estos itinerarios no motorizados, por medio de 
Buffer Geoprocessing , en coherencia con los 3,2 km como distancia crítica señalada con anterioridad, con el objetivo de crear un modelo que sirva como base para que, al utilizar y combinar distintas variables, se puedan realizar diferentes diagnósticos y, por lo tanto, predecir y resolver problemas que se planteen en estos núcleos intermodales de "tren+bici".

Los Sistemas de Información Geográfica, que contienen información espacial, más la utilización de distintos criterios (distancia, accesibilidad en tiempo,...), nos van a permitir que se den diversas interrelaciones entre las diferentes capas o variables del estudio, pudiéndose constatar la potencialidad del método y la capacidad de análisis sobre las conexiones de los elementos que se distribuyen en el territorio, lo que origina una información muy valiosa para las previsiones y actuaciones futuras en materia de movilidad en estos itinerarios. Se trata, además, de una línea de investigación muy actual y aplicada a escala regional, como se constata en trabajos recientes, como los de Pedrosa, A. et al. (2019).

Con este tipo de análisis podemos identificar, al igual que las potencialidades o fortalezas de estos recorridos, también los aspectos que debilitan o amenazan que los territorios se desarrollen o no, y, por lo tanto, que afectan a las posibilidades de una economía sostenible en el medio rural.

La fuente fundamental de este estudio será DERA (Datos Espaciales de Referencia de Andalucía), que es un repertorio de bases cartográficas de diferente naturaleza geométrica (puntos, líneas, polígonos, imágenes raster) referidas al territorio andaluz. Se presenta en bloques temáticos que permiten el acceso centralizado a información de muy distinta procedencia, con garantía de actualización, coherencia geométrica y continuidad territorial. La información se encuentra accesible por capas en formato shapefile (.shp), en sistema de referencia geodésico ETRS89 y proyectadas en UTM huso 30. Es un producto del Instituto de Estadística y Cartografía de Andalucía (IECA), realizado con financiación de la Unión Europea a través del Fondo Europeo de Desarrollo Regional (FEDER).

En su Memoria Técnica se reflejan las diferentes variables, con su tipo de geometría, denominación, códigos y distintos atributos. Exponemos a continuación, mediante el cuadro 2, las capas que se han utilizado para la elaboración de los mapas resultantes de este estudio, perteneciendo, mayoritariamente, al grupo correspondiente a "Viario", si bien también se ha empleado el de "Infraestructuras de transportes" (estaciones de ferrocarril) y el dedicado a "Divisiones Administrativas" (términos municipales).

Cuadro 2. Características básicas de las capas utilizadas de DERA.

\begin{tabular}{|c|c|c|c|c|}
\hline Nombre de la capa & $\begin{array}{l}\text { Tipo de } \\
\text { geometría }\end{array}$ & Grupo & Entidades que se emplean & Metadatos básicos \\
\hline \multirow{3}{*}{$\begin{array}{l}\text { Estaciones de } \\
\text { ferrocarril }\end{array}$} & \multirow{3}{*}{ Puntual } & \multirow{3}{*}{$\begin{array}{l}\text { Infraestructuras de } \\
\text { transportes }\end{array}$} & Estación de circulación & \multirow{3}{*}{$\begin{array}{l}\text { Localización tanto de } \\
\text { estaciones, apeaderos y } \\
\text { descargaderos de ferrocarril } \\
\text { como de instalaciones } \\
\text { logísticas y técnicas }\end{array}$} \\
\hline & & & Estación mixta & \\
\hline & & & Estación de cercanías & \\
\hline \multirow{3}{*}{ Red de carreteras } & \multirow{3}{*}{ Lineal } & \multirow{3}{*}{ Viario } & Carretera convencional & \multirow{3}{*}{$\begin{array}{l}\text { Información acerca del } \\
\text { trazado de la red de } \\
\text { carreteras existente en } \\
\text { Andalucía }\end{array}$} \\
\hline & & & Viario urbano & \\
\hline & & & Caminos & \\
\hline Caminos $^{1}$ & Lineal & Viario & Camino & $\begin{array}{l}\text { Información sobre el trazado } \\
\text { del viario rural que da acceso } \\
\text { a las principales zonas de } \\
\text { diseminado y edificación } \\
\text { rural aislada }\end{array}$ \\
\hline
\end{tabular}

1. Entendemos que esta capa lineal del viario complementa, necesariamente, a la entidad "Caminos" de la Red de carreteras, de cara a un mejor estudio de accesibilidad a los itinerarios no motorizados, aunque su fecha de actualización (2007) sea anterior a la de la segunda (2012). 


\begin{tabular}{|c|c|c|c|c|}
\hline Nombre de la capa & $\begin{array}{c}\text { Tipo de } \\
\text { geometría }\end{array}$ & Grupo & Entidades que se emplean & Metadatos básicos \\
\hline \multirow{2}{*}{ Red de ferrocarriles ${ }^{2}$} & \multirow{2}{*}{ Lineal } & \multirow{2}{*}{ Viario } & ffcc vía doble & \multirow{2}{*}{$\begin{array}{l}\text { Trazado de la red } \\
\text { ferroviaria }\end{array}$} \\
\hline & & & ffcc vía única & \\
\hline Vías pecuarias & Lineal & Viario & Cañada & $\begin{array}{l}\text { Trazado de } \\
\text { las vías pecuarias de } \\
\text { Andalucía incluyendo datos } \\
\text { acerca de su tipología, } \\
\text { anchura, longitud, etc. }\end{array}$ \\
\hline Senderos & Lineal & Viario & Sendero & $\begin{array}{l}\text { Trazado de los } \\
\text { itinerarios peatonales } \\
\text { señalizados existentes en } \\
\text { Andalucía, incluyendo los } \\
\text { senderos de gran } \\
\text { recorrido }\end{array}$ \\
\hline Vías verdes & Lineal & Viario & Vía verde & $\begin{array}{l}\text { Trazado de las vías } \\
\text { verdes de Andalucía, } \\
\text { formadas por trazados } \\
\text { ferroviarios en desuso que } \\
\text { han sido reconvertidos } \\
\text { en itinerarios cicloturistas y } \\
\text { senderistas } 3\end{array}$ \\
\hline Términos municipales & Poligonal & $\begin{array}{l}\text { Divisiones } \\
\text { Administrativas }\end{array}$ & Municipio & $\begin{array}{l}\text { Delimitación de los } \\
\text { municipios andaluces }\end{array}$ \\
\hline
\end{tabular}

Fuente: Elaboración propia a partir del Modelo de Datos de DERA.

\section{RESULTADOS DEL TRABAJO: UNA CARTOGRAFÍA PARA LA TOMA DE DECISIONES}

\subsection{Itinerarios disponibles a menos de $3 \mathrm{~km}$ de estaciones de ferrocarril en funcionamiento}

Los resultados cartográficos obtenidos para aquellos itinerarios que se encuentran a una distancia máxima de $3 \mathrm{~km}$ de las estaciones de ferrocarril en uso y que pueden permitir la práctica de la actividad cicloturística aparecen en el mapa 1.

En primer lugar, debemos destacar que los itinerarios no motorizados en los que ya se han puesto en marcha estas iniciativas son, hasta el momento, las siguientes vías verdes:

- Vía Verde del Aceite, con un recorrido de 127,36 km, empezando su trayecto en Puente Genil, en la provincia de Córdoba, y terminando en Jaén capital. Este itinerario presenta fácil acceso desde estaciones de ferrocarril y, por lo tanto, el desplazamiento en bicicleta desde la red férrea es muy factible. Se trata, en estos momentos, de una oferta muy dinámica y atractiva para el usuario, resultado de la fusión de tres antiguas vías verdes, contiguas pero segmentadas, impulsándose así una economía de escala que es sumamente importante para el sector de la movilidad sostenible.

- Vía Verde de la Campiña, con un recorrido de 91,92 km; itinerario no motorizado que empieza en la localidad de Marchena, en la provincia de Sevilla, llegando hasta las proximidades de Córdoba capital. Además, en el origen de este itinerario convergen cuatro cañadas reales, como son: la Cañada Real de Sevilla, con 5,10 km de recorrido por el municipio marchenero; la de Morón, con 10,31 km en el mismo ámbito; la de Pruna, de 14,04 km; y la propiamente denominada de Marchena (12 km), y

2. La información sobre ferrocarriles abandonados o en desuso nos ha sido facilitada por la Fundación de los Ferrocarriles Españoles (FFE), organismo dependiente de RENFE y promotor del Programa Vías Verdes en el conjunto del Estado.

3. Capa actualizada con información facilitada asimismo por la referida Fundación de los Ferrocarriles Españoles (FFE). 


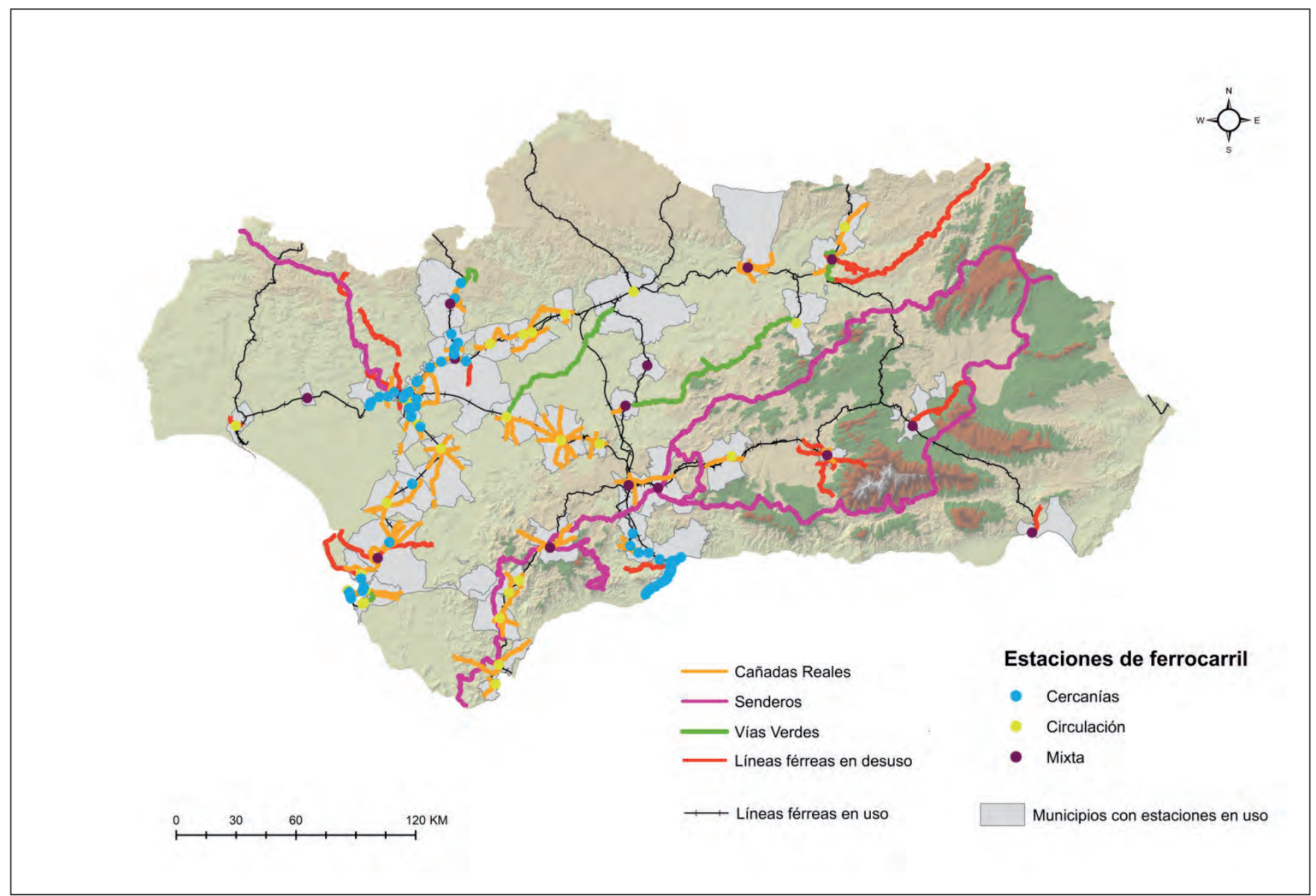

Mapa 1. Itinerarios disponibles a $3 \mathrm{~km}$. de las estaciones de ferrocarril. Fuente: Elaboración propia a partir de datos de DERA y de la Fundación de Ferrocarriles Españoles.

que se une a la Cañada Real de Osuna, llegando a este pueblo, que cuenta también con estación de ferrocarril.

- Vías verdes de Linares y de Guadalimar, con un recorrido la primera de 6,61 km y la segunda de 15,31 km sobre el antiguo trazado de la línea férrea Baeza-Utiel, que dispone de un total de 143,76 km (Cebrián, F., 2011). Se tiene acceso a las mismas a través de la estación de Linares-Baeza, donde convergen además la Cañada Real de Guadalimar, con 25,97 km de recorrido, y líneas férreas ya desmanteladas, entre las que destaca el antiguo tren Linares-Úbeda-Baeza, con 41,73 km de longitud.

- Vía Verde de la Sierra Norte de Sevilla, a la que se tiene acceso desde la estación de ferrocarril de Cazalla-Constantina (inicialmente Los Prados-Cazalla, y en la actualidad última parada septentrional de la línea C-3 del Área de Cercanías RENFE de Sevilla4), presentando un recorrido de 18,28 km, y discurriendo en paralelo durante parte de su trazado con la Cañada Real de la Rivera del Huéznar, que tiene $16 \mathrm{~km}$ y que llega hasta la estación de ferrocarril de Fábrica de El Pedroso, donde también converge con la Cañada Real de Lora a las Minas (en dirección al municipio de Villanueva del Río y Minas), con $9 \mathrm{~km}$ de longitud por el término de El Pedroso. Estas sinergias favorecen que este itinerario no motorizado (todo el mismo inserto en un espacio natural protegido con distintas figuras, entre las

4. En este sentido debemos indicar que, gracias a mejoras horarias recientes, la distribución actual durante los fines de semana es más propicia para el cicloturismo, pues permite llegar a Cazalla-Constantina a las 10:32 h., disponiéndose de un último tren de retorno a las 17:50 h. en horario de verano; lo que permite una estancia de unas 7 horas, suficiente para el recorrido ida y vuelta de la actual vía verde, así como tiempo para el descanso y avituallamiento. 
que destacan el Parque Natural Sierra Norte de Sevilla y la Reserva de la Biosfera Dehesas de Sierra Morena ${ }^{5}$ ) pudiera ampliar su recorrido y se tuviera acceso a él desde diferentes puntos.

- Vías verdes de Puerto Real-San Fernando y de Matagorda, que se localizan ambas en la Bahía de Cádiz, teniendo la primera un recorrido de $8,25 \mathrm{~km}$, y disponiendo la segunda de 3,55 km. El acceso a la Vía Verde de Puerto Real-San Fernando se realiza desde la estación de San Fernando, donde convergen además dos cañadas reales: la de Paterna, con 18,65 km; y la de Medina, de 15,98 km. Por su parte el acceso a la Vía Verde de Matagorda tiene lugar a través de la estación de ferrocarril de la Universidad, en Puerto Real, y se encuentra enlazada en su recorrido con la Cañada Real de Matagorda, que posee una longitud de 5,66 km.

- Vía Verde de Itálica, que posee un recorrido de sólo 1,7 km, y a la que se puede acceder desde la estación de ferrocarril de La Cartuja, en la ciudad de Sevilla, y también por la estación de Camas. Una de las características que diferencia esta vía verde del resto es que es interurbana y, por lo tanto, permite una gran afluencia de usuarios potenciales. Además, en ella convergen otros itinerarios no motorizados que deberían añadirse y ampliar su recorrido actual, como son: el Cordel de Buernas, con una longitud de 148,82 km, que pertenece a un sendero de Gran Recorrido (GR); el tren desmantelado Aznalfarache-Cala, con 81 km de longitud total; y el ferrocarril en desuso Camas-Aznalcóllar, con $30,10 \mathrm{~km}$ de trazado.

También podemos reflejar aquí las potencialidades que presenta el tramo de ferrocarril en desuso entre Guadix y Baza, todo él en la provincia de Granada, y que forma parte del itinerario regional Eje 4, denominado "Intrabético", dentro de las propuestas del PAB. Pertenece a la línea abandonada entre Guadix (Granada) y Almendricos (Murcia), donde ya se han realizado distintas actuaciones de adaptación a vías verdes acondicionadas: Sierra de Baza, Valle del Almanzora y Huércal-Overa (estas dos últimas en la provincia de Almería).

La red de cañadas reales aumenta entre las estaciones de Bobadilla y Antequera, donde encontramos: la Cañada Real Sevilla-Málaga, con un recorrido de 29,94 km, y que enlaza con el Sendero de Gran Recorrido (GR) Europeo E-4; y la Cañada Real de Granada, con un trazado de 15,74 km que conecta también con el mismo Sendero GR Europeo E-4. Igualmente son significativas las cañadas reales existentes entre las estaciones de Jimena de la Frontera y Ronda, como son: la Cañada del Campo de Gibraltar, de 9 km; la Cañada Real de Gaucín (18,64 km); y la Cañada de Granada y Córdoba, con 16,03 km. Por otro lado, la Cañada Real de Soria parte de la estación de Posadas hacia Córdoba ciudad, con un recorrido 30,17km.

Con respecto a las líneas férreas en desuso destacan las siguientes:

- Desde la estación de Jerez de la Frontera, correspondiendo al denominado Ferrocarril de la Sierra, que discurriría hasta Almargen (en Málaga), y que se enmarcaba dentro del planteamiento militar de conectar las bases marítimas de Cádiz y Cartagena (Rincón, J., 2013). Las obras se iniciaron bajo impulso de la dictadura de Primo de Rivera. La Guerra Civil Española supuso obviamente una fuerte paralización en la ejecución de obras, y la dura posguerra no fue tampoco el mejor marco para retomar esta difícil construcción. A mediados de los sesenta del pasado siglo XX un informe del Banco Mundial determinó el definitivo abandono de las obras, estando no obstante concluidas estaciones, viaductos y túneles, a falta del tendido de vías. De los $119 \mathrm{~km}$, sólo llegó a funcionar el tramo de 21 $\mathrm{km}$ que iba de Jerez a la azucarera de Jédula. Se tendieron las vías hasta Arcos de la Frontera (31 km), pero por ellas no llegaron a pasar más que los trenes de prueba. En estos momentos existe una plataforma ciudadana muy activa que promueve la recuperación como vía verde del tramo que va de Jerez a Arcos de la Frontera. Por su parte, el de 36 km que discurre entre El Coronil y Olvera, corresponde a la denominada Vía Verde de la Sierra, la más visitada de las andaluzas según se refleja en la tesis doctoral de Pablo Luque (2012).

5. Cabe indicar aquí que, según el proyecto recientemente concluido sobre “Vías Verdes y Red Natura 2000: Divulgación de Espacios Naturales Protegidos y Geoparques a través de la Red Estatal de Vías Verdes", más del 87\% de estos itinerarios no motorizados se sitúa a menos de $5 \mathrm{~km}$ de un espacio natural protegido por la Red Natura 2000 de la Unión Europea. 
- Desde la estación de Granada, a Sierra Nevada, con 20,43km; a La Zubia, de 6,98km; y Armilla-Dúrcal $(26,48 \mathrm{~km})$.

- Desde la estación de San Julián en Málaga capital a Coín, con un recorrido de 29,77km.

- Y desde Almería a El Chorrillo, de 16,33 km.

Como es lógico, y según se aprecia en los cuadros 3 y 4 que se muestran a continuación, a mayor distancia entre las estaciones de tren y el comienzo de estos itinerarios, existe más disponibilidad de kilómetros de rutas no motorizadas para la realización de actividades cicloturísticas en los ámbitos rurales y, por lo tanto, mayor potencial para la dinamización del territorio, aunque aquí se haya decidido centrarnos en el referido valor crítico de los $3 \mathrm{~km}$, por los motivos antes aducidos.

Cuadro 3. Longitud en km, según tipos de itinerarios no motorizados, a diferentes distancias de las estaciones ferroviarias.

\begin{tabular}{|c|c|c|c|c|c|}
\hline Distancia a estación & Cañadas reales & Senderos & Vías verdes & FFCC en desuso & Total de km \\
\hline$<1 \mathrm{~km}$ & 647,74 & $1.130,43$ & 122,00 & 507,48 & $2.285,65$ \\
\hline$<2 \mathrm{~km}$ & 917,37 & $1.250,85$ & 273,91 & 866,28 & $3.034,50$ \\
\hline$<3 \mathrm{~km}$ & $1.178,45$ & $1.250,85$ & 273,91 & 974,85 & $3.404,15$ \\
\hline$<4 \mathrm{~km}$ & $1.439,06$ & $1.349,63$ & 273,91 & $1.066,69$ & $3.855,38$ \\
\hline$<6 \mathrm{~km}$ & $2.057,26$ & $1.413,37$ & 287,37 & $1.257,32$ & $4.727,95$ \\
\hline
\end{tabular}

Fuente: Elaboración propia a partir de datos de DERA y FFE.

Cuadro 4. Reparto porcentual de los tipos de itinerarios no motorizados a diferentes distancias de as estaciones ferroviarias.

\begin{tabular}{|c|c|c|c|}
\hline Distancia a estación & Cañadas reales & Senderos & FFCC en desuso \\
\hline$<1 \mathrm{~km}$ & $28,33 \%$ & $49,45 \%$ & $22,20 \%$ \\
\hline$<2 \mathrm{~km}$ & $30,23 \%$ & $41,22 \%$ & $28,54 \%$ \\
\hline$<3 \mathrm{~km}$ & $34,61 \%$ & $36,74 \%$ & $28,63 \%$ \\
\hline$<4 \mathrm{~km}$ & $37,32 \%$ & $35,00 \%$ & $27,66 \%$ \\
\hline$<6 \mathrm{~km}$ & $43,51 \%$ & $29,89 \%$ & $26,59 \%$ \\
\hline
\end{tabular}

Fuente: Elaboración propia a partir de datos de DERA y FFE.

Por su parte, en cuanto a la distribución porcentual de los tipos de itinerarios según la distancia máxima a una estación férrea en funcionamiento, se aprecia un progresivo incremento en el peso de la red de cañadas reales, que pasa de poco más del $28 \%$ a menos de $1 \mathrm{~km}$, a más del $43 \%$ a menos de $6 \mathrm{~km}$. Por el contrario, el porcentaje de senderos sigue un sentido totalmente inverso, desde el 49 al 29\%; mientras que los ferrocarriles en desuso presentan mayor estabilidad, con valores entre el 22 y el $28 \%$ en los 5 niveles de distancia que se han establecido.

6. Las Vías verdes no contabilizan en el sumatorio de esta tabla, ni presentan porcentajes específicos en el cuadro 4, puesto que, conceptualmente, no son más que itinerarios de ferrocarriles en desuso debidamente acondicionados para su uso cicloturista, senderista y otros no motorizados. 


\subsection{Análisis de redes: estudio de accesibilidad a menos de 15 minutos desde estaciones ferroviarias en uso}

Se realiza a continuación, según lo anunciado en la metodología, un análisis de redes para medir la accesibilidad desde las estaciones ferroviarias seleccionadas (cercanías, circulación y mixtas) a los distintos tipos de itinerarios en una isócrona de 15 minutos de tiempo máximo de desplazamiento a $15 \mathrm{~km} / \mathrm{h}$. La malla procede de las capas relativas a la red de carreteras andaluzas (excluidas las de doble trazado en las que por su propia tipología está prohibido el tránsito de bicicletas) y la capa específica de caminos andaluces, ya reflejadas en el cuadro 2, y que representan un total de casi $57.718 \mathrm{~km}$.

A partir de la intersección entre el buffer de $3 \mathrm{~km}$ de proximidad y la referida isócrona de 15 minutos de accesibilidad surge el mapa 2, donde, como es lógico, se simplifica la cartografía de itinerarios anteriores. Además, hemos seleccionado en el cuadro 5 los itinerarios que, cumpliendo ambos requisitos, superan los $15 \mathrm{~km}$ de longitud, distancia que, para el caso muy habitual de que no tengan carácter circular o de bucle, representa, al menos, $30 \mathrm{~km}$ entre itinerario de ida y de vuelta al final del mismo, y que se entiende como una longitud atractiva para el cicloturista medio.

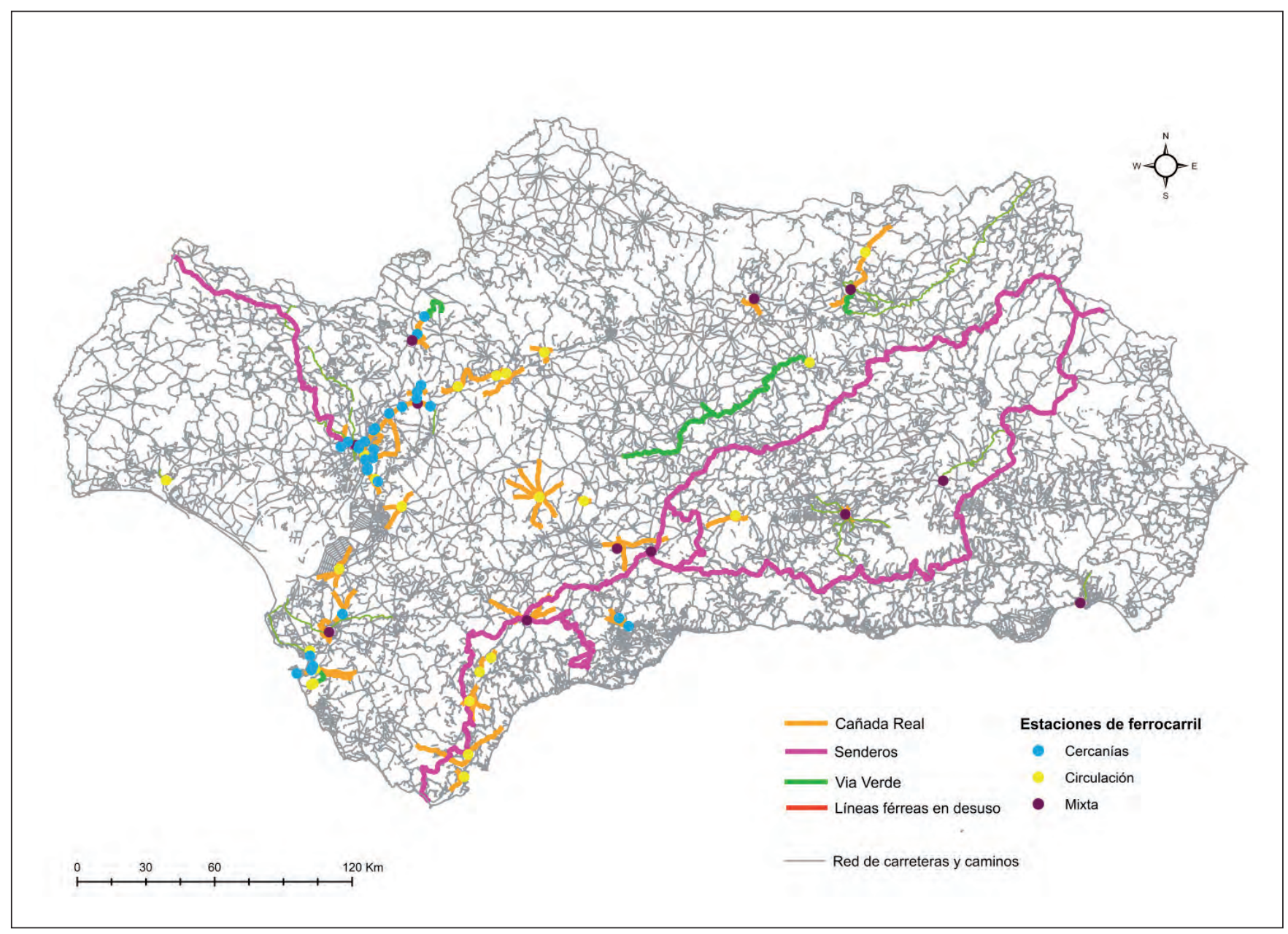

Mapa 2a. Itinerarios a menos de 3 kms. e isócrona de 15’ de estaciones ferroviarias. Fuente: Elaboración propia a partir de datos de DERA y de la Fundación de Ferrocarriles Españoles. 
Cuadro 5. Itinerarios no motorizados de más de $15 \mathrm{~km}$ de longitud a menos de $3 \mathrm{~km}$ y 15 minutos de acceso desde estación ferroviaria en uso.

\begin{tabular}{|c|c|c|c|}
\hline Tipo de itinerario & Nombre del itinerario & Estación/es implicada/as & Longitud en km \\
\hline Sendero & $\begin{array}{l}\text { Sendero Europeo E-4 (Tarifa- } \\
\text { Andorra) GR-7 }\end{array}$ & $\begin{array}{l}\text { Antequera/Jimena de la } \\
\text { Frontera/San Roque-La Línea }\end{array}$ & 981,614 \\
\hline Sendero & Cordel de las Buervas GR-41 & Valencina- Santiponce & 148,821 \\
\hline Ferrocarril en desuso & $\begin{array}{l}\text { Baeza - Utiel. Tramo Baeza- } \\
\text { Bienservida }\end{array}$ & Linares-Baeza & 141,558 \\
\hline Vía Verde & Vía Verde del Aceite & Jaén & 127,357 \\
\hline Sendero & Sierra de las Nieves GR-243 & Ronda & 120,416 \\
\hline Ferrocarril en desuso & Jaén-Campo Real & Jaén & 119,337 \\
\hline Ferrocarril en desuso & Aznalfarache-Cala & Camas & 83,935 \\
\hline Ferrocarril en desuso & $\begin{array}{l}\text { Guadix-Almendricos. Tramo } \\
\text { Guadix-Baza }\end{array}$ & Guadix & 52,331 \\
\hline Ferrocarril en desuso & Linares-Úbeda-Baeza & Linares-Baeza & 41,731 \\
\hline Ferrocarril en desuso & $\begin{array}{l}\text { Puerto de Santa María-Sanlúcar } \\
\text { de Barrameda }\end{array}$ & Puerto de Santa María & 36,014 \\
\hline Ferrocarril en desuso & $\begin{array}{l}\text { Jerez de la Frontera-Arcos de la } \\
\text { Frontera }\end{array}$ & Jerez de la Frontera & 31,076 \\
\hline Cañada Real & $\begin{array}{l}\text { Cañada Real de San Roque a } \\
\text { Medina }\end{array}$ & San Roque-La Línea & 30,881 \\
\hline Ferrocarril en desuso & Camas-Aznalcollar & Valencina-Santiponce & 30,092 \\
\hline Cañada Real & Cañada Real de Sevilla a Málaga & Bobadilla (Antequera) & 29,939 \\
\hline Cañada Real & Cañada Real de Mármol & Lora del Río & 28,544 \\
\hline Cañada Real & $\begin{array}{l}\text { Cañada Real de Navas de San } \\
\text { Juan }\end{array}$ & Vilches & 28,489 \\
\hline Ferrocarril en desuso & Jerez de la Frontera-Bonanza & Jerez de la Frontera & 28,391 \\
\hline Cañada Real & $\begin{array}{l}\text { Cañada Real de Marchena a } \\
\text { Estepa }\end{array}$ & Osuna & 27,188 \\
\hline Cañada Real & Cañada Real de Écija a Teba & Osuna & 26,979 \\
\hline Ferrocarril en desuso & Armilla-Dúrcal & Granada & 26,476 \\
\hline Cañada Real & Cañada Real Guadalimar & Linares-Baeza & 25,971 \\
\hline Cañada Real & Cañada de Sanlúcar a Sevilla & Lebrija & 23,895 \\
\hline Cañada Real & Cañada de Córdoba a Sevilla & Palma del Río & 23,769 \\
\hline Cañada Real & $\begin{array}{l}\text { Cañada Real de Manilva a los } \\
\text { Barrios }\end{array}$ & San Roque-La Línea & 22,593 \\
\hline Ferrocarril en desuso & Granada-Sierra Nevada & Granada & 20,431 \\
\hline Cañada Real & $\begin{array}{l}\text { Cañada Real de Sevilla a } \\
\text { Granada }\end{array}$ & San Francisco de Loja & 20,038 \\
\hline
\end{tabular}




\begin{tabular}{|c|c|c|c|}
\hline Tipo de itinerario & Nombre del itinerario & Estación/es implicada/as & Longitud en km \\
\hline Cañada Real & Cañada Real de Sevilla & Ronda & 19,689 \\
\hline Cañada Real & $\begin{array}{l}\text { Cañada Real del Camino de } \\
\text { Paterna }\end{array}$ & Puerto Real & 18,654 \\
\hline Cañada Real & Cañada Real de Gaucín & Jimena de la Frontera & 18,641 \\
\hline Vía Verde & $\begin{array}{l}\text { Vía Verde de la Sierra Norte de } \\
\text { Sevilla }\end{array}$ & Cazalla-Constantina & 18,281 \\
\hline Cañada Real & Cañada Real de Ronda & Osuna & 17,581 \\
\hline Ferrocarril en desuso & Granada-Fuente Vaqueros & Granada & 17,388 \\
\hline Cañada Real & $\begin{array}{l}\text { Cañada Real de la Rivera del } \\
\text { Huéznar }\end{array}$ & Cazalla-Constantina & 16,507 \\
\hline Cañada Real & $\begin{array}{l}\text { Cañada Real de Leyes o las Ca- } \\
\text { bezas de San Juan y Sevilla }\end{array}$ & La Parra (Jerez de la Frontera) & 16,502 \\
\hline Ferrocarril en desuso & Almería - El Chorrillo & Almería & 16,335 \\
\hline Ferrocarril en desuso & Granada-Pinos Puente & Granada & 16,217 \\
\hline Cañada Real & $\begin{array}{l}\text { Cañada Real de Pero Mingo y de } \\
\text { Palmate }\end{array}$ & $\begin{array}{l}\text { Virgen del Rocío/Padre Pío } \\
\text { Palmete (Sevilla) }\end{array}$ & 16,043 \\
\hline Cañada Real & $\begin{array}{l}\text { Cañada Real de Granada y } \\
\text { Córdoba }\end{array}$ & Ronda & 16,034 \\
\hline Cañada Real & $\begin{array}{l}\text { Cañada Real del Camino de } \\
\text { Medina por Venta Catalana }\end{array}$ & Puerto Real & 15,987 \\
\hline Cañada Real & $\begin{array}{l}\text { Cañada Real de los Palacios a } \\
\text { Carmona }\end{array}$ & Utrera & 15,831 \\
\hline Cañada Real & Cañada Real de Granada & Bobadilla (Antequera) & 15,744 \\
\hline Cañada Real & $\begin{array}{l}\text { Cañada Real de la División de } \\
\text { Términos }\end{array}$ & Brenes & 15,718 \\
\hline Vía Verde & Vía Verde del Guadalimar & Linares-Baeza & 15,313 \\
\hline Cañada Real & Cañada Real de Fuentes & Osuna & 15,148 \\
\hline
\end{tabular}

Fuente: Elaboración propia a partir de un SIG con datos de DERA y FFE.

Esta tabla supone una simplificación a 44 registros de la que se obtenía sin la doble condición, esto es, sólo con el buffer de $3 \mathrm{~km}$ de distancia, y que incorporaba 10 itinerarios más. En el cuadro 6, se reflejan las localidades con estaciones ferroviarias que generan estas 44 rutas, distribuidas según los 6 niveles de jerarquía urbana andaluza establecidos por Gabriel Cano en 2008 (p. 135).

\subsection{Selección de núcleos intermodales e itinerarios no motorizados}

Como consecuencia de todo lo anterior se establecen a continuación los principales núcleos para la implementación de la intermodalidad "tren+bici" que encontramos hoy por hoy en Andalucía, así como una serie de itinerarios no motorizados vinculados a los mismos con sus diferentes características, derivadas del SIG que se ha utilizado como soporte metodológico de esta investigación. Todo ello se refleja en el cuadro siguiente (número 7), y en el posterior mapa 3 de síntesis que ahora también se expone, donde, en principio, 
Cuadro 6. Tipos de localidades andaluzas y denominación de las que generan itinerarios no motorizados de más de $15 \mathrm{~km}$ de longitud a menos de $3 \mathrm{~km}$ y 15 minutos de acceso.

\begin{tabular}{|l|l|}
\hline \multicolumn{1}{|c|}{ Tipología de localidad } & \multicolumn{1}{|c|}{ Nombre de localidades } \\
\hline Capitales de provincia & $\begin{array}{l}\text { Jaén, Granada, Almería y Sevilla (por Virgen del Rocío/ } \\
\text { Padre Pío Palmete) }\end{array}$ \\
\hline Centros comarcales & $\begin{array}{l}\text { Antequera (por Bobadilla), Linares (por Linares-Baeza), } \\
\text { Ronda, Guadix, Jerez de la Frontera (incluye estación } \\
\text { de La Parra), Lora del Río, Palma del Río, Loja (por } \\
\text { la estación de San Francisco), Cazalla (por Cazalla- } \\
\text { Constantina) y Utrera. }\end{array}$ \\
\hline Núcleos en aglomeraciones urbanas & $\begin{array}{l}\text { San Roque (por San Roque-La Línea), Camas, Puerto de } \\
\text { Santa María, Puerto Real y Brenes. }\end{array}$ \\
\hline Localidades en áreas polinucleares & Osuna y Lebrija. \\
\hline Otros centros & Jimena de la Frontera y Las Cabezas de San Juan. \\
\hline Resto de cabeceras municipales & Valencina (por Valencina-Santiponce) y Vilches. \\
\hline
\end{tabular}

Fuente: Elaboración propia a partir de tipología de ciudades andaluzas de G. Cano (2008; p. 135) y estaciones ferroviarias del cuadro 5.

se atiende sólo a itinerarios que, en su conjunto, superen los $20 \mathrm{~km}$ y que partan de las proximidades (con distancia nunca superior a los $3 \mathrm{~km}$ ) de las estaciones correspondientes a localidades adscritas a las categorías de capitales de provincia y centros comarcales del anterior cuadro 6.

No obstante, de la revisión de los 10 itinerarios que sólo cumplían la condición de iniciarse a menos de $3 \mathrm{~km}$ de la estación ferroviaria pero que no se encuentran a menos de 15 minutos de acceso desde la misma, observamos 2 casos excepcionales y significativos, como son los que corresponden a Marchena, donde la Vía Verde de la Campiña se inicia a sólo 364 m de la misma; y la estación de cercanías de San Julián (en Málaga), a 106 m del ferrocarril en desuso Málaga-Coín. El que no aparezcan en la isócrona seleccionada lo consideramos una anomalía consecuencia de la capa fuente utilizada, según comentaremos más adelante, lo que nos ha llevado a considerar también estas dos estaciones, a menos de $500 \mathrm{~m}$ del inicio de sus itinerarios, en la relación de los que aquí se proponen como prioritarios a potenciar en Andalucía.

Como vemos en el cuadro 7 los itinerarios seleccionados presentan una longitud, ordenada aquí de mayor a menor, que oscila entre los 127,36 km de la actual Vía Verde del Aceite, en las provincias de Córdoba y Jaén, y los poco más de $20 \mathrm{~km}$ de la Cañada Real de Granada a Sevilla en las proximidades de la estación de San Francisco, en Loja (Granada). Sólo las provincias de Huelva y Almería, los extremos longitudinales del territorio andaluz, no cuentan con representación en esta selección inicial de itinerarios no motorizados más atractivos para la promoción del cicloturismo en Andalucía. En el caso onubense la amplia oferta de ferrocarriles mineros abandonados (Romero, E. M., 2007) no genera sin embargo ninguno ajustado a los criterios en este estudio; y en el caso de Almería entendemos que es su menguado desarrollo ferroviario (Gavira, A. y Ventura, J., 2017), el que determina que no se establezca ningún itinerario de interés en este primer momento, aunque existen algunas opciones de menor calado.

Ahora bien, la ejecución de estos posibles itinerarios, para el caso de los que todavía no están en activo, dependerá, finalmente, y con independencia de los imprescindibles recursos económicos, de si cumplen una serie de requisitos para la realización de actividades cicloturísticas y recreativas, como son parámetros de pendientes, tipología del terreno que atraviesan y que enlacen lugares de interés natural y cultural, fundamentalmente, lo que implica estudios posteriores de mayor detalle. 
Cuadro 7. Selección de estaciones intermodales “tren+bici” y principales itinerarios no motorizados asociados propuestos para Andalucía.

\begin{tabular}{|c|c|c|c|c|}
\hline $\begin{array}{l}\text { Estación intermodal } \\
\text { "tren+bici" }\end{array}$ & Itinerario no motorizado & $\mathrm{N}^{\circ}$. & $\begin{array}{l}\text { Distancia al Inicio en línea recta } \\
\text { desde estación ferroviaria }\end{array}$ & Longitud \\
\hline Jaén & $\begin{array}{l}\text { Vía Verde del Aceite. Procede de la } \\
\text { fusión de las antiguas vías verdes de } \\
\text { la Subbética, Guadajoz-Subbética y } \\
\text { del Aceite }\end{array}$ & 1 & $1,89 \mathrm{~km}$ & $127,36 \mathrm{~km}$ \\
\hline Marchena & $\begin{array}{l}\text { Vía Verde de la Campiña. Procede de } \\
\text { la fusión de las antiguas vías verdes } \\
\text { de la Campiña sevillana y Campiña } \\
\text { cordobesa }\end{array}$ & 2 & $0,37 \mathrm{~km}$ & $91,92 \mathrm{~km}$ \\
\hline Lora del Río & $\begin{array}{l}\text { Cañada Real de Mármol y Cañada } \\
\text { Real Soriana o de Castilla }\end{array}$ & 3 & $\begin{array}{l}\text { Discurre por la propia estación } \\
\text { de Lora del Río }\end{array}$ & $72,52 \mathrm{~km}$ \\
\hline Guadix & $\begin{array}{l}\text { Línea de ferrocarril en desuso } \\
\text { Guadix-Baza y Vía Verde de la } \\
\text { Sierra de Baza. Tramo inicial del } \\
\text { ferrocarril en desuso entre Guadix y } \\
\text { Almendricos (Murcia) }\end{array}$ & 4 & $\begin{array}{l}\text { Parte de la propia estación } \\
\text { ferroviaria }\end{array}$ & $\begin{array}{l}57 \mathrm{~km} \\
\text { aprox. }\end{array}$ \\
\hline Ronda & $\begin{array}{l}\text { Cañada Real de Sevilla y Cañada Real } \\
\text { de Granada y Córdoba }\end{array}$ & 5 & $\begin{array}{l}\text { Discurre por la propia estación } \\
\text { de Ronda }\end{array}$ & $35,72 \mathrm{~km}$ \\
\hline Cazalla-Constantina & $\begin{array}{l}\text { Vía Verde de la Sierra Norte y Cañada } \\
\text { Real de la Rivera del Huéznar }\end{array}$ & 6 & $0,20 \mathrm{~km}$ & $\begin{array}{l}33 \mathrm{~km} \\
\text { aprox. }\end{array}$ \\
\hline Jerez de la Frontera & $\begin{array}{l}\text { Tramo inicial de ferrocarril } \\
\text { desmantelado, hasta Arcos de la } \\
\text { Frontera }\end{array}$ & 7 & $2,16 \mathrm{~km}$ & $31 \mathrm{~km}$ \\
\hline Granada & $\begin{array}{l}\text { Cañada Real de Trashumancia y } \\
\text { línea de ferrocarril en desuso hasta } \\
\text { Armilla-Dúrcal }\end{array}$ & 8 & $0,40 \mathrm{~km}$ & $\begin{array}{l}30 \mathrm{~km} \\
\text { aprox. }\end{array}$ \\
\hline Bobadilla (Antequera) & Cañada Real de Sevilla a Málaga & 9 & $2,77 \mathrm{~km}$ & $29,94 \mathrm{~km}$ \\
\hline San Julián (Málaga) & $\begin{array}{l}\text { Línea de ferrocarril en desuso hasta } \\
\text { Coín }\end{array}$ & 10 & $0,10 \mathrm{~km}$ & 29,77 km \\
\hline Jerez de la Frontera & $\begin{array}{l}\text { Cañada del Pino Solete y línea de } \\
\text { ferrocarril en desuso Jerez de la } \\
\text { Frontera-Bonanza }\end{array}$ & 11 & $\begin{array}{l}\text { Parte de la propia estación de } \\
\text { Jerez de la Frontera }\end{array}$ & $\begin{array}{l}29 \mathrm{~km} \\
\text { aprox. }\end{array}$ \\
\hline $\begin{array}{l}\text { Virgen del Rocío/Padre } \\
\text { Pío Palmete (Sevilla) }\end{array}$ & $\begin{array}{l}\text { Cañada Real de Pero Mingo y } \\
\text { Palmete y Cañada Real de la Armada }\end{array}$ & 12 & $\begin{array}{l}0,28 \text { km desde la estación Padre } \\
\text { Pío Palmete }\end{array}$ & $27,81 \mathrm{~km}$ \\
\hline Linares-Baeza & $\begin{array}{l}\text { Vías verdes de Linares y de } \\
\text { Guadalimar unidas por línea de } \\
\text { ferrocarril en desuso }\end{array}$ & 13 & $0,20 \mathrm{~km}$ & $24,20 \mathrm{~km}$ \\
\hline Palma del Río & Cañada Real de Córdoba a Sevilla & 14 & $2,37 \mathrm{~km}$ & $23,77 \mathrm{~km}$ \\
\hline Granada & $\begin{array}{l}\text { Cañada Real de Trashumancia y línea } \\
\text { de ferrocarril en desuso a Sierra } \\
\text { Nevada }\end{array}$ & 15 & $0,40 \mathrm{~km}$ & $\begin{array}{l}23,50 \mathrm{~km} \\
\text { aprox. }\end{array}$ \\
\hline San Francisco de Loja & Cañada Real de Sevilla a Granada & 16 & $2,08 \mathrm{~km}$ & $20,03 \mathrm{~km}$ \\
\hline
\end{tabular}

Fuente: Elaboración propia a partir del SIG diseñado para el estudio realizado. 


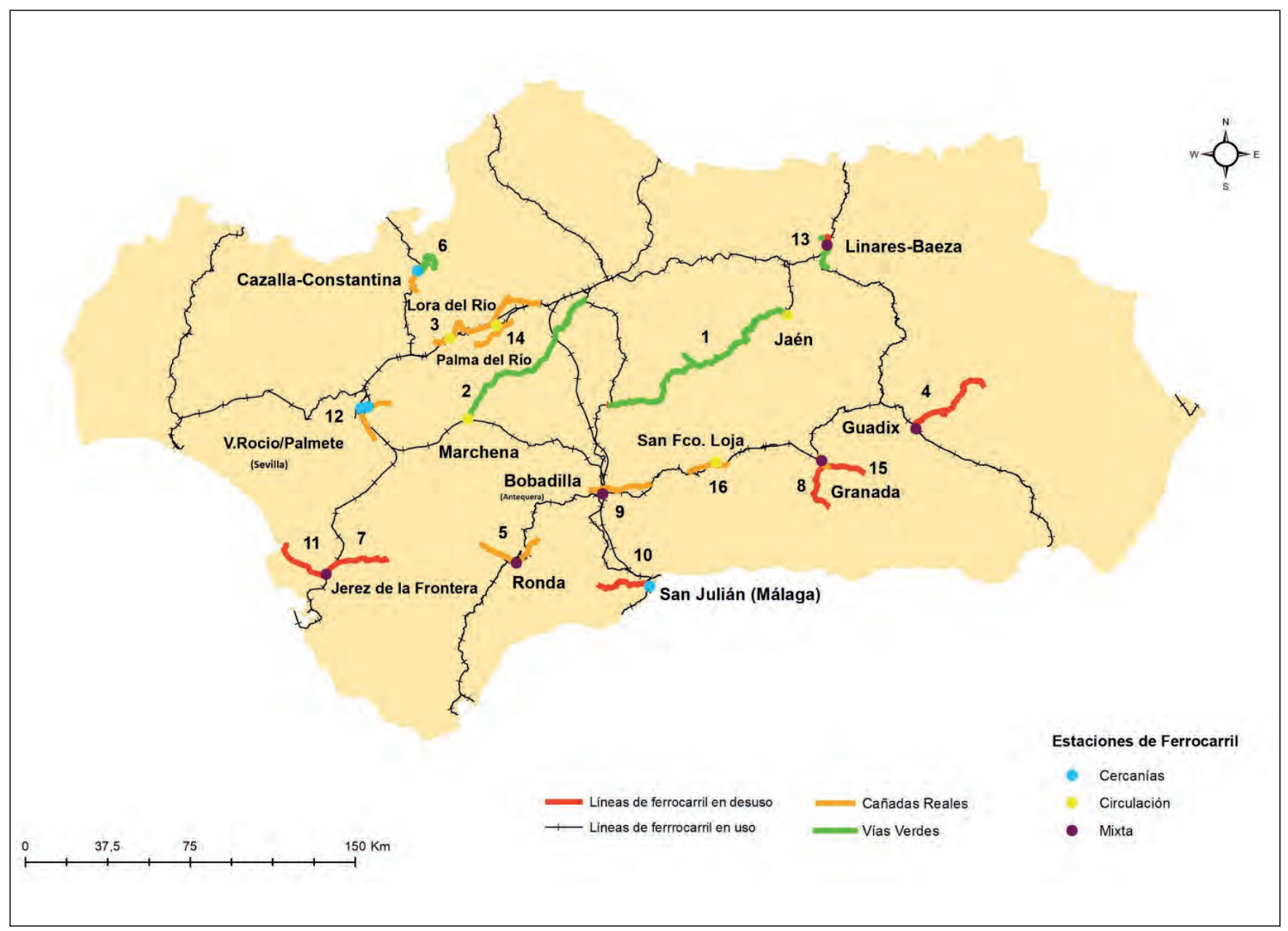

Mapa 3. Estaciones intermodales "tren+bici” y principales itinerarios asociados.

Fuente: Elaboración propia a partir de datos de DERA y de la Fundación de Ferrocarriles Españoles.

\section{DEBATE DE SITUACIÓN Y DISCUSIÓN TÉCNICA}

De este estudio cabe deducir que el cicloturismo se encuentra en estos momentos en España y Andalucía en una fase de despegue, disponiendo, por tanto, de un gran potencial para tener éxito como motor dinamizador de espacios rurales, donde se combinan diferentes características, desde el respeto por la naturaleza, aspectos beneficiosos para la salud y derramas económicas que se aportan a lo largo de estos itinerarios (Fernández, F., 2015; Eizaguirre et al., 2016; y Ventura, J. y Gavira, A., 2016).

También es cierto que nos encontramos ante una disponibilidad reducida para acceder en tren a estos itinerarios no motorizados con bicicletas, ya que la normativa de acceso al transporte ferroviario con ellas es, en España, más restrictiva que en otros países de nuestro entorno, donde existe mayor número de trenes a los que se puede acceder con bicicletas y que presentan además una frecuencia de paso más elevada. Por tanto, el binomio "tren+bici" es, en esos espacios, una forma muy utilizada, fácil y cómoda de llegar a estos itinerarios no motorizados, algo que no sucede aún en España.

No obstante, la actual normativa de RENFE sobre transporte de bicicletas, que data de 2016 (http://www. renfe.com/viajeros/info/bicicletas.html), resulta más favorable para el usuario, al ampliar esta posibilidad a todos sus trenes, aunque con restricciones en los de Larga Distancia, AVE y Avant (https://conalforjas.com/ transportar-bicicleta-tren/), donde éstas tendrán que ir desmontadas o plegadas y enfundadas, sin sobrepasar unas dimensiones de $120 \times 90 \times 40 \mathrm{~cm}$. Este hecho, desde la plataforma Pedalibre (https://pedalibre. org/2016/04/04/la-bicicleta-en-renfe-larga-distancia/), se considera, en general, positivo para el desarrollo de la actividad cicloturística y un avance en la normativa, si bien indican que no ha ido acompañado de me- 
joras en el material para poder transportar las bicicletas dentro de los vagones, condicionando, por tanto, el desplazamiento en grupo, y quedando en manos de la autoridad (interventor) la determinación de las posibles molestias ocasionadas por las bicicletas, pudiéndose en ese caso denegar el viajar en tren con las mismas.

Con respecto a Media Distancia y Cercanías no resulta necesario desmontarlas ni enfundarlas, aunque para trayectos superiores a $100 \mathrm{~km}$ hay que abonar $3 €$ (gratuito para distancia inferior). En los trenes de Cercanías, si van muy completos, el interventor puede denegarnos el acceso con bicicleta, de forma que, en ese supuesto, sólo cabe optar por esperar al siguiente convoy o bien solicitar la devolución del billete. En todo caso, las bicicletas deben de ir en el espacio destinado a las mismas, muy poco habitual, por lo que, de no existir tal área, se situarán en los ámbitos de acceso a los vagones, con la consiguiente incomodidad que ello supone.

Otra de las diferencias significativas que existen entre nuestro país con respecto a otros europeos y del resto del mundo, es el hecho de denominar "vías verdes" (greenways en inglés), sólo a los antiguos trazados ferroviarios que se encuentren en desuso y que ya han sido rehabilitados y acondicionados (de hecho se trata de una marca debidamente registrada por la Fundación de los Ferrocarriles Españoles); mientras que en otros entornos se denominan "greenways", además de a antiguos tramos de ferrocarril en desuso, a aquellos itinerarios no motorizados procedentes de vías pecuarias o caminos rurales,..., siempre que estén debidamente acondicionados (Aycart, C., 2001; Serra, M., 2016). De hecho, en España, y para buscar un punto de encuentro con este planteamiento generalizado en Europa, se ha impulsado el programa de "Caminos Naturales", donde ya no hay condicionante previo en cuanto al origen del itinerario no motorizado, si bien un porcentaje elevados de ellos, como por ejemplo sucede en Andalucía, coincide con las anteriormente referidas "vías verdes" (https://www.mapa.gob.es/es/desarrollo-rural/temas/caminos-naturales/).

Por último hay que poner sobre la mesa de discusión un problema de carácter técnico con el que nos hemos encontrado en este estudio. Se trata de la aparente falta de conectividad entre estaciones ferroviarias en uso e itinerarios que comienzan a menos de $500 \mathrm{~m}$ de las mismas, como son los casos, ya mencionados, que afectan a las estaciones de Marchena (en la provincia de Sevilla) y San Julián (Málaga), donde, como se aprecia en el mapa 4, y ante la falta de una red tupida de conexiones, la isócrona de 15 minutos se establece sobre el viario más próximo a la estación aunque sea por una diferencia ínfima de distancia, lo que puede conllevar a que itinerarios importantes, como sería el caso de una vía verde consolidada (La Campiña), no esté dentro de la misma, y aparentemente no cumpla la doble condición establecida (cercanía y accesibilidad) para formar parte de los itinerarios más destacados.

Entendemos que todo ello constituye, por tanto, una disfunción a tener en cuenta en cualquier análisis de redes, muy dependiente de la calidad de la capa fuente, que, aunque siempre mejorable procurando disponer de otras de mayor detalle, requiere en cualquier caso de una revisión minuciosa que corrija este tipo de circunstancias, tal como aquí se ha hecho para establecer la relación final de itinerarios principales de cara a la promoción del cicloturismo en Andalucía.

\section{CONCLUSIONES}

Las actividades cicloturísticas están teniendo, como se ha visto, un fuerte auge como motor económico, por lo que países como Francia, Alemania, Reino Unido, en Europa, y otros como EEUU o Australia han incrementado su potencial, contando, algunos de ellos, con una larga trayectoria y, por lo tanto, al tratarse de destinos maduros, disponen de infraestructuras modernas y servicios asociados a estos itinerarios y al uso de la bicicleta, con ofertas de información muy detalladas, encontrándose bien señalizados, lo que los hace seguros y muy atractivos.

Estos casos de éxito en Europa, y las rutas cicloturísticas que se están desarrollando en otros continentes, ponen de manifiesto la importancia de determinar los nodos intermodales que combinen el transporte público y colectivo, como es el de carácter ferroviario, y la accesibilidad a los itinerarios no motorizados, sobre todo en una región, como Andalucía, con importantes flujos turísticos, lo que diversificaría su oferta y 


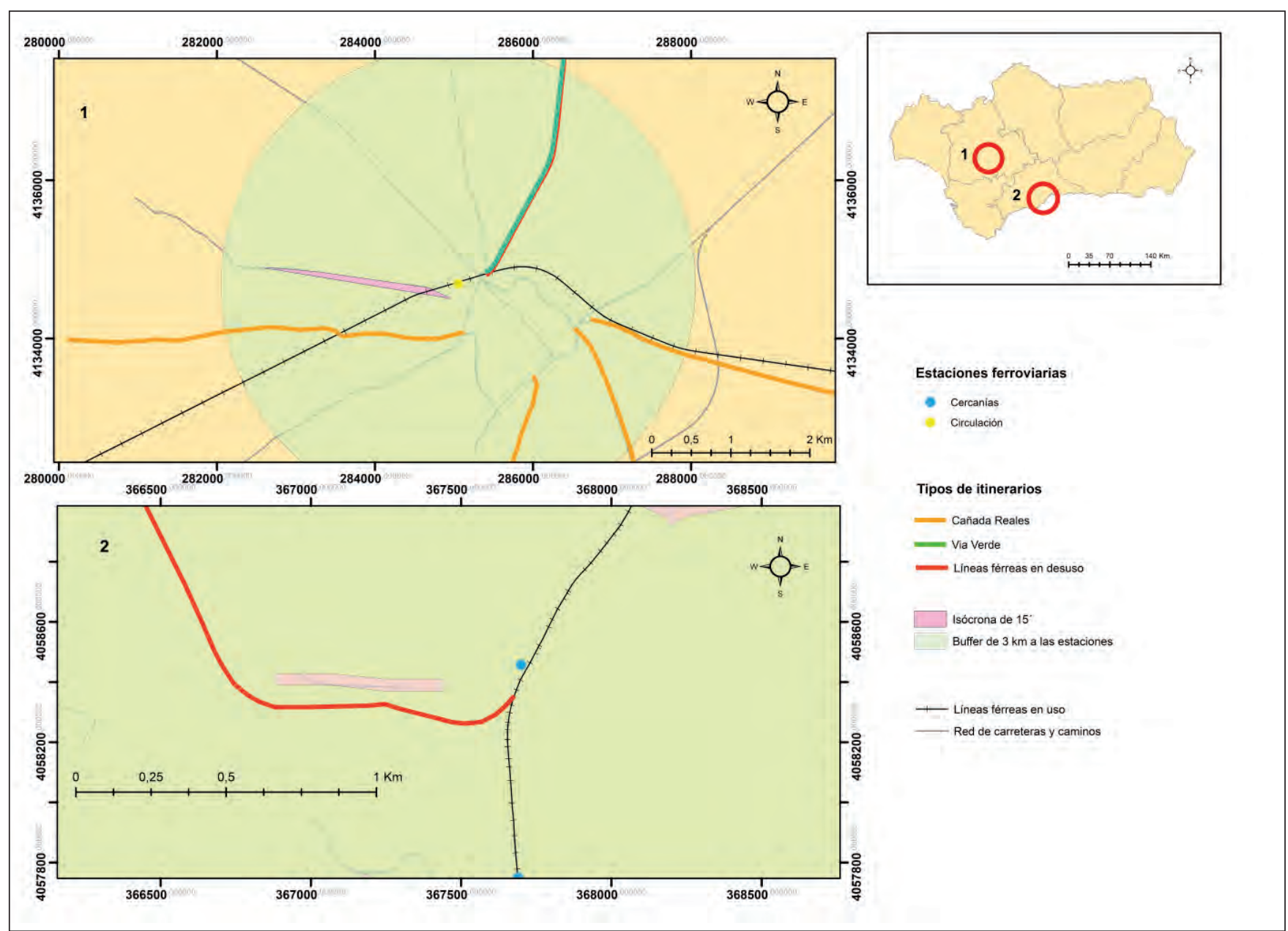

Mapa 4. 1: Vista ampliada del caso de la estación ferroviaria de Marchena (Sevilla). 2: Vista Vista ampliada del caso de la estación ferroviaria de San Julián (Málaga).

Fuente: Elaboración propia a partir de datos de DERA y de la Fundación de Ferrocarriles Españoles.

deslocalizaría la presión turística de ciertas áreas para extenderla a través de su territorio, poniendo en valor el patrimonio natural, cultural, arquitectónico y etnográfico del interior de la Comunidad.

Estos núcleos intermodales deben cumplir con una serie de requisitos para que tengan éxito, y para ello será necesario que sean accesibles a todos, con infraestructuras y servicios adecuados para los usuarios de la bicicleta. En este sentido las asociaciones ciclistas han tenido un papel fundamental en la conservación y en el trazado de nuevas rutas para el desarrollo del senderismo y del cicloturismo y, por lo tanto, para la implantación de un nuevo modelo turístico sostenible y respetuoso con el medioambiente.

En España, desde la Fundación de los Ferrocarriles Españoles (FFE), con su Programa Vías Verdes, existente desde 1993, cuando se inventariaron más de 7.600 km que ya no tenían servicio de trenes, o que incluso nunca llegaron a tenerlo por quedar inconclusas las obras de construcción, se han reconvertido más de $2.700 \mathrm{~km}$ de estas antiguas líneas férreas en itinerarios no motorizados para la actividad cicloturística y senderista, fundamentalmente. Sobre un total de 120 rutas, 27 de ellas se sitúan en la Comunidad andaluza, con más de $580 \mathrm{~km}$ operativos, y una proporción superior a su peso en superficie dentro del conjunto español.

Para Andalucía la cartografía resultante del análisis de las potencialidades intermodales existentes entre líneas férreas e itinerarios no motorizados ha servido para realizar diferentes diagnósticos. En primer lugar, se ha detectado cómo, a sólo $3 \mathrm{~km}$ de estaciones ferroviarias en funcionamiento, de los tipos cercanías, circulación y mixta, comienzan una serie de rutas de distinto tipo (cañadas reales, senderos, vías verdes y líneas de ferrocarriles en desuso sin acondicionar) que alcanzan más de $3.400 \mathrm{~km}$, con un reparto proporcional que oscila entre el $36,74 \%$ que representan los senderos al $28,63 \%$ de las líneas férreas abandonadas. 
De estos trazados, 54 de ellos superan los $15 \mathrm{~km}$ de longitud. Pero para medir su operatividad real se ha añadido al estudio un segundo condicionante, como es el que se acceda a ellos en un tiempo inferior a los 15 minutos, a partir de la red de carreteras (excluidas las de doble trazado) y caminos facilitada por el repertorio DERA del IECA, con una malla de $57.717,82 \mathrm{~km}$. En ese caso los itinerarios que superan los $15 \mathrm{~km}$ de longitud son ya sólo 44.

Con estos planteamientos, y elevando el mínimo de recorrido a los $20 \mathrm{~km}$, pero con la posibilidad de sumar itinerarios de diferente tipología que presenten contigüidad evidente en el Sistema de Información Geográfica elaborado al efecto, se han seleccionado los 16 itinerarios más favorables para promover la intermodalidad "tren+bici" en Andalucía, algunos ya en servicio, como sucede en las denominadas vías verdes (del Aceite, de la Campiña, de la Sierra Norte...).

En cualquier caso, debemos señalar que con los datos derivados de este trabajo queda patente la necesidad de colaboración entre los diferentes agentes locales, administraciones a diferentes escalas, asociaciones de ciudadanos, fundaciones públicas y empresas privadas para el mantenimiento (conservación de los trazados ya existentes) y para la creación de nuevos trayectos.

En definitiva, la aportación de esta investigación radica, pensamos, en la realización un análisis que ha venido a combinar diferentes variables por medio de un SIG, donde se han empleado ítems de distinto tipo junto con un soporte cartográfico que ha servido como modelo de interrelación de éstos para generar una mapificación y una tabulación que ayude a la toma de decisiones por medio de un diagnóstico de situación inicial.

El caso de Andalucía presenta, además, un gran potencial para ser un referente de la actividad cicloturística, pero para ello será necesario, por un lado, que la normativa del transporte de bicicletas sea todavía más flexible; $y$, por otro lado, que las administraciones públicas y las entidades privadas aúnen esfuerzos para poner en marcha proyectos de nuevos itinerarios que faciliten las pernoctaciones con servicios adaptados a las necesidades de los usuarios y la bicicleta.

De este modo, para que estos recorridos y sus actividades cicloturísticas inherentes puedan seguir adelante, resulta imprescindible que exista un mantenimiento efectivo de los ya disponibles y de las nuevas rutas que se diseñen; y que los diferentes actores que intervienen en este sector participen en sus diferentes fases (financiación, diseño y ejecución), así como en el fomento del uso de la bicicleta, con proyectos de movilidad sostenible y turismo en el territorio, existiendo, por consiguiente, una coordinación real y eficiente, algo que, por desgracia, no siempre sucede.

\section{REFERENCIAS}

Aycart-Luengo, C. (2001). Vías Verdes, Reutilización de Ferrocarriles en desuso para la Movilidad Sostenible, Ocio y Turismo. Informes de la construcción, 53 (475), 17-32. doi: https://doi.org/10.3989/ic.2001.v53.i475.653

Aycart-Luengo, C. (2006). El programa español de Vías Verdes. Revista del Colegio de Ingenieros Técnicos de Obras Públicas, $369,22-31$.

Camagni, R. y Capello, R. (2013). Regional Competitiveness and Territorial Capital: A Conceptual Approach and Empirical Evidence from the European Union. Regional Studies, 47 (9), 1383-1402. doi: https://doi.org/10.1080/00343404.201 2.681640

Caminos Naturales. Recuperado de https://www.mapa.gob.es/es/desarrollo-rural/temas/caminos-naturales/ Último acceso: 15/5/2019.

Cano-García, G. (2008). Clasificaciones Urbanas en Andalucía. Las Ciudades Medias, Revista de Estudios Andaluces, 27, 115-153. doi: https://doi.org/10.12795/rea.2008.i27.05

Cebrián-Abellán, F. (2011). Los ferrocarriles olvidados. Reconversión y reinvención como instrumentos de revitalización recreativa y turística: el Baeza-Utiel a su paso por la provincia de Albacete. Cuadernos de Turismo, 27, 205-225.

Conalforjas. Recuperado de https://conalforjas.com/transportar-bicicleta-tren/ Último acceso: 24/6/2019.

Consejería de Fomento y Vivienda (2014). Plan Andaluz de la Bicicleta. PAB 2014-2020. Junta de Andalucía. Recuperado de http://www.aopandalucia.es/planandaluzdelabicicleta/ Último acceso: 10/5/2019. 
Consejería de Turismo y Deporte (2016). Plan General de Turismo Sostenible de Andalucía Horizonte 2020. Junta de Andalucía. Recuperado de http://www.juntadeandalucia.es/turismoydeporte/opencms/areas/turismo/opciones-de-planificacion-turistica/planificacion-turistica-estrategica/plan-general-del-turismo-sostenible-de-andalucia-horizonte-2020/ Último acceso: 10/5/2019.

Eizaguirre-Iribar, A., Igiñiz, L E. y Hernández-Minguillón, R. J. (2016). A multilevel approach of non-motorised accessibility in disused railway systems: The case-study of the Vasco-Navarro railway. Journal of transport geography 57, 35-43. doi: 10.1016/j.jtrangeo.2016.09.009

Escalona-Orcao, A. I. y Díez-Cornago, C. (2005). Retos y problemas de la accesibilidad a los servicios en zonas despobladas: un caso en la provincia de Teruel (España). Scripta Nova: Revista Electrónica de Geografía y Ciencias Sociales, IX, 188.

EuroVelo. Recuperado de http://www.eurovelo.com/en Último acceso: 15/5/2019.

Faulks, P., Ritchie, B. y Fluker, M. (2006). Cycle Tourism in Australia: An investigation into its size and scope. Sustainable Tourism CRC. Recuperado de https://www.back-in-business-physiotherapy.com/images/files/CycleTourismReport.pdf Último acceso: 23/5/2019.

Fernández-Latorre, F. M. (2015). Flujos turísticos, capital territorial y uso de la bicicleta. Andalucía como modelo de destino emergente en cicloturismo. Revista de Estudios Andaluces, 32, 76-107. doi: http://dx.doi.org/10.12795/rea.2015. i32.04

Freire-Valderrama, J. (2018). La bicicleta en Andalucía: Una herramienta para el necesario cambio de modelo económico, social y ambiental. Andalucía Geográfica, 11.

Movilidad Sostenible en Andalucía, 45-55. Recuperado de https://geografosdeandalucia.org/index.php/colegio/andalucia-geografica Último acceso: 10/5/2019.

Gavira-Narváez, Antonio y Ventura-Fernández, J. (2013). Procesos actuales y perspectivas para el transporte ferroviario de viajeros en Andalucía. Investigaciones Geográficas, 59, 25-41. doi: https://doi.org/10.14198/INGEO2013.59.02

Gavira-Narváez, A. y Ventura-Fernández, J. (2017). Evolución y panorama actual de la red ferroviaria en Andalucía. Cuadernos Geográficos, 56 (2), 283-305.

Insall, P. (2004). La red nacional británica de rutas ciclistas: marco para un enfoque integrado de la gestión de la movilidad. Ingeniería y territorio, 69, 38-43.

Instituto de Estadística y Cartografía de Andalucía. Datos Espaciales de Referencia de Andalucía (DERA). Consejería de Economía, Conocimiento, Empresas y Universidad de la Junta de Andalucía. Recuperado de https://www.juntadeandalucia.es/institutodeestadisticaycartografia/DERA/ Último acceso: 10/5/2019.

Luque-Valle, P. (2012). Análisis del modelo de uso-visita de los deportistas-turistas de las vías verdes andaluzas. Editorial Universidad de Granada. Recuperado de http://hdl.handle.net/10481/20995 Último acceso: 22/5/2019.

Martín-Cejas, F. R. y Martínez-Hernández, P. (2017). La movilidad turística en la Isla de Lanzarote: el diseño de una ruta para un autobús turístico. International Journal of Scientific Management and Tourism, 3 (3), 459-477.

Mató, Emili y Troyano, Xandra (2014). Impacto Económico del cicloturismo en Europa. Síntesis de los principales estudios realizados. Agencia de Obra Pública de la Junta de Andalucía de la Consejería de Fomento y Vivienda de la Junta de Andalucía. Recuperado de https://www.viasverdes.com/prensa/documentos/interes/Informe_Cicloturismo_2014. pdf Último acceso: 10/5/2019.

Mercat, Nicolas (2018). El caso de Francia. Ponencias de la Conferencia 25 Años de Vías Verdes, celebrada en Sevilla los días 22 y 23 de octubre de 2018. Recuperado de http://www.viasverdes.com/pdf/Ponencias25VV/S202_Mercat_Inddigo.pdf Último acceso: 10/5/2019.

Pedalibre. Recuperado de https://pedalibre.org/2016/04/04/la-bicicleta-en-renfe-larga-distancia/ Último acceso: 24/6/2019.

Pedrosa, A., Albuquerque, H. y Breda, Z. (2019). Development of Bike Touring Routes in the Aveiro Region Using Geographical Information Systems. 2nd International Conference on Tourism Research, 216-225.

Pucher, J., Buehler, R., Sgm, F. (2008). Making Cycling Irresistible: Lessons from The Netherlands, Denmark and Germany. Transport Reviews, 28 (4), 495-5281464. doi: 10.1080/01441640701806612.

Rails to trails conservancy. Recuperado de https://www.railstotrails.org/ Último acceso: 11/6/2019.

Rebollo-Rico, S. (2003). El turismo deportivo y la formación en ciencias del deporte. Habilidad motriz: Revista de ciencias de la actividad física y del deporte, 21, 11-14. 
Renfe. Recuperado de http://www.renfe.com/viajeros/info/bicicletas.html Último acceso: 24/6/2019.

Romero, E. M. (director, 2008). Los ferrocarriles en la provincia de Huelva. Un recorrido por el pasado. Huelva, Universidad de Huelva.

Rincón-Millán, J. (2013). La antigua línea de ferrocarril Jerez-Almargen: su reconversión en camino natural. Universidad de Sevilla. Recuperado de http://hdl.handle.net/11441/47570

Serra-Serra, M. (2016). El cicloturismo y las vías verdes como ejemplo de turismo sostenible. Revista CIDOB d'Afers Internacionals, 187-209. Recuperado de https://www.jstor.org/stable/pdf/24897287

Stehlíková, J. y Řezník, T. (2018). An accessible Brno city centre for people with impaired mobility, Journal of Maps, 14 (1), 81-87. doi: 10.1080/17445647.2018.1526716

Sustrans. Recuperado de http://www.sustrans.org.uk/ Último acceso: 10/6/2019.

Ventura-Fernández, J. y Gavira-Narváez, A. (2016). Las vías verdes como dinamizadoras del desarrollo territorial sostenible en Andalucía. Recuperado de http://abcblogs.abc.es/riqueza-regiones/2016/02/22/las-vias-verdes-como-dinamizadoras-del-desarrollo-territorial-sostenible-en-andalucia/ Último acceso: 23/5/2019.

Ventura-Fernández, J., González-Relaño, R. y Gavira-Narváez, A. (2017). Accessibility of rail trails in Huelva, Andalusia (Spain), Journal of Maps, 13 (1), 62-66. doi: 10.1080/17445647.2017.1323033

Vías Verdes. Recuperado de https://www.viasverdes.com/ Último acceso: 15/5/2019.

Vías Verdes de Andalucía. Recuperado de www.viasverdesandalucia.es Último acceso: 24/5/2019.

Vías Verdes y Red Natura 2000. Recuperado de www.viasverdesyrednatura2000.com Último acceso: 22/5/2019.

Weston, R. et al. (2012). The European Cycle Route Network EuroVelo. Recuperado de http://www.europarl.europa.eu/RegData/etudes/etudes/join/2012/474569/IPOL-TRAN_ET(2012)474569_EN.pdf Último acceso: 23/5/2019. 


$$
\begin{gathered}
\text { Summary } \\
\text { of } \\
\text { Articles }
\end{gathered}
$$

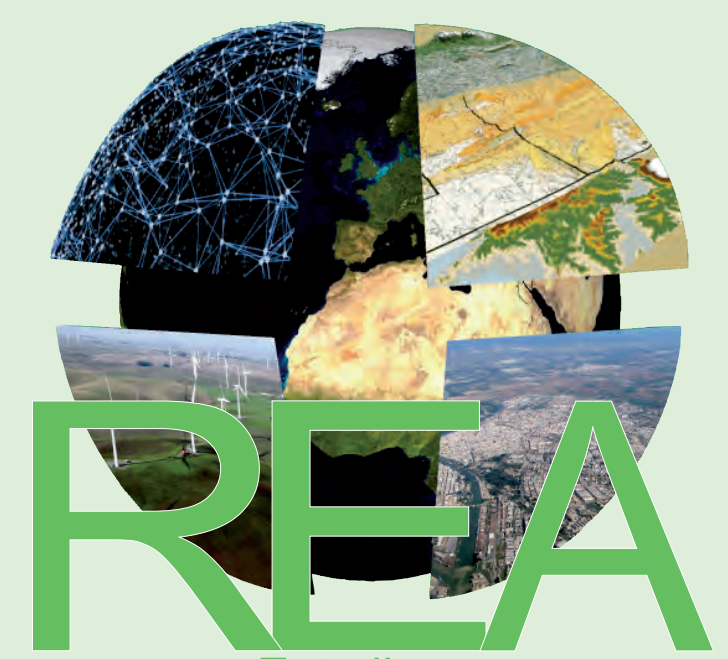

Revista de Estudios Andaluces 


\title{
Economic Trajectories of the Spanish Regions in the Post-Crisis Scenario: Neighborhood, Specialization and Agglomeration Effects
}

\author{
Juan Miguel Albertos-Puebla \\ juan.m.albertos@uv.es. (1) https://orcid.org/0000-0001-7915-2610 \\ Departamento de Geografía e Instituto Interuniversitario de Desarrollo Local. \\ Universitat de València. Av. Blasco Ibañez 2846010 Valencia.
}

\author{
KEYWORDS \\ Spatial shift-share \\ Territorial competitiveness \\ Post-crisis scenario \\ Regional inequalities \\ Spain
}

\section{INTRODUCTION AND OBJECTIVE}

Spanish economic landscape and regional dynamics have been altered during the last decade as a consequence of the succession of a deep crisis (2008-2013) and a recovery still in progress (2013-2017). Although there are considerable differences between what happened during recession years and in the years of recovery, it is possible to detect some underlying trends that imply structural changes affecting the Spanish development model and its territorial configuration.

Nowadays there is a clear consensus considering that the process of regional convergence in Spain stopped, or at least slowed down, in the last decades of the 20th century (Cuadrado, 2010, Tirado et al., 2015). Additionally, in clear contradiction with what would be predicted according to the thesis of the regional convergence, there is already have enough evidence to affirm that since the outbreak of the crisis in 2008 we have entered into a new stage of increasing inequalities: in general terms, the richest regions have better withstood the recession phase and are growing more rapidly in the recovery phase than the poorer regions.

Following the synthetic conception of regional growth proposed by Roberta Capello - models MASST: MAcroeconomic, Sectoral, Social and Territorial model- (Capello \& Fratesi 2012, Capello 2016), the growth differential of a region can be explained, along with the industrial mix, by its territorial capital derived from social, institutional and spatial assets (innovativeness, qualifications, infrastructures, trust relationships and social capital, spatial spills and agglomeration economies). Within this conceptual framework we will try here to quantify the differential dynamism of each region, and to establish its origins, of both sectoral and territorial nature.

\section{METHODOLOGY}

We will apply a shift-share analysis in order to break down the components that explain the differential economic evolution that Spanish regions have shown during the last decade, considering separately the 
years of strong recession and fall in employment and activity (2008-2013) and the post-crisis recovery period (2013-2017). We will use one of the extensions of this technique proposed in recent years, the so-called spatial shift-share (Nazara \& Hewings (2004). The main idea underlying this approach is that, depending on the geographical position of each region, there will be more intense relationships with neighbouring regions, and then we should consider distance (or proximity) between regions in order to establish the different national context affecting each region.

This breakdown of the particular dynamics followed by each region makes it possible to distinguish three different components (or effects), which can be assimilated, and be considered as valid approximations, to the main factors explaining regional growth differential proposed by Capello in her MASST model (Capello \& Fratesi 2012; Capello 2016):

1. A relational component, which can be calculated as the difference between the gross registered national effect and the neighbourhood-weighted national effect. This component could be considered as the relative effect the region receives as a consequence of its position within the network of relationships, interactions and interregional exchanges, reflecting "the capacity of the region to grow by virtue of resources from other regions - growth spillovers "(Capello and Fratesi, 2016, 301).

2. A component derived from the regional sectoral structure-the neighbourhood-weighted structural effect-that, depending on the relative presence of smaller or greater sectors with more or less favourable dynamics, conditions the total growth registered in the region, and would constitute a fundamental part of the "sectoral component of growth" (Capello \& Fratesi, 2016, 300)

3. A component derived from the specific behaviour of the sectors in the region - the neighbourhood weighted territorial effect - that captures the elements that would integrate most of the "assets of territorial capital and integrated by Capello in the MASST model (Capello \& Fratesi 2016, 299-301). This third regional component of growth, which is more markedly territorial in nature, is the one that more accurately indicates the differential dynamism based on the existence of competitive advantages built at the local / regional scale.

In addition, we will build location-specialization matrices for the 17 Spanish regions and 11 sectors in 2008, 2013 and 2017 in order to establish the general processes underway regarding the distribution of economic activity in the territory in order to identify the emergence of regions where location and urbanization economies are presumably present.

\section{MAIN RESULTS}

The results obtained show the role played in the Spanish regional dynamism by the three proposed growth components or effects: neighbourhood, specialization and agglomeration.

During the years of deep crisis, the potentially beneficial effects derived from a more dynamic neighbourhood had the effect of mitigating to some extent the fall in activity in the interior or Northwest regions better connected to Madrid. The panorama changed radically when we entered the recovery phase. At that moment, the Mediterranean axis of development re-entered into growth, and it is in this corridor and in the best regions connected with where the greatest positive spillovers for growth are observed

The different sectoral specialization, has had also a strong impact on the evolution registered by each region. In recession years, it was the specialization in tourism s, and to a lesser extent in agriculture, what made it possible to alleviate in some regions the effects of the crisis, particularly in the Balearic and Canary Islands. On the other hand, the specialization in the construction sector, and to a lesser extent in the manufacturing industry, exacerbated the effects of the crisis in Castilla-la Mancha or the Valencian Community. On the contrary, in the years when growth recovers, the leadership in growth passes to the manufacturing industry, financial services and professional and producer advanced services. Then the industrial regions and Madrid regions improved sharply their structural component of growth.

Territorial concentration of sectors and the sectoral specialization of territories are the result of the response that each region has given to the challenges posed by the crisis. In a context of globalization and 
growing importance of the international market, each region has tended to deepen the previous specializations where experience, a dense business fabric and the presence if services and auxiliary industries help to achieve greater competitiveness. Moreover, changes in the location pattern of economic activities are not the result of a mere passive adaptation to the generalized decline of the construction sector; on the contrary: they are showing active processes of differential growth in based on the internal strengths of each territory.

The presence and strengthening of location-specialization economies, shows a direct correlation with the territorial component of growth. However, it is also true that sectoral agglomeration processes are not always enough powerful to crystallize into a positive or growing territorial component, especially where urbanization economies are weak and/or the general sociodemographic dynamic is markedly regressive.

\section{CONCLUSIONS}

One of the outcomes of the economic crisis in Spain has been a marked increase in interregional inequalities and a growing territorial concentration of economic activity. The new growth pattern, closely linked to international demand (tourism, exports), has contributed to concentrate growth in regions showing competitive advantages based on their particular resource endowment, their productive trajectory and the existence of economies of scale. location and urbanization. This has led to a process of deepening in previous productive specializations (manufacturing industry, tourism, agriculture or advanced services) taking advantage of existing experience, knowledge and capabilities.

The territorial component of growth that we have isolated for each region and period through the shiftshare analysis, can be considered a good approximation to the differential behaviour of the sectors in the territories depending on elements of purely local character: historical trajectory, institutional and cultural elements, quality of entrepreneurship, business structure and a cluster of elements that can be included under the concept of agglomeration economies, both localization and urbanization.

Taking this into account, it can be said that there is a geography of economic recovery very different from the geography of the crisis. In the recession years, only Madrid, the Basque Country and Navarra present a positive territorial component as a result of stronger business structures and more intense innovative behaviour and a healthier fiscal system. At the same time, the territorial component in the Mediterranean regions, from Catalonia to Andalusia, was markedly negative, as a result of a greater impact of the housing bubble and the associated financial and fiscal crisis. The impact of the crisis was undoubtedly asymmetric, as is was the impact of the recovery. Since 2013 the Mediterranean regions along with the Basque Country and Madrid became the leading region. This new turn can be explained by the presence of regional economic structures more focused on foreign markets that build their competitiveness, at least in part, thanks to the use of localization economies

However, the effects of the sectoral agglomeration do not fully explain the differentials observed in terms of the territorial component of growth. It is also necessary to explore other explanatory dimensions that have more to do with urbanization economies, both derived from urban size and the internal variety of economic structures, as well as other specific elements such as innovative behaviour, socio-institutional elements or human capital. In any case, it seems clear that this productive change is associated with a new 'spatial fix' (Harvey, 2001a, 2001b), a new configuration of the map of regional growth that does not suppose a simple return to the prevailing guidelines previous to the crisis. 


\title{
Maritime Transport, Atlantic and Mediterranean Port Networks. The Example of the Canary Islands
}

\author{
Gerardo Delgado-Aguiar \\ gerardo.delgado@ulpgc.es @ https://orcid.org/0000-0002-5947-0483 \\ José Ángel Hernández-Luis \\ jose.hernandez@ulpgc.es @ https://orcid.org/0000-0002-7680-2574 \\ Departamento de Geografía. Universidad de Las Palmas de Gran Canaria. \\ Calle Pérez del Toro, 1. 35004-Las Palmas de Gran Canaria.
}

\section{KEYWORDS}

Ports

Maritime transport

Network systems

Regional spaces

Canary islands

This paper is based on three axes of a research project currently under development:

a. (a) Maritime transport infrastructure contributes to the economic transformation of the territory, especially at regional and subregional levels.

b. (b) The territory is the scene of the processes of location and, consequently, where mobility and transport are developed.

c. (c) European ports (Atlantic and Mediterranean) and African ports are part of an articulated and hierarchical globalisation process through intricate networks, assigning maritime port functions and specialisation.

One of the main objectives focuses on the role played by transport in the territory, particularly the maritime transport. This paper presents some basic theoretical and conceptual reflections and analyses to understand the spatial function of maritime transport, especially in insular environments. A conceptual, geographical and topological view of transport networks is also presented (Taylor \& Potrykowski, 1984; Haggett, 1976, 1988; Hoyle, 1998; Rodrigue, 2006, 2013; Lavissière, 2017) to show the scenario of maritime transport networks in the middle and eastern Atlantic and particularly the case of the Canary Islands.

The theoretical framework based on the role of port systems in territorial development is presented, and the practical case applied to the Canary Islands is analysed in this context. It is a territory in which the remoteness of the continent and territorial fragmentation hints at a high dependence on transport and, in particular, on maritime transport (Fundación Tomillo, 2001; Ramos, 2001; Hernández, 2002).

From a methodological perspective, a basic analysis of land and maritime accessibility between the islands is approached from the basis of the integrating philosophy through transport that arises from the Trans-European Transport Networks, which in the case of the Canary Islands is included in the policy of the Transinsular Transport Axis. In addition, a cursory evaluation of the conditions of port and road infrastructu- 
res is carried out, which makes it possible to detect physical accessibility problems. For this purpose, we take the information provided by the Port Authority of Las Palmas; the Port Authority of Tenerife and "Puertos Canarios", a public entity of the "Consejería de Obras Públicas" of the Government of the Canary Islands. We also collect information from the Autonomous Government's Road Service, especially for the land routes connecting the island capitals with the ports that support the maritime connection with the other islands.

A temporal accessibility analysis is also performed following the steps of previous methodological studies (Yamaguchi, 2007; Neutens, 2012; Chowdhury, 2015).

The Transinsular Axis of Transport has as one of its main objectives that goods in road traffic are transported by the Archipelago on the same day. For this reason, the analysis of maritime timetables is necessary, as it will indicate the territorial integration capacity resulting from the current offer of the shipping companies.

From this point of view, the main source for measuring temporal accessibility is the timetable of the shipping companies, based on two scenarios: a) the real timetable based on the hourly operability provided by these shipping companies; and b) the ideal timetable, which is the result of our elaboration based on the time of land transport between one port and another, always prioritising that the time of permanence of the goods in the port is the minimum and, therefore, providing greater commercial speed from one point to another in the Archipelago.

The analysis of economic accessibility is provided. It is an important variable that measures the mobility capacity of traffic units in the territory. Obviously, the basic source is the tariff of the main maritime operators (Fred. Olsen and Naviera Armas), considering a door-to-door system, as recommended by the Transinsular Transport Axis. There is also an approximation of the costs of depreciation of vehicles, repairs, cost of drivers, which was provided by the "Observatorio de Transportes de Canarias" ("Consejería de Obras Públicas", Government of the Canary Islands).

After assessing the state of infrastructures, economic accessibility and time, the hypothesis is raised as to whether the current state of development of the inter-island maritime network would make possible the territorial integration objectives derived from the Transisland Transport Axis policy.

The Canary Islands is made up of eight inhabited islands and sixteen ports with regular passenger and freight traffic. These ports have a very disparate importance, since the main ones, which coincide - in the case of goods - with the capitals of each island, are in turn of unequal relevance depending on their hinterland. Similarly, it should be pointed out that, in the case of passenger traffic, it is some regional ports that take on this leading role, since here above all the shortest distance between land enclaves of two or more islands, as is the case of Los Cristianos, Agaete, Morro Jable, among others. It is indisputable that the movement of these county ports is also highly conditioned by the hinterland of each island.

The disparity in terms of traffic demand is notorious in line with the aforementioned hinterland and even with the main economic activity developed, as is fundamentally the case of tourism in the islands of Lanzarote and Fuerteventura, with very relevant consequences from the point of view of traffic demand. It should also be said that the particularity of maritime transport, especially its lower transport speed in relation to the air mode, has severe implications from the point of view of enhancing the regional ports, hence, for example, in the case of Lanzarote and Fuerteventura, the capital ports of Arrecife and Puerto del Rosario, barely have significance for traffic between islands in relation to the regional ports of Orzola, Playa Blanca, Corralejo and Morro Jable.

The Transinsular Axis of Transports of the Canary Islands is based on the modal change and, especially, the terrestrial with the short sea shipping. The aim of transport policy is to ensure that a rolling stock, leaving from any island, can reach another in the same day, including also the return to the island of origin (Government of the Canary Islands, 2005; Hernández, 2007). This process is conditioned to the links of the maritime schedules that take place between the previous and the following island, being greater the risk that not even the outward journey can be carried out in the same day as the transit times in other islands increase, for example, between Lanzarote and El Hierro, via Fuerteventura, Gran Canaria and Tenerife.

Although all the islands have some section considered within the transinsular axis, at least three are vital for the objectives pursued with this policy: that a traffic unit can cross the Archipelago in the same day, even that the vehicle that transported this merchandise can return to the point of return in the same day. These 
three routes connect Corralejo with Morro Jable in Fuerteventura; Las Palmas de Gran Canaria and Agaete in Gran Canaria; and Santa Cruz de Tenerife and Los Cristianos in Tenerife.

This paper presents the analysis of hourly accessibility based on travel times (Chowdhury, 2015). By itself, having a high number of moorings, vehicle loading ramps and optimised roads would be meaningless and useless if maritime connectivity, measured in the schedules and travel times of shipping companies, did not allow the smooth movement of transport units.

Another important factor is mobility as a function of the costs to users, which measures the territorial integration of a space (Hernández, 2010), which also suggests the level of development (Tindemans, 2005).

In summary, the total cost can even exceed 800 euros in a single trip of 540 kilometers, including land and sea routes between the port of Santa Cruz de La Palma and Playa Blanca in Lanzarote (through Tenerife, Gran Canaria and Fuerteventura), costs ranging between 1.30 and 1.54 euros per kilometer, compared to 1.05 euros per kilometer in the Iberian Peninsula, ie about 570 euros for the same journey in peninsular territory. Transporting goods in the Canary Islands in a large truck is at least 35\% more expensive than on the mainland.

It has been found that the possibility of having an optimal infrastructure does not guarantee a true integration of island spaces. In particular, a large part of the problems are the tariff policies and the schedules of the shipping companies. Consequently, deregulation of transport has been a good strategic policy, as it has facilitated a greater variety of fares and timetables.

Finally, we conclude that it is more important to have good connections that promote minimum (and sustainable) mobility for those operating in maritime transport, rather than focusing all efforts on monumental port constructions. For this reason, timetables have been considered a priority, while in the current market structure the operating times of truck fleets are measured in costs and territorial integration and, therefore, in possibilities of social and economic development of the territory, which is one of the main objectives. 


\title{
The importance of the territorial articulation of the intermediate scale in the recovery of the work memory. The case of Barbate
}

\author{
Virginia Arnet-Callealta \\ virginia.arnet@mayor.cl @ https://orcid.org/0000-0001-8068-8383 \\ Universidad Mayor (Chile). Av. Portugal N³51, Santiago, Chile, Código Postal 8330231
}

\section{KEYWORDS \\ Identity \\ Industry \\ Memory \\ Landscape \\ Urban recovery}

Western Andalusia presents specific characteristics that they differentiate from the eastern area of the territory. This area has traditionally been dominated by the wild landscapes of the Baetica, which promote a fertile agri-food industry that has a greater commercial wealth. In addition, fishing and sea have built the sustenance of the coastal industry of Andalusia, in the same way it has done with the configuration of its own identity. Across the sea, the first civilizations arrived at Andalusian coast and laid the foundations for a productive system linked to fishing, mainly of tuna, and the manufacture of the products that are derived, as well as the techniques of capture and conservation. The productive activity of the region has shaped the territorial reality of the Iberian Peninsula with a new system of intermediate city networks, between major urban centers and rural settlements, that they are indispensable for the articulation of the territory in the 21st century (Sánchez Escolano, 2010b, p.287).

Due to the significance that they have acquired as an object of research in recent decades, Andalusian intermediate cities have been positioned as fundamental elements within the geographical framework of reference and they have been established as important elements in the definition of the new territorial landscape through the constitution of a system of networks that balance and unify the territory $y$, furthermore, boost the economy through systems of people, goods, capital, knowledge or information flows (Caravaca Barroso, 1999).

While it is true that the Andalusian coast concentrates an extensive number of industrial elements, and that the vast majority of them are defined by an industry dependent on agriculture, fishing and livestock (Sobrino Simal, 1997, 1998), its strategic position, with easy access and communication, together with the industrializing tradition since Phoenician times, besides the immediate link of these activities with the presence of two important networks of medium cities on the coast of this province, make the province of Cádiz a relevant element for this investigation. Furthermore, the network of intermediate cities on the eastern coast of Cadiz has a long fishing tradition, as we can see in the cities of Conil and Barbate, compared to the wine 
industry in the west of Cadiz. Comercio Although in the Cadiz coast there are two industrial sectors strongly differentiated from the rest, the fishing and salting activity and the wine industry, this study will focus on its status as a marine metropolis originated with the Indian trade, the relevance of the sea for the territory and the strong dependence on it in all areas.

In this way, a methodology is set up in three stages that are constantly in a process of permanent reformulation to determine an epistemological positioning before the territorial and industrial reality of Barbateña that, according to the territorial model defined in the Territorial Planning Plan of Andalusia (Junta de Andalucía, 2006), frames Barbate within the system of medium-sized cities as an average second-tier city, belonging to the networks of medium-sized coastal cities and, in turn, included in the territorial unit called 'Units organized by networks of medium coastal cities', within the territorial domain defined by said Plan as Litoral. That is why the understanding of this municipality should not be done in isolation but as an integral part of one of the networks of medium-sized cities that articulate the coast of Cadiz. In addition, the deepening in the perception of local agents regarding the importance of urban industrial heritage allows the study municipality to be included as an integral part of the La Janda Territory Ordinance Plan (Junta de Andalucía, 2011), highlighting its natural and landscape importance, in addition to its value in the influence that fishing activities have had on the definition of the image of this part of the coast of Cadiz; Therefore, the various factors that have characterized the industrialization of the municipality of Barbate can be understood as parts of a common whole, where, despite being of a different nature, each and every one of the elements are arranged in the urban fabric to configure a joint plot. Finally, the stage of propositional contextualization allows distinguishing a clearly differentiated area from the rest of the municipality that recognizes the marks of the past, presenting La Chanca as the ideal place for the recovery of work memory where heterogeneity reigns with diverse functions that historically were united under a common objective, the "almadrabera" production, and that, for that reason, it is constituted as a key space for the recovery of the industrial heritage of the middle cities of the Andalusian coast. In this way, the area of land trapped between the Atlantic Ocean and the Barbate River, facing the marshes, lets read the industrial past of the city through the architectural elements of production that have reached the 21 st century.

Therefore, the need to outline strategic lines that deal with a specific heritage reality, since an integrating perspective that contemplates the architectural elements of the industrial past in order to add them to the urban fabric to which they belong and, thus, reconfigure the collective identity of the society that inhabits it from the logical understanding of the relationship landscape, industry and society.

- LT 1. Re-establish the lost relationship between the city and the territory

In the first place, the characteristics and demands of a natural environment (La Breña Natural Park and Barbate's marshes) will be addressed as a fundamental element in the organization and articulation of the daily life of the citizens of this sector of Barbate. In this way, the Lefebvrian vision of appropriation of the territory through the local assimilation of human beings in specific places is incorporated (Lefebvre, 1969, Muñoz, 2008, Zusman, 2008, Feria Toribio, 2010).

- - LT 2. Recover the industrial memory

On the other hand, the approach from the memory to the old factory structures, emphasizing the spatial, formal, functional and material understanding of the industrial legacy of Barbate, using it as a link between the past and the future of the coastal intermediate cities in Andalusia.

- LT 3. Consider the functional reconversion through contemporary uses that gear to the current environment.

Finally, fundamental guidelines are established for considering the local user and their real needs and taking distances from traditional and romantic patrimonial intervention strategies avoiding "the proliferation of the so-called industrial wastelands" (PARDO ABAD, 2004, p.97).

The current patrimonial contingency reaffirms the need to build intervention instruments that contemplate contemporary conditions in terms of landscape, industry and territory. The immeasurable capacity of resilience presented by the intermedium cities defines the territorial suitability within the complete framework of the Andalusian coastline. This fact helps to support structural changes and conserve their funda- 
mental characteristics after these alterations. On the other hand, the recommendations for the reuse of all the industrial parts of these enclaves contribute to the socio-economic development, in addition to promoting the sustainability of the municipality by reusing old buildings with new uses and returning the huge landscaped potential that La Breña Natural Park and Barbate's marshes had in previous decades.

Touristic use as the main mechanism of attraction offers the possibility of preserving the industrial memory of Barbate by touring the old manufacturing fabric under a new perspective, where touristic, cultural, commercial, leisure, residential, social, sports and, even, new headquarters spaces converge. Thus, the search for sun and beach is combined with the cultural values and the hallmarks of this middle city, whose heritage and the preservation of it are fundamental aspects to keep active the memory of industrialization. In addition, the relations between cities and landscapes promote the understanding of our gaze, of our experience between the natural and the urban (Solà-Morales, 2001).

However, the suggested proposal would not have the desired results if it is not possible to involve citizenship, an essential element in order to design this environment. Therefore, without a true local experience, it would be difficult to suggest a proposal that, finally, reactivates the urban study fabric, so endogenous development is essential to carry out reuse and recycling dynamics.

The use of the legacy of the tuna fishing as a resource for leisure and tourism through the application of new combined uses, recover the architecture, the landscape, the urban fabric and social relations, as well as reaffirm feelings of belonging to the local community, taking advantage of the conjuncture offered by an environment such as Barbate. 


\title{
Delimitation of the Rural Population Sets of the Region of Altiplano in the Region of Murcia
}

\author{
Miguel Ángel Sánchez-Sánchez \\ miguelangel.sanchez2@um.es @ https://orcid.org/0000-0003-0774-2560 \\ Universidad de Murcia. Departamento de Geografía. Campus de La Merced. Calle Santo Cristo, 1, 30001
}

\author{
KEYWORDS \\ Rural environment \\ Human settlements \\ Population center \\ Yecla \\ Jumilla \\ Altiplano \\ Region of Murcia
}

The topic to be treated in this investigation revolves around the population settlements, excluding the archaeological sites, of the Altiplano region in the Region of Murcia, which may be affected by the actions included in the Territorial Ordinance Guidelines of the region. Such actions are directed towards rural settlements of a rural nature. Therefore, it is interesting to know what the Guidelines could affect. Hence, we have as objective to determine that human settlements in the Altiplano region of the Region of Murcia can be classified as rural population groups, and therefore receive future actions included in the Guidelines.

On the other hand, to try to fulfill the marked objective, an algorithm was devised, represented by three flow diagrams, by means of which it is determined if the settlement, in question, is: population nucleus, if it is in a rural environment and finally if it is a rural population nucleus.

The general procedure to follow, the method, was initially to locate the human settlements, through the use of diverse cartography and field trips. To these the flow chart was applied, by means of which it is possible to determine if these are, or not, population centers. The first step, of this diagram, was to determine the existence or not of ten or more buildings, if the answer was affirmative it was passed to the following indicators: existence of streets and squares. For the first case, it was taken as a reference the definition of the same as: public road that runs between buildings or rows of houses that usually has sidewalks and roads, serving for the movement of people through the population center, being a closed and delimited system. In the case of the square, it was considered that part of the territory that "results from the grouping of houses around a free zone, establishing itself as a closed space". But, that, unlike the street is characterized, in addition, by a space, place or place, by its breadth and be spacious. This space is located in the interior of the population center, and, sometimes, several streets tend to flow.

So, if all the steps were affirmative, we were facing a human settlement that constituted a population nucleus. If in the indicator of buildings, the answer was negative, the existence of fifty or more inhabitants 
was confirmed; in the affirmative case, progress was made towards the following indicators (streets and squares). If not, the possibility of constituting a population nucleus was discarded. The same fate befell those settlements that did not have streets or squares.

In parallel, to the flow diagram for the determination of the different settlements as possible "population centers", an attempt was made to determine the degree of rurality of the environment where the human settlements studied are located. For this, among the different conceptions of rural environment (OECD, EU-European Commission, and Spanish Rural Development Law), the most restrictive indicators were used: Having a number of inhabitants equal to or less than 30,000 and an equal population density or less than 100 inhabitants $/ \mathrm{km}^{2}$. Also, the concept of a small rural municipality was used, applying to municipalities and inframunicipal units. Two conditions had to be met: being in a rural environment and having a population equal to or less than 5,000 inhabitants.

The last phase of the process, based on flow diagrams, was the one that allowed us to find out if the human settlements studied were a rural population or not. The third diagram basically consists of two items: being a population center and being located in rural areas.

As far as the results are concerned, it should be noted that among the almost one hundred human settlements that make up the universe of study, only forty-nine fulfill the first condition: having a number equal to or greater than ten buildings, including those located within a radius of 200 meters. Of these, 28 are located in the municipality of Jumilla and 21 in the municipality of Yecla. In turn, of those only eleven were considered as population centers. Then, the pertinent actions were carried out to know if the settlements were in a rural environment or not. To do this, the flow diagram designed to determine if the study area was inserted in a rural environment was used. It began at a county level, to go down to the greatest possible detail, passing through the municipal scale previously. The county territory, with a total of 59,764 inhabitants, would not house a rural environment. In the scale of the municipal scope, the obtained data show that the territory of the municipality of Jumilla would have the aspect of a rural environment. On the contrary, it would not be so for the municipal territories of Yecla. When using the indicator referring to the population density variable, both the county and both municipalities would be classified as rural areas: Comarca (37.95), Jumilla (26.49) and Yecla (56.29). Recall that these municipalities have a considerable municipal area: Jumilla $\left(969.00 \mathrm{~km}^{2}\right)$ and Yecla $\left(605.64 \mathrm{~km}^{2}\right)$. Also, by using the data associated with the administrative figure of "minor entity" -of infra-municipal character-, all human settlements, with the exception of Yecla and Jumilla, would be located in a rural environment. It should also be said that assimilating the smaller entity to the concept of a small rural municipality, all the smaller entities -except those corresponding to Yecla and Jumilla- would have a profile of the type of municipality cited. It should be added that the municipal capitals are home to almost all the inhabitants of the municipality, Jumilla 95.5\% and Yecla 93.17\%.

On the other hand, among the conclusions it should be noted that the method used improves objectivity and speeds up the definition of rural population groups in the study area. Although, it is proposed to move towards a methodology that includes criteria, indices, indicators, etc., with which to make a delimitation of the most accurate rural population sets. This last aspect could be improved by taking into account historical and cultural values. Likewise, the methodology conceived could be extrapolated to other territories, more specifically to the South-East and / La Mancha, for its similarity with the study area.

As far as the study area is concerned, it is worth noting that, in spite of the almost 100 settlements detected and visited, and having passed the first criterion: up to 49; only 9 can be considered as rural villages or nuclei, after the application of the algorithms captured by the different flow diagrams. In this way, it is worth asking: if other criteria had been applied, together with those used, would other results have been obtained? We can only answer: that we do not know. Being able to consider from here other work topics, raised as a hypothesis. Where socio-cultural and historical aspects could greatly modify the results. But, as already said, this could be another hypothesis to contrast, to check. In addition, it is clear from these data the scarce dispersion of the municipal population, which tends to be concentrated in the county capitals, this situation being more significant in the case of the Yeclano municipality.

Back to the human settlements of the region, the rural population groups that were classified as such, are located in the municipality of Jumilla, except Raspay in Yecla. All have in common that they are distributed 
towards the south of the axis that would form the cities of Jumilla and Yecla. Several patterns are observed: the rural population groups located next to the most important communication axes -the national highway and the highway-, surroundings close to Jumilla and next to the limits with the province of Alicante -in the neighboring Valencian Community-. All these patterns of territorial distribution have in common to be found in the most socio-economically dynamic areas of the region. Where in addition, in the case of Jumilla -in regards to its immediate surroundings-, it can be influenced by the provision of services by the city of Jumilla, together with the existence of an industrial estate between it and the districts of: The Alquería and Fuente del Pino. 


\title{
Territorial Vulnerability and Accessibility to Proximity Services for Older People in the City of Valencia
}

\author{
María Dolores Pitarch-Garrido \\ maria.pitarch@uv.es @ https://orcid.org/0000-0001-9109-4687 \\ Félix Fajardo-Magraner \\ felix.fajardo@uv.es@ https://orcid.org/0000-0003-1516-6655
}

Departamento de Geografía. Instituto Interuniversitario de Desarrollo Local. Universitat de València Av. Blasco Ibañez, 28. 46010 Valencia

\section{KEYWORDS}

Public services

Sustainable mobility

Accessibility

Senior poverty

Elderly population

Valencia

The increase in the average age of the population in Western societies is a reality that defines new parameters of coexistence as well as new social demands. In the case of the elderly, the services guarantee not only the care, in particular to the dependents, but also the company (against loneliness). The objective of this research is to identify the vulnerable areas in the city of Valencia in terms of the socioeconomic capacity of its residents and the accessibility to the services supply to the elderly. Our hypothesis is that, despite investment efforts and improvement of the service network, there are still differences in access to them depending on the place of residence, with the central areas of the city being the best served, both from the point of view of the public and private supply. For this, a methodology already contrasted is applied (Pitarch-Garrido, Salom \& Fajardo, 2018). The purpose of the analysis is to know which areas of the city are most vulnerable to the elderly who live there and to facilitate the identification of the main problems that public planning must influence (supply, type, transport, etc.).

The aging process affects all current societies, with cities being particularly vulnerable for this group. In them, the spatial structure of the service supply determines the patterns of mobility of the population and its sustainability. Proximity services, the most frequently demanded by the population, imply a certain use of time with implications for the quality of life.

In 2018 , the aging rate in the city of Valencia is $20.58 \%$ and the over-aging rate is $11.5 \%$ (as defined as those older than 85 as a percentage of those over 65 ). The population over 64 years old is 164,341 people, of whom 25,177 are over 85 years old. The total population of the city is, in $2018,798,538$ inhabitants, one fifth is over 65 years. 
In our research we have considered the services aimed at the elderly population with fixed location that are offered in the city of Valencia, both from the public and private, but particularly the first. Since the end of the last century and, above all, as a result of the economic-financial crisis of 2008, the policy of the regional and local government has tended toward restricting public spending, particularly in this type of services (Activity centres, Day centres and Residences), privatizing its offer and reducing the number of public places. This policy has led to cuts in investments aimed at increasing resources and public facilities for the elderly.

We propose a new term to define poverty or exclusion that appears, especially after the crisis, in this urban and social environment: senior poverty. These are elderly people, in particular very old (over 85 years old, over-aging), in situations of dependency, low mobility, low income (minimum or non-contributory pensions), living alone and without a family environment, residents in neighbourhoods with a low endowment of public social services or forced to move out of their usual place of residence to be able to access care services. An important part of this situation of vulnerability is the one that we propose to analyse in this article for the case of the city of Valencia: the one related to the place, that is, the part that would affect the spatial equity of senior poverty. Next, we will briefly discuss the methodology used to analyse the situation and conclusions.

The methodology developed can be replicable in any other urban context and has already been applied to other types of public services. The elements that we consider are: mobility on foot (the most appropriate and sustainable for this population group), accessibility-proximity, the qualification of such services as proximity, and, therefore, the right of users to be locate your offer in an area within your living space. The services considered are: the municipal activity centres (known as elderly associations), the day centres and the residences for the elderly. For the analysis, a distinction has been made between public, private and total services.

In favour of the sustainability of mobility, the accessibility index has been calculated for the different centres offering services for public and private elderly people on foot and public transport. The number of people that represent potential demand is also analysed, considering the total of the largest population, although not all are currently users of the service, and the area of influence of each of the supply centres is calculated, comparing it with the boundaries of the neighbourhoods. For each one of the resulting areas, both the calculated ones and the neighbourhoods, the socioeconomic variables of the resident population are considered.

From the spatial point of view, the sociodemographic information has been added at the portal level, from a mesh of square polygons of 100 meters drawn on the city of Valencia. In this way it is possible to obtain the information at an intermediate scale, between the neighbourhood (excessively large) and the portal (difficult to represent by the multitude of points). Each cell has been assigned the average value of the points of the residences and the neighbourhood. For the characterization of the different areas of the city, together with the information at the street number level (Padrón), different indicators of the economic situation of the neighbourhood in which they are located have been considered. With these data a Factorial Analysis of Main Components (ACP) has been carried out, which has allowed us to reduce the amount of data, being possible to establish the elements common to the associated variables. The first component has been selected, which accounts for $32.6 \%$ of the variance. The value of this component in a negative sense gives us a very accurate idea of the location of the population with the lowest income level, the lowest functional and environmental quality, low land (and housing) prices, and lack or absence of superior functions. Thus, it has been possible to map the areas (spaces below the neighbourhood level) of the city of Valencia where a low socioeconomic level with a distance relative to the public services considered is given at the same time.

The general figures of the city in terms of the number of people over 65 affected by the distance to a service centre of those analysed give us information about the social impact of their location. We have considered two thresholds from which real and potential users are far from the area of proximity to the service we have established: twenty minutes on foot and forty minutes by public transport.

Apart from general results, it is interesting to analyse the results in the case of the areas of the city that have been classified as more vulnerable. In these areas, of a lower scale than the neighbourhood, the low socio-economic level coincides with poor accessibility to services for the elderly population. We have highlighted here only the accessibility on foot, setting the same threshold as in the previous analysis: twenty 
minutes. The resulting maps show the location of the vulnerable or priority intervention areas, that is, the location of most of what was previously called senior poverty. In them, the largest population affected by a distance to any of the services considered amounts to 191,775 people, of which 36,537 are over 65 years.

Given the results obtained with the application of the proposed methodology, we can affirm that it is a tool with great potential and simple to apply, provided that we have the detailed sociodemographic information at the portal level (detail of scale), both of the service offer as well as demand. The Municipal Register provides such information, although its preparation can be costly and generate resistance in the competent administration given the need to comply with the data protection law. In the case of the city of Valencia, the general results are very positive, although it is possible to detect spaces where the needs, real or potential, are not yet fully covered. It is about detecting these neighbourhoods or areas to qualify them as priorities in terms of provision of services or specific public transport.

In conclusion, and although it is clear that the entire older population, whatever their level of income, should enjoy good accessibility (proximity) to public services of proximity, the reality is that, in a situation of economic recession and containment of spending, it is necessary to prioritize investments. The analysis carried out helps public decision-making. In the analysed case, Valencia, a methodology has been developed that allows to advance in applied geography studies and that can be transferred to other urban environments. 


\title{
The Air Freight Transport at Spanish Airports: Towards Selective Concentration and Internationalization
}

\author{
Carlos López-Escolano \\ cle@unizar.es @ https://orcid.org/0000-0002-1653-7780 \\ Daniel Cruz-Alonso \\ 684072@unizar.es @ https://orcid.org/0000-0001-8264-1263 \\ Ángel Pueyo-Campos \\ apueyo@unizar.es @ https://orcid.org/0000-0003-4103-2116 \\ Universidad de Zaragoza. Edficio Residencia de Profesores, $5^{\circ}$ Izquierda. Ciudad Universitaria \\ Campus San Francisco. C/Pedro Cerbuna 12. 50009 Zaragoza
}

\section{KEYWORDS \\ Freight \\ Air cargo \\ Airports \\ Globalization \\ Spain}

\section{INTRODUCTION}

Globalization has fundamentally modified the organization of the global economy, intensifying the integration and interdependence of cross-border economic activity (Coe, N. M. \& Yeung, H. W.-c., 2015). Therefore, transport is fundamental for the development of globalization at all scales and in all areas. Producers and consumers around the world are now connected through fast and efficient transport, logistics and telecommunications systems that are reconfiguring traditional supply and distribution networks (Dilian, C. D. \& White, C. L., 2010). These processes have important effects on the international scene but also in local spaces. Central and intermediate locations are identified as spatial qualities that improve the traffic levels of the transportation centers and, therefore, indicate which places are strategically located within the global or regional transportation systems (Fleming, D. K. \& Hayuth, Y., 1994).

In this context, air freight transport is an insignificant part of the total of goods movements despite its strategic role in international trade (Yamaguchi, K., 2008), because it is determinant in sectors with high added value and in those that require an immediate distribution (Morrell, P. S., 2011). Air transport can be understood as a practice that allows us to assess the interconnectivity processes that take place in the global order (Gago García, C. \& Córdoba Ordóñez, J. A., 2013). The research carried out focuses mainly on the analysis of the structure and flows of air freight transport networks (Matsumoto, H., 2004; Derudder, B. et al., 2008; Mayer, R., 2016; Sales, M., 2017); as well as in the case study for airport terminals, products and companies (Hesse, M., 2014; Lotti, R., and Caetano, M., 2018; Balliauw, M., et al., 2018; i.e.). Spanish literature 
on this subject is scarce, contrasting with the variety of the research that focus on passengers transportation and airport terminals (Martí-Henneberg, J. et al., 2007; Tapiador, F. J. et al., 2008; Escalona, A. I., and Ramos, D., 2010; i.e.).

Because of their interest in economic development, it is important that planners and stakeholders understand changes in global air networks in order to assess the positioning and hierarchy of cities and territories. In this context, this work advances in the interpretation of the flows of air cargo with the objective of appraise the insertion of Spanish airports in the global distribution networks.

\section{GLOBAL AIR CARGO HIERARCHY}

Air freight transport represents a minor mode over the total volume of world cargo, although its economic value makes it strategic. The aerial distribution of goods is concentrated in a selection of main flows where a reduced number of airports act as central nodes of the system (Guimerà, R. \& Amaral, L. A. N., 2004). 86.3\% of global merchandise transported by air in 2016 passed through the twenty main airports, the $94.1 \%$ in the case of twenty biggest European Union airports, showing the high concentration of the sector. These airports act as hubs of goods as happens with passenger traffic (O'Kelly, 1998). Its location, whether central or intermediate in the global system (Fleming, D. K. \& Hayuth, Y., 1994), matches with strategic spaces located within the global supply chain. Most of these airports are global hubs for passenger traffic; although the needs required for air cargo transport means that some airports that do not have special interest for passenger traffic and are not located in central geographic areas are being configured as optimal nodes for the transport of goods (Behrens, K., 2007) in a role of intermediary terminals, especially when it locates the headquarters of cargo airline companies.

\section{DATA AND METHODS}

In order to analyze the situation and evolution of air cargo in the Spanish airport system, information has been obtained from the statistical service of AENA, a Spanish public company that manages 48 airports. The total volume of cargo managed (2000-2017) and the number of international connections (at the country level) (2004-2017) have been considered as variables to analyze the following issues:

1. The evolution of the total air cargo volume for the period 2000-2017.

2. The variation in the number of international connections according to the number of countries with origin/destination of air cargo in each airport for the period 2004-2017.

3. The evolution of cargo according to origin/destination by volume: national, European Union, rest of Europe, and extra-Europe.

\section{FINDINGS}

\subsection{Evolution of air cargo volume}

Between 2000 and 2017 the Spanish airport network increased the total volume of freight by $48.6 \%$, from $617,808 \mathrm{t}$ in the year 2000 to $918,305 \mathrm{t}$ in 2017. It should be highlighted that the number of airports operating goods has been reduced from 39 in the year 2000 to 34 in 2017, although in the same period the number of airports operated by AENA increased from 42 to 48 . In recent years, the twenty main Spanish cargo airports (which account for $99.5 \%$ of the total volume in 2004 and $99.9 \%$ in 2017) are maintained without the emergence of others. However, internal variations are appreciated, especially in the upper-middle part of the classification: Madrid $\left(1^{\text {st }}\right)$ and Barcelona $\left(2^{\text {nd }}\right)$ have not changed their positions in the hierarchy, while Vitoria has lost one ( $3^{\text {rd }}$ in 2004 and $4^{\text {th }}$ in 2017) and Zaragoza climbs to the $3^{\text {rd }}$ position, replacing Gran Canaria and surpassing other island airports. 
The four main air cargo airports in 2017 increase from $71.1 \%$ to $90.3 \%$ in 2017 of total volume between 2000 and 2017, showing the concentration of the air cargo sector. In this group excels Madrid-Barajas, gathering 51.3\% of the total cargo volume in 2017, a figure that has remained constant since 2000 (50.3\%). Next, Barcelona-El Prat has increased its weight in the system, going from $14.4 \%$ to $17 \%$ of the total volume. Both airports benefit from being the main national hubs for passenger traffic, which means being able to take advantage of international and long-haul flights. Moreover, two secondary airports with little relevance in passenger traffic present an important cargo role, Zaragoza with $15.5 \%$ of the total volume and Vitoria with $6.6 \%$. These airports are specialized in the operation of cargo flights due to their strategic location, excellent accessibility and little congestion.

\subsection{Variation in the number of international connections}

The organization of air cargo presents a diversity of origins and destinations that has evolved in a different way and intensity. Between 2004 and 2017, there were no significant changes since the number of countries with goods exchanges has increased from 93 to 103, and the number of airports has decreased from 382 to 374. There is thus a positive trend towards the internationalization of destinations with a slight increase that, however, is variable between each year, but without implying the existence of a wider network of connected airports. There are nuances between the four main airports. By countries, all except Vitoria have increased the number of origins/destinations, highlighting especially the increase of Zaragoza. Madrid boasts the highest level of internationalization, followed by Barcelona, Zaragoza and Vitoria.

\subsection{Evolution of cargo according to origin/destination}

Finally, the results are presented according to the origin/destination of the cargo according to its geographical scope:

1. The freight between Spanish airports decreases significantly, with Madrid, Barcelona and Vitoria being representative.

2. The exchange with the countries of the European Union remains stable in Madrid and Vitoria, while losing weight in Barcelona and Zaragoza.

3. Madrid and Barcelona increase slightly the traffic with other European airports, while in Vitoria is insignificant and Zaragoza loses this connection.

4. Exchanges with airports from other continents grow in Madrid, increase significantly in Zaragoza and Barcelona, and disappear in Vitoria.

\section{DISCUSSION AND CONCLUSION}

The results present how the volume of air cargo in Spanish airports has increased significantly and how the activity has been concentrated in a smaller number of airports, following a process of concentration in the management of air cargo parallel to the global scheme, as suggested by other investigations (Sales, M., 2017; Wong, W. H. et al., 2019). In this context, certain cities or regions hierarchize global flows (Smith, D. A., and Timberlake, M. F., 2001), specializing in a complex logistics economy that responds to the new models of the global economy. It should also be noted that despite the increase in the total cargo handled, the freight transported between Spanish airports maintain a negative trend while they significantly increase the volumes to and from abroad, especially with countries outside the European Union. For this, Madrid and Barcelona are the main nodes between the global and international systems. However, from the analysis carried out, it is worth reflecting on the role that intermediate airports are acquiring (Zaragoza and Vitoria), to which additional traffic can be given if they are favored by carriers as connection centers or relay points in the system (Fleming, D. K. \& Hayuth, Y., 1994). 
The increase in the volume of cargo in Spain contrasts with a mere increase in the number of connected countries and a slight drop in airports, which would show the configuration of an international network of specialized air cargo hubs following the pattern of passengers (Bryan, D. L. \& O'Kelly, M. E., 1999). The recent improvement and expansion of airport infrastructures in Spain have made possible the conversion of the Iberian Peninsula into a strategic hub for Europe and Latin America that takes advantage of the growing links with Africa and Asia; and where the increase of e-commerce will lead to new demands in logistics related to air transport. 


\title{
From Linear to Zonal Management Contracts: A Proposal for the Public Inter-Urban Transportation of Travelers by Road in Aragón
}

\author{
Ricardo Badía-Lázaro \\ rbadia@unizar.es@ https://orcid.org/0000-0003-0572-3681 \\ Eugenio Climent-López \\ ecliment@unizar.es @ https://orcid.org/0000-0001-6788-4873 \\ Grupo de Estudios de Ordenación del Territorio (GEOT). Universidad de Zaragoza \\ Departamento de Geografía y Ordenación del Territorio \\ Universidad de Zaragoza. C/ San Juan Bosco, $n^{\circ}$ 7. 50009 - Zaragoza
}

\author{
KEYWORDS \\ Public transportation \\ Bus \\ Inter-urban \\ Rural accessibility \\ Management contract
}

\section{INTRODUCTION}

Public transport guarantees a fundamental social right: freedom of movement of persons at different socio-temporal scales. Thus, we could consider it as a public service on which public entities have to be responsible for. With regard to intercity bus services, typically are provided by private companies holding administrative concessions or management contracts.

Intercity bus services need to be planned to address the needs of the population and ensuring social profitability. In the interest of social cohesion, governments must put particular focus on economically, socially or physically disadvantaged groups, such as child, elderly, disabled and other population without car availability.

The regional scope of this research is the Aragón Autonomous Community located in northeast Spain. In this region, all the management contracts expired in December 2017. This situation has allowed the design of a completely new interurban transport system, with a better overview and more adapted to current needs. The sector enterprises, anticipating that date, sponsored a study to make a reorganization proposal, starting from the diagnosis of the current situation. The objective of this article is to present the methodology used and the most relevant results of that study. 


\section{METHODS}

The methodological process is divided into two parts: 1) The diagnosis of the current intercity bus transport system 2) The evaluation of proposals to implement the new system.

As for the diagnosis, we have created a spatial database containing data on the supply of public transport as well as on its demand. For the analysis of these data: Firstly, we have classified all the routes according to the rank of their destination town in the urban hierarchy. Secondly, we have calculated an indicator that states the quality of service, taking into consideration the number of trips along with travel times.

In a second stage, we have proposed a shift from linear to zonal management contracts. This decision has been supported by an iterative process. Primary, we have considered the existence of trunk lines serving certain nodes that centralize feeder lines. Then we have delimited functional areas enclosing a single trunk line and its feeders. For each of these areas, we have redesigned its transport routes itineraries optimizing their costs. Finally, we have undertaken an economic assessment.

\section{DIAGNOSIS OF THE INTERCITY PASSENGER TRANSPORT BY BUS IN ARAGÓN}

The spatial distribution of the population strongly determines the structure of the intercity bus services in Aragón. This region is characterized by a strong contrast between the Zaragoza metropolitan area, where a $57 \%$ of the overall population lives (totalling 744.579 inhabitants), in contrast with the rest of the territory where the population density is very low due to an intense rural depopulation process.

A total of 288 routes, divided into two groups, compose the intercity bus system: a) Trunk routes, whose function is to connect the regional and provincial capital cities with other major towns. b) Feeder routes that serve small settlements in rural areas and connect them with major towns. Due to the low population density, the majority of the latter have even less than a frequency per working day, meaning that way and return trips to satisfy basic needs can only be made twice or three times a week. In parallel to this service, an independent and extensive school bus system operates.

The quality of the intercity bus system has been synthesized through the combination of frequency, measured as the number of trips per day, and accessibility, determined as travel times from each village to the nearest major town. In light to the above, an excellent quality requires more than 10 services a day lasting less than 30 minutes per trip. To the extent that the number of services decreases and travel time increases the quality worsens. 77\% of the Aragon's population has an excellent quality of service, this is people living in major towns and cities, including Zaragoza; $12 \%$ has a good quality of service, $5 \%$ a fair quality, $2 \%$ poor quality and $4 \%$ very poor quality. In the two latter situations, although the population affected is small, there are half of the inhabited settlements since the smallest villages have the poorest level of service.

The intercity bus system cost is 20.8 million euros. The annual income amounts to 13 million euros, covering $63 \%$ of the operating cost. Thus, there is a deficit that is partly covered by the regional and local entities that subsidize transport companies with 4.2 million euros since it is a public service.

The diagnosis of the system brings to light that intercity bus service in Aragon covers the needs of a high proportion of the Aragon's population. Notwithstanding, there are some inefficiencies derived from the fact that the system is based on a big number of linear management contracts. This situation provokes different routes to overlap, resulting in a worse level of service and higher operational costs. School transport is managed as an independent system (although there are a few examples of coordination) incrementing inefficiency of the whole system. Overlapping between networks is more problematic in the smallest settlements since they feature the worst quality of public transport.

\section{PROPOSAL FOR INTERCITY PASSENGER TRANSPORT BY BUS IN ARAGÓN}

This proposal establishes eight zonal management contracts. Each zone is structured around a trunk line that passes through different nodes, located in major towns. Six of these zones have radial trunk lines that 
connect the city of Zaragoza with the following towns respectively: Fraga, Alcañiz, Teruel, Calatayud, Tarazona-Ejea de los Caballeros and Huesca-Jaca. The seventh zone connects Huesca with Barbastro and Monzon. The eighth zone is articulated around the city of Teruel without any clear trunk line.

In our proposal feeder routes interchange with trunk lines at nodes located at major towns and other central places through coordinated transfers allowing travellers to continue their trips towards the provincial or regional capital. As for school transport, is organised with regular transport where possible creating mixed routes. As a consequence, there is a large increment of trip opportunities from rural settlements towards destinations with primary or secondary schools allowing travellers to connect to trunk lines again. Additionally, on-demand transport systems are proposed to serve the smallest villages.

If we compare our proposal with the current situation, we can appreciate the lack of a negative impact in the level of service along with an important reduction in the number of kilometres driven as well as in the operational costs. As a result, the operational deficit is reduced, and so on the number of public subsidies.

\section{DISCUSSION AND CONCLUSIONS}

This study confirms the difficulty of providing an appropriate level of accessibility by public transport in low density areas. The diagnosis reveals that its quality is insufficient on almost half of the Aragon's territory, coinciding with the least populated areas.

The paper demonstrates that there is room for the improvement of the level of service along with a reduction of the operational costs. Systems based on lineal concessions cause important inefficiencies that affect not only the quality of the system but also their deficit. In contrast, zonal management contracts allow a more flexible and coordinated operation. The hierarchy of routes, the choice of strategic nodes and the systematic use of transfers with coordinated schedules create new travel opportunities with considerable savings in kilometres and operating costs.

A joint management of passenger and school transport avoids overlapping routes, saving money and creating new travel opportunities in the least populated places. On-demand transport can complement this system, arriving virtually to all settlements when necessary, in reasonable conditions for passengers and companies.

After this study, the Aragon government has assumed a zonal management system, although its proposal differs from ours in several points. Firstly, the implementation of the government's proposal will offer an improvement in the quality of the service, but it still addresses passenger and school transport as two separate networks. Secondly, it consists of a bigger number of management contracts, specifically 19 zones, what entails that some important overlaps will still be present. Both points lead to an important operational deficit that the regional government will cover with subsidies in order to guarantee the right to mobility of rural communities. 


\title{
Strategic Sectors in the Knowledge Economy and Development in the City of Madrid and its Region
}

\author{
Simón Sánchez-Moral \\ simon.sanchez@ghis.ucm.es@ https://orcid.org/0000-0001-6381-2653 \\ Roberto Díez-Pisonero \\ rdpisonero@ghis.ucm.es @ https://orcid.org/0000-0002-7817-628X \\ Cándida Gago-García \\ cgago@ucm.es@ https://orcid.org/0000-0003-2315-7943 \\ Universidad Complutense de Madrid. Facultad de Geografía e Historia. \\ c/ Profesor Aranguren s/n. Madrid-28040 \\ Alfonso Arellano-Espinar \\ alfonso.arellano@pdi.ucm.es @ https://orcid.org/0000-0002-1464-8751 \\ Universidad Complutense de Madrid. Facultad de Ciencias Económicas y Empresariales. \\ Campus de Somosaguas 28223 - Pozuelo de Alarcón (MADRID)
}

\section{KEYWORDS}

\author{
Strategic sectors \\ Innovation \\ Firm networks \\ Urban strategies
}

The globalisation process and the increasing integration of the world economy have favoured increasing levels of competition between companies and between territories. Large cities would thus see their position at the head of the urban system reinforced, specializing in higher-level sectors and functions such as those that are more technology- and knowledge-intensive. A set of innovative or strategic clusters is usually identified in the context of cultural-cognitive capitalism: high-intensity technological industries, knowledge-intensive services, including advanced business services, as well as cultural industries.

The purpose of this research is to contrast the strategic nature of the activities of the knowledge economy in the case of the city-region of Madrid and provide an update on the diagnosis of recent progress, thereby offering a framework for reflection to guide the city's priorities in terms of the promotion and management of these activities. The study proposes three complementary methodological approaches.

First, the research reviews the strategies undertaken at the different levels of intervention, in relation to the selection and promotion of strategic economic sectors. More specifically, the study focuses on the analysis of nine European cities, selected for their high economic ranking for cities. The sectorial scope of this identification has deliberately not been limited in order to assess the importance given to technology-and knowledge-intensive sectors within the framework of the respective local economies. 
Secondly, there is a study of the importance of strategic activities in the development of the regional productive and research system. For this purpose, the analysis of input-output links (based on the latest input-output data available for the Community of Madrid in 2010) has been proposed. This analysis is completed with an assessment of the role of technology and knowledge-intensive activities from the perspective of other interactions with higher education and research institutions in the region.

Thirdly, there is an analysis of the temporal and spatial dynamics of affiliated employment using Social Security micro-data (2011-2016). Analysis at the two-digit level of the CNAE2009 (National Classification of Economic Activities), in addition to the districts of the city and the municipalities of the Madrid region, allows us to obtain a detailed image of both recent dynamism and spatial trends.

In terms of results, the review of the OECD and EU proposals confirms that sectorial economic policies tend to be replicated in different areas of application. In the case of the nine European cities analysed (London, Paris, Berlin, Amsterdam, Brussels, Zurich, Barcelona, Vienna, Stockholm), different approaches can be observed when identifying strategic sectors, although these are clearly related to the guidelines established by international organizations.

Specifically, four are common to the nine cities analysed, i.e. health and life industries, creative and cultural industries, information technologies and telecommunications. Four other sectors, the financial sector, green industries, higher education and tourism are also considered in most of the cases analyzed. Of note is the coherence in the selection of strategic sectors in European cities with the approach observed in recent decades in the case of Madrid, including its Regional Research and Innovation Strategy 2014-2020 (RIS3).

In terms of inputs and outputs, high-intensity technological industries have a considerable global pull effect, as consumers of intermediate inputs from many other activities. However, high-intensity technological industries show a much more discrete role when considering data from the interior of the Madrid region, with a few exceptions. The important degree of internationalisation and integration of these activities into multinational groups, together with the trend towards the reduction of some regional clusters in recent decades, would explain why the main effects are directed, above all, towards the outside of the region. Faced with this, most advanced business services (such as IT, headquarters and business management, technical services, advertising and market research, as well as legal and accounting activities) are positioned as strategic activities for the operation and value generation of companies in the region. Moreover, most of them also have direct or indirect pull effects outside the regional territory. All this is related to the concentration of advanced tertiary functions in Madrid, as the governing nucleus of the Spanish urban system, through which the bulk of national and international economic flows are channelled and organized.

Other knowledge-intensive service activities, such as telecommunications, financial intermediation or auxiliary financial and insurance services, emerge as fundamental activities for the expansion of the regional productive fabric. Lastly, cultural industries have above-average domestic multiplier effects, although they sometimes involve activities outside the region. The result confirms the strategic nature of the activities of the so-called "creative economy." As the European Commission itself points out, "the cultural and creative industries represent a set of highly innovative companies, with great economic potential, and constitute one of the most dynamic sectors in Europe." Together with all this, there has been a confirmation of the existence of important links within the regional innovation system between the companies of the activities identified and the research groups belonging to higher education institutions and research centres in the region.

Finally, the analysis of employment data and its recent evolution provides results that have been contrasted by innovative clusters. In order of importance, advanced business services stand out ( 269,150 jobs in 2016), ahead of other knowledge-intensive services $(114,894)$, cultural industries $(39,484)$ and technology-intensive industries $(19,865)$. In relation to the resilience of the innovative clusters, there is a decrease between 2011 and 2016 of employment in the high-intensity technological industry (-17.31\%), affected by capacity adjustments during the crisis and the (re)location decisions of the sector's multinationals. Equally negative was the employment performance in the cultural industries (-13.79\%). In contrast, other sectors that experienced an important adjustment during the austerity phase, such as artistic creation, shows or museums and archives, come off better overall in this period. However, other knowledge-intensive services, which experienced a smaller fall (-2.90\%), seem to recover once the restructuring of the financial sector has 
concluded. Meanwhile, advanced business services show a positive rate of change of $14 \%$. In this sense, their capacity to recover is confirmed as the crisis ends and as demand by the productive fabric of Madrid recovers, along with contracting from the public sector.

From the point of view of the level of implementation of strategic activities in the territory of Madrid, the work delves into the spatial dynamics of employment at the regional level and within the city. On the one hand, the existence of different trends in the location of strategic sectors has been confirmed, in relation, for example, to the processes of productive decentralisation and relocation of the high-intensity technological industry to the rest of the metropolitan region, or to the appearance of new forms of advanced tertiary services and cultural sectors (such as corporate cities, business parks, science and technology parks, etc.).

However, at the same time, the central city continues to stand out as the preferred location for many of these activities. This highlights the volume of activity in advanced services and national and international financial companies, which would provide the rest of the business fabric with the strategic knowledge needed for Madrid's inclusion in globalisation and which find in the city advantages of location related to the generation of urbanisation and network economies, not to mention other factors related to being located in prestigious areas. Simultaneously, the attractiveness of the city for cultural industries has been confirmed, especially in relation to the density of the sector's business networks or the symbolic value of its historical-cultural centre.

In short, despite the fact that this type of activity in the knowledge economy tends to be a preferential option when it comes to developing sectorial and innovation policies with a territorial approach, its recent performance has been very heterogeneous in the case of Madrid. In any case, innovative clusters have been confirmed to be playing an important role from the point of view of employment in the region of Madrid and, especially, in the central city, where they now make up a quarter of total employment. They are also fundamental for the internal articulation of the productive system and the regional innovation system, also ensuring the connection with the global economy. All of this, together with the capacity for resilience exhibited by several of these activities (especially advanced services for companies and cultural and creative industries), means that they can be considered strategic for bringing together new urban and regional development programmes. 


\title{
Zones with Potential for the Payment of Environmental Services in the Valle del Mezquital, Hidalgo
}

\author{
Genaro Aguilar-Sánchez \\ g_aguila@correo.chapingo.mx @ https://orcid.org/0000-0003-1518-0801 \\ Reynol González-Vizcarra \\ canas_X@hotmail.com @ https://orcid.org/0000-0002-4983-3164 \\ Universidad Autónoma Chapingo (México) \\ Carretera México-Texcoco, Km 38.5, Chapingo, municipio de Texcoco, Estado de México, \\ México. 56230
}

\section{KEYWORDS}

Environmental services

Mezquital Valley

SIG

Facets

\section{INTRODUCTION}

According to the General Law of Sustainable Forestry Development of Mexico, environmental services are defined as those provided by forest ecosystems in a natural way or through the sustainable management of forest resources, such as: the provision of water in quality and quantity ; the capture of carbon, contaminants and natural components; the generation of oxygen; the damping of the impact of natural phenomena; climate modulation or regulation; the protection of biodiversity, ecosystems and ways of life; the protection and recovery of soils; landscape and recreation, among others (DOF, 2009).

In Mexico, environmental services have received increasing attention, such is the case of payment schemes for their protection. As a result of this, since 2003, the Payment for Environmental Services (PSA) program has been implemented, which works within a national scheme that provides financing for that purpose. In the case of Mexico, the governing body responsible for carrying out the direction and execution of this is the National Forestry Commission (Official Gazette of the Federation 2009).

The objective of the present work is to carry out an identification, at a regional level, of those potential payment zones for environmental services in the Mezquital Valley, Hidalgo State (Mexico).

The Forest Management Unit (UMAFOR) "1304-Valle del Mezquital", which by territorial extension occupies the first place within the state of Hidalgo relative to the other four management units that comprise it, has a total area of 642,654 hectares. It is located southwest of the state of Hidalgo, between the extreme coordinates $20^{\circ} 42^{\prime} 19,98^{\prime \prime}$ 'and $19^{\circ} 4^{\prime} 09.81^{\prime \prime}$ north latitude, and $99^{\circ} 51^{\prime} 06^{\prime \prime}$ and $98^{\circ} 46^{\prime} 44,48^{\prime \prime}$ west longitude 


\section{METHODOLOGY}

In the present work it is considered that the use of combined methodologies derived from simple observation and the help of the Geographic Information Systems (GIS) help to better define the important areas, for PES, of the semi-arid and arid regions. Ancira (2015) and Valdez (2011) support the veracity of the results by using satellite images combined with GIS.

The identification of eligible or priority areas for the PSA was based to a large extent on the combination of the methodology used by Imbach, I., (2005) and Chuvieco E. (2000). In which it is explained through the use of a Geographic Information System (GIS) and the Multicriteria proposed by Malczewski, J. (1999) for the analysis of proposals. This methodology was also used by Paneque (2006) and Paegelow, M., et al (2003) in studies on water governance and landscape modeling.

The methodology consists of two main components whose integration makes it possible to prioritize the PES; this refers to the fact that a map of the provision of ecosystem services is combined with a map of the threat or risk of losing these services. In this methodology, the different eligible activities are prioritized under the current CONAFOR environmental services schemes (which would be forest conservation and Forest Environmental Services, but each one is evaluated differently (González, B., 2011).

SPOT XS sensor satellite images were used, each covering an area of 3,600 km2 with 3 bands of the electromagnetic spectrum. The images cover $100 \%$ of the area covered by UMAFOR 1304, which corresponds to the Mezquital Valley region. Digital thematic cartography is obtained to attend the different variables, it is processed through the use of Geographic Information Systems (GIS) ArcGis @ 9.2. The identification of the areas, of the Mezquital Valley, was carried out through geoprocessing and spatial analysis of the cartographic coverage.

In the present study, the "record-range procedure" was used. For equitable criteria and indicators, Equation 1 was used, while Equation 2 was used for the criteria and cost indicators (Bechhofer, E. 1954) and (Einot, I., and Gabriel, R. 1975).

The interpretation of these equations is that when the criterion or beneficial indicator is the highest, the value is more attractive and the criterion has to be maximized; and when the criterion or cost indicator is higher, the value is less attractive and the criterion has to be minimized (González, B., 2011). Thus, the criteria, which were used to evaluate the areas with priority for their importance for the provision of environmental services, their demand and the risk or threat of losing them, were chosen according to the literature consulted and the information available for the area of study.

Equation 1:

$$
x_{i j}^{\prime}=\left(\frac{x_{i j}-x_{j \min }}{x_{j \text { max }}-x_{j \min }}\right) * 100
$$

Equation 2:

$$
x_{i j}^{\prime}=\left(\frac{x_{j \max }-x_{i j}}{x_{j \max }-x_{j \min }}\right) * 100
$$

where:

$X_{i j}^{\prime}=$ Value of the standardized pixel $X_{i j}=$ Value of all the pixels on the map

$X_{i j}=$ Value of all the pixels on the map

$X_{j m a x}=$ Maximum value of the pixel on the map Xjmin = Minimum value of the pixel on the map

$X_{\text {jmin }}=$ Minimum value of the pixel on the map

In the case of qualitative and categorical variables, Equation 3 was used, by means of which a value with equivalent rank (ascending or descending) is assigned to each class or category. 
Equation 3:

$$
\text { Valor }=\left(\frac{x_{\text {ijmax }}}{n}\right)
$$

where:

$\mathrm{V}=$ value

$\mathrm{X}_{\text {jmax }}=$ Maximum value of the pixel on the map $\mathrm{n}=$ Number of classes or category

\section{RESULTS AND DISCUSSION}

\section{Delineation of Earth Systems and Facets}

Given the climatic conditions of the Management Unit, it was determined that polygons generated by temperate and semi-dry climate types, which converge in UMAFOR 1304, were used as Terrestrial Systems, due to the fact that by default the biological characteristics of flora and fauna they are affected by the climate factor. In such a way that for the present work they were located according to the climate vector layer of the Regional Forestry Study with scale 1: 250,000, nine polygons with own climatic characteristics, which gives us a total of nine Earth Systems to be described. It should be mentioned that according to the data obtained in terms of natural habitats in which the faunal species that will be mentioned below are developed, only a description of the vegetation type of each of the 9 terrestrial systems is made. We also obtained 20 facets in the entire IMAFOR 1304 area.

\section{Importance for the conservation of ecosystems in the Region}

In accordance with the map of land use and vegetation of the state of Hidalgo which is derived from the State Forestry Inventory scale 1: 50000, 23 categories or coverage were reported, of which 19 are of forest importance, because the forest units of abies, oak forest and low deciduous forest, you do not have high percentages.

Also, it can be highlighted that the MDM has a value of 100, the BMM with a value of 94, BQ with 87, Mixed $B$ with a value of 74 and SBC with 59, the other types of vegetation have values under 50. The importance and value of studies on endemic species is mentioned by: León, B., Pitman, N., And Roque, J., (2006) where they make a study of endemic plants in Peru, which is influenced by the Cordillera de los Andes. Andes, with its variations in altitude and as a consequence of climate.

\section{Surface loss at the regional level.}

Using the equation 1 proposed above, the ecosystems with the greatest loss of surface are those with the highest value, for this case the highest value is assigned according to the scale used by the methodology, that is, 100 and this value is the reference to define the lower values, which will be in proportion to the surface loss and will be lower

As a result of the proposed methodology, the eligible zones for the Payment for Environmental Services within the UMAFOR 1304 were identified. The value range of 0-100, highlighting values of 1, 36, and 40, is significant. Higher values correspond to areas that have more value for their conservation. Eligible areas to be proposed for the PSA of higher priority, demand and risk of losing SEs were identified. The results show that only 911 ha of the entire surface in the UMAFOR are areas of high to very high priority due to the supply and risk of losing SE derived from the conservation of biodiversity. 


\section{CONCLUSIONS}

Eligible areas to be proposed for the PSA of higher priority, demand and risk of losing SEs were identified. The results show that only 911 ha of the entire surface in the UMAFOR are areas of high to very high priority due to the supply and risk of losing SE derived from the conservation of biodiversity.

The different methodologies and procedures that we use in this work can be implemented by the state management of CONAFOR, with the objective that decision-making on the choice of priority areas for the PSA be carried out in a decentralized manner and that all the owners of land located in important areas for the PSA, have the same opportunities to participate and be elected.

Studies on the environmental services provided by forests are relatively recent, Domínguez, O., Betancourt, Y. and Rodríguez, G, (2007) indicate that in Cuba, in 2004, institutions and the people in general are unaware of the importance of SA, which provides in forest and, which have been provided spontaneously. They also mention that there are no works on their economic valuation. Therefore, what is done in Mexico is relevant. But in order not to lose SEs, it is necessary that the PSA is greater than what is authorized by CONAFOR, as indicated by Sánchez A., García R M., and Palma A. (2007). Since both the PSA, and the PSAH, are important to conserve and preserve the ecosystems of Mexico. 


\title{
A Methodological Approach to Non-Motorized Itineraries with Greater Potentiality for the "Train+Bike" Intermodality in Andalusia
}

\author{
Isabel Aránzazu García-Bello \\ jargarbel@alum.us.es @ https://orcid.org/0000-0001-9239-4331 \\ Universidad de Sevilla, SigTam Consultores. C/ Gonzalo Bilbao 33, bajo 241003 Sevilla \\ Jesús Ventura-Fernández \\ jventura@us.es @ https://orcid.org/0000-0002-8271-1011 \\ Universidad de Sevilla. Dpto. de Geografía Física y Análisis Geográfico Regional. \\ C/ María de Padilla s/n. 41004 Sevilla
}

\section{KEYWORDS}

Sustainable Mobility

Intermodality "train+bike"

Cycle tourism

Greenways

Geographic Information Systems

\section{SUBJECT}

The boom of cyclo tourism and recreational activities in nature through the use of non-motorized itineraries combined with public transport favors a new tourism typology that makes possible the dynamisation of rural areas, giving rise to a sustainable economic model, especially in European countries such as France, Germany and Switzerland. The mobility studies contemplate, as an essential part, the intermodality between different types of transport, especially those of a public nature, which are not very polluting and collective, as in the case of the railroad.

In Andalusia, there is also a great variety of non-motorized itineraries associated with areas of great landscape and heritage value, showing therefore great potential which they present for the development of contact activities with nature. The choice of these non-motorized itineraries will be linked to the distance that exists between the intermodal urban areas, mainly working train stations of different types. 


\section{OBJECTIVES AND METHODOLOGY}

The presumption is that to understand the potential of the intermodality of the railway lines with non-motorized itineraries for the practice of bicycle touring, everything will depend, at least to a large extent, on the distance of travel or proximity between train stations and access to these itineraries. Emili Mató and Xandra Troyano (2014) consider that the distance traveled in ten minutes by the cyclist is the acceptable limit to arrive from a public transport station at the beginning of an itinerary, so that beyond that time, the route begins to become deterrent. That is why to the user of the bicycle the maximum distance to travel before starting the itinerary proper would be $3.2 \mathrm{~km}$, which implies an average speed of $19.2 \mathrm{~km} / \mathrm{h}$.

The proximity study will be completed here with another accessibility through the ArcGIS Network Analyst extension, which allows to establish different isochrones from the railway station in use according to their type of interest for this work (neighborhood, circulation and mixed ). In this case, the average speed has been reduced to a value closer to that of a new cyclist or with a possible load in their panniers, that is, at $15 \mathrm{~km} / \mathrm{h}$, although the critical time has been increased to 15 minutes, according to the usual way in different studies on accessibility.

Ultimately, through the present research aims to achieve two fundamental objectives:

a. Identify the intermodal urban nucleus with greater opportunities for the development of cycling activities, as well as the non-motorized itineraries that are in the vicinity of the railway stations.

b. Determine which routes could be the most attractive, being able to subsequently design itineraries both for one day and others that involve several overnight stays.

Andalusia has a very dense network of cattle trails (the ones that stand out for their width are the main drovers' roads known as cañadas reales in Spain), trails (some of them classified as Long-Distance) and disused railway lines, known as rail trails when properly conditioned; what represents a great potential for the practice of bicycle touring.

Accordingly, those train stations have been selected for the transport of passengers that are at a distance of less than $3 \mathrm{~km}$ from these non-motorized itineraries, by means of Buffer Geoprocessing, in coherence with the $3.2 \mathrm{~km}$ as a critical distance previously indicated.

The Geographic Information Systems, which contain spatial information, plus the use of different criteria (distance, accessibility in time ...), will allow us to give various interrelations between the different layers or variables of the study, being able to verify the potential of the method and the ability to analyze the connections of the elements that are distributed in the territory.

The fundamental source of this study will be DERA (Spatial Reference Data of Andalusia), which is a repertoire of cartographic bases of different geometric nature (points, lines, polygons) referring to the Andalusian territory.

\section{MAIN RESULTS AND TECHNICAL DISCUSSION}

Regarding the main results, we must point out that the non-motorized itineraries in which these initiatives have already been launched are the following rail trails : del Aceite, with a distance of $127.36 \mathrm{~km}$, beginning its route in Puente Genil, in the province of Córdoba, and ending in the city of Jaen; of the Campiña, with a route of $91,92 \mathrm{~km}$, that begins in the town of Marchena, in the province of Seville, and reaches the vicinity of the city of Cordoba; those of Linares and Guadalimar, with a first route of $6.61 \mathrm{~km}$ and the second of $15.31 \mathrm{~km}$ on the old line of the Baeza-Utiel line; the Sierra Norte de Sevilla, which is accessible from the commuter station of Cazalla-Constantina, and which has a distance of $18.28 \mathrm{~km}$, all inserted in a protected natural area; those of Puerto Real-San Fernando and Matagorda, which are located in the Bay of Cadiz, the first having a route of $8.25 \mathrm{~km}$, and the second of $3.55 \mathrm{~km}$; and that of Itálica, which has a distance of only $1.7 \mathrm{~km}$, and which can be accessed from the La Cartuja railway station, in the city of Seville, and also by the Camas station. 
We must also reflect the potential of the disused railway section between Guadix and Baza, all of it in the province of Granada, belonging to the abandoned line between Guadix (Granada) and Almendricos (Murcia), where various actions have already been carried out of adaptation to upgraded rail trails: Sierra de Baza, Valle del Almanzora and Huércal-Overa (the last two in the province of Almería).

The network of the main drovers' roads increases between the stations of Bobadilla and Antequera; the existing ones between the stations of Jimena de la Frontera and Ronda are significant; and the Cañada Real de Soria, which departs from the Posadas station to Córdoba.

Concerning the unrestored disused railway lines, the following stand out: from the Jerez de la Frontera station, corresponding to the so-called Sierra Railroad, which runs to Almargen (in Málaga), where a citizen platform promotes recovery as a rail trail of the section that goes to Arcos de la Frontera; from Granada station, Sierra Nevada, La Zubia, and Armilla-Dúrcal; from the station of San Julián in city of Málaga to Coín; and from Almería to El Chorrillo.

From the intersection between the buffer of $3 \mathrm{~km}$ of proximity and the referred isochrone of 15 minutes of accessibility, the itineraries have been selected that, fulfilling both requirements, exceed $15 \mathrm{~km}$ in length, a distance that, in the usual case of not having a circular character, represent, at least, $30 \mathrm{~km}$ between a round trip, and that is understood as an attractive distance for the average cyclotourist.

This implies the simplification to 44 records of the relationship that can be obtained without the double condition, that is, only with the buffer of $3 \mathrm{~km}$ away, and that incorporates 10 more itineraries. Finally, as a result of the latter, The main urban nucleus are established for the implementation of the "train+bike" intermodality that we find today in Andalusia, as well as a series of non-motorized itineraries linked to them with their different characteristics, derived from the GIS that have been used as a methodological support for this investigation, provided that, as a whole, they exceed $20 \mathrm{~km}$ and moreover they start from the vicinity (with distance never greater than $3 \mathrm{~km}$ ) from the stations corresponding to localities attached to the urban categories of provincial capitals and county centers.

Nonetheless, from the review of the 10 itineraries that only met the condition of starting less than $3 \mathrm{~km}$ from the railway station but are not within 15 minutes of access from it, we observed two exceptional and significant cases, such as they are those that correspond to Marchena, where the Vía Verde de la Campiña begins to only 364 ms of the station; and the commuter train of San Julián (in Málaga), 106 meters from the disused Málaga-Coín railway. The fact that they do not appear in the selected isochrone is considered an anomaly as a consequence of the source layer used, which has led to the incorporation of these two stations, less than $500 \mathrm{~m}$ from the beginning of their itineraries, among those linked to the 16 routes finally selected.

Nevertheless, the execution of these possible itineraries, in case they are not yet active, will depend, final$l y$, and with the independence of the human resources, on the series of requirements for the realization of cycling and recreational activities, fundamentally, which implies further studies in greater detail.

\section{CONCLUSIONS OF WORK}

In Andalusia it has been detected how, less than $3 \mathrm{~km}$ away from railway stations in operation, a series of different types of routes (drovers' roads, paths, rail trail and disused railway lines) that reach more than 3,400 $\mathrm{km}$ begins with a proportional distribution that oscillates between the $36.74 \%$ that represents the trails to the $28.63 \%$ of the abandoned railway lines.

Of these routes, 54 of them exceed $15 \mathrm{~km}$ in length. But to measure its real operability, a second conditioner has been added to the study, such as access to them in less than 15 minutes, from the road network (excluding double-track) and roadways provided by DERA files, with a mesh of $57,717.82 \mathrm{~km}$. In that case the itineraries are reduced to 44.

With these approaches, and subsequently raising the minimum route to $20 \mathrm{~km}$, but with the possibility of adding itineraries of different types that have obvious contiguity in the Geographic Information System prepared for this purpose, the 16 most favorable itineraries have been selected to promote bicycle train intermodality in Andalusia, some already in service, as in the so-called rail trails (del Aceite, La Campiña, Sierra Norte...). 
In essence, the contribution of this research lies in the realization of an analysis that has come to combine different variables through a GIS, where items of different types have been used together with a cartographic support that has served as a model of interrelation of these to generate a map and a tabulation that helps the decision making by means of a diagnosis of the initial situation. 